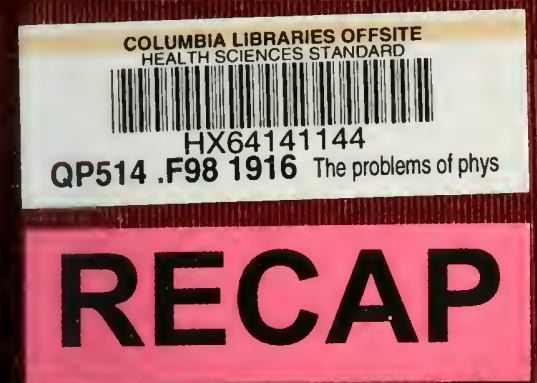



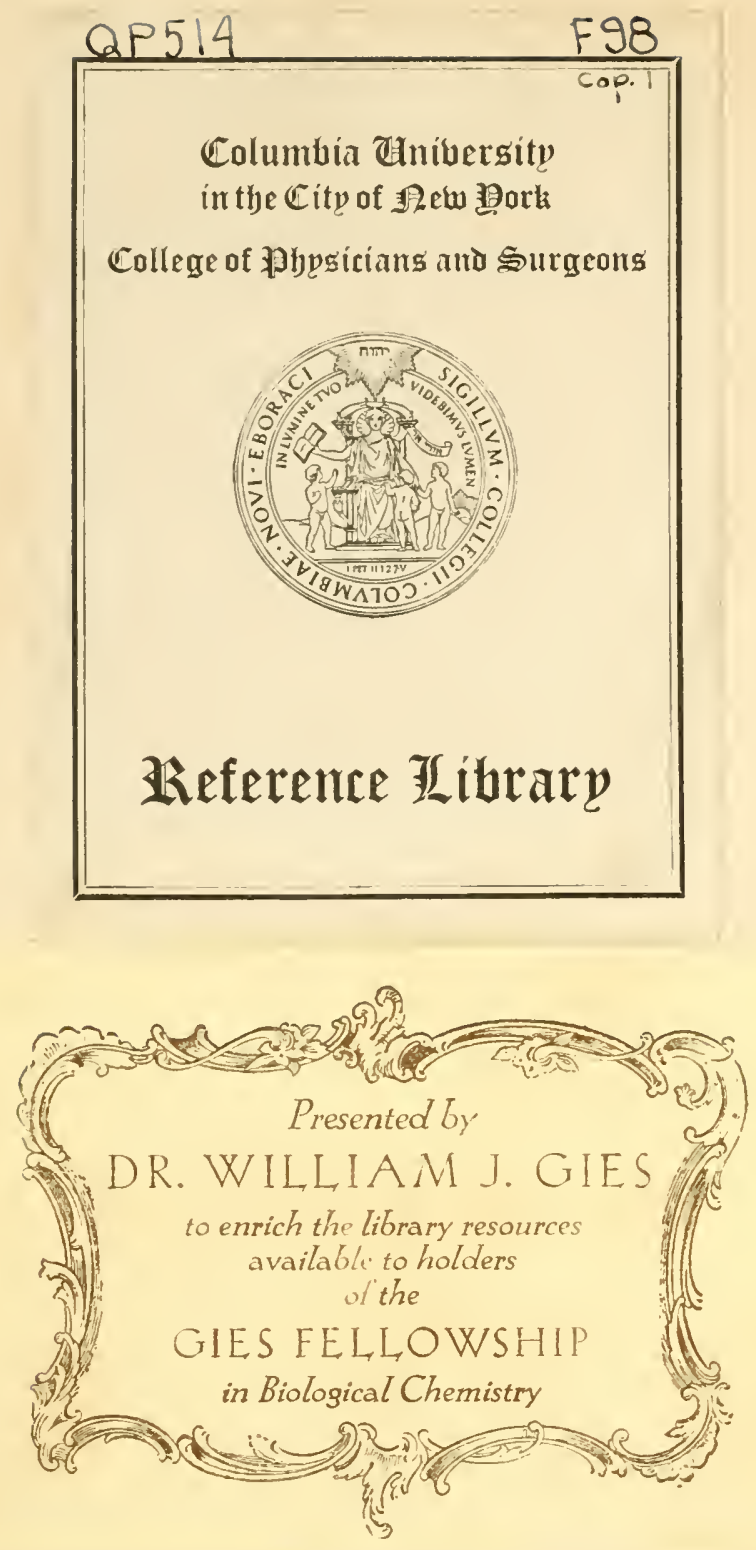
Digitized by the Internet Archive in 2010 with funding from

Open Knowledge Commons (for the Medical Heritage Library project) 
The price of this book is ${ }^{\$ 6.00}$

Please state it in your review 



\title{
THE PROBLEMS \\ OF PHYSIOLOGICAL AND PATHOLOGICAL CHEMISTRY OF METABOLISM
}

FOR STUDENTS, PHYSICIANS, BIOLOGISTS AND CHEMISTS

\author{
BY \\ DR. OTTO VON FÜRTH
}

PROFESSOR EXTRAORDINARY OF APPLIED MEDICAL CHEMISTRY IN THE UNIVERSITY OF VIENKA

AUTHORIZED TRANSLATION BY

ALLEN J. SMITH

PROFESSOR OF PATHOLOGY AND OF COMPARATIVE PATHOLOGY IN THE UNIVERSITY OF PENNSYLVANIA

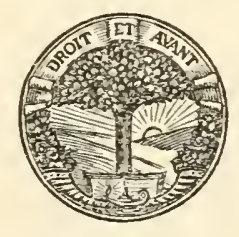

PHILADELPHIA AND LONDON

J. B. LIPPINCOTT COMPANY 
COPYRIGHT, I9I6

BY J.B. LIPPINCOTT COMPANY

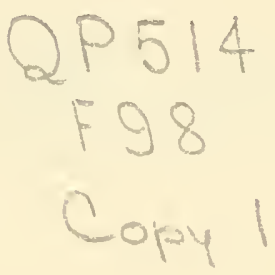

Electrotyped and prirledby J. B. Lippincoll Compary The Washington Square Press, Philadelphia, U. S, A. 


\section{AUTHOR'S PREFACE}

In overseeing the corrections incident to the publication of the volume herewith presented, the author has been fortunate in having the assistance of Dr. Carl Schwarz, Docent in Physiology in the University of Vienna, and of Dr. Adolf Fuchs, Assistant in the Royal and Imperial Franz Joseph Hospital. It is a pleasure to acknowledge here to both these gentlemen the author's most cordial appreciation. Nor can the author fail to express his obligations to $\mathrm{Mr}$. F. Lampe-Vischer, head of the F. C. Vogel Publishing Company of Leipzig, for the readiness of coöperation which he invariably accorded, at every stage of the preparation and publication of this work. 



\section{TRANSLATOR'S PREFACE}

THE wide and cordial appreciation with which ron Fürth's "Problems" has been met, not alone by his students and clinicians, but by technical scientists in physiology and in pathology as well, is ample reason for its presentation in translated form. The book is based upon, and in the original text is cast in the form of twenty-five lectures addressed to students of biological chemistry, and has as its purpose the presentation of the subject of normal and pathological metabolic chemistry as a broad and connected whole. As a well-prepared and enthusiastic gnide, thoroughly conversant with the topography, history, popular activities, spirit and ambitions of the land through which he is conducting a group of thoughtful travellers, seeks to point out the salient features of the landscape and the accomplishments of the people, their successes and their needs, and thus in the end leaves in the minds of the group before him a well-balanced idea of the region, so our author seeks to guide his readers throngh the living body, following the ingestion of the great types of food, their digestion and absorption, pointing out here and there in the unknown field of intermediate metabolism the little which has become known, indicating their resultants, marking the points of departure of disease, presenting the big facts which we know in connection with the metabolic affections, and at all times suggesting the possibilities of further investigation and of orienting our thoughts into conformity with the general plan of nature's chemical performances. The book is thus rather a guide to thought than to the technicalities of the laboratory, and in this appeals alike to students, chemists, biologists and physicians. It is in no sense a compendium, nor is it a book of reference for details, technical or otherwise; but is a presentation of the well-ordered thought of a master of biochemistry, the 
result of well-considered culling of facts and their alignment in probable sequence. A satisfying series of pagereferences serves to direct the reader to the literature in which are recorded the minutiae of details which such a work cannot reasonably be expected to embody.

In the three years since the appearance of the original edition there have, it is true, appeared in current literature facts which the author would doubtless have noted had the times been more fortunate; but the translator has felt that the book is so peculiarly one man's own that to annotate would be meddlesome and intolerable. The possible changes in statement at any rate would have been no more than minor, and the additions, mainly in connection with the sections dealing with proteins and diabetes, would surely not materially modify the general picture which the author has drawn.

In the original German edition Professor ron Fürth's "Probleme der Physiologischen und Pathologischen Chemie" appeared in two separately complete volumes; a translation of the second of which, dealing with the chemistry of normal and pathological metabolism, appears in the following pages. The first volume of the series deals with and is entitied "Chemistry of Tissues"; reference to which from place to place appears in the following text. The translator can only regret that the conditions of publication have permitted of the presentation of no more than a single one of these; but it should be clearly understood that the completeness of the present volume is in no sense involved by the fact that its companion volume remains untranslated.

The translator has endeavored to preserve the spirit of the book, but has not attempted to maintain an absolutely literal translation. Doubtless defects of form and perhaps, unfortunately, of sense as well, may be detected in the translation; if so no one will regret them more than the translator. But these aside, he can and does frankly conmend the book as an orderly and masterful delineation of the important 
features in the plan of chemical function in the animal economy. To the publishers he would here express his appreciation of their unfailing kindness and consideration in spite of many annoying delays in the preparation of the material for publication, arising from the pressure of demands in other lines which at the time seemed insistent.

A. J.S. 



\section{CONTENTS}

I. Introdection to the Study of Metabolism. Protein Digestion

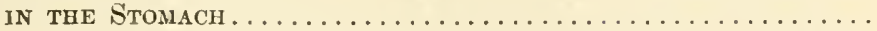

Introduction. Protein Digestion in the Stomach. "Mock Meal" and Pawlow's Ventriculus. Nervous Mechanism of Secretion. Action of Psychic Influences. Excito-secretory Stimuli. Gastric Secretin. Inhibition of Secretion. Origin of Free Hydrochloric Acid in Gastric Mucous Membrane. Physico-chemical Explanations. Acid-production by Marine Snails. Determination of Acidity of Gastric Juice. Binding of Hydrochloric Acid by Proteins. Extent of Protein Digestion in the Stomach. Comparative Physiological Considerations. Efforts to Isolate Pepsin. Methods of Pepsin Determination. Law of Pepsin Fermentation. Propepsin. Pseudopepsin. Passage of Pepsin into Intestine. Resistance of Stomach to Autodigestion. Origin of Round Ulcer of the Stomach. Chymosin. Ultramicroscopic Studies of Lab-process. Association of Bacteria in Lab-process. Plastins. Question of the Identity of Pepsin and Rennin.

II. The Proteolytic Pancreatic Ferment................... Transfer of Food from Stomach into the Intestine. Passage of Intestinal Contents into the Stomach. Pancreatic Fistulas. Secretin. Secretin and Cholin and the Vasodilatins. Enterokinase. Activation of Trypsinogen by Calcium Salts, etc. Individuality of Trypsin. Conversion of Trypsin into Zymoid. Action of Trypsin on Polypeptids. Adaptation of the Pancreatic Secretion to the Food. Quantitative Determination and Ferment Law of Trypsin. Toxicity of Parenterally Introduced Trypsin.

III. Protein-Digestion in the Intestine.................... Erepsin. Extent of Protein Dissociation in the Intestine. Passage of True Proteins and High-Molecular Protein-Derivatives into the Blood. Resorption of Iodized Proteins. Objections to the Resorption of Albumoses and Aminoacids. Residual Nitrogen. Synthesis of Digestive Products. Parenteral Introduction of Protein. Protein Synthesis from Advanced Cleavage of Protein. Abderhalden's Experiments. Application of these Results in Sickroom Dietary. Relation of Amides in Metabolism in Vegetarians. Protein Synthesis from Ammonium Salts. London's Studies. Summary.

IV. Proteolytic and Peptolytic Tissue Ferments.............. Autolysis a Complex Process. Antiseptic Difficulties in Autolysis Experiments. Is Autolysis the Continuation of an Intravital Process? Deamidizing Tissue Ferments. Importance of Autolysis in Various Pathological Processes. Autolysis and the Regressive Changes in the Living Body. Relation to Bacterial Processes. Proteolytic Ferments of Leucocytic Origin. Effect of Extrinsic Factors upon Autolysis. Abderhalden's Investigations upon Proteolytic Tissue Ferments. Detection of Proteolytic Tissue Ferments by Means of Glycyltyrosin, Silk-peptone, and Glycyltryptophane. Optical Method. Inhibition of Proteolytic Processes by the Products of Protein Cleavage. Classification of Proteolytic Ferments. Peptolytic Power of Blood Serum. 
V. Urea. Hippuric Acid Excretion of Aminoacids..............

Urea. Theories of the Formation of Urea in the Living Body.

Uraminoacids. Mechanism of Vital Oxidation of Nitrogenous Substances. Ammonium Carbamate. Place of Urea Formation. Exclusion of the Liver. Alkalosis and Acidosis. Arginase. Postcoenal Urea Excretion. Quantitative Estimation of Urea. Hippuric Acid. Source of Benzoic Acid. Hippuric Acid Elimination in Carnivora and in Man. Hippuric Acid Formation in Herbivora. Behavior of Benzoylated Aminoacids. Synthetic Source of Glycocoll from Acetic Acid and Ammonia. Glycocoll and Ornithin as Detoxifying Agents. Quantitative Estimation of Hippuric Acid. Elimination of Aminoacids. Aminoacids in Normal Urine. Elimination of Aminoacids in Disease. Cystinuria and Diaminuria. Quantitative Determination of Aminoacids.

Vi. Creatin and Creatinin. Other Urinary Bases. Oxyproteic

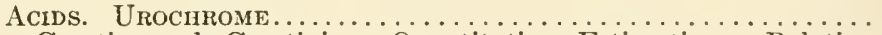
Creatin and Creatinin. Quantitative Estimation. Relation Between Creatin and Creatinin. Creatase and Creatinase. Endogenous and Exogenous Distribution of Creatin-Creatinin Elimination. Relation of Creatin-Creatinin Excretion to Decomposition of Tissue Protein. Muscle as Source of Creatin. Creatin Cleavage from Other Tissues. Test of Hepatic Function. Relation of Creatin Metabolism to Processes in the Female Sexual Organs. Possible Origin of Creatin from Arginin. Other Urinary Bases. Methylguanidin, Dimethylguanidin, Vitiatin. Novain. Trimethylamine. Arnold's Reaction. Urinary Rest-Nitrogen. Oxyproteic Acids. Fractionation of Oxyproteic Acids. Chemical Position of Urochrome. True Urochrome and Dombrowski's Urochrome. Quantitative Estimation of Oxyproteic Acids. Elimination of Oxyproteic Acids in Normal and Pathological Conditions. Other High-Molecular Residual Substances.

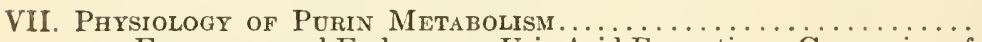
Exogenous and Endogenous Uric Acid Formation. Conversion of Adenin and Guanin into Uric Acid. Guanin Gout in the Hog. Nucleases and Deamidases. Nuclear Disintegration and Urinary Purins. Relation of Purin Metabolism to Muscular Activity. Syntbetic Formation of Uric Acid in Birds and Reptiles. Synthetic Purin Formation in Mammals. Allantoin as an End-product of Mammalian Purin Metabolism. Fate of Intermediary Uric Acid in Man. Absence of Uricase in Human Tissues. Fate of Experimentally Introduced Purins in Human Metabolism. Decomposition of Purins in the Intestine. Reconstruction of Uric Acid. Methylated Purin Derivatives. Quantitative Estimation of Uric Acid. Wiechowski's Method of Estimating Allantoin.

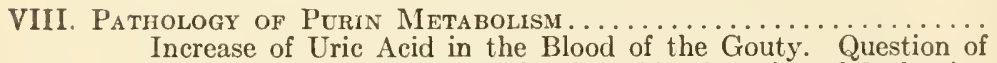
Increase in the Formation of Uric Acid. Question of Reduction of Uric Acid Decomposition in Gout. Curve of Uric Acid Excretion in the Acute Gouty Exacerbations. Delayed Nuclein Exchange in the Gouty. Gout and Nephritis. Uric Acid Retention. Affinity of Tissues for Uric Acid. Alkali Compounds of Uric Acid. Part Taken by Changes in Alkalescence. Lactam and Lactim Forms of Urates. Nucleinic Acid Combination With Uric Acid. Complex Conditions of Solubility of Uric Acid in Relation to Uric Acid Diathesis. Localization of Uric Acid Depositions. Alkalinity of Tissues in Relation to Uric Acid Deposit. Attempts to Produce Gout Experimentally. Alcoholism. Chronic Plumbism. Influence of Excessive Meat Diet. Protracted Feeding of Nucleinic Acid to Dogs. Radium Therapy in Gout. Medicinal Treatment of Gout. The Diet in Gout. 
IX. Digestion of Carbohydrates. Blood Sugar. Diastasic Ferments 194 Carbohydrate Digestion. Ptyalin. Carbohydrate Digestion in the Stomach. Carbohydrate Digestion in the Intestine. Rôle of Pancreas in Production of Carbohydrate-splitting Ferments. Fate of Disaccharides. Dilution of Sugar Solution in the Intestine. Disappearance of Coarse Vegetable Fibres from the Digestive Tract. Determination of Cellulose. Cytases. Part Taken in Digestion by Enzymes Contained in the Food. Importance of Symbiotic Microörganisms. Marsh-Gas Fermentation. Food Value of Cellulose. Importance of Inf usoria in Cellulose Digestion. Blood Sugar. Technic of Estimating the Sugar in the Blood. Existence of Free Sugar in the Blood. Sucre Immediat and Sucre Virtuel. Does the Blood Contain Other Carbohydrates in Addition to Glucose? Sugar Content in the Red Blood Cells. Sugar in the Aqueous Humor. Carbohydrate-splitting Ferments. Quantitative Determination of Diastase. Wiechowski's TissuePowder Method. Hepatic Diastase. Muscle Diastase. Diastases in Embryos. Origin of Diastase. Rôle of Pancreas in the Production of Blood Diastase. Maltases, Invertases and Glucases in the Blood-serum. Action of Diastase on Various Forms of Starch.

X. Grycogen. Formation of Sugar from Protein and Fat...... Glycogen. Quantitative Determination of Glycogen. Chemistry of Glycogen. Relation Between Consumption of Sugar by the Muscles and the Disappearance of Glycogen in the Liver. Production of Glycogen Impoverishment in the Body. Glycogen Formation in the Perfused Liver. Glycogen Formation from Glucose, Fructose, and Galactose. Behavior of Disaccharides and Polysaccharides. Other Substances of the Sugar Series. Glycogen Formation from Formaldehyde. Limit of Saturation and Utilization. Formation of Sugar from Protein. Carbohydrate Group in the Protein Molecule. Elinination of Sugar and Protein Decomposition. Respiration Experiments. New Formation of Carbohydrate in Glycogen-Free Tissues. Formation of Sugar from Various Proteins. Origin of Sugar from Animoacids. Formation of Sugar from Fat. Sugar Formation from Glycerine. Seegen's Experiments. Respiratory Quotient in Diabetes. Sugar-Nitrogen Quotient. Fat Impoverishment in Phloridzin Animals. Influence of the Introduction of Higher Fatty Acids upon Sugar Elimination.

XI. Pancreatic Diabetes. Human Diabetes ........................
Pancreatic Diabetes. Discovery of Pancreatic Diabetes. Pancreatic Diabetes. Discovery of Pancreatic Diabetes. Inter-
rupted Extirpation of the Pancreas. Function of Islands of Langerhans. Duodenal Diabetes. Does the Internal Secretion of the Pancreas Pass with the Lymph through the Thoracic Duct into the Blood? Blood Transfusion and Parabiosis. Glycogen Formation, Diastasic Power and Formation of Sugar from Carbohydratefree Material in the Liver in Pancreatic Diabetes. Glycolysis. Oxidation Processes in the Diabetic Economy. Metabolism in Pancreatic Diabetes. Partial Extirpation of Pancreas. Antipancreatin Serum. Isolation of the "Pancreatic Hormone." Human Diabetes. Degeneration of the Pancreas in Human Diabetes. Glycogen Content of the Liver. Hyperglycæmia. MethyleneBlue Reaction of the Blood. Urinary Dextrine. Protein Destruction. Diabetic Lipæmia. Respiration Experiments in Diabetes. Substitutes for Bread for Diabetics. Oat Treatments. Influence of Mineral Waters. Medicinal Treatment of Diabetes.

XII. Phloridzin Diabetes. Lafulosuria. Lactosuria. PentoSURIa. EXPerimental Glycosurias of Different Kinds....
Phloridzin Diabetes. Lack of Hyperglycæmia. Rôle of the Kidney. Formation of Sugar in the Kidney. Fate of Phloridziz 
in the Body. Lævulosuria. Detection of Lævulose. Transformation of Glucose into Lævulose. True Lævulosuria. Alimentary Lavulosuria. Lactosuria. Lactosuria of Puerperal Women. Lactosuria in Infants. Alimentary Galactosuria in Disturbances of Hepatic Functions. Pentosuria. $\lambda$-xylose. Alimentary Pentosuria. Pentosuria in Diabetes. Chronic Pentosuria. Detection of Pentoses. Cammidge Reaction. Experimental Glycosurias of Various Kinds. Renal Glycosurias. Sugar Puncture. Toxic Glycosurias. Salt Glycosuria. Glycosuria from Chill.

XIII. Relation of Glands with Internal Secretion to Carbohy-

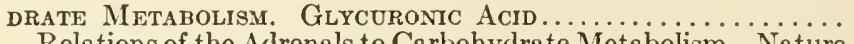
Relations of the Adrenals to Carbohydrate Metabolism. Nature of Adrenal Diabetes. Dependence of Adrenin Glycosuria upon the Renal Function. Hypothesis of the Regulating Influence of Adrenin upon Normal Carbohydrate Metabolism. Does the Sugar Puncture Act through the Adrenals to Cause Glycosuria? Failure of Effect of Gly cosuric Puncture After Exclusion of the Adrenals. Chromium Affinity of the Adrenals. Question of Increase of Adrenin after Sugar Puncture. Do the Adrenals Have a Regulating Influence upon the Normal Carbohydrate Metabolism? Relations of the Thyroid Gland to Carbohydrate Metabolism. Removal of the Thyroid and of the Parathyroids. Hyperthyroidism. Interaction of the Internal Secretory Glands. Relation of Hypophysis to Carbohydrate Metabolism. Glycuronic Acid. Constitution. Conjugation Conditions. Origin of Glycuronic Acid from Oxidation of Sugar. Oxaluria. Conversion of Glycuronic Acid into $\lambda$-xylose. Occurrence of Glycyronic Acid in the Body. Importance of Glycuronic Acid in Diagnosis of Intestinal Disturbances and Diseases of the Liver. Detection and Estimation of Glycuronic Acid.

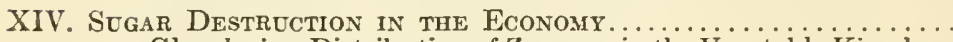
Glycolysis. Distribution of Zymases in the Vegetable Kingdom. Supposed Occurrence of Zymases in Animal Tissues. Cohnheim's Pancreas-Muscle Experiments. Objections of Claus and Embden. Possible Existence of Glycolytic Tissue Ferments. Experiments upon Surviving Tissues. Glycolysis in Blood. Importance of Leucocytes in Blood-Glycolysis. Sugar Catabolism from the Influence of Alkali. Importance of Catalyzers in the Catalysis of Sugar. Electrolytic Cleavage of Sugar. Mechanism of Alcoholic Fermentation of Sugar. Butyric Acid Fermentation. Citric Acid Fermentation.

XV. Digestion and Resorption of Fats................................
The Lipase of the Stomach. Problems of Fat Resorption. Fat Cleavage and Solution of Cleavage Products. Fat Synthesis in the Intestinal Wall. Behavior of Non-Saponifiable Emulsions. Histological Observations Bearing upon Fat Resorption. Resorption of Soaps. Method of Study with Isolated Intestinal Loops. Influence of Pancreatic Juice and Bile upon Fat Digestion. Influence of Extirpation of Pancreas upon Fat Resorption. Activation of Pancreatic Steapsin by Salts of the Biliary Acids. Question of Complex Nature of Pancreatic Steapsin. Synthetic Production of Fat by Reverse Ferment Action of Lipase. Tat Cleavage in the Intestine in the Absence of Pancreatic Secretion. Solvent Power of the Bile. Lipæmia. Resorption Path of the Fat. Hæmoconiosis. Masking of the Fat in the Blood. Relation of the Masking of Fat to Fatty Degeneration. Pathological Lipæmias. Lipæmia from Mobilization of Fat Deposits. Diabetic Lipæmia. Lipæmia from Narcosis. Passage of the Fat out of the Blood Stream. Fetal Lipæmia. Diet Lipæmia. Pavy's Theory. 
XVI. Fat Metabolism. Obesity................................. portance of Lipoids in Nutrition. Parenteral Fat Absorption. Fat Storage in the Body. Deposit of Foreign Fat. Transformation of Fat in the Body. Depot Fat and Cell Fat. Oxidative Function of the Liver in Catabolism of Higher Fatty Acids. Formation of Fat from Sugar. Transformation of Fat into Carbohydrate in the Vegetable Economy. Characteristics of Fat which is Formed de novo from Carbohydrates. Place of Origin of Fat from Carbohydrates. Chemistry of Fat Formation from Sugar. Experiments upon the Disintegration of Fat by Plants. Catabolism of Fatty Acids in the Animal Body. Nature of Obesity. Corpulence and Over-feeding. Antifat Treatments. Fattening.

XVII. Fat-Splitting Tissue Ferments. Fat Formation From Protein. Fatty Infiltration and Fatty Degeneration. Origin

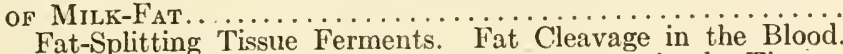
Lipase of the Ieucocytes. Cleavage of Esters in the Tissues. Fat-Splitting Tissue Ferments. Formation of Fat from Protein. Fatty Degeneration and Fatty Infiltration. Fat Phanerosis in Autolysis. Nature of Fat Phanerosis. Formation of Higher Fatty Acids by Microörganisms. Hoffmann's Experiment with Fly-Maggots. Adipocere. Formation of Fat in Ripening of Cheese. Accumulation of Fat in the Liver in Phosphorus Poisoning. Fatty Degeneration of the Liver. Fatty Infiltration in Other Pathological Conditions. Rosenfeld's Theory. Association of Fat Phanerosis in the Phenomena of Fatty Degeneration. Fatty Change of the Kidney. Cholesterol-Ester Steatosis. Origin of Milk Fat. Passage of the Fat of the Food into the Milk. Origin of Milk Fat from the Carbohydrates of Food. Lower Fatty Acids in Milk. Sebaceous Glands and Coceygeal Gland. Haptogenic Membranes.

XVIII. Acetone Bodies.............................................. Acetone Bodies. Relation of Acetone Body Formation to the Bodies from the Lower Fatty Acids with Even Carbon Atom Chain. Possibility of Disintegration of the Longer Fatty Acid Chains into Short Parts. Is $\beta$-oxybutyric Acid a Product of Normal Metabolism? Derivation of Acetone Bodies from Compounds with Branched and Cyclical Chains. Carbohydrate Deficiency and Acidosis. Diabetic Coma. Alkaline Treatment of Coma. Antiketogenic Substances. Ammonia Elimination and Acidosis. Interrelations of Acetone Bodies. Determination of Acetone and Diacetic Acid. Quantitative Determination of Oxybutyric Acid.

XIX. Lactic Acid. Fate of Body-Foreign Substances in the Economy 452 Lactic Acid. Quantitative Estimation of Lactic Acid by the Method of Fürth and Charnass. Determination of Lactic Acid and $\beta$-oxybutyric Acids Together. Ryffel's Method of Lactic Acid Determination. Postmortem Formation of Lactic Acid. Origin of Lactic Acid from Sugar. Embden's Schema of Sugar Catabolism in the Living Body. Glycerol-Aldehyde as an Intermediate Product between Sugar and Lactic Acid. Racemic Acid as an Intermediate Product. Appearance of Lactic Acid in the Urine. Fate of Body-Foreign Materials in the Economy. Decomposition of Fatty Acids and Aliphatic Sidechains. $\mathrm{Ca}$ tabohism of a-aminoacids. Oxidation of Cyclic Nuclei. Reduction Processes in the Economy. Deaminization. Synthetic 
Formation of Aminoacids in the Animal Body. Acetylizing Processes in the Animal Body. Alkylation. Detoxification by Sulphuric Acid and Sulphur-containing Rests. Conjugation with Glycocoll and Ornithin. Uraminoacids. Behavior of Stereoisomeric Substances in the Body.

XX. Nutritional Requirements. Fasting. Parenteral Nutrition 482 Nutritional Requirements. Amount of Food. Metabolic Minimum. Protein Minimum. Relation Between Protein Requirement and Total Energy Requirement. Vegetarianism. Mechanical Preparation of Vegetable Food. Nitrogen Balance. Tissue Protein and Circulating Protein. Specific-Dynamic Action of Protein. Physiological Value of Various Proteins. Heterospecific and Homospecific Proteins. Food Composed of Simple Substances. Velocity of Protein Catabolism. Metabolism in Fasting. How Long May Hunger and Thirst be Endured? Loss of Weight of the Organs. Total Metabolism in Inanition. Protein Economics in Inanition. Carbohydrate Metabolism. Urine in Inanition. Respiratory Quotient. Hibernation. Rhine Salmon; Batrachian Larvæ. Sensation of Hunger. Parenteral Introduction of Protein. Parenteral Feeding with Sugar. Parenteral Feeding with Fat.

XX1. Technic of Study of Gas Exchange. Maintenance Metabolism and Growth. Energy Exchange from Ingestion of Food 514 Methods of Gas Exchange Studies. Pettenkofer Type of Respiration Apparatus. Regnault and Reiset Type of Respiration Apparatus. Respiration Calorimeter of Atwater and Benedict. Method of Zuntz and Geppert. Other Methods. Question of Part Taken by Elemental Nitrogen and Hydrogen in Metabolism. Maintenance Exchange and Growth. Significance of Surface Development and Volume of Body Protein. Energy Calculation in Infancy. Laws of Growth. Energy Exchange after Ingestion of Food. Physiological Utilization Value. Range of Metabolic Increase. Work of Digestion. Specific-Dynamic Effect of Proteins.

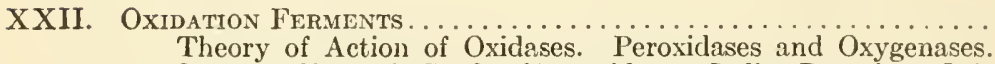
Sources of Error in Study of Peroxidases. Iodine Reaction. Oxidation of Formic Acid. Purpurogallin Method. Phenolphthalin Method. Leucomalachite-green Methods. Measurement of Oxygen Consumption. Limit of Availability of Above Methods. Peroxidase-like Action of Hæmoglobin. Chemico-Legal Detection of Blood by Means of Peroxidase Reactions. Respiratory Coloring Substances. Artificial Peroxidases. Doubt as to the Ferment Character of Peroxidases. Indophenoloxidases. Purin Oxidases. Aldehydases. Summary.

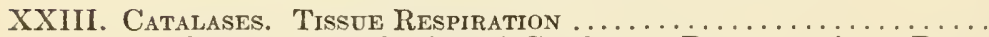
Catalases. Definition of Catalases. Demonstration. Determination of Activity of Catalase Preparations. Physiological Significance of Catalases. Tissue Respiration. Cardinal and Accessory Respiration. Reducing Tissue Components. Oxygen Consumption in the Blood. Living and Dead Protein. Methods of Study of the Respiration of Isolated Organs. Barcroft and Haldane Blood Gas Analysis. Cohnheim's Respiration Apparatus for Isolated Organs. Thunberg's Microrespirometer. Gas Interchange of Muscle. Oxygen Requirement of Nervous Tissue. Gas Interchange of Salivary Glands. Gas Exchange in the Liver and Kidney. Gas Exchange in the Intestine. Anoxybiotic Processes. 
XXiV. The Coloring Matter of the Blood. Blood Gases. Gas InterChange in the Lungs. Physiology of Alpinism .......... 579 Hæmoglobin. Production of Hæmoglobin Crystals. Variability of Hæmoglobin. Hæmochrome and Crystallized Blood Coloring Niatter. Individuality of Hæmoglobin. Importance of Iron in the Blood Coloring Matter. Methæmoglobin. Blood Gases. Teclnic of Blood-Gas Analysis. Objective Hæmoglobinometry and Spectrophotometry. Coefficients of Absorption, Invasion and Evasion. Tension Curves. Influence of Carbonic Acid Pressure. Influence of Temperature. Influence of the Salts in the Medium and Other Factors. Physical-Chemical Conception of Oxygen Fixation by Hæmoglobin. Carbonic Acid Combination in Blood. Process of Exchange Between the Blood Corpuscles and Scrum. Gas Exchange in the Lung. Mechanism of Gas Exchange. Secretion of Oxygen in the Swim-Bladder of Fish. Partial Pulmonary Exclusion. Cutaneous Respiration. Intestinal Respiration. Physiology of Alpinism. Sources of Observation Material. Influence of Climatic Factors. Increase of Blood Corpuscles. Changes in Cardiac Activity. Changes of Respiration. Acapnia. Loss in Alkalescence of the Blood. Increase of Energy Exchange. Nitrogen Retention.

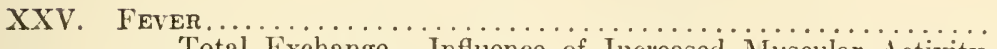

Total Exchange. Influence of Increased Muscular Activity. Increase of Reaction Velocity of Metabolic Processes with the Temperature. Frugality of Body in Chronic Febrile Conditions. Respiratory Quotient. Reduction Power of Tissues. Decreased Heat Elimination. Protein Destruction. Inhibition of Febrile Protein Destruction by Increasing Carbohydrate Food. Elimination of Nitrogenous Metabolic End-Products. Acidosis and Fat Destruction. Relation of Carbohydrate Metabolism to Fever. Changes in the Constitution of Blood Plasma. Water Economy in Fever. Swelling of Cellular Protoplasm. Chlorine Retention. Chemical and Physical Heat Regulation. Importance of Nervous System in-Regulation of Temperature. Fixation of Heat Regulation at a Higher Level. Increased Excitability of Heat Regulating Centres in Fever and its Reduction by Antipyretics. Pyrogenic Properties of Proteins and Protein Derivatives. Fever Following the Introduction of Corpuscular Elements into the Circulation. Hyperthermias Produced by Chemically Definite Substances. Salt- and Sugar-Fever. Significance of Fever. Epilogue. 



\title{
THE PHYSIOLOGICAL AND PATHOLOGICAL CHEMISTRY OF METABOLISM
}

\author{
CHAPITER I
}

INTRODUCTION TO THE STUDY OF METABOLISM. PROTEIN DIGESTION IN THE STOMACH

\section{INTRODUCTORY}

Every one knows full well with what feelings of joy and satisfaction the mountain climber after long and tiresome trudging at last reaches some hoped-for height and views the silent space around and about him. If fortune smile and the blue dome arch out before him without a cloud to its farthest reaches, how easy it is for the wanderer to lose himself in contemplation of the unending, shining distances, and to allow to dawn within him a shadowy presentment of the eternal and infinite. But days of such good luck are rare; much more often the traveller on the heights must be satisfied if spiteful mists do not completely cheat him of the reward of his labor, and if some little part of the majesty he had hoped to look upon remain unfilched from view. It may well be that only one small part in all that mountain world stands forth in sharply outlined configuration to satisfy his gaze. All other regions seem covered by a, vast cloak of vapor, with only the uncertain shadows of grosser outlines shown. In the far distances lie thick banks of clouds and rolling, steaming shapes of mist, sweeping out from the clefts, clinging in the valleys, and refusing to permit even a guess of what lies buried behind them.

So, too, with us, after long and tiresome wandering, this mountain pass is attained $;^{1}$ from which we may hope to. advance some little way, perchance, into the broad, mysterious domain of the physiology of metabolism. In allur-

${ }^{1}$ Referring to the series of lectures preceding the present text, in the volume entitled "Chemistry of the Tissues," in the original German edition. 
ing change are unfolded splendid open stretches in full bright light, and dark cloaks of vapor with only here and there a ray breaking through; thick, still banks of clouds, and rolling veils of mist through which the picture, before clear and transparent, becomes in the next moment dark and uncertain.

We view with wonder and admiration the vast amount of labor which has been devoted to the study of metabolism since the days when Lavoisier first recognized the vital combustion processes and since, long after, Robert Meyer and Herman v. Helmholtz inflamed with their genius a torch destined to cast its beams of light into the darkness of all fact and error in the domain of vital phenomena. Under the dominance of the law of conservation of energy the newer physiology of nutrition, founded by Liebig, Pettenkofer, Voit and Pflüger, is seen to arise; modern chemistry at the task of uncovering the secrets of the intermediate metabolism; and pathologists in earnest endeavor to open to physiology the experiments on man which nature provides. But, on the other hand, liow slow the steps of progress to one who never turns to observe the long path already traversed but keeps ever before him the goal constantly receding into the distance before his advance.

In undertaking to present a clear outline of the problems which mainly occupy the attention of metabolic physiologists to-day it seems best to the author, in conformity with the plan followed in the preceding volume upon the Chemistry of the Tissues, which started with a discussion of the protein problem, to begin this study of metabolism also with the proteins. The proteins and their catabolic products will be first considered, tracing them from their ingestion into the stomach as food, in their course through the body until their derivatives disappear in the unknown processes of intermediate metabolism. In turn the carbohydrates and fats will be taken up in the same way; in preparation for the consideration, finally, of the vital combustion processes, the most important phases of metabolic physiology. It is no short and 
easy path along which the student is invited to trudge witl the author. Yet it is scarcely in harmony with the duty of a guide that at the very beginning of an ascent he should paint fearful pictures of its difficulties. It is very much better to take up the way confidently and without misgivings, and to postpone to convenience all matters of reflection.

Without further introduction, therefore, the subjectmatter of the lecture may be taken up:

\section{PROTEIN DIGESTION IN THE STOMACH}

In all the mammalia, it need scarcely be said, the food after mechanical preparation by mastication passes to a reservoir, the stomach, where its proteid constituents undergo at once the first phase of digestion under the influence of the peptic ferment of the stomach.

"Mock Meal" and Pawlow's Ventriculus.-Investigations bearing upon the secretion of the gastric digestive juice in subjects having operative or traumatic gastric fistulas date back to the first half of the past century. A systematic experimental study of the problem of the secretory function of the gastric mucous membrane was first made possible when Pawlow ${ }^{1 a}$ perfected a satisfactory technic of artificial production of gastric fistula.

In his method the osophagus is diverted in the neck, in a $d o g$ in which a gastric fistula has been produced, to the surface and the orifice is stitched into the skin wound; so that by the passage of a "mock meal" considerable quantities of pure gastric juice without admixture of food substances may be obtained from the fistula, as all the food given the hungry animal passes out of the upper part of the gullet to the exterior, while at the same time the nervous secretory stimulus ("psychic secretion") excited by the act of chewing operates without complicating factors.

Pawlow contributed another important step by his modification of Haidenhain's method of making a ventriculus or

${ }^{1}$ a J. P. Pawlow, Arbeit der Verdauungsdrüsen, Wiesbaden, 1898; and Nagel's Handb. d. Physiol., 2, 699-762, 1907. 
"little stomach." By simply cutting out of the gastric wall a section, closing the wound in the stomach and stitching the blind sac constructed from the exsected patch into the abdominal wound, a "ventriculus" is formed, which during digestion secretes coincidently with the stomach itself. In the older method, however, the secretory nerves are divided and the secretory conditions are therefore by no means normal. Pawlow corrected this fault in his method of operating, by freeing completely only the mucous membrane of the patch and sparing a pedicle of the serous and muscular coats in attachment with the stomach proper, so that the vagus fibres going to the mucosa may pass from the wall of the large stomach to that of the small stomach by route of the pedicle. He has been able to show that the vagus nerve actually conducts secretory impulses to the stomach by the following methods. If both vagi are excluded, either by section or by atropine, the usual result of the "mock meal" fails to appear; by stimulation of a peripheral vagus segment gastric secretion can be induced, provided stimulation is not practiced immediately after the section but preferably after sufficient time has elapsed for the degeneration of the vagus cardiac fibres.

Nervous Mechanism of Secretion.-Efficient secretory stimulus, passing from the cortex of the brain by way of the vagus nerves to the stomach, producing in case of the "mock meal" experiment a full complement of active gastric juice, fails after section of the vagi; but after a time a certain amount of gastric adaptation takes place whereby a continuous secretion is maintained sufficient for the digestive requirements. ${ }^{2}$ Bickel has observed continuous secretion of normal gastric juice in the nerveless stomach in a dog in which he cut all the extra gastric nerves of a gastric diverticulum. ${ }^{3}$

${ }^{2}$ P. Katschowsky (Pawlow's Laboratory), Pflüger's Arch., 84, 6, 1901.

${ }^{3}$ A. Bickel, Deutsche med. Wochenschr., 1909, 704. Literature on the neuro-secretory mechanism of gastric secretion: A. Bickel, Handb. d. Biochemie, $3^{\prime}, 58-63,1910$. 
By a long series of painstaking and carefully conducted investigations, the majority of which were done in the Institute of St. Petersburg and in the laboratory of A. Bickel in Berlin, the excito-secretory influence exerted upon the gastric secretion by a great variety of physiological and pathological factors lias been determined, including foodstuffs, condiments, mineral waters, medicinal substances, and the like. ${ }^{4}$ These studies have been very materially supplemented by observations upon human beings with gastric fistulas, ${ }^{5}$ in whom occasionally the same conditions have existed as obtain in the experimental "mock meal" procedures. For example, in the case of a girl who had had a gastric fistula produced after a corrosive lesion of the œsophagus, an œsophagotomy was later performed, and by means of a rubber tube direct communication established between the end of the upper csophageal segment and the gastric fistula. Well-masticated morsels were transmitted with considerable force by the muscles of the gullet along this artificial œsophagus into the stomach; while by removal of the communicating tube the precise arrangement of a regular "mock-meal" experiment was obtained.

Action of Psychic Influences.-In endeavoring to come to some definite understanding from the various studies upon animals and human beings as to the factors by which the secretion of the gastric juice is most actively affected, we cannot fail to recognize the dominating agency of psychic influence. We know to-day that under appropriate conditions the mere idea of a toothsome meal, and to a greater degree the actual mastication of such food, not only "make the mouth water" but also make the juices of the stomach flow. An associative gastric-juice production has been clearly proved to

- Literature: O. Cohnheim, Nagel's Handb. d. Physiol., 2, 534-542, 1907. A. Bickel, Handb. d. Biochemie, 3', 66-70, 1910.

- Observations of F. A. Hornborg, F. Umber, H. Bogen, A. Bickel, Sasaki, H. Kaznelson, Pflüger's Archiv., 118, 327, 1907 ; R. S. Lavenson, Arch. Int. Med., 4, 271, 1909; Cf. O. Cohnheim, Die Physiologie d. Verd. u. Ernährung, p. 57, 1908. 
exist in the case of a child with gastric fistula. Each time the little patient received food a certain note was sounded on a child's trumpet; and after' a time, during which this practice was continued, the sound of the trumpet alone, without the actual food, sufficed to cause a flow of gastric secretion. ${ }^{6}$ That anger and agitation disturb the appetite is a comparatively common experience of almost every one of us. But Bickel has produced experimental evidence in the same line, by showing that a dog whose equanimity was banished by the irritating sight of a cat not only manifested loss of appetite from anger, but in addition suffered actual cessation of gastric secretion during his period of indignation. ${ }^{7}$ The normal taste perceptions are, however, not invariable precedents of actual gastric secretion; as Coronedi observed in the course of a "mock meal" experiment the production of an entirely normal gastric juice after having completely anæsthetized the tongue of the experiment animal against sense-perception by painting it with cocaine solution. ${ }^{8}$

Excito-Secretory Stimuli.-Mechanical irritants have little effect in inducing secretion of the gastric juice. However, although Pawlow has denied their influence completely, Arthur Schiff has been able to present evidence that chronic irritation, as from sand particles and similar substances in fluid suspension, may be effective, at least in the sense of increasing the secretory flow. ${ }^{9}$ In the same connection may be mentioned the fact that in dogs with the pylorus constricted by a silver band there occurs a continuous gastric secretion. ${ }^{10}$

In comparing various foodstuffs, the most active secretory flow is noted after feeding meat. It has been shown, too, that meat-extractives are particularly influential; but

'H. Bogen (Kinderklinik, Heidelberg), Pflüger's Arch., 117, 150, 1907.

${ }^{7}$ A. Bickel, Deutsclie med. Wochenschr., 1905, 1829.

${ }^{8}$ G. Coronedi and F. Delitala, Arch. di Fisiol (Festschr. f. Fano), 7, 17 ; Centralbl. f. d. Ges. Biol., 10, No. 1915, 1910.

'A. Schiff (Inst. R. Paltauf), Zeitschr. f. klin. Med., 61, 220, 1907.

${ }^{10}$ N. B. Foster and A. V. S. Lambert, Proc. Soc. Exper. Biol., 5, 109, 1908. 
it is not known to what particular component of the extract this special secretion-stimulation is due. The flesh of fish seems to be more effective than other meats. ${ }^{11}$ Extracts of yeast are much less active than meat-extract. ${ }^{12}$ The latter shows marked influence, too, if introduced subcutaneously or per rectum. It is scarcely practicable liere to enter into detailed mention of the action of the great mass of bitter stuffs, alkaloids, alcohol, mineral waters and neutral salts upon gastric secretion ${ }^{13}$; but in actual practice all these substances are of medicinal interest in the therapy of hyperacidity and hypersecretion. It is but fair to remark, however, that in this connection we are not upon safe ground, particularly as many of the affections which clinicians have been in the habit of classifying under the terms just stated, should, perhaps, be classed as disturbances of gastric motility, hyperæsthesia of the gastric mucous membrane and other comparable conditions. ${ }^{14}$

While not assuming from a theoretical standpoint to enter into a full discussion of this subject, the author is unwilling to pass over a group of other factors of significant physiological character, of importance in stimulating secretion of the gastric juice. An attempt has been made to establish a relation between the salivary glands and gastric secretion, from the circumstance that total extirpaion of the former in the dog has seemingly occasioned a considerable diminution of the gastric secretion ${ }^{15}$; but the correctness of this assertion has been questioned. ${ }^{18}$

Gastric Secretin.-It has been observed that when neutralized gastric juice or the product of acid-extraction of the gastric and intestinal mucous membranes and of many other

${ }^{11}$ Cf. B. Lönnquist, Skand. Arch. f. Physiol., 18, 194, 1906. W. N. Boldyreff, Arch. f. Verdauungskr., 15, 268, 1909.

${ }^{12} \mathrm{~W}$. Hofimann and M. Wintgen, Arch. f. Hrgiene, 61, 187, 1907.

${ }^{23}$ Literature: A. Bickel, Handb. d. Biochem., 3', 66-69, 1910.

${ }^{14} \mathrm{Cf}$. V. Rubow, Arch. f. Verdauungskr., 12, 1, 1906; R. Kaufmann, Zeitschr. f. klin. Med., 5\%, 491, 1905.

is Hemmeter, Biochem. Zeitschr., 11, 238, 1908.

${ }^{18}$ A. S. Löwenhart and D. R. Hooker, Proc. Soc. Exper. Biol., 5, 114, 1908. 
tissues is introduced subcutaneously or intravenously, secretion of gastric juice ensues. ${ }^{17}$ Bayliss and Starling are therefore disposed to accept the existence of a "gastric secretin." According to this view the normal secretory activity of the gastric mucous membrane is to be referred to two factors: the more important rôle is to be ascribed, of course, to the nervous stimuli transmitted by the vagus nerves; but a second influence, determining the continuation of secretion long after the influence of the first has ceased, is held to be an agency of chemical nature. This is believed to be a specific substance generated in the pyloric mucous membrane under the influence of acid, which, passing into the blood, is returned to the mucous membrane of the stomach as a "hormone" or chemical messenger, stimulating it to renewed secretory activity. ${ }^{18}$ Discussion of the hypothesis is postponed to the following lecture in connection with the subject of the pancreatic secretin.

Inhibition of Secretion.-In addition to those influences which induce secretion of gastric juice, others are known which act to inhibit it, an example being manifested in the failure to secrete following the introduction of fatty foods into the stomach. Pawlow has shown that the inhibition in such case arises rather from the duodenum than from the stomach. Apparently alkalies also act to inhibit the secretion at times by an influence arising from the intestine. Attention has recently been called by clinicians to the absence of free hydrochloric acid in the gastric secretion in cases of disease of the gall-bladder, and to the value of this phenomenon in diagnosis. ${ }^{19}$

Origin of Free $\mathrm{HCl}$ in Mucous Membrane of Stomach.This brings us again to the old problem of the nature of

${ }^{17}$ Edkins, Jour. of Physiol., 34, 133, 1906.

is E. H. Starling, Lectures on Recent Advances in the Physiology of Digestion, p. 75, et seq., London, 1906; W. M. Bayliss and E. H. Starling, Ergebn. d. Physiol., 5, 676-677, 1906.

${ }^{10} \mathrm{H}$. Hohlweg (Voit's Clinic at Giessen), Deutsche Arch. f. klin. Med, $108,255,1912$. 
the particular process by which the gastric mucosa is enabled to separate a free mineral acid as a secretory product. There is no occasion to weary the reader with a statement of the older attempts to explain the phenomenon. Neither the idea of mass-action of carbonic acid, nor that of alkali-binding by lecithin-albumen, nor that of a supposed impermeability of the gastric mucous membrane to chlorine ions has withstood criticism ${ }^{20}$; and it has been impossible to find in the mucous membrane of the stomach any organic compounds of chlorine from the dissociation of which hydrochloric acid could by any possibility be produced. ${ }^{21}$ It is entirely reasonable to regard the sodium chloride of the ingested food as the source of the gastric hydrochloric acid. Rosemann has established by careful investigation the fact that it is impossible to produce any important reduction of the chlorine stored in the economy by starvation and the use of food poor in chlorine, because the system is able to protect itself against chlorine impoverishment by lowering the excretion of chlorine in the urine to a minimum. It is possible, of course, to withdraw considerable amounts of chlorine from the body by "mock feeding" because of the hydrochloric acid secretion thus induced. In the end secretion of fluid ceases, and that, too, at a time when the general body still contains a notable amount of chlorine. Apparently only abcut one-fifth of the total chlorine content of the body can be discharged in the gastric secretion. ${ }^{22}$ From studies conducted upon a professional female starvationist it has been determined that even after a twenty-four day fast the stomach will respond to the stimulus of a test-breakfast by production of a fluid which

${ }^{\circ}$ Cf. L. v. Rhorer, Pflïger's Arch., 150, 416, 1905.

^H. Dauwe, Arch. f. Verdauungskr., 11, 137, 1905.

$\approx$ H. Rosemann (Münster), Pflüger's Arch., 142, 208, 1911; cf. also references of J. Wohlgemuth, Exp. Untersuchungen über den Einfluss des Kochsalzes auf den Chlorgehalt des Magensaftes, Berlin, Hirschwald, 1906; and also the older investigations of Nencki, Külz, A. Kahn and others. 
while showing decided lowering of the hydrochloric acid is nevertheless entirely able to digest. ${ }^{23}$

If free hydrochloric acid is to be derived from sodium chloride, the latter must react with water in conformity with the equation: $\mathrm{NaCl}+\mathrm{H}_{2} \mathrm{O}=\mathrm{NaOH}+\mathrm{HCl}$. For each molecule of hydrochloric acid thus separated a molecule of sodium hydroxide must remain in the organism. This may explain why at the height of the acid secretion the sodium chloride excretion in the urine is diminished and why in the ensuing period of resorption of the strongly acid contents of the stomach more ammonia fails to be synthesized into urea, being utilized to neutralize the free acid. ${ }^{24}$ We may conceive, too, why the body of an animal in the state of chlorine starvation reacts to sodium chloride administration by a notable increase of alkalinity of the urine (as pointed out by the author's lamented friend, Leo Schwarz, in Hofmeister's laboratory ${ }^{25}$ ). The fact that the hydrochloric acid of the gastric juice can be replaced by hydrobromic acid up to a certain degree indicates that sodium bromide acts in a comparable manner.

Physicochemical Explanations.-Attempts have been frequently made to apply the modern ideas of physical chemistry to the problem of the production of $\mathrm{HCl}$ in the gastric juice. When the ion theory began slowly to penetrate into the minds of biologists it came to be recognized that often an explanation may be realized by expressing a problem in the terms of the theory of ions. As a matter of fact, as you know, if to-day a problem is laid before the great public, no matter how learnedly, in technical phrases, the real meaning is no more grasped than if it had been told in the Spanish or Russian language. Unfortunately here and there we can

${ }^{23}$ L. Rütimeyer (Basel), Zentralbl. f. innere Med., 1909, 233.

"A. Müller and P. Saxl (I. Med. Clinic, Vienna), Zeitschr. f. klin. Med., $56,546,1905$; A. Loeb (Med. Clinic, Strassburg), ibid., 56, 1905; S. A. Gammeltoft (Copenhagen), Zeitschr. f. physiol. Chemie, 75, 57, 1911.

${ }^{25}$ L. Schwarz (Physiol. Chem. Instit., Strassburg), Hofmeister's Beiträge, 5, 56, 1903 ; cf., ibid., also the work of FaIck, M. Gruber, and Rosell. 
still find in modern science (especially in medicine) some lingering residuum of the painstaking endeavors of the masters of the Middle Ages to impress properly the audience with the fact of the extreme difficulty of understanding their very learned disquisitions.

However, a physicochemical explanation in point is to be found in the proposition which Daneel predicates upon the principle of ion activity: If it be conceived that free organic acids are produced in the gastric mucous membrane (and we have every reason for assuming that the production of free lactic acid is a function common to cells in general, although the acid is quickly neutralized by the alkalies of the circulating fluids), we may represent by the symbol $R$ an organic acid radical; and the dissociation of sodium chloride and of acid would follow the formulas:

$$
\begin{aligned}
& \mathrm{NaCl}=\mathrm{Na}^{\prime}+\mathrm{Cl}^{\prime} \\
& \mathrm{HR}=\mathrm{H}^{\prime}+\mathrm{R}^{\prime} .
\end{aligned}
$$

Of the two cations $\mathrm{H}^{\prime}$ is more active than $\mathrm{Na}^{\prime}$ and of the anions $\mathrm{Cl}^{\prime}$ more active than $\mathrm{R}^{\prime}$; wherefore from a mixture of sodium chloride and organic acid it is possible for $\mathrm{HCl}$ to form by diffusion, as if the stronger mineral acid were driven out of its salt by the much weaker organic acid. It would, of course, not be difficult for any physical chemist to raise exception to this method of explanation. The author, however, has a constant feeling that more attention should be given to the matter; but further progress in the chemistry of colloids, particularly in the obscure field of the phenomena of adsorption, must doubtless be attained before the subject can be further clarified.

Acid-production by Marine Snails.-In this place it is possible only in the briefest manner to remind the reader that the gastric production of acid among mammals is by no means an isolated phenomenon of this sort in nature. When Johannes Müller visited Messina in 1854 he saw with astonishment that a streak of fluid from the proboscis of the 
large "partridge-shell"' snail, Dolium galea, on coming in contact with the marble tiles with which the room was paved, caused an effervescence just as if some strong acid had been dropped upon the tile. Since then we have come to know that a number of marine snails secrete an acid salivary fluid, and that that of Dolium contains appreciable amounts of free sulphuric acid. ${ }^{26}$

Determination of Acidity of Gastric Juice.-In any observation relative to acid secretion in the gastric juice the quantitative determination of the free hydrochloric acid is naturally a matter of much importance; some of the more definite advancements of method deserving brief mention at this time. A number of new features have been added to the old color reactions for the recognition of free hydrochloric acid, as the employment in modification of Günzberg's reagent of a mixture of p-oxybenzaldehyde with phloroglucin or of a mixture of dimethylamidobenzaldehyde with indol. It is of more importance, however, that we have come to recognize that estimation of the true acidity of the gastric juice, that is, its hydrogen ion concentration, is impossible by simple titration. For this we need either measurement of the electromotor power of the actual hydrogen-concentration chains ${ }^{27}$ or the indicator method. In Müller's method gastric juice is mixed with a solution of tropæolin; the fluid then assumes a color, which ranges according to the degree of acidity between a reddish brown and yellow, and by comparison with a color scale the percentage presence of "free hydrochloric acid" can be directly determined.28 The method of Dreser ${ }^{29}$ is based on quite a

${ }^{26}$ Literature upon Acid Secretion in Gastropoda: O. v. Fürth, Vergleichende chemische Physiologie der niederen Tiere, pp. 208-215, Jena, 1903.

${ }^{27}$ C. Foà, C. R. Soc. de Biol., 1905, I, 865; Il, 2; F. Tangl, Pflïger's Arch., 115, 64, 1906. L. Michaelis and H. Davidsohn, Zeitschr. f. exper. Pathol. 8, 398, 1910; J. Christiansen (Copenhagen), Deutsche Arch. f. klin. Med., 102, $103,1911$.

${ }^{28}$ A. Müller (Clinic of v. Noorden, Vienna), Med. Klinik, 1909, 1438.

${ }^{29}$ H. Dreser, Hofmeister's Beitr., 8, 285, 1906. 
different principle. An excess of relatively insoluble barium oxalate is added to the gastric juice as "ground substance" and the quantity of oxalic acid thrown into solution by the hydrochloric acid is estimated by titration with potassium permanganate. In another test ${ }^{30}$ the amount of iodine freed from a mixture of potassium iodide and potassium iodate in the presence of hydrochloric acid is determined by titration and used as measure of the latter. The test proposed by Holmgren ${ }^{31}$ is particularly original; it is based upon the adsorption of acids in capillary media. If an acid solution is allowed to drop from a pipette upon a filter paper spread out horizontally it will be observed that, as the drop spreads out circularly, only the central part of the moist cirele shows an acid reaction, the peripheral part containing nothing but water. The acid moieties are thus more freely adsorbed by the filter paper than the water molecules. And it has been shown that the more concentrated the acid the narrower the acid-free ring at the margin; and that the surface of the central circular acid area and that of the peripheral acid-free zone vary in relation to each other, according to the acidity of the solution employed. The outcome is strikingly regular, and the results may be obtained almost at a glance if the paper used has been colored with litmus; and the test, carried out in a very few moments, accords a fairly delicate estimate for practical purposes of the acidity of a sample of gastric juice. A very small quantity of the latter, about one-tenth of a cubic centimeter, serves for the determination.

Binding of the Hydrochloric Acid by Protein Bodies.There is no lack of methods, it is true, for the determination of the free bydrochloric acid in the gastric juice; but the question then comes up as to what can be the particular value of them at best. For it must be confessed that the importance of determining free hydrochloric acid, especially

${ }^{30}$ M. Wegrumba (Berne), Internat. Beitr. z. Pathol. u. Ther. d. Ernährungsstörungen, $3,53,1911$.

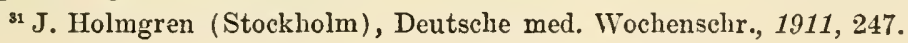


for clinical purposes, has been very much overestimated. The actual facts may from a practical standpoint be stated without hesitation as follows: The free hydrochloric acid of the gastric juice in the presence of albuminous food is quickly linked either completely or partly to the proteins or their cleavage products. It should be kept in mind that proteins are such weak bases that their salts are open to extensive hydrolytic dissociation ${ }^{32}$-so much so that in dissolving them a part only of a given protein-salt remains as such, the remainder reverting at once to protein and free hydrochloric acid. The old belief was that the free acid alone had any important bearing upon the digestion, and it was for this reason that so much stress was laid upon its estimation. ${ }^{33}$ It was doubted, for example, because the measurement of the concentration of hydrogen-ions in the infant's stomach showed only very low tension, whether the pepsin here could have as its chief function a digestive activity or whether it would not much more likely act as a lab ferment. $^{34}$ It seems important that, as Julius Schütz demonstrated, the presence of $\mathrm{H}$-ions is not absolutely necessary for peptic digestion; the process begins at once in the presence of no more than a very small amount of combined acid (hydrochloric acid linked to albumin). Schütz believes that the principal purpose of the excessive (i.e., "free") hydrochloric acid is probably to protect the native proteins from loss of the hydrochloric acid linked to them which the proteid catabolic products arising in the course of digestion endeavor to abstract; that therefore it is no more than a reserve stock. From this point of view it is not the relative concentration but the absolute quantity of free acid present which should stand as a measure of the

Literature: O. Cohnheim, Nagel's Handb. d. Physiol., 2, 543-547, 1907.

${ }^{8}$ Cf. A. Müller (I. Med. Clinic, Vienna), Deutsche Arch. f. klin. Med., 94, 27, 1908.

${ }^{34}$ H. Davidsohn, Zeitschr. f. Kinderheilk., 2, 420, 1911. 
intensity of the digestive process. ${ }^{35}$ Then, too, there exist very suggestive observations indicative of the impossibility of obtaining by distillation free hydrochloric acid from gastric juice during active digestion. ${ }^{36}$ In contradistinction to this idea there are, of course, other authors who insist that the presence of free hydrochloric acid is absolutely essential for thorough utilization of the food. ${ }^{37}$

Extent of Protein Digestion in the Stomach.--Let us now turn to the question as to the extent to which protein digestion actually takes place in the stomach and the catabolic products which are normally produced there. This subject has been so well worked out that the actual facts of the matter can be stated very briefly, even though the literature thereupon is extensive. ${ }^{38}$ This is due primarily to the labors of Edgard Zunz, of Brussels, ${ }^{39}$ conducted by him with much success through a long series of years, and also to the united work of London and Abderhalden ${ }^{40}$ and their numerous collaborators, their studies combining happily the most advanced ideas of a finished fistula-technique with those of the chemistry of proteins.

"The coagulated proteins of meat," to quote E. Zunz, writing about ten years ago, "41 "are in turn dissolved in the

${ }^{3} \mathrm{~J}$. Schütz, Wiener med. Wochenschr., 1906, Nos. 41 and 42; Biochem. Zeitschr., 22, 33, 1909; Arch. f. Verdauungskr., 17, 11, 1911; note Literature in latter article; cf., also, H. Jastrowitz (Siegfried's Lab.), Biochem. Zeitschr., $2,157,1906$.

${ }^{38} \mathrm{~F}$. Landolph, Nouvelles études chimiques sur le suc gastrique: Buenos Aires, 1911; Zentralbl. f. Physiol., 25, 539, 1911.

${ }^{37}$ Cf. G. Ewald (Med. Clinic, Erlangen), Deutsche Arch. f. klin. Med., 106, 498, 1912 .

${ }^{38}$ Literature upon the extent of gastric digestion: E. Zunz, Ergebn. d. Physiol., 5, 622-663, 1906 ; E. S. London, Handb. d. Biochemie, 3", 68-80, 1909.

${ }^{3}$ E. Zunz, l. c. and Bullctin de la Société roy. des Sciences méd. et natur. de Bruxelles, 1910, No. 3; Mémoires couronnés et autres mémoires publiés par l'Acad. roy. de méd. de Belgique, 19, 3, 1906; 20, 1, 1908; Bull. de l'Acad. roy. de méd. de Belgique, 24, 241, 1910; abstracted in Jahresb. f. Tierchem., 40, 371.

${ }^{40}$ E. Abderhalden and E. S. London, together with K. Kautsch, L. Baumann, O. Prym, K. v. Körösy, C. Vögtlin, Zeitschr. f. physiol. Chem., 48, 549, 1906 ; $51,383,1907 ; 53,147,343,1907$.

E. Zunz, Hofmeister's Beitr., 3, 339, 1902. 
stomach by the gastric juice, in which process there arise a very small proportion of acid-albumin, a large quantity of albumoses and a smaller quantity of more advanced digestive products (peptone, peptoids, and perhaps some of the crystallizable end-products). The portion which has been dissolved passes for the most part into the small intestine, where it rapidly undergoes further dissociation and resorption. A small residue is resorbed directly in the stomach; the advanced products of digestion are next to be absorbed, while albumoses are taken up with difficulty." The author has in a previous volume (Vol. I of this series, p. 77, et seq., The Chemistry of the Tissues) taken occasion to indicate the change of view which has arisen within the past decade in respect to the albumoses, which in strict parlance are no longer accepted. The schematic tables of the sequence of the various types of "albumoses" and "peptones" in the course of gastric digestion, on which so much time and labor used to be expended, have today become practically meaningless. But it is important, as established by Abderhalden and London, that cleavage of aminoacids from the protein molecule scarcely occurs at all in the stomach, as, too, that synthetic polypeptids supplied are not appreciably affected. ${ }^{\mathbf{2}}$ The velocity of solution depends upon the nature of the protein (for instance, gelatine is "digested" much more rapidly than serum-albumin or egg-albumin). The dissolved proteins of the gastric contents correspond for the most part to the old definition of "albumoses." Another important matter is the rapidity of passage of the dissolved material in the stomach into the intestine. It has been long known that the degree of coagulation of the proteins is here an important matter and that it makes decided difference whether they are ingested raw or cooked. There are, moreover, other items not well understood. For example, while raw egg-albumin has left a dog's stomach, for the most part

${ }^{12}$ E. Abderhalden and E. S. London, 1. c. 
changed, within but little more than an hour, raw meat is retained for considerably longer time. ${ }^{43}$

The resorption of the products of protein cleavage in the stomach is always of very minor importance. Meat and albumin leave the stomach of the dog, according to London, without having undergone any notable nitrogenous resorption. Moreover, the products of protein catabolism, which are readily absorbed in the intestine, can be quantitatively recovered if in the stomach even for a number of hours. is true, however, that Salaskin, in agreement with the older views, insists upon the actual absorption of protein substances in the stomach.) ${ }^{44}$

In this connection the reduced ability of proteins which have been acted upon by pepsin and hydrochloric acid to withstand the subsequent action of trypsin, as pointed out by Carl Oppenheimer and Aron ${ }^{45}$ and by Emil Fischer and Abderhalden ${ }^{46}$ has important physiological bearing.

As the gastric function in protein digestion therefore is in a general way a preparatory one it cannot be regarded as a very wonderful thing that it has been found possible to perform complete gastrectomy in animals and in man, since the well-known experiments of Karl Ludwig and Ogata and the actual total extirpation of the human stomach by Czerny. ${ }^{47}$

As to the extent of resorption, opinions vary widely. While London, as above stated, regards it as of little consequence, Scheunert ${ }^{48}$ accepts for the stomach a fixed power of absorption as proved (basing his opinion upon the observa-

${ }^{4}$ E. S. London, with W. Polowzowa, A. Th. Sulima, C. Schwarz, Zeitschr. f. physiol. Chemie., 46, 209, 1905; 49, 328, 1906; $68,378,1910$.

4 S. Salaskin, Zeitschr. f. physiol. Chem., 51, 167, 1907.

${ }_{45}$ C. Oppenheimer and H. Aron, Hofmeister's Beitr., 4, 279, 1903.

* E. Fischer and E. Abderhalden, Zeitschr. f. physiol. Chem., 40, 215, 1903.

${ }^{4}$ M. Ogata, G. Carvallo and V. Pachon, Langenbuch, C. Schlatter; also

A. Carrel, G. M. Meyer and P. A. Levene, Amer. Jour. of Physiol., 26, 369, 1910 ;

E. S. London and W. F. Dagaew, Zeitschr. f. physiol. Chem., 7/, 330, 1911.

A A. Scheunert, Zeitschr. f. physiol. Chem., 51, 519, 1907. 
tions of Lang and Tobler, as well as his own, upon horses and dogs).

Comparative Physiological Considerations.-Our view of physiological processes of any sort is bound to be unduly warped and limited if we confine ourselves to human beings and the ordinary laboratory experiment animals. Nothing less than a consideration of all classes of life forms can assure a thoroughly scientific basis. William Biedermann ${ }^{49}$ by the monumental work in which he has collected and critically dealt with the whole mass of material bearing on digestion from the standpoint of comparative physiology, has certainly earned a claim to general gratitude from all who are concerned with biological studies. The author feels that at least a few brief considerations should be given to this side of the subject, restricting himself, however, to the vertebrates because he has elsewhere dealt with the chemistry of digestion in invertebrates. ${ }^{50}$

In the first place, among fishes ${ }^{51}$ there occur forms without stomachs (among others, amphioxus, the cyclostomata and cyprinoids). In the cyprinoid fishes the opening of the gall duct lies just back of the osophageal opening into the intestine; and, of course, it is impossible that in such case there could be the least trace of gastric digestion in its ordinary meaning. Most fishes, however, possess a stomach, the glands of which secrete an enzyme capable of digesting protein substance in an acid reaction. The most exact work in this connection has been done upon the selachians. There is divergence of opinion as to the existence of free hydrochloric acid in the gastric juice of sharks (recently

${ }^{49}$ W. Biedermann, Handb. d. vergl. Physiol., H. Winterstein, 2' (Die Aufnahme, Verarbeitung und Assimilation der Nïhrung, pp. 1563, Jena, 1911). ${ }^{{ }^{\circ}} \mathrm{O}$. v. Fürth, Vergleichende chemische Physiologie der niederen Tiere, pp. 140-330, Jena, 1903.

${ }^{11}$ Literature upon gastric digestion in fish: A. Scheunert, Handb. d. Biochem., 3"' 163-167, 1909; W. Biedermann, 1. c., pp. 1088-1106; cf. also D. D. Van Slyke and G. F. White, Journ. of Biol. Chem., 9, 209, 1911. 
discussed by E. Weinland and by M. van Herwerden) ${ }^{52}$ but for that matter the entire question is of lessened importance, since we have come to recognize the positive influence of combined hydrochloric acid in peptic digestion (v. sup.). Besides, the pepsin of fishes apparently is not entirely identical with that of the mammalia.

Gastric digestion in amphibia, reptiles and birds ${ }^{53}$ corresponds doubtless with the peptic type. In graminivorous birds, whose food is first acted upon in a crop, the peptic catabolism of protein may begin even in this organ.

From the point of systematic investigation of the comparative physiology of digestion in mammals ${ }^{54}$ Ellenberger and Scheunert, scientists in the Veterinary High School in Dresden, have rendered most important service. In the ruminants, with three complex proventricles preceding the glandular stomach, it goes without saying that complicated processes of digestion are met. The hamster with its twochambered stomach presents interesting features, the first lined with a cutaneous type of mucous membrane and connected by a very narrow opening with the glandular stomach proper, thus occupying an intermediate position between the many-chambered stomach of the ruminants and the singlechambered stomach of the solipeds, the hog and other mammals. The digestion of the food proteins by the gastric juice takes place only in the gland-bearing stomach, while

${ }^{6}$ M. van Herwerden (Physiol. Institut., Utrecht), Zeitschr. f. physiol. Chem., 56, 453, 1908; E. Weinland, Zeitschr. f. Biol., 55, 58, 1911.

${ }^{23}$ Literature upon gastric digestion in Amphibia, Reptiles and Birds: A. Scheunert, Handb. d. Biochem., $\Im^{\prime \prime}, 168-170,1909$; W. Biedermann, l. c., pp. 1272-1281.

* Literature upon the comparative physiology of gastric digestion in Mammalia: A. Scheunert, Handb. d. Biochem., 3", 153-162, 1909; W. Biedermann, l. c., pp. 1299-1311; W. Ellenberger and A. Scheunert, Lehrb. d. vergl. Physiol., Berlin, P. Parey, 1910; A. Scheunert, Vergleichende Studien über den Eiweiszabbau im Magen, O. Wallach, Festchrift, Göttingen, 1909; and Pfliiger's Arch., 109, 145, 1905, and 139, 131, 1911; A. Scheunert and E. Rosenfeld, Deutsche tierïrztl. Wochenschr., 17, No. 25; A. Scheunert and IV. Grimmer, Zeitschr. f. physiol. Chem., 58, 27, 1906; E. Rosenfeld, Inaug. Diss., Leipzig, 1908; A. Schattke, Inaug. Diss., Dresden, 1909; F. Bengen and G. Haane, Pflüger's Arch., 106, 267, 286, 1905. 
in the proventricle processes of bacterial decomposition of the proteins may be in play. However, even in animals with simple stomachs the details of the process may show variations. For example, in the dog, as above mentioned, the proteid catabolic products arising in the stomacl consist for the most part of albumoses; while in the horse the quantity of albumoses is never marked enough to permit their predominance over syntonins, peptones and abiuret products.

At this point we may take up at least briefly a consideration of the digestive ferment of the stomach, pepsin. ${ }^{55}$

Efforts to Isolate Pepsin.-A great deal of effort has been expended in attempts to isolate pepsin, ${ }^{56}$ and an apparently albumin-free ferment has a number of times been obtained, although usually it is thrown down along with other precipitates of extremely varied types. Thus in Hofmeister's laboratory ${ }^{57}$ a pepsin, "albumin-free"' in the ordinary sense, has been produced by expression by a Buchner press from gastric mucous membrane ground up with infusorial earth, filtration of the fluid through a Chamberland filter, subsequent dialysation (Brücke's method), and displaced with an alcohol-ether solution of cholesterin. The pepsin adheres to the separating cholesterin precipitate. By suspending the latter in water and removing the cholesterin with ether, there remains a clear fluid with active digestive power failing to show protein reaction or lab activity. These occasionally recurring efforts to produce "analytically pure" pepsin are growing more and more infrequent, as it is gradually being appreciated that at best it is a fruitless labor. Even if in the end, after much care and effort, a ferment is obtained so thoronghly isolated that a protein reaction can no longer be

${ }^{65}$ Literature upon pepsin: A. Cohnheim, Nagel's Handb. d. Physiol., 2, 548-552, 1907; F. Samuely, Handb. d. Biochem., 1, 546, 1909; A. Bickel, ibid., 3', 100, 1910; C. Oppenheimer, Fermente, III. Aufl., 256-280, 1910; W. Biedermann, 2, I. Hälfte, 1257-1264, 1911.

${ }^{6 B}$ Recent experiments of Sundberg, Sjöquist, Mrs. Schoumow-Simonowsky, Friedenthal, Pekelharing, Schrumpf and others.

${ }^{\circ} \mathrm{P}$. S'chrumpf, Hofmeister's Beitr., 6, 396, 1905. 
obtained there is bound to remain the objection that this means nothing more than that enzyme action may continue in degrees of dilution in which the most delicate reactions fail to show protein. It is utterly impossible for any man at the present time to say whether the ferments are of a proteid nature or not. When a French physiologist gave it as his opinion that ferments are in no sense material, but energy alone, his statement called forth vehement opposition. To-day, however, when a slow but sure change is taking place in our fundamental ideas about atoms, and the rery basis of our older conception of nature, the duality of matter and force, is decidedly wavering, such heretical theories would scarcely excite anything like the same indignation.

Methods for Estimation of Pepsin.-Numerous methods have been applied to the quantitative determination of pepsin. Grützner estimates the amount of coloring matter passing into solution in the digestion of fibrin stained with carmine, using a wedge-colorimeter. ${ }^{58}$ In Mett's method the length of a column of coagulated albumin enclosed in a fine glass tube is measured after a fixed period of digestion. Hammerschlag estimates by precipitation with Esbach's reagent the amount of undigested protein remaining after digestion of a known albumin solution for a certain fixed time. Spriggs tries to draw a conclusion from the loss of viscosity of a protein solution as to the progress of its digestion. Vollhard begins with a known solution of casein; throws out the undigested casein by sodium sulphate, and estimates the amount of digested protein in the filtrate by its alkali-binding power determinable by titration: the more advanced the digestion the more potassium or sodium hydrate required. E. Fuld arranges a series of small beakers each containing the same quantity of a hydrochloric acid solution of a pure protein, edestin, adding graduated quantities of the solution whose peptic quantity is to be

${ }^{59}$ P. v. Grützner (Tübingen), Pflüger's Arch., 144, 545, 1912. 
determined; after appropriate time for digestion sodium chloride is added to all of the samples, and the result estimated by the degree of turbidity ensuing (absent in fully digested specimens). M. Jacoby and Solms substitute ricin for edestin; Gross casein; and Rose protein (globulin) of garden-pea in modification of the latter method. ${ }^{59}$

Law of Pepsin Fermentation.-Based upon these methods it has been thought possible to establish a "fermentation law" for the activity of pepsin. The SchützBorissow rule, making the effectiveness of the pepsin proportionate to the fourth root of its quantity, has attained considerable popularity and has been very much discussed. ${ }^{60}$ Without going into the details of ferment activity it may be stated that $P$. v. Grützner ${ }^{61}$ has concluded from his careful and critical studies in reference to pepsin and trypsin "that there is no uniform law prevailing during the entire course of a process. . . . In the processes of digestive fermentation at the beginning one rule prevails, which is not the same for the intermediate stage or for the terminal part. Moreover, as stated, the absolute and relative quantity of a ferment will cause variation of the law and it is impossible to speak of a law in the usual meaning of the term for any one ferment."

Propepsin.-Pepsin does not exist in completed state in the glands of the gastric mucosa, as shown by the studies of Ebstein and Grützner and those of Langley, but in the form of a proferment which (in contrast to pepsin, which is very sensitive to alkalies) is resistant to alkali, and immediately changes into pepsin when brought in contact with hydro-

${ }^{50}$ Cf. critique of methods, P. v. Grützner (Festschr. f. G. Fano), Arch. di F'isiol., 7, 223, 1909; E. Henrotin, Ann. de la Soc. roy. des Sciences méd. et natur. de Bruxelles, 18, fasc., 2, 1908; W. C. Rose, Arch, of Intern. Med., 5, 459, 1910; A. Fubini, Gaz. Osped., 30, 409, 1909; P. W. Cobb (Cleveland), Amer. Journ. of Physiol., 13, 448, 1905.

${ }^{60} \mathrm{Cf}$. J. Schuitz (Laborat. Hofmeister), Zeitschr. f. physiol. Chem., 30, 1, 1900 ; Reichel, Wiener klin. Wochenschr., 1908, No. 30.

T. v. Griitzner, Pfliger's Arch., 1/1, 115, 1911. 
chloric acid. Glässner ${ }^{62}$ has succeeded in separating propepsin from labproferment by precipitation with uranyl acetate.

Pseudopepsin.-The existence of a pseudopepsin, obtained from the pyloric mucous membrane by the investigator mentioned, said to act under weakly alkaline reaction and to split protein with production of tryptophane, is a matter of considerable doubt; as in the first place it can scarcely be distinguished from autolytic tissue enzymes and, as is well known, the entrance of trypsin into the pylorus is not an infrequent occurrence. ${ }^{63}$

Passage of Pepsin into the Intestinal Canal.-Abderhalden has made interesting observations showing the marked readiness with which pepsin is taken up by elastin and similar substances. The pepsin may be practically all removed from the gastric juice by means of elastin. Protected within such albuminoids the enzyme may be carried into the intestine and there complete its action. Considerable amounts of active pepsin have been detected in the upper portion of the intestine by the elastin method; and apparently peptic digestion is not limited entirely to the stomach, but plays an important rôle in the intestine as well. ${ }^{64}$

Resistance of Stomach to Autodigestion.-The physiology of gastric digestion includes another problem which has long stimulated investigation in a marked degree. This concerns the method of protection of the digestive organs against self-digestion. Every thoughtful person who has ever noticed the rapidity with which a bit of albumin is digested by active gastric juice, has necessarily asked him-

${ }^{82} \mathrm{~K}$. Glässner, Hofmeister's Beitr., 1, 24, 1901.

${ }^{a s}$ Cf. the publications of F. Klug, A. Scheunert and Grimmer, Pekelharing (cited in Handb. d. Biochem., 1, 551, 1909) and F. Reach (Hofmeister's Beitr., 4, 143, 1903).

E. Abderhalden in association with F. W. Strauch, F. Wachsmuth, O. Mejer and K. Kiesewetter, Zeitschr. f. physiol. Chem., 71, 314, 339, 1911; 74, $67,411,1911$. 
self how it is that the mucosa of the living human and animal stomach is able to withstand the peptic action of the gastric juice. As early as in the eighteenth century Hunter was searching for an answer to this question; and ever since the great Claude Bernard interested himself in it it has never been dropped from the list of the day's work awaiting the physiologist. ${ }^{65}$

The author has in an earlier volume taken up the discussion of anti-ferments (in the first volume of this series, $p$. 559, Chemistry of the Tissues). Following A. Danilewski's demonstration of the existence of an antipepsin in the lining of the stomach and that of Ernst Weinland ${ }^{66}$ proving the resistance of parasitic worms to the gastric and intestinal ferments from this standpoint, numerous investigations have been made upon the subject. A diffusible agent has been found in the gastric juice which withstands heating, is resistant to acids and alkalies and is capable of inhibiting peptic activity ${ }^{67}$; but it should be remembered that blood serum freed of diffusible material by dialysis may also show antipeptic activities. ${ }^{68} \quad$ O. Schwarz, working in Hofmeister's laboratory, found after heating pepsin soluticns to above $60^{\circ}$ C. a substance capable of inhibiting peptic activity which apparently had been in the solutions before subjection to heat and which was not formed directly from the pepsin itself. ${ }^{69}$ Whether any of these contributions, however, have a physiological bearing seems decidedly questionable.

For example, knowing that pepsin can be easily separated from a solution by animal charcoal one might hesitate to

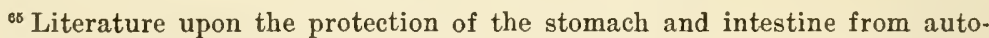
digestion: Cl. Fermi (Sassari), Centralbl. f. Bakteriol., 56, 55, 1910, and Arch. di farmacol. sperim., 10, 449, 1911 ; cf., Centralb. f. d. ges. Biol., 13, No. 369, 1912 ; C. Oppenheimer, Fermente, 3d ed., 270-271, 1910.

${ }^{66}$ E. Weinland (Physiol. Inst., Munich), Zeitschr. f. Biol., 44, 1, 45, 1902.

${ }^{67}$ L. Blum and E. Fuld, Zeitschr. f. klin. Med., 58, 5-6, 1906.

*s. Jacoby, Biochem. Zeitschr., 2, 247, 1906.

8 O. Schwarz (Physiol. Chem. Institut., Strassburg), Hofmeister's Beitr., $6,524,1905$. 
think that the prevention of the action of a gastric juice after addition of gastric epithelial cells is due solely to "antipepsin." 70

The following experiment by E. S. May in the laboratory of René du Bois-Reymond ${ }^{71}$ is instructive. The serosa and mucosa of a dog's stomach were separately prepared and spread out over glass plates, and placed in gastric juice. After eighteen hours the mucosa was not changed; but the serosa was markedly acted upon, at one place with complete penetration.

The question has been approached from another standpoint, too, by introducing living tissue into the opened stomach of an animal. Although these experiments have not been productive of uniform results (a living spleen with its blood vessels attached has been digested quite rapidly), we must accept the fact that, for example, the foot of a live frog introduced into the stomach of another frog, or perhaps a loop of living intestine placed into an incised stomach, may remain intact for many hours. ${ }^{72}$ On the other hand, very active solutions of trypsin have been known to digest living tissue (tails of rats and mice). ${ }^{73}$

In conclusion mention may be made of such observations as those of Claudio Fermi showing that many aquatic animals (protozoa, worms, crustaceans, insects) may live without the least harm in trypsin-solutions. ${ }^{74} \mathrm{~A}$ solution of trypsin, capable of rapidly digesting a large lump of coagulated albumin, has been found to be without any effect upon the tiny mass of protoplasm of an infusorian, unpro-

${ }^{70}$ R. duBois-Reymond, Berl. physiol. Ges., July 21, 1911, Centralbl. f. Physiol., 25, 774, 1911.

${ }^{71} 1 . \mathrm{c}$.

${ }^{12}$ Neumann, Centralbl. f. allg. Pathol., 18, 1, 1907; Kathe, Berliner klin. Wochenschr., 1908, 2135; Katzenstein, ibid., 1749; G. Hotz, Mitt. a. d. Grenzgebieten d. Med. u. Chir., 21, 143, 1909; R. du Bois-Reymond, l. c.

${ }^{73}$ L. Kirchheim (Labor. M. Cremer, Cologne), Arch. f. exper. Pathol., 26, $352,1911$.

16 Cl. Fermi, l. c. 
tected by any tegumentary covering, after as much as a month's exposure. The Italian author just mentioned has concluded therefore that the living cell protects itself against the digestive enzymes of the stomach, intestine, and pancreas, not by antienzymes, nor by protective coverings, nor yet by any special sort of impermeability, but much more likely by the resistive ability of the whole living cell itself. The simple reply to the question why the living cell is not attacked is therefore this: "Because it is alive." With such an answer the problem has circled back to exactly the same point where Hunter started one hundred and forty years ago. It is to be hoped that perhaps the next century and a half will really accomplish something in the way of progress.

Origin of the Round Ulcer of the Stomach.-In a limited way the question as to the mode of origin of the round ulcer of the stomach is related with that of gastric autodigestion. Time after time explanations for this lesion have proposed some local circulatory disturbance in a given area of the mucosa (from a spasm of the vessels, thrombosis or hemorrhage) with autolysis of the portion involved.75 We have been able repeatedly, too, to produce gastric ulcers experimentally in animals, as by injection of diphtheria toxin, ${ }^{76}$ gastrotoxic serum, ${ }^{77}$ by feeding bouillon cultures of bacterium coli, ${ }^{78}$ by repeated serum injections ${ }^{79}$ (as one of the features of anaphylaxis), as well as by the poison of the Gila monster (Heloderma suspectum). ${ }^{80}$ The last mentioned experiments (conducted under Leo Loeb)

${ }^{75} \mathrm{Cf}$. the extensive material of R. Beneke, Verh. d. Deutsche pathol. Ges., Kiel, 1908, 284.

${ }^{78}$ Rosenau and Anderson, Journ. Infect. Diseases, 4, 1, 1907.

7 M. J. Bolton, Proc. Roy. Soc., 1905-06, Series B, 77; 1909, Series B, 79, cited by Rehfuss, v. infra.

${ }^{78}$ F. B. Turck, Journ. Amer. Med. Assoc., 1906, 1753, cited by Rosenau and Anderson, $\nabla$. sup.

${ }^{79}$ Gay and Southard, Journ. of Med. Research, 1908, cited by Rehfuss, จ. infra.

${ }^{80}$ M. E. Rehfuss, University of Pennsylvania Medical Bulletin, 22, 105, 1909. 
suggest that the hemorrhages in the mucosa as well as thromboses may not be primary lesions in the production of ulcers, but rather secondary to and produced by the ulceration.

Chymosin.-A short review of the problem of the labcoagulation will serve to conclude the present lecture.

It may be confidently asserted that the question of the rennet-ferment or chymosin is the oldest physiologicalchemical problem which has concerned mankind. For, many, many thousands of years ago, when humanity was not interested in observation of nature and in contemplations about natural philosophy, the nomadic herdmen were well acquainted with the use of the gastric mucous membrane in curdling milk.

A mere glance over the extremely extensive literature dealing with the lab process gives one the impression of an impenetrable thicket of apparently diametrically opposed observations and theories, just as in the study of blood coagulation.

Starting with the observations of Hammersten many attempts have been made to outline the lab-process as a double-phased one in which the bulk of the casein is first changed into paracasein, which upon the addition of a suificient amount of ealcium salts is thrown down as the almost insoluble calcium paracaseinate or cheese, a small part of the protein remaining, however, in solution as an albumoselike whey-albumin from a coincident splitting process. This simple formulation has not entirely harmonized, however, with all the experimental findings of a large group of investigators who have been interested in the subject, relating to ferment-kinetics, the physical-chemical characteristics of milk, the inhibition and stimulation of the lab-process by various agents, to parachymosin and prochymosin, the part played by calcium salts, antiferments, and other comparable 
factors. ${ }^{81}$ The many contradictions are not to be wondered at when we remember that the lab-coagulation is really a complex process. Ivar Bang concludes his exhaustive investigations upon the subject with the opinion that the calcium salts of the milk are distributed among the organic and inorganic acids, the lactalbumin, lactoglobulin and casein; that the casein by virtue of its acid nature combines with the whole group of milk bases; that there is not one paracasein alone but that there are formed, long before coagulation is apparent, a number of different paracaseins with variable but increasing affinity for calcium phosphate, and that at a certain stage these compounds separate from solution and coagulation takes place. ${ }^{82}$

Ultramicroscopic Studies of Lab-process.-Kreidl and Neumann ${ }^{83}$ have been able to explain very satisfactorily by direct ultramicroscopic observation a number of features (especially that involved in the differences between cow's milk and human milk) which have more than once been regarded as due to variation in the degree of solution of the casein in the milk. In the milk of different species of animals there are visible minute bodies (lactokonids), possibly identical with suspended casein or caseinated calcium. "It has been shown by ultramicroscopic study of milk of various animals that in all kinds of milk except human there may be found in addition to the fat globules great numbers of a second corpuscular element. The plasmatic space

${ }^{51}$ M. Artlius, J. Bang, G. Becker, L. Blum, E. Fuld, M. van Herwerden, S. G. Hedin, H. Köttlitz, S. Löwenhart, E. Laqueur, L. Morgenroth, L. Pinkussolnn, E. Petry, C. Pagès, H. Reichel, K. Spiro, W. Sawjalow, B. Slowzoff, S. Schmidt-Niclsen, G. Warneken, J. Wohlgemuth and many others. Literature upon the Lab-process and the Proteins of Milk: E. Fuld, Ergebn. d. Physiol., 1, 408-504, 1902; R. W. Raudnitz, ibid., 2, 193-251, 1903; E. Laqueur, Biochem. Centralbl., 4, 318, 1905; F. Samuely, Handb. d. Biochem., 1, 567-570, 1909; C. Oppenheimer, Fermente, 3d ed., 286-312, 1909; A. Schlossmann and S. Engel, Handb. d. Biochem., $\Im^{\prime}, 405-432,1910$.

${ }^{62}$ I. Bang (Lund), Skandin. Areh. f. Physiol., 25, 105, 1911.

${ }^{83} \mathrm{~A}$. Kreidl and A. Neumann (Physiol. Instit., Univ. of Vienna), Sitzungsbericht d. Wiener Akad. Mathem-Naturwiss., kl., 117'", March, 1908; cf. also Centralbl. f. Physiol., 22, 133, 1908, Pflüger's Arch., 123, 523, 1908. 
between the fat globules is full of very minute particles in active molecular movement, often in such great numbers that nothing of the otherwise dark looking plasma is to be seen, and the whole field of vision is apparently filled by a dancing mass in which the fat globules lie embedded. . . . Fresh human milk may be distinguished from this picture at the first glance. In the human milk the plasmatic field looks black. - . . If a preparation be made of a milk with labferment added it will be seen that at first the particles collect into minute groups recognizable as composed of the lactokonids; the smaller aggregates then unite into larger ones, the latter entangling the fat globules and finally sinking to the bottom of the container. . . . Coincidently in the tube from which the preparation was taken coagulation can be grossly seen.",

From this one would picture the lab coagulation as a process characterized by the gradual clumping of suspended colloidal particles, the individual phases of which are constantly intermingling and therefore beyond any chance of schematic arrangement in chemistry. Here, just as in case of the process of blood coagulation, one cannot but feel that too much importance has been assigned to the details of a separation process which is an expression of disturbance of equilibrium, and that too at tremendous expense of effort and ingenuity. An architect who is seeking information about the collapse of a building is, of course, particularly anxious to discover the cause of the collapse. But he would scarcely waste any great amount of energy in finding out in detail whether at the moment of the fall a certain gable or a certain arch had given way a little earlier or later or a little to one side or to the other.

Bacterial Involvement in Lab-process.-Recent observations have been made by Kreidl and Lenk ${ }^{84}$ which deserve

s. Kreidl and E. Lenk, Biochem. Zeitschr., 36, 357, 1911. 
notice, bearing upon the participation of a hitherto neglected factor, that of bacterial infection, in the process of labcoagulation. They point out that sterile milk will not coagulate in sterile vessels if treated with sterile rennin; but merely touching the milk with the non-sterile finger or the addition of a few drops of ordinary milk will cause curding.

Much thought has been devoted to the formulation of an acceptable conception of the physiological purpose of the lab-process. That an eventual change of the milk introduced into the stomach into a firm curd, so that this can pass into the intestine only bit by bit, gradually, thus protecting the intestine against being flooded with food-proteins, and that this in many animals is of importance in the nourishment of the young,-all this goes without question. There is reason to question, however, whether the greatest value of the remnin, which is found widely distributed in the digestive organs of vertebrates, many invertebrates and, too, in the juices of many plants, ${ }^{85}$ should not be sought for in an altogether different direction.

Plastins.-Observations of A. Danilewski and his numerous students ${ }^{86}$ that rennin (and also extracts of intestine and of pancreas) gives rise to precipitation in solutions of products of peptic digestion suggest that these precipitates may be considered as an expression of a synthetic fermentation, possibly directed toward the regeneration of the split protein. But the attractive prospect that in plastins we are seeing intermediate products of a fermentative protein synthesis, has unfortunately all too soon met the fate of the most of the brilliant expectations of this world.

Question of the Identity of Pepsin and Rennin.-Observations of this kind (mainly from Pawlow and his

${ }^{85}$ W. Biedermann, Handb. d. vergleich. Physiol., 2', 1289, 1911.

${ }^{88}$ Kurajeff, Lawrow, Lukomnik, Nürnberg, Okunew, Salaskin, Sawjalow, Schapirow and others. Cf. also R. O. Herzog, Zeitschr. f. physiol. Chem., 39, 305, 1903; H. Bayer (Hofmeister's Laborat.), Hofmeister's Beitr., 4, 554, 1903. 
school) have developed the idea that pepsin and rennin are fundamentally identical; that the lab-action is nothing else than the reversed synthetizing manifestation of the same ferment which normally behaves as a peptic protein cleavage-enzyme. This view undoubtedly is an attractive one, and meets our demand for simplification of our concepts of complicated natural phenomena. The great interest manifested in this view is probably explicable on this basis. An unusually large number of comprehensive researches have been devoted within recent years to this question of the identity of pepsin and lab-ferment. Pawlow's many associates ${ }^{87}$ are constantly directing attention to the distinct parallelism between the action of pepsin and lab. They have been unable to separate the two ferments either by diffusion, ${ }^{88}$ filtration ${ }^{89}$ or by electric conduction. ${ }^{90}$ Hammersten and very many other authors, ${ }^{91}$ on the other hand, have unquestionably produced in different ways solutions of pepsin which no longer coagulate milk, and, too, lab solutions which no longer manifest any peptic ability. An American writer ${ }^{92}$ has demonstrated that on passing an electric current under certain conditions through a fluid containing both rennin and pepsin the latter will be completely destroyed while the lab remains unchanged. The physiologist Duc-

${ }^{87}$ Cf. J. W. A. Gewin (Physiol. Instit., Utrecht.), Zeitschr. f. physiol. Chem., 54, 32, 1907; W. Sawitsch, ibid., 55, 84, 1908; IV. van Dam, ibid., 64, 316, 1910; Th. J. Migay and W. Sawitsch, ibid., 63, 405, 1909; W. Sawitsch, ibid., $68,13,1910$.

${ }^{s s}$ R. O. Herzog (Karlsruhe), Zeitschr. f. physiol. Chem., 60, 306, 1909.

${ }^{\circ}$ C. Funk and A. Niemann, Zeitschr. f. physiol. Chem., 68, 263, 1910.

${ }^{90}$ C. A. Pekelharing and W. E. Ringer, Zeitschr. f. physiol. Chem., 75, 282,1911 .

${ }^{91}$ O. Hammersten, Zeitschr. f. physiol. Chem., 56, 18, 1908; 68, 119, 1910 ; \%., 142, 1911; S. Schmidt-Nielsen (Hanımersten's Laboratory), ibid., 68, 92, 1906; A. Rakoczy, ibid., 68, 421, 1910; J. F. B. van Hasselt, ibid., 70, 171, 1910 ; A. E. Porter, Journ. of Physiol., 42, 389, 1911 ; L. Blum and IV. Böhme, Hofmeister's Beitr., 9, 74, 1906; A. E. Taylor, Journ. of Biol. Chem., 5, 399, 1909 ; A. Rakoczy (Kiew), Zeitschr. f. physiol. Chem., 68, 421, 1910.

${ }_{22}$ WV. E. Burge (Jolıns Hopkins Univ.), Amer. Journ. of Physiol., 29, $330,1912$. 
ceschi, ${ }^{93}$ working in Argentina, has shown that pepsin but not chymosin is to be found in the stomach of certain marsupials (Didelphis). In view of positive evidence like this, indicating the duality of pepsin and rennin, the frequent failure to establish such differentiation cannot, in the opinion of the author, be held as contradictory; positive results are of more significance, it seems to the author, than negative ones in such a matter. Identity between pepsin and rennin for the present at least certainly does not seem to be proved. As for the frequently expressed suggestion that the two ferments may not be precisely identical but different "sides" of one single ferment, slightly different sidechains of one "giant enzyme molecule," the author confesses his complete ignorance, not knowing how to proceed in attempting to make an exact differentiation between different enzymes and "different sidechains of some one ferment." To use the expression of a distinguished jurist, the author is not enough of an expert in this matter to see even darkly.

${ }^{93}$ V. Ducceschi (Cordova), Arch. di Fisiol., 5, 413, 1908. 


\section{CHAPTER II}

THE PROTEOLYTIC PANCREATIC FERMENT

Transfer of the Food from the Stomach into the Intestine.-The previous chapter having been devoted to the process of protein digestion in the stomach, the subject of the method of transfer of the food from the stomach into the intestine may with propriety be next considered.

This process has been approached experimentally in a variety of ways, as by the production of gastric and duodenal fistulas, by röntgenoscopy of the stomach after introducing bismuth nitrate into the food ingested, by tube analysis of the gastric contents, etc. Hofmeister and Schütz studied by direct observation the movements of a living exsected stomach kept in a moist chamber; P. v. Grützner examined frozen sections of stomachs of animals killed in different stages of digestion; Scheunert followed the movements and partition of the gastric contents by the special means of administering colored food, etc. Although it is impossible to go at length into the subject the attention of the reader should be directed at least to the importance of chemical regulation of the reflex pylorus closure from the intestine; our knowledge of which is mainly due to the recent studies of Pawlow, Moritz, Cannon, London, Cohnheim, Tobler and others. ${ }^{1}$ We know from observation that a dog with a duodenal fistula discharges the water through the fistula

${ }^{1}$ Literature upon the Passage of the Food from the Stomach into the Intestine: O. Cohnheim, Nagel's Handb. d. Physiol., 2, 560-568, 1907; Physiol. d. Verd. u. Ernähr., pp. 13-26, 1908; E. S. London, Handb. d. Biochem., 3" 6873, 1909; O. Cohnheim and F. Marchand, Zeitschr. f. Physiol. Chem., 63, 41, 1909 ; F. Best and O. Cohnheim, ibid., 69, 113, 1910; Sitzungsber. d. Heidelberger Akadamie, 1910; W. B. Cannon (Harvard Medical School), Amer. Jour. of Physiol., 20, 283, 1900; ef. also F. Meyer (Kissingen), Zeitschr. f. physiol. Chem., 71, 466, 1911; M. Kirschner and E. Mangold (Greifswald), Mitteil. a. d. Grenzgebieten d. Medizin u. Chir., 23, 446, 1911; R. Kaufmann and R. Kienböck, Med. Klinik, 1911, 1150. 
about as it is drunk, quite naturally suggesting comparison with Baron Münchhausen's well known horse, with all its drinking merely pouring out the water from the cut which has severed away the posterior half of its body. But if, instead of water, acid gastric contents come in contact with the duodenal mucous membrane, there at once occurs a reflex closure of the pylorus. In this way the intestine is protected from further flooding with acid gastric material. At the same time entrance of alkaline digestive fluids (the bile, pancreatic juice and intestinal juice) into the duodenum is brought about by the acid material, these juices neutralizing the acid. As soon as the pylorus opens again another charge of acid is expelled into the duodenum; and the same performance automatically repeats itself. According to Cannon reflex relaxation is induced directly by contact of the acid chyme apon the pars pylorica. Besides the influence of acid from the intestine, closure of the plorus may be caused by fat; and according to the studies of $\mathrm{O}$. Cohnheim and his associates it is not a matter of consequence where the oil or acid is placed in the small intestine. From the fact that cocainizing the intestine prevents the contraction the reflex nature of the act cannot be in doubt. There are, too, in all probability a number of other factors involved in the regular discharge of the gastric contents besides the hydrochloric acid and the fat of the chyme, especially the consistence of the food.

Passage of the Intestinal Contents into the Stomach.-In contrast, a matter of physiological interest, first brought to attention within the past few years, is that of the entrance of intestinal contents into the stomach, observed by Pawlow and Boldyreff. After the introduction of fatty foods particularly, but sometimes also after fasting, and, too, when there is an especially high degree of gastric acidity, it may happen that a mixture of intestinal secretion, pancreatic juice and bile regurgitates into the stomach to such an extent that the hydrochloric acid of the stomach may be neutralized and 
peptic digestion interfered with. Abderhalden and his associates have shown that the splitting of a dipeptid, glycyll-tyrosin, which is not produced normally in the stomach, can in these cases be detected in the gastric juice by polarimetry (after neutralizing the acidity of the gastric juice by sodium bicarbonate). It has been proposed to base a method for obtaining the human pancreatic juice for diagnostic purposes upon this fact. In application an "oil test-breakfast," consisting of about $200 \mathrm{ccm}$. of olive oil, containing free oleic acid, is introduced by a stomach-tube after neutralization of the gastric acidity by alkali. The gastric content withdrawn after a half hour is readily freed from the oil and often is found stained greenish by bile and may show the presence of trypsin. Whether the method, for which great expectations were entertained, will prove of actual value in diagnosis must for the present be held in judgment. ${ }^{2}$

Pancreatic Fistulas.-As is well known, the chyme having passed into the intestine becomes mixed with the secretion of the pancreatic gland, to the secretory process of which organ attention should next be called. Although Claude Bernard had introduced canulas into the excretory duct of the pancreas and had endeavored to thus study the method of secretion of this important organ, for a long time progress was not satisfactory, simply because there was too great a departure from the normal physiological conditions arising from the severity of the operative procedure. Very often after such a "temporary" fistula has been made, even if the experimental animal be in the height of digestion, but little or no secretion can be obtained. Here again the incomparable Russian physiologist, Pawlow, ${ }^{3}$ was the first to overcome

${ }^{2}$ Literature upon the Passage of Pancreatic Juice and Intestinal Fluid into the Stomach: Important monographs by W. Boldyreff, Ergebn. d. Physiol., 11, 127-213, 1911; cf. also W. Boldyreff, Pflüger's Arch., 121, 13, 1908; E. Abderhalden and F. Medigreceanu, Zeitschr. f. physiol. Chem., 57, 317, 1908; E. Abderhalden and Schittenhelm, ibid., 59, 230, 1909; J. Lewinski (Minkowski's Clinic, Greifswald), Deutsche med. Wochenschr., 1908, 1582.

${ }^{3}$ Literature upon Production of Pancreatic Fistulas: J. Pawlow, Ergebn, d. Physiol., 1, 266-272, 1902; Nagel's Handb. d. Physiol., 2, 728-742, 1907. 
the special technical difficulties. He proceeded to bring a patch of the duodenal wall surrounding the orifice of the excretory duct to the skin surface and stitched it into the cutaneous margins of the wound. In this way he obtained a permanent fistula and the advantage of continuous observation of the glandular activity at his convenience. Even with this advance in technique the results obtained were not thoroughly satisfactory because of the activation of the secretory fluid obtained from the fistula by the enterokinase (v. infra.) of the mucous membrane surrounding it. Only by careful removal of this mucous membrane which had been healed into the cutaneous wound and by isolating the orifice of the duct by stitching it to the margins of the wound can there be obtained sufficient approach to physiological conditions to insure that really normal pancreatic fluid will be obtained.

Such conditions being established it is possible to determine the influences by which the pancreas is normally stimulated. Undoubtedly the most important factor in this connection is the entrance of the acid content of the stomach into the duodenum. The hydrochloric acid is, it is safe to say, the most effective stimulant to pancreatic secretion; the influence of the fatty substances of the food is apparently more or less questionable ${ }^{4}$; but a psychic agency must in all likelihood be recognized. As to the method by which the secretion of the gland is set in operation, doubtless both nervous and chemical mechanism must be held possible.

Secretin.-Bayliss and Starling were able to demonstrate that the introduction of acid into an intestinal loop will maintain the pancreas in activity even after section of both vagi and the splanchnic nerves, and after extirpation of the solar plexus. After exclusion of all nervous communication between the intestinal loop and the rest of the body the flow of pancreatic juice is quite as free as if the nerves were in-

${ }^{4}$ O. Cohnheim and $\mathrm{Ph}$. Klee, Zeitschr. f. physiol. Chem., 78, 464, 1912. (Soaps apparently have more influence than do the neutral oils.) 
tact. From this fact the authors named conclude "it was clear that the message from the isolated loop was carried by way of the blood to the pancreas and that it must be some new type of chemical substance which originated in the intestinal mucous membrane under the influence of the acid. In confirmation of this conclusion the mucous membrane of the upper portion of the small intestine may be scraped off, mixed with 0.4 per cent. $\mathrm{HCl}$ and the mixture filtered, when it will be found that injection of this filtrate directly into the circulation will induce a special flow of pancreatic fluid. To this new substance produced under the influence of acid in the intestinal cells we have applied the name 'secretin.' ", 5

The work of the authors quoted has been amply confirmed in many quarters; and the chain of proof has been in a sense completed by Wertheimer's discovery of secretin in the blood of an isolated intestinal loop into which acid had been introduced. The well considered and masterly studies of Bayliss and Starling should be regarded as truly classical. In this connection Swale Vincent ${ }^{6}$ in a critical review of the whole question of internal secretion regards the action of secretin (after the glycogenetic function of the liver) as the best-attested example of an "internal secretion" and in strict sense more definitely established than the internal secretions of the thyroid gland and the adrenal. And yet the conditions of pancreatic secretion remain so confused that the question of the role and significance of secretin is in the author's opinion still far from final solution.

In the first place it should be remembered that, as shown by Wertheimer and Fleig, the flow of pancreatic secretion may be induced by the introduction of acid into an intestinal loop even if the blood of the loop is completely cut out from

${ }^{5}$ Literature upon Secretin: W. M. Bayliss and E. H. Starling, Ergebn. d. Physiol., 5, 670-676, 1906; E. H. Starling, Lectures on Recent Advances in the Physiology of Digestion, London, 1906; J. Pawlow, Nagel's Handb. d. Physiol., 2, 734-742, 1907 ; S. Rosenberg, ibid., 3', 141-146, 1910; C. Oppenheimer, Fermente, 3d ed., 193-194, 1910.

- Swale Vincent, Ergebn. d. Physiol., 9, 496-500, 1910. 
the general circulation and fails to pass to the pancreas. A number of authors, especially those of the Pawlow school, are disposed to assume that the pancreatic secretion is governed by a dual mechanism, partly nervous and partly humoral. ${ }^{7}$

Secretin seems to be a thermostabile substance, soluble in alcohol, not specific for any particular kind of animal, but apparently identical in all vertebrates. The belief that it is formed from a "prosecretin" when acid comes in contact with the intestinal mucosa is improbable, as it can be shown ${ }^{8}$ that solutions having secretin-like influence may be obtained by treating the mucous membrane of the intestine with sodium chloride solution, soaps, alcohol, peptone, chloral hydrate or even with hot water; the usual employment of mineral acids is readily explicable from the fact that such an agent prevents the destruction or masking of the secretin action by other agents contained in the extracts of intestinal mucous membrane. Fleig's assumption of the necessity of recognizing different kinds of secretin ("sapokrinin," "ethylokrinin," etc.), according to the method of derivation, is probably not justified. ${ }^{9}$

Secretin and Cholin and the Vasodilatins.-From an investigation which the author's friend, Carl Schwarz, ${ }^{10}$ and the author conducted, it was found that cholin exists in the secretin prepared according to the method of Bayliss and Starling. The influence of such an extract is unquestionably to be partly attributed to this base,

'Cf. A. Bylina (Institut. exp. Med., St. Petersburg), Pflüger's Arch., 142, $531,1911$.

B Delezennes, and Pozerski, Fleig, Camus, Falloise, Gley and others.

- While C. Delezennes and E. Pozerski, Journ. de Physiol., 14, 521, 540, 1912, in their most recent publications insist upon the non-existence of a "prosecretin," W. Stepp (Univ. College, London: Journ. of Physiol., 49, 441, 1912) holds that secretin practically always is to be found in the intestinal mucous membrane as prosecretin, free secretin being found only occasionally in small quantities; cf. also S. Lalou, Journ. de Physiol., 14, 241, 465, 530, 1912 ; E. Gley, ibid., 507.

${ }^{10}$ O. v. Fürth and C. Schwarz, Pflüger's Arch., 124, 427, 1908; cf. Literature thereto appended. 
the physiological influence and significance of which have elsewhere (Vol. I of this series, Chemistry of the Tissues, pp. 185-190) been detailed. Secretin cannot, however, be identified as cholin, the activities of the two substances being in no wise parallel; the secretory effect of cholin (but not of secretin) being completely eliminated by atropin. "Secretin" is, however, apparently not a simple substance, but is perhaps a mixture of a number of agents capable of exciting secretory activity, in the group of which cholin doubtless is included. Keeping in mind the fact that cholin is an exceedingly labile substance, subject to marked changes from comparatively simple disturbances (as seen, for instance, in its transformation into neurin, muscarin and acetylcholin) and to functional exaggerations (cf. Vol. I, p. 189, of this series, The Chemistry of the Tissues), it is not easy to get rid of the idea that perhaps secretin is nothing more than a mixture of cholin and of its transformation products. Of course this is no more than an unproved conjecture, which it is true would serve to bring secretin and the "vasodilatins" (probably closely related to cholin) under a common heading.

As previously indicated, cholin is one of the general tissue constituents; and from the investigations of Popielski ${ }^{11}$ and his students "vasodilatins" can doubtless be extracted from practically all tissues. These are powerful substances capable, when injected intravenously with proper precautions, of inducing fall of blood-pressure, secretion of saliva, of gastric, intestinal and pancreatic fluids, increase of peristalsis, spasms, loss of hæmic coagulability and increased flow of the lymph. Popielski believes that a relative anæmia, dependent upon the lowered blood-pressure, and consecutive irritation of the nervous centres are fundamen-

${ }^{11}$ L. Popielski (Lemberg), Centralbl. f. Physiol., 16, 505, 1902; 19, 801, 1906; Pflüger's Arch., 120, 451, 1907; 121, 239, 1908; 126, 483, 1909; 128, $191,223,1909$. 
tal to the symptom-complex; he does not accept the physiological importance of secretin for normal production of the pancreatic secretion, and, while willingly acknowledging the existence of a nervous mechanism as operative in the process, does not recognize a humoral factor. However, it must be insisted upon that, from the studies of Bayliss and Starling, the substance in intestinal extracts which depresses the blood pressure is not identical with secretin, and that secretin-containing solutions can be prepared which are apparently free from the former. It must be acknowledged that a clear insight into the matter has by no means been attained.

The attendant difficulties may be the more readily apprehended if it is recalled that the nervous mechanism concerned in the pancreatic secretory process is a complex one and is really very little understood. We know that the pancreas receives its nervous impulses both from the vagus and the splanchnic; both nerves furnish fibres to the blood vessels of the gland, and from stimulation of either according to circumstances there may be induced either increase or inhibition of the secretion. C. Schwarz ${ }^{12}$ was able to show that cholin can influence the pancreatic secretion in one way or the other according to the quantity injected, on the one hand inhibiting the flow through its excitation of the vagus centre, on the other inducing activity by stimulation of peripheral autonomous secretory nerves. It may therefore be appreciated without further discussion that it is difficult if not impossible to come to a satisfactory conclusion as to the identity or differentiation of any of the active constituents of organic extracts from simple comparison of their influences upon the pancreatic secretion and from other physiological factors. Until we are able to deal with chemically definite substances, it is to be feared we will be unable to escape from such contradictions.

${ }^{12}$ C. Schwarz (Vienna), Centralbl. f. Physiol., 23, 337, 1909. 
Mention should be made also of the fact that acid exhibition is capable of stimulating reflexly the pancreatic secretion not only from the duodenum but also, as discovered by Popielski, ${ }^{13}$ and by London and C. Schwarz, ${ }^{14}$ from a large part of the small intestine. London and Schwarz determined the fact that besides the duodenum, the whole of the jejunum and the upper portion of the ileum, but not the middle part of the ileum, manifest this ability, which therefore resides in about two-thirds of the entire length of the intestine.

Besides secretin and cholin, pilocarpin is capable of stimulating the secretory activity of the pancreas if introduced into the blood; albumoses and other similar substances may act in the same way. ${ }^{15}$

Enterokinase.-Passing to consideration of the pancreatic secretion itself, Pawlow is to be credited with the important discovery that trypsin is not secreted in a completed form. The secretion as it passes out of the duct of the gland contains rather a trypsin-zymogen, which is activated by contact with an agent arising from the intestinal mucosa, enterokinase, and is transformed thereby into true trypsin. This puzzling agent, which is also doubtless of importance in activating the human pancreatic secretion, ${ }^{16}$ has been the object of intensive study for the past few years. A group of eminent French authcrs ${ }^{17}$ and a number of other investigators ${ }^{18}$ have endeavored to determine the real nature of enterokinase; but opinions arrived at are at wide variance. ${ }^{19}$ The belief that the substance is a ferment has met with considerable oppo-

${ }^{13}$ L. Popielski, Zeitschr. f. physiol. Chem., 71, 186, 1911.

${ }^{14}$ E. S. London and C. Schwarz, Zeitschr. f. physiol. Chem., 68, 346, 1910.

${ }^{15}$ E. Gley, Journ. de Physiol., 1/f, 507, 1912.

${ }^{16}$ Observations of A. Ellinger, M. Kohn, K. Glässner and J. Wohlgemuth.

${ }^{17}$ Dastre, Camus, Delezennes, Frouin, Gley and associates.

${ }^{18}$ Bayliss and Starling, O. Cohnheim, Ciaccio, C. Foà, Hamburger and Hekma, Vernon, E. Zunz.

${ }^{19}$ Literature upon Enterokinase: Th. Brugsch, Handb. d. Biochem., 3', 115116, 1910; S. Rosenberg, ibid., 3', 127-136, 1910; C. Oppenheimer, Fermente, 3d ed., 20S-215, 1910; W. Biedermann, Winterstein's Handb. d. vergleich. Physiol., 2', 1409-1415, 1911. 
sition. A number of authors would relate the adsorptive readiness of enterokinase (as in its ready fixation by fibrin) with its action, and believe that, in the same way as in hæmolysis complement is fixed to a red blood cell by the intermediation of an amboceptor, trypsinogen is fixed to the protein molecule as complement by the binding power of enterokinase (as amboceptor). Enterokinase is a thermolabile substance; but $O$. Cohnheim's observation that it is soluble in 90 per cent. alcohol is clearly not in harmony with the idea that it is of the nature of an enzyme. It is scarcely believed any longer that enterokinase is derived from leucocytes; it is apparently directly produced from the cells of the intestinal mucous membrane, although there seems to be some active material of similar character also present in leucocytes at times.

Activation of Trypsinogen by Calcium Salts and Similar Substances.-Besides enterokinase a considerable group of other agents is known to be capable of activating trypsinogen. Calcium salts particularly have been the object of careful investigation by Delezenne in their marked relations with trypsinogen. Activation of an inactive dyalized pancreatic juice, after the latter, mixed with a salt of calcium, has been kept in an incubator for a number of hours, may result suddenly, as if explosively; if paraffined tubes have been used activation by calcium salts may be postponed for some days. $^{20}$

With special precautions activation of trypsinogen may be induced by quite a variety of colloids (as by toluidin blue). It is therefore scarcely remarkable that the expressed juices from various organs, milk and similar substances, have been found capable of inducing the same result. Even bacteria can convert trypsinogen into trypsin; the author has in an earlier volume (cf. Vol. I of this series, Chemistry of the

${ }^{20}$ Cf. also J. Wohlgemuth (Experimental Division of the Pathol. Institut., Berlin), Observations upon Human Pancreatic Fluid, Biochem. Zeitschr., 39, $302,1912$. 
Tissues, p. 501) discussed their probable relation with the genesis of the once celebrated freighting-theory (in accordance with which the pancreas was freighted with digestive ferment from the spleen).

Even trypsin itself seems to belong to the group of activators of trypsinogen; at any rate when the least amount of trypsin is introduced into an inactive solution of the ferment it is spontaneously activated.

Individuality of Trypsin.-Question has arisen whether the digestive pancreatic ferment is chemically one single substance. L. Pollack has asserted that besides the trypsin there is a mucin digesting ferment, "glutinase," in the pancreatic juice; Vernon has accepted the existence of a peptonesplitting ferment ("pancreatic erepsin"). Other investigations rather favor the idea of the individuality of the proteindigestive ferment of the pancreas. For example, the explanation of the observed fact that trypsin, first acidulated with hydrochloric acid and then neutralized, will freely digest gelatin but no other proteins is to be found in the fact that in highly alkaline conditions it digests all proteins but on addition of acid digests only gelatine; if, thereafter, alkali be added the normal digestive properties recur. ${ }^{21}$ In a recent study K. Glässner and A. Stauber have again asserted the existence of an erepsin in the pancreatic fluid along with trypsin..$^{22}$

Doubtless the activity of trypsin is influenced very largely by the ions present in the solution. A dialysed solution of trypsin, for instance, shows diminished activity; but

${ }^{21}$ H. M. Vernon, Jour. of Physiol., 30, 330, 1903; K. Mays (Laboratory of A. Kossel), Zeitschr. f. plıysiol. Chem., 38, 502, 1903; 49, 124, 188, 1906 ; W. M. Bayliss and E. H. Starling, Journ. of Physiol., 30, 61, 1903; L. Pollack, Hofmeister's Beitr., 6, 95, 1905; Arch. f. Verdauungskr., 11, 362, 1905; M. Ehrenreich, Arch. f. Verdauungskr., 11, 261, 364, 1905; A. Ascoli and B. Neppi, Zeitschr. f. physiol. Chem., 56, 135, 1908; G. Schaeffer and E. F. Terroine, Journ. de Physiol., 12, 884, 906, 1910.

${ }^{23}$ K. Glässner and A. Stauber (E. Freund's Lab.), Biochem. Zeitschr., 25, 204,1910 . 
it is interesting to note the return of its efficiency as soon as the normal salts of pancreatic fluid are added. ${ }^{23}$ Only the briefest comment can here be made upon the extensive literature dealing with the influence of variations of alkalinity, temperature, neutral salts, poisons of various kinds, "antiferments" and adsorbing media upon the activity of trypsin; the author must refer for fuller details of these subjects to Carl Oppenheimer's valuable work on ferments. ${ }^{24}$

Conversion of Trypsin into Zymoid.-The observations of Bayliss are presumably of general interest as they may perhaps bring us a step nearer to comprehension of the mystery of ferment activities. By determination of conductivity Bayliss discovered that trypsin inactivated by standing does not lose its power of fixation of protein. $\mathrm{He}$ compares the inactivation of trypsin to Ehrlich's conception of the change of a toxine into a toxoid. In the transformation of trypsin into a "zymoid" he supposes it loses its ergophore group, still retaining, however, its haptophore group, which serves to fix it to a protein molecule. There has been no lack of experiments with other ferments to apply to the enzyme problem the conceptions which have come in spite of all opposition to dominate our theories as to immunity. We may think as we will of these modes of thought; the heuristic value of these and of similar schematic ideas cannot be controverted. Their justification can be maintained, however, only until something better can be substituted..$^{25}$

Action of Trypsin Upon Polypeptids.-Undoubted progress has been accomplished by the systematic researches of Emil Fischer, Abderhalden and Bergell in determining the

${ }^{23}$ A. Frouin and A. Compton, Compt. rend., 153, 1032, 1911.

${ }^{24}$ C. Oppenheimer, Fermente, 3d ed., pp. 185-202, 1909; cf. also S. G. Hedin, Biochem. Journ., 1, 474, 484, 1906; 2, 81, 1907 ; L. Michaelis and H. Davidsohn, Biochem. Journ., 36, 280, 1910.

${ }^{25}$ W. M. Bayliss, Arch. Sciences biol., St. Petersburg, 11, supplement 261, cited by O. Cohnheim, Nagel's Handb. d. Physiol., 2, 582, 1907. 
field of tryptic action upon definite proteins, particularly in relation to chemically pure polypeptids; the situation is comparable to one in which of two unknowns in an equation, if one may somehow be eliminated, the theoretical possibility of a solution attained is probable. What are the structural peculiarities upon which the possibility of a given polypeptid being acted upon by trypsin depends? "The (molecular) structure of the individual compounds comes into consideration at once," says Abderhalden. ${ }^{26}$ "An instructive example is found in the relation of alanyl-glycin $\left(\mathrm{CH}_{3} \cdot \mathrm{CH}\left(\mathrm{NH}_{2}\right)\right.$. $\mathrm{CO}$. $\left.\mathrm{NH} . \mathrm{CH}_{2} \cdot \mathrm{COOH}\right)$ and its isomer glycyl-alanin $\left(\mathrm{NH}_{2} \cdot \mathrm{CH}_{2}\right.$. CO.NH.CH $\left(\mathrm{CH}_{3}\right)$.COOH). The former is split, the latter is not. The particular kind of amino acid is also of importance. In the dipeptids, for example, hydrolysis is favored if alanin acts as acyl. The resistance of dipeptids containing $a$-aminobutyric acid, a-aminovalerianic acid and leucin as acyl is very notable. The number of aminoacids concerned in the structure of a polypeptid is also of importance. The glycin group illustrates this nicely. Gylcyl-glycin, diglycylglycin and triglycyl-glycin are not split; while hydrolysis takes place in case of tetraglycyl-glycin." It is of special interest, however, that pancreatic fluid splits only those polypeptids in whose molecular structure the natural opticallyactive aminoacids take part; and that the economy, if raceme bodies are at its disposition, may often be able to utilize only one of the two optically opposite components. This is true both for the mammalian body and for the lowest forms of plants (cf. Vol. I of this series, Chemistry of the Tissues, p. 15).

Adaptation of Pancreatic Secretion to the Food.-The Pawlow school has assumed a general adaptability of the secretion of the pancreas to the particular type of food which may obtain at any given time; in other words, that

${ }^{26}$ E. Abderhalden, Lehrb. d. physiol. Chem., 2d ed., 626-628, 1909; cf. Literature, thereto appended. 
the pancreas adapts itself to its work in, as it were, an intelligent manner, by increasing its proteolytic ferment for meat, its amylolytic ferment for a meal of bread, or its lactose ferment for milk. This view, however, cannot withstand criticism; it bespeaks an effort to realize a harmonious principle pervading the arrangements of nature which goes somewhat too far afield. ${ }^{27}$

Quantitative Determination and Ferment Law of Trypsin.-The realization that there are a number of physiological questions related with trypsin which rest upon the possibility of its quantitative determination, has, as in case of pepsin and by employment of similar principles, led to numerous attempts to accomplish this. Thus Metts' tubes of albumin or gelatin have been used. ${ }^{28}$ Trypsin has been allowed to act upon dissolved casein, after Vollhard's method, ${ }^{29}$ and from the increase of acidity of the resulting albumoses the degree of digestion has been determined by titration. Gross ${ }^{30}$ dissolves casein in soda solutions (as in E. Fuld's method), arranges a series of tubes with increasing amounts of trypsin, and observes after a time whether acidulation with acetic acid continues to give rise to turbidity. Jacoby ${ }^{31} \mathrm{ob}-$ serves the degree of clearing of deposits of ricin or edestin; V. Henri ${ }^{32}$ and Bayliss ${ }^{33}$ follow the progress of digestion physico-chemically by determining the conductivity, and Brailsford Robertson ${ }^{34}$ by determining the refraction index of a soda-casein-solution after precipitation of undigested casein by acetic acid. A simple and apparently very precise

${ }^{27}$ Literature upon Adaptation of Pancreatic Secretion to Food: S. Rosenberg, Handb. d. Biochem., 3', 138-140, 1910.

${ }_{29}$ P. Hattori, Arch. internat. de Pharm., 18, 255, 1909.

${ }^{20}$ W. Löhlein, Hofmeister's Beitr., 7, 120, 1905; Faubel, ibid., 10, 35, 1907.

${ }^{30}$ O. Gross, Arch. f. exper. Pathol., 58, 157, 1908.

${ }^{81}$ M. Jacoby, Biochem. Zeitschr., 10, 299, 1908.

${ }^{82} \mathrm{~V}$. Henri, and Larguier des Bancels, C. R. Soc. de Biol., 55, 563, 787, 866; Jahresber. f. Tierchem., 38, 512-514, 1903.

${ }^{83}$ W. M. Bayliss, 1. c.

${ }^{84} \mathrm{~T}$. Brailsford Robertson, Journ. of Biol. Chem., 12, 23, 1912. 
method has been devised by P. . Grützner ${ }^{35}$ on the principle of his method of estimating pepsin. Fibrin is stained with Spiritblau (diphenylrosanilin) and the color given to the digestive fluid when the fibrin is digested in a 0.1 per cent. soda solution is determined colorometrically.

While the Schütz-Borissow rule may be found applicable within certain limits for the digestion of solid proteins, there seems to exist for dissolved proteins a simple ratio between the quantity of ferment and quantity of protein dissolved by it. "Both groups," thinks Palladin, "6re "are correct, those who believe that the Schütz-Borissow rule obtains for trypsin and those who think that Vollhard's rule of direct ratio applies. It is not of consequence which method is used. Probably the truth is that one ferment molecule does exactly as much work as any other, that $\mathrm{n}$ molecules will do $\mathrm{n}$ times as much as one in case no accidental inbibition occurs and the ferment molecules can have full access to their prey (if the term be permitted), that is to the protein, which is all that Grützner proved for pepsin originally."

Toxicity of Parenterally Introduced Trypsin.-Reference may here be made to a matter of general physiological interest, the toxicity which parenterally introduced trypsin or pancreatic tissue manifests upon the body. In spite of the resistance of living tissues to digestive ferments, mentioned in the preceding lecture, there unquestionably is a decided production of necrosis when trypsin is injected subcutaneously. When the pancreas of a dog undergoes necrosis death quickly ensues, and that whether the pancreas was that belonging to the animal or a foreign gland transplanted under aseptic precaution. It is very interesting, as discovered by Achalme, that animals may be immunized to a high degree against this toxic influence by

${ }^{35}$ A. Palladin (Physiol. Institut., Tübingen), Pflüger's Arch., 134, 337, 1910 ; W. Wald sehmidt, ibid., 143, 189, 1911.

${ }^{36}$ P. Palladin, 1. c., p. 364 . 
previous gradual treatment with trypsin. G. v. Bergmann has been able to induce in dogs such a high grade of immunity that the animals were able to bear the implantation of an entire foreign pancreas, a procedure which in unprepared animals is followed by death within twenty hours at most. ${ }^{37}$

It may be conjectured that the toxic effect of the parenterally introduced trypsin depends upon a sudden hydrolytic cleavage of the proteins in the living body produced in the same way as trypsin in vitro dissociates proteids. To determine this point experimentally the author with his colleague, Carl Schwarz, ${ }^{38}$ has studied the effect of intraperitoneal injections of emulsions of pancreas introduced under aseptic precautions. Although acute toxic symptoms were produced in the experiment animals, the latter could be protected by previous treatment with increasing dosage of trypsin, and rendered resistant to comparatively large amounts of the pancreatic material. By careful metabolic studies the investigators were able to prove that intraperitoneal injections of large amounts of trypsin or pancreatic tissue disturbs the nitrogen balance so that for one or two weeks the nitrogen excretion is irregular (a series of irregular increases and decreases). The total nitrogen output was, however, not altered, as might have been expected if an exaggerated protein destruction and important catabolism of the tissue proteids had taken place. It is by no means safe to conclude that the marked toxicity of parenterally introduced trypsin is to be referred to a direct influence upon protein-metabolism. According to Fischler, animals which have been previously treated with trypsin

${ }^{\text {ar }}$ P. Achalme, Ann. de l'Instit. Pasteur., 15, 737, 1901; G. v. Bergmann, Zeitschr. f. exper. Pathol., 3, 400, 1906; G. Dorberauer, Beitr. z. klin. Chir., 48, 456, 1906; N. Gulecke, Arch. f. klin. Chir., 85, 644, 1908; G. v. Bergmann and N. Gulecke, Münchener med. Wochenschr., 57, 1673, 1910; D. Kirchheim (Cologne), Verh. d. Kongr. f. innere Med., 27, 595, 1910.

${ }^{s}$ O. v. Fürth and C. Schwarz, Biochem. Zeitschr., 20, 384, 1909. 
react to very small amounts of phosphorus or hydrazin by suffering marked fatty degeneration of the liver. ${ }^{39}$

The question of "antitrypsin" in the serum has been elsewhere discussed, and the author prefers not to return to this rather uninteresting subject. In what manner trypsin normally gains access to the blood circulation cannot easily be determined with certainty; especially when the body is flooded with the enzyme it has been recognized in the urine. ${ }^{40}$ When it is remembered how little we know of the changes many chemically well-defined substances undergo in the animal body, it does not seem at all remarkable that the fate of so indefinite a substance as trypsin remains unknown.

${ }^{30}$ Fischler and Wolff, 29. Kongr. f. innere Med., 19, IV, 1912.

${ }^{40} \mathrm{~K}$. Bamberg (II Med. Clin., F. Kraus, Berlin), Zeitschr. f. exper. Pathol., 5, 742, 1909; E. Graf von Schönborn, Zeitschr. f. Biol., 53, 386, 1910. 


\section{CHAPTER III}

\section{PROTEIN-DIGESTION IN THE INTESTINE}

Erepsin.-In the preceding chapters we have dealt in some detail with pepsin and trypsin. Our attention is now turned to a third ferment directly involved in protein-digestion, the erepsin of the intestinal secretion, the discovery of which is due to the acuteness of observation of Otto Cohnheim.

Erepsin is an enzyme which does not act upon most of the native albumins, but reduces albumoses and peptones to crystallizable products. "In connection with the action of erepsin upon the individual intermediate substances between albumin and the amino acids," Cohnheim observes, "it should be said that peptones, that is peptones corresponding to Kühne's conception, lose the ability to respond to the biuret-reaction very quickly, within minutes or hours, when in contact with erepsin-solutions, very much more rapidly than I have ever observed when they are brought in contact with active pancreatic extract. Erepsin acts much more slowly upon the various albumoses, weeks elapsing before the disappearance of the biuret-reaction, which is in fact a rather deceptive phenomenon. Kutscher, Seemann and Weinland, who have worked with erepsin only upon albumin and who because of the slowness of the loss of biuret-reaction have denied any real importance to erepsin in digestion, are contradicted by these differences." The influence of erepsin is, however, not limited to the protein derivatives of higher molecular composition. Polypeptids are also split, as shown by the investigations of Abderhalden and his associates and the studies of $\mathrm{H}$. Euler. Thus the albumoses and peptones formed from ingested proteins by the action of 
pepsin and trypsin fall very quickly as prey to erepsin and are broken down into their final crystallizable dissociationproducts. ${ }^{1}$

At first 0 . Cohnheim's brilliant discovery was questioned by many, but later was so fully confirmed ${ }^{2}$ that its correctness cannot logically be doubted. Erepsin is neither identical with trypsin nor does it come from the pancreas. Even where the pancreatic secretion cannot gain access to the intestine, as in case of a Thiry fistula ${ }^{3}$ or after ligation of the pancreatic ducts, ${ }^{4}$ a rich supply of erepsin is found in the intestine and its association with pepsin under these circumstances accounts for the continlied albumin dissociation in the intestine. ${ }^{5}$

If, however, the pancreas be completely extirpated or atrophied, general metabolic disturbances ensue of so marked a type that there can be no wonder that protein digestion should eventually suffer. It is a misconception to class erepsin among the autolytic tissue ferments. Some such erepsin-like influence may be met, according to Vernon, in many different tissues, which will be considered in the following lecture; this is really a phenomenon due entirely to endocellular enzymes, whereas erepsin undoubtedly belongs in the intestinal secretion. It is, however, not a matter of much consequence about the name, if the facts of its capability are kept clearly in mind.

${ }^{1}$ Literature upon Erepsin: O. Cohnheim, Nagel's Handb. d. Physiol., 2, 583-585, 1907; Physiol. d. Verd. u. Ernährung, Berlin and Vienna, 1908, p. 217 ; F. Samuely, Handb. d. Biochem., 1, 555, 1909; Th. Brugsch, ibid., 3', 112115, 1910; C. Oppenheimer, Fermente, 3d ed., 181-184, 1909.

${ }^{2}$ Kutscher and Seemann, S. S. Salaskin, A. Falloise, J. I. Hamburger and E. Hekma, L. Tobler, M. Nagajama, Lambert, C. Foâ, L. Weekers, E. Raubitschek, L. Langstein and Soldin, G. Amantea and others.

${ }^{3}$ L. Weekers, Arch. intern. de Physiol., 2, 49 ; eited Centralbl. f. Physiol., $19,90,1905$.

'Th. Brugsch, Zeitschr. f. exper. Pathol., 6, 326, 1909; K. Glässner and A. Stauber (E. Freund's Lab.), Biochem. Zeitschr., 25, 204, 1910; E. Zunz and L. Mayer, Bull. Acad. de Méd. de Belgique (4), 19, 509; Jalıresber. f. Tierchem., 85, 491, 1905.

'Literature: O. Prym, Handb. d. Biochem., $3^{\prime \prime}$, 106-107 (1909). 
There can be no objection to regarding erepsin in the light of a "heterolytic" ferment, however, even if it be not an "autolytic" one.

From such considerations it is evident that nature has fully provided means to insure the splitting of the proteid constituents of the food into their end-products. We are in position, therefore, to proceed a step further and take up the question whether there is any evidence that the provision can be traced as actually operative in normal digestion in further measure. ${ }^{6}$

Extent of Protein Dissociation in the Intestine.-The classical investigation by Carl Ludwig and Salvioli should be recalled showing that peptone solution may disappear from the lumen of a loop of the small intestine (artificially perfused with blood) without peptone becoming demonstrable in the blood used in perfusion. Later, in 1881, Franz Hofmeister, whose pupil the author was, demonstrated the disappearance of peptone when brought in contact with gastric mucosa in extracorporeal conditions; and N. Neumeister made a similar demonstration for the intestinal mucosa. The interpretation of these fundamental and amply corroborated observations suggesting a resorption process, at a later date was modified by the discovery, mainly due to work by Kutscher and Seemann, Cohnheim, Cathcart and Leathes, ${ }^{7}$ that, while albumoses and peptones disappear when brought in contact outside the body with intestinal mucosa, this is due not to their resorption but to their dissociation into more simple protein derivatives.

Moreover, the investigations of these authors, and chiefly

${ }^{6}$ Literature upon the Extent of Protein Dissociation in the Intestine: J. Munk, Ergebn. d. Physiol., 1, 310-317, 1902; O. Cohnheim, Nagel's Handb. d. Physiol., 2, 629, 1907; H. Lüthje, Ergebn. d. Physiol., \%, 800-804, 1908; 0. Prym, Handb. d. Biochem., 3", 102, 1909; W. Biedermann, Winterstein's Handb. d. vergl. Physiol., $2^{\prime \prime}, 1448-1449,1911$.

${ }^{2}$ F. Kutscher and J. Seemann, Zeitschr. f. physiol. Chem., 3.4, 528, 1902; 35, 432, 1902; 49, 298, 1907; O. Cohnheim, ibid., 33, 451, 1901; 36, 13, 1902; $49,64,1906$; 51, 415, 1907; E. P. Cathcart and J. B. Leathes, Journ. of Physiol., 39, 462, 1905. 
numerous studies prosecuted by Abderhalden, London and their associates, ${ }^{8}$ left no doubt as to the constant presence of considerable amounts of aminoacids in the contents of the intestine (even if dissociation is apparently not complete), and too of notable quantities of polypeptoids. ${ }^{9}$ The intestinal contents differ decidedly in this from the gastric content, which, as a rule, shows no aminoacids at all or at most only traces. (In the instances in which these substances do occur in the stomach, as in the omasum of ruminants, the possibility of the existence of ferments in the food itself must be considered, ${ }^{10}$ as it has been indicated from the work of the Ellenberger Institute that under certain circumstances autolytic ferments may relieve the animal intestine in part of its work of digestion and may act as substitutes for the body enzymes.) ${ }^{11}$

The later advances in the chemistry of proteins, especially Emil Fischer's ester method, formol-titration of aminoacids, etc., harmonize with these studies. The ester method cannot be applied to the determination of aminoacids in the intestinal content unless special provisions (as refrigeration during the estering process, etc.) are employed, as in the process of estering it is possible that aminoacids may be split off from proteid substances. ${ }^{12}$

It is impossible to deny that proteid substances are separated into their final derivatives; but it is another question whether resorption normally occurs only after such advanced dissociation. Three possibilities must be taken into cousideration. In the first place absorption of an impor-

${ }^{8}$ Baumann, Funk, Kautzsch, v. Körösy, Medigreceanu, Oppler, Reemlin. Literature: O. Prym, l. c.

${ }^{\circ}$ E. Aberhalden, Zcitschr. f. physiol. Chem., $74,436,1911$.

${ }^{10}$ E. Abderhalden, W. Klingemann and Th. Pappenhusen, Zeitschr. f. physiol. Chem., 71, 411, 1911.

${ }^{11}$ IV. Grimmer (Ellenberger's Lab.), Biochem. Zeitschr., 4, S0, 1907; cf. Literature, there appended.

${ }_{12}$ B. O. Pribram (Vienna), Zeitschr. f. physiol. Chem., $71,472,1911$; 72 , 504,1911 . 
tant part of the protein dissociation-derivatives as understood in the older conceptions may take place in the stage of "albumoses" and "peptones." If, however, this be not the case, and if the dissociation proceeds to the extent of producing crystallizable products, two further possibilities present themselves: either these crystallizable derivatives are absorbed as such, or they undergo a synthetic change, before entering the blood, into high-molecular protein derivatives in the intestinal wall.

Passage of True Proteins and High-molecular Proteinderivatives into the Blood.-In considering the first of these possibilities it must be granted that under certain circumstances high-molecular protein dissociation-products and, too, true proteins, can pass from the bowel into the blood. ${ }^{13}$ The precipitin reaction and anaphylactic methods assure us of the possibility of determining, with precision hitherto undreamed of, the most minute quantities of foreign proteins in the blood. ${ }^{14}$ We know today that it is possible under given conditions to determine by such methods proteid substances absorbed from the bowel, as, for example, after flooding the intestine with uncooked eggs, raw milk or blood-serum. The normal protective influence of the intestinal epithelium is apparently undeveloped in the newly-born; and, too, may be decidedly impaired by pathological processes. ${ }^{15}$ It may be shown experimentally in vitro, too, that foreign serum, toxins, hæmolysins, ferments and antiferments of various kinds diffuse more rapidly through an inflamed intestinal wall than through the normal wall of the bowel; this perhaps

${ }^{13}$ Literature upon Absorption of True Proteins and High Molecular Protein Dissociation-products from the Bowel: O. Cohnheim, Nagel's Handb. d. Physiol., 2, 624, 1907; H. Luithje, Ergebn. d. Physiol., 7, 830-835, 1908; C. Oppenheimer and L. Pincussohn, Handb. d. Biochem., 4', 705, 1011 ; P. Nolf, Journ. de Physiol., Nov., 1907.

${ }^{14}$ F. Micheli ('Turin), Giorn. Accad. Med. Torino, 73, 205, 1910.

${ }^{15}$ Ganghofner and J. Langer (Prague), Münchener med. Wochenschr., 51, 1497, 1904. 
being related to a variation in the degree of swelling. ${ }^{16}$ Where there coexists with the increased permeability of the intestinal wall a diminished retention by the urinary filter, passage of the foreign protein into the urine can be detected, ${ }^{17}$ although this does not require special renal permeability as it has long been known that after subcutaneous injection of albumoses, albumin and similar substances these substances may at times pass directly into the urine. ${ }^{18}$ It goes without saying that such facts are not only of physiological interest but are also of importance in medical practice. For instance, repeated rectal administration of egg albumin may under certain circumstances induce in experiment animals a fatal marasmic condition with anaphylactic phenomena. ${ }^{19}$ The well-known attempts of Behring to introduce anti-bodies of various kinds into children in milk is in direct relation with the question in hand. A full discussion of the subject can be found in a study made by Uffenheimer in the laboratory of Max Gruber. ${ }^{20}$

Borchhardt has been able after feeding to recover in the blood two proteids, recognizable in minute amounts because of their characteristic chemical peculiarities, hemielastin and Bence-Jones albumin (v. Vol. I, of this work, The Chemistry of the Tissues, p. 511).21 And yet Abderhalden has failed to find elastin in the blood, tissues or in the urine after administration of large quantities. ${ }^{22}$

${ }^{18}$ E. Mayerhofer and E. Przibram (R. Paltauf's Instit., Vienna), Zeitschr. f. exper. Pathol., 7, 247, 1909; Biochem. Zeitschr., 24, 453, 1910; M. Loeper and Ch. Esmonet, C. R. Soc. de Biol., 64, 445, 1908.

${ }^{17}$ R. Hecke (M. Gruber's Labor., Munich), Münchener med. Wochenschr., $56,1875,1909$.

${ }^{15} \mathrm{H}$. de Waele and A. J. J. Vandevelde (Ghent), Biochem. Zeitschr., 30, $227,1910$.

${ }^{19}$ L. Petit and J. Minet, C. R. Soc. de Biol., 64, 22, 1908.

${ }^{20}$ A. Uffenheimer, Arch. f. Hygiene, 55, 140, 1905.

${ }^{21}$ L. Borchhardt, Zeitschr. f. physiol. Chem., 51, 506, 1907; 57, 3C5, 1908; L. Borchhardt and H. Lippmann (Med. Clinic, Königsberg), Biochem. Zeitschr., פ5, 6, 1910 .

${ }^{23}$ E. Abderhalden and Rüehl, Zeitschr. f. physiol. Chem., 69, 301, 1910. 
The numerous positive findings ${ }^{23}$ of albumoses in the blood of animals during digestion are contradicted by a series of other studies in which the higher molecular products of protein dissociation were entirely missed in the blood at the height of digestion. ${ }^{24}$ A recent controversy between E. Abderhalden and E. Freund in reference to this discrepancy brings out distinctly the difficulties involved both in method and in the significance of the results of experimentation. $^{25}$ It is extremely difficult to coagulate fully the entire mass of hæmic proteins; and small protein residua which have escaped coagulation may very easily come to be looked upon as "albumoses." Then, too, as discussed in the previous volume of these lectures (Chemistry of the Tissues, p. 246), the possibility exists that noncoagulable proteid substances ("seromucoid," etc.) may be formed in the blood itself. And besides, autolytic ferments exist throughout the body, and where small amounts of albumose-like products are found in the blood they may as well have come from autolysis of the hæmic proteins as from the intestine as resorbed products of digestion. And finally it may be very properly maintained that, even if small quantities of digestion albumoses are positively detected, this does not contradict the proposition that the bulk of the products of digestion is resorbed only after complete dissociation.

${ }^{23}$ G. Embden and F. Knopp, Hofmeister's Beiträge, 3, 120, 1903 ; L. Langstein, ibid., 3, 373, 1903; G. v. Bergmann and L. Langstein, ibid., 6, 27, 1905; F. Kraus (E. Freund's Labor.), Zeitschr. f. exper. Pathol., 3, 52, 1906; E. Freund, ibid., 4, 3, 1907; O. Schumm, ibid., 4, 453, 1904; Erben, Zeitschr. f. Heilk. (Inn. Med.), 24, 70, 1903.

${ }^{24}$ R. Neumeister, Zeitschr. f. Biol., 24, 272, 1Ss8; E. Abderhalden and C. Oppenheimer, Zeitschr. f. physiol. Chem., 42, 155, 1904; E. Abderhalden, Funk and London, ibid., 51, 269, 1907 ; O. Cohnheim, Nagel's Handb. d. Plysiol., 2, 626, 1907; P. Morawitz and R. Ditschy, Arch. f. exper. Pathol., 54, 88, 1906 ; S. B. Shryver (Univers. College, London), Biochem. Journ., 1, 123, 1906.

${ }^{25}$ E. Abderhalden, Biochem. Zeitschr., 8, 368, 1908; E. Freund, ibid., 7, 361, $1908 ; 9,463,1908 ; 11,541,1908$. 
Resorption of Iodized Proteins.--The author, in association with M. Friedmann, has attempted to solve this difficulty by a study of the resorption of iodized proteid substances. ${ }^{26}$ Isolation of no particular metabolic product containing iodine was sought, but rather the iodine distribution. One can in this way determine after administration of an iodized protein what part of the iodine present at a given time in the intestinal content, the intestinal wall, in the blood and urine, exists in the form of incoagulable organic substances which can be precipitated by phosphotungstic acid (albumoses and peptones), in the form of incoagulable organic substances not precipitated by phosphotungstic acid (aminoacids), and finally how much exists in inorganic combination. The results obtained indicate that at least the bulk of the determined iodo-proteid substance (iodo-proteic acid) in absorption from the intestine of a cat is so completely dissociated that the iodine in the intestinal wall and blood appears, not in form of iodized albumoses or peptones, but as inorganic alkali iodides.

Objections to the Resorption of Albumoses and Aminoacids.-Otto Loewi ${ }^{27}$ has pointed out that as a matter of fact the toxicity of albumoses and peptones introduced directly into the blood circulation (referring to the reduction of blood coagulability and the lowering of vascular tone in the splanchnic area, shown by the investigations of SchmidtMühlheim, Fano and others) is contradictory to the idea that albumin is taken up in the form of peptone. To the objection that any important formation of aminoacids in the intestine would represent a waste of chemical tension energy lost to no purpose in the splitting process, Loewi has shown from Rubner's calorimetric determinations that in such a process certainly not above 10 per cent. of energy is lost,

${ }^{28}$ O. v. Fürth and M. Friedmann (Vienna), Arch. f. exper. Pathol. (Schmiedeberg's Festschrift), p. 214, 1908.

${ }^{27}$ O. Loewi (H. H. Meyer's Labor., Marburg), Arch. f. exper. Pathol., $48,327,1902$. 
and therefore that it is not in any sense a "purposeless waste of energy."

Residual Nitrogen.-It might very properly be supposed that, in case the aminoacids resulting from the advanced protein dissociation are actually resorbed as such, it would be a matter of little difficulty in an animal in the midst of digestive activity to detect a notable increase of residual nitrogen in the blood in the form of incoagulable compounds. ${ }^{28} \mathrm{As}$ a matter of fact, however, this is very difficult. G. v. Bergman and Langstein ${ }^{29}$ have calculated that, if, as supposed, tissue assimilation proceeds in full harmony with resorption, only a few hundredths of one per cent. of aminoacids in the portal blood will suffice to cover the total nitrogen transportation from intestine to the blood required for protein metabolism. O. Cohnheim believes that it may be concluded from observations upon the rapidity of meat digestion and the rapidity of blood circulation that even with the most active absorption and if no other tissues were involved not more than $0.03 \mathrm{~g}$. of albumin or protein dissociation products could be taken up in a litre of blood. ${ }^{30}$ According to an investigation conducted under the direction of Hofmeister ${ }^{31}$ the residual nitrogen of the blood may be reduced to three fractions: urea, "albumoses" precipitable by tannin, and aminoacids (not precipitated by tannin). The bulk, actually about threefourths, of the residual nitrogen in the blood of either the fasting or of the digesting dog, consists of urea. Of the other two fractional parts that of the aminoacids always shows definite increase during digestion. The albumose fraction is an inconstant one; even after feeding albumoses no increase was noted indicative of their entrance to the

${ }^{28}$ Literature upon the Incoagulable Nitrogen-containing Bodies of the Blood Serum: P. Morawitz, Handb. d. Biochem., 2", 80-86, 1909.

${ }^{20} \mathrm{l}$. c.

${ }^{30}$ O. Cohnheim, Physiol. d. Verd. u. Ernähr., p. 227, 1908.

${ }^{31} \mathrm{H}$. Hohlweg and H. Meyer (Physiol. Chem. Instit., Strassburg), Hofmeister's Beitr., 11, 381, 1908. 
blood in unsplit state. Folin found on resorption of glycocoll or alanin from the stomach or large intestine an increase in the residual nitrogen, usually too of the urea, in the blood..$^{32}$

There is another series of observations which are at least not contradictory to the supposition that the aminoacids pass into the blood. Pringle and Cramer ${ }^{33}$ found the blood of a digesting animal to contain a somewhat higher residual nitrogen than that of a fasting animal. Embden and his pupils have been able to detect the presence of small quantities of aminoacids in the blood and their passage into the urine by means of the naphthalin-sulphochloride method. ${ }^{34}$ In pathological states the aminoacids in the blood can doubtless be increased. According to Neuberg and Richter ${ }^{35}$ in acute yellow atrophy of the liver aminoacids may be found in such quantities as to suggest that perhaps in some way owing to the loss of hepatic function a further change of the catabolic products of proteids (split in the intestine into crystallizable products) fails to take place. In uræmia, too, at times the aminoacids are apparently increased in the blood.

Moreover it should not be overlooked that O. Cohnheim ${ }^{36}$ in his studies upon invertebrates, octopods particularly, came to the conclusion that albumin is completely catabolized in the intestine and resorbed in the form of aminoacids. These may thereafter according to requirements undergo either combustion or synthesis in the tissues.

Synthesis of the Products of Digestion.-Assuming then, as we seem fully justified in doing, that the dietary protein undergoes an advanced grade of cleavage in the

$\approx$ O. Folin, W. Denis and H. Lymann (Harvard Med. School), Journ. of Biol. Chem., 12, 141, 253, 259, 1912.

${ }^{33} \mathrm{H}$. Pringle and W. Cramer, Journ. of Physiol., 3r, 158, 1908.

$\approx$ G. Embden and H. Reese, Hoimeister's Beitr., $\%, 411$, 1905; A. Bingel, Zeitschr. f. physiol. Chem., 5\%, 382, 1908.

${ }^{33} \mathrm{C}$. Neuberg and Richter, Deutsche med. Wochenschr., 190't, 499.

${ }^{86}$ O. Cohnheim, Nagel's Handb. d. Physiol., 2, 629, 1907. 
intestine, the further question arises whether the resultant cleavage-products do not undergo either locally in the intestinal wall or in their passage thence into the blood a synthetic reconstruction in such manner that the nitrogen from the intestine comes to be found in the circulatory fluids, not in the form of aminoacids, but in high-molecular combinations. Attention may be called to the fact that Van Slyke ${ }^{37}$ has recently applied his delicate nitric acid method of determination of the aliphatic amino-group (cf. Vol. I of this series, Chemistry of the Tissues, p. 18) to the detection of aminoacid nitrogen in the blood. By this method it has been established that even large amounts of aminoacids injected intravenously disappear very quickly from the blood without anything like an important part appearing in the urine. For example, of twelve grams of alanin injected intravenously there remained after half an hour only a few decigrams in the blood, the rest being apparently transferred into the tissues. Van Slyke concludes from his investigations that the supposition of synthetic change of the aminoacids in the bowel wall is superfluous and that the smallness of the increase of aminoacids in the blood of digesting animals is entirely explicable by the avidity with which these substances are taken up by the tissues and further elaborated by them.

The results obtained by efforts to arrive at a conclusion in regard to synthetic processes from analytic comparison of the composition of the intestinal mucous membrane of fasting and digesting animals are in no sense consistent. ${ }^{38}$ It should always be remembered, however, that a number of direct observations indicate the possibility of condensation processes in the intestine.

${ }^{37}$ D. D. Van Slyke, and G. M. Meyer (Rockefeller Instit., New York), Journ. of Biol. Chem., 12, 399, 1912.

s F. Botazzi, Arch. di Fisiol., 5, 317, 1908; cited in Biochem. Centralbl., 8, 374, 1908; E. S. London, Zeitschr. f. physiol. Chem., 61, 69, 1909; P. Glagolew (St. Petersburg), Biochem. Zeitschr., 32, 222, 1910. 
Kutscher and Seemann ${ }^{39}$ have determined that relatively simple abiuret substances are included in the extractives of the intestine, which split when treated with boiling mineral acids with the production of leucin in considerable amounts. This observation may perhaps have some bearing upon the possibility of the leucin from the intestinal mucous membrane (and of many other simple products of protein cleavage) having previously undergone a process of coupling directly in the intestinal wall. Bearing upon condensation processes, the extensive observations of Danilewski and his students (vide supra, p. 30) upon plastein formation should be noted. In albumose solutions autolysed with intestinal mucous membrane an inerease of coagulable nitrogen at the expense of incoagulable nitrogen has been found,,$^{ \pm 0}$ interpreted tentatively as transformation of albumoses into serum albumin. A mixture of the digestionproducts of casein has been observed to "jell" under the influence of intestinal secretion supposedly due to the action of a ferment. ${ }^{41}$ Ernst Freund observed that upon bringing together fresh horse-serum and a solution of Witte's peptone a portion of the albumoses become coagulable, and, further, that of the serum-proteins only euglobulin shows this characteristic, and that after addition of the peptone to serum the euglobulin fraction diminishes, while the pseudoglobulin and albumin fractions increase. ${ }^{42}$ Italian authors have stated that precipitates are given by various tissue extracts, some with blood-serum, some with peptone; and have suggested the former type of precipitation as an expression of a binding of the circulating dietary protein with the tissue proteins. ${ }^{43}$

${ }^{8}$ F. Kutscher and J. Seemann (Physiol. Instit., Marburg), Zeitsch. f. physiol. Chem., 35, 432, 1902.

"Grosmann (Kurajeff's Lab., Charkow), Hofmeister's Beitr., 6, 192, 1905.

${ }^{41}$ E. S. London, Zeitschr. f. physiol. Chem., 74, 301, 1911.

42 E. Freund, Wiener med. Wochenschr., 1905, No. 47; 1909, 108.

${ }^{43}$ Pacchioni and Carlini (Pediatric Clinic, Florence), Arch. di Fisiol., 2, 297, 1905; abstract, Biochem. Centralbl., 4, 1490, 1905-06. 
Interesting as such observations in themselves may be, the greatest caution should be observed in interpreting their physiological significance. That the physico-chemical relations in as complicated colloid system as blood serum on the addition of a second, no less complex system, like Witte's peptone, may be decidedly disturbed is in nowise surprising. It is very questionable whether any sort of conclusion is justifiable from such static change as to the actual physiology of absorption.

Parenteral Introduction of Protein.-E. Freund ${ }^{44}$ is of the opinion that the very fact of elaboration of parenterally introduced albumoses by the tissues, etc., bespeaks collaboration of the intestine. "Five minutes after intravenous injection of Witte's peptone, renal elimination being prevented, only about half the injected substance remains in the blood. The fate of the peptone remaining in the blood apparently depends upon whether or not the intestinal blood vessels be traversed or not. If these are closed off the great bulk of the injected incoagulable substance remains in the blood . . ." Other experiments, ${ }^{45}$ as those conducted by von Körösy, upon the fate of parenterally introduced proteins in conditions of intestinal exclusion are, however, not confirmatory of Freund's assertion; according to these all protein to undergo cleavage in the organism must first pass the intestine and there undergo a particular preparation.

Returning to the major question, as to the ability of the intestine to dissociate protein to its elementary buildingstones: there can no longer be the least doubt of this if Abderhalden's investigations are to be accepted. ${ }^{46}$ The older view that proteid nitrogen is absorbed exclusively in the form of "albumoses" and "peptones" is no longer tenable in the light of this knowledge. Another question, how-

" E. Freund and H. Popper, Biochem. Zeitschr., 15, 272, 1909; G. Töpfer, Zeitschr. f. experimental Pathol., 3, 45, 1906; E. Freund and G. Töpfer, ibid., \$, 633, 1906; E. Freund, ibid., 4, 1, 1907.

${ }^{45}$ K. v. Körösy (Budapesth), Zeitschr. f. physiol. Chem., 62, 68, 1909.

${ }^{4}$ Cf. E. Abderhalden, Zeitschr. f. physiol. Chem., 74, 436, 1911. 
ever, upon which there is no unanimity, is to what stage maximal cleavage actually proceeds in physiological conditions. Many authors retain the older view "that," as E. Freund ${ }^{47}$ says, "the body does not follow a single restricted principle, but manifests a many-sided ability in correspondence with the varying demands upon it." "Just as in ordinary household activities there is need not only of small firewood but also of larger timber, so the organism makes use of the protein material in form of all kinds of cleavageproducts without first reducing all to the smallest grade."

Protein Synthesis from Products of Advanced Cleavage of Protein.-The view that all protein undergoes advanced cleavage before resorption assumes the possibility, for maintenance of the body in nitrogen equilibrium, of its being provided, not with protein, but with the sum total of the lowest products of protein cleavage. The credit of having first experimentally proved this possibility belongs to Otto Loewi. In 1902 Loewi, working in the laboratory of Hans HorstMeyer, showed experimentally by feeding with pancreatic tissue autolysed to the point of loss of biuret reaction that the aggregate of the biuret-free end-products can be substituted for dietary protein (that is, enters into the composition of every part of the body protein undergoing metabolic disintegration). ${ }^{48}$ At first this fundamental proposition was received with widespread doubt; but later, especially following the experiments of Henriques and Hansen ${ }^{49}$ and, above all, the studies of Abderhalden and his school it has been adopted as beyond doubt..$^{50}$

${ }^{47}$ E. Freund., Wiener klin. Wochenschr., 1905, No. 47.

${ }^{13} \mathrm{O}$. Loewi (Pharmacolog. Instit., Marburg), Arch. f. exper. Pathol., 58, $303,1902$.

- V. Henriques and C. Hansen, Zeitschr. f. physiol. Chem., 43, 417, 1904; 49,$113 ; 54,406,1907$.

${ }^{\circ 0}$ Literature upon the Synthesis of Protein from the Low Protein Cleavage Products: H. Lüthje, Ergebn. d. Physiol., 7, 805-830, 1904; P. Rona, Handb. d. Biochem., 4', 540-560, 1910 ; E. Abderlualden, Synthesis of Cellular Building. stones in Plant and Animal, Berlin, J. Springer, 1912, 128 pp. 
Abderhalden's Experiments.-Abderhalden and his associates have by a long series of carefully conducted experiments so fully solved many of the problems relating to this field of our study that it is possible to regard it as fairly comprehensible. It is known today that by appropriate and long continued combined action of pepsin, trypsin and erepsin proteid matter may be completely (that is, comparably to total acid hydrolysis) dissociated, and that a mixture of the products of such process is capable of maintaining in nitrogen equilibrium for many weeks animals and human beings, whether in course of growth, in conditions of pregnancy or of lactation. The integrity of the hepatic function is moreover not a matter of necessity in connection therewith; for Abderhalden and London were able to maintain in nitrogen balance a dog with Eck's fistula upon a diet made up of advanced protein cleavage products. Contrary to the belief that only the aggregate of split products from digestive ferment action and not those from acid hydrolysis are capable of replacing protein, Abderhalden has been able to keep in full nutrition for fourteen days a dog fed upon meat completely hydrolysed by boiling with strong sulphuric acid. Removal of tryptophane from the mixed digestive products rendered the mixture unfit for maintenance of nitrogen balance. The same inefficiency was found in employing a mixture of aminoacids obtained by cleavage of silk, this proteid being characterized by its high proportion of glycocoll, alanin and tyrosin, and its poverty in a number of the important "building stones" of the typical protein molecule. Similar results were obtained with gelatine, a substance rich in glycocoll, containing very little alanin, and neither tyrosin nor tryptophane. If the glycocoll of the split gelatine is proportionately diluted by addition of the other building-stones which occur in small quantities the combination may be made to be entirely equivalent to protein. It may be questioned whether the dissociated protein is capable of replacing normal protein 
not only in a qualitative but also in a quantitative sense. Experiments of E. Voit and Zisterer, ${ }^{51}$ in which the matter of "economy" comes forward, apparently bear upon this point, uncleft casein being superior to digested casein and the latter superior to casein hydrolyzed by acid. With advance of cleavage the physiological nutritive value of a substance apparently decreases, larger and larger amounts at any rate being required for maintenance of nitrogen balance. On the other hand a recent series of experiments by Abderhalden, Frank and Schittenhelm would indicate that protein equivalence of the combined cleavage products is a complete one. Acquiescence may be granted to the first of these investigators only in the sense that positive results in such experiments are always of more significance than are negative ones. Experiments carried on by Buglia ${ }^{52}$ in Botazzi's laboratory clearly confirm the view that the products of meat digestion can be substituted for the meat itself without noteworthy difference of result in nitrogen fixation and increase of body weight in growing animals.

Finally Abderhalden in a very interesting experiment has fed animals upon a general diet, not merely proteid substances, in state of complete cleavage. Dogs were given, besides the fully split protein, the cleavage products of fat (glycerol and the higher fatty acids), monosaccharids, cholesterol, the structural units of mucleinic acid and the necessary ash constituents. In the course of experiments extending over more than two months the experiment animals not only maintained their nitrogen equilibrium but actually increased in weight.

This is an example of indefatigable and purposeful labor ending in the solution of a great problem. If one reflects,

${ }^{51}$ E. Voit and J. Zisterer (Veterinary School, Munich), Zeitschr. f. Biol., $53,457,1910$.

${ }^{82}$ G. Buglia (F. Bottazi's Lab., Naples), Zeitschr. f. Biol., 5\%, 365, 1911. 
we may often find that the very greatest advances in physiology may be formulated in a few simple words; in this case they mu: "the problem of the rôle of foodstuffs of complicated structure is solved by their most simplified structural units." 53

Application of these Results in Sickroom Dietary.These results are not only of interest to physiologists, but are of extreme importance in practical medicine. Abderhalden, Frank and Schittenhelm ${ }^{54}$ have actually prevented nitrogenous loss for weeks in a patient by rectal feeding with beef split by the combined action of trypsin and erepsin until the biuret reaction no longer showed. This proves the possibility of introduction into human beings of their daily nitrogenous requirement without bringing the parts concerned with protein cleavage into activity. The nitrogen may thus be introduced in fluid form in small volume for quick and complete resorption. It may be predicted that in the future the employment of preparations of this sort will find a field in the treatment of gastric ulcer, stenoses, cancerous and ulcerous processes of any sort wherever they may exist in the digestive tube. Where there is occasion to spare the digestive tract, theoretically it is unquestionably more rational to introduce the physiologically definite mixture of the end products of protein cleavage than to administer the usually indefinite prepared foods with which people in recent years have been so richly favored (largely through insistent laudatory advertising and in a much less measure

${ }^{2}$ E. Abderhalden, Synthese der Zellbausteine in Pflanz und Tier, p. 74, Berlin, J. Springer, 1912. Cf. therein (pp. 116-118) a summary of the studies conducted by Abderhalden in association with P. Rona, B. Oppler, E. S. London, J. Olinger, E. Meszner, H. Windrath, F. Frank, A. Schittenhelm, F. Glamser, D. Manoliu, and A. Suwa. Cf. also Zeitschr. f. physiol. Chem., $7 \%, 22,1912$.

ik E. Abderhalden, F. Frank and A. Schittenhelm, Zeitschr. f. physiol. Chem., 63, 214, 1909; F. Frank and A. Schittenhelm (Med. Clinic, Erlangen), Münchener med. Wochenschr., 1911, 1288; Therap. Monatsch., 26, 112, 1912. 
upon the ground of actual scientific investigation). Of course every soluble protein preparation has in the end a certain "nutritional value" ; whether the "nutritional value" in any individual case bears any direct proportion to the price charged for the preparation is a matter which may here be gladly omitted. Unfortunately, however, as far as odor and flavor are concerned, the applicability of the cleavage products of protein is far from what one would wish; and moreover, perhaps because of amines present, a variety of collateral effects are likely to appear and for the present detract from the therapentic appreciation of these substances.

After what has been said above, the possibility of various nitrogenous substances serving as partial substitutes for protein in nutrition may be readily understood. A number of investigations bearing upon this point, concerning the nutritive value of leucin, various albumoses, peptones, protamines, etc., have been published..$^{\tilde{5}}$ It may at least be seen that such preparations may serve to conserve protein and that their value as more or less complete substitutes for protein must primarily depend upon just what and how many of the metabolically essential structural units of the protein molecule are missing from their atomic grouping.

Relation of Amides in Metabolism of Vegetarians; Protein Synthesis from Ammonium Salts.-Although the above questions, at least in a fundamental way, seem fairly solved, this certainly cannot be said of another matter, the relation of the amides and aminoacids in metabolism. Because of the wide distribution of aminoacids and amides in plants and owing to the fact that the determination of the value of the various foodstuffs (as turnips, molasses, etc.) is of very great

${ }_{55}$ A. Ellinger (Physiol. Instit., Munich), Zeitschr. f. Biol., 33, 201, 1896; L. Blum (Hofmeister's Lab.), Inaug. Diss., Strassburg, 1901; V. Henriquez and C. Hansen, Zeitschr. f. phrsiol. Chem., 48, 383, 1906; 49, 113, 1906; P. Rona and W. Müller, ibid., 50, 263, 1906; J. R. Murlin, Amer. Journ. of Physiol., 20, 234, 1907-08; cf. therein literature appended. 
practical interest in agriculture, an unusually large number of studies have been directed to the question of how far amides, especially asparagin (as W. Völtz and others have maintained), are capable of replacing the protein of food. ${ }^{56}$ It is readily appreciable that amides and aminoacids may serve as conservers of protein. There is, however, a constantly recurring idea that at least in herbivora protein may be replaced by such amides. N. Zuntz, O. Hagemann and other writers would find the key to the whole problem in the rôle of the intestinal bacteria. Introduction of asparagin and similar substances they believe not only serves to conserve protein and preserve the dietary protein from the influence of the bacteria; but the amides are a medium from which the bacteria because of their plant characteristics are able to construct protein. If in the end the bacteria die, this protein of theirs is of advantage to the vertebrate animal. In this manner not only asparagin, but ammonium acetate and many other ammonium salts may indirectly, of course, become a source of protein for the animal body. In the course of the last few months the question of the availability of ammonium salts and amides to enter into protein synthesis has been brought into prominence from the studies of E. Grafe and of Abderhalden.

E. Grafe and Schläpfer from extensive metabolic studies determined that in dogs receiving a full diet of nonnitrogenous material not only nitrogen balance but actual nitrogen retention and increase of weight can be obtained by feeding ammonium citrate, without subsequent outpouring

Ks. Anderlik, K. Velich and Vl. Stanck, K. Friedländer, S. Gabriel, O. Hagemann, V. Henriques and C. Hansen, J. Just, O. Kellner, C. Lehman, A. Morgen, C. Beger and F. Westhauser, Mauthner, M. Miiller, J. Munck, E. Peschek, G. Politis, B. v. Strusiewicz, F. Rosenfeld, W. Thär, W. Völtz, H. Weiske, N. Zunz. Literature: H. Lüthje, Ergebıl. d. Physiol., \%, 828-830, 1908; E. Abderhalden, Vorlesungen, 2d ed., pp. 301-303, 1909; P. Rona, Handb. d. Biochem., 4', 554-559, 1911; E. Peschek (Zootech Instit. of Agricul. School, Berlin), Pflüger's Arch., 112, 143, 1911. 
of the retained nitrogen taking place. ${ }^{57}$ It would, however, be decidedly misleading to regard this as evidence indicating protein synthesis from ammonia and nitrogen-free material.

The above findings have been confirmed by independent observations of Abderhalden to the extent that after addition of ammonium acetate to a nitrogen-free diet consisting of rich fatty and carbohydrate constituents there may ensue a nitrogen retention..$^{58}$

In connection with the observations (to be discussed later in detail) of Knoop, Embden and their associates upon the transformation of $\alpha$-ketonic acids into aminoacids by the following schema:

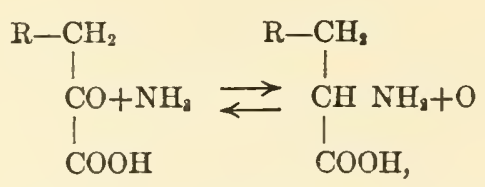

it is not difficult to think of a shifting of the equation between aminoacids and ketonic acids by the introduction of ammonia in a way to bring about synthesis of aminoacids, the ketonic acids, however, to be derived from nitrogen-free food constituents.

In further studies ${ }^{59}$ Abderhalden, however, pointed out that it is a matter of great difficulty to draw any consistent conclusion from the results. In reality it turned out that even without nitrogen administration he was able by full diet of carbohydrates and fats to maintain for a long time constant body weight and, in fact, for short periods to induce increase of weight of the experiment animals; so that apparently it is inadmissable to come to any conclusions as to protein synthesis after administration of ammonium salts whether there be weight loss or weight increment.

${ }^{5 z}$ E. Grafe, Kongr. f. innere Med., Wiesbaden, 1912; E. Grafe and V. Schläpfer, Zeitsch. f. physiol. Chem., $7 \%, 1,1912$; E. Grafe, ibid., $78,485,1912$; ef. claim for priority by IV. Völtz, ibid., $\% 9,415,1912$.

${ }^{\text {ss }}$ E. Abderhalden, ibid., $\% 8,1,1912$.

${ }^{8}$ E. Abderhalden and P. Hirsch, Zeitschr. f. physiol. Chem., 80, 136, 1912. 
In another series of experiments ${ }^{60}$ Abderhalden fed gelatin which is not a full equiralent for protein because the animal cells are apparently unable to form de novo certain building stones which are absent from gelatin. He then sought to increase the chance of protein synthesis in the organism during a full diet of carbohydrates and fats by adding ammonium acetate to the gelatin. But the nitrogen record constantly remained negative. "From these experimental results we may conclude," he says, "that the basis for protein synthesis is not to be found in ammonium salts with carbohydrate or fatty material."

London's Studies.-It is impossible to conclude the subject of protein digestion in the intestine without special consideration of the investigations which for years E. S. London with a number of collaborators has been conducting in the Institute of Experimental Medicine in St. Petersburg. London has developed the technic of intestinal fistulas to a high degree of perfection. He is not satisfied to provide a single fistula in the experimental animal; his "polyfistulous dogs" enable him to make comparative studies of various intestinal levels at one given time; his " panchymotic dog," wearing in addition to a double-chambered duodenal canula a gastric and a jejunal canula, puts him in position to obtain coincidently the gastric secretion, the bile, the pancreatic juice and the intestinal secretion in proper isolation from each other.

For a number of years London has been publishing the results of his studies in a very long series of contributions embracing a wealth of individual observations. ${ }^{61}$ They take up the rate of protein catabolism, the resorption intensity and morement of the intestinal contents in particular

${ }^{60}$ E. Abderhalden and A. E. Lampé, Zeitschr. f. physiol. Chem., 80, $160,1912$.

${ }^{61} \mathrm{E}$. S. London and associates, numerous publications in the last thirty volumes of Zeitschr. f. physiol. Chem. 
segments of the bowel, nitrogen partition in the intestinal contents, the completeness of food utilization, the results of exclusion of special segments of the intestine, of the bile and of the pancreatic secretion, protein digestion in mixed diet especially in presence of carbohydrates and fats, the specific adaptation of the digestive juices and the relative amounts of enzymes in the intestinal chyme in different diets, the differences between raw and cooked proteids, the behavior of various proteins (as serum albumin, egg albumin, muscle albumin, casein, gliadin, gelatin and elastin) and of digestive mixtures (removed through a fistula from one dog and introduced by a fistula into another dog), the resorption of individual aminoacids, the mechanism of secretory flow, the influence of blood pressure and other physiological factors upon secretion of the individual digestive juices, and other similar subjects. He has endeavored, too, to deduce a mathematically fixed relation between the different secretory factors (as the relations between the amount of food, the concentration of the gastric juice, the quantity of the bile and pancreatic juice, the alkali-content of the pancreatic and intestinal secretions, the nitrogen-content of the different secretions and the digestion time of solid albumins) in which as in chemistry of the ferments "quadrate root rules" (in Arrhenius' sense) play an important part. ${ }^{62}$

The author confesses that he does not regard himself as fitted to criticise with full appreciation this remarkable wealth of undoubtedly very valuable observations. It would be a real service were London to take upon himself the duty of critically reviewing them in their proper relations and of bringing out clearly the lines of thought he has followed, which are now so divided among so many separate publications that the outsider is bound to lose their connection.

${ }^{c 2}$ Consult also E. London and C. Schwarz, Zeitschr. f. physiol. Chem., 68, 346, 1910 ; L. Popielski, ibid., 71, 186, 1911. 
This done, we may well hope that from these studies and others dealing with related matters (of which special mention may be made in passing of those of Cohnheim, ${ }^{63}$ E. Zunz, ${ }^{64}$ Brugsch, ${ }^{65}$ A. Scheunert, ${ }^{66}$ and K. Glässner ${ }^{67}$ ) a well rounded picture of protein dissociation in the intestine in each of its phases will gradually take shape. ${ }^{68}$

Summary.-If in conclusion another glance be cast back over the long way behind us, it will be realized that as the actual accomplishment of an almost interminable expenditure of effort and experimental work we may say that we know that by the combined action of pepsin, trypsin and erepsin the protein in the alimentary canal can be effectively split into its most simple structural units and that a mixture of these constituent fragments is not only qualitatively but quantitatively in every sense equivalent to the protein as supplied intact. To be able to say that means something, but by no means all. Abderhalden says very properly "that up to this time it is entirely impossible from examination of the intestinal contents to draw exact conclusions as to the degree of catabolism of the food, because besides the products of complete cleavage we must take into consideration also the intermediate substances." He states explicitly, too, "from our finding that a combined mixture of aminoacids is capable of fully maintaining protein metabolism for weeks and months we cannot conclude at once that necessarily in

${ }^{e 3}$ R. Baumstark and O. Cohnheim (Physiol. Instit., Heidelberg), Zeitschr. f. physiol. Chem., 65, 477, 483, 1910.

${ }^{6}$ E. Zunz, Bulletin de l'Acad. Roy. de Méd. de Belgique, 30, April, 1910; cf. here Literature and review of author's numerous earlier contributions in same connection.

${ }^{65}$ Th. Brugsch, Zeitschr. f. exper. Pathol., 6, 326, 1909.

${ }^{66}$ A. Scheunert, Pflüger's Arch., 121, 169, 1908; 139, 131, 1911; 141, 411,1911 .

${ }^{67}$ K. Glässner (F. Kraus' Clinic, Berlin), Zeitschr. f. klin. Med., 52, 361, 1904.

${ }^{68}$ Cf. also V. Lieblein (Prague), Zeitschr. f. Heilk., Aìt. f. Chirurgie, 1906; F. Keller, Inaug. Diss., Breslau, 1909, abstract in Centralbl. f. Physiol., 23, $616,1909$. 
normal conditions the cleavage of protein by digestion in the gastro-intestinal canal ultimately extends to the stage of aminoacids." 69 We lose track, practically under our very eyes, of the split products of the protein molecule as they pass out from the intestine into the blood. Accumulation of albumoses or of aminoacids in the blood of an individual in the course of digestion under entirely normal and physiological conditions has not been established beyond doubt, and on the other hand has not been definitely disproved. There is some justification therefore in the suspicion that there occurs a protein reconstruction in the wall of the intestine. The author believes, too, that it is by no means improbable that both the smaller and the larger cleavage products of the protein molecule may enter the circulation, be carried to the various organs and in the latter be further elaborated according to the local requirements, either being condensed into new protein molecules, or in further dissociation finally passing into various end-products (ammonia, carbon dioxide and water).

The biological serum reactions (precipitin-reactions, etc.) have led to an appreciation of the almost endless multiplicity and specific peculiarities of the proteid substances with which nature deals. Axiomatically we come to the assumption, from the fact that every individual contains in the various fluids and tissues an enormous number of chemically variant proteid substances, that doubtless no two different kinds of animals contain exactly identical proteins.

This tremendous multiplicity may be appreciated if we think of the equally tremendous number of variations in which the great numbers of "mosaic stones" of the protein molecule may enter into combination in its construction. That a given individual, no matter the extreme variety of proteids entering into its food, is capable, always and under

${ }^{6}$ E. Abderhalden, Synthese der Zellbausteine in Pflanze und Tier, pp. 53 and 71, Berlin, J. Springer, 1912; cf. Zeitschr. f. physiol. Chem., 78, 382, 1912. 
all conditions and for the whole period of its life, of maintaining the specificity of its own peculiar proteins can be understood and conceived of, as far as the author is personally concerned, only by adopting the idea that every proteid in the food is probably, before it can be assimilated, broken down into aminoacids. This conception must be acknowledged, however, to be purely a personal one, and is offered only as such. In the last count every man can think only with his own brain. 


\section{CHAPTER IV}

\section{PROTEOLYTIC AND PEPTOLYTIC TISSUE FERMENTS}

\section{AUTOLYSIS}

Aften the consideration in the previous chapters of the processes of protein digestion in the stomach and intestine, and with the future consideration of the fate of the final nitrogenous eleavage products in the intermediate metabolism before us in succeeding ones, the present discussion may very properly be devoted to the proteindigesting tissue ferments. At this point study of that mysterious change which is inclusively spoken of as "autolysis" may serve in part to bridge the great gap, or perhaps in more exact verbiage to conceal it, between the two phases of the metabolic process. It has been pointed out that the products of cleavage of the protein molecule are lost sight of at the very moment when they are resorbed through the wall of the bowel; and their first traces reappear when the endproducts of metabolism begin to escape from the body. That which lies between is the unexplored and completely unknown field of the intermediate metabolism. The hope of throwing some light from a single point of view upon a little part of this field, as with the light-cone of a projection lamp, lends special interest to the study of the phenomena of autolysis. Even if these expectations, at best provisional ones, fail of fulfilment, the enigmatic process is in itself sufficiently interesting to temporarily hold our attention.

As early as 1890 Ernst Salkowski recorded the occurrence of post mortem self-digestion ("autodigestion") in animal tissues. He noted, for example, that in a pulplike suspension of tissue in chloroform water autodigestive processes take place, with disappearance of coagulable albumins to give place to their cleavage products. Then ten years later in Hofmeister's laboratory Martin Jacoby ${ }^{1}$

${ }^{1}$ M. Jacoby (F. Hofmeister's Lab., Strassburg), Zeitschr. f. physiol. Chem., 30, 149, 174, 1900 . 
investigated more exactly the bearing of these phenomena in relation to various physiological and pathological processes; since when they have been the subject of general attention. Thereafter "autolysis" (a term introduced by Jacoby which has since been adopted generally) has remained an important subject in the list of problems of physiological pathology. At this point we may as well attempt to explain the process in as practical a manner as possible, whaterer the outcome.

Autolysis a Complex Process.-It is essential that we keep in mind that the autodigestive processes are really of complex nature, for the reason that they are not the result of the isolated action of any one given enzrme but of a number of ferments. Side by side in their operation are the proteinsplitting "tryptases," "erepsines" (concerned in completing the dissociation of the high molecular cleavage products of the protein molecule), "arginases," ammonia-splitting "deamidases," "mucleases" splitting the nucleins, the mysterious "oxidases," and besides these undoubtedly many more for which we do not even have a name. It is not at all remarkable therefore that in the study of autolytic mixtures we have to do with a decidedly "mixed group"; along with the typical cleavage products of proteins and nucleinic acids, and besides the derivatives of these (as guanidin, tetramethylendiamin and aminobutyric acid) are to be met a variety more of products (as lactic acid, succinic acid, volatile fatty acids), the origin of which is by no means certain. $^{2}$

Antiseptic Difficulty in Autolysis Experiments.-There is, however, one very great difficulty in conducting experiments in autolysis, namely, that of insuring antisepsis.

${ }^{2}$ A. Magnus-Levy, Hofmeister's Beitr., 2, 261, 1902; S. Isaak (F. Hofmeister's Lab.), Inaug. Diss., Strassburg, 1904; M. Schenk (Physiol. Instit., Marburg), Wochenschr. f. Brauerei, 1905, No. 16; abst. Centralbl. f. physiol. 19, 519, 1905; P. A. Levene, Zeitschr. f. physiol. Chem., 41, 393, 1904; Amer. Journ. of Physiol., 11, 437, 1904; 12, 276, 1904. 
Only within the last few years has this difficulty come to be definitely realized and technically avoided, thanks to the studies of Salkowski and his pupils. ${ }^{3}$ For instance, it might be supposed that when a finely divided organ is undergoing autodigestion in a medium well saturated with chloroform and toluol, there would be no danger of the unwelcome presence of bacteria. In actual practice, however, such exact care has by no means been insisted upon; and it has usually been supposed that if a few drops of toluol or a few bits of thymol were added to a thick emulsion of some organ it would be quite safe to let it stand in the incubator for some months and that the danger of bacterial invasion would be surely and for all time eliminated by such a purely symbolic performance (for that is actually about all it represents). It is quite obvious why "discoveries" prospered and multiplied in our literature on the same scale as did the bacteria in the pots and jars of the experimenters. But in addition, even with precautions to avoid such gross technical faults, other difficulties often arose in the way of microbic contaminations. H. C. Jackson ${ }^{4}$ pointed out that fresh canine livers even if removed with the utmost precaution are rarely entirely sterile, but are apt to contain an anærobic organism similar to the hay bacillus which does not grow on the ordinary culture media but which grows readily in "sterile" tissues. Jackson believes that the appearance of lactic acid, succinic acid, butyric acid, hydrogen and sulphuretted hydrogen (as noted, for example, by Magnus-Levy in "aseptic autolysis," and their origin referred by him to the corporeal carbohydrates and fats) is due to the presence of microörganisms in the autolysing mixtures. Here again we are confronted with that intolerable dilemma besetting every point and every side of the chemistry of fermentation: either we are destroying the normal physiological course of the processes by introduc-

\footnotetext{
${ }^{3}$ E. Salkowski, Yoshimoto, Kikkoji and others, Zeitschr. f. physiol. Chem., $63,109,1036,1909$.

${ }^{4}$ H. C. Jackson, Journ. of Med. Research, 21, 281, 1909.
} 
ing disinfecting agents which in the very nature of things cannot be without effect upon the enzymes;-or else we keep on, making allowance as we may for the danger of bacterial invasion.

Is Autolysis the Continuation of an Intra-vital Process? - It may be assumed with certainty that no one would have devoted as much effort and care to these rather bothersome subjects if it were not for the impression that just here there is a chance to remove one part of the intermediate metabolism from the dark interior of the living economy into the transparency of the test tube. It was believed that in the phenomena of post-mortem autodigestion there may be recognized a continuation of a normal intra-vital process, that of the physiological protein dissociation which takes place in the living cell. The first point therefore to be determined is whether such a belief is or is not justified. ${ }^{5}$

Autolytic tissue ferments, it must be accepted, have been met throughout the animal and vegetable kingdoms generally, wherever any pains have been taken to recognize them, in the lowest as well as in the most highly organized living entities. Ferments have been differentiated which, on the one hand, act best in acid reaction, and on the other those best acting in alkaline conditions $\bar{\alpha}$ - and $\beta$-proteases of Hedin and Rowland). Vernon emphasizes "erepsines" above other proteases, and proposes to estimate the relative amount of enzyme in tissue extracts colorimetrically by application of the biuret test (supposing the time required to cause the biuret reaction to disappear from a given quantity of a standard solution of Witte's peptone to be in reverse proportion to the amount of ferment present). By compari-

${ }^{5}$ Literature upon the Physiological Significance of Autolytic Processes: M. Jacoby, Ergebn. d. Physiol., 1, 225-229, 1902, and Handb. d. Biochem., 2', 175-182, 1910; E. Salkowski, Deutsche Klinik, 11, 147-182, 1907; H. M. Vernon (Oxford), Ergebn. d. Physiol., 9, 147-15s, 1910; J. Wohlgemuth, Handb. d. Biochem., 3', 180-181, 1910 ; C. Oppenheimer, Die Fermente, 3d ed., pp. 242252,1910 . 
son of various organs Vernon found the duodenal mucous membrane richest in erepsin, that of the lower portions of the intestine poor in erepsin; of the other organs the kidney showed the highest content of ferment.

It can be readily appreciated that there is difficulty in attempting to deal with all of the observations upon autolysis as it were under one heading, because of the extreme complexity of the chemical processes concerned. It may be regarded as a step in advance that R. L. Benson and H. G. Wells ${ }^{6}$ have perfected a physico-chemical method of following continuously the course of autolysis by determining the freezing-point and electrical conductivity of the autolysate, in place of depending exclusively upon the increment of incoagulable nitrogen or the disappearance of the biuret reaction.

The whole idea of the physiological significance of the autolytic ferments is in close relation with the proposition that increase in the "physiological activity" of an organ is somehow related with increase of its intrinsic autolytic capacity. Accepting provisionally the correctness of such a statement, if we endeavor to satisfy ourselves as to the actual basis thereof, it is astonishing to find upon how little foundation of fact it rests. A few observations from Hofmeister's laboratory bear upon the subject. That autolysis in the tissues of children of low vitality proceeds more slowly (measured by increase of incoagulable nitrogen) than in those of normal individuals, ${ }^{7}$ and that the autolytic activity of a functionating mammary gland is higher than of a resting gland ${ }^{8}$ (cf. Vol. I of this series, p. 361, Chemistry of the Tissues) should be mentioned; and in addition a few of Vernon's observations ${ }^{9}$ are applicable. According to this author the average quantity of "erepsin" in a tissue is prac-

${ }^{6}$ R. L. Benson and H. G. Wells, Journ. of Biol. Chem., 8, 61, 1910.

'E. Schlesinger (F. Hofmeister's Lab.), Hofmeister's Beitr., 4, 87, 1903.

${ }^{8}$ P. Hildebrandt (F. Hofmeister's Lab.), Hofmeister's Beitr., 5, 463, 1904.

'I. c. 
tically constant and virtually independent of diet; nevertheless it varies with the state of functional activity of the tissue. In fetal tissues it is at minimum, but the amount of erepsin rapidly increases as development proceeds, reaching the maximum soon after birth. It is asserted, too, that the increased protein destruction which is brought about by excessive thyroid substance entering the system is also manifested by increase of post-mortem autolysis ${ }^{10}$; although these statements have been opposed. Addition of thyroid material has not been found to directly increase autolysis (consult Vol. I of this series, p. 450, Chemistry of the Tissues). It has been found that autolysis is decidedly more active in case of animals which have fasted before death than in those that were well nourished. ${ }^{11}$ It is possible to interpret this as a continuation of the tissue destruction which is going on in marked degree in fasting; but one might on the other hand be justified in assuming just the opposite, namely, that the "functional activity" of the tissues is lowered in states of fasting while their digestive ability is increased, in line with the fall in quantity of erepsin in the tissues of hibernating animals and persons reduced by disease which Vernon very satisfactorily demonstrated. ${ }^{22}$

A number of objections have been presented against regarding autolysis as a physiological or vital process. It is said that autolysis cannot possibly be a direct continuation of a vital process because it does not appear immediately when death occurs, but after a period of latency of several hours. ${ }^{13}$ Then, too, the predilection of the autolytic ferments for an acid reaction has been made an objection ${ }^{\mathbf{1 4}}$; (although this is answered by the fact that even with the natural reaction

${ }^{10}$ Cf. G. Bayer (MI. Löwit's Lab., Inusbruck), Sitzungsbericht d. Wiener Akad., 118"', 181, 1909.

${ }^{11}$ J. E. Lane-Claypon and S. B. Schryver, Journ. of Physiol., 31, 169, 1901.

${ }^{12}$ H. Mr. Vernon, Journ. of Physiol., 33, 81, 1905.

${ }^{13}$ Lane-Claypon and Schryver, 1. c.

${ }^{14}$ H. Wiener (J. Pohl's Lab., Prague), Centralbl. f. Physiol., 19, 349, 1905. 
of the blood and tissue-fluids autolytic processes can proceed ${ }^{15}$ ). In a study carried out in the laboratory of Julius Pohl ${ }^{16}$ it has been shown that allantoin, which appears in large amounts in autolysis of dog's liver ${ }^{17}$ and for which there is no reduction capacity on the part of the canine economy, appears nevertheless in but very small amounts among the normal excretory products. (Of course, if autolysis were actually a complete duplicate of intravital changes, we would necessarily expect that allantoin would normally be excreted as a product; yet autolysis might well be only one part of a vital process and it might well be that in conditions where the other components, particularly the vital oxidations, are absent it would not necessarily give rise to exactly the same end-products as found in life.) To the persistent question of exactly why, if autolysis actually occur's in the living body the living cells are not digested, here again we have presented, one after the other, antiferments, the immune bodies of the serum, the alkaline conditions, etc., in short the whole arsenal of problematic hypotheses with which, as the author has previously insisted, we are in the vain habit of trying to conceal our ignorance of the exact reason why the stomach, intestine and pancreas are prevented from digesting themselves.

Deamidizing Tissue Ferments.-The atmosphere surrounding this subject is rather unattractive and obscure, making it a field to which the author is glad to devote no more time than is actually necessary. Before proceeding to better understood matters, however, he wishes at least briefly to refer to the deamidizing ferments. As originally observed by Martin Jacoby ${ }^{18}$ in Hofmeister's laboratory, in the course

${ }^{15}$ J. Baer and A. Loeb, Arch. f. exper. Pathol., 53, 1, 1905; A. v. Drjewecki, Biochem. Zeitschr., 1, 229, 1906; Preti, Zeitschr. f. physiol. Chem., 5.2, 485, 1907.

${ }^{16}$ R. Poduschka (Pohl's Lab., Prague), Arch. f. exper. Path., 4/, 59, 1900.

${ }^{17}$ Borrissow (Baumann's Lab.), Zeitschr. f. physiol. Chem., 19, 499 (1904).

${ }^{18}$ M. Jacoby (F. Hofmeister's Lab., Strassburg), Zeitschr. f. physiol. Chem., $30,149,1900$. 
of autolytic cleavage of tissue proteids there occurs a much more marked production of ammonia (presumably from the non-fixed nitrogen which is split off as ammonia by hydrolysis) than in acid hydrolysis. Thereafter Sigmund Lang ${ }^{19}$ in the same laboratory determined the autolytic separation of ammonia both from acid amides (as asparagin, $\mathrm{COOH}-\mathrm{CH}_{2}-\mathrm{CH} \cdot \mathrm{NH}_{2}-\mathrm{CONH}_{2}$, and glutamin) and from aminoacids. It is now recognized that deamidization of the first of these series takes place very readily in alkalihydrolysis according to the schema: R.CONH $\mathrm{CH}_{2}+\mathrm{H}_{2} \mathrm{O}=$ R.COOH $+\mathrm{NH}_{3}$. The anthor has not failed to obtain this result in any of his studies, conducted in association with M. Friedmam, in quantitative comparisons of autolytic asparagin cleavage in various animal tissues. ${ }^{20}$ The frequent occurrence of amide-cleaving ferments in vegetable tissues, which are rich in acid amides, has been fully established by a number of investigators. ${ }^{21}$ Of more interest than this group of enzymes are the deamidases, which are capable of splitting off from an aminoacid its firmly attached nitrogen, which successfully resists the cleaving power of boiling fuming hydrochloric acid. Just as yeasts or moulds can split ammonia from aminoacids and transform them into oxy-fatty acids ${ }^{22}$ (according to the schema: \left.\left.${\stackrel{\mathrm{COOH}}{\mathrm{R}} \mathrm{NH}_{2}}_{\mathrm{C}}+\mathrm{H}_{2} \mathrm{O}=\mathrm{NH}_{3}+\stackrel{\mathrm{COOH}}{\mathrm{R}} \mathrm{OH}\right)_{\mathrm{O}}\right)$, so precisely the same ehanges can apparently take place in autolysis of animal tissues. ${ }^{23}$ Colnheim has observed a demidization of this sort in the passage of aminoacids through the living intes-

${ }^{10}$ S. Lang (F. Hofmeister's Lab., Strassburg), Hofmeister's Beiträge, 5, 320, 1904.

${ }^{20}$ O. v. Fürth and M. Friedmann, Biochem. Zeitschr., 26, 435, 1910.

${ }^{21}$ K. Shibata, N. Castoro, H. Pringsheim, IV. Butkewitsch, A. Kiesel. Literature: O. v. Fürth and M. Friedmann, 1. c.

${ }^{22}$ H. Pringsheim, Biochem. Zeitschr., 12, 15, 1908.

${ }^{23}$ S. Lang, 1. c., O. Schumm, Hofmeister's Beitr., 7, 175, 1906; F. Simon (Salkowski's Lab.), Zeitschr. f. physiol. Chem., 70, 65, 1910; W. Lindemann (Physiol. Instit., Halle), Zeitschr. f. Biol., 55, 36, 1910. 
tinal wall of fishes in the course of resorption; ${ }^{24}$ which calls to mind the oft-repeated statement as to the excessive presence of ammonia in the portal blood as it leaves the intestinal wall. The author sometimes noted in the course of the above mentioned autolytic experiments an amount of ammonia obtained from asparagin by autolytic cleavage with intestinal mucous membrane, so large that it surely represented more than the loose amido-nitrogen present and probably was in part derived from cleavage of the closelycombined nitrogen of the aminoacid. The author acknowledges, however, on further consideration that perhaps, in spite of every ordinary precaution, microörganisms may have played some part-a thought which materially disturbs his satisfaction in this as well as in other similar results.

Importance of Autolysis in Various Pathological Processes.-It must be accepted, therefore, that the importance of autolysis in physiological processes is by no means satisfactorily established. With feelings of grateful satisfaction akin to those of the traveler who after the discomfort of a boggy moor finds firmer foothold again beneath his feet, we approach the question of the significance of autolysis in pathology. An important example of an autolytic process taking place in the living body has come to be recognized through Martin Jacoby's studies of the condition of the liver in phosphorus poisoning, ${ }^{25}$ and very probably, too, in acute yellow atrophy of the liver which is very similar in its manifestations to phosphorus poisoning.. ${ }^{26}$ In koth processes an impression is given that some toxic agent has impaired the vitality of the hepatic cells, and that the auto-

${ }^{24} \mathrm{O}$. Cohnheim and F. Makita (Heidelberg), Zeitschr. f. physiol. Chem., 61, 189, 1909; O. Cohnheim, Sitzungsber. d. Heidelberger Akad. d. Wiss., math.naturw. Klasse, 1911, $30 \mathrm{Abh}$.

${ }^{25}$ M. Jacoby, Zeitschr. f. physiol. Chem., 30, 174, 1900; O. Porges and Przibram, Arch. f. exper. Pathol., 59, 20, 1908.

${ }^{26}$ C. Neuberg and P. F. Richter, Deutsche med. Wochenschr., 1904, No. 14; A. E. Taylor, Journ. Med. Research, 8, 424, 1902; Zeitschr. f. physiol. Chem., 34, 550, 1902; H. G. Wells, Journ. of Exper. Med. 9, 627, 1907. 
lytic ferments thereafter are free to "complete the burial" (cf. Vol. I of this series, p. 558, Chemistry of the Tissues). Apparently the proteins in the course of the process become impoverished in their basic fractions ${ }^{27}$ (especially in arginin), presumably because the basic moiety being a relatively instable component is rather readily lost in the catabolism of the protein molecule. ${ }^{28}$ As the dissociation advances the final cleavage products, the aminoacids, are found in such quantity in the circulation that their presence in the blood and elimination in the urine become striking. In the course of these changes the exaggerated autolysis is by no means limited to the liver, although in the latter it is most manifest. Hæmic alterations in phosphorus poisoning, such as the loss of fibrinogen and of coagulability, have also been referred to autolytic changes. P. Saxl, in the Vienna Physiological Institute, has shown that even if dead tissues are treated with yellow phosphorus their autolysis is increased and the appearance of cellular "fatty degeneration" is induced, the fat present in the constitution of the cells becoming histologically visible. ${ }^{29}$

Besides phosphorus there are undoubtedly many other toxic agents capable of increasing autolysis. Thus H. G. Wells ${ }^{30}$ recognized extensive autolytic changes in the liver of a man dead from chloroform poisoning; a fact explicable from a study made in the laboratory of H. H. Meyer ${ }^{31}$ indicating that a great number of narcotic substances, either in liquid or in gaseous form, are capable of hastening and increasing tissue autolysis. Apparently this is dependent

${ }^{27}$ A. Kossel, Berliner klin. Wochenschr., 190\%, 1065; A. J. Wakeman (Labor. of Kossel, Heidelberg, and of Herter, New York), Journ. of Exper. Med., 7, 292 (1905) ; H. G. Wells, l. c.

${ }^{29} \mathrm{~J}$. Wohlgemuth, Biochem. Zeitschr., 1, 161, 1906.

${ }^{20}$ P. S'axl, Hofmeister's Beitr., 10, 447, 1907 (under direction of O. v. Fürth in Physiol. Instit., Univ. of Vienna).

${ }^{30}$ H. G. Wells (Chicago), Journ. of Biol. Chem., 5, 129, 1909.

${ }^{81}$ R. Chiari (H. H. Meyer's Lab., Vienna), Arcl. f. exper. Pathol., 60, 255, 1909. 
upon the lipoid-solvent ability of such substances which causes extensive changes in the intrinsic permeability of the cellular protoplasm. Another observation which should be noted in the same connection is that of L. Hess and P. Saxl 32 that tissue autolysis is apparently increased by the addition of diphtheria toxin, tetanus toxin and also of tuberculin (after a period of inhibition); from which these authors are disposed to suggest that toxines exert an influence toward protein cleavage. Further prosecution of similar studies is very desirable in order to determine to what extent the results are due directly to the toxines and not to other coincident circumstances.

Autolysis and the Regressive Changes in the Living Body.-The above is, however, by no means the only bearing of autolysis upon pathological processes. Its importance in the liquefaction and resorption of pneumonic exudates was recognized by Friedrich v. Müller and by O. Simon ${ }^{33}$; and there can be but little error in assuming that autolysis plays an important part generally wherever tissue structures, cellularized exudates, tumors, fibrinous clots, tissue grafts, etc., are resorbed in the living body. The author has had occasion (Vol. I of this series, p. 370, Chemistry of the Tissues) to point out that it is reasonable to believe that autodigestion likewise takes part in such physiological regressive processes as the involution of the uterus after delivery. The whole subject has such extensive practical bearing that it is really astonishing how little is actually known with reference to it.

If autolytic processes occur thus widely in the living body it may naturally be expected that the system may be flooded with the products of autolytic digestion. From this

${ }^{32}$ L. Hess and P.'Saxl (v. Noorden's Clinic, Vienna), Wiener klin. Wochenschr., 21, 248, 1908; cf. also A. Barlocco, Pathologica, 2, 195; abstracted in Jahresber. f. Tierchem., 40, s87, 1910.

${ }^{33}$ F. Müller, Verh. des 20. Kong. f. innere Med., 1902, 192; O. Simon, Deutsch. Arch. f. klin. Med., 70, 604, 1901. 
standpoint it is not without interest to note the appearance in the urine of albumoses after liquefaction of pneumonic exudates, in connection with large abscesses, and in instances of softening of tumors. Ramond ${ }^{34}$ observed after ligation of the circulation in the hind leg of a rabbit for some hours that general disturbances follow when it is reëstablished (dyspnœa, rapid pulse, etc.), perhaps due to autolytic products which have gained access to the circulation. It seems quite possible, too, that "autointoxication" following the resorption of products of regressive autolytic changes may be an important factor in human pathology (to mention only the common term, "resorption fever") ; although it is true we have but little positive knowledge in this connection. It would not be hard to fancy, for instance, that the system is not indifferent to the influence of a wave of cholin and certain of its conversion products (v. Vol. I of this series, p. 190, Chemistry of the Tissues) which might find origin in autolytic cleavage of tissue lecithids (even if in a general way we know that the digestion products of the latter are harmless after passing through the intestinal wall).

Relation to Bacterial Processes.-In a further sense autolytic processes may have important pathological application in the fact that certain bacterial endotoxines, as those of the typhoid and cholera organisms, become active only after being set free by destruction of the bacteria themselves. It seems very likely to the author that there is an important meaning in the antibacterial and antitoxic influence of tissue autolysates (for example, the autolysate of lymph glands has a detoxifying influence upon tetanus toxine), as observed first in Hofmeister's laboratory. ${ }^{35}$

Proteolytic Ferments of Leucocytic Origin.-Within the past few years especial attention has been very properly devoted to a particular kind of autolytic fer-

s* F. Ramond, Jour. de Physiol., 10, 1052, 1908.

${ }^{25}$ Conradi, Hofmeister's Beitr., 1, 193, 1901; L. Blum, ibid., 5, 142, 1904. 
ments, the proteolytic leucocytic enzymes, and their relation to suppuration. The way the tissues break down in these latter processes and the "eating" influence of the pus upon the surrounding tissues, striking even for non-medical people, is sure to suggest the idea of an association of fermentative changes. As a matter of fact, in a suppurative process the digestive ferments of the leucocytes, of the bacteria, of the blood plasma, and, too, those of the disintegrating tissues, may all take part. ${ }^{36}$ The importance of each particular factor is naturally difficult of definition. Some would have it that the greater tendency of a staphylocóccus infection (in comparison with a streptococcus infection) to produce suppuration is due to a lower proteolytic power on the part of the latter microörganisms. ${ }^{37}$ It is probably quite correct to ascribe to the white blood corpuscles an especially marked digestive power. It is thought that in this respect the polynuclear leucocytes are more important than the mononuclears; and that the lymphocytes develop scarcely any proteolytic power. ${ }^{38}$ According to Jochmann and others the proportion of proteolytic enzymes in tissues and essential body fluids depends very largely upon the number of leucocytes present in them. By placing the tissues of either the lymph glands, spleen, bone-marow or the blood of myeloid leukæmic cases, or material from tuberculous lymph nodes with mixed infection, or staphylococcus pus in the incubator for a time on a Loeffler's plate, their digestive power is shown by delle-erosion in the medium. In contrast the tissue of normal lymphatic glands and, too, of those in lymphatic leukæmia, and unmixed tuberculous

${ }^{38}$ H. G. Wells, Chemical Pathology, p. 93, 1907.

${ }^{87}$ Knapp, Zeitschr. f. Heilk. (Chirurgie), 23, 236, 1902.

${ }^{35}$ Literature upon Leucoproteases and Antileucoproteases: C. Oppenheimer, Die Fermente, 3d ed., pp. 216-221, 1910; cf. especially the works of Opie and Barker, Jochmann and Miiller and their associates (Ziegler, Lockemann, Kantarowitsch, Kolaczek), and also M. Fiessinger and P. L. Marie, Journ. de Physiol., 11, 613, 1909. 
caseous material are said to be inactive. In contrast to the typical leucoprotease which is active in weakly alkaline solutions, a ferment derived from the mononuclear leucocytes, active in acid solutions, has been described. Attempts have been made to "isolate" the ferment by precipitating with alcohol the autolysates of pus, spleen, marrow, etc., with subsequent solution of the precipitate in dilute glycerine, and to differentiate it from trypsin. Experiments have been made to "quantitatively estimate" the proteolytic leucocytic ferment by separation of the white blood corpuscles in citrated blood by centrifugation, dissolving them in water, and allowing the ferment to act upon a solution of casein, the loss in casein thus occasioned being thereafter determined by the aid of a specific precipitin serum. ${ }^{32}$ There is little need to call attention to the lack of exactness naturally inherent to all such experiments.

To briefly refer to the matter of antileucoproteases: were it correct to hold that suppurative destruction of tissue is due to the digestive action of the lencoproteases, it would be entirely logical to hope to overcome suppuration by the antiferment of leucoprotease or by the "normal antiferment" of the blood serum. As it was believed, following Jochmann, that antileucoprotease is identical or at least very similar to antitrypsin, attempts have been made to deal with suppurations by antitrypsin treatment. ${ }^{40}$ The author has already (Vol. I of this series, p. 560, Chemistry of the Tissues) pointed out the more than problematic nature of "antitrypsin" and has not been impressed with the idea that the practical results of antitrypsin treatment have been brilliant enough to set aside all theoretical doubt.

Effect of Extrinsic Factors Upon Autolysis.-Although the effort to influence autolysis within the living body has

${ }^{30}$ M. Franke (Lemberg), Wiener klin. Wochenschr., 1910, No. 33.

${ }^{40} \mathrm{Cf}$. Jochmann and W. Bätzner, München. med. Wochenschr., 1908, 2473; R. Chiarolanza, Med. Naturw. Arch., 2, No. 1, 1909. 
had, even in the treatment of abscesses, no dazzling results, studies upon the influence exerted by extrinsic factors upon autolysis are full of practical interest in view of the unquestionable importance the process has in every question of tissue resorption ( $v$. supra). Only the most interesting references will be briefly made here from a rich literature bearing upon the subject. ${ }^{41}$

It is known from experiment that autolysis, which can set in at the natural reaction of the animal juices, is very notably increased by addition of small amounts of acid, eren of so weak an acid as carbonic acid. ${ }^{42}$ From this it may be concluded that autolysis is relatively dependent upon the intra-vital and postmortem proportion of acid in the tissues; that, for instance, the insignificance of autolysis in embryonal tissues is perhaps due to the low porrel of these tissues to form acid. ${ }^{43}$ The idea has been suggested that the increased tissue-protein destruction seen in the asphyxias may have some connection with an increased autolysis made possible by the increased carbonic acid present under such cireumstances. ${ }^{44}$ As blood serum ${ }^{45}$ exerts an inhibitory influence upon autolysis (which is, however, in no wise specific, and inheres moreover to other colloids, as egg-albumin and gelatin ${ }^{46}$ ) it may be supposed that this factor may be involved in a regulative way over catabolism of the tissue proteins. It should not be forgotten, however, that the relation supposed to exist between the latter and autolysis is at least for the present entirely hypothetical.

41 Literature upon Effect of Extrinsic Factors upon Autolysis: C. Oppenheimer, Die Fermente, 3d ed., pp. 245-246, 1910.

S. Arinkin (Salkowski's Lab., Berlin), Zeitschr. f. physiol. Chem., 59, 192, 1907; S. Yoshimoto, ibid., 58, 341, 1909.

${ }^{43}$ L. B. Mendel and C. S. Leavenworth, Amer. Journ. of Physiol., 21, $69,1908$.

${ }^{4}$ L. Bellazzi (Ascoli's Lab., Pavia), Zeitschr. f. phrsiol. Chem., j\%, 389, 1908.

s. Baer, Arch. f. exper. Pathol., 56, 68, 1906.

${ }^{\text {*H }}$ W. T. Longcope, Journ. of Medical Research, 18, 45, 1908. 
In addition to the above it has been discovered that the alkaline earths as well as phosphorus, as above stated, hasten autolysis ${ }^{47}$; arsenic, ${ }^{48}$ quinine ${ }^{49}$ and quite a number of other drugs manifest, at least when present in considerable quantities, an inhibitory influence. Many drugs seem to accelerate in very small dosage, but to inhibit when in higher proportions.

The influence of colloidal metals ${ }^{50}$ in stimulating autolysis, made known by observations of Ascoli in Pavia and his associates, seems to the author worthy of much consideration. Recently a contribution by C. Neuberg and Caspari has attracted considerable attention, dealing with the results obtained in treating mouse cancers with colloids of the heavy metals. A very rapid softening and liquefaction of the tumors was produced, and in a number of cases actual tumor destruction was attained, apparently without danger to the life of the experiment animals (v. Vol. I of this series, p. $555 \mathrm{ff}$, Chemistry of the Tissues). One cannot but hesitate to spoil the pleasure this fine result inspires by stating the fact that mouse cancers are incomparably more benign than the analogous tumors of man (a point which Wassermann explicitly brings out in warning against employing the method in human therapy, in an article announcing a similar result attained in animals by the use of selenium preparations).

There is food for further thought in the fact that

${ }^{47}$ L. Launoy, C. R. Soc. de Biol., 6., 487, 1907; L. Brüll (V. Noorden's (linic, Vienna), Biochem. Zeitschr., 29, 408, 1910.

${ }^{48}$ L. Hess and P. Saxl, Zeitschr. f. exper. Pathol., 5, 89, 1908.

* E. Laqueur, Arch. f. exper. Pathol., 55, 240, 1906; cf. also Biochem. Centralbl., 8, 564, 1909; Centralbl. f. Physiol., 22, 717, 1909; G. Izar (Ascoli's Lab., Pavia), Biochem. Zeitschr., 21, 46, 1909.

${ }^{50}$ M. Ascoli and C. Izar, Biochem. Zeitschr., 6, 192, 1907; 7, 142, 1907; 10, 356, 1908; 14, 491, 1908; 17, 361, 1909; L. Preti, Zeitschr. f. physiol. Chem., 58, 539, 1909; 60, 317, 1909; G. Izar, Biochem. Zeitschr., 22, 371, 1909; M. Truffi, ibid., 23, 270, 1910, and earlier publications from the same laboratory. 
besides radium, ${ }^{51}$ consideration of which in the treatment of tumors has been given in an earlier lecture (v. Vol. I of this series, pp. 557-558, The Chemistry of the Tissues), two other great blessings to man, mercury and iodine, are to be numbered among the agents capable of increasing autolysis. While the addition of iodide of potassium to an autolysing mass is without effect, a very decided increase of hepatic autolysis has been attained in animals by long preadministration of the salts of iodine.52 May it not be that the favorable influence, confirmed in hundreds of thousands of cases, which this agent exerts upon luetic processes, is in some way connected with stimulation of autolysis? The few observations here referred to give us, of course, no justification for such a conclusion. But as a pointer for continued investigation they deserve constant reflection.

Abderhalden's Investigations Upon Proteolytic Tissue Ferments.-We are indebted for very real progress in the study of proteolytic tissue ferments to the extensive investigations of Emil Abderhalden and his army of collaborators. ${ }^{53}$ By his method of work, testing the tissue enzymes, not as was always done before upon indefinable proteins, but upon numerous well-defined polypeptids, Abderhalden, it may be said, dragged the whole problem from the depth of a dismal cloud-mass into an enlightened level; and it is not a difficult thing to prophesy that when this series of studies has

${ }^{51} \mathrm{~J}$. Wohlgemuth, Berliner klin. Wochenschr., 1904, No. 26, 704; S. Löwenthal and E. Edelstein, Biochem. Zeitschr., 1'f, 484, 1908.

${ }^{62}$ L. Kepinow (Instit. for Cancer Investigation, Heidelberg), Biochem. Zeitschr., 3\%, 238, 1911 ; L. B. Stookey, Proc. Soc. Exp. Biol., 5, 89; abst. in Jahresb. f. Tierchem., 38, 842, 1908.

${ }^{53}$ E. Abderhalden, in association with C. Brahm, H. Deetjen, A. Gigon, Mr. Guggenheim, A. Hunter, K. B. Immisch, A. Israel, E. Kämpf, A. H. Koelker, W. Manwaring, J. S. McLester, F. Lussana, L. Pinkussohn, A. Pringsheim, B. Oppler, A. Rilliet, P. Rona, B. Schilling, A. Schittenhelm, J. G. Sleiswyk, E. Steinbeck, J. Teruuchi, I. Wacker, W. Weichhardt. Literature: E. Abderhalden, Lehrb. d. physiol. Chem., 2d ed., pp. 266-268, 1909; and Synthese der Zellbausteine in Pflanze und Tier, p. 119, Berlin, J. Springer, 1912; C. Oppenheimer, Die Fermente, 3d ed., pp. 172-176, 1910. 
reached a definite conclusion many fundamental problems of physiology and of pathology will be regarded very differently than is now possible.

Detection of Proteolytic Tissue Ferments, by Employing Glycyltyrosin, Silk-peptone and Glycyltryptophane.-Mention may first be made of some part at least of the progress in technique contributed by Abderhalden in this field. A useful method of determining peptolytic tissue ferments is based upon their action on a solution of some polypeptid, which, like glycyltyrosin or a given silk-peptone, contains a relatively insoluble aminoacid. The ferment solution to be tested or a section of an organ is put in a 25 per cent. solution of silk-peptone and placed in the incubator after toluol has been added; after a few hours presence of the ferment manifests itself by the separation of tyrosin. The tyrosin is to be found limited to the cortical surface of sections of renal tissue, for example, the medulla remaining free; in fatty kidneys the tyrosin separation is distinctly decreased. It is equally simple to determine the presence of peptolytic ferments in sections of vegetable material. Another process which is also available for microchemical work is based upon the fact that a polypeptid containing tryptophane, as glycyltryptophane, when treated with bromine water will yield a violet color, not at once, but after the separation of the tryptophane.

Optical Method.-The "optical method" introduced by Emil Fischer and Abderhalden has yielded excellent results in this field; the author has previously referred to this (Vol. I of this series, p. 555, Chemistry of the Tissues, and in the present volume, Chapter II). This method demands the use of a suitably sensitive polarization apparatus with which to follow and accurately determine each step of the course of cleavage of optically-active polypeptids in which the individual "building stones" are loosened from their structural positions in the complexly constructed polypeptid. An illus- 
tration may serve to make the method clear. ${ }^{54}$ The tripeptid d-Alanyl-glycyl-glycin shows in aqueous solution a specific rotation of $+30^{\circ}$. This substance can give rise in cleavage to d-Alanyl and to glyeylglycin. The former rotates light but $+2.4^{\circ}$, and the latter is optically inactive. When cleavage occurs therefore there is a sudden decrease in the rotative power. Quite a different result is seen, however, if a cleavage occurs which produces glycocoll and d-alanylglycin. The latter of these two substances is characterized by a very high rotative power, of $+50^{\circ}$, and this type of cleavage therefore shows itself by access of optical rotation.

Emil Fischer and Abderhalden made the important statement that racemic polypeptids are split asymmetrically by proteolytic ferments. Examining a dipeptid, $\mathrm{NH}_{2}$ : $\stackrel{*}{\mathrm{R}} \mathrm{H} . \mathrm{CO}-$ NH.CH.COOH, it may be seen there are two asymmetrically
$\dot{\mathrm{R}}^{\prime}$ placed carbon atoms. From this it follows, in accordance with the well-known principle of van't Hoff, there exist four isomers, which group themselves into two racemoid bodies, thus:

d-Alanyl-1-leucin $\longleftrightarrow$ 1-Alanyl-d-leucin (racemic body A). d-Alanyl-d-leucin $\longleftrightarrow$ l-Alanyl-l-leucin (racemic body B).

It has developed that the two racemic compounds behave entirely differently toward pancreatic juice. Only that one which presents the combination of the natural aminoacids $\mathrm{d}$-alanin and l-leucin-that is, racemic body A-is split, and this is attacked asymmetrically as only the combination d-Alanyl-l-leucin is split; while the combination of l-Alanyld-leucin remains unchanged. In this respect the proteolytic ferments of animal tissues are shown to be analogous in their influence to that of the pancreatic juice.

\footnotetext{
${ }^{5:}$ E. Abderhalden, Lehrb. d. physiol. Chem., 2d ed., pp. 266, 626, 1910.
} 
Inhibition of Proteolytic Processes by the Products of Protein Cleavage.-It has long been known that the action of proteolytic ferments is inhibited by the presence of protein cleavage products. It has been repeatedly shown that the inhibitive influence is due to the optically active aminoacids, in which this power resides, which exist in the proteins. It is suggested in explanation that these aminoacids (and only these) bind the ferment and thus prevent its fixing its object of prey, the protein molecule. This is merely suggested because the test tube is incapable of affording a true picture of the proteolytic processes which are going on in the living body. It should be realized that in the living body, whether proteolysis is taking place in the digestive canal or in the tissues, the cleavage products of protein are removed, as they are formed, from further contact with the proteolytic enzyme, and thus the inhibition inevitable in the test tube is avoided.

Moreover a natural prolongation of proteolytic cleavage may be conceived from the fact that ceteris paribus the longer molecular chains are more readily preyed upon than short ones; with equal amounts of ferment and equal molecular concentration of polypeptids, a tetrapeptid is split more quickly than a tripeptid, and the latter in turn more quickly than a dipeptid.

Classification of Proteolytic Ferments.-By substitution of definite polypeptids for high-molecular proteins a basis will be found for construction of a rational classification and differentiation of proteolytic ferments. We know today, for example, that pepsin is incapable of acting upon any of the hitherto demonstrated polypeptids; that trypsin will separate some of them but by no means all; while erepsin can dissociate even those polypeptids which, like glycylglycin, successfully resist trypsin. Keep in mind that every cell and every cellular combination in animals and plants, from infusorium and bacterium up to 
the highly differentiated organs of man, is in reality a chemical laboratory, in which proteolysis is going on in myriads of different forms! Think of the crudeness of our attempts to classify all these heretofore! Many a time in the last ten years when busily engaged in collecting material for a comparative chemical physiology of the lower animals, has the author lost his temper on seeing how learned men, in endless controversy as to whether this or that secretion possess a "peptic" or "tryptic" character, quarrel among themselves, without the least thought on the part of any one of them of some better trophy than that of their trivial "clearly reddened" or "distinctly blued" litmus papers. It is to be hoped that as the methods elaborated by Abderhalden come into general appreciation it will all be very different. It is quite likely that these methods will not be as easy of prosecution as litmus-paper processes; and it is to be expected, too, that facility in them will require progressively a more and more comprehensive chemical training.

Peptolytic Power of Blood Serum.-In conclusion reference may again be made to the promise held out by the recent methods of study, of information regarding the active proteolytic agencies in the blood serum. Abderhalden and his collaborators have discovered that subcutaneous or intravenous injection of specifically foreign but not of specifically homologous protein increases the peptolytic capacity of blood serum. The normal serum of a dog, for example, is incapable of catabolizing silk-peptone. Its proteolytic ability is apparently increased by parenteral introduction of horse serum, gliadin, casein, diphtheria toxin, tuberculin, but not by dog serum. Serological studies in this line, applying the optical method, are full of suggestive promise for many of our important problems (as anaphylaxis). It is a matter of regret that further discussion of the theme cannot be pursued; the whole subject is thus far too undeveloped to permit a definitive conclusion. 
Mere mention can be given a very interesting practical application of the optical method, that of its employment in the diagnosis of pregnancy. Abderhalden started out with the idea that if it be correct, as many gynecologists testify, that cellular elements of the chorionic villi pass into the circulating blood of pregnant females, these being in a sense foreign to the blood should increase the proteolytic capacity of the blood against them. Investigation actually corroborated the assumption, it being possible to demonstrate by optical means that serum from gravid females has the power of inducing cleavage of a placental peptone (obtained by partial hydrolysis of human placental tissue by sulphuric acid), while the same power does not exist in the serum of normal, non-gravid individuals. The chemical diagnosis of pregnancy can be made, however, in much simpler manner, by dialyzing the serum of the pregnant woman in which bits of boiled placental tissue have been suspended against water, and then testing the dialysate for material responding to the biuret reaction. At the present time Abderhalden is still engaged in so far perfecting the method that it may be adapted to the requirements of medical practice. ${ }^{55}$

${ }^{5}$ E. Abderhalden and M. Kiutsi, Zeitschr. f. physiol Chem., $7 \%, 249,1912$; E. Abderhalden, ibid., 81, 90, 1912. (Employment of triketohydrindenhydrate as peptone reagent.) 


\section{CHAPTER V}

UREA. HIPPURIC ACID. EXCRETION OF AMINOACIDS

\section{UREA}

IT has been the earnest wish of the author to present in logical sequence as fully as possible the world of biochemical fact and error; but, as has been said before, and that not without feelings of decided rebellion, at a single stride the darkly yawning chasm of intermediate metabolism must be passed, with the vast number of unsolved enigmas it harbors, and attention next directed to the end-products of protein metabolism.

The present chapter has first to deal with urea, the most important of the nitrogenous end-products of mammalian metabolism. What do we know of the method and manner of urea-formation?

Theories of the Formation of Urea in the Living Body.Of the many theories which have been proposed to explain the origin of urea there are today practically, in the author's opinion, only two worthy of consideration, that of Schmiedeberg and that of Hofmeister. The former, the "anhydride theory," regards urea as originating from ammonium carbonate by withdrawal of water:

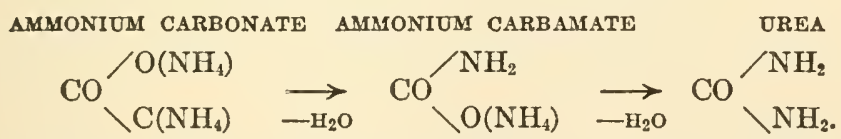

In this schema the carbamate of ammonium may be regarded as an intermediate product. Hofmeister, on the other hand, in his theory holds that urea is formed by an oxydative synthesis, in which one of the components is supposed to be an $\mathrm{NH}_{2}$ "rest" arising from oxidation of ammonia, and the other an $\mathrm{NH}_{2}$. $\mathrm{CO}$ rest. The hydrocyanic acid theory of Hoppe-Seyler, which for decades has trailed through the 
literature of the subject, may to-day be consigned finally to well deserved rest. There was a time when it was entirely proper to think it possible that urea may be formed in the body precisely as in Wöhler's synthesis by transformation from ammonium cyanate; but after vainly searching for hydrocyanic acid for a number of decades in the intermediate metabolism the theory may be finally dropped, in the author's opinion, from current consideration. If we are to drag along the whole dead weight of wornout mistakes of former generations on our backs, how can we be expected to acquire the strength and vigor required for the grinding effort to reach the higher levels of the future?

Uraminoacids.-The formation of certain conjugate products, the uraminoacids, suggesting the possible availability of free $\mathrm{CONH}_{2}$ complexes, may be regarded as favoring Hofmeister's theory. Thus, as Salkowski discovered, aminobenzoic acid and sulphanilic acid introduced into the system, as, too, taurin, can attach $\mathrm{CONH}_{2}$ groups to themselves; and even ingested tyrosin may be observed linked with such a complex (cf. Vol. I of this series, p. 47, Chemistry of the Tissues):

$\mathrm{m}=$ AMINOBENZOIC ACID

SULPEANILIC ACID

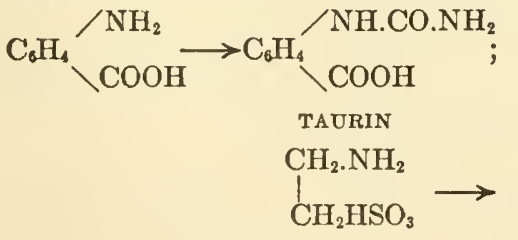

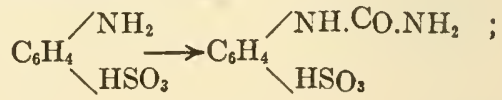

$\mathrm{CH}_{2} \cdot \mathrm{NH} . \mathrm{CO}: \mathrm{NH}_{2}$
$\mathrm{CH}_{2} \mathrm{HSO}_{3}$

TYROSIN
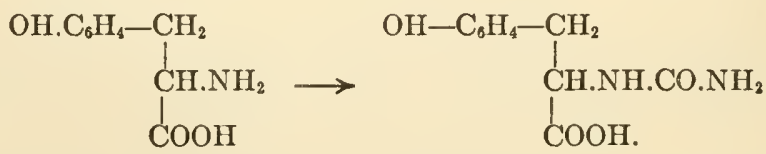

But it has been proved that in alkaline reaction aminoacids with urea are very readily transformed into uraminoacids. ${ }^{1}$ 1908.

${ }^{1}$ F. Lippich, Ber. d. deutsch. chem. Ges., 39, 2953, 1906; 41, 2053, 2074, 


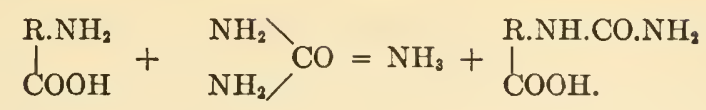

It is sufficient, for example, to heat an alkaline urine containing tyrosin to steaming to effect such a transformation. ${ }^{2}$ One must believe therefore that we are no longer justified in any conclusions bearing upon the mechanism of urea formation from the formation of these conjugate products.

From experiments in Hofmeister's laboratory ${ }^{3}$ it was determined that by perfusing the isolated living liver with taurin the linking of $\mathrm{CONH}_{2}$, as above suggested, does not directly take place; this group becoming available only if glycocoll is introduced at the same time. The $\mathrm{CONH}_{2}$ group at all events appears from oxidation of the latter; whether, however, from finished urea (as in the formation of a uraminoacid from aminoacid and urea in the laboratory) or from some precursor of urea,

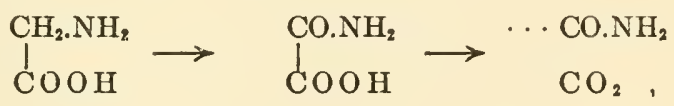

cannot at present be determined.

Mechanism of Vital Oxidation of Nitrogenous Substances.-Schmiedeberg's anhydride theory is based on the assumption that protein is burned in the living body to its end-products, all the carbon eventually becoming $\mathrm{CO}_{2}$, all the hydrogen water, the nitrogen appearing as ammonia, just as in preparation of a protein for Kjehldahl determination.

At present the great riddle of the vital combustion processes, it is safe to say, is incomprehensible to us; and it is beyond our understanding how the living body manages at a temperature less than $40^{\circ} \mathrm{C}$. to effect an oxidation which in the laboratory we are able to accomplish only by great heat

${ }^{2}$ H. D. Dakin, Jour. of Biol. Chem., 8, 25, 1910.

${ }^{3}$ P. Philosophow (F. Hofmeister's Lab., Strassburg), Biochem. Zeitschr., 26, 131, 1910; ef. therein Literature upon the Uraminoacids. 
or by powerful reagents like fuming sulphuric acid. This is one of life's great mysteries. That the living cell, however, after successfully performing the trick of burning protein into $\mathrm{CO}_{2}, \mathrm{H}_{2} \mathrm{O}$ and $\mathrm{NH}_{3}$, can finally change the carbonate of ammonium into urea by withdrawal of two molecules of water (carbonate of ammonium necessarily resulting from the combination of the carbonic acid with ammonia in aqueous solution), is apparently much less inconceivable; and from this stage forward it is rather hard to comprehend why Schmiedeburg's theory should present any particular difficulties. Schmiedeburg's famous pupil, v. Schroeder, whose work was ended by his premature death, was able to show by his frequently-quoted perfusion experiments that the isolated liver is able to transform not only ammonium carbonate but also the ammonium salts of organic acids, as formate of ammonium, into urea. Thereafter Salaskin demonstrated that aminoacids are liable to the same change. How this is actually accomplished and what intermediate products are produced are entirely unknown. We have no knowledge, for example, in the oxidation of glycocoll whether the oxygen combines first with the carbon or with the nitrogen, and whether glyoxylic acid (occasionally appearing in metabolism) is an intermediate product: ${ }^{4}$

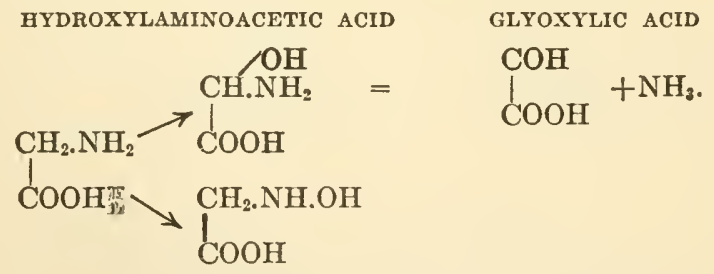

Ammonium Carbamate.-As previously stated, in anhydration-production of urea ammonium carbamate, $\mathrm{CO}\left\langle\mathrm{OH}\left(\mathrm{NH}_{4}\right)\right.$, may appear as an intermediate material. For considerable time this compound, occasionally found in the blood, urine

'H. Eppinger (Hofmeister's Lab., Strasssburg), Hofmeister's Beitr., 6, 481, 1905 . 
and tissues, has been regarded as important in pathology, being looked upon as especially toxic and as responsible for the symptoms of intoxication appearing after administration of meat to animals with Eck fistulas. The import and credibility of these ideas have been completely lost, however, since it has been shown that anywhere, as in the urine, where an ammonium salt in aqueous solution comes in contact with sodium carbonate ammonium carbamate is produced, the $\mathrm{NH}_{3}$ and $\mathrm{CO}_{2}$ being distributed proportionately to form ammonium carbamate and ammonium carbonate in connection with the disturbance of equilibrium and water transportation. ${ }^{5}$

Place of Urea Formation. Exclusion of the Liver.In literature the question of the place of urea formation occupies a very disproportionate amount of space. That a process of this sort actually takes place in the liver is amply proved by v. Schroeder's experiments; but it is by no means settled that the liver is the sole location in which urea is formed. Efforts have been made to come to some conclusion upon this point by study of the sequels of hepatic exclusion. Experiments along this line of inquiry by Nencki and Pawlow (with Hahn and Massen) in which they made use of the Eck fistula (cf. Vol. I of this series, p. 296, Chemistry of the Tissues), have become famous. Here, too, we may class the experiments in Hofmeister's laboratory in which the liver is destroyed by injection of acid into the biliary duct, and by ligation of the hepatic vessels. In addition a number of observations upon nitrogen elimination in acute yellow atrophy, phosphorus poisoning and hepatic cirrhosis are of significance. ${ }^{6}$ The conclusion from this

J. J. Macleod and H. D. Haskins (Cleveland), Jour. of Biol. Chem., 1, $319,1905$.

${ }^{6}$ Literature upon Formation of Urea in the Living Body and its Relation to Defect of Hepatic Function: M. Jacoby, Ergebn. d. Physiol., 1, 532, 1902; A. Magnus-Levy, Noorden's Handb. d. Pathol. d. Stoff w., 1, 99-117, 1906; E. Weinland, Nagel's Handb. d. Physiol., 2, 481, 1907 ; J. Wohlgemuth, Handb. d. Biochem., S', 183, 1910; A. Ellinger, ibid., 3', 563, 1910. 
whole group of studies may be briefly condensed into the statement, that the liver can be practically excluded without abolishing or in any marked degree reducing the formation of urea. It is true that in these subjects there sometimes occurs a lowering of the urea (from 90 to 75 per cent. of the total nitrogen), with corresponding increase of ammonia (the latter increasing from about 3 to 5 per cent. of the total nitrogen to 20 per cent. or more). But on the other hand it is known that loss of hepatic function coincides frequently with an "acidosis," that is, with accumulation of acid metabolites; and it is not at all unreasonable to think that this may very satisfactorily explain the diminution of urea formation and coincident ammonia increase $(v$. inf.). In dog fish, in the tissues of which there is an unusually large proportion of urea, it has not been possible to reduce this by extirpation of the liver. ${ }^{7}$ Recent clinical observations have invariably indicated that ammonia elimination is very commonly heightened in severe liver affections, although scarcely more than in fever or in conditions of acidosis; and it is altogether impossible to conclude that observation of urea-ammonia-elimination affords a safe basis or deduction as to the hepatic function. ${ }^{8}$

Generally speaking, the inclination at the present time is increasingly toward the belief that the ability to form urea is by no means confined to the liver, but is one of the common characteristics of all living cells, just as is the power of protein combustion. In very low types of life, in fact, urea does not appear as such in the excretory products; instead we find uric acid, which may be conceived as built up of two molecular urea rests and one tri-carbon group. ${ }^{9}$

'W. v. Schroeder, Zeitschr. f. physiol. Chem., 14, 576, 1890.

'W. Frey (Gerhardt's Clinic, Basel), Zeitschr. f. klin. Med., 72, 383, 1911.

- Literature upon Excretion in Lower Animals: O. v. Fürth, Vergl. chem. Physiologie d. nieder. Tiere, Jena, 1903. 
Alkalosis and Acidosis.-The views as to the special intoxication picture which tends to manifest itself in Eck fistula animals after meat diet have recently undergone an unexpected change. F. Fischler, in Krehl's Clinic in Heidelberg, from observations based on a large amount of material, differentiates the toxic symptom complex into two groups, only one of which he is willing to attribute directly to the meat diet. The other group of symptoms he believes to be determined by degenerative changes in the liver, referable to lesions of the pancreas produced in the course of the operation and to consequent escape of free pancreatic ferment. Against these latter features of the toxic complex it should be possible to prepare the animal by appropriate immunization with trypsin. As far as the features of meat intoxication are concerned (thus in some sense isolated in purer form), Fischler states that he has never met among his Eck fistula dogs, in spite of excessive meat feeding, excretion of an acid urine; and because ostensibly administration of phosphoric acid may prevent or cure the toxic features, he believes it may be assumed that an "alkalosis" is of importance in their production, a pathological influence of alkaline material upon the tissues. ${ }^{10}$ As before stated other authors have held to the idea of an acidosis in the study of this and of allied conditions, and have explained the increased ammonia elimination in consonance therewith. The same view is applied, for example, in the hepatic lesions observed by Gautrelet after injection of methylene blue or sodium fluoride. ${ }^{11}$ It is not hard to understand how a disinterested observer might be unable to resist a feeling of general distrust in such a position. And yet the difference may be only an apparent one; and perhaps the following may approximate the truth. One should recall

${ }^{10}$ F. Fischler (Med. Clinic, Heidelberg), Deutsch. Arch. f. klin. Med., 104, $300,1911$.

13. Gautrelet, with K. Mallie and H. Gravelat, C. R. Soc. de Biol., 60, 551, $714,1906$. 
( $v$. supra., p. 82) that, after ingestion of a meal rich in protein, deamidization processes may begin at once in the intestinal wall, and the portal blood thereby loaded with ammonium salts passes to the liver, where these are transformed into urea. ${ }^{12}$ But what if the liver be excluded or so seriously altered that formation of urea does not take place in the organ as normally from the ammonia which is swept into it with the portal blood? In that case the general circulation, of course, will next be flooded with ammonia, probably in the form of carbonate. As doubtless the liver does not monopolize the matter of forming urea, a part is probably taken up by other organs and in them changed into urea, while another portion of the ammonia may perhaps be rendered inert by acids which the organism mobilizes. We know that the organism protects itself against an excess of acid by mobilization of alkaline material; and it is perhaps possible, vice versa, that it may protect itself against an alkaline excess by mobilization of acid substances, or possibly by elaboration of unusual kinds and quantities of acids, as in the acidosis actually seen in a number of hepatic affections (icterus catarrhalis). ${ }^{13}$ If, however, both methods of protection are insufficient or act too slowly, the result may ultimately be an alkaline intoxication, an "alkalosis." The author wishes, however, not to be misunderstood as saying that this is actually true; these suggestions are presented only in the way of tentative explanation.

The important part taken by ammonia in correction of excessive acidity in the living body was clearly recognized a number of years ago by Walter, in Schmiedeberg's laboratory. The usually more marked acid-resistance of carnivores, in contrast with vegetarian animals, is apparently

${ }^{12}$ K. Kowalevsky and M. Markiewicz, Biochem. Zeitschr., 4, 196, 1907 ; cf. therein the older literature, especially in reference to the differences of view of Salaskin and Zaleski and of Biedl and Winterberg.

${ }^{13}$ N. Janney (F. v. Müller's Clinic, Munich), Zeitschr. f. physiol. Chem., $76,99,1911$. 
fully explained by the difference of food. According to Eppinger it is not difficult to poison with acid dogs kept on protein-free diet; conversely the inherently low acid-resistance of rabbits and sheep is at once raised by food rich in protein. ${ }^{14}$ That a similar defensive influence is manifest also from injected urea and aminoacids is denied by Pohl. ${ }^{15}$

Arginase.-A small cleavage fraction of the nitrogen in the protein molecule arises, not by the roundabout way of total dissociation and combustion, but by direct separation from the arginin-group by the action of a special ferment, arginase of Kossel. In an earlier lecture (Vol. I of this series, p. 94, Chemistry of the Tissues) some attention was given to the mode of action of the latter. Experiments on protamines have indicated that arginase is able to seize upon not only the free arginin but to attack even that which is present in the interior of the protein molecular structure. Racemic arginin undergoes asymmetrical cleavage; creatin and guanidin are not affected. ${ }^{16}$ It is probable that some of the older statements in literature with reference to fermentative production of urea ${ }^{17}$ in tissue extracts are explicable as due to the influence of arginase.

Postcenal Urea Excretion.-The catabolism of ingested protein in the normal organism occurs so promptly that the process is complete within the course of a few hours. $\mathrm{Ob}$ servations upon the excretion of urea from hour to hour after meals, conducted in the laboratory of Ernest Freund, have shown that in normal individuals it reaches its maximal grade as early as four to five hours after the ingestion

${ }^{\star \star}$ H. Eppinger, Wiener klin. Wochenschr., 1906, No. 5; Zeitschr. f. exper. Pathol., 3, 530, 1906; H. Eppinger and F. Tedesko, Biochem. Zeitschr., 16, 207, 1909.

${ }^{15} \mathrm{~J}$. Pohl and E. Münzer, Centralbl. f. Physiol., 20, 232, 1906; J. Pohl, Biochem. Zeitschr., 18, 24, 1909.

${ }^{16}$ A. Kossel and H. D. Dakin, Zeitschr. f. physiol. Chem., 41, 321, 1904; 42, 181, 1904; H. D. Dakin, Journ. of Biol. Chem., 3, 435, 1907; Rieszer (Kossel's Lab., Heidelberg), Zeitschr. f. physiol. Chem., 49, 210, 1906.

${ }^{17}$ Ch. Richet, Chassevant, Spitzer, D. Löwi ; cf. O. Löwi (Hofmeister's Lab., Strassburg), Zeitschr. f. physiol. Chem., 25, 512, 1898. 
of nitrogenous food. If the ingested material has been in the form of protein already advanced in catabolism the maximum is reached more quickly and the greatest urea excretion is to be noted within one to two hours. ${ }^{18}$

Quantitative Estimation of Urea.-The very great physiological importance of urea is apparently sufficient reason for the fact that there has been no dearth of effort to improve the methods for its quantitative determination. ${ }^{19}$ The old method of Liebig by titration with mercuric nitrate continues to appear here and there in literature; but has become practically unimportant, and efforts to reinstate the method have attained but little success. ${ }^{20}$ The most modern methods as a rule are based upon the principle of transforming the urea into ammonia by hydrolytic agents and distilling the ammonia. Other nitrogenous constituents present, especially those of basic nature, may be separated by phosphotungstic acid (Pflüger-BleibtreuSchöndorf method) or by phosphomolybdic acid (Haskin's method). ${ }^{21}$ Some prefer to at least partially separate the urea from other constituents by the Mörner-Sjöquist method (precipitation by alcohol and ether in presence of baryta). Hydrolysis of the urea is accomplished by heating with magnesium chloride and hydrochloric acid (Folin's method), ${ }^{22}$ with lithium clloride and hydrochloric acid (Saint Martin), ${ }^{23}$ with hydrochloric acid in sealed tubes (Salaskin and Zaleski), with sulphuric or hydrochloric acid

${ }^{18}$ A. Stauber (E. Freund's Lab., Vienna), Biochem. Zeitschr., 25, 187, 1910.

${ }^{19}$ Literature upon the Quantitative Estimation of Urea: P. Rona, Handb. d. biochem. Arbeitsmethoden, 3', 774-782, 1910; 5', 295, 1911 ; Neubauer-Huppert, Harnanalyse, 11 th ed., article by W. Wiechowski, I, 560-576, 1910; C. Neuberg, Der Harn, article by A. C. Anderson, 1, 631-641, 1911; Cl. Sallerin, Journ. de Physiol., 1903, No. 2.

so B. Glaszmann (Odessa), Ber. d. Deutsch. chem. Ges., 39, 705, 1906.

${ }^{21}$ H. D. Haskins, Jour. of Biol. Chem., 2, 243, 1906.

$\approx 2$ O. Folin, Zeitschr. f. physiol. Chem., 36, 333, 1902; 37, 548, 1903; E. P. Cathcart, Jour. of Physiol., 35, Proc. viii, 1906.

${ }^{23}$ L. G. Saint Martin, C. R. Soc. de Biol., 58, 89, 1905. 
in an autoclave (Benedict and Gephart, ${ }^{24}$ and Henriques and Gammeltoft ${ }^{25}$ ), or very conveniently by heating with glacial phosphoric acid in open vessels (Braunstein), or finally by heating with potassium acetate and addition of acetic acid and zine (Folin). ${ }^{26}$ Naturally there are any number of variations and combinations of these methods possible. In spite of this apparent richness it must be confessed that all of these methods are indirect; and that in case other related substances occur in addition to urea, with their nitrogen similarly combined in the structural molecule, it would be difficult to detect them against the urea, to say nothing of estimating them.

Attempts to determine urea quantitatively by splitting it into carbonic acid and nitrogen by means of nitric acid, with subsequent determination of nitrogen by Dumas' method have been repeatedly proposed. ${ }^{27}$

\section{HIPPURIC ACID}

After the preceding presentation of the knowledge we at present possess of the formation of urea in the living body, our attention naturally is directed to other nitrogenous end-products of protein metabolism, of which hippuric acid may first be dealt with.

As is well known hippuric acid is a combination product arising from the union of glycocoll and benzoic acid:

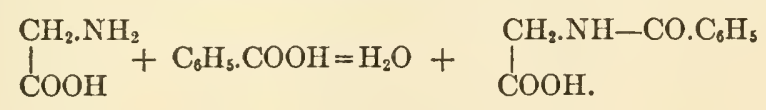

Source of Benzoic Acid.-As far as the benzoic acid component is concerned our knowledge is fairly established. It

${ }^{24}$ S. R. Benedikt and F. Gephart, Journ. of the Amer. Chem. Soc., 30, 1760, 1908; P. A. Levene and G. H. Meyer, ibid., 31, 717; G. L. Wolf and E. Osterberg, ibid., 31, 421 ; F. W. Gill, F, G. Allison and H. S. Grindley, ibid., 31, 1078; abstract in Centralbl. f. Physiol., 23, 1909.

${ }^{25} \mathrm{~V}$. Henriques and S. A. Gammeltoft (Copenhagen), Skandin. Arch., 25, $153,1911$.

${ }^{26}$ O. Folin (Harvard Medical School), Jour. of Biol. Chem., 11, 507, 1912.

mTh. Ekekrantz, with K. A. Södermann and S. Erikson (Stockholm), Zeitschr. f. physiol. Chem., 76, 173, 1912; 79, 171, 1912. 
may originate from one or other of two sources: First, from aromatic products of vegetable food, as cinnamic acid, hydrocinnamic acid, quinic acid, etc., which in metabolism are catabolized to benzoic acid. It is not remarkable, therefore. that the quantity of benzoic acid, excreted in the form of hippuric acid, may be decidedly increased by free ingestion of vegetables and fruit (normally present in human urine in amounts of 0.7 to 1 . gram daily, on mixed diet); and that herbivora eliminate a much larger quantity than carnivores. A second important source is phenylalanin, one of the molecular structural units of protein. Apparently this compound (cf. Vol. I of this series, p. 47, et seq., Chemistry of the Tissues) readily undergoes complete dissociation in normal metabolism; however the phenylpropionic acid which is produced in intestinal putrefactions from phenylalanin (cf. Vol. I of this series, p. 32, Chemistry of the Tissues) is oxidized freely into benzoic acid when it is resorbed.

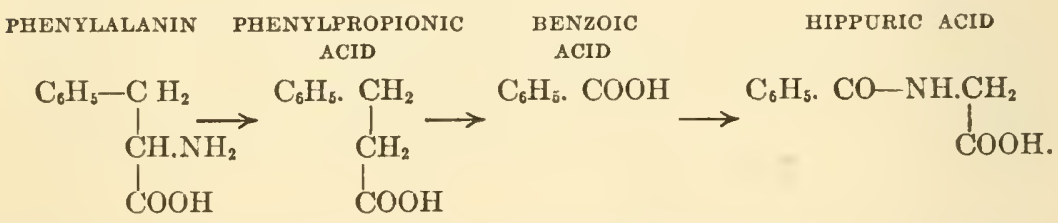

The importance of protein putrefaction to the production of hippuric acid and the fact that in dogs whose intestinal canal has been largely disinfected by means of calomel the hippuric acid may be materially lowered in the urine were fully recognized by Baumann.

The history of the second component part of hippuric acid, glycocoll, is, however, incomparably more complicated than that of the benzoic acid. Probably a clearer conception of the processes here concerned can be had if herbivorous and carnivorous animals are considered separately, as it is becoming more and more evident, as Ernst Friedmann ${ }^{28}$ has

${ }^{28}$ E. Friedmann and H. Tachau (First Med. Clinic, Berlin), Biochem. Zeitschr., 35, 88, 1911. 
stated, "that the synthesis of hippuric acid in rabbits not only occurs in different organs but also in a different chemical manner than in dogs."

Hippuric Acid Elimination in Carnivora and in Man.In carnivora, from the classical perfusion studies of Bunge and Schmiedeberg, the kidney is the sole seat of hippuric acid synthesis. It should here be recalled, however, that according to Schmiedeberg the kidney contains a ferment, histozyme, which is capable of splitting hippuric acid into benzoic acid and glycocoll, ${ }^{29}$ which may be identical with the ferment synthesizing the hippuric acid, as we have come to recognize a number of examples of the reversibility of enzyme action. Generally speaking the phenomena in the carnivora present nothing surprising. If the living animal be flooded with benzoic acid a large part is passed uncombined; a portion unites with some otherwise unknown reducing substance; and that part which appears in the urine as hippuric acid is not so great that it cannot be explained by the amount of glycocoll preëxisting in the protein molecule and separable by hydrolysis from the dietary and tissue protein. ${ }^{30}$ (This amount of glycocoll corresponds to only 4 to 5 per cent. of the total nitrogen mobilized in protein catabolism.)

In human beings, too, in the opinion of Brugsch ${ }^{31}$ the findings after administration of benzoic acid apparently do not indicate any other mode of formation of hippuric acid, than by hydrolytic protein cleavage, to be at all convincing. At least the general opinion is distinctly contrary to such a belief. ${ }^{32}$

Hippuric Acid Formation in Herbivora.-In herbivora an essentially different situation exists. The mutually

\footnotetext{
${ }^{29}$ N. Mutch, Journ. of Physiol., 44, 176, 1912.

${ }^{30}$ Th. Brugsch and J. Hirsch, Zeitschr. f. exper. Pathol., 3, 663, 1906.

${ }^{21}$ Th. Brugsch and J. Tsuchija, Zeitschr. f. exper. Pathol. 5, 731, 737, 1909.

${ }^{32}$ J. Lewinski (Minkowski's Clinic, Greifswald), Arch. f. exper. Pathol., 58, 397, 1908; Th. Brugsch, Zeitsch. f. exper. Pathol., 5, 731, 1909.
} 
confirmatory statements of Magnus-Levy, ${ }^{33}$ Wiechowski, ${ }^{34}$ Ringer, ${ }^{35}$ and Abderhalden ${ }^{36}$ leave no doubt that when benzoic acid is introduced in quantity into the body of a herbivorous animal about a third or more of the total nitrogen may be excreted as hippuric acid. It is true the economy is not operating under entirely normal conditions; there is probably a higher cleavage of the intrinsic proteins under the toxic influence of the benzoic acid than normally. ${ }^{37}$ But it seems altogether improbable that the small quantity of glycocoll of the protein molecule would be enough to form the nitrogenous moiety of the synthesis. (Abderhalden has shown, too, that the tissue protein of vegetarians is no richer in glycocoll than that of carnivores.) $)^{38}$ Wiechowski, who met in some of his experiments on rabbits with more than fifty, and once as much as sixty-four, per cent. of the total nitrogen coming from protein cleavage appearing as glycocoll, believes that these animals actually produce glycocoll, as he found that the synthesis increased, other things being equal, the longer the benzoic acid continued in circulation, and remained the same in continuous full-day intoxication. He suspects, too, that in rabbits glycocoll is the precursor of a great, if not the greatest, part of the urea eliminated. E. Friedmann ${ }^{39}$ has been able to show by perfusion that the liver of the rabbit is capable of transforming benzoic acid into hippuric acid; from which, as the amount of hippuric acid synthesis is not influenced by introduction

${ }^{33}$ A. Magnus-Levy, Münchener med. Wochenschr., 1905, No. 45; Biochem. Zeitschr., 6, 523, 1907.

${ }^{3}$ W. Wiechowski (Pharmacol. Instit., Prague), Hofmeister's Beitr., 7, 258$262,1905$.

${ }^{3}$ A. J. Ringer (Cornell Univ., New York), Jour. of Biol. Chem., 10, $327,1911$.

${ }^{30}$ E. Abderhalden and P. Hirsch, Zeitschr. f. physiol. Chem., 78, 292, 1912 ; cf. also A. A. Epstein and S. Bookman (New York), v. infra.

${ }^{37}$ A. A. Epstein and S. Bookman (New York), Jour. of Biol. Chem., 10, $353,1911$.

${ }^{38}$ E. Abderhalden, A. Gigon and E. Strauss, Zeitschr. f. physiol. Chem., 51, $311,1907$.

${ }^{30}$ E. Friedmann and H. Tachau, l. c. 
of actual glycocoll, it may be deduced that the glycocoll component or a predecessor thereof originates in the liver of the rabbit under the influence of benzoic acid.

Behavior of Benzoylated Aminoacids.-How are all these considerations to be harmonized? The possibility has been suggested that the benzoic acid primarily binds the $\mathrm{NH}_{2}$ group of the aminoacids and adheres to it, the remaining carbon skeleton of the molecule undergoing disintegration:

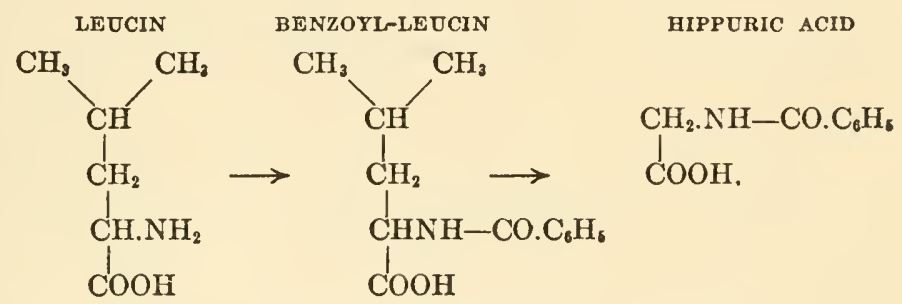

A number of feeding experiments by Magnus-Levy with benzoylated aminoacids cannot be regarded as supporting this theory. ${ }^{40}$

Synthetic Source of Glycocoll from Acetic Acid and Ammonia.-At present appearances again favor the idea that glycocoll may originate synthetically from ammonia and acetic acid. R. Cohn ${ }^{41}$ years ago observed in the laboratory of Jaffe in Heidelberg that $\mu$-nitrobenzaldehyde or $\mu$-toluidine, introduced into a living rabbit, was transformed into $\mu$-aminobenzoic acid, but that this combined with acetic acid :

$$
\text { NITROBENZALDEHYDE }
$$

These examples of a combination of acetic acid with ammonia rests suggested the idea of determining whether the

40 A. Magnus-Levy, Biochem. Zeitschr., 6, 541, 1907.

41 R. Cohn, Zeitschr. f. physiol. Chem., 17, 274, 1892; Arch. f. exper. Pathol,, $53,435,1305$. 
rabbit is able to form glycocoll synthetically from ammonia and acetic acid; and as a matter of fact a very appreciable increase in hippuric acid elimination was observed in several experiments in which ammonium acetate and benzoic acid were simultaneously administered. Although, it is true, these studies are not definitely conclusive, E. Friedmann ${ }^{\mathbf{4 2}}$ has recently declared the possibility of a synthetic formation of glycocoll from acetic acid and ammonia, with the very actively combining glyoxylic acid $\left(\begin{array}{l}\mathrm{COH} \\ 1 \\ \mathrm{COOH}\end{array}\right)$ as a possible intermediate product. A simple synthesis of acetic acid with ammonia can result only in acetamide $\left(\begin{array}{l}\mathrm{CH}_{3} \\ 1 \\ \mathrm{CO} \mathrm{NH}_{2}\end{array}\right)$ but never in glycocoll $\left(\begin{array}{l}\mathrm{CH}_{2} \cdot \mathrm{NH}_{2} \\ 1 \\ \mathrm{COOH}\end{array}\right)$. Here may be a special $\left(\begin{array}{l}\mathrm{H} \\ 1 \\ \mathrm{CO} \\ \mathrm{COOH}\end{array}\right)$ instance of the previously discussed ( $v$. supra., p. 69) synthesis of aminoacids from $a$-ketonic acids and ammonia following the schema:

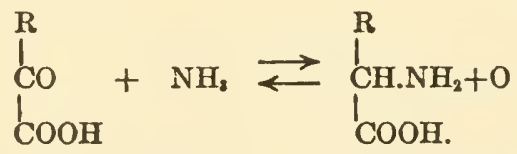

Glycocoll and Ornithin as Detoxifying Agents.-We have come to regard this synthetic union of glycocoll and benzoic acid as peculiarly important in that it may be looked upon as eliminating the toxic benzoic acid. It is well known that quite a number of other aromatic acids analogous to benzoic acid may combine with glycocoll in the economy. One of these, phenylpropionic acid $\left(\mathrm{C}_{6} \mathrm{H}_{5} \cdot \mathrm{CH}_{2}\right.$. $\mathrm{CH}_{2}$. COOH.), Dakin has shown to be very toxic to cats, ${ }^{43}$ being transformed in the animal partly into acetophenone $\left(\mathrm{C}_{6} \mathrm{H}_{5} \cdot \mathrm{CO} \cdot \mathrm{CH}_{3}\right)$; although its synthetic compound with glycocoll, phenylpropionylglycocoll $\left(\mathrm{C}_{6} \mathrm{H}_{5} \cdot \mathrm{CH}_{2} \cdot \mathrm{CH}_{2} \cdot \mathrm{CO}-\mathrm{NH}\right.$.

22 E. Friedmann and H. Tachau, 1. c., p. 90.

${ }^{43}$ H. D. Dakin (C. A. Herter's Lab., New York), Jour. of Biol. Chem., 5, $413,1908$. 
$\mathrm{CH}_{2} \cdot \mathrm{COOH}$ ) is nontoxic. This suggests the thought that perhaps in another synthetic process which takes place in the body, between glycocoll and cholic acid, with formation of the glycocholic acid of the bile (Vol. I of this series, p. 306, Chemistry of the Tissues), glycocoll may be playing the part of a detoxifying agent. Benzoic acid introduced into living birds is, however, not rendered harmless by glycocoll; in birds another cleavage product of the protein molecule takes its place, as pointed out by the celebrated Königsberg pharmacologist, M. Jaffe (recently deceased), viz.: ornithin

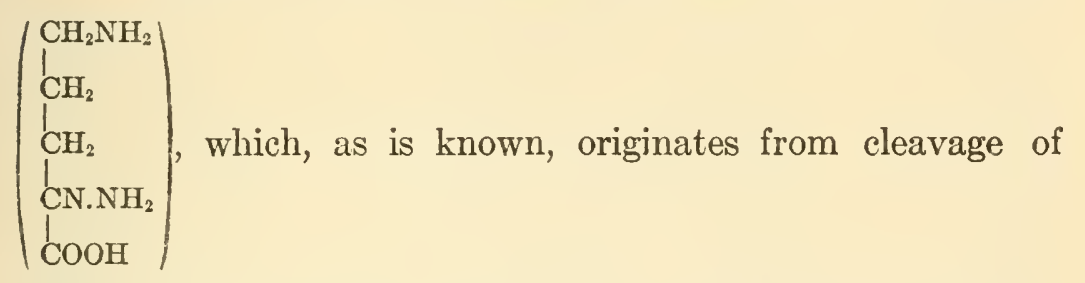

arginin (Vol. I of this series, p. 10, Chemistry of the Tissues). ${ }^{44}$ This appears in the urine as a dibenzoyl compound, ornithuric acid :<smiles>CCOC(=O)CCC(CCCNC(=O)OCC)C(=O)O</smiles>

Quantitative Estimation of Hippuric Acid.-Before leaving this part of the subject reference should be made to the method of quantitative determination of hippuric acid, a substance of decided importance physiologically. The hippuric acid in an animal fluid may be estimated as such; or its glycocoll may be determined; or the benzoic acid. The first of these plans is followed in the method of Bunge and Schmiedeberg, in which the hippuric acid is extracted by acetic ether from urine, purified by passing through animal charcoal, and weighed. Henriques and Sörensen employ their method of formol titration to estimate the glycocoll separated out from the hippuric acid.

${ }^{4}$ In the text referred to in the formula for ornithin an unfortunate typographical error occurs, in that one $\mathrm{CH}_{2}$ group too many is shown. 
The fact that hippuric acid is exceedingly unstable, being readily dissociated by evaporating the urine in weak alkaline reaction by heat, or by urinary fermentation, has led to the introduction of an increasing number of methods in which the hippuric acid is estimated as benzoic acid. The latter compound because of its stability and ready solubility in ether and other solvents offers certain advantages. ${ }^{45}$ The method of Wiechowski ${ }^{46}$ is exact but time consuming, the benzoic acid being separated by aqueous distillation. Steenbock ${ }^{47}$ oxidizes the alkalinized urine with peroxide of hydrogen, separates the phenols with bromine water after acidulation, and removes the benzoic acid by shaking with ether; after evaporation of the ether the benzoic acid is sublimed in a special glass apparatus and weighed. Folin ${ }^{48}$ oxidizes the urine with nitric acid, extracts with chloroform, washes the chloroform solution with a saturated salt solution containing hydrochloric acid and determines the benzoic acid by titration with alcoholic sodium hydrate solution.

Recently one of the author's pupil's, Hryntschak, ${ }^{49}$ has elaborated what is apparently a very satisfactory method. The urine is oxidized after treatment with boiling sodium hydrate solution by an excess of potassium permanganate; the manganese which separates is dissolved by sodium bisulphite and sulphuric acid; and the clear colorless fluid then extracted with ether. After evaporation of the ether the benzoic acid is taken up with chloroform, and finally in pure, crystallized form is weighed. Control determinations of hippuric acid in known solutions show that the method is,

${ }^{45}$ R. Cohn, Th. Pfeiffer, C. Bloch, R. Riecke, IV. Wiechowski. Literature upon the Estimation of Hippuric Acid: Th. Hryntschak, Biochem. Zeitschr., 43, 316,1912 . Conducted under direction of O. v. Fürth.

${ }^{40}$ W. Wiechowski, Hofmeister's Beitr., $7,262,1906$.

${ }^{4 \pi} \mathrm{H}$. Steenbock (Univ. of Wisconsin), Jour. of Biol. Chem., 11, 201, 1912.

4s O. Folin and F. F. Flanders (Harvard Med. School, Boston), Jour. of Biol. Chem., 11, 257, 1912.

${ }^{4}$ 1. c. 
with careful practice of precautions, capable of recovering 95 to 98 per cent.

\section{ELIMINATION OF THE AMINOACIDS}

The above consideration of the part of glycocoll in intermediate metabolism serves to introduce another interesting problem, that of the conditions under which the $a$-aminoacids, the essential products of the catabolism of the protein molecule, may escape the normal combustion and appear in appreciable quantity in the urine.

Aminoacids in Normal Urine.-That a-aminoacids, at least their optically active forms, which are normally structural parts of the proteins, may easily undergo complete disintegration is beyond question and has been proven experimentally many times; although in case of artificial introduction of formed aminoacids it has been proved that a portion sometimes escapes as such in the urine. ${ }^{50}$ Nolmally, the amount of aminoacids in the urine is, of course, quite small. Different explanations liave been proposed for this fact, as it has been determined that hippuric acid in standing urine is very readily subject to cleavage ${ }^{51}$ from action of bacteria, and its glycocoll may then be detected by the naphthalinsulphochloride method. Other aminoacids than glycocoll have apparently thus far not been certainly obtained from nornal urine. ${ }^{52}$ However, it might be easily conceived how, if small quantities of glycocoll, which had escaped synthesis into hippuric acid or had been produced

${ }^{50}$ E. Abderhalden and P. Bergell, Zeitschr. f. physiol. Chem., 89, 10, 1903 ;

K. Stolte (F. Hofmeister's Lab., Strassburg), Hofmeister's Beitr., 5, 15, 1904 ; M. Plaut and H. Reese (under direction of G. Embden), Hofmeister's Beitr., 7, 425, 1905; E. Reisz, ibid., 8, 332, 1906: S'. Oppenheimer, ibid., 10, 273, 1907 ; R. Hirsch, Zeitschr. f. exper. Pathol., 1, 141, 1905; E. Abderhalden and J. Markwalder, Zeitschr. f. physiol. Chem., $72,63,1911$; E. Abderhalden, A. Furmo, E. Goebel and P. Stübel, ibid., 74, 481, 1911. 1908.

${ }^{51}$ Y. Seo (Minkowski's Clinic, Greifswald), Arch. f. exper. Pathol., 58, 440,

${ }^{62}$ E. Abderhalden and A. Schittenhelm, Zeitschr. f. physiol. Chem., 47, 339,1906 . 
by a fermentative cleavage of formed hippuric acid, were present in the blood and tissues, they might enter the urine. ${ }^{53}$

Elimination of Aminoacids in Disease.-It is of more interest than the occurrence of small amounts of aminoacids in normal urine to know that in certain pathological conditions the excretion of these compounds has been found to be notably increased, as in some of the severe infectious fevers (typhus fever, spotted fever, scarlet fever, pneumonia and small pox, but not in measles and diphtheria). ${ }^{54}$ A number of investigators have found increased aminoacid excretion in phosphorus poisoning and acute yellow atrophy of the liver ${ }^{55}$; a symptom which, as already stated, has been referred to the increased autolysis in the liver peculiar to these conditions. It is noted also in other severe hepatic disturbances, ${ }^{56}$ as in poisoning by arsenuretted hydrogen, prussic acid, and in various degenerative changes in the liver, especially cirrhosis, cancer, fatty degeneration and syphilis. It was at one time hoped that the recognition of an increase in aminoacid elimination, especially after purposeful administration of aminoacids (as it were an "alimentary aminuria"), might be utilized in diagnosis as to the functional integrity of the liver. ${ }^{57}$ How-

$\bowtie$ G. Embden and A. Marx, Hofmeister's Beitr., 11, 308, 1908; A. Bingel (G. Embden's Lab., Frankfurt a. M.), Zeitschr. f. physiol. Chem., 57, 382, 1908; G. Forssner (F. v. Müller's Clinic), ibid., 4\%, 15, 1906 ; F. Samuely, ibid., 4\%, 376, 1906; G. Oehler, Biochena. Zeitschr., 21, 48, 1909; A. v. Reusz, WViener klin. Wochenschr., 22, 158, 1909.

o4 v. Jaksch, Zeitschr. f. klin. Med., 4r, 1, 1902; 50, 167, 1903; R. Erben, Zeitschr. f. Heilk., 25, 33, 1904; Zeitschr. f. physiol. Chem., 43, 320, 1905; Internat. Beitr. z. Path. u. Ther. d. Ernährungsstörungen, 2, 252, 1911; A. Primavera (Naples), Giorn. Internaz. di. Scienze Med., 30; abstract in Biochem. Centralbl., 9, No. 8S0, 1909-10.

${ }^{\text {s }}$ Literature upon Metabolism in Phosphorus Poisoning, Acute Yellow Atrophy of the Liver, etc.: C. Neuberg, Handb. d. Biochem., 4", 336-337, 1910.

${ }^{56}$ W. Frey (D. Gerhardt's Clinic, Basel), Zeitschr. f. klin. Med., 72, 383, 1911; F. Falk and P. Saxl (v. Noorden's Clinic, Vienna), ibid., 73, 131, 1911. N. Masuda (Fr. Kraus' Clinic, Berlin), Zeitschr. f. exper. Pathol., 8, 629, 1911. ${ }^{87}$ K. Gläszner, Zeitschr. f. exper. Pathol., 4, 336, 1907 ; H. Jastrowitz (Med. Clin., Pragne), Arch. f. exper. Pathol., 59, 463, 1908. 
ever, it is doubtful at present whether any practical result will be attained.58 Increase in the aminoacid excretion has also been met in a variety of conditions in which it is not at all evident that we are dealing with disturbances of the hepatic function, as in pregnancy, ${ }^{59}$ gout, ${ }^{60}$ diabetes, ${ }^{61}$ lenkæmia, ${ }^{62}$ and after large hemorrhages. ${ }^{63}$ Physiologically the excretion of aminoacids is apparently greater in infants than in grown persons. ${ }^{64}$ It is worthy of special attention that an enormous access of aminoacids occurs in the urine of hibernating marmots, with corresponding reduction in the urea. $^{65}$ It may well be a time will come when it will be possible to recognize and appreciate a common basis for these heterogeneous facts; but at the present as far as the author is concerned it is entirely impossible to offer any suggestion save by labored and arbitrary theorization. However much the author realizes the importance of hypotheses towards future discovery, he feels that in this case the metabolic chemist has every reason for keeping close to the fundamental facts lest he risk loss of all the footing on which he stands.

${ }^{58}$ Cf. H. Ishihara, Biochem. Zeitschr., 41, 315, 1912 (under direction of O. v. Fürth) .

so E. C. van Leersum, Biochem. Zeitschr., 11, 121, 1908; C. Rolla, Pathologica, 2, 575; abstract in Jahresber. f. Tierchem., 40, 1910; F. Falk and O. Hesky (Clinic of v. Noorden and Schauta, Vienna), Zeitschr. f. klin. Med., $71,261,1910$.

A. Ignatowski (Fr. v. Müller's Clinic, Munich), Zeitschr. f. physiol. Chem., 42, 388, 1904; ef. to the contrary, A. Lipstein (v. Noorden's Clinic, Frankfurt a. M.), Hofmeister's Beitr., \%, 527, 1906.

"Mies, München. med. Wochenschr., 1894, 671; Nicola, Giorn. d. R. Acad. di Torino, anno 67, Ser. IV, Vol. 10, p. 83, 1904; E. Abderlalden, Zeitschr. f. physiol. Chem., 任, 51, 1905; M. Labbè and H. Bith, C. R. Soc. de Biol., 71, 348, 1911.

Ignatowski, l. c.

${ }^{63}$ D. Fuchs (Klausenberg), Zeitschr. f. physiol. Chem., 69, 482, 1910.

et F. W. Sichultz, Jahresber. f. Kinderheilk., \%2, Ergänzungsheft, 1910; R. Kadlich and P. Grosser, ibid., 75, 4.

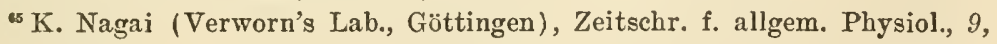
306-334, 1906. 
Cystimuria and Diaminuria.-Our interest in the discovery of the aminoacids in the urine has taken on special interest since we liave learned to look upon two rare and important metabolic anomalies, cystinuria and diaminuria, as belonging in the same category. ${ }^{66}$ It has been known for a long time that cystin is excreted in the urine and may be found in concretions and in urinary sediments in its striking crystalline form (regular hexagonal plates). E. Baumann and L. v. Udránzky have recognized in a case of cystinuria the presence of diamines in the urine. In the light of A. Ellinger's investigations, previously considered (v. Vol. I of this series, p. 34, Chemistry of the Tissues), there can be little doubt that in such a subject certain of the "building stones" of the protein molecule come, so to speak, to the surface of metabolism which should ordinarily undergo complete disintegration in its depths; and that here we have to deal on one hand with the sulphurcontaining fraction of protein, cystin $\left(\begin{array}{ccc}\mathrm{CH}_{2} \mathrm{~S}-\mathrm{S}-\mathrm{CH}_{2} \\ \mathrm{CH} . \mathrm{NH}_{2} & \stackrel{\mathrm{CH} . \mathrm{NH}_{2}}{1} \\ \mathrm{COOH} & \mathrm{COOH}\end{array}\right)$, and on the other hand with the diamines, putrescin (tetramethylendiamine $-\mathrm{CH}_{2} \cdot \mathrm{NH}_{2}-\mathrm{CH}_{2}-\mathrm{CH}_{2}-\mathrm{CH}_{2} \cdot \mathrm{NH}_{2}$ ) and cadaverin (pentamethylendiamine- $\mathrm{CH}_{2} \cdot \mathrm{NH}_{2}-\mathrm{CH}_{2}-\mathrm{CH}_{2}-$ $\mathrm{CH}_{2}-\mathrm{CH}_{2} \cdot \mathrm{NH}_{2}$ ), the first arising from ornithin and the latter from lysin by separation of $\mathrm{CO}_{2}$. Ornithin is, repeating a statement previously made in the present lecture, a cleavage derivative of arginin. The true significance of cystinuria and diaminuria was first correctly explained by the observations of A. Löwy and C. Neuberg. These writers noted in an individual under their observation that he was unable to oxidize introduced mono- and di-aminoacids, which in the

${ }^{66}$ Literature upon Cystinuria and Diaminuria: E. Friedmann, Ergebn. d. Physiol., 1, 16, 1902; F. Umber, Lehrb. d. Ernähr. u. d. Stoff wechsclkr., 1909, pp. 385-389 ; J. Wohlgemuth, Handb. d. Biochem., 3', 192-195, 1900; A. Ellinger, ibid., 3', 660-664, 1910; C. Neüberg, ibid., 4", 338, 1910; C. E. Simon and D. G. Campbell, Johns Hopkins Hospital Bulletin, 15, 365, 1904. 
normal economy undergo complete destruction. While ingested mono-aminoacids appeared in part in the urine unchanged, cadaverin was excreted when lysin was introduced and putrescin when arginin was given. According to Neuberg we should recognize different grades of cystinuria, which is a pronounced familial diathesis: (a) mild cases who excrete cystin but who oxidize other aminoacids, ${ }^{67}$ and (b) moderately severe cases by whom no mono-aminoacids at all are spontaneously excreted but in whom an alimentary aminuria and diaminuria exists. Only in (c) the most severe cases are the aminoacids spontaneously excreted, as in an instance observed by Abderhalden and Schittenhelm.

Special interest attaches to the case of a cystinuric individual, who was able to use up aminoacids but poorly, dipeptids to better advantage, but with still more efficience the more complex protein derivatives. ${ }^{68}$ It can be seen from such a case that this anomaly need not be associated with serious metabolic faults and may continue for years without manifesting itself by evident symptoms. As previously stated (Vol. I of this series, p. 307, Chemistry of the Tissues), cystin is closely related with taurin, one of the two synthetic products of cholic acid occurring in the bile:

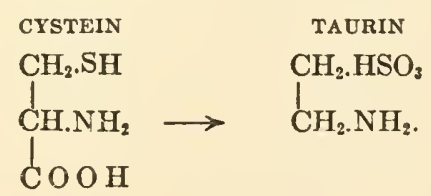

If cystin be administered to normal individuals a large part of its sulphur appears in the urine in oxidized form, as sulphuric acid. If, however, along with cystin sodium cholate be given, in the first place taurocholic acid in the bile is apparently increased, ${ }^{69}$ and a correspondingly increased

${ }^{\circ}$ Cases of Chas. E. Simon, C. Alsberg and O. Folin, A. E. Garrod and W. H. Hurtley, H. B. Williams and C. G. L. Wolf.

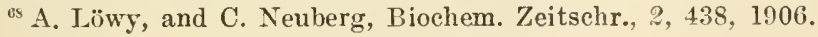

${ }^{60}$ G. v. Bergmann (F. Hofmeister's Lab., Strassburg), Hofmeister's Beitr., 4, 192,1904 . 
amount of the sulphur of the cystin fails to undergo oxidation into sulphuric acid. In a cystinuric individual, however, this latter result of administration of cholic acid does not occur, presumably depending upon a failure to synthesize taurocholic acid. ${ }^{70}$ An interesting addendum to these observations is afforded by a case of hepatic cirrhosis presenting a combination of acholia and cystinuria, interpreted as an instance of failure of normal taurocholic acid synthesis because of disease of the hepatic parenchyma, as a result of which the available (for transformation into taurin) cystin passed unchanged into the urine. ${ }^{71}$

Quantitative Determination of the Aminoacids.-The great number of physiological and pathological problems related to the excretion of aminoacids in the urine is sufficient explanation for the amount of attention devoted in recent years to the elaboration of methods for the isolation and estimation of these substances. For isolating the aminoacids the method of binding them with naphthalinsulpho chloride or with naphthylisocyanate is of service (Vol. I of this series, p. 15, Chemistry of the Tissues). For estimation of the aminoacid nitrogen the van Slyke method (ibid., p. 18), depending upon displacement of the aliphatic amino group by nitric acid, ${ }^{72}$ will be found valuable; or, too, the formol-titration method of Henriques and Sörensen. The latter is based on the fact that $a$-aminoacids in excess quantitatively bind formaldehyde:

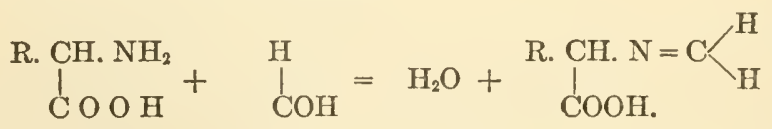

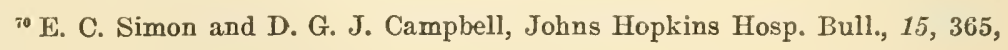
1904.

${ }^{71}$ Observation of Morawsky, cited by J. Wohlgemuth, Deutsche Klinik, 11, $329,1907$.

${ }^{12}$ P. A. Levene and D. D. van Slyke (Rockefeller Instit., New York), Jour. of Biol. Chem., 12, 301, 1912. This method serves to determine not only the free aminoacids, but also those combined in form of polypeptids, etc., in the urine. 
If the solution be carefully neutralized before its transformation with formaldehyde, the masking of the basic $\mathrm{NH}_{2}$ groups becomes evident at once by the development of an acid reaction; and as a matter of fact this increase of acidity after addition of formol, which may be determined by titration, is a precise measure of the amount of amino groups present. It cannot be questioned that the method, the technique of which has received much criticism and has been improved in a number of ways, is really a valuable addition to our scientific equipment. ${ }^{73}$

${ }^{73}$ V. Henriques and S. P. L. Sörensen, Zeitschr. f. physiol. Chem., 63, 27, 1909 ; 64, 120, 1910; V. Henriques, ibid., 60, 1, 1909; S. P. L. Sörensen, Biochem. Zeitschr., 25, 1, 1910; H. Malfatti, Zeitschr. f. physiol. Chem., 61, 499,1909 ; 66, 152, 1910; L. de Jager, ibid., 65, 185, 1910; 67, 1, 105, 1910; W. Frey and A. Gigon, Biochem. Zeitschr., 22, 309, 1909; T. Yoshida, ibid., 23, 239, 1909 ; cf. also Neubauer-Huppert's Analyse des Harnes, 2 ed., article by A. Ellinger, 1, 641 to 647,1910 ; Neuberg, Der Harn., article by A. C. Andersen, 1, 569-630, 1911. 


\section{CHAPTER VI}

CREATIN AND CREATININ. OTHER URINARY BASES. OXYPROTEIC ACIDS. UROCHROME.

\section{CREATIN AND CREATININ}

Is the current lecture two important end-products of metabolism will first be carefully considered, creatin and creatinin. The importance of these two closely related substances is at once apparent when we recall that a fully grown human being excretes as an average about one gram of creatinin in the urine in the course of twenty-four hours, and that this substance, from a quantitative standpoint, is a prominent member of the group of excretory products which represent the nitrogen fraction escaping transformation into urea.

In attempting to present a precise statement of the knowledge we possess as to the nature and importance of these substances, the first impression obtained by tracing the history of this metabolic problem is a very confusing and, indeed, a depressing one. If, however, one works with determination through the tangle of actual and seeming contradiction which involves the subject, he will gradually realize a pleasant satisfaction in learning that conditions are not really as bad as they at first appear. The pioneer work of the last ten years has basically cleared the ground, and if to-day a survey be made free view in more than one direction is found possible.

Quantitative Estimation.-In the development of the creatin problem may be seen, as often is the case in physiological chemistry, how actual progress first became appreciable after analytical chemistry had provided an applicable method of estimation with which the physiological investigator could work with satisfaction. In this instance we are much indebted to $\mathrm{O}$. Folin ${ }^{1}$ for his carefully elaborated

${ }^{2}$ O. Folin, Zeitschr. f. physiol. Chem., 41, 223, 1904. 
method for the determination of creatinin. Jaffe's reaction, with its bright red color produced by the addition of sodium hydrate and picric acid to creatinin, is made use of in the method for colorimetric determination. Creatin may likewise be estimated after complete transformation into creatinin by chemical agents (as by the process of Benedict and Meyers ${ }^{2}$ by heating the creatin with hydrochloric acid in an autoclave). ${ }^{3}$ It would unquestionably be very desirable to discover a direct method of satisfactorily estimating creatin. Whether the proposal to utilize the orange color which diacetyl ${ }^{4}\left(\mathrm{CH}_{3} \cdot \mathrm{CO} \cdot \mathrm{CO} \cdot \mathrm{CH}_{3}\right)$ strikes with creatin (but not with creatinin) will prove successful for colorimetric determination remains to be seen; the results reported are apparently not entirely equivalent to those obtained by Folin's method.

Relation Between Creatin and Creatinin.-Solution of the creatin problem ${ }^{5}$ has been retarded by the fact that physiological relation between creatin $(\mathrm{C}(\mathrm{NH}) \overbrace{\mathrm{NH}_{2}}^{\mathrm{N}\left(\mathrm{CH}_{3}\right)-\left.\right|_{\mathrm{COOH}} ^{\mathrm{CH}_{2}}})$ and its anhydride, creatinin

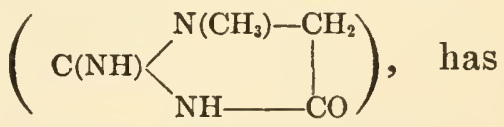

been repeatedly denied. It is, of course, proper to assign no particularly important place in physiological chemistry to "feelings"; but to say the least we cannot well do entirely without them. In the author's judgment a discerning biochemical sense must necessarily tell us that two substances, like creatin and creatinin, one of which may be transformed

${ }^{2}$ F. G. Benedict and V. C. Meyers (Wesleyan Univ.), Amer. Jour. of Physiol., 18, 397, 1907.

${ }^{8}$ In the presence of sugar, where the method is attended with certain difficulties, according to W. C. Rose (Univ. of Pennsylvania), Jour. of Biol. Chem., 12, 73,1912 , the creatin may be changed into creatinin by heating with phosphoric acid in the autoclave.

${ }^{4}$ G. S. Walpole (Wellcome Research Lab.), Jour. of Physiol., 42, 301, 1911.

${ }^{5}$ Literature upon Creatin Metabolism: C. A. Pekelharing, Centralbl. f. Stofi wechselkr., 1909, No. 8; A. Schittenhelm, Handb. d. Biochem., 4', 535-539, 1910. 
into the other by the simplest sort of chemical interference (boiling with acid) are bound to bear a direct physiological relation to each other. To-day such a relation may be looked upon as definitely proved from the works of Pekelharing and his school; and we are justified in assuming that the urinary creatinin owes its origin to anhydration of the creatin (primarily appearing in the tissue protoplasm of the body or introduced with meat food). ${ }^{6}$ This anhydration is not necessarily always a complete one, as greater or smaller amounts of creatin usually coexist with creatinin in the urine. For this reason in biological studies it is never regarded as sufficient to make an estimation of creatinin alone, but to deal with the total amount of the two substances. In the urine of birds the creatinin is of decidedly less importance than creatin. ${ }^{7}$

Creatase and Creatinase.-Added difficulty in the study of the problem arises from the fact that along with the change of creatin into creatinin (apparently from the influence of anhydrating ferments) there also occurs a decomposition of both substances in the tissues. Gottlieb and Stangassinger, ${ }^{8}$ who are responsible for this important observation, ascribe it to the influence of special ferments (creatase and creatinase). Arginase is not involved in the process. ${ }^{9}$ The chemical conrse of this process of decomposition, which is also to be met in excised living organs, is unknown. The cyclically formed creatinin is apparently affected with more difficulty than the creatin. Creatin which has been introduced parenterally into the circulation of mammals is partly decomposed in the body ac-

${ }^{6}$ Cf. E. P. Cathcart (Glasgow), Jour. of Physiol., 39, 320, 1909; D. Noël Paton, ibid., 39, 485, 1910.

${ }^{7}$ D. Noël Paton, l. c.

${ }^{8}$ R. Gottlieb and R. Stangassinger, Zeitschr. f. physiol. Chem., 52, 1. 1907; 5.5, 295, 322, 1908.

'H. D. Dakin (C. A. Herter's Lab., New York), Jour. of Biol. Chem., 3, $435,1907$. 
cording to the studies of Pekelharing and his associates, ${ }^{10}$ partly excreted without change, partly excreted after anhydration into creatinin; and according to these writers the liver is apparently of importance both in the decomposition and also in the process of dehydration. Besides this mode of destruction, in experiments in which creatin or creatinin has been introduced by the mouth decomposition may take place of either substance from the agency of bacteria in the intestine; so that it is not at all surprising in such experiments if nothing but a fraction of the substances introduced appears in the urine. ${ }^{11}$

Endogenous and Exogenous Distribution of CreatinCreatinin Elimination.-In trying to recognize the precise sources of the urinary creatin and creatinin reference to a recent illuminating presentation of the subject by Lafayette Mendel ${ }^{12}$ with the following schema based thereupon may serve to most quickly orient ourselves upon the subject:

Preformed creatin from meat food

Protein

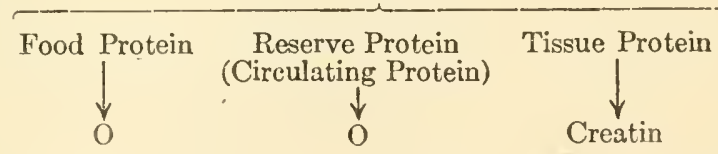

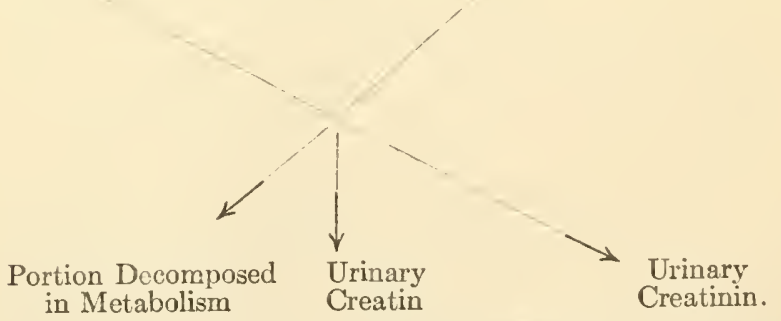

10 C. A. Pekelharing and C. J. C. Van Hoogenhuyze, Zeitschr. f. physiol. Chem., 69, 395, 1910; cf. also P. A. Levene and L. Kristeller, Amer. Jour. of Physiol., 24, 44, 1909.

„W. Czèrnecki (E. Salkowski's Lab.), Zeitschr. f. physiol. Chem., 44, 294, 1905 ; P. Nawiasky (M. Rubner's Lab.), Arch. f. Hygiene, 66, 239, 1908; R. H. A. Plimmer, M. Dick and C. C. Lieb, Jour. of Physiol., 39, 112, 1909-10.

${ }^{12}$ L. B. Mendel and IV. C. Rose, Jour. of Biol. Chem., 10, 249, 1911. 
It is apparent from this that (just as we are accustomed to recognize an endogenous and an exogenous fraction of the purin bodies in the urine) we are in position to make an analogous differentiation in case of the creatin-creatinin excretion. The possibility of increasing the proportion of creatin and creatinin in the urine by free intake of creatin in meat food or Liebig's meat extract has been repeatedly observed. This exogenous part can readily be excluded by starvation or by exhibition of food which does not contain creatin. In this connection the interesting fact has been developed that under such circumstances individual variations may be observed and these may remain constant for a given normal individual for as long a time as a year, ${ }^{13}$ reminding one of the observations of Burian and Schur, who were able to establish a similar individual constancy in case of the endogenous purins.

Taking up next the question as to how far we are justified in assuming a relation between the disintegration of tissue protein and creatin formation in metabolism, it may be assumed, as indicated in the above schema, that neither the food protein nor the readily mobilizable "circulating", protein forms a source of creatin and its anhydride, creatinin. This is directly apparent from the fact that the excretion of creatin-creatinin does not proceed in precisely parallel lines with the total protein exchange, ${ }^{14}$ and moreover seems to be fairly independent of the intake of proteid food.

Relation of Creatin-Creatinin Excretion to Decomposition of Tissue Protein.-However, an increase in the excretion of creatin and creatinin is to be observed in those conditions where (and here probably is the kernel of the whole problem) there is extensive decomposition of the tissue

${ }^{13}$ O. Folin (Waverley), Amer. Jour. of Physiol., 13, 84, 1905; C. J. C. Van Hoogenhuyze and H. Verploegh (Physiol. Lab., Utrecht), Zeitschr. f. physiol. Chem., 57, 161, 1908; 59, 101, 1909.

${ }^{14}$ J. Forschbach and S. Weber (Minkowski's Clinic, Greifswald), Centralbl. f. Physiol. u. Pathol. d. Stoffw., 1906, 569. 
protein, as in starvation, ${ }^{15}$ in fever, ${ }^{16}$ in diabetes, ${ }^{17}$ in poisoning by phloridzin ${ }^{18}$ and phosphorus, ${ }^{19}$ after being in an atmosphere poor in oxygen, ${ }^{20}$ and after strenuous muscular exertion. ${ }^{21}$ It is extremely suggestive that this is especially true in the last mentioned condition if the muscular effort is performed after insufficient nutrition, at the expense of the part involved in the exertion. It appears that work does not necessarily induce increase of creatin-creatinin elimination in well fed human beings and animals; but in conditions of hunger this is quite apt to be the result. In phloridzin diabetes the elimination of creatinin is particularly increased when there is an insufficiency of carbohydrate in the food. It is a fact, too, that in protein starvation the creatin-creatinin elimination can be prevented by exhibition of carbohydrate (or especially of fat). ${ }^{22}$ This recalls the well-known antagonism of carbohydrates to the elimination of acetone bodies; in both instances there may be recognized the ability of carbohydrates to satisfy the immediate needs of the body, as it were by payment of available small change, and thus to avert the necessity of liquidation of its fixed assets. That no direct relation, but merely a parallelism, exists between the elimination of acetone bodies

${ }^{15}$ E. P. Catheart (Glasgow), Jour. of Physiol., 39, 311, 1909; L. B. Mendel and W. C. Rose (Yale Univ.), Jour. of Biol. Chem., 10, 255, 1911.

${ }^{16} \mathrm{H}$. Rietschel, Jahrb. f. Kinderheilk., 61, 621, 1905; O. af Klercker (Lund), Zeitschr. f. klin. Med., 68, 22, 1909; A. Skutetzky (v. Jaksch's Clinic, Prague), Deutsch. Arch. f. klin. Med., 103, 423, 1911.

${ }^{17}$ R. A. Krause (Edinburgh), Quarterly Jour. of Physiol., 3, 289, 1910; R. A. Krause and W. Cramer, Jour. of Physiol., 40, 1, 1910.

${ }^{18}$ E. P. Catheart, and M. R. Taylor (Glasgow), Jour. of Physiol., 41, 276, 1910.

${ }^{10} \mathrm{G}$. Lefmann (Heidelberg), Zeitschr. f. physiol. Chem., 5\%, 476, 1908.

${ }^{20} \mathrm{C}$. J. C. van Hoogenhuyze and H. Verploegh (Pekelharing's Lab., Utrecht), Zeitschr. f. physiol. Chem., 41, 101, 1909.

${ }^{21}$ Older literature upon the Relation Between Creatin and Muscular Activity : Liebig, Sarakow, Ranke, Nawrocki, C. Voit, Monari, Grocco, Moitessier, Gregor; cf. O. v. Fürth, Ergebn. d. Physiol., 2, 603-605, 1903.

${ }^{2}$ L. B. Mendel and W. C. Rose (Yale Univ.), Jour. of Biol. Chem., 10, $213,1911$. 
(acidosis) and that of creatinin ${ }^{23}$ is readily appreciable, the former process involving a drain upon the fat deposit, the latter upon the tissue proteins.

Muscle as the Source of Creatin.-In harmony with the hypothesis of consumption of tissue protein in the construction of creatin may be offered the observation, made long ago in the laboratory of Hoppe-Seyler, and recently confirmed, ${ }^{24}$ that in conditions of inanition the muscles are rich in creatin.

That muscle may be the source of creatin may be directly inferred from the large amount of this substance contained in it. Marked increase of the creatin-creatinin content ensues in isolated frog's muscle upon nervous stimulation ${ }^{25}$; and the excised functionating mammalian heart in Ringer's solution may discharge considerable quantities of creatin and creatinin into the surrounding fluid. ${ }^{26}$ From recent studies of Pekelharing and his pupils the impression is given that tonic contracture of a muscle is more favorable than the short contraction of ordinary muscular action to induce a high degree of cleavage production of creatin. ${ }^{27}$ With the work of Gottlieb and his associates, the results of which are in consonance with this view, and those of Seemann (cf. Vol. I of this series, p. 148, Chemistry of the Tissues) before us, we may well assume as a working hypothesis (in spite of the negative results of Mellanby) that creatin can be produced by cleavage from a colloid precursor in muscle tissue not only by vital but also under certain circumstances by post

${ }^{23}$ E. P. Catheart and M. R. Taylor, 1. c.

${ }^{24}$ B. Demant, Zeitschr. f. physiol. Chem., 3, 388, 1879; L. B. Mendel (Yale Univ.), Jour. of Biol. Chem., 10, 255, 1911.

${ }^{25}$ T. Graham-Brown and E. P. Catheart, Jour. of Physiol., 3\%, XIV, 1908.

${ }^{26}$ S. Weber (Minkowski's Clinic, Greifswald), Arch. f. exper. Pathol., 58, . 93, 1907.

${ }^{27}$ C. J. C. Van Hoogenhuyze and H. Verploegh, Zeitschr. f. physiol. Chem., $46,415,1905$; C. J. C. Van Hoogenhuyze, Jahresber. f. Tierchem., 39, 445, 1909 ; C. A. Pekelharing and C. J. C. Van Hoogenluyze, ibid., 6\%, 262, 1910; C. A. Pekelharing, ibid., 75, 207, 1911. 
mortem autolytic processes. ${ }^{28}$ In further course of autolysis the creatin undergoes partial anhydration into creatinin; and thereafter both substances may be decomposed by fermentation.

Cleavage of Creatin from Other Tissues.-Assuming, for a time at least, the formation of creatin in muscle autolysis as proven, the further question presents itself as to whether production by autolytic cleavage is limited to the musculature or whether the same possibility resides in other tissues as well. Gottlieb and Stangassinger ${ }^{29}$ (after observing in experiments in which they employed expressed tissue juices, that, as in case of muscle, so, too, in kidneys in an early stage of autolysis there appears an increase of the creatin and creatinin present) have expressed the opinion, based upon perfusion experiments, that probably "quite a number of different tissues are to be considered as possible sources of the blood creatin. The formation of creatin in the perfused livers of well nourished animals is apparently quite important. . . . It is therefore entirely possible that the liver in lifetime may be an important site of creatin formation." The above statements bearing upon the topography of creatin formation are unmistakably very meagre. The fact that many tissues contain creatin, and, too, that many bacteria ${ }^{30}$ are able to produce creatinin, should perhaps be interpreted as indicating that we really have here to do with a widespread function of living cells.

Test of Hepatic Function.-Our knowledge of the topography of the other phases of creatin metabolism (anhydration of creatin into creatinin, and the decomposition of both substances) is likewise by no means satisfactory. It

${ }^{2} \mathrm{~F}$. Urano (Hofmeister's Lab.), Hofmeister's Beitr., 9, 104, 1906; R. Gottlieb and R. Stangassinger, Zeitschr. f. physiol. Chem., 52, 1, 1907; A. Rothmann (Gottlieb's Lab.), ibid., 57, 131, 1908; J. S'eeman, Zeitschr. f. Biol., 55, 322, 1905; 69, 333, 1907; E. Mellanby, Jour. of Physiol., 36, 447, 1908. 1908.

${ }^{2}$ R. Gottlieb and R. Stangassinger, Zeitschr. f. physiol. Chem., 55, 322, 336,

${ }^{80}$ N, Antonoff, Centralbl. f. Bakter., 43, 209, 1907. 
was hoped that the study of creatin metabolism would lead to a method of determining the functional condition of the liver, from the rather undefined idea that the liver was the site of enzymic anhydration of the creatin. In phosphorus poisoning, ${ }^{31}$ and in degenerative processes involving the hepatic parenchyma, especially in hepatic carcinoma, ${ }^{22}$ it is said that urinary creatin is increased, with reduction of creatinin. However, exclusion of the liver from the portal circulation does not materially affect creatin metabolism. ${ }^{33}$ One of the author's pupils, H. Ishihara, ${ }^{34}$ was likewise unable to detect any influence of the kind in the course of subchronic phosphorus poisoning in dogs; and the author feels there is little to be expected from this point of view as far as a clinical test of the hepatic function is concerned.

Relation of Creatin Metabolism to Processes in the Female Sexual Organs.-The recognition of a relation between creatin metabolism and the cyclical processes of the female genital organs is of decided interest. Creatin appears in the urine of women in increased amount after menstruation, but may be entirely absent in the intermenstrual period. It may occur in the latter part of pregnancy and, too, in the period of involution of the uterus after delivery. $^{35}$ It would be decidedly gratuitous to attempt to explain these phenomena on the basis of a lowering of the anhydrizing ability of the liver; there is at least as much reason to suppose that they are due to changes in the myometrium itself; for that matter, however, the one

${ }^{81}$ G. Lefmann, Zeitschr. f. physiol. Chem., 57, 468, 1908.

${ }^{32}$ C. J. C. Van Hoogenhuyze and H. Verploegh, Zeitschr. f. physiol. Chem., $58,161,1908$.

${ }^{33}$ E. S. London and N. Bolgarski, Zeitschr. f. physiol. Chem., 62, 465, 1909; C. Towles, and C. Voegtlin (Johns Hopkins Univ.), Jour. of Biol. Chem., 10, $479,1912$.

${ }^{34} \mathrm{H}$. Ishihara (Instit. of Physiol., Univ. Vienna), Biochem. Zeitschr., 41, $315,1912$.

${ }^{35}$ R. A. Krause (Edinburgh), Quarterly Jour. of Physiol., 4, 293, 1911; R. A. Krause and W. Cramer, Jour. of Physiol., 42, Proc. of Phys. Soc., XXXIV, 1911 ; J. R. Murlin (New York), Amer. Jour. of Physiol., 28, 422, 1911. 
hypothesis is as far from proof as the other. Experiments on the excised living uterus have, however, constantly indicated that the amount of creatin, in proportion to the weight of the uterine muscle, increases with the muscular activity which has been in play. ${ }^{36}$

Possible Origin of Creatin from Arginin.-It must be confessed at the last that we really do not know the ultimate derivation of ereatin. Apparently it originates from protein. Even if we actually had proved to our satisfaction that it is formed in the course of tissue autolysis, this would not prove, however, that it necessarily originates from the proteins. Other tissue components, known and unknown, might, with equal propriety, enter into question. If, however, the graphic formula of creatin is examined and compared with that of arginin,
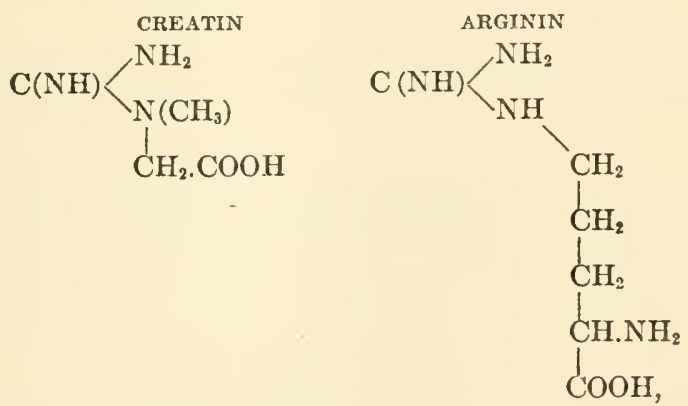

our biochemical sense suggests (it must be confessed that even with the best of intentions we cannot get on without something of the sort) that a relation between the substances, even if not proved, is, a priori, extremely probable. From arginin, which forms one of the important constituents of the protein molecule, by a typical oxidation there may be produced guanidin acetic acid $\left(\begin{array}{r}\mathrm{C}(\mathrm{NH}) \\ \mathrm{NH}-\mathrm{CH}_{2} \\ \frac{1}{\mathrm{NHOH}_{2}}\end{array}\right)$, which requires only a simple methyl binding for transformation into

${ }^{36}$ Rübsamen and Gusikoff (E. Kehrer's Clinic, Berne), Arch. f. Gynäkol., $95,461,1912$. 
creatin. A whole series of examples may be appealed to to show that the living body actually is engaged in bringing about such a process of methylation. Metabolically from telluric or selenic acid, as Franz Hofmeister noted, ${ }^{37}$ tellurium methide or selenium methide can be formed; from pyridin, methylpyridylammonium hydroxide, $\mathrm{HC} \mathrm{CH}$; from diethylsulphide, $\begin{aligned} & \mathrm{C}_{2} \mathrm{H}_{5} \\ & \mathrm{C}_{2} \mathrm{H}_{5}\end{aligned}>\mathrm{S}$, according to Neuberg and Grosser, ${ }^{39}$ diethylmethylsulphinium hydroxide $\left(\begin{array}{l}\mathrm{C}_{2} \mathrm{H}_{5} \\ \mathrm{C}_{2} \mathrm{H}_{5}\end{array}>_{\mathrm{S}}\left\langle\begin{array}{l}\mathrm{CH}_{3} \\ \mathrm{OH}\end{array}\right)\right.$. It is rather difficult to appreciate precisely why, therefore, we should deny the possibility of methylation of guanidinacetic acid in metabolism. Even the negative or varying results of experiments intended to influence the elimination of creatin and creatinin in the urine and the amount of creatin in the muscles by administration of guanidin acetic acid or of proteins rich in arginin ${ }^{40}$ prove but little. It is a well known fact that attempts are not always successful to reproduce at will the processes which accompany protein decomposition in the living body by experimental introduction of their decomposition products.

${ }^{37}$ F. Hofmeister, Arch. f. exper. Pathol., 33, 198, 1894.

${ }^{38}$ W. His, Arch. f. exper. Pathol., 22, 253, 1887.

${ }^{39} \mathrm{C}$. Neuberg and Grosser, 2. Tagung d. deutsch. physiol. Gesel., Centralbl. f. Physiol., 19, 316, 1905.

${ }^{40}$ W. Czernecki (Salkowski's Lab.), Zeitschr. f. physiol. Chem., 44, 294, 1905; M. Jaffe, ibid., 48, 430, 1906; G. Dorner (Jaffe's Lab.), ibid., 5\&, 225, 1907; O. af Klercker, Hofmeister's Beitr., 8, 59, 1906; E. Mellanby, l. c. 


\section{OTHER URINARY BASES}

Methylguanidin; Dimethylguanidin; Vitiatin.-Besides creatin and creatinin small quantities of other bases closely related to them may be met at times in the urine. In the Marburg Physiological Institute methylguanidin, $\mathrm{C}(\mathrm{NH})\left\langle\mathrm{NH}_{2} \cdot \mathrm{CH}_{3}{ }^{\prime}\right.$ has been isolated from normal human urine in its relatively insoluble picrolonic acid combination; and in the urine of dogs, after ingestion of meat extract, dimethylguanidin,

has been found. Vitiatin, with its ascribed

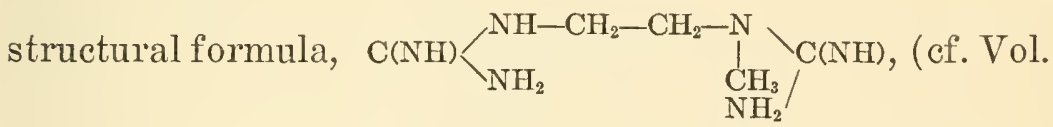

I of this series, p. 149, Chemistry of the Tissues) has also been met in the urine. ${ }^{41}$

Small quantities of methylpyridin may occur, probably produced from vegetable foods; pyridin compounds are introduced into the body with the nicotine of tobacco smoke and with some of the constituents of coffee. ${ }^{42}$

Novain.-Then, too, small quantities of bases may appear in the urine, having a number of methyl groups linked to nitrogen. Kutscher ${ }^{43}$ encountered novain (as previously stated in these lectures, Vol. I of this series, p. 151, this substance may be regarded as identical with carnitin,

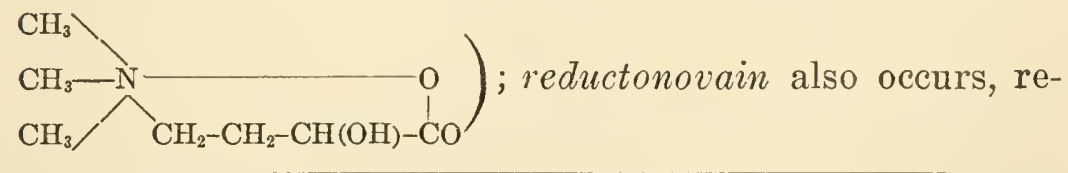

${ }^{41}$ F. Kutscher and Lohmann, Zeitschr. f. physiol. Chem., 48, 422, 1906; 49, 81, 1906; W. Achelis, ibid., 50, 10, 1906; F. Kutscher, ibid., 51, 457, 1907; R. Engeland, ibid., 5\%, 49, 1908.

${ }^{42}$ F. Kutscher, 1. c.

${ }^{43}$ F. Kutscher, 1. c. 
lated to novain in the same way as is neurin to cholin. These bases characteristically yield by cleavage trimethylamine when distilled with alkali.

Trimethylamine.-In connection with the question whether trimethylamine occur's as such in the urine, Takeda, one of Kutscher's pupils, has brought forward the necessity of employing a partial vacuum distillation method. The residue of the urinary distillate taken up in dilute hydrochloric acid is separated into a fraction soluble in alcohol and one insoluble in alcohol; and from the latter the gold chloride combination of trimethylamine is obtained. ${ }^{44}$

Takeda found that preformed trimethylamine does not exist in the urine of dogs and of horses, but may sometimes be present in human urine; it, however, always appears when alkaline ammoniacal fermentation takes place in urine.

Erdmann was unable to detect trimethylamine in normal fresh human urine. However, it has been learned that if the urine is treated with concentrated sulphuric acid as if for Kjeldahl estimation, and the fluid alkalinized after decolorization and distilled, alkylamine, including trimethylamine, passes over with the ammonia. ${ }^{45}$

The author's student, Kinoshita, ${ }^{46}$ proceeded as follows : He distilled off under lowered pressure the volatile amines from the urine in presence of magnesia, taking them up in a receiver containing dilute bydrochloric acid. In the chloride residue which remained after evaporation of the distillate, consisting mainly of ammonium chloride and a small admixture of the chlorides of other volatile bases, the amount of alkyl in nitrogen combination was determined by the method of J. Herzig and H. Meyer, and as a conclusion

4 Takeda (Physiol. Instit., Marburg), Pflüger's Arch., 129, 82, 1909.

${ }^{45}$ O. Folin, C. C. Erdmann (Waverley), Jour. of Biol. Chem., 3, 83, 1907 ; $8,41,57,1910 ; 9,85,1911$.

${ }^{40} \mathrm{~T}$. Kinoshita (University Physiol. Instit., Vienna), Centralbl. f. Physiol., 24, No. 17, 1910. 
from the preliminary findings it was held that the alkyl was really present in the form of trimethylamine. In conformity with the above the amount of trimethylamine recoverable by distillation from normal fresh urine was found extremely small. And, too, expectation of obtaining larger amounts after acid or alkaline hydrolysis was not fulfilled. Somewhat larger amounts of the base were found in spoiled urines; and the largest proportions (about 3 to 6 centigrams in the liter of urine) were met in a few urines which, with or without addition of toluol, had been standing for a long time at room temperature, from which it must be inferred that the cleavage production of trimethylamine is the result of a fermentative process acting on some "mother substance.', Doubtless the physiological significance of the appearance of trimethylamine in urine has been much overestimated by the earlier investigators. ${ }^{47}$

Arnold's Reaction.-One more peculiar substance should be mentioned, which appears in the urine particularly after ingestion of meat or meat bouillon and which underlies the "Arnold reaction." Upon addition of sodium nitroprusside and alkali a violet color is assumed, which changes to blue when acetic acid is added. The nature of this reaction is not known; and the substance producing it is, to say the least, very fugitive, disappearing from the urine in the course of a few days, even if the specimen be preserved by addition of sublimate. It has been stated that the reaction is a "typical meat reaction," but this probably cannot be maintained as it has also been observed after use of milk, cheese and eggs. ${ }^{48}$

${ }^{47}$ C. Serena and A. Percival, Jahresber. f. Tierchem., 29, 338, 1890; F. de Filippi, Zeitschr. f. physiol. Chem., 49, 433, 1906.

$\star$ V. Arnold (Lemberg), Zeitschr. f. physiol. Chem., 49, 397, 1906; Th. Holobut (Lemberg), ibid., 56, 117, 1908; X. Buss, Inaug. Dissert., Züirich, 1910, cited in Centralbl. f. d. ges. Biol., 11, No. 1702; J. Caretti, Bull. Scienze Med., 80, 253, 1909. 
Urinary Rest-nitrogen.-If the nitrogen of the various known urinary constituents for a given specimen be added together and the total compared with the determined total nitrogen, will any noticeable difference be found? It has been shown that this actually is the case. By far the major portion of the nitrogen, estimated as from 87 to 95 per cent. of the total nitrogen ordinarily and in states of full diet, ${ }^{49}$ is referable in man and the mammals to urea. After calculating the fractions referable to uric acid, the purin bases and creatinin, hippuric acid and ammonia, there still remains a nitrogen rest which in human urine has been estimated at from 2.5 to 8.5 per cent. by Donzé and Lambling, ${ }^{50}$ at about 5 per cent. by Folin, and 11 per cent. of the total nitrogen by Maillard. These figures are changed as soon as the diet becomes abnormal, the urea varying especially, falling, particularly where opportunity for an acidosis occurs, with corresponding increase in the ammonia. O. Folin observed a fall of the urea nitrogen to 60 per cent. of the total nitrogen in as full as possible restriction of proteid metabolisin by means of a starch-cream diet. But even this is probably far from the lowest limit which may be met. In an insane patient, who took almost no food, Folin found only 15 per cent. of the total nitrogen represented by the urea, and 40 per cent. as ammonia; ${ }^{51}$ one would hesitate to give credence to these figures if they were not published by one who is a master of the technique of urinary analysis. It should be remembered in this connection that similar perverse metabolism proportions have been observed in the hibernating marmot ( $v$. supra., p. 117), and have been described as an enormous increase in the aminoacids at the expense of the urea.

${ }^{49}$ Cf. B. Schöndorff, Pflüger's Arch., 117, 275, 1907.

${ }^{50}$ G. Donzé and E. Lambling, Jour. de Physiol., 5, 225, 1903; O. Folin, Amer. Jour. of Physiol., 13, 45, 1905; L. C. Maillard, Jour. de Physiol., 10, $1017,1908$.

${ }^{51}$ O. Folin, 1. c. 


\section{OXYPROTEIC ACIDS}

It would seem that the bulk of the "non dosé" in the urine, the undetermined nitrogen rest, is to be referred to the group of the oxyproteic acids. These substances have been dealt with in a previous lecture in connection with the subject of the elimination of the residual material of protein metabolism in cancerous affections ( $\mathrm{Vol}$. I of this series, pp. 547-551, The Chemistry of the Tissues). The oxyproteic acids, discovered in the urine in 1897 by $\mathrm{S}$. Bondzynski and R. Gottlieb, ${ }^{52}$ constitute a group of protein derivatives containing both nitrogen and sulphmr, and apparently of high molecular structure; they seem to be characterized by an acid nature, the solnbility in water and insolubility in alcohol of their baryta salts, and by their precipitation by mercuric acetate in weakly alkaline reaction. In general they no longer retain the character of polypeptids, failing to give the biuret reaction, and not being precipitable, as are other protein derivatives of high molecular structure, by phosphotungstic acid in the presence of excess of mineral acid.

Fractionation of the Oxyproteic Acids.-The investigations of Bondzynski and his collaborators ${ }^{53}$ indicated that separation of thése acids is possible by precipitation as salts of the heavy metals, and in fact led to the differentiation of alloxyproteic acid (precipitated by acetate of lead), autoxyproteic acid (precipitated by mercuric acetate in acid reactions) and oxyproteic acid (precipitated by the same in neutral or weakly alkaline reaction). These Polish investigators are also to be credited with the important determination that the autoxyproteic fraction includes the yellow

${ }^{52}$ S. Bondzynski and R. Gottlieb, Centralbl. f. d. med. Wiss., 1897, No. 33.

${ }^{\text {Bs }}$ S. Bondzynski and K. Panek, Ber. d. deutsch. chem. Ges., 35, 2959, 1903; S. Bondzynski, S. Dombrowski, K. Panek, Zeitschr. f. physiol. Chem., 46, 83, 1905 ; S. Dombrowski, ibid., 5', 188, 1907, Bull. de l'Acad. de Cracovie; Cl. des Sciences Math. et Natur., October, 1907; J. Browinski and S. Dombrowski, Jour. de Physiol., 10, 819, 1908; W. Gawinski, Zeitschr. f. physiol. Chem., 58, 458, 1909 ; S. Bondzynski, Kosmos, 35, 680, 1910. 
urinary coloring matter, urochrome. Moritz Weiss ${ }^{54}$ has shown in the course of his investigations (partly carried out in the Vienna Physiological Institute) that urochrome is produced from a chromogen, urochromogen, which is likewise an oxyproteic acid. This chromogen is characterized by two striking peculiarities, viz., by its ability to pass over into urochrome upon oxidation (a faintly tinted yellowishgreen solution assuming an intense yellow color when permanganate of potassium is added drop by drop), and by the interesting fact that it is the particular substance involved in Ehrlich's curious diazo-reaction. Very shortly after the Polish authors happened upon the fact that autoxyproteic acid will give the well known color reaction with the necessary diazo-reagents the relation between urochromogen and the diazo-reaction was determined by Weiss.

It is therefore apparent that we are dealing with a decidedly confusing group of phenomena. In the hope, however, of simplifying the current status of proteic acid fractionation, the following schema is presented: ${ }^{55}$

\section{PROTEIC ACID FRACTION}

(The group of substances which form baryta salts which are soluble in water, but precipitated by alcohol.)

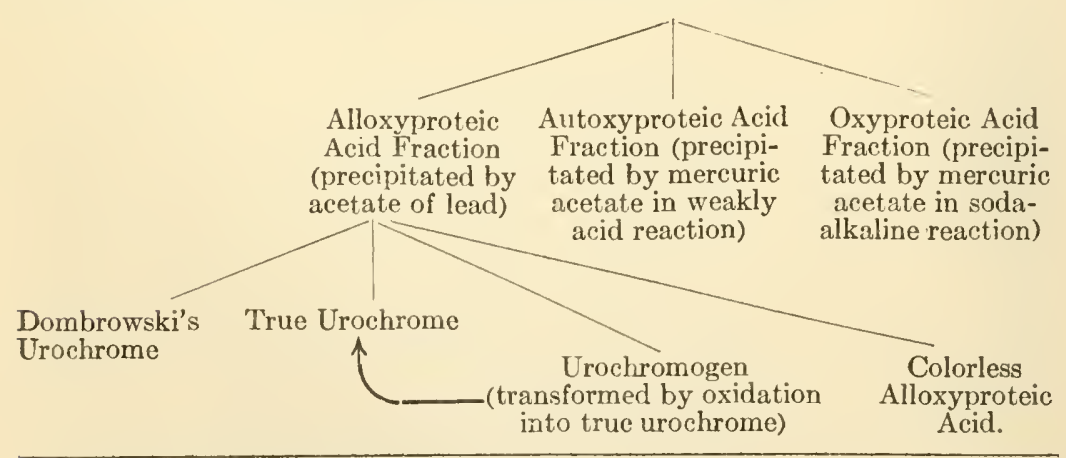

${ }^{4}$ M. Weiss (Alland Hosp.), Wiener klin. Wochenschr., 190\%, No. 31; Beitr. z. Klinik der Tuberculose, 8, 117, 1907; Biochem. Zeitschr., 27, 175, 1910; 30, 333,1911 , under direction of O. v. Fïrth, Physiol. Instit. Vienna; Med. Klinik, 1910, No. 92; Münchener med. Wochenschr., 1911, No. 25.

is M. Weiss, Biochem. Zeitschr., 30, 338, 1911. 
The alloxyproteic acid fraction apparently contains at times four substances: Dombrowski's urochrome (recognizable by its precipitation by neutral lead acetate and by copper acetate, and the insolubility of its lead salt in dilute acetic acid), true urochrome of Weiss and the colorless alloxyproteic acid of the Polish writers True urochrome, the normal yellow coloring matter of urine, is not the same as Dombrowski's urochrome, and may be differentiated from the latter by the solubility of its lead salt in dilute acetic acid. In addition urochromogen, occurring in pathological urines, is found for the most part in this fraction (careful precipitation avoiding excess of lead acetate); but sometimes, it is true, it is met in the autoxyproteic acid fraction.

Weiss ${ }^{56}$ has devised a method by which it is possible to estimate by comparative colorimetry the amount of urochrome and urochromogen in a urine with great exactness. The urine is first freed of other coloring materials by saturation with ammonium sulphate (urobilin, hæmatoporphyrin and uroerythrin); and the color of the filtrate is then compared by means of a Dubosq colorimeter with a true yellow solution of known content. If urochromogen is present along with urochrome a dilute solution of permanganate is cautiously added as long as increase in the yellow color can be clearly recognized or until the Ehrlich's diazo-reaction, if at first present, begins to fail; thereafter the process is as above. The difference between the quantities of urochrome obtained before and after the full oxidation represents the quantity of urochromogen present in the specimen. In examining urines with positive diazo-reactions there is always to be noted a direct proportion between the intensity of the diazo-reaction and the amount of urochromogen in the urine. The technical simplicity and the sensitiveness of the urochromogen reaction with permanganate makes it possible to substitute the diazo-reaction by the former.

${ }^{*}$ M. Weiss, Biochem. Zeitschr., 30, 345, 1911. 
Chemical Position of Urochrome.-It is at present not advisable to say more in reference to the chemical classification of urochrome, the urinary coloring matter which is mainly responsible for the yellow color of normal urine, than that we are dealing with one of the substances included in the group of protein residual matter which from its characteristics of solubility and precipitability should be classed among the oxyproteic acids. There is a contradiction in the matter of its sulphur content between the statements of the above-named Polish authors, who found the coloring material to contain sulphur, and the results obtained in Hofmeister's laboratory. ${ }^{57}$ The latter indicate that the yellow material, which can be separated from the urine by animal charcoal and can subsequently be freed from the latter by glacial acetic acid (known as "uropyrryl" because of the large proportion of pyrrol left when it is subjected to dry distillation), does not contain any sulphur. It may be thought that this contradiction may be explained on the supposition that the urochrome, which has its sulphur bound so loosely in the molecular structure that sulphuretted hydrogen separates, even without heating, when it is acted upon by alkali, ${ }^{58}$ may likewise undergo cleavage in the course of the above process of demonstration with loss of its sulphur; but this has not been proven. There may possibly be a close relation between such a sulphur partition and the peculiar reduction power of urochrome which can be directly estimated by titration by separation of iodine from iodic acid. ${ }^{59}$ The suggestion that urochrome owes its coloring to one of the cyclic groups of the protein molecule included in some form in its structure (or a transformation product of such a substance) is not improbable. There is not the least foundation, however, for assuming a relation between

${ }^{3 i}$ H. Hohlweg, K. E. Salomonsen, S. Mancini (Lab. of Physiol. Chem., Strassburg), Biochem. Zeitschr., 13, 199, 205, 208, 1908.

${ }^{88}$ S. Bondzynski, S. Dombrowski and K. Panek, Zeitschr. f. physiol. Chem., 46, 83, 1905; S. Dombrowski, ibid., 62, 358, 1909.

${ }^{50} \mathrm{~J}$. Browinski and S. Dombrowski, Jour. de Physiol., 10, 819, 190 S. 
urochrome and hæmatin and urobilin. Direct evidence of the cyclic nature of urochrome may perhaps be seen in the striking diazo-reaction of urochromogen. (A color reaction, less brilliant however, is given by the diazo-compounds with formed urochrome; it corresponds closely with the diazoreaction of the normal urine. ${ }^{60}$ ) The fact that when urochrome is boiled with hydrochloric acid melanin-like products ("uromelanin') may be formed ${ }^{61}$ is, if the author is correct in his previous statements as to the nature of melanin production ( $\mathrm{v}$. Vol. I of this series, p. 526, et seq.: Chemistry of the Tissues), certainly not contradictory of a eyclic character of urochrome. It suggests, too, that certain ring-form groups in the protein-molecule escape complete dissociation in the course of metabolism and may finally appear as urinary coloring materials. In the author's laboratory there are in course at present certain experiments bearing upon a possible part taken by histidin in the construction of urochrome; an idea suggested by the fact that this compound is distinguished among the molecular cleavage products (as also tyrosine) by responding to the diazoreaction.

True Urochrome and Dombrowski's Urochrome.-The marked tendency to undergo decomposition shown by the yellow coloring substance of the urine, is, moreover, the cause of the differences of opinion obtaining between M. Weiss and the Polish authors with reference to it. While the latter authors look upon the urochrome discovered by themselves as the peculiar urinary coloring matter, Weiss, as stated, differentiates between true urochrome and the urochrome of Dombrowski. The impression is that this latter product, which is isolated from urine by precipitating it by

${ }^{60}$ K. Feri (Chvostek's Clinic, Vienna) recommends substitution of the Ehrlich reagent by azophen red, that is, paranitrodiazobenzolsulphate $\left(\mathrm{NO}_{2} \cdot \mathrm{C}_{6} \mathrm{H}_{4}-\mathrm{N}=\mathrm{N}-\right)_{2} \mathrm{SO}_{4}$; Wiener klin. Woclienschr., 1912, No. 24.

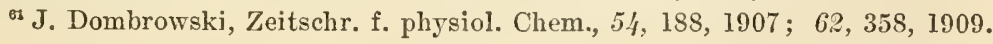


means of copper acetate, with subsequent dissociation of the copper compound by sulphuretted hydrogen, is nothing but an oxydation transformation product of the true urochrome. Browinski and Dombrowski ${ }^{62}$ in their most recent publication with special stress suggest "that urochrome is an unusually easily decomposable compound and readily undergoes oxidation. Its precipitation from the urine and from pure solutions by means of cupric acetate is due to the formation of a cuprous compound which is soluble in water; and can occur only with reduction of the copper acetate. The precipitation is therefore incomplete, because necessarily the combination is formed with oxidation of a portion of the urochrome." Thus far it is possible to agree with the Polish authors. But with their further statement the author's views become directly opposed: "The oxidation product (of the urinary coloring matter) which remains in solution imparts the faint yellow tint to the filtrates of copper precipitation peculiar to them.' According to this the substance in the filtrate would be an insignificant remnant of the true urinary coloring matter which has escaped precipitation and has undergone oxidation. Actually, however, as Weiss has shown in his colorimetric estimations, ${ }^{63}$ the opposite is the case. If Dombrowski's urochrome (a sallow brownish yellow coloring substance) be removed, by far the greater part of the coloring matter remains in the filtrate, which shows the characteristic pure tint (yellow with a greenish cast) of the former [true urochrome]. Any unprejudiced person must grant that when one knows that a given substance is very ready to undergo oxidation there is little propriety in using an oxidizing agent like copper acetate in isolating it. If, however, such an agent is employed and, too, if it has been clearly proved that oxidation has actually

${ }^{2}$ J. Browinski and S. Dombrowski (Instit. of Med. Chem., Lemberg), Zeitschr. f. physiol. Chem., 7\%, 105, 1912.

${ }^{83}$ M. Weiss, Biochem. Zeitschr., 30, 340, 1911. 
been effected in the course of demonstration, it may undoubtedly be said that nothing but an oxidation product can be expected as the result.

It may be, too, that a portion of the true urochrome may undergo spontaneous decomposition in the urine with formation of its oxidation product. In any case we must regard, not Dombrowski's urochrome, but Weiss's so-called 'true urochrome" as the native urinary yellow coloring material. The attempt of the authors indicated to introduce a polemic spice in their latest publication can have not the least influence upon the actual fact.

Quantitative Determination of Oxyproteic Acids.Our appreciation of the physiological rôle and significance of the various substances of the group of oxyproteic acids is of slow development. The reason for this is mainly that as yet we are unable to overcome the technical difficulties attending a quantitative determination of these substances. In discussing the elimination of the oxyproteic acids and of neutral sulphur in cancerous disease (v. Vol. I of this series, pp. 547-551, Chemistry of the Tissues) this fact was fully presented. Recently objection has been raised by F. Erben ${ }^{64}$ to the method of Ginsburg ${ }^{65}$ for estimation of the oxyproteic fraction in urine, that besides the oxyproteic acids practically all the aminoacids are thrown down. There is something, however, against the correctness of this charge in the fact that Ginsburg has been unable to find more than minute amounts of aminoacid nitrogen in his oxyproteic acid fraction both by formol titration and, too, by Van Slyke's method ${ }^{66}$ (v. Vol. I of this series, p. 18, Chemistry of the Tissues). Although Erben summarily characterizes Ginsburg's method as "vseless," it should be observed that the method, although (as already stated, v. Vol. I of this series,

${ }^{84}$ F. Erben (Vienna), Internat. Beitr. z. Pathol. u. Ther. d. Ernährungsstörungen, 2, 252, 1911.

${ }^{{ }^{6}}$ W. Ginsburg (Univers. Physiol. Instit., Vienna), Hofmeister's Beitr., $10,411,1907$.

${ }^{8 в}$ Personal communication from WT. Ginsburg, Halle a. d. Saale. 
p. 548, Chemistry of the Tissues) far from an ideally exact mode of determination, is still undoubtedly of greater scope than that of Erben, who sought no more than the autoxyproteic acids (by precipitation of the baryta syrup by mercuric acetate after faint acidulation with acetic acid). This mode of separation must be regarded as largely open to the personal equation,-if for no other reason because, as is well known, a part of the mercurial salts of the oxyproteic acids is soluble in a greater surplus of acetic acid. On the other hand it should be acknowledged that it would be a good thing if a modification of the Ginsburg method were worked out by ascertaining the possible admixture of urea and of aminoacids in the fraction of oxyproteic acids, and making correction therefor.

Elimination of Oxyproteic Acids in Normal and Pathological Conditions. - With this in view it is best to state only in a provisional way that the quantity of oxyproteic acid in normal urine represents from 3 to 7 per cent. of the total nitrogen in case of adults, ${ }^{67}$ and 10 per cent. in infants. ${ }^{68}$

Probably the oxyproteic acids in the "rest nitrogen" of the blood are in greater proportion than they are in the urinary rest nitrogen (it is said that 40 per cent. of the rest nitrogen of the blood serum is here included); and it is probable that a part of the hæmic oxyproteic acids may be oxidized before they reach the kidney for elimination. ${ }^{69}$

In disease an increased elimination of substances belonging to the group of oxyproteic acids is usually met in cases in which an increased decomposition of cellular protein is proceeding under the influence of toxic metabolic disturbances. This may be expected in phosphorus poisoning, in

${ }^{67}$ W. Ginsburg, 1. c.; IV. Gawinski (Instit. of Med. Chem., Lemberg), Zeitschr. f. physiol. Chem., 58, 454, 1909.

${ }^{\text {es }}$ S. Simon (Children's Clinic, Univ. Munich), Zeitschr. f. Kinderheilk., $2,1,1911$.

${ }^{\natural} \mathrm{J}$. Browinski (Instit. Med. Chem., Lemberg), Zeitschr. f. physiol. Chem., 58, 134, 1908; W. Czernecki, Bull. de l'Acad. de Cracovie, 1910, abst. in Jahresber. f. Tierchem., 40, 189, 1910 ; cf. also ibid., 39, 820, 1909. 
febrile infectious diseases, hepatic affections, the cachexia of cancer and in the later stages of tuberculosis. In any such condition an increased excretion of oxyproteic acids may be told from the increase in the elimination of neutral sulphur, ${ }^{70}$ which, as previously pointed out (v. Vol. I of this series, pp. 548-550, Chemistry of the Tissues), may serve as an index for the former. The degree of complexity of the subject may, however, be inferred from the fact that, according to circumstances, now one, now another fraction of the oxyproteic acids may predominate in a given case. Thus in tuberculosis a much greater amount of urochromogen is excreted than in cancerous cachexias. It is a well-known fact that a practical significance is ascribed to the appearance and disappearance of the Ehrlich diazo-reaction (now known to be referable to urochromogen) in the matter of prognosis of the course of tuberculosis. ${ }^{71}$

In considering the diazo-reaction ${ }^{72}$ it should be observed that besides urochromogen other substances may occur in the urine which yield color reactions with the diazo-bodies, as, according to Clemens, tyrosin (OH. $\mathrm{C}_{6} \mathrm{H}_{4} \cdot \mathrm{CH}_{2} \cdot \mathrm{CH}\left(\mathrm{NH}_{2}\right)$. $\mathrm{COOH}$ ) and p-oxyphenylpropionic acid (OH. $\mathrm{C}_{6} \mathrm{H}_{4} \cdot \mathrm{CH}_{2} \cdot \mathrm{CH}_{2}$. $\mathrm{COOH}$ ) and p-oxyphenylacetic acid ( $\left.\mathrm{OH}_{2} \mathrm{C}_{6} \mathrm{H}_{4} \cdot \mathrm{CH}_{2} \cdot \mathrm{COOH}\right)$. Kutscher and Engeland state that even in normal urine after removal of the aromatic oxyacids by ether certain bodies may remain which form red products with diazo-benzolsulphurous acid when in an alkaline soda solution. This

reaction apparently is peculiar to the imidazol nuclei,

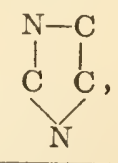

${ }^{70}$ Cf. M. Halpern, Centralbl. f. d. ges. Biol., 11, No. 2547, 1911; E. Salkowski, Biochem. Zeitschr., 32, 356, 1911; ef. M. Weiss, Münchener med. Wochenschr., 1911, No. 25.

${ }^{11}$ F. Kutscher, Sitzungsher. d. Ges. z. Bef. d. ges. Naturw., Marburg, 4, 83, 1908; abst. in Centralbl. f. Physiol., 22, 516, 190s; R. Engeland (Physiol. Instit., Marburg), Miinchener med. Wochenschr., 1908, 1643; M. WVeiss and A. Weiss, Wiener klin. Wochenschr., 1912, No. 31.

'2 Literature upon the Diazo-reaction in Urine: P. Clemens (Biiumler's Clinic, Freiburg), Deutsch. Areh. f. klin. Med., 63, 74, 1899. 
which may be found in the urine in the form of imidazol-

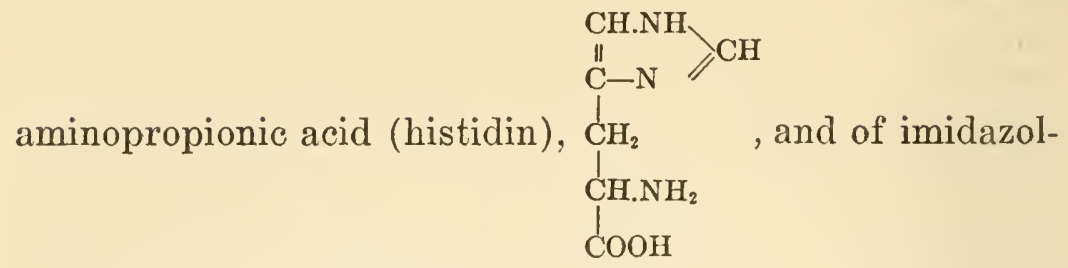
aminoacetic acid, $\stackrel{\mathrm{I}}{\mathrm{C}}-\mathrm{N} \cdot \mathrm{N} \mathrm{N}_{2}$. It is said that the puzzling<smiles>[R]OC(=O)O</smiles>

"urocaninic acid" of dogs" urine is also an imidazol deriva-<smiles>CCCCCC(C)C(C)C(=O)O</smiles>

obtainable from histidin by ammoniacal cleavage. $^{73}$

Other High-molecular Residual Substances.-In addition to the oxyproteic acids there are other high-molecular metabolic residual substances of various kinds in the urine, about which we know practically nothing. E. Abderhalden and F. Pregl, ${ }^{74}$ after freeing an alcoholic extract of urine of urea and other easily diffusible materials by dialysis, obtained a mixture of substances which contained no free aminoacids but after acid hydrolysis yielded a number of typical protein cleavage products. It is impossible at the present to decide the extent to which these substances are related with the oxyproteic acids (which unquestionably hydrolytically yield aminoacids ${ }^{75}$ ) or with typical polypeptids. It seems that they may be met in small amount in normal urine and somewhat more in disease, as in cancer

\footnotetext{
${ }^{73}$ A. Hunter (Cornell Univ.), Jour. of Biol. Chem., 11, 537, 1912.

"E. Abderhalden and F. Pregl, Zeitschr. f. physiol. Chem., 46, 19, 1905.

T. W. Ginsburg, Hofmeister's Beitr., 10, 441, 1907; J. Browinski and S. Dombrowski (Lemberg), Zeitschr. f. physiol. Chem., $7 \%, 92,1912$.
} 
and hepatic affections (v. Vol. I of this series, p. 550, Chemistry of the Tissues). The chemical position of the urinary constituent known as "uroferric acid," isolated by Siegfried's iron-peptone method, is at present indefinable ${ }^{76}$; and the same may be said of a substance obtained by P. Hári is by precipitation by phosphotungstic acid, and the urinary colloids of Salkowski (v. Vol. I of this series, p. 550, Chemistry of the Tissues) precipitable by salts of the heavy metals and insoluble in alcohol. But it would be a mistake to assume that all nitrogenous colloids of the urine are of the nature of high-molecular protein derivatives. Investigations in the laboratory of $F$. Hofmeister indicate on the contrary that among the nondialysable urinary constituents (which can be quantitatively estimated by diffusion methods employing very fine fibre capsules), we may meet even such materials as chondroitin-sulphuric acid (Vol. I of this series, p. 281, Chemistry of the Tissues) or nucleinic acid as important compounds; their quantity may be found increased in renal diseases, in eclampsia and in various febrile states (pneumonia). ${ }^{i s}$

It will probably be a long time before the misty atmosphere at present enveloping these subjects, and in fact covering them as in thick clouds, will be dissipated by the sun. However, even here there is beginning to be a little more light.

"O. Thiele, H. Liebermann (Siegfried's Lab., Leipzig), Zeitschr. f. physiol. Chem., 37, 251, 1903; 52, 129, 1907.

${ }^{7}$ P. Hári (Budapesth), Zeitsshr. f. physiol. Chem., 46, 1, 1905.

${ }^{78} \mathrm{~K}$. Sasaki, Hofmeister's Beitr., 9, 386, 1907; M. Savaré, ibid., 9, 401 ; 11, 71, 1907; Ch. Pons, ibid., 9, 393, 1907; U. Ebbecke, Biochem. Zeitschr., 12, 485 , 1908; all from the laboratory of F. Hofmeister, Strassburg. 


\section{CHAPTER VII}

\section{PHYSIOLOGY OF PURIN METABOLISM}

HAVING in the last several lectures dealt with the nitrogenous end-products of protein metabolism, we may next take up the difficult subject of purin metabolism. First, however, it should be said that the general mass of observations bearing upon this phase of our subject is so huge that no honest man, even if he has busied himself with nothing else for year's, dare feel that he has reached the bottom facts and become thoroughly conversant therewith. The author would be presumptuous, moreover, being himself not continnously engaged in this field, but concerned rather with the single purpose of tracing the general subject, to attempt to surround himself here with dogmatic assertions. The purpose of these lectures does not go beyond the arrangement and presentation of a picture of this world of phenomena so far as the writer has from honest study come to understand and appreciate them; and it should not be forgotten at any time that this picture may for other eyes have a very different aspect. In the end every mau has a right to use his own eyes in inspecting the things about him; only he should realize that his impressions in such case are essentially subjective ones. So much in introduction.

Exogenous and Endogenous Formation of Uric Acid.The first question to occupy us is-what do we know of the origin of uric acid in the mammalian body?

In precise answer it might be replied: it originates from the free nuclein bases and the nuclein bases fixed in the molecular structure of nucleinic acids. These are in part introduced into the living body with food (exogenous fraction) and in part are freed by nuclear disintegration or other processes within the living organism from its molecular combinations of which they are structurally a part (endogenous fraction). 
The recognition of this relation had its beginning in the classical studies of Horbaczewski in 1889 upon the formation of uric acid in the splenic pulp; and slowly crystallized into its present form from a great number of investigations, among which those of Kossel and his school, and of W. Spitzer, H. Wiener, A. Schittenhelm, N. Jones, R. Burian, L. B. Mendel and their collaborators stand out prominently. ${ }^{1}$

Conversion of Adenin and Guanin into Uric Acid.As previously stated (Vol. I of this series, p. 112, Chemistry of the Tissues), the physiological relation between the two bases in the nucleinic acid molecule, adenin and guanin, with hypoxanthin, xanthin and uric acid may be expressed by the following schema:
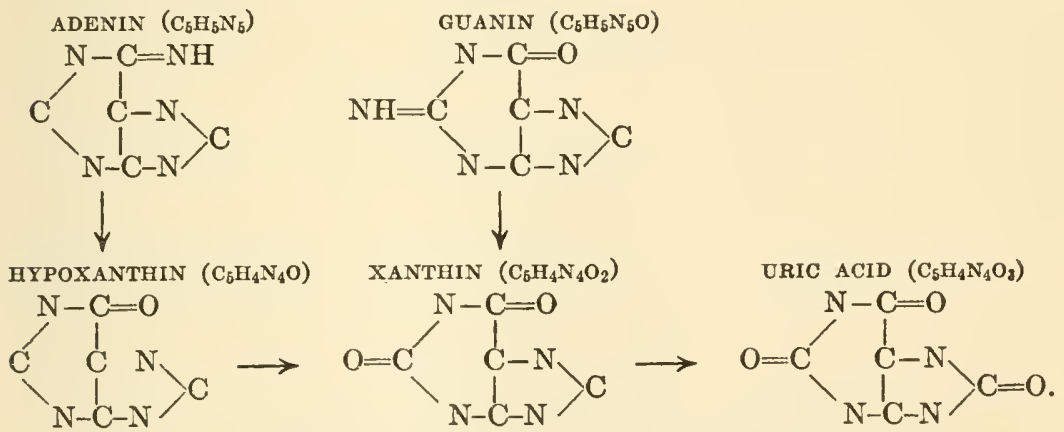

The transformation of adenin and guanin into hypoxanthin and xanthin by replacement of their NH group by an atom of oxygen is ascribed to "deamidases" which must effect changes of the type indicated in the formula: $\mathrm{R}: \mathrm{NH}+$ $\mathrm{H}_{2} \mathrm{O}=\mathrm{R}: \mathrm{O}+\mathrm{NH}_{3}$. Jones recognizes two of these enzymes, "adenase" and "guanase." In the conversion of hypoxanthin into xanthin and the latter into uric acid, oxidizing ferments known as "xanthoxydases" are concerned.

${ }^{1}$ Literature upon the Formation of Uric Acid from the Nucleins: $H$. Wiener, Ergebn. d. Physiol., 1, 575-606, 1902; F. Samuely, Handb. d. Biochem., 1, 565-566, 1909; A. Ellinger, ibid.,3', 575-576, 1910; A. S'chittenhelm, ibid., 4', 490-514, 519-531, 1910; C. Oppenheimer, Die Fermente, 3d ed., 5, 166-170, 370-372, 1910; H. M. Vernon, Ergebn. d. Physiol., 9, 162-167, 1910. 
A great deal of careful work has been devoted to the study of the distribution of these ferments in various animal species, in experiments with tissue pulp. ${ }^{2}$ Schittenhelm $^{3}$ was doubtless correct in questioning whether all the differential detail involved should be accepted literally; and whether, if one of these ferments were missed in a given organ it would be justifiable to infer therefrom that it is also absent from the living organ. In some aspects, however, investigations of this sort may be productive of results.

Guanin Gout in the Hog.-For example, it was found that in tissues of the hog "guanase" occurs only in small amount and that addition of guanin to extracts of spleen and liver was followed by but insignificant increase in the quantity of xanthin produced in course of the digestion; but that adenin is freely converted into hypoxanthin. An interesting correlation may be recognized in the fact that normally in the urine of hogs the purin bases are more prominent than uric acid, and that there is a disease, guanin-gout of the hog, in which uric acid apparently disappears completely from the urine, and at the same time (in analogy to the deposit of uric acid in the tissues in human gout) guanin is deposited in the muscles, cartilages, and in the liver. The lack of "guanase" apparently interferes here with the normal formation of uric acid, which in the hog is for the most part further catabolized into allantoin. ${ }^{4}$

Nucleases and Deamidases.-The chemical conversion of the purin bases must, however, be preceded by their cleavage from the molecule of nucleinic acid, which takes place in the nucleins of the food in the intestine through the agency of

${ }^{2} \mathrm{Cf}$. especially the numerous studies of A. Schittenhelm, as, too, of W. Jones (with C. L. Partridge, W. C. Winternitz, C. R. Austrian, Amberg and others).

${ }^{3}$ A. Schittenhelm, Handb. d. Biochem., 4', 509, 1910; W. Jones, Zeitschr. f. physiol. Chem., 45, 84, 1905.

${ }^{3}$ A. Schittenhelm, Handb. d. Biochem., 4', 509, 1910; IV. Jones, Zeitschr. f. W. Jones and C. R. Austrian (Johns Hopkins Univ.), ibid., 48, 110, 1906; L. B. Mendel and J. F. Lyman (Yale Univ.), Jour. of Biol. Chem., 8, 115, 1910; A. Schittenhelm, Zeitschr. f. physiol. Chem., 66, 53, 1910; L. B. Mendel, and P. H. Mitchell (Yale Univ.), Amer. Jour. of Physiol., 22, 97, 1907. 
"nucleases"' (cf. Vol. I of this series, p. 128, Chemistry of the Tissues). From recent experiments of London, Schittenhelm and $K$. Wiener, in which a series of dogs (normal, without stomach, without pancreatic juice-ligation of the excretory ducts of the pancreas, and without pancreas) were fed upon nucleinic acid, it was determined that the cleavage of the nucleinic acid is to be entirely ascribed to the ferments of the intestinal juice. The cleavage always stops at the stage of nucleosides, which undergo no further dissociation in the intestine, the purins remaining in combination with the sugar of the nucleinic acid molecule (as do also the pyrimidin bases) in all experiments. In the lower segments of the bowel the splitting influence of bacteria may be associated with that of the intestinal ferments. ${ }^{5} \quad$ The resorption of the purin bodies takes place by way of the blood, not with the lymph. ${ }^{6}$

Cleavage of the nucleinic acids in the animal tissues is undoubtedly a very complicated process. Two kinds of nucleases involved are differentiated: "purinnucleases," which split off the purin bases, and "phosphornucleases," which separate phosphoric acid from the molecule; the nucleosides (combinations of purin bases and carbohydrate), however, remaining intact. ${ }^{\top}$ It may be recalled (cf. Vol. I of this series, pp. 123-125, Chemistry of the Tissues) that the carbohydrate group in the nucleinic acid molecule is intercalated between phosphoric acid and the base:

Phosphoric acid $\longleftarrow$ Carbohydrate $\longrightarrow$ Base.

Further complication of the situation arises from the fact that deamidization of the purin bases may also take place at this stage, provided they are still in organic combination, in

${ }^{5}$ E. S. London, A. Schittenhelm and K. Wiener (Erlangen and St. Petersburg), Zeitschr. f. physiol. Chem., $7 \%, 86,1912$.

${ }^{-} J$. Biberfeld and J. S. Schmid (Breslau), Zeitschr. f. physiol. Chem., 60, $292,1909$.

${ }^{7}$ Amberg and W. Jones (Johns Hopkins Univ.), Zeitschr. f. physiol. Chem., $\tau 3,407,1911$. 
such manner that, according to Schittenhelm, ${ }^{8}$ deamidization may involve either free or fixed purin bodies; and for that reason it is essential to distinguish between purindeamidases and mucleosiddeamidases.

It may be seen that in the catabolism of the purin bases included in the nucleinic acid molecule into uric acid a great many different possibilities enter, and that we must assume a coördination of nucleases and nucleoside-splitting ferments, of purin-deamidases and nucleosiddeamidases, as well as a number of oxidases. According to Levene and Medigreceanu' the nucleinic acids are made up of nucleotids, a type of which, according to these authors, may be seen in guanylic acid (Vol. I of this series, pp. 125-128, Chemistry of the Tissues), to which they ascribe the simple constitution of phosphoric acid-pentose-guanin. They then differentiate in the fermentation-cleavage of nucleinic acids between nucleinases, which split up the nucleinic acid molecule into nucleotids, and mucleotidases, which in turn catabolize the nucleotids.

What an enormous amount of work is still to be accomplished before we can be in position to clearly define the physiological and pathological influence of any one of these factors! As a matter of fact this is only the beginning of the difficulty.

Nuclear Destruction and Urinary Purins.-The next question is that of the origin of the endogenous and exogenous urinary purins, about which it is safe to say that veritable rivers of ink have run dry in advancing to a point where (and this is always a good sign) the matter can be properly stated in a few words. At present we know that the exogenous portion of the urinary purins depends in mammals upon the quantity of free or combined purins in the food, bearing in mind moreover the further conversion of

${ }^{8}$ A. S'chittenhelm and K. Wiener (Erlangen), Zeitschr. f. physiol. Chem., $\pi \%, 77,1912$.

- P. A. Levene and F. Medigreceanu (Rockefeller Instit., New York), Jour. of Biol. Chem., 9, 65, 375, 389, 1911. 
uric acid, especially the formation of allantoin which is so prominent in many animals (vide infra).

As far as the endogenous fraction is concerned it is known that the purin bases set free in the disintegration of cellular nuclei in all tissues eventually appear in the form of urinary purins. There is reason for avoiding a restricted conception which would make the leucoeytes, the muscles, the digestive glands ${ }^{10}$ or the kidneys alone responsible for the endogenous production of uric acid; it is better to look upon it as the expression of a continuous and general cellular wear. Precisely because this process of wearing out and gradual removal of cells is a very constant and regular one, at least when serious pathological changes are not present, a relative constancy in the endogenous urinary purin fraction is to be expected for each individual, as first observed by R. Burian and H. Schur and afterwards confirmed by a number of other writers. ${ }^{11}$ Briefly stated, the active metabolism of the growing body, the experimental exaggeration of glandular activity by pilocarpin, the increase of cell destruction by use of Röntgen rays, and very many pathological disturbances like phosphorus poisoning, hepatic atrophic cirrhosis, jaundice, Eck's fistula, fever', leukæmia, etc., are all capable of increasing the endogenous fraction of urinary purins. ${ }^{12}$

Relation of Purin Metabolism to Muscular Activity.There is only one point which requires any further discussion in this commection, namely, that of the relation of the purins to muscular labor, ${ }^{13}$ a matter heretofore dealt with in

${ }^{10} \mathrm{O}$. Sivén (Helsingfors), Pflüger's Arch., 146, 449, 1912.

${ }^{11}$ Cf. E. W. Rockwood, Amer. Jour. of Physiol., 12, 38, 1904; F. Mares, vide infra.

${ }^{12}$ B. Hirschstein (F. Umber's Clinic), Arch. f. exper. Path., 57, 229, 1907; Th. Brugsch and A. Schittenhelm, Zeitschr. f. exper. Path., 4, 761, 1907; O. Sivên (Helsingfors), Skan. Arch. f. Physiol., 18, 177, 1906; S. Bondi and F. König, Wiener med. Wochenschr., 1910, Nos. 44-4j; F. Mareš, F. Smetanka (Physiol. Institut. Czech. Univ., Prague), Pflüger's Arch., 13\%, 59, 1910; 138, $217,1911$.

${ }^{13}$ R. Burian, Med. Klinik, 1905, No. 6, and 1906, Nos. 19-21. 
considering the chemistry of muscular tissue (v. Vol. I of this series, p. 159, Chemistry of the Tissues). It cannot be doubted that muscular activity has a part in the formation of the endogenous urinary purins. The fact, however, that Schittenhelm ${ }^{14}$ has found no striking reduction of the endogenous amount in human beings with well marked muscular atı ophy would, however, contradict the idea that the bulk of these substances originates in muscle tissue. Siven, too, failed to recognize any characteristic influence of free muscular movements upon the endogenous purin metabolism in man ${ }^{15}$; while Goudberg invariably found the uric acid increased in starving rabbits after muscular spasms produced by faradism. ${ }^{16}$ Finally it should be noted that muscular involvement in processes concerned with heat regulation is apparently more likely to influence the purin excretion than voluntary contractions. The increased uric acid excretion of fever and its nocturnal diminution are perhaps related to the same type of processes. ${ }^{17}$

Synthetic Formation of Uric Acid in Birds and Reptiles. -Being in some measure satisfied of the production of uric acid through processes of oxidation from nucleins, attention should be directed to the synthetic production of uric acid. ${ }^{18}$ It is known that the major portion of the nitrogen, which in mammals, amphibians and fish is excreted as urea, is represented in birds, reptiles and also in many invertebrates ${ }^{19}$ by uric acid, which is produced in them synthetically. What is known of the mechanism of this process?

${ }^{14}$ A. Schittenhelm, Handb. d. Biochem., 4' 521, 1910.

${ }^{15} \mathrm{~V}$. O. Sivén, l. c.

${ }^{16}$ A. Goudberg (Hamburg), Zeitschr. f. Neurol. u. Psych., 8, 487, 1912.

${ }^{17}$ E. P. Catheart, J. B. Leathes, E. L. Kennaway, eited by A. Ellinger, Handb. d. Biochem., 4', 576, 1910.

${ }^{13}$ Literature upon the Synthesis of Uric Acid: H. Wiener, Ergebn. d. Physiol., 1, 606-615, 1902; A. Magnus-Levy, v. Noorden's Handb., 1, 126-129, 1906 ; A. Schittenhelm, Handb. d. Biochem., 4', 522-525, 1910.

${ }^{10}$ Cf. O. v. Fürth, Vergl. chem. Physiol. d. niederen Tiere, pp. 258-303, Jena, 1903. 
The skeletal plan of the uric acid molecule may be represented as consisting of two fractions of urea fixed to a chain of three atoms of carbon:

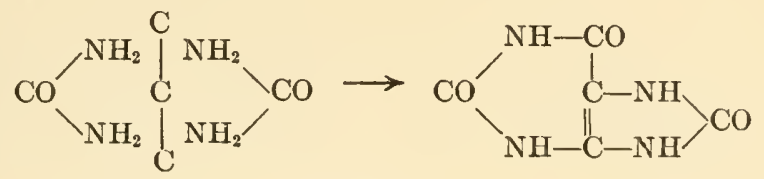

Our ideas in reference to the urea rests required in the synthesis of uric acid are fairly clear. According to the investigations of Knieriem, Jaffe and Hans H. Meyer, as well as those of Schröder, there can be no question as to the ability of the liver in birds to construct uric acid from ammonia salts, aminoacids, as well as from urea. The hypothesis that in the avian body, just as in mammals, the protein nitrogen is first broken down into urea, and subsequently as a secondary process is synthesized into a complex of two urea rests and a group of three carbon atoms is an entirely satisfying. one.

What is the significance of this triple group of carbon atoms? Minkowski's well-known experiment, in which he noted the appearance of lactic acid and ammonia in the urine of geese from which the liver had been extirpated, has forced lactic acid for the past nearly twenty years prominently into consideration, and has apparently harmonized the general subject. It has been proved that the appearance of lactic acid is due to the loss of the hepatic function; as ligation of all of the hepatic vessels produces the same effect, but if even a single branch of the hepatic artery be open there is no formation of lactic acid. To prove that the failure of uric acid formation is actually due to the exclusion of the liver and is not in some way a secondary result of accumulation of lactic acid in the body, requiring considerable ammonia for neutralization and thus interfering with synthesis of uric acid, we may recall the fact that (as Sigmund Lang was able to show in Hofmeister's laboratory) introduction of alkali into geese with excluded livers is not followed by any increase in the 
disturbed uric acid synthesis. H. Wiener has noted in dehepatized birds that if the economy is experimentally flooded with urea, lactic acid and especially, too, a number of dibasic acids in whose structure there occurs a chain of three carbon atoms, as malonic acid (COOH.CH $2 . \mathrm{COOH})$, tartronic acid (COOH - CH $(\mathrm{OH})-\mathrm{COOH})$ and mesoxalic acid $(\mathrm{COOH}-\mathrm{CO}-\mathrm{COOH})$ are capable of giving rise to an increase in the uric acid elimination. The synthesis of uric acid in such case may proceed somewhat as follows:

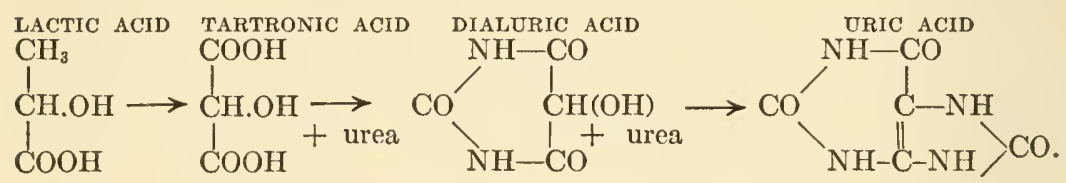

The recent recognition of a synthesis of uric acid from dialuric acid and urea ${ }^{20}$ may be regarded as the capstone of the construction.

An important recent investigation by Ernst Friedmann and $H$. Mandel ${ }^{21}$ would indicate that we are still far from the truth. Contrary to Kowalewski and Salaskin, who found an increase in the amount of uric acid in the blood used in perfusion of the excised goose-liver after lactate of ammonia was added, the above named authors were unable to in any way influence uric acid formation by introducing either lactate of sodium and urea, or malonate of sodium and urea. On the contrary a remarkably large formation of uric acid was a striking feature when perfusion was performed with normal blood unchanged by any additions, clearly not dependent upon washing out of previously formed uric acid but indicative rather of an actual new formation. This brings up the question whether perhaps the synthesis of uric acid is not accomplished in a very different manner than indicated in the above schema. It is

${ }^{20}$ G. Izar (Ascoli’s Lab., Catania), Zeitschr. f. physiol. Chem., $73,317,1911$.

${ }^{21}$ E. Friedmann and H. Mandel (First Med. Clinic, Berlin), Arch. f. exper. Pathol. (Schmiedeberg Festschrift), p. 199, 1908. 
very evident that the problem cannot be regarded at present as solved.

It has been actually shown in Minkowski's laboratory that, as previously suspected, besides the synthetic formation in the avian body there is also an oxidation formation of uric acid in small amounts in complete analogy to the process in mammals.

Synthetic Purin Formation in Mammals.-There is no evidence at all at present to indicate that uric acid is synthetically produced in mammalian animals and man along with its oxidative production, in analogy to the process seen in birds, as was asserted by H. Wiener. ${ }^{22}$ However, there is no doubt as to the ability even of the mammalian body to construct purin complexes in preparation for their incorporation in the molecules of nucleinic acid. The most important points in this connection have been previously considered (Vol. I of this series, p. 129, Chemistry of the Tissues). Proof is available not only in case of the eggrs of the silk moth and of the hen, the salmon in starvation, but also in case of growing sucklings and of rats fed upon purin-free diet, that the animal body is able to construct de novo the bases necessary for purin formation out of practically any components of the protein molecule; and that it is not restricted exclusively to purin bases of exogenous origin.22a But no one knows just how this construction takes place. It has not been successfully shown by feeding experiments that transformation takes place of derivatives of the pyrimicin nuclens, ${ }^{23} \overbrace{\mathrm{N}-\mathrm{C}}^{\mathrm{N}-\mathrm{C}}$, (Vol. I of this

${ }^{22}$ R. Burian, Zeitschr. f. physiol. Chem., 43, 497, 1905; W. Pfeiffer (F. Hofmeister's Lab., Strassburg, and Quincke's Clinic, Kiel), Hofmeister's Beitr., 10, $324,1907$.

22a E. V. MeCollum (IVisconsin), Amer. Jour. of Physiol., 25, 120, 1909; L. S. Fridericia (Copenhagen), Skandin. Arch. f. Physiol., 26, 1, 1912; cf. therein Literature. 77,1910 .

${ }^{23}$ L. B. Mendel and V. C. Myers (Yale Univ.), Amer. Jour. of Physiol., 26, 
series, p. 113, Chemistry of the Tissues) or of a derivative of the imidazol nucleus, $\underset{\mathrm{C}-\mathrm{N}}{\stackrel{\mathrm{C}}{\mathrm{C}}-\mathrm{N}}>\mathrm{C}$, histidin, ${ }^{24}$ into the purin nucleus,<smiles>C1NC2NCNC2N1</smiles>
in which both the former nuclei are, so to say, included.

Allantoin as an End-product of Mammalian Purin Metabolism.-We come now to the most abstruse and debated portion of the uric acid problem, that of uric acid destruction in the body, uricolysis. For the past decade, in spite of all the study devoted to it, this problem has remained fixed, undoubtedly for the reason, at present easily appreciable, that the dominating position which is occupied by allantoin in the nuclein metabolism in mammals was entirely overlooked. The ignorance which previously prevailed upon the general subject first began to lessen when Wilhelm Wiechowski contributed to metabolic investigation an exact method of determining allantoin and took up in definitive manner the problem of uric acid destruction in a series of very carefully conducted studies. ${ }^{25}$

After it became known from repeated investigations ${ }^{26}$ that living excised tissues of mammals are capable of destroying uric acid, Wiechowski proved that it is completely oxidized in the process into allantoin without undergoing further change:
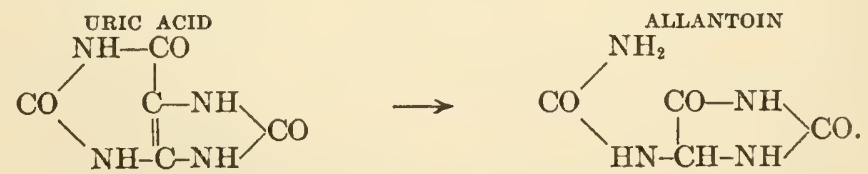

E. Abderhalden, H. Einbeck and J. Schmid, Zeitschr. f. physiol. Chem., $68,395,1911$.

${ }^{25}$ W. Wiechowski (J. Pohl's Lab., Prague), Hofmeister's Beitr., 9, 247, 295, 1907; 11, 109, 1907; Arch. f. exper. Pathol., 60, 185, 1909; Biochem. Zeitschr., 25, 431, 1910; cf. in this last the Literature upon Uricolysis.

${ }^{28}$ Stokvis, Chassevant and Richet, Ascoli, Jacoby, Schittenhelm, Burian, Austin, Almagia, Wiener. Cf. H. M. Vernon, Ergebn. d. Physiol., 9, 168, 1910. 
That this is really the expression of a physiological process is evidenced directly by the fact that in the mammals carefully studied from this point of view (dog, cat, rabbit, hog, cow) excretion of uric acid and of the purin bases is decidedly overshadowed by allantoin, as shown from observations of Schittenhelm, Abderhalden, Underhill, L. B. Mendel and others. Parenterally introduced uric acid is completely excreted by dogs and rabbits, in by far the greater proportion as allantoin, and only in minor amount as uric acid. Nucleinic acid from thymus derivation, too, when introduced with the food, according to Schittenhelm ${ }^{27}$ undergoes cleavage in the body of the dog in a way that the great bulk (93-97 per cent.) of its purins appear as allantoin, and only the small residual percentage is partitioned as uric acid and purin bases. The author's pupil, W. Hirokawa, ${ }^{28}$ obtained similar figures when nucleinic acid was fed to dogs; although the purins did not appear in the urine entirely free from residue. Likewise, too, in the pig ${ }^{29}$ after administration of nucleinic acid the purins for the most part appear in the allantoin fraction. On the basis of these observations, supplemented by numerous older findings bearing upon the conversion of uric acid and nucleinic substances into allantoin, ${ }^{30}$ Wiechowski has been thoroughly corroborated in his statement that allantoin is to be regarded and accepted as an end-product of uric acid metabolism, and that besides allantoin no other products (neither oxalic acid, glycocoll nor urea) of the intermediate uric acid metabolism are met in mammalian animals.

Further explanation is not necessary for appreciation of the fact that allantoin, an end-product of the normal vital catabolism of nucleoproteids and nucleinic acids, appears in the catabolism of the same substances in case of intoxication

${ }^{27}$ A. Schittenhelm, Zeitschr. f. physiol. Chem., 62, 80, 1909.

${ }^{2 s}$ W. Hirokawa, Biochem. Zeitschr., 26, 441, 1910; under direction of O. v. Fürth.

${ }^{20}$ A. Schittenhelm, Zeitschr. f. physiol. Chem., 66, 53, 1910.

so Salkowski, Minkowski, Th. Cohn, L. B. Mendel and others. 
with protoplasmic poisons (hydrazin, hydroxylamine and semicarbazide) as well as in autolysis, as repeatedly observed by Borissow and by J. Pohl and his collaborators. ${ }^{31}$

In what organs the change from uric acid into allantoin takes place is not known; that it is not limited to the liver is proved by observations on dogs with Eck's fistulas. ${ }^{32}$

While parenterally introduced nucleinic acid is apparently changed practically completely into allantoin by the mammalian body, this is not by any means always the case with the nucleinic acid introduced by the mouth. In rabbits only half or less of the nitrogen of the bases appears as allantoin in the urine under such circumstances. According to Wiechowski this may be easily explained by the fact that in the alkaline intestinal contents extensive destruction of allantoin takes place, apparently without necessity for intervention of bacteria, but certainly with such aid. On the other side of the intestinal wall, however, the allantoin is a stable product.

Fate of the Intermediary Uric Acid in Man.-As far as uricolysis in the lower animals is concerned there is a fair unanimity of opinion; the more divergent, however, the opinions as to the destruction of uric acid in human metabolism.

For a decade the physiology and pathology of purin metabolism remained unchanged under the domination of the hypothesis that a marked destruction of uric acid takes place in the human body. In conditions in which (as in gout) special accumulation of uric acid was assumed to exist, the fault was always referred to some lowering of the power of the tissues to destroy uric acid. In the course of the last few years these ideas have undergone appreciable change.

Absence of Uricase in Human Tissues.-As has been said, uric acid destruction, with formation of allantoin,

as Literature: W. Wiechowski, Hofmeister's Beitr., 9, 306, 1907.

${ }^{32}$ E. Abderhalden, E. S. London and A. Schittenhelm, Zeitschr. f. physiol. Chem., 61, 413, 1909. 
takes place with great intensity in the pulp of mammalian tissues. (It takes place apparently in other vertebrates as well; it is said that the liver of the ray is from this standpoint more capable than any other rertebrate tissue.) ${ }^{33}$ There have been a number of attempts to isolate an actual ferment, "uricase" (as far as it is possible to speak of isolation in case of enzymes). ${ }^{34}$ Wiechowski here made the important discovery that living excised human tissues are unable to break down uric acid under conditions in which the tissues of lower mammals prove efficient, and that the former therefore must be regarded as not conforming to the usual rule. This has been confirmed from so many sources ${ }^{35}$ that there can be no doubt as to its correctness. ${ }^{36}$ The objection raised that invariably a preuricase is present but is prevented from manifesting itself because of the antagonism of inhibiting substances can scarcely be accepted, if for no other reason than that other ferments which are active against purins, as xanthinoxydase and guanase, are found without any difficulty in the human tissues. "If," says Wiechowski, "ais is amply confirmed by all observers, human tissues build up uric acid with ease from guanin and xanthin but do not catabolize the substance thus formed, in contrast to animal tissues, which oxidize the uric acid further into allantoin, it seems to me the assembling of these

${ }^{33}$ V. Scaffidi (Zool. Station, Naples), Biochem. Zeitschr., 18, 506, 1909; $25,296,411,415,1910$.

* IV. Wiechowski and W. Wiener (J. Polıl's Lab., Prague), Hofmeister's Beitr., 9, 247, 1907; F. Battelli and L. Stern (Geneva), Biochem. Zeitschr., 19, 219, 1909; G. Galeotti (Naples), ibid., 30, 374, 1911.

${ }^{35}$ Battelli and Stern, Miller and Jones, J. G. Wells and H. J. Corper, eited by Wiechowski, Biochem. Zeitschr., 25, 434, 1910 .

${ }^{33}$ It would probably be going too far to deny entirely all possibility of a uricolysis in human tissues, as there have been positive findings also in this direction, as those of W. Pfeiffer, Croftan and Schittenhelm. Consult in reference to the physiological importance of the subject: W. Wiechowski, Arch. f. exper. Pathol., 60, 199- 00,1907 . "I believe that 1 am in position to conclude with a fair certainty," says Wiechowski, "that in carefully prepared experiment-conditions in which living excised animal tissues oxidize uric acid vigorously, human tissues are practically inactive."

${ }^{a 7} \mathrm{~W}$. Wiechowski, Biochem. Zeitschr., 25, 436, 1000. 
findings constitutes a valuable scientific contribution to our knowledge of the fate of uric acid in human beings."

Fate of Experimentally Introduced Purins in Human Metabolism.-Another point of considerable importance is the fate of artificially introduced uric acid in the human metabolism. After feeding nucleinic acid to human beings Schittenhelm, Brugsch and Frank have recovered as a rule the greater part of the purin base nitrogen in the urea fraction, a smaller portion in the uric acid fraction and only a very small proportion as nitrogen of the purin bases. ${ }^{38} \mathrm{Al}$ lantoin which predominates in metabolism in animals is of little importance here, and is found only in very small amounts in the human urine. However, according to Wiechowski's results, uric acid introduced subcutaneously is recovered for much the most part as such (up to 90 per cent.) in the urine.

There is a difference of opinion as to the importance of this last result, between Wiechowski on the one hand, and Brugsch and Schittenhelm on the other. Schittenhelm believes that because of its toxicity subcutaneous injections of uric acid are not suited for conclusions with reference to normal metabolic processes, and thinks it cortain that uric acid is in some proportion further catabolized in human metabolism, with production of urea. ${ }^{39}$ This view agrees with that of Burian, who assumes that of the uric acid which enters the circulation from without or which is produced in the body by the breaking down of the nucleins, in man always about half is destroyed and only the other half is excreted unchanged; for which reason he multiplies the amount of excreted uric acid by the "integrative factor 2 " in order to obtain the total uric acid which entered the circulation in the course of a day upon purin-free diet. ${ }^{40}$

${ }^{38}$ R. H. Plimmer, M. Dick and C. C. Lieb, Jour. of Physiol., 39, 98, 1909.

${ }^{2}$ A. Schittenhelm, Handb. d. Biochem., 4', 516, 1910; cf. also L. B. Mendel and J. F. Lyman (Yale Univ.), Jour. of Biol. Chem., 8, 115, 1910.

${ }^{40} \mathrm{R}$. Burian, Mled. Klinik, 1905, No. 6, and 1906, Nos. 19-21. Consult in these and in the contributions of $\mathrm{R}$. Burian and H. Schur the Literature. 
To this Wiechowski makes adverse reply. He acknowledges that the subcutaneous injection of uric acid severely taxes the metabolism. It is not impossible that a toxic action, which must be taken into consideration, but permitted to proceed, may afford correct conclusions in animal experimentation; in no case, however, can the metabolic disturbance produced explain why the greater part of uric acid which has been parenterally introduced into a human being is excreted unaltered.

Schittenhelm's ${ }^{41}$ finding, that experimentally introduced allantoin is not affected in human metabolism, is an important one. Were uric acid catabolized in man, as in animals, in important degree into allantoin, we might expect that the latter would appear in the urine; but actually very small amounts only of this substance occur normally therein. ${ }^{42}$

In harmony with earlier opinions of Otto Löwi ${ }^{43}$ and of Soetbeer and Ibrahim, ${ }^{44}$ Wiechowski concludes that intermediate uric acid is not broken down in man in any really important amount. "For this conclusion the individual constancy of endogenous uric acid excretion is a favorable point. For how else can this be explained if, as shown, the reality of a so-called integrative factor of the amount decomposed is not to be assumed. And the established difference between the urine of mammals and of man on purin-free diet (in one ease a rich and individually constant daily allantoin elimination with very low uric acid elimination in the other a rich and individnally constant excretion of uric acid in the twenty-four hours with mere traces of allantoin excretion) may be looked upon as entirely satisfactory and logical evidence of the inferred position of the human being in relation to uric acid." ${ }^{45}$ Finally Wiechowski ${ }^{45 a}$ comes to the point

${ }^{4}$ A. Schittenhelm and K. Wiener, Zeitschr. f. physiol. Chem., 63, 283, 1909.

${ }^{42} \mathrm{~K}$. Ascher (Prague), Biochem. Zeitschr., 26, 370, 1910.

${ }^{48}$ O. Löwi, Arch. f. exper. Pathol., 41, 22, 1900.

4 F. Soetbeer and J. Ibrahim (Heidelberg), Zeitschr. f. physiol. Chem., $35,1,1902$.

${ }^{45}$ W. Wiechowski, Arch. f. exper. Pathol., 60, 206, 1904.

45a W. Wiechowski, Biochem. Zeitsch., 25, 445, 1910. 
that all the objections raised by Schittenhelm and others are unsound. "I am compelled to remain of the same opinion as before, believing it to be well founded and not contradicted; that is, that the changes in intermediate uric acid proceed in man qualitatively precisely as in the other mammals, that is, that it is transformed by oxidation into allantoin; but quantitatively they lag behind so much that uric acid must be regarded as the principal product of purin metabolism in man.",

Wiechowski's view has very recently received important support from the results of a personal experiment conducted by Lewinthal in Friedrich v. Müller's Clinic in Munich, ${ }^{46}$ in which the investigator injected into himself xanthin (dissolved in piperidin) and recovered the bulk (89 per cent.) in the urine mainly as uric acid. Sivén, in Helsingfors, ${ }^{47}$ likewise concludes from experiments upon himself that the human body is devoid of uricolytic ability and that purins when they have once gained access to the circulation are to be looked upon as end-products of metabolism.

In connection with the exceptional position of man as to purin metabolism it is instructive to note that the uricolytic power of the tissues of the macacus rhesus species of monkey is more like that of the tissues of other animals than of human beings. ${ }^{48}$ According to Wiechowski, in the lower monkeys, as in other mammals, allantoin is the principal endproduct of purin metabolisin. The urine of the chimpanzee, however, corresponds in this particular with human urine. ${ }^{49}$

Decomposition of Purins in the Intestine.-The fact that dietary purins, whether free or combined, fail to appear either as uric acid or allantoin in the urine can-

${ }^{43}$ W. Lewinthal (F, v. Müller's Clinic, Munich), Zeitschr. f. physiol. Chem., \%7, 273-274, 1912.

${ }^{47}$ V. O. Sivén (Helsingfors), Pflüger's Arch., 145, 283, 1912.

${ }^{4}$ H. G. Wells (Chicago), Jour. of Biol. Chem., 7, 171, 1909-10.

${ }^{40}$ W. Wiechowski, Prager med. Woshenschr., 1912, 275. 
not be harmonized with the assumption that these substances are to be regarded as end-products of intermediary metabolism, except by acknowledging the possibility of an important degree of purin destruction in the bowel.50 As a matter of fact, we have no ground for doubting such a possibility. It has been shown that uric acid undergoes a spontaneous dissociation even at the low alkalinity of sodium bicarbonate when in a warm temperature, ${ }^{51}$ and is even more readily catabolized in alkali solution when acted upon by an oxidizing agent: 52

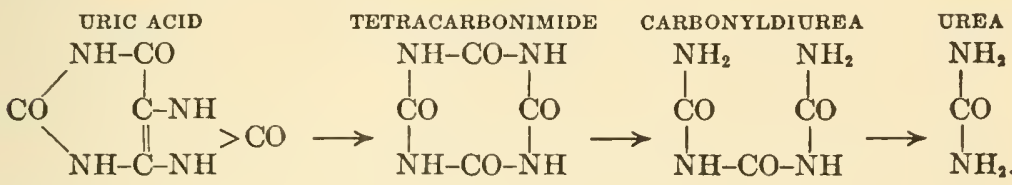

The oxidation takes place in a strongly ammoniacal solution with separation of imino-allantoin, ${ }^{53}$<smiles>N=C(NC(N)=O)C(NC(=O)O)NC(=O)O</smiles>

It is doubtful, it is true, whether such oxidation-cleavage processes play any part in the usually strongly active reducing intestinal contents. However, bacterial cleavage processes must not be overlooked, an example of which may be seen in the action of the uric acid bacillus isolated from chicken excrement, producing a fermentation of uric acid into urea and carbonic acid as end-products. ${ }^{54}$

Reconstruction of Uric Acid.-It is difficult to realize the

${ }^{50}$ P. A. Levene and F. Medigreceanu (Rockefeller Instit., New York), Amer. Jour. of Physiol., 27, 438, 1911.

${ }^{5}$ W. Wiechowski, Arch. f. exper. Pathol., 60, 200, 1907.

${ }^{62}$ A. Schittenhelm and K. Wiener, Zeitschr. f. physiol. Chem., 62, 100, 1909; cf. also R. Behrend, Ann. d. Chem., 333, 141, 1904; 365, 21, 1909.

${ }^{t s}$ G. Denicke, Ann. d. Chem., 3/99, 269, 1906.

${ }^{*}$ C. Ulpiani and M. Cingolini, Gazzetta Chimica Ital., 1908, 34, 377, 1904 ; cit. in Centralbl. f. Physiol., 19, 166, 1904. 
statements of Ascoli and Izar ${ }^{55}$ to the effect that uric acid may reform after it has undergone a previous decomposition. These authors observed the disappearance of sodium urate which had been added to hepatic pulp in the incubator when a stream of air was conducted through it. When the material was left in the incubator with air excluded it is said reformation of the uric acid took place. Control experiments are said to have shown that the newly formed uric acid did not come from any cleavage of nucleins belonging in the liver pulp, but from a real regeneration of the decomposed uric acid. From what has been said (vide supra) it would be necessary to assume that in oxidation-destruction of uric acid in liver extracts allantoin would be formed. That this is the case has meanwhile recently been shown by Fasiani, although he was unable to confirm the regeneration of the uric acid. ${ }^{56}$ The author prefers to postpone any definite opinion upon the matter until the conclusion of experiments now in course in his laboratory.

MethylatedPurin Derivatives.-Besides the typical purin bases there is a series of methylated purin derivatives present in small quantities in urine, which originate from the caffein, theobromin and theophyllin of coffee and tea. Their nature has been fully demonstrated, in the first place by their synthetic production by Emil Fischer and, too, especially by the studies of Rost, Albanese, Bondzynski and Gottlieb, Salomon, Krüger, J. Schmid and Schittenhelm. ${ }^{57}$ The schema below printed may serve to indicate their relation (in which, as in previous instances the writer has omitted for brevity hydrogen atoms and double bindings):

*s. Ascoli and G. Izar, Zeitschr. f. physiol. Chem., 58, 529, 1909 ; G. Izar, ibid., 65, 88, 1910 .

* Fasiani, Arch. Ital. de Biol., 5\%, 222, 1912.

${ }^{57}$ Literature: A. Ellinger, Handb. d. Biochem., $3^{\prime}, 579-581,1910$; A. Schittenhelm, ibid., 4', 525-528, 1910. 


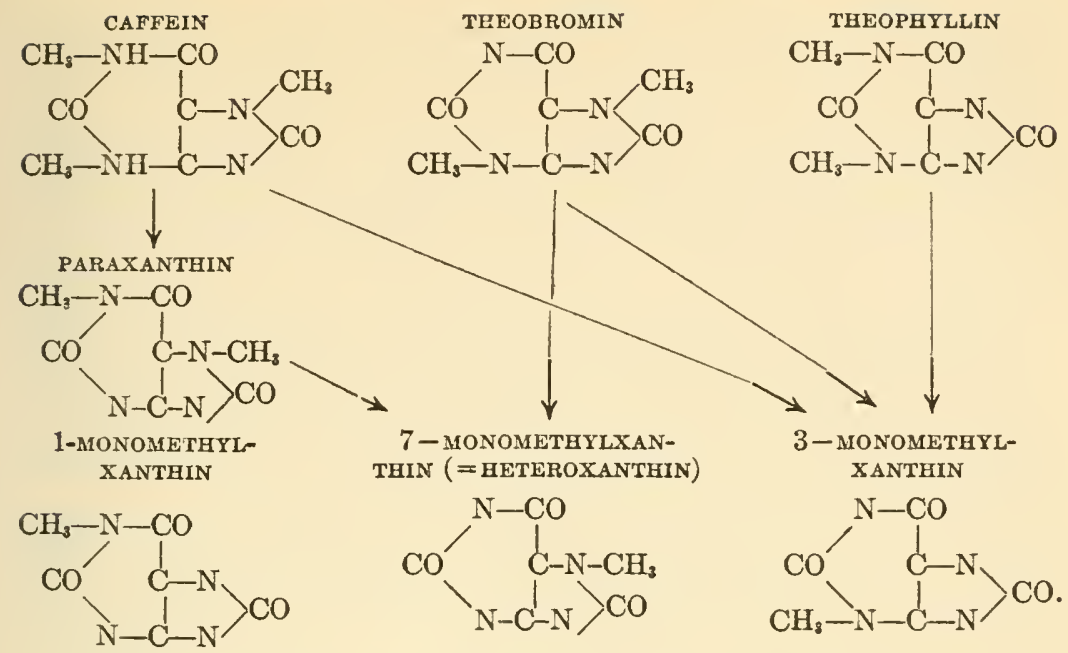

It is possible apparently that the demethylation, however, can proceed further and may in the end lead to the production of uric acid and allantoin, for which reason the prohibition of coffee, tea and chocolate is probably always advisable in prescribing diet for a case of gout ${ }^{58}$; although the methylxanthins are likely to increase the purins sooner than the uric acid in the urine. The methyl derivatives of xanthin are entirely absent from the urine of an individual who has abstained completely from coffee and tea; but this

is not true of epiguanin $\left(\left.(\mathrm{NH}) \mathrm{C}_{\mathrm{N}-\mathrm{C}-\mathrm{N}}^{\mathrm{N}-\mathrm{CO}}\right|_{\mathrm{C}} ^{\mathrm{C}-\mathrm{N}}>\mathrm{CH}_{3}\right)$, a guanin derivative which cannot originate from any of the known purins of coffee and tea.59 It is possible that we are here dealing with an example of the methylation processes in the body which have been previously considered ( $v$. supra, p. 132). Demethylation of methylated xanthin deriva-

${ }^{23}$ A. Schittenhelm, Therap. Monatsch., 1910, 113; P. Fauval, Compt. Med., $142,1428,1906 ; 148,1541,1909$.

M. Krüger, Biochem. Zeitachr., 15, 361, 1909. 
tives has been directly observed in experiments with tissue pulp. ${ }^{60}$

Quantitative Estimation of Uric Acid.-In concluding the present lecture a few words may be devoted to enumeration of recent advances in the analysis of the urinary purins.

Besides the time-honored method of E. Ludwig and Salkowski, which, as is well known, depends upon precipitating the uric acid by magnesia mixture and ammoniacal silver solution, the method of Hopkins has met with the most popularity. In the latter the uric acid is thrown down by ammonia and ammonium chloride as ammonium urate. The uric acid, freed from the urate by hydrochloric acid, may be weighed or determined by the Kjeldahl method. Folin and Schaffer have modified this method, by titration of the acid in sulphuric acid solution with permanganate. According to Ronchèse the uric acid separated by the Hopkins method may readily be titrated with a solution of iodine in an alkaline medium, employing starch paste as an indicator. ${ }^{61}$ Kowarski ${ }^{62}$ proposes to free the uric acid from the urate of ammonium precipitated as in the Hopkins method, by means of hydrochloric acid, then to wash with water and alcohol until the reaction becomes neutral, and finally to titrate with $\mathrm{n} / 50$ piperidin solution against phenolphthalein. According to Krüger and Schmid ${ }^{63}$ precipitation of uric acid and the purin bases with copper sulphate and acid sulphite of sodium has proved useful; after breaking up the precipitate with sodium sulphide the uric acid may be caused to crystallize out by rendering the solution acid with sulphuric acid; by which means it may be separated from the purin bases. His's method of uric acid estimation consists in acidifying

${ }^{\infty}$ Brugsch, Pincussohn and Schittenhelm, cited in Handb. d. Biochem., 4', 528; Y. Kotake, Zeitschr. f. physiol. Chem., 5\%, 378, 1909; J. Schmid (Breslau), ibid., 6\%, 155, 1910.

${ }^{81}$ A. Ronchèse, C. R. Soc. de Biol., 60, 504, 1906.

${ }^{c 2}$ A. Kowarski, Deutsche med. Wochenschr., 1906, 997.

${ }^{63}$ J. Kriiger and J. Schmid, Zeitschr. f. physiol. Chem., 45, 1, 1905. 
the urine with hydrochloric acid, inoculating it with a bit of uric acid and subsequently shaking the urine for a long time when the salt-like combined uric acid is separated, presumably completely. However, this method furnishes distinctly lower results than the Ludwig-Salkowski and other methods, probably because it leaves complex uric acid combinations intact. It may, however, possibly serve, if more fully elaborated, to separate the uric acid which is in the blood in loose salt-like form from that in firmer combination. ${ }^{64}$

Wiechowski's Method of Estimating Allantoin.-Reference has been made to the very great importance of Wiechowski's method of determining allantoin, and the statement made that the introduction of this method, which had been worked out very precisely, had determined the turning point in the historical development of the study of purin metabolism. The method consists first of removal of all substances from the urine which can be precipitated by means of phosphotungstic acid, acetate of lead and acetate of silver, after which the allantoin is thrown down by mercuric acetate with addition of sodium acetate after careful neutralization. In animal urine the nitrogen content of the precipitate may then be directly determined; the impurities in the precipitate being in such small amount that they are scarcely appreciable analytically in proportion to the relativeiy large amount of allantoin. However, in case of the very scant quantities of allantoin in human urine, the conditions are quite different. In this case simple nitrogen determination of the precipitate cannot be used, and it is essential to have recourse to purifying processes to enable us to separate and weigh the allantoin in crystalline form.$^{65}$

${ }^{8}$ A. Nicolaier and M. Dohrn, Deutsch. Arch. f. klin. Med., 91, 151, 1907; B. Bloch (Med. Clinic of W. His, Basel), Deutsch. Arch. f. klin. Med., 83, 499, 1905; Meisenburg, ibid., 8\%, 425, 1906.

${ }^{\infty}$ W. Wiechowski, Hofmeister's Beitr., 11, 121-131, 1907; Biochem. Zeitschr., 25, 446-453, 1910. 


\section{CHAPTER VIII}

\section{PATHOLOGY OF PURIN METABOLISM}

Having attempted in the previous lecture to orient ourselves in relation to the present status of the theory of normal purin metabolism, we may at once proceed to picture to ourselves the nature of gout as it is viewed to-day. Quite naturally the author prefers to limit the present discussion to the basic physiological chemical problems, and would therefore refer to the recent monographs on the subject for the various details, particularly those involving the clinical symptoms, the pathological anatomy and questions as to the therapy concerned in this affection. ${ }^{1}$

Increase of Uric Acid in the Blood of the Gouty.The views held as to the nature of this puzzling anomaly of metabolism are so changing that it is by no means easy for the biological chemist to find a fixed point in the flood of phenomena. Perhaps such a point of inception may be recognized in the increase of uric acid in the blood in gouty subjects. It is true that even at the present day there are earnest persons who doubt whether uric acid, the local depositions of which characterize the morphological picture of the disease, is to be looked upon as the actual materia peccans of gout, and whether it does not play merely a collateral and secondary part. But, for at least a half century, the fact pointed out by Garrod in 1848 that the blood of gouty individuals is at times richer in uric acid than that of normal persons has maintained its position. Garrod's primitive experiment (he demonstrated by his "thread test" that threads laid in blood serum to which an acid was added would, from the crystallization of uric acid, after a time be

${ }^{1}$ H. Wiener, Ergebn. d. Physiol., 2, 377-432, 1903; O. Minkowski, Die Gicht, Vienna, 1903 (in Nothnagel's Handb. d. spez. Pathol.); W. Ebstein, Die Natur u. Behandl. d. Gicht, 2 d ed., 1906; C. v. Noorden, Handb. d. Pathol. d. Stoffwechsel, 2d ed., 2, 138-188, 1907; F. Umber, Lehr. d. Ernähr. u. d. Stoffwechselkr., pp. 262-340, 1909; A. Schittenhelm, Handb. d. Biochem., 4' 529-535, 1910. 
covered over with glistening crystals) has given place to more modern methods. Yet the more recent investigators, as Klemperer, Magnus-Levy and Brugsch, have confirmed his original statement that uric acid is usually increased in the blood of the gouty. This holds good in a remarkable manner, according to Brugsch and Schittenhelm, ${ }^{2}$ for the gouty even on purin-free diet; from which therefore it may be inferred that the accumulation of the acid in the blood results from an abnormality in the usual course of the endogenous purins originating in tissue destruction, independently of the dietary purin exchange.

It was, however, early recognized that the increase of uric acid in the blood could not by any means be held fully explanatory of gout as an entity of disease, precisely analogous increments being met in other conditions entirely different from gout. After exhibition of food rich in nucleins (as thymus) an alimentary uriccmia has been observed; there is a uriccemia of endogenous source in leukæmia, and, too, in pneumonia, at the time when with the exudate cellular constituents are being massively resorbed. In addition, a retention uriccmia is recognized in conditions of functional renal disturbance, as in chronic affections of the kidneys of all types and their sequel, uræmia. ${ }^{3}$

It is to be presumed, therefore, that the increase of uric acid in the blood of gouty patients is to be ascribed either to an increased entrance or a diminished escape of the material.

Question of Increase in the Formation of Uric Acid.For a long time the first of these possibilities was the dominating one in discussions of the problem. Many agreed that the fundamental point in the disease is to be looked for in an increase in the destruction of the tissue nucleins. As a matter of fact, however, there was absolutely no basis for

${ }^{2}$ Th. Brugsch and A. S'chittenhelm, Zeitschr. f. exper. Ther., 4, 438, 1907; B. Bloch (Med. Clinic, Basel), Zeitschr. f. physiol. Chem., 51, 472, 1907; Th. Brugsch (F. Kraus' Clinic), Berlin klin. Wochenschr., 1912, No. 34.

Literature upon the Various Forms of Uricæmia: A. Schittenhelm, Handb. d. Biochem., 4', 529-540, 1910. 
assuming that the primary factor in the pathology of gout is to be ascribed to cellular destruction. A uniform increase of phosphorus elimination was not to be found in gout, although necessarily this should be coincident with any increase in the decomposition of nucleins. It cannot, of course, be denied that in the course of gout, just as in many other affections, there does at times take place an exaggerated destruction of tissue. This is brought out in the carefully conducted studies of the protein metabolism in gout by Magnus-Levy. We frequently refer to a "toxogenic protein decomposition" in acute gouty exacerbations, and often recognize in the paroxysms of gout that a period of nitrogen retention succeeds this increased protein decomposition. In. gouty individuals it may often be observed that periods of nitrogen retention and of nitrogen deficit are likely to occur intermittently without any regularity; and v. Noorden believes "that in a subject of gout even in the intervals there exist (specific?) gout-substances, which exert now more, now less harmful influence upon protein decomposition just as in other chronic affections." "4 However, the author is unable to appreciate the least reason for forcing these points into the foreground of the general problem. ${ }^{5}$

There is therefore no basis for seeking the cause of gout in an increased formation of uric acid from oxidation processes; but there is actually less reason for assuming that it is to be met in an increased synthetic formation of uric acid, for we have seen that while this method plays an important rôle in birds and reptiles we have no right to assert its existence in the mammalian economy.

If the uric acid accumulation in the blood, character-

"Literature upon Protein Exchange in Gout: K. v. Noorden, v. Noorden's Handb. d. Pathol. d. Stoffwechsels, 2d ed., 2, 139-143, 1907.

"That, however, an increased cellular destruction, as induced experimentally, for example, by exposure to Röntgen rays, is capable of raising the hæmic content of uric acid in a gouty subject and of precipitating a gouty paroxysm, may be inferred from the observations of P. Linsen (Romberg's Clinic): Therap. d. Gegenw., 49, 159, 1908. 
istically met in gout, in conformity with the above statements is not due to an increase in formation, the logical conclusion is that it must be dependent upon some interference or prolongation in the elimination of uric acid.

Question of Reduction of Uric Acid Decomposition in Gout.-The elimination of uric acid from the blood may, doubtless, be accomplished by its destruction by oxidation. This, as has been seen, occurs physiologically in the experiment animals in laboratory investigation upon this point, the uric acid being changed into allantoin. This, however, is not true of man, in whom the latter process of conversion takes place only in a very minor degree. At once, then, a question which has been discussed in the previous lecture recurs. Is uric acid in man to be looked upon, as Wiechowski believes, as an end-product of metabolism; or is it, as Brugsch and Schittenhelm and Burian opine, subject in some degree in man to further catabolic change, perhaps to the formation of urea? In the author's opinion Wiechowski's arguments are entirely obvious; and in consonance with this view he would conclude that the basis of gout cannot be referred to a reduction in the ability of the body to decompose uric acid by oxidation, because this process camnot physiologically be an important one in the human body. The author appreciates thoroughly that others have different opinions upon these matters; but, as was remarked in a previous lecture, every man can observe only with his own eyes and think only with his own brain. Fortunately, every problem in the natural sciences is bound sooner or later to come to a stage where a natural end is fixed for all subjective conceptions and where the actual state of affairs objectively viewed assumes a more or less obvious aspect.

If then it is correct, in accordance with the author's belief, that in gout we are not dealing with a reduction of uric acid decomposition, there is obviously only one possible explana- 
tion remaining: that in some way and from some cause the excretion of uric acid is itself at fault.

Curve of Uric Acid Excretion in Acute Gouty Exacerbations.-In review of the literature of gout two groups of phenomena (apparently beyond question of doubt) stand out prominently, which may be held to indicate that faults of excretion play an actually important part in the pathology of gout. These are the characteristic curve of urinary excretion of uric acid in acute gouty exacerbations and the fact of the delayed transformation of nucleins in the gouty subject.

Primarily, in reference to the first of these features, Friedrich Umber may be cited as a clinical witness. This authority says in his valuable text-book upon nutrition and the diseases of metabolism: "The curve of uric acid excretion in the gouty subject on purin-free diet is so characteristic in the periods of exacerbation as to be of distinctly pathognomonic value. The essential endogenous curve of uric acid sinks, as His has pointed out, immediately before the paroxysm to a still lower level (which I may speak of as an anacritical stage of depression), to quickly increase as soon as the paroxysm has begun (a uric acid wave, according to E. Pfeiffer, who first observed this point), and reaches its acme on the second or third day; after which with the gradual disappearance of the gouty paroxysm it again sinks into a second or postcritical stage of depression succeeding the paroxysm. . . . This course of the endogenous purin curve may, it is true, . . . be modified by frequently recurring gouty exacerbations; but aside from this it is of decided significance as a feature in differential diagnosis." 6

Delayed Nuclein Exchange in the Gouty.-Along with this fact of the damming back of the uric acid and its breaking through the dam in some degree in the acute paroxysms

- F. Umber, Lehrb. d. Ernährung u. d. Stoffwechselkrankheiten, p. 269, Berlin and Vienna, Urban and Schwarzenberg, 1909. 
of the disease, we may probably regard as one of the most important advances in our appreciation of the pathologenesis of this anomaly of metabolism the recognition that conversion of nucleins is slow in the course of gout.

The fact that the gouty individual after ingestion of purin-containing food shows a delayed excretion of uric acid has been proved by a number of investigations ; ${ }^{7}$ he does not, as a normal person, throw off his excess of uric acid in a short time, but "spreads out" the excretion over a number of days. This feature is sufficiently characteristic to have come into employment in diagnosis of gouty affections, the uric acid excretion-curve being kept under observation after addition of a given quantity of nucleinic acid to the food. ${ }^{8}$

Gout and Nephritis. - This has suggested the thought that the cause of this uric acid stagnation may reside in the kidneys; the frequent coincidence of nephritis (particularly contracted kidneys) and gout was emphasized, and the point made that both alcoholism and lead poisoning may play an important part in the etiology of both affections. C. $\nabla$. Noorden in his valuable monograph upon gout ${ }^{9}$ very properly says that it is not right to do violence to the facts by assuming in a case which presents no other evidence of nephritis a "latent nephritis" to explain the gouty uric acid stagnation. When one remembers the fact that usually the kidneys of a case of Bright's disease perform effectually the uric acid excretion required of them, it is clearly evident that in supposing that the nephritis causes the gout there has been a confusion of cause and effect; actually the reverse is sometimes the truth.

${ }^{7}$ Vogt, Reach, Soetbeer, Kaufmann and Mohr, L. Pollak, Brugsch, Hirsch. stein, Lesser, Bloch, Schittenhelm, Rotky and others. For Literature, consult Umber, l. c., p. 271 ; A. Schittenhelm, Handb. d. Biochem., 4', pp. 531, 532, 1910.

${ }^{8} \mathrm{H}$. v. Hösslin and K. Kato (Med. Clinic, Halle), Deutsche Arch. f. klin. Med., 99, 301, 1910.

' C. v. Noorden, Handb. d. Pathol. d. Stoff wechsels, 2 d ed., 2, pp. 164, 165, 1907. 
Uric Acid Retention.-Umber has observed that gouty individuals may at times retain all of a given amount of uric acid which has been injected intravenously, at times may excrete it in small fractions; while a normal individual under similar circumstances eliminates it completely. ${ }^{10}$ (Similar retention has been met only in individuals suffering from chronic lead poisoning and pronounced alcoholism, conditions which if not allied to gout are certainly allied to a disposition toward gout.) A positive statement like this is surely of more force than the negative results of v. Benczur, ${ }^{11}$ who, after intramuscular injection of uric acid in a gouty case, found that it appeared promptly in the urine. Apparently, too, an individual with renal disease excretes his uric acid better on the whole than does a gouty subject with sound kidneys. ${ }^{12}$ Observations like those of Schmoll, Magnus-Levy, Vogt, Reach ${ }^{13}$ and Bloch, ${ }^{14}$ who state that after feeding thymus to gouty persons they found far less uric acid in the urine than in case of normal persons, seem to have practically but a single meaning; and the acute outbursts of the disease, which were repeatedly brought on by feeding thymus in cases of chronic gout, and undoubtedly are to be thought of as experiments having identical bearing, are especially impressive.

Affinity of the Tissues for Uric Acid.-If the kidneys are not to be looked upon as responsible for the scantiness of purin excretion in gout, search must be made elsewhere. The author believes Umber is correct when he states that an increased affinity of the tissues for uric

${ }^{10} \mathrm{~F}$. Umber and H. Retzlaff (Altona), 27th Congress of Internists, Wiesbaden, 1910 , p. 436 .

${ }^{11}$ G. v. Benczur (Sec. Med. Clinic, Berlin), Zeitschr. f. exper. Pathol., 7, $339,1909$.

${ }^{12}$ Cf. Tollens, Zeitschr. f. physiol. Chem., 53, 164, 1904.

${ }^{13}$ F. Reach (F. v. Müller's Clinic, Basel), Münchener med. Wochenschr., 190?, No. 29; vide there Literature.

${ }^{14}$ B. Bloch (Med. Clinic, Basel), Zeitschr. f. physiol. Chem., 51, 473, 1907. 
acid is the real reason for the diminished urinary excretion of purins, for the retention of uric acid in the blood, lymph and tissues (which may lead to gross uratic deposits in the body), and for the gouty exacerbation after a purincontaining diet. "To attempt to refer the entire complex of gout completely to faults in the catabolism of nucleinic acid due to insufficiency in the enzymes concerned," says Umber, ${ }^{15}$ "as Schittenhelm and Brugsch recently declared, is not satisfactory, entirely apart from the fact that Wiechowski, in the course of his studies as to the possibility of uric acid decomposition in the human body, was never able to detect any uricolysis worth mentioning. If we were to refuse the idea of retention in the tissues, it would be a particularly difficult thing to understand why gouty patients do not simply expel by a compensatory hyperexcretion the uric acid which is accumulated from a supposed failure of uricolysis; precisely as in leukæmia the patient compensates simply by an exaggerated excretion of the excessive uric acid which is mobilized in the body from the excessive purin decomposition. In the gouty individual there must exist some cause which makes a compensatory uric acid excretion impossible; and that is plainly a retention-affinity of the tissues, because of which the uric acid is actually held in the tissues."

The impression grows on one that this hitherto little considered factor, of an increased affinity of the tissues for uric acid in the gouty subject, ${ }^{16}$ is very much closer to the real kernel of the gout problem than, for example, the question of the fixation of uric acid in the blood, about which there has been so much contention and with which of necessity we are compelled at least to some little extent to concern ourselves.

${ }^{15}$ F. Umber, Lehrbuch der Ernährung und der Stoffwechselkrankheiten, p. $273,1909$.

${ }^{\mathrm{s}} \mathrm{Cf} . \mathrm{F}$. Umber and K. Retzlaff, 1. c. 
In what form does the uric acid, a substance relatively difficult of solution when free, exist when it is dissolved in the blood?

Alkali Compounds of Uric Acid.-One would undoubtedly first think of the uric acid as being in some alkali combination for its solution in the circulating blood. What are the known types of alkali-compounds of uric acid? First may be mentioned combinations of the type of sodium monourate $\left(\mathrm{C}_{5} \mathrm{H}_{3} \mathrm{~N}_{4} \mathrm{O}_{3} \cdot \mathrm{Na}\right)$ and of sodium biurate $\left(\mathrm{C}_{5} \mathrm{H}_{2} \mathrm{~N}_{4} \mathrm{O}_{3} \cdot \mathrm{Na}_{2}\right)$; but it should also be noted that the readily soluble biurate of sodium cannot exist in the presence of the hæmic carbonic acid. Besides these the existence of combinations of the type $\mathrm{C}_{5} \mathrm{H}_{3} \mathrm{~N}_{4} \mathrm{O}_{3} \mathrm{Na} . \mathrm{C}_{5} \mathrm{H}_{4} \mathrm{~N}_{4} \mathrm{O}_{3}$ is assumed. These last have been called "quadriurates" by Bence-Jones and Roberts; but the name should for logical reasons be changed to "'hemiurates." The assumption that these (met with in the latericious urinary sediment and in the excrement of birds and snakes) correspond structurally to a fixed molecular proportion (one atom of sodium to two molecules of uric acid) is not confirmed by recent investigations. In all probability the quadriurates are in reality a mirture of primary urate and free uric acid, which is usually fairly constant under uniform external conditions, thus necessarily suggesting the formation of mixed-crystals (solid solutions). ${ }^{17}$

Part Taken by Changes in Alkalescence.-In the older conceptions of the pathology of gout the hypothesis that separation of the uric acid from the blood into the tissues was due to a lowering of the alkalescence of the blood or of the tissue-juices, was maintained strongly. In spite of the fact that one of the greatest experts on gout, C. v. Noorden, ${ }^{18}$ long since characterized all theorizations upon

${ }^{17}$ W. E. Ringer (Physiol. Instit., Utrecht.), Zeitschr. f. pliysiol. Chem., 67, 332,1910 ; 75, 13, 1911; R. Kohler (His's Clinic, Berlin), ibid., 70, 360, 1911; \%2, 169, 1911; O. Rosenheim, ibid., \%1, 272, 1911.

${ }^{28}$ C. v. Noorden, Handb. d. Pathol. d. Stoffwechsels., 2d ed., 2, 168, 169, 1907. 
the interrelations of blood alkalescence, local changes of tissue alkalescence, and gouty deposits as "swinging loosely in the air,' it will doubtless take a very long time before physicians will stop making their patients believe that their malady is due to too much acid in the blood, and that nothing but continued drinking of this or that alkaline water (n.b., to be taken at the spring) can possibly eradicate this acid. Unfortunately there are many instances in the chemical physiology of metabolism in relation with which material interests directly interfere with the acceptance of scientific facts. The opportunity should not be passed over here to point out too, how irrational it is to try to draw any sort of conclusions from the analysis of a single specimen of urine (whether from its "degree of acidity" or its "content of uric acid") for application in the diagnosis of gout or in the recognition of improvement or regression of this condition. This is possible only, and then with great caution, from a long series of careful quantitative examinations during purin-free diet, or perhaps in the way that C. V. Noorden tests the limits of tolerance of his patients, by increasing dosage of purin and determining how much purin the subject can handle without manifesting a retention in the daily balance-test. When a plysician allows a quantitative analysis to be made of any arbitralily collected specimen of urine of his patient and then makes a diagnosis of presence or absence of a "gouty diathesis" after a glance at the list of data of the analysis, he is really not proving by his actions his possession of diagnostic acumen as much as he is laying bare his total ignorance of biochemical matters.

Lactam and Lactim Forms of Urates.-Among the factors to be considered in reference to the solubility of uric acid in the blood and its removal therefrom, is the important point, first discovered by Gudzent, that uric acid forms two series of primary salts, and that one of these, a readily soluble, instable urate, has the tendency in its solutions to change over into the second, a less soluble (about one-third), 
stable urate. Following the conceptions originating with Emil Fischer in relation to the tautomeric forms of uric acid, we may suppose that we have here a transformation of instable lactamurate into stable lactimurate:
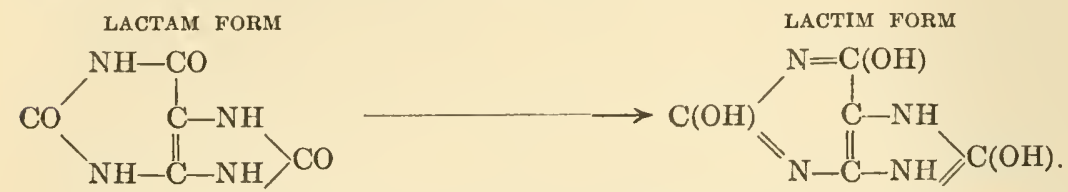

A transformation of this kind, from the instable to the stable form, seems to take place in the circulating blood. ${ }^{19}$ It is supposed that because of the difference in solubility of these two interchangeable forms of monourate, the blood of gouty individuals must at times represent a supersaturated solution of uric acid, which can only gradually resume its equilibrium by removal of urates by crystallization. That gouty blood is not comparable, however, at least not in all conditions, to a supersaturated solution of uric acid is evident from Klemperer's results, showing that the blood of a gouty subject is capable of dissolving considerable amounts more of uric acid. Apparently it were best to hold that the subject is not at present proved to be a matter of pathological importance.

Nucleinic Acid Combination With Uric Acid.-From the observation that uric acid ean no longer be precipitated either by acetic acid or by alkaline ammonio-silvermagnesia mixture from a mixed solution of uric acid and nucleinic acid, Minkowski has held that it is probable "that uric acid primarily exists in the blood and the tissue juices in combination with nucleinic acid, and that not only the conversion of the purin bases into uric acid, but also the solubility and transportation as well as the further changes of the uric acid in the living body is regulated by

${ }^{19} \mathrm{G}$. Gudzent (His's Med. Clinic, Berlin), Zeitschr. f. physiol. Chem., 60, 38,1909 ; 63, 455, 1909; Centralbl. f. Stoffw., 5, 289, 1910. 
this linking with a nucleinic acid rest." 20 It has been supposed, too, that uric acid by being linked with nucleinic acid is protected to a certain degree from oxidation in the body. ${ }^{21}$ It may be remarked with direct reference to this last statement, that, if Wiechowski's results are to be accepted, there is every reason to doubt whether uric acid is open to oxidation in the human economy; it would therefore have no need of protection by the nucleinic acid to insure its escape from combustion. Then, too, aside from the traces found in the urine, we have not the least basis for supposing that nucleinic acid is actually present in the circulating blood..22 Nor is the prevention of precipitation shown by uric acid in the presence of nucleinic acid to be looked upon as at all remarkable; it is not necessarily indicative of a true acid combination with nucleinic acid. ${ }^{23}$ Such inhibition of precipitation is rather to be referred to the general group of variations of solubility which are manifested by crystalloid substances in the presence of all sorts of colloids

Complex Conditions of Solubility of Uric Acid in Relation to the Uric Acid Diathesis.-Complex phenomena of solubility of this type are to be seriously considered in connection with the uric acid of the circulating blood. The nucleinic acid is not alone important; the general mass of blood proteins are particularly to be thought of. It has been stated that uric acid is much more soluble in serum than in pure water. ${ }^{24}$ In the urine, again, the solubility of the uric acid is largely influenced by the presence of urea and disodium phosphate $\left(\mathrm{Na}_{2} \mathrm{H} . \mathrm{PO}_{4}\right)$, and relation of this to monososodium phosphate $\left(\mathrm{NaH}_{2} \mathrm{PO}_{4}\right) .^{25}$ There is no doubt of the importance of such interrelations, too, in the formation of

${ }^{20}$ O. Minkowski, Die Gicht, in Nothnagel's Handb. d. spez. Pathol., pp. 189, $190,1903$. 1908.

${ }^{21}$ Y. Seo (Minkowski's Clinic, Greifswald), Arch. f. exper. Pathol., 58, 75,

${ }_{22}^{2}$ Th. Brugsch, Zeitschr. f. exper. Pathol., 6, 278, 1909.

${ }^{23}$ A. Schittenhelm, Zeitschr. f, exper. Pathol., \%, 110, 1910.

2 A. E. Taylor, Jour. of Biol. Chem., 1, 177, 1905.

${ }^{25}$ Investigations of Pfeiffer, Rüdel, Ritter, Strauss and others. 
renal and cystic calculi, the "uratic diathesis," as well as in the formation of uric acid deposits in the tissues. (It may be casually added that Virchow, however, long ago expressed doubt of the existence of any close relation between gout and the genesis of urinary concretions; and at the present time there are metabolic pathologists of wide experience, like C. v. Noorden, G. Klemperer and F. Umber, who believe that we are not justified in looking upon nephrolithiasis as the result of uric acid accumulation in the blood or in the tissues, and that it would be better to drop entirely the popular, very comprehensive and very much misused term of "the uric acid diathesis."') ${ }^{26}$ Although the importance of these complex conditions of solubility, as they prevail among colloid and crystalloid substances in the animal juices, may be accepted in relation to the formation of uric acid sediments and concretions, there is no real reason for seeking the explanation of gout in this sphere. We may see one sign of progress in the fact that at the present we have no appreciation of a sharp distinction between "loosely combined" and "fixed" uric acid (Pfeiffer for one tried to bring out such a differentiation by means of filters charged with uric acid, on which gouty urines gave up a part of their uric acid). In our modern conceptions of physico-chemical solution-interrelations there is no longer room for such schematic representations and for different kinds of uric acid fixation. That we know but incompletely the individual physico-chemical factors which determine the "fixedness" of uric acid combination, is quite another matter.

Localization of the Uric Acid Depositions.-The reason for localization of the uric acid deposits in certain positions of predilection as cartilages, joint capsules, tendons, muscles and skin is directly related with the question of the complex conditions of solubility of uric acid.

${ }^{26}$ Literature upon Uratic Diathesis: F. Umber, Lehrbu. d. Ernährung und Stoffwechselkrankheiten, pp. 350-356, 1909; cf. on the contrary Neubauer, Internat. Kongr., Wiesbaden, 1911. 
Probably special importance for the interpretation of the general problem may be attributed to a discovery made in Hofmeister's laboratory ${ }^{2 \pi}$ that when thin sections of cartilage are left for some hours in a solution of sodium urate they will take up uric acid. The degree of concentration of the urate solution is diminished; and at the same time when the sections of cartilage are directly inspected they frequently show white foci and diffuse opacities of uric acid deposits. The great affinity of normal cartilage for uric acid is manifested by the fact that when large amounts are introduced into the peritoneal cavity in rabbits, the acid may often be detected by the murexide reaction in the cartilages although not apparent in other tissues. The accumulation of uric acid in cartilage in states of increase of uric acid in the blood may be explained in the same way. The well-known theory of Ebstein that the dissolved uric acid infiltrating the tissues acts primarily to produce an inflammation and that an antecedent necrosis precedes the deposition of the uric acid is no longer to be accepted in the light of the above outlined discovery. That an excess of purins in the body fluids may produce inflammatory changes is not to be denied; confirmation may be seen in a number of observations, as that of Levinthal, ${ }^{28}$ who, in a personal experiment, injected half a gram of xanthin (dissolved in piperazin) into his cubital vein, and a few days later, after a moderate strain upon the limbs irom dancing, he was suddenly seized with a fairly acute painful attack in one of his knees, attended with some swelling and local heat. Depositions may form in the tissues, however, as shown by numerous observations upon gradually developing tophi exhibiting no inflammatory reactions, entirely independently of any antecedent necrosis.

${ }^{27}$ M. Almagia (Instit. of Physiol. Chem., Strassburg), Hofmeister's Beitr., ヶ 466, 1906.

${ }^{23}$ W. Levinthal (F. v. Mïller's Clinic, Berlin), Zeitschr. f. physiol. Chem, $7 \%, 273,1912$. 
Alkalinity of the Tissues in Relation to Uric Acid Deposit.-It is difficult to decide at present to what extent physical factors, in contrast to chemical factors, are involved in increasing the absorbing power of individual types of tissue for uric acid. We are unquestionably here again dealing with a very complex problem of physical chemistry. It has been stated, for example, that aminoacids tend to. inhibit the absorption of uric acid by cartilage. ${ }^{29}$ But, on the other hand, monourates are separated from uric acid solutions, and in the same way urates deposit in the tissues the more readily, apparently, the higher the proportion of sodium present. Van Loghem ${ }^{30}$ has from this suggested that the predilection of cartilage and connective tissue for uric acid bears some relation to the large amounts of sodium contained by these tissues; and he suggested that the formation of tophi might be restricted by the use of hydrochloric acid or increased by alkalies. It is the same old story! At any rate one can derive this one point from it: The constant effort to favorably influence gout by flooding the body with "curative" alkaline waters is without the least theoretical foundation. "That by the use of certain spring waters gout can be therapeutically influenced," says Umber, ${ }^{31}$ "is attested by a century of practice. But it is practically proven that the essential reason for this fact does not exist in any immediate influence of the inorganic constituents of these waters upon the disturbances of purin-metabolism in gout. The importance of the thorough flushing of the body, in which even Garrod believed the pith of mineral water treatment lies, the regulated life of the patients, their isolation, and, not the least, the intelligent interest of specially trained

${ }^{20}$ Th. Brugsch and J. Citron (F. Kraus's Clinic, Berlin), Zeitschr. f. exper. Pathol.. 5, 401, 1908.

${ }^{80}$ Van Loghem (Amsterdam), Deutsche Arch. f. klin. Med., 85, 416, 1906; Centralbl. f. Stoffw., 190\%, 244; consult also Roberts, His and Paul, Gudzent, E. d'Agostino: Rendic. della Società Cliim. Ital., 2. fasc. 6, 1910.

${ }^{31}$ F. Umber, Lehrbu. d. Ernährung und Stoffwechselkrankheiten, p. 329, 1908. 
physicians in their little and their great complaints,-all this in the methods of a health resort for the gouty is a more important therapeutic factor than the minerals that are contained in the waters."

Attempts to Produce Gout Experimentally.-Research upon the nature of gout would surely be in position to show more rapid progress, were it not that experimental attempts to produce this fault of metabolism have thus far always proved failures. The part taken by uric acid in avian metabolism (in birds the bulk of nitrogen excreted appears as uric acid, and in them the latter is without doubt formed synthetically) is so fundamentally different from its rôle in the economy of man and the mammalia, that it is decidedly difficult to recognize much of importance to the study of gout in the uric acid deposits obtained in the viscera of birds after ligation of the ureters (by Ebstein) or after exclusive meat diet (by Kionka). His has been experimentally able to produce tophi by local injections of relatively insoluble sodium monourate in dogs with coincident administration of alcolol. These coincide in detail with spontaneous gouty nodules, and confirm the view (vide sup.) that urie acid deposits may act as local irritants and cause the surrounding tissue to become the seat of an inflammatory infiltration, and produce a capsule from the granulation tissue thus occasioned. Spontaneous formation of gouty nodules (as by flooding the circulation with urates) has up to the present time not been successfully induced; and this is the real object to be attained.

Among the different factors which favor the development of gont, as is well known, alcoholism, chronic plumbism, and long continued and excessive ingestion of foods rich in purin bodies are the most prominent.

Alcoholism.-The belief in a close causal relation between chronic alcoholism and gout has been fully confirmed by thousands of examples, from the days when the lusty Herr von 
Rodenstein after liquidation of his villages "had the gout in his neck from too many malmseys," down to the present time. We have no knowledge of how alcoholism disturbs the purin metabolism. According to Beebe ${ }^{32}$ it is the exogenous fraction of the purins, according to London ${ }^{33}$ the endogenous as well, which bears the brunt. The latter believes that destruction of cellular nucleins is heightened by the toxic effect of the alcohol. L. Pollak, ${ }^{34}$ in metabolism experiments in the clinic of Friedrich v. Müller, observed a retention and retarded elimination of uric acid in alcoholics, such as we customarily regard as characteristic of the uric acid metabolism of the gouty; which serves to indicate the close relationship existing between alcoholism and gout. Why the excretion is retarded, however, is as much a puzzle in the one case as in the other. If, as we have done before, we speak of an "increased retention effort of the tissues," we are practically throwing aside the humoral gout theories. There is, however, no occasion to pretend either to ourselves or to others that this is the same thing as a real explanation.

Chronic Plumbism.-In cases of chronic lead poisoning Schittenhelm and Brugsch ${ }^{35}$ found the endogenous uric acid reduced markedly; while Preti ${ }^{36}$ found the absolute quantity of excreted purin-base nitrogen above normal in three cases of chronic plumbism. In rabbits in Julius Pohl's laboratory ${ }^{37}$ with chronic lead poisoning there was invariably met an increase in the nitrogen fraction representing the purin group, this often advancing in a striking manner on increasing the intoxication. However, the uric acid manifested no such 1904.

${ }^{32}$ S. P. Beebe (Yale Univ., New Haven), Amer. Jour, of Physiol., 12, 13,

${ }^{33}$ A. Landau, Deutsch. Arch. f. klin. Med., 95, 280, 1909 ; cf. also Jahresber. f. Tierchem., 38, 639, 1908 .

${ }^{24}$ L. Pollak (F. v. Müller's Clinic, Munich), Deutsch. Arch. f. klin. Med., 88, $224,1906$.

${ }^{35}$ A. Schittenhelm and Th. Brugsch, Zeitschr: f. exper. Pathol., 4, 494, 1907.

${ }^{36}$ Preti, Deutsch. Arch. f. klin. Med., 95, 411, 1909.

${ }^{87}$ Rambousek (J. Pohl's Lab., Prague), Zeitschr. f. exper. Pathol., 7, 1910, S. A. 
relative proportions. Here, too, therefore, the subject is open to further study.

Influence of Excessive Meat Diet.-Along with alcoholism and chronic lead poisoning, excessive ingestion of foods rich in purin bodies, particularly meat, plays an important part in the etiology of gout. Some evidence of this is to be observed in the geographical distribution of this fault of metabolism. In Japan, China, Arabia and the tropics, where meat is but little used, the affection is apparently rare. It is not common in southern Europe; in middle Europe it occurs more frequently, but in the countries lying about the North Sea and the Baltic it is very frequently met, in England and Holland being almost endemic. Perhaps the preference which Austrians show for boiled beef, which is generally disliked by the northerners, explains why gout is not very common in Austria, as the purin-rich extractives remain within the meat when it is roasted, but are removed through boiling. For this reason well-boiled meat, provided. the broth is not included, presumably, may be considered as food poor in purins.

Protracted Feeding of Nucleinic Acid to Dogs.-With view of determining the effect of long-continued inundation of the mammalian body with purin, the author's pupil, Hirokawa ${ }^{38}$ has carefully studied under direction the purin metabolism of a dog fed very regularly with additions of nucleinic acid for months. A small dog regularly fed on mixed food was given daily five grams of sodium nucleinate for three months without manifesting any strikingly harmful result and without any loss of weight. However, a marked change in the purin exchange was noted. Whereas in the first part of the experiment out of the total purin- and allantoin-nitrogen the results showed 98.5 per cent. as allantoin and only 1.5 per cent. as purin bases and uric acid together,

${ }^{28}$ W. Hirokawa, Biochem. Zeitschr., 26, 441, 1910; under the direction of O. v. Fürth. 
the uric acid proportion gradually increased until after ten weeks about ten times as much was being excreted as in the first week on nucleinic acid (13 per cent. of the combined purin nitrogen and allantoin nitrogen). Coincident increase of the purin bases was not appreciable. The results show that the metabolism of the animal was influenced by long continued flooding with the products of nucleinic acid cleavage in such a way that the ability of the dog's economy to oxidize uric acid almost completely into allantoin was apparently impaired, and a larger fraction of the former appeared unchanged in excretion. However, there was no change in the transformation of the purin bases into uric acid, only a a minimal amount of the former appearing unchanged first and last.

Radium Therapy of Gout.-Among the newer attempted methods of cure of gout the use of radium for the moment assumes the greatest interest; and it is undesirable to pass it over without at least brief consideration. The basis for its employment was developed in certain experiments of Gudzent, ${ }^{39}$ in the Clinic of W. His, upon the effect of radium emanations upon the solubility of monosodium urate. As previously mentioned Gudzent assumed that the monourate of sodium in the blood may exist in two forms capable of intertransformation by intramolecular rearrangements (tautomeric forms), the lactam- and the lactim-forms, the former of which, instable and the more soluble of the two, tends to cliange into the relatively more insoluble and stable lactim. It is claimed that radium rays are not only capable of inhibiting this conversion but of causing the relatively more insoluble salt to revert to the more soluble form, ${ }^{40}$ and of catabolizing the uric acid in turn

${ }^{\approx}$ F. Gudzent (His's Clinic, Berlin), Med. Klin., 1909, No. 37, p. 1381; Deutsch. med. Wochenschr., 1909, 921; 27th Intern. Kongress, Wiesbaden, 1910, p. 539; Med. Klin., 1910, No. 42; Therapie d. Gegenw., 1910, 529; Zeitschr. f. ärztliche Fortbildung, 8, 198, 1911.

4 Cf. H. Bechhold and J. Ziegler, Berliner klin. Wochenschr., 1910, 712; Biochem. Zeitschr., 20, 189, 1909. 
into more soluble substances, finally into carbonic acid and ammonia. It is said this solvent influence of the radium rays is effective in the living body and that the gouty individual is benefited by this mode of treatment, which it is claimed will destroy existing uric acid deposits in the tissues and reduce the uric acid accumulation in the blood. W. His ${ }^{41}$ regards the beneficial influence of radium upon the manifestations of gout as proved, commending its use especially by inhalation of the rays, but also advising that radiumized water be drunk, radium baths be employed and radium salts injected in the immediate neighborhood of the affected parts. His statements have had many confirmations, but have also called forth contradiction in as many instances. Incidentally, at the last Congress of Internists (Wiesbaden, 1912), the opposing opinions were brought out in sharp contrast. Acceptance of a favorable influence of radium treatment upon the symptoms of the malady aside, the procedure can with difficnlty be interpreted either in the sense of increasing the solubility of the monourate of sodium or of decomposing the uric acid. From exhaustive experiments conducted by E. v. Knaffl-Lenz and W. Wiechorski in the Vienna Pharmacological Institute, ${ }^{42}$ no effect at all from even large amounts of the rays were recognized, either in destruction or in increasing the solubility of monosodium urate. As uric acid is readily oxidized by ozone, it might perhaps be supposed that some such process is involved; but it has been demonstrated that the quantity of ozone produced in the air by the radium preparations is incapable of producing any appreciable decomposition of uric acid. It is not clearly stated under what precise conditions Gudzent's contrary results were obtained. The above-named experimenters state that when an impure alkaline preparation of radium was em-

«1 W. His, Internisten Kongress, 1910 u. 1912 ; Berliner klin. Wochenschr., $1911,197$.

${ }^{42}$ E. v. Knaff-Lenz and W. Wiechowski (H. H. Meyer's Lab., Vienna), Zeitschr. f. physiol. Chem., $\gamma \%, 303,1912$. 
ployed decomposition readily took place and suggest that the alkali given off from the glass container may also be of some import. "If there is no direct influence of the rays upon monourate of sodium," say v. Knaffl-Lenz and Wiechowski, "there may possibly be an activation of a uric acid oxidase existing in the human tissues in mere traces to explain the favorable effect of the emanation upon gout. . . . Such an influence of the rays, however, seems improbable to us, because in almost all experiments in human metabolism the amount of uric acid excreted has been found increased. ${ }^{43}$ In trying to explain the curative influence of radium rays in gout there is still left the supposition that the elimination of uric acid through the kidneys is made easier by the effect of the rays. Whether this is to be thought of as a direct action on the process of secretion of the uric acid, or whether it is an indirect one, as His and his pupils hold, facilitating the excretion of the uric acid by inhibiting inflammation of the organs, is a matter in which further experimentation in appropriate lines is to be desired." Since, according to Knaffl-Lenz's observations on the effect of large amounts of radium emanations, there may not only be an influence exerted upon the respiratory apparatus but upon the central nervous system as well, caution is always requisite in the radium treatment of gout. ${ }^{44}$ Recent investigations in Neuberg's laboratory have given results in accord with those of Knaffl-Lenz and Wiechowski, showing that radium rays have no influence upon the solubility of sodium monourate or upon its decomposition into $\mathrm{CO}_{2}$ and ammonia. ${ }^{45}$

${ }^{43} \mathrm{H}$. Mandel (Radium in Biol., 1, 163, 1911, cited in Centralbl. f. d. ges. Biol., 12, No. 2879) found the excretion curve of uric acid absolutely uninfluenced in cases of gout which manifested distinct improvement from the effect of radium rays. No 12.

${ }^{4}$ E. v. Knaffl-Lenz (H. H. Meyer's Lab.), Wiener klin. Wochenschr., 25,

${ }^{45}$ P. Lazarus, 29th Kongr. f. innere Med., Wieshaden, Apr. 17, 1912; J. Kerb and P. Lazarus (Chem. Dept., Physiol. Instit. of the Berlin Agric. High School), Biochem. Zeitschr., 42, 82, 1912. 
Medicinal Treatment of Gout.-So far as the medicinal treatment of gout ${ }^{46}$ is concerned, one must confess frankly that there is little satisfactory to be said. Colchicin, the immemorially lauded poison of meadow-saffron, still has its adherents, but no one has ever been able to explain its mode of action. It is said that the much used salicylic acid and its many related substances increase uric acid elimination; but whether its beneficial (frequently questioned) influence on gout is due to this or simply to some "antirheumatic" effect, is unknown. Quinic acid (hexalydrotetraoxybenzoic acid) with its numerous derivatives may, perhaps, be named in the same class; but the hypotheses upon which its therapeutic use was based were unfounded. (It was supposed that quinic acid, which is transformed in the body into benzoic acid and undergoes a hippuric acid synthesis, prevents glycocoll from entering into synthetic production of uric acid; but it is now known that synthetic formation of uric acid from glycocoll does not occur in mammalia.)

It is hard to say what there may be in the idea that the quinolincarboxylic acids increase uric acid elimination ${ }^{4 i}$; the very favorable effects attributed to phenylquinolincarboxylic acid (atophan) have recently been given considerable prominence..$^{48}$ Efforts to increase the solubility of uric acid in the blood by administration of piperazin, substances producing formaldehyde by cleavage like hexamethylentetramine (urotropin), meleinic acids, urea, alkalies and alkaline waters, have as little justification in theory as in practice. A recent conclusion goes so far (vide supra) as to declare that alkalies are not only useless in gout, but are actually

${ }^{46}$ Literature upon the Therapy of Gout: O. Minkowski, Die Gicht, pp. 299322, Vienna, 1903.

${ }^{47}$ A. Nicolaier and M. Dohrn, Deutsch. Arch. f. klin. Med., 93, 331, 1908.

4 IV. Weintraud, Therapie d. Gegenwart, 1911, 97; R. Feulgen, Inaug. Dissert., Kiel, 1912, Centralbl. f. d. ges. Biol., 1912, No. 2S40; B. Bauch (IVeintraud's Clinic, Wiesbaden), Arch. f. Verdauungskr., 17, Ergänz. Heft, 186, 1911; E. Frank, in collaboration with Przedborski (Minkowski's Clinic, Breslau), Arch. f. exper. Pathol., 68, 349. 
harmful, and that it is possible to obtain beneficial results from long continued use of hydrochloric acid, which is supposed to alter the absorption capacity of the blood and tissues for the uric acid. ${ }^{49}$ Altogether, F. Umber ${ }^{50}$ comes to the rather unedifying conclusion "that all the medicinal methods introduced with view of increasing uric acid elimination, of determining solution of the uratic deposits or of limiting the formation of uric acid, are entirely worthless. To the present time we have not known of any means of influencing the gouty metabolism, and the good results which we are getting as our knowledge advances are clearly due to the matter of diet." Whether radium or atophan will make any difference in the force of such a statement can only be awaited with patience.

The Diet in Gout.-The present view of the general subject is somewhat as follows: The true nature of gout is still unknown; but we at least know that the affection is in some way due to an accumulation of uric acid in the blood and that increase of this accumulation is an unfavorable feature. Therefore, in the dietetic management one may proceed on the idea that the ingestion of substances which form uric acid are to be limited as far as possible. Here belong particularly the extractives of meat, as well as those tissues which are highly nucleated and therefore contain considerable nucleinic acid, like thymus, spleen, liver, lungs and kidneys. These latter may be forbidden with propriety, as sufficient instances are known where a gouty patient has suffered an acute paroxysm directly traceable to a meal of thymus (bries). Meat should be eaten only when well boiled, not roasted. Meat broths and "whole" soups, as well as all use of meat extract, are to be prohibited. In the proscription list coffee and tea should also be placed because of the methylpurins they contain, together with alcohol in all

${ }^{40}$ Falkenstein, Berl. klin. Wochenschr., 1906, 22s; J. J. Schmidt, Münchener med. Wochenschr., 1911, No. 83, 1764; consult also van Loghem, 1. c.

${ }^{50}$ F. Umber, Lehrbu. d. Ernährung und der Stoffwechselkr., p. 333, 1909. 
forms. While the harmful effects of the latter upon gout are not understood in a theoretical way, that they are real is proved from a practical standpoint. Finally, thorough flushing of the body with water seems a rational measure. These provisions form the theoretical fundamentals of diet in gout, as the author understands them. For the rest he would refer to the methods of practicing physicians as they appear in numerous monographs. It would be impolitic and essentially wrong to simply ignore whatever judicious objective observers have found appropriate after decades of study merely because no theoretical explanation therefor has been found. It should never be forgotten that the observations of the practitioner may be true and the theories may be false, and that a judicious natural scientist generally values the former more than he does the latter. But unfortunately objective observation, especially in the treatment of chronic internal affections, is endless and difficult, and for that very reason this has been and will be at all times and among all people the favorite field for both scientific and unscientific charlatanry. 


\section{CHAPTER IX}

\section{DIGESTION OF CARBOHYDRATES-BLOOD SUGAR- DIASTASIC FERMENTS}

\section{CARBOHYDRATE DIGESTION}

Turning away for a time from the processes of metabolism which concern the proteins and nucleins, our path leads into a new field stretching out interminably before us - the field of carbohydrate metabolism. Even though the road be long, there comes a feeling of relief as we plod the way, a feeling not unlike that the mountain climber experiences as he reaches the tree-line on a heated day after toiling painfully up through the high forest. Let the trail before him be grievous as it will, he trudges blithely along, with freer vision, no longer shut in on every side by the dusk of the thickset woods. It really is a dusk which surrounds us in the domain of protein metabolism. How could it be otherwise? The chemical nature of the proteins is so unknown, that in tracing their destinies in the depth of the living body there can be expected no wealth of light. In taking up the carbohydrates we at least are dealing with a chemically well-defined material.

We may at once undertake to follow the carbohydrates in their transit through the body, beginning as in case of the proteins with their fate in the digestive tract.

Ptyalin.-As is well known, the food in man and many of the animals is at once mixed in the mouth with a diastasic (carbohydrate splitting) secretion, the saliva. Because of the fact that the hydrochloric acid of the stomach inhibits the glycogenic action of ptyalin even when in relatively low concentration and destroys the ferment entirely when in higher concentration the opinion of many has been and is now that ptyalin action is of comparatively little importance and is quickly terminated when the food arrives in the stomach. As a matter of fact, however, this cannot be the case. 
It should be kept in mind that when any considerable amount of food is ingested only that first swallowed comes into direct contact with the gastric mucous membrane. The acidity need by no means prevail in the interior of the food mass, and the diastasic action of the saliva incorporated in the mass may continue for some time in the performance of its work. ${ }^{1}$

Carbohydrate Digestion in the Stomach.-There can be no doubt of the fact that there is a carbohydrate cleavage beginning in the stomach itself, particularly as hydrochloric acid alone, without the aid of enzymes, especially at the incubator temperature of the stomach of the warm-blooded animal, is effective in this sense. According to the investigations of the Ellenberger school ${ }^{2}$ and others it may be accepted that many mammals, as the hog, produce a special gastric diastase. And in the dog, the canine saliva being devoid of diastase, it is said the stomach is capable of forming a diastasic ferment, one which is active even in strongly acid reaction. Others, it is true, have reached the conclusion that the carbohydrates generally undergo no appreciable alterations in the stomach of the dog, and that a slight degree of cleavage met there may be explained by the influence of the hydrochloric acid of the gastric juice, so that to them the assumption of an amylolytic or inverting ferment seems unnecessary. ${ }^{3}$

Carbohydrate Digestion in the Intestine.-However, it may be said that both the cleavage and the resorption of the carbohydrates for the most part reach their height primarily in the intestine, where they are subjected principally to the powerful influence of the pancreatic diastase, but also to other enzymes as well (invertin, maltase, lactase). Starch unquestionably undergoes a series of catabolic

${ }^{1}$ O. Cohnheim, Physiol. d. Verd. u. Ernährung, p. 142, 1908.

${ }^{2}$ F. Bengla and G. Haane (Ellenberger Lab.), Pflüger's Arch., 106, 267, 286, 1904; consult there and also O. Cohnheim (1. c.) for Literature.

${ }^{3}$ London and his associates, Zeitschr. f. physiol. Chemie., 56, 1908. 
stages in the intestine. Whether this is the proper time to replace the old, much-discussed schema

Starch Erythro-dextrine Achroodextrine $\longrightarrow$ Maltose $\longrightarrow$ Glucose

with a more modern one need not be further considered here.

Role of the Pancreas in the Production of Carbohydratesplitting Ferments.-As the lion's share of the normal cleavage of carbohydrates in the intestines is referable, as above said, to the pancreatic diastase, it is inconceivable without further knowledge how it happens that in the dog, even after exclusion of the pancreatic secretion ${ }^{4}$ by ligation of the pancreatic ducts, as in the experiments of Rosenberg, nine-tenths of the starchy materials may be resorbed. It is fundamentally all the more remarkable because in the dog we are practically unable to recognize any diastasic infuence in the saliva, the bile and the intestinal juice, at least in normal conditions. If the pancreas be extirpated the resorption of carbohydrate is apparently very much disturbed (although Minkowski and Abelmann even in this state found their dogs capable of resorbing more than a half of the amylaceous material fed). Whether we are in fact constrained to ascribe to the pancreas, in addition to its known function of internal secretion, another specialized puzzling role in resorption, as Lombroso belives, ${ }^{5}$ is to the author's way of thinking rather doubtful. It should be kept in mind that total excision of the pancreas is a very severe interference, which "mixes up," so to say, the whole economy. Why should it be expected to leave the carbohydrate resorption completely without disturbance?

Pawlow has insisted, it may be remembered, upon his doctrine of the adaptation of the digestive fluids to the particular quality of food ingested according to the requirements. Weinland ${ }^{6}$ and others ${ }^{7}$ have concluded, in special

- Cf. inclusive Literature: J. Munk, Ergebn. d. Physiol., 1, 308, 1902.

${ }^{5}$ W. Lombroso (Turin), Hofmeister's Beitr., 8, 51, 1906. 
reference to the milk-sugar splitting function of the pancreas, that it is greatly increased or primarily induced by milk diet in dogs and newly born human beings; but other investigations failed to adduce any confirmation of such statements. ${ }^{8}$

In view of the fact (to be discussed later) that the pancreatic fat-splitting ferment is very materially increased in its effectiveness by the access of bile, it is not without interest that the bile also favorably influences the digestion of starch, probably because the bile salts reduce the surface tension of the starch paste. ${ }^{9}$

Fate of the Disaccharides.-In the resorption processes in the intestine it is particularly important to note that the intestinal wall is strikingly less permeable not only for the high-molecular colloids, but also for the disaccharides than for the monosaccharides. It is correct to say that the bowelwall apparently allows only those sugars to pass readily which can easily be used by the tissue cells. ${ }^{10}$ The cells are not adapted to deal with the majority of disaccharides, as may be recognized in the fact that if cane-sugar or lactose be introduced parenterally, that is, subentaneously or intravenously, they are simply excreted without change. Although this is not true for maltose there is a special reason, in that the blood contains a ferment, "maltase," which is capable of splitting the parenterally introduced sugar, after it has entered the circulation, into glucose. But when we consider the fact that a man can take up from the intestine large amounts of cane sugar (three hundred grams and more) without any appearing in the urine, it is obvious that double

${ }^{6}$ E. Weinland (Munich), Zeitschr. f. Biol., 38, 607, 1899; 40, 386, 1900.

${ }^{7}$ F. A. Bainbridge (Univ. College, London), Jour. of Physiol., 31, 98, 1905; P. Sioto (Fano's Lab.), Arch d. Fisiol., 4, 116, 1907; O. Martinelli (Bologna), Centralbl. f. Stoffwechselkr., 8, 481, 1907.

${ }^{8}$ R. Aders Plimmer, Jour. of Physiol., 34, 93, 1906; 35, 20, 1906-07; J. Ibrahim and L. Kaumheimer, Zeitschr. f. physiol. Chem., 62, 1909.

- G. Buglia (Bottazzi's Lab., Naples), Biochem. Zeitschr., 25, 239, 1910.

${ }^{10}$ Cf. E. H. Starling, Handb. d. Biochem., 3", 241, 242, 1909. 
sugars generally and certainly the high-molecular carbohydrates undergo complete cleavage before they gain access to the blood-stream. ${ }^{11}$

This rule is not invalidated by the fact that after a diet rich in carbohydrates, as pointed out by v. Mering, Otto and others, dextrin-like carbohydrates may gain access in the portal blood, ${ }^{12}$ and that they are recognizable in small amount in urine normally, but to a much greater extent in diabetes. ${ }^{13}$

Dilution of a Sugar Solution in the Intestine.-According to the investigations of London carbohydrate absorption in the stomach is of little importance. If a concentrated sugar solution be introduced into the small intestine sugar is absorbed, and at the same time water is given off into the intestinal lumen until the degree of sugar concentration in the latter is reduced to about 6 or 8 per cent., after which at this dilution the resorption proceeds rapidly. ${ }^{14}$ From researches published from Röhmann's laboratory, the resorption of glucose from the intestine reaches its relative maximum at a concentration corresponding with the osmotic pressure of the blood serum. ${ }^{15}$

The author would next pass to the consideration of one of the problems relating to the fate of carbohydrates in the digestive tract, which is at present of special interest to him, the problem of digestion of cellulose.

Disappearance of Coarse Vegetable Fibres from the Digestive Tract.- In view of the great quantities of cellulose which vegetarians ingest with the food the question naturally presents itself as to whether and how this can physiologically be made use of in the body. Even the early investigations of

\footnotetext{
${ }^{11}$ H. Bierry, Biochem. Zeitschr., 4f, 402, 405, 426, 1912.

${ }^{12}$ J. Munk, Ergebn. d. Physiol., 1, 306, 1902.

${ }^{13} \mathrm{~K}$. v. Alfthan, Ueber dextrinartige Substanzen im diabetischen Harne, Helsingfors, 1904.

${ }^{14}$ E. S. London and W. W. Polowzowa, Zeitschr. f. physiol. Chem., 56, 513, $1908 ; 5 \%, 529,1908$.

${ }^{15}$ K. Omi (Röhmann's Lab., Breslau), Pflïger's Arch., 126, 428, 1909.
} 
Haubner, Henneberg and Stohmann, v. Hofmeister, Weiske, Knieriem and others left no doubt that in vegetarians a portion of the ingested "coarse vegetable fibre" (a mixture of celluloses, hemicelluloses, pentosans, lignin and similar substances remaining after exhausting vegetable food with dilute acids, caustic soda, alcohol and ether) actually disappears in the intestine. ${ }^{16}$ We are not dealing here with a subtile matter, but on the contrary with decidedly gross relations in that the fraction of the ingested cellulose which vanishes within the digestive tract and fails to appear in the excrement in the herbivorous domestic animals is estimated to amount to from 30 up to 70 per cent. The degree to which it can be used in the body depends upon the character of the cellulose. That of hay and still more that of tender young plants is more readily handled than, for example, is that of the bran of oat-seed and of barley, which is practically or entirely indigestible. Surprisingly, birds, even the typical graminivorous species, seem entirely unable to digest cellulose; W. Biedermann ${ }^{17}$ believes this is perhaps explicable by the thought that birds which live upon vegetable food generally possess a powerfully developed muscular stomach, by which they are mechanically able to break up into fine bits the seeds they swallow without the need of chemical solvents for the cellulose of the hulls. The ability to digest cellulose is entirely absent from the carnivorous animal, especially the dog; this may be looked upon as settled by the studies of Scheunert and others after much controversy. ${ }^{18}$

Man is apparently to be classed among the vegetarian animals from his position in relation to cellulose. It is said that about 50 per cent. of the cellulose and hemi-

${ }^{18}$ Literature upon Cellulose Digestion: A Scheunert, Handb. d. Biochem., 3", 134-138, 1909; W. Biedermann, Handb. d. vergleich. Physiol., 2' 1314-1344, 1911.

${ }^{17}$ W. Biedermann, 1. c., p. 1314.

${ }^{19}$ A. Scheunert and E. Lötsch, Berl. tierärztl. Wochenschr., 1909, No. 47; Zeitschr. f. physiol. Chem., 65, 219, 1910; Biochem. Zeitschr., 20, 10, 1910; H. Lohrisch, Zeitschr. f. physiol. Chem., 69, 143, 1910; H. v. Hösslin (Med. Clinic, Halle), Zeitschr. f. Biol., 54, 395, 1910. 
cellulose ingested in vegetables and fruits is digested in the human canal, in habitual constipation as much as 80 per cent. The proposal to use it as a substitute for the ordinary, readily-resorbed carbohydrates in cases of severe diabetes is related to the assumption (which, as we will see later, is not yet satisfactorily proven) that cellulose undergoes a cleavage into sugars in full analogy to starch, but much more slowly than the latter. ${ }^{19}$

Determination of Cellulose.-The differences of opinion upon the availability of cellulose in the body are partly to be ascribed to the unsatisfactoriness of the methods used for its quantitative estimation. The commonly used method of Lange is based upon the unconfirmed proposition that cellulose is not acted upon by caustic alkali. The practice of Simon and Lohrisch, in which the material under examination is heated with 50 per cent. solution of caustic soda and then decolorized with peroxide of hydrogen is attended by great losses, according to Scheunert. ${ }^{20}$ The latter author recommends that the substance to be examined be first heated with a highly concentrated sodium hydrate solution and the undissolved residue washed well on a hardened filter, and finally weighed. The ash of the cellulose thus obtained must eventually be taken into consideration.

Cytases.-How is the digestion of cellulose accomplished? One naturally at once assumes that the organism of the vegetarian can furnish ferments especially adapted for the cleavage of cellulose just as it produces ferments for the splitting of protein, sugar and fat. And for the lower forms of animals an experimental foundation has been found for this assumption. The brilliant researches of Biedermann ${ }^{21}$

${ }^{19}$ H. Lohrisch (Med. Clinic, Halle), Zeitschr. f. exper. Pathol., 5, 478, 1909 ; F. Moeller (Med. Clinic, Halle), Inaug. Dissert., Halle, 1911, and Intern. Beitr. z. Pathol. u. Therap. d. Ernährungsstörungen, 1, 325, 1910; F. Schilling, Arch. f. Verdauungskr., 16, 720, 1910; W. Biedermann, Handb. d. vergl. Physiol., 2', $1315,1911$.

${ }^{20}$ A. Scheunert, Handb. d. biochem. Arbeitsmeth., 3, 277-280, 1910; W. Grimmer and A. Scheunert, Berlin. tierärztl. Wochenschr., 1910, No. 7.

${ }^{21} \mathrm{~W}$. Biedermann and P. Moritz, Pflüger's Arch., 73, 219, 1898. 
have established the fact that the hepatic secretion of certain molluses and crustaceans contains a very effective cellulosesolving ferment, a "cytase." If, for instance, the liver secretion of a Weinberg snail is allowed to act on a thin section of the starchy endosperm of a grain of wheat it will be apparent that the cell membranes are rapidly dissolved even before the enclosed starch granules are visibly affected. The energy with which the gastric secretion of the snail dissolves the thick and very resistive cell walls of date seeds, ivory nuts or coffee-beans is still more striking. It has been ascertained, moreover, that the various celluloses and hemicelluloses are broken down into the same cleavage products (glucose, mannose, galactose, pentoses, etc.) by the action of cytase, as occur from the cleavage from boiling with mineral acids. There is, therefore, a real hydrolytic cleavage in operation. The statements of Biedermann have been fully confirmed by a series of control tests, ${ }^{22}$ especially by French author's. ${ }^{23}$

The expectation that an analogous ferment might be found in the intestine of vegetable eating animals has not been realized. The mammalian intestinal contents, carefully sterilized by being passed through a Berkefeld or similar filter, has always been found inactive for cellulose. ${ }^{24}$ If the cellulose be protected by the addition of sugar which many bacteria, particularly anaërobic forms, prefer as their source of energy above any other material, the cellulose does not undergo cleavage,-a result which would scarcely be expected if we were actually dealing with a hydrolytic cleavage from cytases. ${ }^{25}$

${ }^{22}$ E. Müller, Pflüger's Arch., 83, 619, 1901.

$\approx$ H. Bierry, J. Giaja, M. Pacaut, G. Seillère and others in C. R. Soc. de Biol.; H. Bierry and J. Giaja (Sorbonne, Paris), Biochem, Zeitschr., 40, 370, 1912.

${ }^{24}$ A. Scheunert, Zeitschr. f. physiol. Chem., 48, 9, 1906; and the experiments of Ellenberger, V. Hofmeister, Holdefleiss and H. T. Brown, eited by Scheunert in Handb. d. Biochem., 3" 135, 1909.

${ }^{25}$ H. v. Hösslin and E. J. Lesser (Physiol. Inst. and Med. Clinic, Halle), Zeitschr. f. Biol., 6: $, 47,1910$. 
Part Taken in Digestion by Enzymes Contained in the Food.-A number of years ago Ellenberger ${ }^{26}$ showed that enzymes contained in vegetable food itself (especially those capable of reducing sugars and proteolytic enzymes) may become active when the food is in course of digestion, and may aid the digestive juices contributed by the animal body. It was thought this was especially true of the cytases of the food, ${ }^{27}$ although apparently this has proved incorrect. The fact that in autolysis of wheat seeds no diminution is manifest in the cellulose may be taken to indicate, as Scheunert believes, ${ }^{28}$ that these vegetable cytases are of no practical importance in the digestion of cellulose.

Importance of Symbiotic Microörganisms.-There is nothing left, therefore, but to accept the view that the digestion of cellulose is effected by the microörganisms of the digestive tract. Reference has previously been made (Vol. I of this series, p. 40, Chemistry of the Tissues) to the biological importance of the enormous quantities of minute organisms inhabiting the intestine. "It is of the greatest interest, and, in my own opinion, scarcely sufficiently emphasized," says W. Biedermann, ${ }^{29}$ "that we are here dealing with a typical instance of symbiosis, in which foreign microörganisms, originating from the external world, by their vital processes not only facilitate and promote the thorough utilization of ingested foodstuffs, but actually are more capable of effecting this result than any other agents."

Marsh-gas Fermentation.-What do we actually know of the mechanism of this process of utilization? In the first place marsh-gas fermentation (cleared up especially by the studies of Popoff, Zuntz, Hoppe-Seyler, Tappeiner and Omeliansky) should be mentioned, a process which the cellu-

${ }^{26}$ W. Ellenberger, Skandin. Arch. f. Physiol., 18, 306, 1906; and earlier works.

${ }^{27}$ P. Bergmann (I. Bang's Lab., Lund), Skandin. Arch. f. Physiol., 18, $119,1906$.

${ }^{28}$ A. Scheunert and W. Grimmer, Zeitschr. f. physiol. Chem., 48, 27, 1906.

${ }^{29}$ W. Biedermann, Handb. d. vergl. Physiol., 2' 1330, 1911. 
lose undergoes in the intestine and in which it is broken down into $\mathrm{CH}_{4}, \mathrm{CO}_{2}$ and volatile fatty acids (acetic acid, isobutyric acid, valerianic acid). Hitherto marsh-gas fermentation of cellulose has been usually regarded as about equalled by its hydrogen fermentation. From recent investigations, emanating from the laboratory of N. Zuntz ${ }^{39}$ (in which the gases of fermentation were obtained directly by puncture from the digestive apparatus of a goat, in which the paunch was sutured into a wound of the abdominal wall) it is apparent, however, that the hydrogen of the total fermentation gases never amounts to more than 10 per cent. of the methane found with it. Under normal circumstances it would appear that the $\mathrm{CH}_{4}$ fermentation preponderates to a marked degree, at least as long as the reaction of the fermenting mixture is acid. A simple chemical formulation of this fermentation process is at the present out of the range of possibility. The part of the tract in which food rich in cellulose is principally broken up is in ruminants in the proventricle (paunch); in other herbivora with single-chambered stomach, as the horse and rabbit, an analogous rôle is to be assigned probably to the highly developed cxcum in handling cellulose. $^{31}$ In man the colon seems to be the part concerned in cellulose digestion. ${ }^{33}$

Food Value of Cellulose.-This brings us to the main point at issue-has cellulose or its fermentation products a real value as a nutrient? ${ }^{33}$ A number of physiologists especially interested in metabolism have absolutely denied this view, as Weiske, who experimented upon a sheep, and E. Wolff, who worked on a horse; while others, as Knieriem, Kellner, ${ }^{34}$ and recently Ellenberger and Scheunert, take the

${ }^{30}$ J. Markoff (N. Zuntz's Lab., Berlin), Biochem. Zeitschr., 3', 211, 1911.

${ }^{3}$ N. Zuntz, Verh. d. Berlin. physiol. Ges., March 10, 1905; Centralbl, f. Physiol., 19, 581, 1905; W. Ustjanzew (Zuntz'z Lab.), Biochem. Zeitschr., ', $154,1907$.

${ }^{82}$ F. Schilling, Arch. f. Verdauungskr., 16, 720, 1910.

${ }^{33}$ Cf. W. Biedermann, Handb. d. vergl. Physiol., p. 1336, 1911.

${ }^{34}$ O. Kellner, Die Ernährung d. landwirtschaftl. Nutztiere, Berlin, Parey, 1906. 
position that cellulose, especially if no other more easily utilizable foods are readily available, may be drawn on as a food, and that its nutritive value is to be ascribed as equivalent to that of starch under proper circumstances. ${ }^{35}$

How are we to interpret the situation? Apart from the fact that cellulose fermentation extracorporeally (by inoculating a suspension of cellulose in meat extract with a bit of intestinal contents) proceeds only very slowly, while in the animal body large amounts of cellulose disappear relatively quickly, in its fermentation there arise products (like methane, acetic and butyric acids) which either camnot be handled at all or only with considerable difficulty by the economy. ${ }^{36}$ Here is an open break in our knowledge. In case cellulose really has an important value as a food (although this does not seem so thoroughly determined as to make further investigation undesirable) there must be hidden back of the method of its utilization some process of which we are entirely in the dark.

Certain recent investigations by Pringsheim ${ }^{37}$ are probably of importance in this connection. If the full fermentative power by cellulose-splitting microörganisms, which normally produce only methane, hydrogen, carbonic acid, lactic acid and the lower fatty acids, be inhibited by means of antiseptics, or (in case of thermophilic microörganisms) by reduction of temperature, one may without difficulty find in the cultures in the course of a few days glucose and cellobiose (a disaccharid). Then, too, it must be remembered that lactic acid is also readily oxydized by the body and may be utilized by it.

Importance of Infusoria in Cellulose Digestion.-Perhaps, too, the very reasonable hypothesis suggested by

${ }^{a s}$ W. Ellenberger and A. Scheunert, Lehrb. d. vergl. Physiol. d. Haussäugetiere, p. 354, Berlin, Parey, 1910.

${ }^{36}$ Cf. S. Fränkel, Dynamische Biochem., p. 37, et seq., 1911.

${ }^{87}$ H. Pringsheim (Chem. Instit., Berlin), Zeitschr. f. physiol. Chem., 78, 266, 1912. 
Eberlein may afford some aid in solving the puzzle. In the digestive tract of vegetarian animals, as in the proventricle of ruminants, besides bacteria there are always great numbers of infusoria of different kinds which have been introduced with the hay and grasses, which increase there tremendously and may possibly be of importance in the normal process of cellulose digestion. We cannot overlook the possibility that these microörganisms may relieve herbivorous animals of part of the labor of digestion by transforming the cellulose into sugar by means of cytases for their own needs and utilizing it for building up their own corporeal structure; then later on when they die and are in turn digested, the material they have assimilated may indirectly come to be of use to the host animal. The proof of this suggestion is somewhat difficult because thus far the parasites of the stomach of ruminants have apparently never been artificially cultivated, although this should not be very difficult of accomplishment. ${ }^{38}$

\section{BLOOD SUGAR}

In continuation of the study of the passage of the carbohydrates through the living organism the next question to be considered is that of the form in which the sugar, when resorbed from the intestine, circulates in the blood.

Technio of Estimating the Sugar in the Blood.-Progress in the problem of blood sugar depends upon our ability to recover the minute amounts of the sugar unchanged from the great quantities of albumenoid blood colloids in which it may be said to be buried. The technic of analysis of hæmic sugar ${ }^{39}$ is therefore closely connected with processes of removal of albumin. An important and very welcome improvement in this connection is the method proposed by

${ }^{38}$ R. Eberlein, Zeitschr. f. wissensch. Zoöl., 49, 233, 1895; A. Scheunert, Berlin. tierärztl. Wochenschr., 1909, No. 45; E. Liebetanz, Arch. f. Protistenk., 19, 19, 1910; W. Biedermann, Handb. d. vergl. Physiol., 2' pp. 1337-1344, 1911.

${ }^{29}$ Cf. O. Schumann and C. Hegler, Mitt. a. d. Hamburger Staatskrankenanstalten, 12, 429, 1911 ; cited in Centralbl. f. d. ges. Biol., 1911, No. 1773. 
Michaelis and Rona for the removal of albumin by shaking with a colloidal iron solution, based on the physical-chemical principle that two colloids of different content will precipitate each other ${ }^{40}$; (liquor ferri oxydati dialysati is not inappropriate for the purpose). The same principle is employed by Möckel and Frank ${ }^{41}$ in their method of estimation of sugar in the blood. Ivar Bang and his collaborators ${ }^{42}$ remove the albumin with alcohol, and get rid of the protein residue by shaking with blood charcoal in the presence of hydrochloric acid. The older approved methods of removing albumin by precipitation by mercuric chloride and mercuric nitrate or phosphotungstic acid are in comparison unquestionably valuable methods ${ }^{43}$; the author confesses he could not well dispense with them. When the albumin has been separated, there is no further difficulty in the actual estimation of the sugar in the highly concentrated fluid by some one of the reduction methods, or by polarization or fermentation in the usual way. Comparison of these procedures show that the old Fehling's method and the reduction methods of Bertrand and Kumagawa-Suto give practically the same results, while the hydroxylamine method of Bang yields higher figures. ${ }^{44}$ Tachau has proposed a modification of Knapp's method, consisting of adding excess of cyanide of mercury, separating the reduced mercury, then precipitating the mercury which remains in solution and weighing it. ${ }^{45}$ Attempts have also been made to use various color re-

${ }^{40}$ Cf. P. Rona and L. Michaelis, Biochem. Zeitschr., 16, 60, 1909.

${ }^{41} \mathrm{~K}$. Möckel and E. Frank (Wiesbaden), Zeitsclır. f. physiol. Chem., 65, 323,$1910 ; 69,85,1910$.

${ }^{42}$ I. Bang, H. Lyttkens and J. Sandgren (Lund), Zeitschr. f. physiol. Chem., $65,497,1910$.

${ }^{48}$ B. Oppler, Zeitschr. f. physiol. Chem., 64, 393, 1910; J. J. R. Macleod, Jour. of Biol. Chem., 5, 443, 1909; H. Bierry and Portier, C. R. Soc. de Biol., $66,577,1909$.

${ }^{44}$ Cf. I. Bang, Biochem. Zeitschr., 7, 327, 1908; D. Takahaschi, Biochem. Zeitschr., 37, 30, 1911.

${ }^{45}$ H. Tachau (Schwenkenbecher's Clinic and Embden's Lab., Frankfurt a. M.), Deutsch. Arch. f. klin. Med., 102, 597, 1911. 
actions peculiar to the carbohydrates in colorimetric estimation of the blood sugar. Wacker has elaborated a method ${ }^{46}$ which utilizes a sensitive red color reaction given by p-phenylhydrazinsulphonic acid with carbohydrates in presence of alkali (also with a number of alcohols and aldehydes.) By comparing the red color with a color seale worked out from a standard sugar solution the method is said to successfully differentiate as small amounts as 0.05 $\mathrm{mg}$. of glucose and too requires only small quantities of blood (about 10 to 15 drops). In view of certain inherent sources of error ${ }^{47}$, the method is of doubtful availability.

Existence of Free Sugar in the Blood.-It has been frequently asked whether the blood sugar is present in the blood free or in colloidal combination, as many authors have concluded from a variety of physiological and analytical observations (particularly from the fact that sugar, which diffuses readily, does not normally pass through the renal filter). Primarily F. Schenk, in connection with his pioneer work on the sugar of the blood, concluded because of its diffusibility that the sugar is not combined in any way with albuminoid substances, but that it exists free in the blood. Further observations in the same line have been published by Arthus, and, too, by Asher, ${ }^{48}$ who has been able to prove that diffusion of sugar takes place when, instead of water, a like sample of blood, but previously freed from sugar by fermentation, is used as the outer fluid. Finally, Michaelis and Rona ${ }^{49}$ have shown in detail how the sugar proportions in an isotonic salt solution may be prepared so that in

${ }^{46}$ L. Wacker (Würzburg), Zeitschr. f. physiol. Chem., 6\%, 197, 1910; L. Wacker and F. Poly, Deutsch. Arch. f. klin. Med., 100, 567, 1910; 102, 597, 1911.

${ }^{47}$ Forschbach and Severin (Minkowski's Clinic, Breslau), Centralbl. f. Stoffwechselkr., 6, 54, 1911.

${ }^{48}$ L. Asher and R. Rosenfeld (Berne), Biochem. Zeitschr., 8, 351-358, 1907; consult therein Literature; consult also the objections of E. Pflüger, Pflüger's Arch., 117, 217, 1907.

${ }^{49} \mathrm{~L}$. Michaelis and P. Rona, Biochem. Zeitschr., 1', 476, 1908, and earlier contributions. 
dialysis against blood, sugar will not enter the blood or diffuse from it; and in the author's opinion have, by this "method of osmotic compensation," furnished the final proof that the sugar exists free in the blood or at least in a condition to become free spontaneously.

"Sucre Immédiat" and "Sucre Virtuel."-A second question, however, presents itself: whether we may assume that the total amount of sugar in the blood is in free form. From this point of view the writer regards the results of Lépine and Boulud, ${ }^{50}$ after a long series of careful studies, as apropos. These authors differentiate in the blood between "sucre immédiat" and "sucre virtuel." The first is determined by catching the blood directly in an acid solution of mercuric nitrate, filtering, pressing the blood cake dry and determining the sugar in the collected filtrate after separation of the mercury. The virtual sugar, supposed to be combined in the blood as glucosides, is determined from the increase of reduction power observed in the blood after keeping it for an hour in the incubator with added invertin or emulsin before estimating the sugar. Apparently, however, the conversion of the virtual sugar into the determinable form will take place spontaneously if it be allowed to stand for a quarter of an hour; and it has been proposed to always allow fifteen minutes to elapse after withdrawal of the blood before beginning the sugar estimation. $^{51}$ It is obvious from this that in the above noted diffusion experiments the virtual sugar must in reality appear as free sugar.

Does the Blood Contain Other Carbohydrates in Addition to Glucose? - It may, therefore, be asked what significance is to be ascribed to the "sucre virtuel"? This is certainly not a simple matter. The French anthors, for example, continue to speak of "sucre virtuel" even after heating the

${ }^{50}$ R. Lépine and Boulud, Jour. de Physiol., 11, 12, 557, 1909; 13, 178, 1911 ; and a number of other contributions in C. R. and C. R. Soc. de Biol.

${ }^{61}$ E. Frank (Wiesbaden), Zeitschr. f. physiol. Chem., \%0, 129, 1910. 
blood cake for twenty-four hours with hydrofluoric acid. They must in this case certainly be dealing with some glucosamine compounds, connected with the structural composition of the blood proteids (and too, in that of other proteins) separable by hydrolytic cleavage from the latter; these are not, howerer, a part of the true blood sugar. ${ }^{52}$

Contrary to the statement that a fourth or more of the blood sugar which is concerned in normal reduction experiments is in the form of a non-fermentescible rest-sugar, ${ }^{53}$ no such substance could be recognized by estimating the reducing power of blood by Bertrand's method after fermentation either in the blood or in the serum. ${ }^{54}$

It will be readily realized that the blood at times may contain not inconsiderable quantities of maltose and glycogen (carbohydrates which may decidedly increase the reducing ability of the blood after fermentative cleavage). ${ }^{55}$ It seems doubtful, however, whether these substances are sufficient to fully explain the observations recorded in reference to "virtual sugar." In the author's opinion it is more probable that in this we have to do with phenomena of a physicalchemical nature, which we know very well are able to markedly influence the conditions of solubility of sugar. Occasion has been taken in a previous lecture (v. Vol. I of this series, p. 170, Chemistry of the Tissues) to call attention to the enveloping phenomena which gave rise to the mistaken assumption of a chemical combination between lecithin and glucose ("jecorin"). ${ }^{50}$ One may easily imagine how a part of the sugar in the blood in some such

${ }^{62}$ Literature upon the Carbohydrate Groups of Proteins: L. Langstein, Ergebn. d. Physiol., 1, 91-98, 1902; Monatshefte f. Chem., 26, 531, 1905.

${ }^{53}$ J. G. Otto, Pflüger's Arch., 35, 474, 1885; N. Anderson (Lund), Biochem. Zeitschr., 12, 1, 1908.

E. Frank and A. Brettschneider, Zeitschr. f. physiol. Chem., $\sim 1,157,1911$.

${ }^{55}$ Literature: A. Magnus-Lery, Handb. d. Biochem., 4' 318-319, 1909;

E. Frank and Brettschneider, Zeitschr. f. physiol. Chem., i6, 226, 1911; F. Spallitta (Palermo), Arch. ital. de Biol., 53, 356, 1910.

${ }^{5 B}$ Note the doubt expressed by P. Mayer (Salkowski's Lab.), Biochem. Zeitschr., 4, 545, 1908, as to the chemical individuality of jecorin. 
colloidal investment might be carried along in the precipitation of the other blood colloids and thus escape estimation; while in the sense of "virtual sugar" it would be recognized as soon as freed from its investment in the lecithid by any suitable separating agent. Whether this, in a general way, will satisfactorily explain the activity of glucoside-splitting ferments, as understood by Lépine and Boulud, must be left unanswered. But at any rate we cannot insist specifically upon lecithids as the enveloping factors.

Sugar Content of the Red Blood Cells.-In the last few years the question whether glucose is found in the red blood corpuscles as well as in serum has been freely agitated. The statement that these cells contain, not glucose, but only a nonfermentescible carbohydrate, a polysaccharide, ${ }^{57}$ is apparently contradicted by numerous investigations. There is sufficient positive evidence ${ }^{58}$ that the red cells of fresh blood (in contrast with washed cells, which vary $)^{59}$ are permeable for glucose and actually absorb it (in addition, the corpuscles, as well as the plasma, contain variable amounts of a complex carbohydrate which is converted into fermentescible sugar by hydrolysis). The sugar is not always in proportionate distribution in the plasma and cellular elements; sometimes, especially in hyperglycæmias, very striking differences have been found in the proportionate amounts found within and outside the corpuscles, which has been taken to indicate that the blood cells play an independent rôle in sugar metab-

${ }^{67} \mathrm{H}$. Lyttkens and J. Sandgren (Instit. Med. Chem., Lund), Biochem. Zeitschr., 26, 382, 1910; 31, 153, 1911; 36, 261, 1911; S. E. Edie and D. Spence (Liverpool), Biochem. Jour., \&, 103, 1907.

${ }^{8}$ L. Michaelis and P. Rona, Biochem. Zeitschr., 16, 60, 1909; 18, 375, 514, 1909; 37, 47, 1911; P. Rona and A. Döblin, ibid., 31, 215, 1911; R. Lépine and Boulud, ibid., 32, 287, 1911, and earlier contributions; A. Hollinger (Frankfurt a. M.), ibid., 1\%, 1, 1909; D. Takahaschi (Rona's Lab.), ibid., 3\%, 30, 1911; E. Frank and A. Brettschneider (Wiesbaden), Zeitschr. f. physiol. Chem., 76, 226, 1911.

${ }^{59}$ Consult the studies of Hamburger, Gryns, Koeppe, Hedin and others: Literature upon the Permeability of Red Blood Cells: E. Overton, Nagel's Handb. der Physiol., 2, 828-839, 1907. 
olism. ${ }^{60}$ Fundamentally, the fact that red blood cells contain sugar is, in the writer's opinion, a self-evident one; and he cannot suppress feelings of regret for the loss of valuable time deroted by so many noted investigators to this matter. We have absolutely no reason to doubt that sugar may penetrate into every living cell in the system, to become, as it were, the ready cash for defraying the expenses of the vital combustion processes. Why should the red blood cells especially be held different from the rest?

Sugar in the Aqueous Humor.-In conclusion a new method, devised by R. H. Kahn, ${ }^{61}$ should be mentioned for rapid and simple reckoning of the proportion of blood sugar in experiment animals. The anterior chamber of the eye is punctured with a sharp hypodermic needle and the fluid from the chamber caught in a tube. It is best to puncture one eye before the experiment, and the other after the conclusion of the experiment, and to determine the difference in the fluid from the separate eyes. If care be taken not to wound the iris this interference is likely to cause no more than a temporary disturbance of vision in the animal, as the anterior chamber is very soon filled again. A hyperglycæmia, as that brought on by puncture in the fourth ventricle (sugar puncture), or by adrenin, or phloridzin becomes readily appreciable by an increased reducing power of the fluid.

\section{CARBOHYDRATE-SPLITTING FERMENTS}

Another large group of phenomena, which next demand our attention, is that due to the ferments which induce cleavage of carbohydrates, including the diastases, maltases, invertases, lactases, etc. It must suffice to bring out here only a few points of physical and pathological significance, and for the rest, especially for all those questions which

${ }^{60}$ R. Höber (Kiel), Biochem. Zeitschr., 45, 207, 1912.

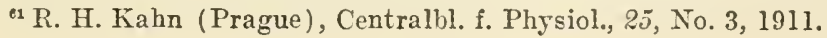


relate to the kinetics of fermentation, to make reference to the comprehensive monographs which have appeared. ${ }^{62}$

Quantitative Determination of Diastase.-Each advance of our knowledge of the physiological rôle and importance of the "carbohydrases," especially of the diastases, presupposes the possibility of their being quantitatively estimated with reasonable exactness in animal fluids and tissues. In a fluid this is not particularly complicated, aside from the difficulty, which obtains in all fermentation investigations, that it is impossible to estimate the ferments directly, but only possible to determine them in terms of their actire strength. If a fluid containing diastase be treated with an excess of soluble starch or glycogen solution, and after a time the quantity of newly formed reducing sugar calculated, an applicable measure of the activity of the ferment is obtained. Because of the difficulties of detail attendant in such a method there is need of methods capable of affording a quicker means of orientation. The method of delle production on a starch-paste plate, for example, has proved a simple aid for this purpose in the study of diastasic ferments. ${ }^{63}$ In Pawlow's Institute, in imitation of the wellknown Mett method of estimating pepsin, the shortening of starch cylinders (made by packing the starch in glass tubes) has been employed for the same purpose. ${ }^{64}$ A colorimetric method devised by Wohlgemuth has, howerer, proved to be the most useful of these measures; being based upon the determination of the amount of ferment solution required to so change a known solution of starch, at given temperature and length of time, that further bluing of the solution will not follow when iodine is added. The tints appearing in serially arranged tests when iodine is added

${ }_{22}$ Literature upon Carbohydrate-splitting Ferments: F. Samuely, Handb. d. Biochem., 1, 537-546, 1909; C. Oppenheimer, Die Fermente, 3d ed.; II, 66108, 1910; H. M. Ternon, Ergebn. d. Physiol., 9, 183-193, 1910; W. Biedermann, Handb. d. vergl. Physiol., 2' 1397-1402, 1911.

${ }^{63}$ E. Müller, Centralbl. f. innere Med., 1908, 386.

Walter, cf. Pawlow, Arbeit. der Verdauungsdrüsen, Tiesbaden, 1898. 
(blue, violet, red, yellow), representing the progressive dissolution of the starch, are sufficiently characteristic to make a convenient estimation possible from them. W. Schlesinger has also proposed a method based on the same principle. $^{65}$

It becomes a much more difficult matter when it is desirable to estimate the diastases, not in a fluid, but in a tissue. A process may be employed on the lines followed by $\mathrm{F}$. Kisch (in connection with an investigation made at the author's suggestion upon the gradual loss of glycogen in the muscles after death) by adding a large excess of a glycogen solution to a mushy mass of the tissue, and then determining the amount of newly formed sugar after lapse of a given time. ${ }^{66}$ An undesirable uncertainty is inherent to methods of this general type, however, because there is no guarantee that there is not some ferment included in tissue pulp which may fail to come in contact with the available carbohydrate. The author looks upon a method devised by Wiechowski for quantitative ferment estimation as a very important advance in technique, but insufficiently appreciated as a general thing, and as having first made possible a precise treatment of a large number of important problems of the physiology and pathology of metabolism:

Wiechowski's Tissue-Powder Method.-Wiechowski's method ${ }^{67}$ is carried ont as follows: Tissue obtained from a freshly killed animal, is perfused with normal salt solution until free from blood; is then chopped into small pieces and passed through a fine sieve. The pulp is then spread out in thin layers upon large glass plates and dried by a strong stream of air from a special ventilator constructed in properly adapted form. The tissue powder is next treated

${ }^{65}$ J. Wohlgemuth, Biochem. Zeitschr., 9, 1, 1908; W. Sehlesinger, Deutsch. med. Wochenschr., 1908, 593.

${ }^{66} \mathrm{~F}$. Kisch, Hofmeister's Beitr., 8, 210, 1906; under direction of $\mathrm{O}$. $\mathrm{v}$. Fürth.

${ }^{67} \mathrm{~W}$. Wiechowski, Hofmeister's Beitr., 9, 232, 1907; Handb. d. biochem. Arbeitsmethoden, 3', 282, 1909. 
with toluol in a special extraction apparatus in the cold, and thus freed of fats and lipoids. At this stage the tissue consists of a fine pulverulent mass which includes proteins and ferments in soluble and well preserved form, and affords an excellent and well adapted supply of material for quantitative fermentation studies. If a weighed amount of the powdered tissue be rubbed up with physiological salt solution in a mortar, a very fine emulsion is obtained which sediments only very gradually, and may be subdivided with graduated pipettes; and is very well suited for employment in comparative study with similarly prepared powdered tissue from other source.

In applying this method to determination of the diastases in tissues, Starkenstein, ${ }^{68}$ in the laboratory of J. Pohl, found it essential to keep up a continuous agitation so as to insure adequate contact of the ferment and the substrate, lest the tissue protein, quickly coagulating at room temperature, take up by mechanical adsorption both starch and ferment, and in this way be sure to occasion too low a result in the quantity of the latter. Thereafter the actual estimation may be conducted by the method of Wohlgemuth.

From what has been said we may be satisfied that many of the older statements as to the effect of various physiological and pathological factors upon the quantity of diastase in the tissues have but doubtful value.

Hepatic Diastase.-As for the liver, it can be finally said that the constantly recurring doubt as to whether its vital diastasic activity is really due to an enzyme, has been conclusively settled. ${ }^{69}$ The present attitude is to regard the quantity of diastase in the liver as subject to a nervous regulation; and the tendency is to relate starvation diabetes of the dog, as well as the glycosurias following brain injuries, Claude Bernard's puncture, or administration of adrenin,

${ }^{ø}$ E. Starkenstein (J. Pohl's Lab.), Biochem. Zeitschr., 24, 191, 1910.

${ }^{\oplus}$ Consult Literature in F. Pick, Hofmeister's Beitr., 3, 163, 1902. 
phloridzin, phloretin, morphin, strichnin, etc., with a supposed increase of hepatic diastase. It is claimed, too, that section of the vagus is followed by marked increase in the hepatic diastase. ${ }^{70}$ In view of all such statements it must be regarded as very important that Starkenstein, ${ }^{71}$ employing a technical method said to be highly perfected, has been unable to recognize any important increase of diastasic power of the liver, either in case of Bernard's puncture or after injections of adrenin. Wohlgemuth, and, too Möckel and Rost have also failed in case of adrenin glycosuria and puncture glycosuria to find any increase of diastase in the blood and tissues. ${ }^{72}$ It therefore seems highly improbable that the exaggerated output of glycogen from the liver, produced by various physiological and toxic agencies, is really an expression of an activation of the hepatic diastase.

Muscle Diastase.-In view of the great physiological importance of muscle diastase the author assigned to $\mathrm{F}$. Kisch ${ }^{73}$ inquiry into the question whether muscle is able to accommodate itself to the varying requirement of the body for mobile sugar, perhaps by changing its diastasic power, possibly by forming fresh diastase from an inactive proferment whenever a need for increased sugar arises in states of hunger or fatigue. No apparent difference was found, however, in diastatic ability of the muscles of a given animal whether at rest or after excessive functional effort, whether after full feeding or in starvation. We cannot but assume, therefore, that the body has recourse to other means than the production of diastase to mobilize its carbohydrate supply at the precise time when it is needed.

${ }^{70}$ I. Bang, M. Ljungdahl and V. Bohm, Hofmeister's Beitr., 9, 408, 1907 ; 10, 1, 312, 1907; P. Zegla, Biochem. Zeitschr., 16, 111, 1909.

${ }^{71}$ l. c.

${ }^{72}$ J. Wohlgemuth, Biochem. Zeitschr., 22, 381, 460, 1909; K. Miöckel and F. Rost, Zeitschr. f. physiol. Chem., 67, 433, 1910.

${ }^{73}$ F. Kisch, Hoimeister's Beitr., 8, 210, 1906, under direction of O. v. Fürth; cf. therein Literature upon Postmortem Loss of Glycogen in Muscles; ef. also Z. Gatin-Gruzewska, Jour. de Physiol., 1907. 
It is impossible to say at this time why the cardiac muscle has so much higher diastasic ability than the skeletal muscles of the same animal ${ }^{i 4}$; the marked access of diastasic power, noted by Kisch, in a tissue pulp transfused with oxygen in the presence of blood may possibly have some relation with retardation of postmortem lactic acid production.

Diastases in Embryos.-The observation of Alice Stauber in Exner's Institute is not without interest, showing that at an early stage of embryonal development diastase exists in the parotid gland and in the pancreas (at a time long before any digestive activity of the alimentary apparatus could possibly be considered); the embryonal thymus, too, is scarcely inferior to the pancreas and parotid (organs naturally destined to secrete diastasic ferments) in its diastasic ability. ${ }^{75}$ The diastasic ability of muscle at an early stage of embryonal life exceeds that of the liver, as shown by the careful quantitative examinations of Lafayette Mendel. ${ }^{76}$

Origin of Diastase.-L. Haberlandt has determined in Zoth's Institute that the ability to form diastasic ferment is a property of leucocytes (particularly of the polymorphonuclear leucocytes), the enzyme partly remaining within these cells, partly passing into the surrounding fluid. In massive collections of leucocytes in the subcutaneous connective tissue (as induced by some local irritant) the diastasic power of the tissue of such a part becomes increased and Haberlandt believes the assumption justified that at least in part the diastatic ferment of the blood-serum has its origin in the leucocytes. ${ }^{77}$

This introduces the important subject of the relation of

${ }^{74}$ Boruttau, Kisch, l. c.

${ }^{75}$ A. Stauber (S. Exner's Lab., Vienna), Pflüger's Arch., 11', 619, 1906.

${ }^{76}$ L. B. Mendel, with P. H. Mitchell and Saiki (Yale Univ.), Amer. Jour. of Physiol., 20, 81, 1907; 21, 64, 1908.

${ }^{7}$ L. Haberlandt (Zoth's Lab., Gratz), Pflüger's Arch., 132, 175, 1910. 
the tissue diastase and blood diastase and the source of the latter.

Role of the Pancreas in the Production of the Blood Diastase.-Observations showing that the amount of diastase in milk in the first part of lactation may be from one to two hundred times greater than that of the blood, ${ }^{\text {77a }}$ clearly indicate that the ferment, for the most part at least, cannot in such cases come from the blood but rather from the tissues themselves. Comparative physiology, too, would suggest that diastases are to be classed among the enzymes common to the general tisues and found in all forms of life from the lowest to the highest. ${ }^{78}$ For this reason especially the author has never had any sympathy with ideas referring the production of the diastase of the blood and other tissues solely to one or more definite organs, as the pancreas and salivary glands. Yet it does not in itself seem implausible that diastase may be resorbed into the circulation from the pancreas and eventually pass into the urine; but statistics as to the quantity of diastase in the blood of the pancreatic veins are in general- contradictory to this idea. However, extirpation of the pancreas seems sometimes to diminish, for a time at least, the amount of diastase in the blood; while conversely, after ligation of the pancreatic duct, the ferment dammed up in the gland may pass in decidedly increased amount into the blood and thence into the urine. For this reason examination of the urine for its diastase has been recommended as a diagnostic test of the function of the pancreas. $^{79}$ Recent observations from Carlson's laboratory

\footnotetext{
${ }_{77 a}$ J. Wohlgemuth and M. Strich, Sitzungsber. d. preuss. Arcad., 1910, 520 .

${ }^{78}$ Cf. Literature in O. v. Fürth, Vergl. chem. Physiol. d. niederen Tiere, Jena, 1903.

${ }^{70}$ W. Schlesinger, Deutsch. med. Wochenschr., 1908, 593; A. J. Carlson and A. B. Luckhardt (Chicago), Amer. Jour. of Physiol., 23, 148, 1908; J. Wohlgemuth and collaborators, Biochem. Zeitschr., 21, 381, 422, 432, 447, 460, 1909 ; K. Möckel and F. Rost, Zeitschr. f. plyssiol. Chem., 6\%, 433, 1910; J. J. R. Macleod and R. G. Pearce (Cleveland), Amer. Jour. of Physiol., 25, 255, 1910; G. Hirata, Biochem. Zeitschr., 2\%, 23, 1910; E. Marino (M. Jacoby's Lab.), Deutsch. Arch. f. klin. Med., 103, 325, 1911; J. v. Benczur, Wiener klin. Wochenschr., 23, 890, 1910.
} 
prove beyond doubt that the pancreas cannot possibly be the only source of the blood diastase. They show that the curve of the blood diastase, which is deeply depressed after pancreatic extirpation, rises again after a few days, without, however, fully regaining its normal level. ${ }^{80}$ It is not improbable that the liver may also give off diastasic ferment into the blood, ${ }^{81}$ more plausible in fact than the reverse hypothesis that the hepatic ferment should be derived from the blood.

Maltases, Invertases and Gluceses in the Blood-serum.Besides diastase maltase also is met in the blood serum. This has been recently investigated closely in F. Röhmann's laboratory. In connection with these studies brief inquiry was made as to whether the maltase of the blood serum is capable in concentrated solutions (as proved by Croft-Hill for yeast maltase) of building disaccharides and polysaccharides from glucose molecules; points were noted fundamentally corroborative of the conception of such synthetic fermentation. Following a terminology proposed by Euler we would here have to recognize the existence of a "glucese" in the blood serum. ${ }^{82}$

There is, too, much of interest in the recognition by Abderhalden that in the blood serum after parenteral introduction of a group of carbohydrates which do not normally enter the circulation (as cane sugar, milk sugar or starch) ferments may be found which are capable of inducing cleavage of such substances. ${ }^{83}$

${ }^{80}$ H. Otten and T. C. Galloway (Carlson's Lab., Chicago), Amer. Jour. of Physiol., 26, 347, 1910; cf. also S. van de Erve (Carlson's Lab.), ibid., 29, 182, 1911.

${ }^{81}$ A. Pugliese, Arch. di Farmacol., 12, 1, cited in Centralbl. f. Physiol., 20, $827,1906$.

${ }^{52}$ Cl. Kusumoto, L. Doxiades (F. Röhmann's Lab.), Biochem. Zeitschr., $14,217,1908 ; 32,410,1911 ; 38,306,1912$.

${ }^{83}$ E. Abderhalden, with C. Brahm, G. Kapfberger and E. Rathsmann, Zeitschr. f. physiol. Chem., 64, 429, 1910; 69, 23, 1910; 71, 367, 1911. Literature upon Animal Invertases: C. Oppenheimer, Die Fermente, 3d ed., II, p. 40, 1910. 
Action of Diastase on Various Forms of Starch.-The utilization of complex carbohydrates by the body is clearly a very complicated process as was believed. Sigmund Lang confirmed this in his comparative studies upon the influence of pancreatic diastase upon starches from different sources, showing that oats stareh, which is highly resistive to catabolism into products which do not give a color reaction with iodine, is very readily converted into sugar; that potato starch, conversely, while very readily decomposed into achroödextrin, is converted into sugar only very slowly. This behavior of oats starch to diastase is scarcely consonant with the strikingly favorable results obtained by the "oats treatment" employed by v. Noorden for diabetes. On the other hand, it is questionable whether it is really proper, as is usually done at the present time, to make the disappearance of the iodine reaction the basis of quantitative determination of the effect of diastase, and whether it would not be better, as Lang proposes, to estimate the effectiveness of diastasic ferments from the amount of end-product, glucose, than from such arbitrary intermediate product. In the end it is undoubtedly the end-product which concerms the requirements of the body. ${ }^{84}$ It is well to recall here besides that the individual phases of starch cleavage are by no means well known, and that the "dual enzyme theory" (strongly opposed by plant physiologists) is still a matter of dispute (this theory assuming that diastase is not a single ferment but is composed of two different enzymes, maltase and dextrinase). ${ }^{85}$

Attempts to "isolate" diastase have failed of satisfactory result, precisely as in the case of other ferments. ${ }^{86}$ In contrast, the physical-chemical behavior of diastase is apparently an inexhaustible mine of notable observations.

${ }^{84}$ S. Lang (F. Kraus's Med. Clinic, Berlin), Zeitschr. f. exper. Pathol. und Ther., 8, 1910, s. a.

${ }^{85}$ Literature: C. Oppenheimer, Die Fermente, 3d ed., III, pp. 84-86, 1910.

${ }^{86}$ S. Fränkel and M. Hamburg, Hofmeister's Beitr., 8, 389, 1906 ; E. Pribram (Fränkel's Lab.), Biochem. Zeitschr., 44, 293, 1912. 
Thus it has been noticed that diastases are at least partly inactivated by prolonged dialysis and may be reactivated by the addition of certain salts ${ }^{87}$; that the blood serum contains a substance which is resistive to boiling and is soluble in alcohol, which apparently augments the diastases ${ }^{88}$; that hydrolysis of starch is strengthened by alternating currents of low intensity ${ }^{89}$; that there is a hydrolyzing influence in the ultra-violet rays of a mercury quartz lamp, ${ }^{90}$ etc. For the most part, however, these matters fall within the sphere of physical-chemistry; and are beyond the limitations set for these lectures.

${ }^{87}$ H. Bierry and J. Giaja, C. R. Soc. de Biol., 60, 749, 1131, 1906; 62, 432, 1907 ; C. R., 143, 300, 1906; L. Preti, Biochem. Zeitschr., 4, 1, 1909; I. Bang, ibid., 32, 417, 1911.

${ }^{88}$ J. Wohlgemuth, Biochem. Zeitschr., 39, 303, 1911.

${ }^{89}$ A. Lebedew (Moscow), Biochem. Zeitschr., 9, 392, 1908.

${ }^{80} \mathrm{H}$. Bierry, V. Henri and A. Rane, Jour. de Physiol., 13, 700, 1911; L. Massol, C. R., 152, 902, 1911 ; J. Giaja, C. R. Soc. de Biol., 72, 2, 1912. 


\section{CHAPTER $\mathrm{X}$}

GLYCOGEN. FORMATION OF SUGAR FROM PROTEIN AND FAT

\section{GLYCOGEN}

IN the present lecture we have first to take up the subject of glycogen. This is a reserve form of carbohydrate which plays very much the same rôle in animal metabolism as starch does in plant life, and its lot stands in very close connection with the general questions of carbohydrate metabolism. One need not wonder, therefore, that the literature upon the subject is a very extensive one, so bulky in fact that there would be occasion for doubt whether it would be possible to properly systematize even its principal features, were it not for the fact that two scientists, Edward Pflüger and Max Cremer, had devoted themselves to the laudable task of sifting and arranging it. Thanks to their work it is no longer a matter of great difficulty to review with a reasonable degree of clarity the problems which glycogen research faces for the immediate future. ${ }^{1}$

Quantitative Determination of Glycogen.-Our ability to estimate with precision the glycogen supply accumulated in the tissues has been of the greatest importance for research in carbohydrate metabolism. In some of the later years of his activity Edward Pflüger performed a service of lasting value by devoting his attention to the problem of quantitative estimation of glycogen, applying to it his phenomenal ability and thorough critical acumen. It will not be easy for posterity to replace Pflüger's method with a better. This process consists in dissolving the tissues in a highly concentrated solution of caustic potash, precipitating the glyco-

${ }^{1}$ Literature upon the Physiology of Glycogen: E. Pflüger, Das Glycogen, 2d ed., Bonn, 1905, and Pflüger's Arch., 96, 1-398, 1903; M. Cremer, Ergebn. d. Physiol., 1', 803-909, 1902; E. Pflüger, Pflüger's Arch., 96, 55-127, 1903. 
gen from solution by alcohol, converting it by hydrolysis into sugar and determining the latter directly. ${ }^{2}$

Chemistry of Glycogen.-The chemical study of glycogen is almost stationary. It is true, Madame Gatin-Gruzewska ${ }^{3}$ seems to have succeeded once in Pflüger's laboratory in obtaining it in the form of minute prismatic crystals; the method pursued consisting in adding alcohol to a weak solution of glycogen until turbidity began to appear, dissolving the precipitate in water and allowing this solution to stand in the refrigerator. Little further has been heard of the procedure. The molecular weight of glycogen is undoubtedly very great. Zdenko Skraup, in collaboration with E. v. Knaffl-Lenz, has attempted its determination, treating the glycogen with acetic acid anhydride saturated with hydrochloric acid. With polysaccharides it is possible in this way to obtain chloracetyl products, the chlorine of which may then be used in deduction of the molecular weight of the original substances; in case of glycogen the figure obtained was about 24000. Really, however, the molecule is probably even larger. ${ }^{4}$ The well-known opalescence of glycogen solutions depends upon ultramicroscopic particles suspended in it, as observed by Rählmann and others, these particles being capable of uniting to form granules of larger size, and determining the physical-chemical characteristics of the solutions. ${ }^{5}$ It goes without saying that under these circumstances it is difficult to expect much from cryoscopic determinations. ${ }^{6}$

${ }^{2}$ Literature upon the Quantitative Estimation of Glycogen: E. Salkowski, Biochem. Zeitschr., 1, 337, 1903; K. Grube, Handb. d. Biochem., 2, 159-166, 1910; cf. also W. Grebe, Pflüger's Arch., 121, 602, 1908; B. Schöndorff, P. Junkersdorf and G. Franke, ibid., 126, 578, 582, 1909; 127, 277, 1909.

${ }^{3}$ Z. Gatin-Gruzewska, Pflüger's Arch., 102, 569, 1904.

${ }^{4}$ Zd. H. Skraup, Monatsh. f. Chem., 26, 1415, 1905; E. v. Knaffl-Lenz (Chem. Instit., Gratz), Zeitschr. f. physiol. Chem., 46, 293, 1905.

${ }^{3}$ Cf. Z. Gatin-Gruzewska and W. Biltz, Pflïger's Arch., 105, 115, 1904 ; F. Bottazzi and G. d'Errico (Naples), ibid., 115, 359, 1906.

${ }^{8}$ Literature upon the Chemistry of Glycogen: C. Neuberg and B. Rewald, Biochem. Handlexikon, 2, 255-264, 1911. 
One can readily understand how a colloidal substance like glycogen, distributed as it is in another colloidal substrate, the cellular protoplasm, often comes to show an atypical behavior. Thus the microchemical identification of glycogen by iodine-iodide of potassium (as in a frog's ovary) may be attended with difficulties even though glycogen is abundantly present; but if the combination between glycogen and the tissue be released by repeated freezing and thawing of the latter, the reaction readily takes place. $^{7}$ We are manifestly here dealing with a phenomenon of physical chemistry; as we have no foundation at present for assuming a chemical combination of the glycogen within the tissue. ${ }^{8}$ Moreover, R. Türkel (in opposition to the statements of Seegen and others) was unable to convince himself that liver-extracts, freed of their glycogen, fermentescible sugar and albumen, contain any appreciable quantities of a substance which may be precipitated by alcohol or which will yield sugar by hydrolytic cleavage. ${ }^{9}$

That the tremendous application of work devoted during the past decades to experimental investigation of the physiology of glycogen, the details of which obviously cannot here be discussed, has not been without result, may be realized when it is stated that we are able even now to indicate concisely the conditions under which the body draws upon its glycogen supply. ${ }^{10}$ (We have more definite information about this phase of the subject than in regard to the manufacture of glycogen in the body, a feature undoubtedly related with the important and very imperfectly understood questions of formation of sugar from proteins and fats.)

'M. Bleibtreu, K. Kato, Pflüger's Arch., 127, 118, 125, 1909.

${ }^{8} \mathrm{H}$. Ioeschke (Pflüger's Lab.), Pflüger's Arch., 102, 592, 1904.

${ }^{\circ}$ R. Türkel, Hofmeister's Beitr., 9, 89, 1906; cf. therein Literature.

${ }^{10}$ Literature upon Physiological and Pathological Catabolism of Glycogen in the Body: O. v. F'ürth, Ergebn. d. Physiol., 2, 584-589, 1902; R. Tigerstedt, Nagel's Handb. d. Physiol., 1, 495-502, 1905; E. Weinland, ibid., 2, 430, 1907 ; A. Magnus-Levy, Handb. d. Biochem., 4' 311-316, 1909; J. Wohlgemuth, ibid., 3', 160-161, 168-174, 1910 . 
Relation Between the Consumption of Sugar by the Muscles and the Disappearance of Glycogen of the Liver.-It is commonly accepted that glycogen is one of the generally distributed tissue constituents. Its distribution in the economy is, however, by no means uniform, by far the greatest proportions being accumulated in muscle and the liver. The extent of its accretion in these latter structures is illustrated by the fact that in a frog's liver glycogen may actually constitute more than half of the dried substance. ${ }^{11}$ In view of the unquestioned importance of sugar as a source of muscular power it may be appreciated why the living body should generally show a more constant fixation of muscle glycogen than of liver glycogen; and among the different muscles why the heart should give up its glycogen least readily. By long-continued strychnine convulsions, which is one of the most effective means of inducing the body to use up its supply of glycogen, P. Jensen ultimately succeeded in getting the frog's heart free of glycogen and showing that even then it is capable of continuing its activity. As long as the body has a carbohydrate supply at its disposal, however, the functionating muscles are sure to find some means and some way to obtain it; but how they actually accomplish this is, it must be confessed, at present unknown. There has been a hypothesis that in muscular contraction the intramuscular nerve-endings are stimulated and transmit, as it were, telegraphic information to the great central supply office in the liver to provide additional fresh nutrient material; but as a matter of fact no one has proved such relationship. It is quite possible that nervous telegraphic lines have nothing whatever to do with notifying the liver and other organs that assistance is needed for the muscles. It may very well be that the circulating blood enacts this rôle of messenger automatically when its level of sugar is lowered. There is no doubt that in a general way the

${ }^{11}$ M. Bleibtreu, Mitt. a. d. Naturwiss. Vereinigung für Neuostpommern und Rügen, 190\%, cited in Centralbl. f. Physiol., 22, 448, 1908. 
mobilization of sugar in the liver is presided over by nervous influences, following the evidence given by the gifted Claude Bernard when he announced his "sugar puncture" and showed that injury of the floor of the fourth ventricle is followed by glycosuria. The same thing has since then been noted after divers wounds in the general field of the nervous system; and the present belief is that the function of the liver in carbohydrate metabolism is under the regulating influence of a "sugar centre" in the medulla oblongata, the vagus nerves carrying centripetal impulses and the splanchnics centrifugal. According to Ernst Freund and H. Popper in the dog an abundant deposit of glycogen can be obtained in the liver from intravenous injections of sugar, only if all cerebral stimulation is eliminated, either by narcosis or by interruption of the centrifugal nervous paths. $^{12}$

Production of Glycogen Impoverishment in the Body.Besides muscular activity there are a great number of other physiological and pathological factors known which may produce reduction in the body supply of glycogen. All forms of inanition should be prominently named in this comnection in which loss of sugar from the economy as in pancreatic, phloridzin or adrenin diabetes may give rise to such serious exaggeration as to impoverish the system of its carbohydrates. Here, too, should be classed increased heat production, as seen in fever and, too, in exposure to cold; and, finally the influence of local hepatic lesions (as from ligation of the hepatic duct or from injection of acid into the bile duct) and of intoxications (as from phosphorus, arsenic, chloroform, amyl nitrite and many others) should be added. Among the poisons which cause degeneration of the liver parenchyma and disturb its glycogen function, according to Asher, ${ }^{13}$ lymphagogues, like peptone, extract of crab-muscle and leech-extract, are to be included.

12 E. Freund and H. Popper, Biochem. Zeitschr., 41, 56, 1912.

${ }^{13}$ L. Asher and Kusmine (Berne), Zeitschr. f. Biol., 46, 554, 1905. 
There is little occasion, however, for lingering over these essentially obvious features, which take up a large part of the literature of the subject. Briefly stated there is scarcely any form of pathological change in the body which may not, at times, come to involve the reserve supplies of carbohydrate which have been stored up when times were good; but the author confesses he cannot bring very much interest to bear upon the details of these processes.

Attention should here be called to the fact that the importance of the liver as the place of greatest deposit of glycogen has been much over-estimated in connection with the normal course of carbohydrate metabolism. Dogs can undoubtedly readily assimilate and consume large quantities of carbohydrates, even after the liver has been excluded from the portal circulation, as by the establishment of an Eck's fistula or by transient compression of the portal vein (by a suture carried about the vein and through the abdominal wall) ${ }^{14}$ (Cf. Vol. I of this series, p. 296, Chemistry of the Tissues).

Formation of Glycogen in the Perfused Liver.-Turning next to the manner in which the body builds up its glycogen it may be said that conclusive information upon the formation of glycogen was reasonably to be expected from perfusion experiments, in which substances believed capable of contributing the material for its construction are introduced into the blood used in perfusing the living, excised liver. While at first the procedure required the determination of the glycogen in a portion of the liver before the inception of the experiment and thereafter the perfusion of another part of the organ, Grube ${ }^{15}$ has devised a method (based on

${ }^{14}$ F. de Filippi (Rome), Zeitschr. f. Biol., 50, 38, 1908; F. Verzâr (Tangl's Lab.), Biochem. Zeitschr., 34, 52, 63, 1911; E. Wehrle (Basel), ibid., 34, 233, 1911; N. Burdenko (Dorpath), Internat. Beitr. z. Pathol. u. Ther. d. Ernährungsstörungen, 4, 93, 1912.

${ }^{15}$ K. Grube (Pflüger's Lab.), Pflüger's Arch., 10\%, 483, 1905; cf. opp. H. Sérégé (Bordeaux), C. R. Soc. de Biol., 5\%, 600, 1904.

${ }^{16} \mathrm{~K}$. Grube (Haliburton's Lab., London), Pflüger's Arch., 10\%, 590, 1905. 
the fact ${ }^{16}$ that glycogen is uniformly distributed in the hepatic parenchyma proper, and that any slight analytical differences are related with the variations in amount of connective tissue in the portions under examination), which permits in the turtle artificial circulation to be maintained for two completely separated portions of the liver. J. de Meyer ${ }^{17}$ has since succeeded in applying an analogous method to the mammalian liver. It is thus possible to perfuse one lobe of the liver with blood containing sugar and a second with blood free from sugar. We have learned from observations of this type, that a marked new-formation of glycogen takes place in a liver when perfused with blood containing sugar; and the assertion ${ }^{19}$ that the liver is able to form glycogen from glucose only after the latter has undergone a preparatory polymerization in the course of its resorption in the bowel has been thoroughly disproved. ${ }^{19}$

We may go a step further and take up the question of what must be the constitution of a sugar to fit it as material for the formation of glycogen. Based upon an extensive literature, the details of which cannot be taken up here, this question would be answered somewhat as follows at the present. $^{20}$

Formation of Glycogen from Glucose, Fructose and Galactose.-Besides glucose, which has naturally occupied the central place in the whole carbohydrate problem, there are two hexoses which are undoubted glycogen-formers, fructose and galactose, the stereo-chemical configurations of which closely approach that of glucose. The capability of a

\footnotetext{
${ }^{17} \mathrm{~J}$. de Meyer (Solvay Instit., Brussels), Arch. intern. de Physiol., 8, 204, 1909.

${ }^{18}$ A. C. Croftan (Chicago), Pflïger's Arch., 126, 407, 1909.

${ }^{19}$ E. Pfiüger, Pflüger's Arch., 126, 416, 1909; K. Grube (Pflüger's Lab.), Pflüger's Arch., 127, 529, 1909.

${ }^{20}$ Literature upon Glycogen Formation from Sugars and Related Substances: M. Cremer, Ergebn. d. Physiol., 1' 896-901, 1902; R. Tigerstedt, Nagel's Handb. d. Physiol., 1, 502-503, 1905; E. Weinland, ibid., 2, 433-499, 1907 ; J. Wohlgemuth, Handb. d. Biochem., 3', 160-164, 1910; A. Magnus-Levy, ibid., 4' 323-326, 352-353, 1909; H. Hafimanns, Inaug. Diss., Univ. Berne, 1910, cited in Jahresber. f. Tierchem., 40, 414.
} 
number of other hexoses, as the mannoses, sorbose and chitose, to form glycogen seems, to say the least, questionable. Glycogen formation from the first-named types of sugar was proved even as early as C. v. Voit and his school. They are by no means equally capable, galactose normally being fixed in the form of the reserve carbohydrate with more difficulty than are glucose and lævulose. A fasting, healthy human being can take up as much as 100 . to 150 . grams of glucose from the stomach at one time without excreting sugar in the urine; the "limit of assimilation" for galactose is very much lower, about 30. to 40. grams. Galactose is assimilated with especial difficulty by carnivora; canine urine showing reducing power even when the animal is merely kept on a milk diet, as observed many years ago by F. Hofmeister. When Grube perfused the living excised turtle-liver with Ringer's solution to which was added sugar of different kinds, he noted that large amounts of glycogen were produced from glucose and from fruit sugar but far less from galactose. It is a strange thing that galactose is better assimilated by the human diabetic, according to F. v. Voit, than is glucose, the diabetic patient having lost the capacity of utilizing the latter. The same is true of lævilose, as shown by Minkowski in case of pancreatic diabetes and by $\mathrm{L}$. Pollak $^{21}$ in case of adrenin diabetes. From a further investigation (in the Vienna Pharmacological Institute) ${ }^{22}$ it would seem that in phosphorus-poisoning the liver, although it has lost its power of forming glycogen from glucose, is still able to freely construct glycogen when lævulose is exhibited. It is impossible thus far to explain this remarkable peculiarity. It might be conjectured that the glycogens formed from lævulose or galactose are in some way different from the form of glycogen from dextrose; that perhaps the glycogen from lævulose would hydrolyse, 1909.

${ }^{21}$ L. Pollak (Pharmacol. Instit., Vienna), Arch. f. exper. Pathol., 61, 149,

${ }^{22}$ E. Neubauer (Pharmacol. Instit., Vienna), Arch. f. exper. Pathol., 61, 174, 1909 . 
not into grape-sugar, but into fruit-sugar. However, a series of special investigations conducted by Pfluger, ${ }^{23}$ with this point in view and using glycogen from animals after a diet rich in lævulose, have failed to give the least foundation for such assumption. The liver and the other organs as well must be looked upon as capable of inverting the polarizing properties of sugars introduced.

Behavior of Disaccharides and Polysaccharides.-The facts concerning the disaccharides are fairly well known. Cane-sugar and milk-sugar can be completely assimilated only if they enter the blood from the intestine, that is, after undergoing full fermentation cleavage. When introduced parenterally they pass for the most part unchanged into the urine. Nor are they found capable of forming glycogen when directly perfused through the living, excised liver (vide sup., p. 228). Maltose, however, does not follow the same rule, as the blood and tissues contain "maltases," ferments capable of splitting this disaccharide when introduced parenterally into the circulation; for which reason it is readily assimilable. (Because of the readiness with which maltose undergoes cleavage into dextrose, Murschhausen's statement ${ }^{24}$ that this sugar produces much less glycogen than grape-sugar, fruit-sugar and cane-sugar cannot well be understood.) It is not to be understood that the normal body has absolutely no power of splitting parenterally introduced cane-sugar. Small amounts of this carbohydrate (one or two grams per kilo) introduced subcutaneously or intravenously into a dog or a cat (as Lafayette Mendell has recently discovered) ${ }^{25}$ are not entirely excreted in the urine. Ernst Weinland ${ }^{26}$ observed that when cane-sugar was injected in large amounts subcutaneously into grown dogs it was usually entirely excreted; but when solutions of this same sugar were injected into young dogs in increasing

${ }^{23}$ E. Pflüger, Pflüger's Arch., 121, 559, 1908.

${ }^{24}$ Pflüger's Arch., 139, 255, 1911.

${ }^{25}$ L. B. Mendel and J. S. Kleiner, Amer. Jour. of Physiol., 26, 396, 1910.

${ }^{20}$ E. Weinland, Zeitschr. f. Biol., 47, 279, 1906. 
doses over a longer period of time, the serum would take on inverting properties. This is evidently nothing more than an exaggeration of a property which is already normally possessed, perhaps in analogy to the phenomena noted in the observations of Abderhalden already mentioned (vide sup., p. 218). The same thing is indicated by the studies of Hohlweg and Voit, ${ }^{27}$ who noted almost complete elimination after subcutaneous injection of twenty grams of cane-sugar into normal rabbits; while in animals with their metabolic processes increased by overheating a loss of about twenty per cent. was obtained.

That polysaccharides like starch and inulin, which undergo cleavage into glucose or lævulose in the intestine, contribute to glycogen formation is self-explanatory. As resorption of these substances can take place only after complete cleavage has occurred, large amounts may be ingested by human beings without necessarily inducing excessive presence of sugar in the system and without consequent alimentary glycosuria.

Other Substances of the Sugar Series.-Statements as to the glycogen forming properties of the pentoses are more or less confusing ${ }^{28}$; off-hand it must be regarded as very questionable whether they possess such properties. Conversion of the pentoses into glycogen, as a matter of fact, would be possible only in a very round-about way (decomposition into molecular groups with two or three carbon atoms).

It is rather singular that glucosamine cannot be classed among the glycogen producers when one thinks how close it stands to grape-sugar stereochemically ${ }^{29}$; the body is evi-

${ }^{27}$ H. Hohlweg and F. Voit (Giessen), Zeitschr. f. Biol., 51, 491, 1908.

${ }^{28}$ M. Cremer, Salkowski, Frentzel, Neuberg and Wohlgemuth; ef. critical review of the Literature; M. Cremer, Ergebn. d. Physiol., 1' 898-899, 1902; ef. also L. B. Stookey and A. H. Jones, Proc. Soc. Exper. Biol., 5, 123; cited in Jahresber. $\mathrm{f}$. Tierchem., 38, 446, 1908.

${ }^{20}$ Fabian, S. Fränkel and Offer, Cathcart, Bial, Forschbach, K. Meyer, Hofmeister's Beitr., 9, 134, 1907 ; F. Rogozinski, C. R., 153, 211, 1911. 
dently unable to replace its amine group by a hydroxyl group and thus effect its transformation. It is a matter of importance in connection with the question of sugar formation from protein that the amidized sugar group in the protein molecule is not capable of direct and immediate transformation into grape-sugar.

We have no proof that any of the alcohols or of the acids of the sugar group (glyconic acid, saccharic acid, glycuronic acid) take part in glycogen formation, which may be easily appreciated when it is recalled that their transformation into sugar presupposes complicated oxidation or reduction processes.

Formation of Glycogen from Formaldehyde.-Nor has Grube's statement ${ }^{30}$ to the effect that formaldehyde, ${ }_{\mathrm{COH}}^{\mathrm{H}}$ which to all appearances plays an important rôle in the lightsynthesis of sugar in plants, is formed into glycogen when perfused through the surviving liver, remained withont contradiction. $^{31}$ A synthetic process of this sort would not be very hard to imagine. According to the latest studies of R. Przibram and A. Franke, ${ }^{32}$ the action of ultraviolet light rays upon an aqueous solution of formalydehyde is sufficient to produce the "simplest sugar," glycolaldehyde, as well as higher condensation products. The process may be supposed to follow the adjacent schema with possible eventual formation of sugar :

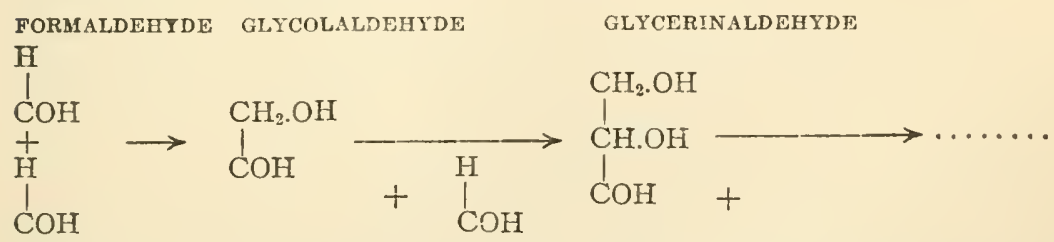

Limit of Saturation and Utilization.-The subject of as-

${ }^{30}$ K. Grube (Bonn), Pflüger's Arch., 121, 636, 1908; 126, 585, 1909; 139, $428,1911$.

${ }^{81}$ B. S'chöndorff and F. Grebe (Bonn), Pflüger's Arch., 138, 525, 1911.

${ }^{32}$ R. Przibram and A. Franke, Sitzungsber. d. Wiener Akad., Mathem. Naturw. Klasse, 71, IIb, Feb., 1912. 
similation limit of the various sugars has attained considerable importance from studies which have been conducted in F. Hofmeister's laboratory. ${ }^{33}$ Using the same rabbit in a series of injections of varying dosage of sugar into the auricular vein one may determine the dose which the animal can take without glycosuria ensuing in the course of a few minutes. This amount, determined by F. Blumenthal as 1.8 to 2.8 grams for a rabbit, proved repeatedly for the individual animal remarkably constant (within 0.1 gram). These figures, an expression of the ability of the body to take up the sugar and its conversion products from the circulation to a point of saturation, is known as the "saturation limit." It furnishes a useful means of measuring the actual appropriating power of the body for any given time. It is not quite the same thing as the "utilization limit," which is determined by finding out by intermittent, graded sugar injections the largest amount which can be borne continuously when introduced regularly at short intervals without ensuing glycosuria. Apparently when the saturation limit has been once reached by a large administration of sugar, a very small continued additional amount is sufficient to maintain a glycosuria.

It may be readily seen that an alimentary glycosuria 33 a is more likely to occur in an individual whose glycogen deposits are excessive from previous indulgence in carbohydrate food, than in one poor in glycogen; and that muscular labor ${ }^{34}$ and over exposure to heat, ${ }^{35}$ by increasing the requirement of sugar, raise the limit of assimilation. A number of other agencies which are apt to modify the assimilation limit will be taken up later.

${ }^{88}$ F. Blumenthal (F. Hofmeister's Lab., Strassburg), Hofmeister's Beitr., $6,329,1905$.

${ }^{33}$ a Literature upon Alimentary Glycosuria: A. Magnus-Levy, Handb. d. Biochem., 4', 323-327, 1909.

${ }^{\circledR}$ G. Comessati (F. Hofmeister's Lab., Strassburg), Hofmeister's Beitr., 9, 66, 1907; Grober (Stintzing Clinic, Jena), Deutsch. Arch. f. klin. Med., 95, $137,1909$.

${ }^{35}$ H. Hohlweg and F. Voit (Giessen), Zeitschr. f. Biol., 51, 491, 1908. 


\section{FORMATION OF SUGAR FROM PROTEIN}

Coming next to one of the great fundamental problems. of the study of metabolism, one upon which biologists from the olden times of Claude Bernard to the present have time and again tested their acumen, we have to consider the question of the formation of sugar from protein.

Carbohydrate Group in Protein Molecule.-Long after the possibility of separation of a reducing compound from mucinous substances was known, the discovery that a carbohydrate group is a natural component of the proteins was made by Pavy. Friedrich v. Müller, the clinician, and his pupils contributed mainly to establish the fact that protein sugar is not identical with glucose or any of the other typical hexoses, but is rather an amidized sugar, glucosamine, $\mathrm{CH}_{2}(\mathrm{OH})-\mathrm{CH}(\mathrm{OH})-\mathrm{CH}(\mathrm{OH})-\mathrm{CH}(\mathrm{OH})-\mathrm{CH}\left(\mathrm{NH}_{2}\right)-$ $\mathrm{COH}$, obtained also by Ledderhose by cleavage of chitin. ${ }^{36}$ While mucins and many mucoids (as the egg envelopes of the frog and of cephalopods $)^{3 \tau}$ are about one-third made up of glycosamine, and the amount of this material in ovalbumin, which is especially rich in sugar, is commonly estimated at about ten per cent., in other true proteids a low percentage or only a fraction of one per cent. is present. Many, as casein, contain no carbohydrate at all. (It is not difficult to determine the amount of carbohydrate of a protein if the latter is hydrolyzed by boiling with a mineral acid, by separating from the mixture the substances which can be precipitated by phosphotungstic acid, and estimating the amount of sugar in the filtrate in the usual manner.) The expectation of finding in the carbohydrate group of the protein molecule the key to the problem of forming sugar from protein soon proved fruitless. We were forced to recognize very soon that the quantity of proteid sugar cannot by any means

${ }^{36}$ Literature upon the Carbohydrate Group in Protein: L. Langstein, Ergebn. d. Physiol., 1', 77-99, 1902; 3', 456-467, 1904; O. Colınheim, Chemie der Eiweisskörper, 4th ed., 82-89, 1911.

${ }^{37}$ O. v. Fürth (F. Hofmeister's Lab., Strassburg, and Zoölogical Station at Naples), Hofmeister's Beitr., 1, 252, 1901. 
suffice to cover even a small fraction of the large amount of sugar which the body under certain circumstances is capable of producing from protein. Before long, too, the previously mentioned ( $v$. sup., p. 231) fact became unexpectedly apparent that the body, which, with a readiness that almost smacks of play, performs so many chemical transformations that put to shame the art of the chemist, is mable to bring about the simple substitution of the amine group of glucosamine by a hydroxyl radical; and that for this reason glucosamine cannot be classed among the typical sugar- and glycogenformers. The logical conclusion was, therefore, that the sugar which in human diabetes, pancreatic diabetes, phloridzin-diabetes, etc., to all appearances originated from proteins is not a direct hydrolytic protein cleavage-product, but must be due to some more complicated chemical changes.

Elimination of Sugar and Protein Decomposition.-For several decades a bitter controversy was waged upon the question of accepting the reality of sugar being formed from protein. Most prominent of all its opponents, Edward Pflüger, with an obstinacy here as inseparable from the character of this great physiologist as was his earnestness in the search for the truth, never wearied of contesting by one new ingenious argument after another against the doctrine of sugar production from protein; and yet in the end he was unable to prevent the theory, well founded as it now is, from taking a permanent place in our science. Today the details of this controversy have no more than historical interest; and there is no occasion for us to enter into the matter more fully at this time. It will probably be sufficient to briefly call to mind the steps by which we have come to know that sugar may be formed from protein.

For this we are indebted primarily to a long series of metabolic researches upon human diabetes, and, too, upon pancreatic diabetes and phloridzin diabetes in animals, with which are prominently connected the names of Claude Bernard, Külz, Wolfberg, Naunyn, v. Mering, Minkowski, 
Cantani, Bendix, Prausnitz, Cremer, Lüthje, O. Löwi, Magnus-Levy, Graham Lusk, Friedrich Kraus, Mohr, Falta, Gigon, and others. ${ }^{38}$ It was proved time and time again that the glycogen supply of the body cannot possibly account for the large quantities of sugar excreted in the urine; and the many observations upon the relation $\mathrm{D} \mid \mathrm{N}$ (Dextrose: Nitrogen) indicate, in a manner which, to the writer's mind, must be convincing to any unprejudiced person, that there exists a relation between sugar formation and protein decomposition. Positive statements were sure to be given after findings like those of Lüthje, ${ }^{39}$ who fed a dog whose pancreas had been removed upon carbohydrate-free diet for a protracted period and in the end found that four times more sugar had been excreted by the animal than could have possibly been deposited in the form of reserve carbohydrate (following Pflüger's maximal figures for the quantity of glycogen in the tissues). Finally even the indefatigable sceptic of Bonn was forced to acknowledge that the sugar produced by a diabetic individual could not possibly come from the glycogen constituent of the body, and that it must arise from some other source which he was unwilling to accept as protein but was inclined to put down as fat. Later on the pros and cons of sugar formation from fat will be taken up; here it is proper to say only that Pflüger did not continue in this interpretation. He found in dogs, whose supply of glycogen had been much reduced by starvation and phloridzin, and which were then fed upon codfish meat, which is very poor in carbohydrates, such a marked accumulation of glycogen in the liver that he frankly acknowledged it as due to the formation of sugar from protein. ${ }^{40}$

${ }^{3 s}$ Literature upon Formation of Sugar from Protein: M. Cremer, Ergebn. d. Physiol., 1, 872-S87, 1902; L. Langstein, ibid., 1, 62-109, 1902; 3, 453-496, 1904; R. Tigerstedt, Nagel's Handb. d. Physiol., 1, 502-508, 1905 ; E. Weinland, ibid., 2, 440-442, 1907; A. Magnus-Levy, Handb. d. Biochem., 4', 340-345, 346356, 1909 ; J. Wohlgemuth, ibid., 3', 165-166, 1910.

$\approx$ H. Liithje, Deutsch. Arch. f. klin. Med., 79, 498, 1904.

E. Pflïger and P. Junkersdorf, Pflüger's Arch., 131, 201, 1910. 
This ended the first act of this eventful scientific drama. All the more honor to the investigator to whom had fallen the rôle of the "spirit that would not down," that at the close of his arduous life he, as it were, went over to the enemies' camp; this he did as soon as he was persuaded that there was where the truth lay. May the coming generations forget the acerbities and the many unfriendly words, but not forget that even this controversy was not entirely without value and that Eduard Pflüger is to be honored for what he stood in science, a true seeker after the truth.

Respiration Experiments.-The formation of sugar from protein has also been determined, aside from the method of feeding experiments, in another way, by respiration experiments. It has been proved that if abundant protein be fed after a previous period of starvation practically all of the nitrogen of the protein employed will appear in the excreta, but a portion of the carbon will remain in the body. "Here the only alternative," says Max Cremer, "unless one is willing to take refuge in unknown and hitherto unproven modes of retention, is to think of this carbon as contributing to form either glycogen or fat. To anyone who like myself holds the formation of fat in a strictly synthetic production only as succeeding a prior stage of glucose these experiments are thoroughly conclusive of the new formation of glucose."

New Formation of Carbohydrate in Glycogen-free Tissues.-Even the man who is dissatisfied with such observations cannot gainsay the fact of the new formation of glycogen in the starving animal. Rabbits can be made entirely devoid of glycogen by being starved for a number of days and then subjected to strychnine convulsions. If such glycogenfree animals are allowed to starve further and are killed at the first sign of the premortal increase of nitrogen elimination (indicative of the complete consumption of the supply of reserve material and that thereafter the protein constituents of the tissues are of necessity being drawn upon), they will 
again be found to contain glycogen, according to Rolly. ${ }^{41}$ Apparently a portion of the mobilized tissue proteins has been changed into sugar. In the same way new formation of carbohydrate occurs in glycogen-free animals if an increase in protein decomposition be induced by an infectious fever (produced by inoculation with bacterium coli). ${ }^{42}$ Pflüger himself proved that mere starvation, as a rule, is incapable of ridding the body of glycogen, because glycogen will be newly formed from substances which are not carbohydrates. ${ }^{43}$ G. Embden ${ }^{44}$ has proved that a marked access of sugar occurs when the living, excised, glycogen-free liver of a dog is perfused, referable to the sugar antecedents in the blood or in the liver; and MI. Löwit ${ }^{45}$ has been able to show that the glycogen-free livers of cold-blooded and warmblooded animals under proper circumstances can form sugar eren postmortem (or in course of life after excision), although postmortem glyconeogenesis could not be proved for the blood or other tissues. It is safe to say that here, too, we can tentatively think of a formation of sugar from proteid substances, particularly as we have no ground for assuming the existence of any sort of unknown high molecular carbohydrates in the liver different from glycogen. There may be some justification in placing in this same category certain discoveries referable to the formation of sugar in autolysis, as that of Seegen in which sugar was said to have been formed from peptone in portions of liver, and that of Weinland, who assumed that sugar was produced from protein, supposed to have taken place in a mush of fly-larva when oxygen was introduced. It should, however, be explicitly stated that the former of these findings has not been

${ }_{41}^{41}$ Rolly, Deutsch. Arch. f. klin. Med., 83, 107, 1905.

${ }^{42} \mathrm{C}$. Hirsch and Rolly (Med. Clinic, Leipzig), Deutsch. Arch. f. klin. Med. $78,380,1903$.

${ }^{43}$ E. Pflüger, Pflüger's Arch., 119, 117, 1907.

* G. Embden, Hofmeister's Beitr., 6, 44, 1903; Biochem. Zeitschr., 6, 66, 1904.

${ }^{45}$ M. Löwit (Innsbruck), Pflüger's Arch., 136, 572, 1910. 
confirmed, ${ }^{46}$ and that Weinland's work, ${ }^{47}$ to the author's mind, should be repeated by a number of different methods before final credence can be given it. ${ }^{48}$

Formation of Sugar from Various Proteins.-Considerable work has been expended upon the question of the relation of various proteins to the amount of sugar which they are capable of producing in metabolism, but with little other result, as far as the writer can observe, than the fact that the quantity of carbohydrate preformed in the proteid substances (glucosamine) is by no means striking. Quite recently experiments have been repeated in M. Cramer's laboratory showing in comparative feeding tests on a phloridzin dog with meat and casein (casein is a carbohydratefree protein) a difference in favor of casein. ${ }^{49}$ The amounts of sugar which can be produced from protein (based on calculation of the $\mathrm{D} / \mathrm{N}$ relation) have been given in highly varying proportion; incidentally it was calculated that after feeding meat half of the energy of the protein can take on the form of sugar and can be stored as glycogen for future use. Such statements cannot, however, as yet be regarded as final. ${ }^{50}$

Origin of Sugar from Aminoacids.-Having clearly before us the facts of sugar formation from protein, we may proceed to the question of the chemistry of this process.

Explanation of the mechanism of sugar production from protein has been sought by administering the individual "building stones" of protein, the aminoacids, to dogs with pancreatic diabetes and phloridzin diabetes, and determining their influence upon sugar elimination and glycogen formation. Investigations with this in view (particularly

${ }^{47}$ Cf. L. Langstein, Ergebn. d. Physiol., 1', 108, 1902.

${ }^{47}$ E. Weinland, Zeitschr. f. Biol., 49, 421-466, 1907.

${ }^{48}$ O. Krummacher and E. Weinland, Zeitschr. f. Biol., 52, 273, 1909.

19 P. Rohmer (M. Cremer's Lab.), Zeitschr. f. Biol., 54, 455, 1911.

${ }^{80}$ Investigations by Külz, Lusk, Halsey, Lüthje, Bendix, Berger, Lehmann, Schumann-Leclerc, Mohr, Falta, Therman, G. Müller and others. Literature: P. Rohmer, l. c. 
those of Röhmann, R. Cohn, Nebelthau, Neuberg and Langstein, Knopf, Halsey, F. Kraus, Embden and Salomon, Glässner and E. Pick and Graham Lusk) ${ }^{51}$ have led to the conclusion that sugar production from aminoacids, at least from glycocoll, alanin, asparaginic acid and glutaminic acid, cannot well be doubted. The conceptions framed to explain the process are entirely hypothetical. The synthesis of sugar may possibly take place through the formation of substances containing one, two or three carbon atoms, as formaldehyde, glycolaldehyde and lactic acid, the fitness of which for taking part in direct construction of sugar is more or less to be expected. The author personally is more sympathetically attracted to such a conception as that which supposes leucin to be decomposed into two triple-carbon compounds ${ }^{52}$ to be synthesized into sugar, than to any idea of a "stretching" of the branched

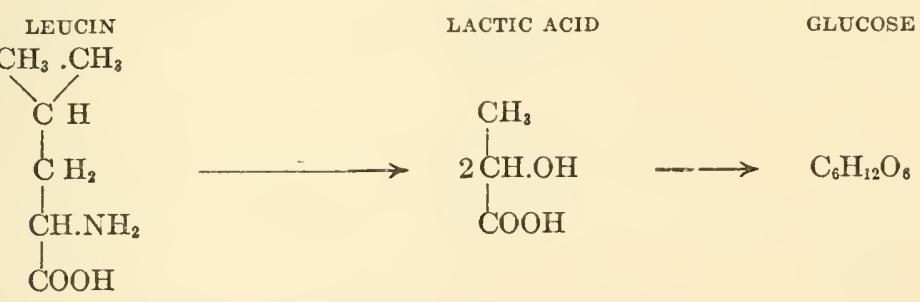

six-carbon chain of leucin to bring about its transformation into sugar.

Ringer and Graham Lusk ${ }^{53}$ by the employment of an excellently adapted method succeeded in producing in dogs a very uniform glycosuria; and, after the $\mathrm{D} \mid \mathrm{N}$ ratio in the urine had become constant, fed aminoacids to the animals. By measuring the resultant increases of sugar excretion they concluded that glycocoll and alanin can be all utilized in formation of sugar, but of the four carbon atoms of

\footnotetext{
${ }^{81}$ Literature: J. Wohlgemuth, Handb. d. Biochem., 8', 165-166, 1910.

${ }^{2}$ Cf. L. Langstein, Ergebn. d. Physiol., 3', 473, 1904.

${ }^{3}$ A. J. Ringer and Graham Lusk (Cornell Univ., New York), Zeitschr. f. physiol. Chem., 66, 106, 1910; Jour. Amer. Chem. Soc., 32, 671, 1910; cited in Centralbl. f. d. ges. Biol., 10, No. 2348.
} 
asparaginic acid and of the five of glutaminic acid presumably only three are available as material for sugar.

The following schema of these authors may perhaps prove useful as guides in further investigations:

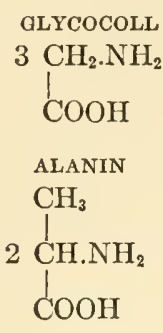

ASPARAGINIC ACID

$\mathrm{COOH}$

$2 \mathrm{CH}_{2}$

CH. $\mathrm{NH}_{2}$

$\mathrm{COOH}$

GLUTAMINIC ACID

$2 \mathrm{COOH}$

!

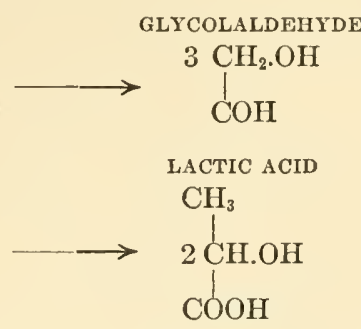

$\beta$-LACTIC ACID

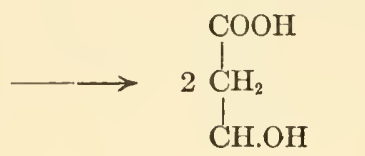

GLYCERINIC ACID
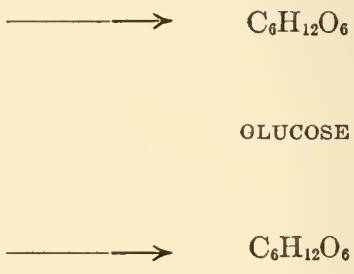

OLUCOSE

$\mathrm{C}_{6} \mathrm{H}_{12} \mathrm{O}_{6}$

GLUCOSE

$2 \underset{\mathrm{CH} . \mathrm{OH}}{\mathrm{CH}_{2} . \mathrm{OH}}$

FORMATION OF SUGAR FROM FAT

Having adjusted our ideas as best we can in the matter of the production of sugar from protein, our attention should next be given the difficult problem of the formation of sugar from fat.

It should primarily be understood that we are dealing here not with a single problem but with two. Fat is made up of two components (glycerine and higher fatty acids), and it is essential to clearly distinguish the production of sugar from glycerine from that involving the fatty acids.

Formation of Sugar from Glycerine.-As far as the first of these items is concerned, we can be very brief. Experiments have been frequently made in which glycerine has been 
administered to diabetic human beings and animals, which have proved beyond doubt that this substance is a true sugar- and glycogen-producer. ${ }^{54}$. This was to have been expected when one recalls that Emil Fischer by condensation of the glyceroses, resulting by simple bromoxidation from glycerine, directly obtained sugar (i-fructose) : ${ }^{55}$

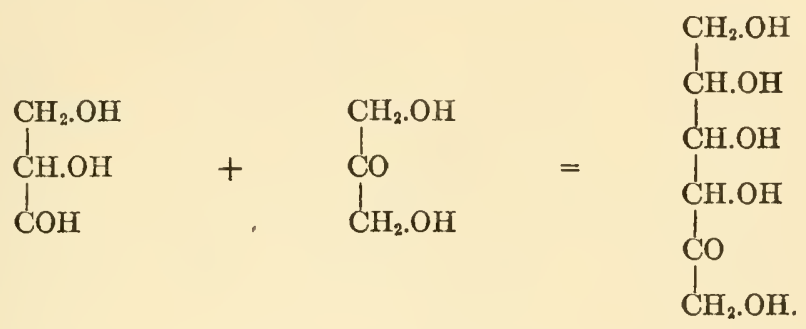

However, the fact that glycerine constitutes but a small part (about one-tenth) of the molecule of fat, indicates that the difficult part of the general problem is not in this, but in the question of the production of sugar from the higher fatty acids. ${ }^{56}$ Let us therefore at once consider the fundamental facts which have been evolved for this latter.

Seegen's Experiments.--Seegen's conception of a large volume of sugar, originating from protein and fat decomposition, passing from the liver by the hepatic vein and permeating the body, has not withstood criticism any more than his statements (supported by Weiss) of the existence of a process of an autolytic new-formation of sugar in bits of liver tissue digested with fat and soaps. ${ }^{57}$ These matters are now all relegated to the past.

${ }^{54}$ Van Deen, Luchsinger, Weiss, Salomon, Külz, Frerichs, Cremer, Luithje. Literature upon the Formation of Sugar from Glycerine: M. Cremer, Ergebn. d. Physiol., 1' 888-890, 1902; J. Wohlgemuth, ibid., 3', 167, 1910.

${ }^{55}$ Arranged without reference to the stereochemical configuration.

${ }^{58}$ Literature upon the Formation of Sugar from the Higher Fatty Acids: M. Cremer, Ergebn. d. Physiol., 1, 888-895, 1902; A. Magnus-Levy, Noorden's Handb., 1, 178-181, 1906; Handb. d. Biochem., 4' 345-316, 1909.

${ }^{57}$ A. Montuori, Ber. d. Acad. Neapel, 1895, cited in Handb. d. Biochem., 3', 167, 1910; M. Jacoby (Salkowski's Lab.), Virchow's Arch., 157, 255, 1897 ; E. Abderhalden and P. Rona, Zeitschr. f. physiol. Chem., 41, 303, 1904. 
Respiratory Quotient in Diabetes.-Attempts have also been made to prove that sugar is produced from fat from a study of the ratio of the respiratory quotient in diabetes. It is well known that the respiratory quotient, the ratio between the output of $\mathrm{CO}_{2}$ and the intake of oxygen, when combustion of carbohydrates alone is in process, is $\frac{\mathrm{CO}_{2}}{\mathrm{O}}=1$, because the different sugars contain $\mathrm{H}$ and $\mathrm{O}$ in the proportions of water and necessarily no oxygen is needed to oxidize the hydrogen into water. But as this is involved to a marked degree when fat (very poor in oxygen) is burned, the respiratory quotient falls to 0.7 in the actual consumption of fat. The portion of oxygen intake which is employed in the oxidation of $\mathrm{H}$ into water of course does not appear as $\mathrm{CO}_{2}$. In the combustion of protein the quotient is about 0.8. What may be expected, however, if in a diabetic there takes place transformation of higher fatty acids into sugar and this be excreted as such? As there must of necessity be a number of $\mathrm{CH}_{2}$ complexes reformed into CH.OH., a considerable amount of oxygen will be required; and, as the new-formed sugar is not consumed but is excreted, the intake of oxygen cannot at all coincide with the $\mathrm{CO}_{2}$ output. It is evident, therefore, that a marked lowering of the respiratory quotient must manifest itself. Magnus-Levy has calculated that the respiratory quotient will of necessity fall to 0.6 or lower under such conditions; but even in diabetes of severe type he found an actually higher proportion, while Pfliger, taking the same observations as his basis but other methods of calculation, actually obtained in the case of a severe diabetic a quotient of almost exactly 0.6 , and believed that this proved beyond doubt that fat is a source of sugar. ${ }^{58}$ Unfortunately it must be acknowledged that the elements, which have been basically assumed for calculation, are not as yet established with the

${ }^{58}$ A. Magnus-Levy, Verhandl. d. physiol. Ges. Berlin, March 1, 1904; Centralbl. f. Phrsiol., 18, 373, 1904; Zeitschr. f. klin. Med., 56, 83, 1905; consult therein the Literature. E. Pilïger, Pflüger's Arch., 108, 473, 1005. 
certainty which is essential for precision in a physical experiment of this sort.

Sugar Nitrogen Quotient.-Further evidence of the formation of sugar from fat has been recognized in observations upon the sugar-nitrogen quotient, D $\mid \mathrm{N}$. In many cases of severe diabetes in man and the lower animals such large amounts of sugar, in comparison with the nitrogen output, have been met that protein decomposition does not seem sufficient to explain the sugar production; and it has seemed impossible not to refer it in part at least to formation from fat. ${ }^{59}$ The possible correctness of this mode of interpretation cannot be well denied; but such observations cannot readily be accepted as complete proof, ${ }^{60}$ particularly because fundamentally in these conclusions we have to take into consideration the tacit assumption that the nitrogen output at a given time is invariably regarded as a correct indicator of the protein decomposition going on in the body. O. Löwi ${ }^{61}$ has, however, called attention to the important point that this assumption does not always obtain in full. Nitrogen retention in the body may exist at times, and it is possible that the protein decomposition may be actually greater than the coincident nitrogen elimination would indicate.

Fat Impoverishment in Phloridzin Animals.-Kolisch's observation that white mice in chronic phloridzin intoxication (in comparison with control animals) show extensive impoverishment of fat, is distinctly interesting, but not at all conclusive from this standpoint. ${ }^{61 \text { a }}$

Influence of the Introduction of the Higher Fatty Acids Upon Sugar Elimination.-It might be supposed that the

${ }^{59}$ Observations by Rumpf, Lüthje, Hartogh and Schumm, Rosenquist, Mohr, Hesse, Junkersdorf, Pflüger's Arch., 137, 269, 1910, and of v. Noorden's school.

${ }^{\infty} \mathrm{Cf}$. criticism of above by F. r. Mïller, Landergren and Magnus-Lery, Literature: A. Magnus-Levy, v. Noorden's Handb., 2d ed., 1, 178, 1906, and Handb. d. Biochem., 'f', 345, 1909.

${ }^{\text {e1 }}$ O. Löwi (Lab. of H. H. Meyer, Marburg), Arch. f. exper. Pathol., 47, $68,1902$.

"1a Kolisch, Wiener. klin. Wochenschr., 19, 559, 1906. 
most simple and direct means of settling the question of the production of sugar from the higher fatty acids would be by determining whether on introduction of a large quantity of such substances into a diabetic the excretion of sugar would be increased. In the great majority of observations with this point in view, not only has such increase been missed as a matter of fact, but in addition in a number of cases there has been a noted lowering of the sugar excretion after administration of fatty acids (interpreted on the supposition that the combustion of the latter serves to protect the protein from undergoing destruction and in this way reduces the formation of sugar from the protein). ${ }^{62}$ It would, however, be another mistake to regard such negative results as a satisfactory proof that formation of sugar from the higher fatty acids is impossible. Reference may be made here to the interpretation of A. Magnus-Levy, ${ }^{63}$ whose perspicaciously conducted investigations have distinctly advanced the physiology of metabolism in so many ways, upon these points: "In contrast to the conditions prevailing with varying introduction of protein, where as a matter of fact every addition of protein occasions a corresponding increase in protein exchange, the most marked addition of fat increases but little the fat exchange. Fat does not in any sense displace other food from metabolism. In the starving dog it replaces the previously consumed body fat; is consumed in its place. An excess is deposited almost in its total amount without essentially increasing metabolism. We can also subscribe to the statement here outlined in this, that fat as the most passive of all the foodstuffs always takes part in the combustion process after all the other foods, after protein, the carbohydrates and alcohol, and takes part only as far as an existing demand is not

${ }^{62}$ L. Mohr (F. Kraus's Clinic, Berlin), Zeitschr. f. exper. Pathol., 2, 463, 481, 1906; E. Pflüger, Pflüger's Arch., 108, 115, 1905; S. Bondi and E. Rudinger, Wiener klin. Wochenschr., 19, 1029, 1906 ; F. Maignon, Jour. de Physiol., $10,866,1908$; cf. therein the older literature.

${ }^{\text {es }}$ A. Magnus-Levy, Handb. d. Biochem., 4' 343-344, 1909. 
satisfied by some other material. Other things being equal it is always easy to force the other three foods into metabolism by increasing their assimilation; but this is impossible in the case of fat. Increased combustion of fat occurs in the diabetic animal, which is kept on protein and fat alone, only when protein is withdrawn. As a given degree of lowering of protein exchange is followed by a decrease in sugar, so some degree of increase of sugar elimination would be entirely covered after increased fat combustion." In this connection it may be stated that (as in a case of very severe diabetes in v. Noorden's elinie ${ }^{64}$ ) after administration of large amounts of fat an enormous sugar elimination has been observed, the sugar-nitrogen ratio $(\mathrm{D} \mid \mathrm{N})$ reaching the extraordinary height of 10 . Falta, in his valuable efforts to establish the rules of sugar elimination in diabetes mellitus, came to the conclusion that many facts of the pathology of metabolism are entirely inexplicable without the assumption that sugar may be formed from fat, and that the evidence in favor of this has been distinctly enlarged by his own and his associates' investigations. ${ }^{65}$

The question of sugar formation from fat today is in about the following status: that it has not been absolutely proved, but has on the other hand not been disproved or even become improbable. Magnus-Levy ${ }^{66}$ very properly suggests that the body, as shown by all experiments in spontaneous and experimental diabetes, has a relentless need for carbohydrates which it tries to satisfy under all circumstances. For this end the carbohydrate supply in the body first comes in question; thereafter the formation of sugar from protein; and only in the third place the formation of sugar from fat. If, however, the position be taken (and

${ }^{6}$ S. Bernstein, C. Bolaffio, v. Westenrijk (v. Noorden's Clinic, Vienna), Zeitschr. f. klin. Med., 66, Heft. 5/6, 1908; cf. also W. Falta and A. Gigon, Zeitschr. f. klin. Med., 65, 326, 1908. 7,1308 .

${ }^{6}$ W. Falta (v. Noorden's Clinic), Zeitschr. f. klin. Med., 66; separate, p.

${ }^{\infty}$ A. Magnus-Levy, Noorden's Handb., 2d ed., 1, 179, 1906. 
doubtless there may be much said for it) that the body can execute its manifestations of energy (in a certain sense, render its cash payments) only on a carbohydrate standard, the assumption of sugar formation from fat is still asserted even if not in so many words; for it can scarcely be questioned that in the starving animal the performance of work must draw upon its supplies of fat, or that a human being in a long continued fever, or a hibernating marmot, undoubtedly sustains the output of energy for the most part at expense of its body fat. If in such examples the direct source of mechanical and thermic energy were to be referable to the combustion of sugar alone, the conclusion must be that a great part of this sugar must come from fat. The problem of sugar formation from fat therefore falls in a certain sense in the same class with that of the sources of energy of the living body, and any one who adheres to Zuntz's belief (v. Vol. I of this series, p. 159, Chemistry of the Tissues) in the dynamic equivalence of the three main classes of foods, will necessarily refuse to acquiesce in the last mentioned argument.

There is no doubt that in the plant in the germination of its oily seed (where the reserve substances in the cotyledons and in the endosperm furnish the material for the growth of the embryonal plant) there takes place a transformation of fat into carbohydrate to a very great degree. The fat that is disappearing from the reservoirs of reserve substance actually forms the material from which the cell-walls of the young plants are built up. But it is perhaps not apposite to apply facts which have been discovered in plant physiology to animal metabolism. ${ }^{67}$

${ }^{67}$ Literature upon the Behavior of the Fat in Germination of Oil-bearing Seeds: O. v. Fürth, Hofmeister's Beitr., 4, 430, 1903. 


\section{CHAPTER XI}

\section{PANCREATIC DIABETES-HUMAN DIABETES}

\section{PANCREATIC DIABETES}

THE preceding lectures have introduced the fundamental facts of carbohydrate metabolism well enough to permit us to venture into one of the most interesting but at the same time one of the most difficult problems in the study of metabolism, that of pancreatic diabetes.

In the current of the sciences, just as in the life of man, there are periods when every good intention and the most honest effort are insufficient to make any decisive and productive progress possible; evil days when ability is compelled to employ a good part of its innate energy to keep from sinking into dejected inefficiency. Then all of a sudden some new event takes place, changes the situation of affairs and brushes aside the impediments which have opposed the free development of the long accumulated latent energy. And at once a period begins of heightened, feverish activity that endeavors to make up for all that was missed in the dull times of stagnation.

Discovery of Pancreatic Diabetes.-One of these fortunate events occurred in the development of metabolism study when in 1889 Oskar Minkowski and Josef v. Mering discovered pancreatic diabetes in Naunyn's laboratory in Strassburg. ${ }^{1}$

At the same time, and independently of the authors just named, N. de Dominici, in Naples, also discovered the existence of pancreatic diabetes (an example of the strange law of the doubling of events which often has appeared even in physiology, probably because a discovery cannot be made

${ }^{1}$ Literature upon Pancreatic Diabetes: O. Minkowski, Ergebn. d. Pathol., 1, 69, 1896; C. v. Noorden, Handb. d. Pathol. d. Stoffwechs., 2d ed., 2, 38-43, 1907; A. Biedl, Innere Sekretion, pp. 375-399, 1910. 
before the times are ripe for it, and in a sense it is in the air).

Although it must be reluctantly confessed (for that matter it would be recognized all too soon even without such a confession) that to-day, after almost a quarter of a century has elapsed since this discovery, we are not in position to offer a satisfactory explanation of the real nature of pancreatic diabetes, yet it is impossible to mistake the fruitful influence which even this single possible means of artificially producing a metabolic disturbance analogous to human diabetes has had on the whole field of physiology and pathology of metabolism.

Interrupted Extirpation of the Pancreas.-It is well known that extirpation of the whole of the pancreas is requisite to produce a typical pancreatic diabetes, and that the preservation of a small portion of the gland will suffice to prevent this metabolic fault. If the bulk of the gland is removed and the rest located subcutaneously diabetes does not ensue, but will promptly follow with all its symptoms upon subsequent removal of the transplanted portion. The fact that it is possible to cause a diabetes of the severest form by a trivial interference requiring but a few minutes for its completion, in which the peritoneal cavity is not opened at all and in which there can be no question of irritation of the system of peritoneal nerves, eliminates all objections, as Minkowski ${ }^{2}$ properly suggests, to the belief in a direct relation between diabetes and loss of pancreatic function. An interrupted process, recently suggested by Hédon, ${ }^{3}$ makes the extirpation of the pancreas in the $\mathrm{dog}$, which is by no means easy of technic, decidedly less difficult. It is best in carrying out the procedure to first remove only the gastrosplenic portion of the gland and to transplant the lower part of the tail of the organ with its nervo-vascular pedicle under the

${ }^{2}$ O. Minkowski, Pflüger's Arch., 111, 13, 1906.

${ }^{3}$ E. Hédon (Montpellier), Arch. intern. de Physiol., 10, 350, 1911; cf. therein Literature. 
skin, with the intention of taking it away some time later, after recovery is assured. It seems of much importance for the success of the operation that the separation of the head of the pancreas from the wall of the duodenum be properly performed. Hédon strongly advises that the gland be torn away from the bowel wall and the latter curetted; a tedious stoppage of hemorrhage by ligature is avoided, a more thorough extirpation is accomplished, and necrosis of the intestine prevented, which is the principal point.

A very severe diabetes is invariably thus produced, setting in after completion of extirpation and lasting until the death of the experiment animal (two to four weeks later). A diabetes thus produced proceeds in typical fashion with symptoms of hyperglycæmia, polyphagia, polydypsia, polyuria, wasting and acidosis. After partial extirpation a diabetes of less marked severity may be induced, with a course of perhaps many months' duration, which if total extirpation be completed later on will at once change to a severe type. By transplanting pancreatic tissue into the spleen ${ }^{4}$ the duration of life of a dog with pancreatic diabetes has been successfully lengthened to a very distinct degree.

The statement of Chauveau and Kaufmann that the result of pancreatic extirpation may fail to appear if the cervical cord be divided has not been confirmed. Even if this be done and in addition the vagus and sympathetic nerves be cut, thus completely excluding influences from the cerebral centres, the glycosuria, according to Hédon, appears. $^{5}$

Function of the Islands of Langerhans.-In the literature upon pancreatic diabetes a very large part is devoted to experiments which have as their purpose determination whether the function of the organ concerned with carbohydrate metabolism is connected with the secreting paren-

"Martina, cited by Jacoby, Einführung in die experimentelle Therapie, p. 136, 1910.

${ }^{B}$ E. Hedon (Montpellier), Arch. intern. de Physiol., 11, 195, 1911. 
chyma of the pancreas or with the "islands of Langerhans." B. A. Kohn classes the islands of Langerhans along with the parathyroids, the epithelial part of the hypophysis and the cortex of the suprarenal glands, among glands without duct or glandular lumen.

Here it may be sufficient to state as a matter of reference that U. Lombroso ${ }^{6}$ after sifting the general material (collected experiments with ligature of the ducts, artificially induced atrophy of the parenchyma, pathological observations and studies in comparative anatomy), came to the conclusion in a monograph upon the subject that both forms of epithelial tissue of the pancreas, acini and islands, take part in internal secretion. Swale Vincent, ${ }^{7}$ in a recent critical review, says: "Whatever may be found out in the future in regard to the true function of the islands of Langerhans, their essential anatomical relation with the zymogenous tubules, the many transition forms met in all vertebrate genera, and the transformation of acini into islands and vice versa, apparently prove conclusively that the islands are not sui generis, but that they are integral constituents of the ordinary pancreatic tissue. Whether the temporary transformation into insular tissue means a particular specialization of function, our present evidence does not indicate." In the author's personal opinion, it can no longer honestly be doubted, in view of the recent investigations of Weichselbaum (vide infra), that the anatomical cause of diabetes is to be sought in lesions of the islets.

Duodenal Diabetes.-Some years ago Pflüger took occasion to use the observation that section of the intramesenteric nervous connections between the pancreas and duodenum in the frog may under certain circumstances give rise to a glycosuria, as a basis for calling into question the existence of a pancreatic diabetes, and for substituting for the latter a "duodenal diabetes." The whole discussion

${ }^{6}$ U. Lombroso, Ergebn. d. Physiol., 9, 1-89, 1910.

'Swale Vincent, Ergebn. d. Physiol., 9, 489-495, 1910. 
growing therefrom has proved practically fruitless, and was basically altogether superfluous as the above stated observations of Minkowski and his numberless followers ${ }^{8}$ permitted but one interpretation. But it served to show again that if a single bit of pancreas completely detached from its nervous comunications be left it will suffice to prevent the appearance of glycosuria. The whole duodenum can be excised from a dog, as Minkowski had already shown, without producing diabetes, provided a portion of the pancreas has been transplanted under the skin; but if the latter at a later time be removed from the animal the diabetes promptly sets in. Strictly speaking nothing at all has been gained in this whole campaign fought with an array of heavy artillery of authority and between strategists of note, except the reëstablishment of a fact that has been known long before, that of the influence of nervous irritations of all sorts (corrosion of the duodenum or ileum, injection of nicotine into the stomach, chilling) to cause the liver to discharge its supply of carbohydrate and sometimes give rise to glycosuria. ${ }^{9}$

We know conclusively that pancreatic diabetes is possible not only in many mammalia, but also in birds, turtles, frogs and fishes, and that in those instances in which a true glycosuria has not been found (as in many birds and in sharks) there may be noted at least a distinct hyperglycæmia. ${ }^{10}$ We may apparently, therefore, regard the

${ }^{3}$ Lépine, Hédon, Gley, Thiroloix, Caparelli, Harley, Schabad, Cavazzani, Sandmeyer, Selig. Rumbolt and others; cf. Literature in A. Biedl, 1. c.; also E. Hédon, Jour. de Physiol., 14, 907, 1912.

${ }^{9}$ E. Pflüger, Pflüger's Arch., 106, 181, 1905; 118, 265, 267, 1907; 119, 227, 297,1907 ; 122, 267, 1908; 123, 323, 1908; 124, 1, 529, 632, 1908; 128, 125, 1909 ; R. Gaultier, C. R. Soc. de Biol., 64, 826, 1908; A. Herlitzka, Pflüger's Arch., 123, 331, 1908; M. Löwit, Arch. f. exper. Pathol., 62, 47, 1908; U. Lombroso, Arch. di Farmac., 9, 146, cited in Jahresber. f. Tierchem., 40, 811, 1910 ; O. Minkowski, Arch. f. exper. Pathol., 58, 271, 1908; S. Rosenberg (N. Zuntz's Lab.), Biochem. Zeitschr., 18, 956, 1909; Pflüger's Arch., 12, 358, 1909 ; H. Eichler and H. Silbergleit, Berliner klin. Woohenschr., 1908, 1172; W. Tscherniachowski, Zeitschr. f. Biol., 53, 1, 1909; A. Visintini (Pavia), Med. Kiin., 1908, 1613; E. Zack, Wiener klin. Wochenschr., 1908, 82. 
existence of pancreatic diabetes as established beyond peradventure.

Does the Internal Secretion of the Pancreas Pass with the Lymph Through the Thoracic Duct into the Blood?-We may, however, proceed farther and take up the question whether the presence of an internal secretion influencing the carbohydrate metabolism can in any manner be directly recognized in the blood.

At the outset an interesting fact observed by Biedl ${ }^{11}$ may be mentioned, namely, that in dogs in which the thoracic duct is tied or opened through a fistula, glycosuria will usually occur. This fact has been verified in Gottlieb's laboratory, ${ }^{12}$ and has been supplemented, too, by clinical observations of the occasional coincidence of chyluria and glycosuria. ${ }^{13}$ Naturally one feels a strong temptation to interpret these observations on the hypothesis that the lymph duct is carrying to the blood, a secretion originating in the pancreas the cessation of which occasions the glycosuria; but it cannot be settled offhand whether the glycosuria may not have been induced in some very different way in such cases (as by nervous irritation, etc.).

Blood Transfusion and Parabiosis.-Besides there is at least a chance that this "internal secretion" of the pancreas does not gain entrance into the general circulation indirectly by way of the lymph passages, but directly into the blood vessels. It is true the blood of the pancreatic vein has shown no influence upon sugar elimination in a dog with the pancreas removed. ${ }^{14}$ But when Hédon united two dogs by anastomosing their carotid arteries, one deprived of its

${ }^{10}$ W. Kausch (Naunyn's Clinic), Arch. f. exper. Pathol., 3\%, 274, 1896; M. Löwit (Innsbruck), ibid., 62, 47, 1909; V. Diamara (Siena), Arch. Ital. de Biol., 55, 94, 1911; cf. therein the Literature.

${ }^{11}$ A. Biedl, Centralbl. f. Physiol., 1898, 624; Biedl and Th. Offer (R. Paltauf's Lab.), IViener klin. Wochenschr., 190\%, 1530.

${ }^{12}$ J. L. Tuckett, Jour. of Physiol., 41, 88, 1910.

${ }^{13}$ A. Magnus-Levy, Zeitschr. f. klin. Med., 66, 482, 1908; 67, 524, 1909.

${ }^{14}$ A. Alexander and R. Ehrmann (Berlin Pathol. Instit., Dept. Exp. Biol.), Zeitschr. f. exper. Pathol., 5, 367, 1909. 
pancreas and diabetic and the other a normal animal, and procured thorough commingling of the blood of the two by "crossed carotid transfusion," there was occasioned in the normal animal only a transitory glycosuria, while in the dog deprived of its pancreas (the experiment being continued a sufficient length of time) the glycosuria disappeared sometimes but returned after the carotid anastomosis had been separated. ${ }^{15}$ It is true these findings are neither constant nor entirely convincing, because a lowering of the renal secretion takes place in connection with them. Forschbach, in Minkowski's Clinic, was more fortunate in bringing about a blood mixture by an ingenious expedient by which he joined surgically a normal dog and one with pancreatic diabetes into one parabiotic double animal. In this experiment there not only occurred a lowering and actual disappearance of the glycosuria in case of the animal with pancreatic diabetes, "but the condition of the animals scarcely differed from that of health, and the disappearance of cachexia suggests the idea that the diabetic metabolic fault was attacked at the root."16 Basically considered one can readily appreciate that in such a pair of animals the pancreas of the normal individual with its internal secretory function is at the disposition of the partner without a pancreas, with the effect that the resultant symptoms are not necessarily manifested. According to Carlson the internal secretion can apparently pass in pregnancy from the fotus into the blood of the mother. ${ }^{17}$

Formation of Glycogen, Diastasic Power and Formation of Sugar from Carbohydrate-free Material in the Liver in Pancreatic Diabetes.-After complete extirpation of the pan-

${ }^{15}$ E. Hédon (Montpellier), C. R. Soc. de Biol., 66, 699, 1909; 67, 792, 1909 ; 68, 341, 1910; 72, 584, 1912; Rev. de Méd., 30, 617, 1910.

10 J. Forschbach (Minkowski's Clinic, Greifswald), Deutsch. med. Wochenschr., 1908, 910; Arch. f. exper. Pathol., 60, 131, 1909; cf. also E. Pflüger, Pflïger's Arch., 12ł, 633, 1908.

${ }^{17}$ A. J. Carlson and F. M. Drennan (Chicago), Amer. Jour. of Physiol., 28, $391,1912$. 
creas there is always seen after a time a marked impoverishment of glycogen in the canine liver. The muscles, especially the heart muscle, always retain their glycogen supply more obstinately than the liver. In contrast to this loss of glycogen from the large depots a striking glycogenic infiltration, according to Ehrlich, may be noted in the leucocytes; which is to be interpreted as a carbohydrate engorgement of these cells caused by the enrichment of the blood serum with sugar. When we consider the dominant position of the liver in carbohydrate metabolism we cannot be far wrong in relating the real nature of pancreatic diabetes with a disturbance of the glycogen function of the liver.

Actually what does the inability of the liver to fix glycogen in pancreatic diabetes (Naunyn has coined the term dyszooamylia for the condition) mean? Primarily it should be noted that the dyszooamylia applies only to dextrose, not to lavulose, Minkowski having shown that formation of glycogen from the latter substance may continue without disturbance even in the severest pancreatic diabetes. According to the investigations of J. de Meyer ${ }^{18}$ it would appear that the surviving liver of a dog with pancreatic diabetes may be found capable of storing glycogen provided pancreatic extract is added to the perfusing fluid. However, we can by no means assert an absolute inability of the liver to form glycogen in individuals with pancreatic diabetes, as Nishi ${ }^{19}$ (in a research under the direction of $\mathrm{O}$. Löwi) has been able to show that in turtles with pancreatic diabetes the formation of glycogen is the same as in normal turtles when the liver is perfused with Ringer's fluid containing glucose. Here, too, matters are by no means simple.

It is possible that an interpretation of the following kind

${ }^{18}$ J. de Meyer (Instit. Solvay, Brussels), Arch. intern. de Physiol., 9, 1, 1910.

${ }^{10}$ M. Nishi (Pharmacol. Instit., Vienna), Arch. f. exper. Pathol., 62, $170,1910$. 
might be proposed: that the liver itself is not actually incapable of building up glycogen in pancreatic diabetes, but that an increased activity of the hepatic diastasic ferment (normally kept in due bounds by the internal secretion of the pancreas) makes it impossible that the glycogen be retained. But apparently after extirpation of the pancreas the amount of diastase in the blood undergoes reduction. ${ }^{20}$ Statements indicating that the diastasic power of the liver is increased in diabetes ${ }^{21}$ are contradicted by other completely negative results. ${ }^{22}$ So there is no outlet apparent in this direction.

Pflüger noticed that in dogs with pancreatic diabetes, with marked emaciation and their fat largely lost, the liver in contrast with other organs had distinctly increased in weight. This suggests that the hepatic function here is not depressed, but that the organ really is working under abnormal stress to form out of carbohydrate-free material the large amounts of sugar which appear in the urine. Yet in this connection it may be noted that in Embden's laboratory in the artificially perfused liver of the depanereatized dog, practically free of glycogen, the new formation of sugar proved to be no greater than in an organ freed of its glycogen by work or by strychnia convulsions. ${ }^{23}$

For the present, therefore, we possess no satisfactory explanation for the mystery of pancreatic diabetes either in the formation of glycogen in the liver, its diastasic power, or in its ability to produce sugar from carbohydrate-free material.

Glycolysis.-The hypothesis framed by Lépine seems much more attractive. The pancreas is supposed by him

${ }^{20}$ W. Schlesinger (Vienna), Deutsch. med. Wochenschr., 1908, 593; L. K. Goult and A. J. Carlson (Chicago), Amer. Jour. of Physiol., 29, 165, 1911.

${ }^{21}$ A. Hinselmann (Med. Clinic, Heidelberg), Zeitschr. f. physiol. Chem., $61,265,1909$.

${ }^{22}$ I. Bang, Hofmeister's Beitr., 10, 320, 1907; F. A. Bainbridge and A. P. Beddard, Biochem. Jour., 2, 89, 1907; cf. also O. J. Wynhausen (Amsterdam), Berlin. klin. Wochenschr., 1910, 2107.

${ }^{23}$ L. Lattes, Biochem. Zeitschr., 20, 215, 1909. 
normally to produce a glycolytic ferment, which is missing in the depancreatized animal, for which reason the animal is unable to bring the sugar to its usual catabolism; the sugar, therefore, accumulates in the blood and thence passes into the urine. The original idea in this theory which would seek to place glycolysis normally in the blood, has been practically altogether given up; our present conception is that the sugar undergoes its destructive changes for the most part in the fixed tissues, not in the blood.

Otto Cohnheim ${ }^{24}$ believes he has evidence from studies upon the expressed juices of tissues that muscle contains an enzyme which is capable of inducing combustion of grapesugar to carbonic acid; which however does not exist in the muscle in active form for the most part, but requires for activation a material arising in the pancreas and passed thence into the blood stream, a "pancreatic activator." Occasion will be taken later, in summing up our conclusions upon glycolysis, to discuss the objections which have been made to Cohnheim's experiments.

In view of the undoubtedly very great difficulty of positively excluding interference from bacterial processes in experiments with expressed juices, it is a matter for special congratulation that certain recent comparative experiments upon the consumption of sugar by the normal and by the diabetic heart by one of the best of our living biological experimenters, E. H. Starling, ${ }^{25}$ are available. By an ingenious experimental mechanism he has succeeded in arranging a heart and lung preparation ${ }^{26}$ so as to keep a dog's heart beating for hours, working at normal arterial pressure and maintaining the normal amount of blood in

${ }^{24}$ O. Cohnheim, Zeitschr. f. physiol. Chem., 39, 396, 1903; 42, 401, 1904; $47,253,1906$.

${ }^{25}$ F. P. Knowlton and E. H. Starling (Univ. College, London), Centralbl. f. Physiol., 26, 169, 1912; Jour. of Physiol., 45, 146, 1912.

${ }^{28}$ Cf. E. Jerusalem and E. H. Starling, Jour. of Physiol., 40, 299, 1910. 
circulation. As shown by several investigators, ${ }^{27}$ a normal heart in beating is able to take up and consume a not inconsiderable amount of sugar from the circulating fluid. Starling found that the sugar consumption by the heart of a pancreatic-diabetic dog (transmitting its own blood) is minimal or practically nil. If, however, a heart from an animal with pancreatic diabetes was supplied with normal blood, it was able to consume sugar. Moreover when a small amount of pancreatic extract was added to the diabetic blood there always followed a marked rise in the sugar consumption in the diabetic heart. Starling states that "meanwhile the conclusion seems justified that normally a hormone is produced by the pancreas, the presence of which in the blood is essential to the assimilation and utilization of the blood sugar. Our experiments are proof that pancreatic diabetes is more likely to be caused by a diminished capacity of the tissue to make use of the sugar than by a primary exaggeration of its production." 28

The next question which presents itself is whether we are in position to frame some reasonable theory as to the kind of disturbance of function which interferes with the tissues consuming the sugar in a normal manner.

Oxidation Processes in the Diabetic Economy.-That we are not dealing here with a diminution of the oxidizing power of the tissues in general has been long known. On the contrary, recent investigations upon animals with pancreatic diabetes show that an increased consumption of oxygen may be regarded as a characteristic symptom in severe diabetes. $^{29}$ It luas also been shown that the first products of sugar oxidation, gluconic acid, glycuronic acid and saccharic acid,

${ }^{27}$ Chauveau and Kaufmann, Locke and Rosenheim, and Rohde.

${ }^{2 s}$ In reference to the hypotheses (Chauveau, Hédon, Kaufmann and others) which attempt to refer pancreatic diabetes to an increased sugar production dependent upon the effectiveness of the liver and of the central nervous system, see A. Biedl, l. c., pp. 391-392.

${ }^{20}$ C. v. Voit, Leo, Weintraud, Falta, Grote and Stähelin, Mohr; for Literæ ture consult R. Umber, Lehrb. d. Ernähr., p. 138, 1909. 
undergo combustion readily also in the diabetic organism ${ }^{30}$

$\begin{array}{lccc}\text { GLdCOSE } & \text { GLUCONIC ACID } & \text { GLYCURONIC ACID } & \text { SACCHARIC ACID } \\ \mathrm{CH}_{2} \mathrm{OH} & \mathrm{CH}_{2} \mathrm{OH} & \mathrm{COH} & \mathrm{COOH} \\ (\mathrm{CH} . \mathrm{OH}) & (\mathrm{CH} . \mathrm{OH})_{4} & (\mathrm{CH} . \mathrm{OH})_{4} & (\mathrm{CH} . \mathrm{OH})_{4} \\ \mathrm{COH} & \mathrm{COOH} & \mathrm{COOH} & \mathrm{COOH}\end{array}$

(as, too, it finds no difficulty in oxidizing a substance as close to dextrose as glucosamine, $\mathrm{CH}_{2} \cdot \mathrm{OH}-(\mathrm{CH} . \mathrm{OH})_{3}-$ CH. $\left.\mathrm{NH}_{2}-\mathrm{COH}\right){ }^{31}$ It might possibly be thought that the diabetic has merely lost the ability to manage the first step in sugar combustion (the oxidation of glucose into gluconic acid). If that were the case, however, it would be difficult to interpret the fact that diabetics react to the introduction of chloral, camphor, etc., just as the normal individual does, by the excretion of combined glycuronic acids. ${ }^{32}$ This shows clearly that the diabetic has the power to carry sugar oxidation as far as glycuronic acid. One might draw the conclusion from this that normal, physiological combustion of sugar does not follow the path through gluconic acid and glycuronic acid, that glycuronic acid is only produced exceptionally, if occasion demands detoxification of some foreign substance or other. It might be conceived, too, that in diabetes the economy still retains the ability to oxidize the sugar into glycuronic acid, but loses its ability to effect the normal, physiological catabolism of the sugar (presumably disintegration of its molecule into compounds with two or three carbon atoms, like lactic acid).

Metabolism in Pancreatic Diabetes.-As for the other metabolic features of pancreatic diabetes, the affection is characterized by a decided increase of protein and fat destruction and by an increased elimination of the mineral

${ }^{30}$ O. Baumgarten (Med. Clinic Halle), Zeitschr. f. exper. Pathol., 2, 53, 1905.

${ }^{31}$ J. Forschbach (Minkowski's Med. Clinic, Cologne), Hofmeister's Beitr., $8,313,1906$.

${ }^{32}$ See H. G. Wells, Chemical Pathology, p. 530, 1907; O. Baumgarten, Zeitschr. f. exper. Pathol., 8, 206, 1910. 
constituents. $^{83}$ Acidosis may be regarded as a symptom resulting from the destruction of fat (accumulation of $\beta$-oxybutyric acid, diacetic acid and acetone), which is met in pancreatic diabetes as well as in severe human diabetes. Whether these features are entirely and satisfactorily explained on the basis of a lowering of the consumption of sugar (by which the respiratory quotient is diminished) must for the present be left unanswered. ${ }^{34}$

From the above it might be expected that if the consumption of sugar in a dog with pancreatic diabetes be raised by physical exertion or exposure to cold, there would result a lowering of the sugar elimination. This is, however, by no means always the case, as shown by the studies of Embden and Lüthje. ${ }^{35}$ According to Minkowski, increased sugar consumption from physical exercise occurs only if some functionable remnant of the pancreatic tissue is present in the subject. After complete exclusion of the pancreatic function it seems that sugar can practically no longer be utilized to defray an increased demand for energy, and at best the latter would only lead to a heightened mobilization of sugar at the expense of the noncarbohydrate stores and therefore (as the mobilized sugar is not oxidized but excreted unchanged) to an increased intensity of the diabetes. Heat regulation in diabetic animals is correspondingly encroached upon apparently.

J. de Meyer, from a study conducted in Heger's laboratory in Brussels, would have it that the impermeability of the normal kidney to sugar is related with the internal secretion of the pancreas. If Locke's solution containing about the same proportion of sugar as occurs in the blood be perfused through the fresh (taken from a dog) kidney, sugar passes into the "urine." On adding a small amount

${ }^{3}$ S. la Franca (Naples), Zeitschr. f. exper. Pathol., 6, 1, 1909.

${ }^{34}$ Cf. F. Verzár (Tangl's Lab., Budapesth), Biochem. Zeitschr., 44, 201, 1912.

${ }^{35}$ H. Lüthje, Verh. d. 22. Kongress f. innere Med., Wiesbaden, 1905, 268; G. Embden, H. Lüthje and E. Liefmann (Frankfurt, a. M.), Hofmeister's Beitr., $10,265,1907$. 
of pancreatic extract to the circulating fluid this "glycosuria" diminishes appreciably. Other tissue extracts, however, apparently have no specific influence upon the renal permeability. Although these experiments may well permit other interpretations, they seem to deserve further consideration from the standpoint in view. ${ }^{36}$

Partial Extirpation of the Pancreas.-Attention should be directed to the recent reports upon partial pancreatic extirpation issued by F. Reach ${ }^{37}$ from Durig's laboratory. A long time since Sandmeyer noted an increased output of sugar in dogs after partial removal of the pancreas and administration of a mixed diet of raw horsemeat and raw pancreas; and explained it on the supposition of an augmentation in the utilization of the glycogen in the meat by the pancreatic ferment. Reach has shown that this explanation is not correct, but that the raw meat (compared with boiled meat) contains a poison, labile to boiling, which forces up the sugar-excretion in slightly diabetic dogs.

Antipancreatin Serum.-One can readily believe that it has not been possible to entirely resist the temptation of applying the advances in immunology to the great puzzle of pancreatic diabetes. That the blood of animals after extirpation of the pancreas does not contain any "toxine" capable of rendering normal animals diabetic was shown a long time ago by Minkowski and Mering. According to J. de Meyer, ${ }^{38}$ after injection of extracts of dog pancreas (heated previously to $70^{\circ}$ C.) a supposedly specific antibody ("antipancreatin") appears in the blood serum of rabbits, which not only reduces in vitro the glycolytic power

${ }^{36} \mathrm{~J}$. de Meyer (Instit. Solvay, Brussels), Arch. Internat. de Physiol., 8, 121, 1909; Recherche sur la signification et la valeur de la sécretion interne du Pancréas, Liége, Imprimerie H. Vaillant-Carmanne, 1910.

${ }^{27}$ F. Reach (Durig's Lab.), Wiener klin. Wochenschr., 1910, No. 41; Biochem. Zeitschr., 33, 436, 1911; cf. also J. Thiroloix and Jacob, Bull. et Mém. de la Soc. des Hôpit. de Paris, 1910, 492.

${ }^{88} \mathrm{~J}$. de Meyer, Arch. internat. de Physiol., 7, 317, 1909; 8, 121, 1909; 9, 1, $1910 ; 10,239,1910 ; 11,131,1911$; Recherche sur la signification, etc., 1. c.; Ann. Instit. Pasteur., 22, 778, 1908. 
of dog's blood, but in the living animal induces a hyperglycamia and a glycosuria of low grade. Objection has been raised to these findings, suggestion being made that the hyperglycrmia is not due to "antipancreatin" but simply to withdrawal of the blood required for examination. The writer is not in position to decide whether this objection is well founded or not, but all these matters are so complicated and ambiguous that he is not disposed to promise any too much from them for the future of the problem.

Isolation of the "Pancreatic Hormone."-There seems to be no more promise in the attempts to isolate the active principle of the pancreas which is concerned in carbohydrate metabolism, the so-called "pancreatic hormone." Realization of the pious wish to solve the enigma of pancreatic diabetes in the reagent glass seemed almost within grasp some few years ago when at the Congress of Internists of 1907 Zuelzer ${ }^{39}$ excited attention by his announcement that by injection of pancreatic preparations it is possible to check the course of adrenin glycosuria, and by administering pancreatic substance to the experiment animal prior to injection of adrenin to prevent it. Based upon this observation, which has been confirmed from many sources, ${ }^{40}$ Zuelzer ${ }^{41}$ later endeavored to apply the discovery to the treatment of human diabetes. The decided toxicity of the pancreas preparations (occasioned by the trypsin), however, interfered. But Zuelzer believed, nevertheless, that by a method which he kept secret, he had successfully detoxified his "pancreatic hormone" sufficiently to permit him to venture to inject it intravenously into diabetic subjects. In a number of cases of diabetes he succeeded in

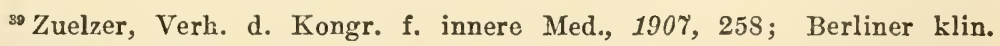
Wochenschr., 190\%, 474.

${ }^{40}$ C. Frugoni, Makaroff, J. Gautrelet, J. Forschbach, K. Glässner and E. P. Pick; for Literature, cf. O. v. Fürth, and C. Schwarz, Biochem. Zeitschr., 31, 114,1911 .

"Zuelzer, Dohrn and Marxer, Deutsch. med. Wochenschr., 1908, 1380; Zuelzer, Zeitschr. f. exper. Pathol., 5, 307, 1909. 
distinctly reducing the elimination of sugar and of acetone bodies. However, in these as well as in a test undertaken in Minkowski's Clinic, ${ }^{42}$ the suggestive fact was manifested that injections of "pancreatic hormone" were often followed by chills, fever of several days' duration and malaise. Still later the writer's colleague, C. Schwarz, and the writer ${ }^{43}$ were able to show, at least in case of intraperitoneal introduction of pancreatic substance, that this inhibition of adrenin glycosuria is not due to a mysterious antagonism between the "hormones" of the pancreas and of the adrenal glands, but probably is to be explained naturally and easily as depending upon a condition of peritoneal irritation ( $\mathrm{v}$. Vol. I of this series, p. 383, Chemistry of the Tissues). This may so affect the secretory ability of the kidneys that elimination of the dissolved constituents of the urine including sugar, is lowered without the quantity of fluid necessarily undergoing any coincident striking diminution. When this fact is considered along with the fact that a great variety of disturbances, perhaps not directly related with the peritoneum (as fever, suppression of urine, introduction of materials with lymphagogue action, etc.), ${ }^{44}$ are capable of inhibiting adrenin diabetes, there is apparently not sufficient ground here for a pancreatic treatment of diabetes. If in addition the statements of numerous authors ${ }^{45}$ are accepted, that injecting and feeding pancreatic substance not only does not arrest the glycosuria in animals with pancreatic diabetes, but in many instances actually intensi-

${ }^{42} \mathrm{~J}$. Forschbach (Minkowski's Clinic, Breslau), Deutsch. med. Wochenschr., 1909, No. 7.

${ }^{43}$ O. v. Fürth and C. Schwarz, Wiener klin. Wochenschr., 1911, No. 4, and Biochem. Zeitschr., 31, 113, 1911.

${ }^{44} \mathrm{Cf}$. the report of Mikulicich upon the inhibition of adrenin diabetes by hirudin (O. Löwi's Lab., Gratz), Arch. f. exper. Pathol., 69, 128, 1912.

${ }^{45}$ Cf. Literature in E. Leschke (Physiol. Instit., Bonn), Arch. f. Anat. 1t. Physiol., 1910, 401; Münchener med. Wochenschr., 1911, No. 26; cf. also N. Tiberti and A. Franchetti (Florence), Lo Sperimentale, 62, 81, 1908; E. L. Scott (Carlson's Lab., Chicago), Amer. Jour. of Physiol., 29, 306, 1912. 
fies it, Schwarz and the writer ${ }^{46}$ (as well as Leschke) can scarcely fail to be justified in characterizing the efforts to relieve human diabetes by intravenous injection of "pancreatic hormone" as physiologically incorrect and (in view of the danger attending) entirely inadmissible. Nor can the attempts of Vahlen, ${ }^{47}$ who believes he has isolated a substance from the pancreas which, while not directly attacking the sugar, accelerates alcoholic fermentation of the sugar, and lowers the sugar excretion in phloridzin diabetes and adrenin diabetes, make any difference in their conclusion.

The writer feels that it would be a good thing to consider carefully the above stated experiences in connection with the inhibition of glycosuria by administration of hydrazin, ${ }^{48}$ opium, ${ }^{48}$ atropine, ${ }^{50}$ zyzigium jambolianum and other drugs. ${ }^{51}$

\section{HUMAN DIABETES}

Degeneration of the Pancreas in Human Diabetes.-We may now pass to the consideration of human diabetes.

After the best informed experts in this affection, men like Naunyn, Minkowski and v. Noorden, as well as numerous pathological anatomists, had repeatedly pointed out a relation between diabetes and some functional fault of the pancreas, this in the author's opinion, seems to have been finally proved, whatever the contrary opinions, by the comprehensive investigations of the Viennese pathologist, Weichselbaum. He proved from a large amount of material at his disposal that degeneration of the islands of Langer-

${ }^{40} \mathrm{O}$, v. Fürth and C. Schwarz, l. c.

${ }^{47}$ E. Vahlen (Halle), Zeitschr. f. physiol. Chem., 59, 194, 1909.

${ }^{4}$ R. P. Underhill and M. Fine (Yale Univ., New Haven), Amer. Jour. Physiol., 10, 271, 1911.

${ }^{40}$ A. Gigon (Basel), Verh. d. 26. Kongr. f. innere Med., Wiesbaden, 1909, p. 441.

${ }^{80}$ Cf. Rudisch, Arch. f. Verdauungskr., 15, 469, 1909.

${ }^{51}$ M. Mikulicich (O. Löwi's Lab., Gratz), Arch. f. exper. Pathol., 69, 133, 1912, holds a specific renal impermeability for sugar responsible for the inhibition of adrenin glycosuria by ergotoxin as well as for inhibition of the hyperglyexmia. 
hans is to be looked upon as the anatomical basis of diabetes, and that as a matter of fact the severity of the case stands in direct relation with the degree of involvement of the islands. Weichselbaum differentiates a hydropic degeneration of these structures, a peri- and an intra-insular sclerosis and a hyaline degeneration, the last characterized by swelling of the connective tissue about the vessels of the islands into a homogenous mass. The negative findings of other author's in this line may be satisfactorily explained by the fact that these changes may very readily be overlooked, if particularly attentive examination be not made and if imperfect preservation of the material has obtained. ${ }^{52}$

As far as the cause of the pancreatic disease is concerned many authors are disposed to believe that a relationship with previous acute infectious diseases, although clinically this can only rarely be proved, is more important than the influence of arteriosclerosis, alcoholism, syphilis, intestinal infections, etc. ${ }^{53}$ That infectious diseases, even those of frankly mild type as influenza or angina, may make existing diabetes permanently worse and that transient glycosurias often occur in the course of febrile affections has been long known. Doubtless, too, from the studies of Weichselbaum, arteriosclerosis plays an important rôle in many forms of diabetes.

The liver has frequently been examined for anatomical changes in diabetes; but there can be little mistake in believing that in the great bulk of cases in which diabetes has appeared as a sequel of hepatic disturbances, as cirrhosis or cholelithiasis, secondary lesions of the pancreas are the real point in fault. Thus we may appeal to the frequent connective tissue hyperplasia in the pancreas in connection with cirrhosis of the liver (chronic pancreatitis of Hanse-

${ }^{52}$ A. Weichselbaum, Wiener klin. Wochenschr., 24, 153; Sitzungsber. d. Wiener Akad., 119, III, 73, 1910; consult therein, and also in U. Lombroso, Ergebn. d. Physiol., 9, 1-89, 1910, the Literature.

${ }^{*}$ Cf. F. Hirschfeld, Deutsche med. Wochenschr., 1909, 137. 
mann); and in the occasional cases of diabetes in which previous examinations have found a cirrhosis of the liver along with an apparently normal pancreas, it is very questionable whether there did not exist the above-mentioned hydropic changes of the islands of Langerhans, described $\bar{b} y$ Weichselbaum, which are so difficult of recognition. ${ }^{54}$ No doubt nervous lesions of very many types may give rise to glycosuria and be causative of true diabetes; and we may accept as a fact that nervous irritations are capable of inducing a liquidation of the glycogen stored in the liver, as seen in case of the experimental sugar puncture. This does not, however, at all affect our referring true human diabetes to the pancreas.

We are, therefore, fully justified from the present status of our knowledge in regarding human diabetes as a special type of pancreatic diabetes.

The writer can scarcely be expected to enter into any detailed description of this affection, the literature of which is enough to fill a whole library; it will probably suffice if a few points are brought out which, considered from the standpoint of a biological chemist, seem for the time to be of special interest, and to refer for the rest to Naunyn's classical work upon diabetes ${ }^{55}$ and to the recent excellent monographs by von Noorden, ${ }^{56}$ Magnus-Levy, ${ }^{57}$ and Umber. ${ }^{58}$

Glycogen Content of the Liver.-A point requiring at least brief consideration is the amount of glycogen found in the liver in human diabetes. As previously stated, Naunyn assigned to "dyszooamylia" an important position; and most writers are of the impression that, in severe diabetes at least, the power of the liver to store glycogen has been

*4 Cf. F. Umber, Lehrb. der Ernähr. u. Stoffwechselkr., p. 161, 1909.

${ }^{55}$ Naunyn, Diabetes Mellitus, 2d ed., Vienna, 1906.

${ }^{60}$ C. v. Noorden, Die Zuckerkrankheit, 5th ed., 1910; Handb. d. Pathol. d. Stoff wechsels, 2, 1-113, 1907.

${ }^{57}$ A. Magnus-Lery, Handb. d. Biochem., ' 4 , 356, et seq., 1909.

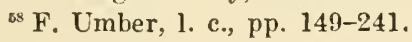


more or less seriously disturbed.59 Remembering the rapidity of postmortem disappearance of glycogen and the fact that the small amount of intake of nutrition before death may also influence the amount of glycogen in the liver, it is naturally somewhat difficult, to say the least, to come to any precise conclusions in a human diabetic as to his glycogen stock. The noted clinician, Frerichs, satisfied his curiosity in this respect (by a very direct method, but one scarcely to be commended for general use) by removing during life bits of liver tissue by puncture in two cases of diabetes; one of the specimens contained glycogen. When we recall that diabetic patients are able to change lævulose into glycogen more readily than they can transform glucose, it is very suggestive that, as a study in the Vienna Pharmacological Institute ${ }^{60}$ indicates, a rabbit's liver damaged by phosphorus poisoning makes a like differentiation between dextrose and lævulose; this particular power of differentiation is, therefore, by no means a characteristic of diabetes exclusively.

It has been previously stated that quantitative examination of the diabetic liver for its diastase has not led to definite conclusions.

Hyperglyccemia.-Hyperglycæmia indiabetic cases is generally accepted. While the amount of sugar in the blood of a normal human individual amounts to about 0.1 per cent., the proportions in the diabetic have been noted as high as one per cent. or even more. This in itself is sufficient reason for the presence of a considerable amount of sugar in the cerebrospinal fluid (obtained by lumbar puncture); notably, the highest figures (as high as three per cent.) having been met in comatose cases the urine of which contained only moderate amounts. ${ }^{61}$

Methylene-Blue Reaction of the Blood.-This character-

Cf. Literature: A. Magnus-Levy, 1. c., pp. 357-358.

${ }^{60}$ E. Neubauer (Pharmacol. Instit., Vienna), Arch. f. exper. Pathol., 61, 174, 1909.

e1 N. B. Foster, Boston Med. and Surg. Jour., 15\$, 441, 1905. 
istic color reaction of the blood in diabetes is supposed to be due to the hyperglycæmia. It has been noted that diabetic blood has the property of changing the color of methyleneblue to a yellowish red, apparently by some reduction process. Naturally it was supposed that the phenomenon is referable to the reducing power of the sugar in the blood. However, it was found that the red corpuscles of a diabetic, after they have been entirely freed from the sugar-containing plasma by repeated centrifugation with isotonic salt solution, fail to give the normal appearance of erythrocytes (when stained with methylene-blue). It is said, too, that this blood test may be met in cases long after the sugar has disappeared from the urine from withdrawal of carbohydrates. It may be, of course, that even in such cases the proportion of sugar in the erythrocytes is abnormally high. C. v. Noorden properly calls attention to the need of making quantitative comparisons between the proportion of sugar in the blood and staining qualities in order to gain an explanation of this reaction. ${ }^{62}$

Another question which is connected with the hyperglycæmia is whether the increased proportion of sugar in the blood in diabetes is necessarily due to an increased "impermeability of the kidneys for sugar."

Urinary Dextrine.-Very little attention has been given to the question whether besides the sugar it is possible that polymeric carbohydrates may also pass from the blood into the urine in diabetes. Alftan's ${ }^{63}$ estimations of an average excretion of 0.15 gram of "urinary dextrine" for a normal man and in severe diabetes of perhaps from 5 to 24 grams per diem apply here. The exact meaning of this "urinary dextrine," chemical study of which is as yet lacking, is another problem.

${ }^{69}$ C. v. Noorden, Handb. d. Pathol. d. Stoffw., 2d ed., 2, 104-105, 1907; ef. therein Literature.

${ }^{\circledR}$ K. v. Alftan, Ueber dextrinartige Substanzen im diabetischen Harne, Helsingfors, 1904. 
Protein Destruction.-In trying to come to some reasonably clear appreciation of the general course of metabolism in diabetes we must take prominently in consideration what is known of protein destruction in this abnormal condition. While, as has been noted above, in the pancreatic diabetes of the dog the decomposition of tissue proteins is apparently markedly increased, in severe cases of diabetes mellitus (as shown by the metabolic studies of Falta and Gigon) ${ }^{64}$ the destruction of protein does not proceed any more rapidly, and in special cases may be slower, than in normal persons who are examined under the same condition of nutrition. This is all the more remarkable when one considers that the diabetic patient undoubtedly fixes a distinctly smaller amount of material as reserve carbohydrate, and that the sugar excreted with the urine escapes combustion and cannot, therefore, serve to save the protein. The loss is apparently compensated for as far as possible by abundant intake of food protein. That the carbolydrate group in proteins is not of very great importance to the formation of sugar in the body has been shown to be true in case of human diabetes just as in other forms of glycosuria. ${ }^{65}$

Falta ${ }^{66}$ based his calculations upon the "excretion coefficient," that is, the ratio of sugar excretion, D, to the sugar value of the transformed material. He obtains this by the formula $q=\frac{D}{5 N+K}$, in which $\mathrm{N}$ is the amount of urinary nitrogen and $K$ the quantity of carbohydrate in the food ingested. This method of calculation is based upon Rubner's dictum that for each gram of transformed protein nitrogen a maximum of five grams of sugar are produced (that is to say, the sugar value of 100 grams of protein would be roughly $16 \times 5=80$ grams of dextrose).

That a combustible material like alcohol may serve to

${ }^{4}$ W. Falta and A. Gigon (W. His's Clinic, Basel, and C. v. Noorden's Clinic, Vienna), Zeitschr. f. klin. Med., 65, 3-4, 1908.

${ }_{85}$ Cf. E. Thermann (Helsingfors), Skandin. Arch. f. Physiol., 17. 1, 1905,

${ }^{6}$ W. Falta, J. H. Whitney (v. Noorden's Clinic), Zeitschr. f. klin. Med., $65,5-6,1908$. 
spare the proteins of the body and in this way lessen the sugar elimination at times in diabetics ${ }^{67}$ is easily appreciable; as, too, the fact that an influence tending to cause tissue break-down, as exposure to Röntgen rays, is likely to occasion an increase in the glycosuria in diabetes. ${ }^{68}$

There seem to be times when aminoacids pass into the urine in diabetes in increased amount; but little certain knowledge is had of this phenomenon. ${ }^{69}$

While to a certain extent toxic protein decomposition in human diabetes is, from what has been said, a matter of minor importance, the fat breakdown often dominates the general situation. This is really, as far as we can readily appreciate, what is actually meant when we are forced to say that the body must finally draw on some source to cover the necessary requirements for energy-production; if the sugar is eliminated unconsumed, if the tissue protein is preserved from destruction, and if the food protein is insufficient, there is nothing else left the body to draw upon except its stores of fat. Many writers are inclined to accept a possibility of sugar being formed from fat in severe diabetes. ${ }^{70}$ Later, in connection with acidosis in relation to fat decomposition, this subject will be more fully reverted to.

Brief reference should be made at this point to the relationship of obesity to diabetes. Very frequently in literature a "lipogenic diabetes" (diabète gras of the French) is spoken of. C. v. Noorden ${ }^{71}$ has suggested a very plausible idea in this connection, that there exists a form of masked diabetes in which the sugar does not pass into the urine even though the capacity for sugar combustion is

${ }^{6 \pi}$ H. Benedict and B. Török, Zeitschr. f. klin. Med., 60, 329, 1906.

${ }_{68}^{6}$ P. Menetrier and A. Touraine, Arch. Maladies de Coeur, 3, 641, 1910.

${ }^{69}$ P. Bergell and F. Blumenthal, Zeitschr. f. exper. Pathol., 2, 413, 1906; L. Mohr, ibid., 2, 665, 1906.

${ }^{70}$ Cf. E. Grafe and Ch. G. L. Wolf (Med. Clinic, Heidelberg), Deutsch. Arch. f. klin. Med., 10\%, 201, 1912.

${ }^{71}$ C. v. Noorden, Handb. d. Pathol. d. Stoff wechs., 2d ed., 2, 25-26, 1907. 
diminished; in such cases the excess of sugar is changed into fat and deposited as such. A "diabetogenous obesity" of this sort may, if glycosuria come to accompany it, be changed into the ordinary diabetes of the obese, and in the end into a severe diabetes, with development of a progressive loss of flesh.

DiabeticLipamia.-Finally among the disturbances of fat metabolism noted in diabetes, diabetic lipæmia ${ }^{72}$ presents special interest. While the quantity of lipoid substances in the blood plasma is normally scarcely more than one per cent., in diabetes it may rise to many times this proportion. Cases have been known in whom the blood from the veins looks like chocolate and cream, ${ }^{73}$ and in whom the vessels at autopsy appear as whitish cords. In one case more than one-fourth volume was obtained by ether extraction from the blood. ${ }^{74}$ Sometimes the fat is present in practically normal amount, but the cholesterin and lecithin are much increased. ${ }^{75}$ Upon what the lipæmia essentially depends, it is impossible to say. The fact that it frequently parallels the acidosis, and becomes especially marked in the coma, strongly suggests a connection with tissue disintegration, especially some process which sets free the fat. At one time a reduction of the lipolytic power of the blood was supposed to be an important factor. In recent times, however, our views have changed essentially in that (as will be discussed more fully hereafter) it has been recognized that the supposed destruction of fat in the blood is really a masking of the fat. We are likely, too, to view with a proper hesitancy statements to the effect that diabetic blood containing excessive fat shows a loss in the fat when mixed with normal blood. We did not in those earlier days clearly understand

${ }^{72}$ Literature upon Diabetic Lipæmia: C. v. Noorden, Handb. d. Pathol. d. Stoffwechs., 2d ed., 2, 102-104, 135, 1907.

${ }^{73}$ E. Neisser and E. Derlin, Zeitschr. f. klin. Med., 51, 428, 1904.

${ }^{74}$ C. Frugoni and G. Marchetti (Florence), Berlin. klin. Wochenschr., 1908, 1844.

${ }^{75} \mathrm{G}$. Klemperer and H. Umber, Zeitschr. f. klin. Med., 61, 145, 1907. 
the importance of the great changes which physical-chemical adsorption is likely to induce in colloidal systems.

Respiration Experiments in Diabetes.-Reference has already been made to the fact that we cannot seriously attribute any general reduction of oxidation processes to the diabetic organism. Numerous respiration experiments, first by Pettenkofer and Voit and later by other investigators, ${ }^{76}$ have shown in diabetics either normal ratios or in some instances a notable increase in the utilization of oxygen, ${ }^{77}$ just as has been noted in case of animals with pancreatic diabetes and supposedly due to stimulations caused by the sugar and acetone bodies. ${ }^{78}$

The hypothesis of Falta ${ }^{\text {i9 }}$ that diabetes is due to some disturbance in the equilibrium between the internal secretory glands (pancreas, the chromaffine system, the thyroid and parathyroids) which are presumed to regulate the metabolism of carbohydrate material, will be reverted to later.

Of course it is impossile here to take up fully the matter of dietetic treatment of diabetes, desirable and important as it is for the practitioner; at best it must suffice to briefly refer to a few points of special biochemical interest.

Substitutes for Bread for Diabetics. - The fact that lævulose is invariably assimilated with more readiness by the diabetic economy than dextrose has led to the employment of its polysaccharide, inulin (which occurs in Jerusalem artichoke meal, black salsify and artichokes) as an article of diet for diabetics. Experiments in Naunyn's clinic have, however, indicated that while occasional use of this sugar or its polysaccharide is well tolerated, the toleration soon de-

${ }^{76}$ Leo, Katzenstein, Weintraud and Laves, Magnus-Levy, Mohr. Literature: A. Jaquet, Ergebn. d. Physiol., 2', 555-556, 1903; Umber, Lehrb. d. Ernähr., p. 171, 1909.

${ }^{n} \mathrm{Cf}$. the experiments of W. Falta (with Benedict), conducted with the respiration calorimeter in Boston: Wiener klin. Wochenschr., 22, 565, 1909.

${ }^{7 s}$ A. Leimdörfer (v. Noorden's Clinic), Biochem. Zeitsehr., 40, 326, 1912. ${ }^{70}$ W. Falta (v. Noorden's Clinic), Zeitschr. f. klin. Med., 66, 5-6, 1908. 
creases in continued ingestion, in consequence of which little can be promised for these types of carbohydrate as a diabetic food.80 Nevertheless "inulin treatment"' has recently been strongly recommended again. ${ }^{81}$

The desirability of discovering some form of harmless carbohydrate for diabetics has led to many experiments in this line. ${ }^{82}$ Thus it is said that a hemicellulose preparation made from agar-agar, which yields principally galactose on hydrolysis, has proved useful in continuous administration of diabetics, ${ }^{83}$ although galactose occasions an increase of dextrose in the urine in diabetic animals. ${ }^{84}$ From Iceland moss, which contains dextrine-like substances, hemicelluloses and pentosans, after modifying its bitter materials by mixing with proteins, a bread has been baked. ${ }^{85}$ Aleuronat bread has been used as a carbohydrate-poor bread-substitute; it is prepared from a mixture of ordinary flour with aleuronat meal which is rich in protein but poor in carbohydrate.

Oat-Treatments.-C. v. Noorden's observation as to the influence of "oat-meal teatment" in diabetes is interesting and of practical importance. The method presents the superficial paradox that many severe cases of diabetes pass less sugar in the urine when given considerable amounts of oat-meal than when kept on the strictest diet.8 ${ }^{86}$ Most authors who have tried von Noorden's suggestion have been forced to acknowledge that the treatment in certain cases is followed by a diminution of the glycosuria and acidosis and by an increased tolerance for carbohydrates. ${ }^{87}$ It is

${ }^{\mathrm{s} 0}$ Cf. F. Umber, Lehrb. der Ernähr., p. 201, 1909.

${ }^{81}$ H. Strauss (Berlin), Berl. klin. Wochenschr., 1912, 1912.

${ }^{82}$ Cf. A. Magnus-Levy, Berl. klin. Wochenschr., 1910, 233.

${ }^{53}$ A. Schmidt and H. Lohrisch (Halle), Deutsch. med. Wochenschr., 1908, 2012.

${ }^{84} \mathrm{IV}$. Brasch, Zeitschr. f. Biol., 50, 113, 1908.

${ }^{85}$ E. Poulsson, Festschr. f. O. Hammersten, Wiesbaden, 1906; cited in Centralbl. f. Physiol., 21, 196, 1907.

${ }^{86}$ C. v. Noorden, Berlin klin. Wochenschr., 1903, 817.

${ }^{87}$ Cf. Literature: C. v. Noorden, Handb. d. Pathol. d. Stoffwechs., 2d ed., 2, 63, 1907, and F. Umber, Lehrb. d. Ernähr., pp. 20S-210, 1909; Klotz (Strassburg), Zeitschr. f. exper. Pathol., 8, 601, 1911. 
not known how to explain this remarkable influence. By some it is said that the oatmeal shows its full specific influence only when used in whole form, the individual constituents failing of effect. ${ }^{83}$ Others ${ }^{89}$ hold that experiments with isolated oat-starch give practically the same favorable results as does ordinary oat-meal diet. Oat-starch, if this be true, is different from other starches in its behavior in the diabetic economy.

Influence of Mineral Waters.-It is generally known that the use of certain mineral spring waters has long played a large rôle in the treatment of diabetes. "The real factors in the undoubtedly favorable influence of residence in establishments at Carlsbad, Neuenahr, etc., upon certain forms of diabetes," remarks F. Umber ${ }^{90}$ in his excellent book, full of the spirit of the wholesome critic, "are certainly not due to the effects of the waters themselves, but to other conditions, as the rest, the well-regulated mode of living, change of surroundings and, by no means the last, to physicians especially experienced in this field of pathology. The diabetic subjects who are most benefited on the spot from this sort of treatment are those belonging in the milder type of the disease, possibly afflicted by disturbances of the liver, the digestive organs, etc., upon which as experience shows the methods of treatment at the baths have an especially good influence. These people are likely to be particularly benefited at such cures if they are not in position, for special professional or other reasons, to live a properly regulated life at home."

Medicinal Treatment of Diabetes.-Naunyn is disposed to pass a practically quashing judgment upon the medicinal therapy of diabetes, characterizing the whole numberless

${ }^{88}$ O. Baumgarten and G. Grund (Halle, a. S.), Deutsch. Arch. f. klin. Med., 104, 168, 1911.

${ }^{8}$ A. Magnus-Levy, Verhandl. d. 28. Kongr. f. innere Med., Wiesbaden, p. 246, 1911; cf. also discussion ensuing.

${ }^{90}$ F. Umber, Lehrb. d. Ernähr., usw., p. 236, 1909. 
group of remedies which have been used and lauded, as untrustworthy or ineffective (with the exception of opium). It is not known which of the alkaloids of opium is responsible for the influence clearly manifested in many cases by the drug in lowering glycosuria. One can scarcely expect that as long as the real nature of diabetes is not thoroughly appreciated any particularly brilliant result will be attained by an essentially desultory prying around with physiologically different or even indifferent substances. 


\section{CHAPTER XII}

PHLORIDZIN DIABETES. LEVULOSURIA. LACTOSURIA. PENTOSURIA. EXPERIMENTAL GLYCOSURIAS OF DIFFERENT KINDS

\section{PHLORIDZIN DIABETES}

HAVING familiarized ourselves in the last lecture with the general nature of pancreatic diabetes, our attention may be devoted to other physiologically important forms of glycosuria, of which phloridzin diabetes is the first to be taken up for consideration.

As is well known we are indebted to J. von Mering for the discovery that a glucoside found in the roots of apple-, pear- and cherry-trees, known as phloridzin, when given to human beings or to animals, is capable of causing a notable excretion of sugar. On hydrolysis phloridzin splits into glucose and phloretin, the latter substance also manifesting diabetogenous properties. If the phloridzin be given regularly at intervals of a few hours, a persistent "phloridzin diabetes'" will result, as pointed out by M. Cremer and by Graham Lusk. ${ }^{1}$

Absence of Hyperglyccmia.-It was soon recognized that phloridzin diabetes differs essentially from pancreatic diabetes, and fails to show one of the principal characteristics of the latter, as well as of most of the other forms of glycosuria, namely, hyperglycæmia. The amount of sugar in the blood, as proved by numerous investigators, is not only not increased in phloridzin diabetes, but on the contrary is often diminished. ${ }^{2}$ While in pancreatic diabetes after removal of the kidneys or ligation of the ureters large

${ }^{1}$ Literature upon Phloridzin Diabetes: M. Cremer, Ergebn. d. Physiol., 1', 883-886, 1902; K. Glässner, Centralbl. f. Stoffwechselkr., 1, 673-705, 1906 ; F. Umber, Lehrb. d. Ernährung, pp. 143-146, 1909; A. Magnus-Levy, Handb. d. Biochem., 4’, 366-368, 1909; Graham Lusk, Ernährung u. Stoffwechsel (German translation by L. Hess), p. 247, et seq., 1910.

${ }^{2}$ Cf. P. Junkersdorf (Bonn), Pflüger's Arch., 136, 306, 1909; A. Erlandsen (Lund), Biochem. Zeitschr., 23, 329, 1910; 24, 1, 1910. 
amounts of sugar accumulate in the blood, here one cannot find evidence of any sugar stagnation. The explanation of this peculiarity is simply that the kidney is concerned here, not merely with the excretion of the sugar that is brought to it, but that in phloridzin diabetes the latter is, at least in large part, produced in the kidney itself. Here, therefore, we are dealing with a "renal diabetes."

Rôle of the Kidney.-There can be no doubt as to the essential part played by the kidneys in phloridzin diabetes. This was impressed long ago by the experiment of N. Zuntz, who noted when he injected the glucoside into one of the renal arteries that the corresponding kidney eliminated sugar earlier and more freely than its fellow. ${ }^{3}$ In the same line are to be classed the perfusion experiments upon excised living kidneys conducted by Biedl and Kolisch ${ }^{4}$ and by Pavy ${ }^{5}$ and his collaborators. Exactly what is the renal activity in phloridzin diabetes? Wohlgemuth believes we are justified in concluding there is an increase of diastases in the kidneys, produced from the influence of the phloridzin, leading to an increased enzymic activity of the renal cells. ${ }^{6}$ Otto Löwi ${ }^{7}$ was able to show, contrary to opposite opinions, ${ }^{8}$ that sugar elimination by a phloridzin kidney is not increased by setting up in addition a salt diuresis. There is, therefore, an increased activity of a special kind seen in the effect of phloridzin.

Many writers were disposed to interpret phloridzin diabetes on the assumption that normally the blood sugar is retained by the kidneys because it is not in a free state but in colloid combination; that in phloridzin diabetes this com570.

${ }^{3}$ N. Zuntz, Verh. d. Berlin. Physiol. Ges., Arch. f. Anat. u. Physiol., 1895,

${ }^{4}$ A. Biedl and Kolisch, Verh. d. 18. Kongr. f. innere Med., p. 573, 1900.

${ }^{5}$ F. W. Pavy, T. G. Brodie and R. L. Siau (London), Jour. of Physiol., 29, 467, 1903.

${ }^{6} \mathrm{~J}$. Wollgemuth, and J. Benzur, Biochem. Zeitschr., 21, 460, 1909.

'Otto Löwi and E. Neubauer (Pharm. Instit., Vienna), Arch. f. exper. Pathol., 59, 57, 1908.

${ }^{8}$ S. Weber (Minkowski's Clinic), Arch. f. exper. Pathol., 5/, 1, 1905. 
bination is broken in the kidneys and these organs are then enabled to filter the sugar out of the blood. Under the influence of phloridzin very considerable quantities of sugar may appear in the urine, to be invariably made good at expense of the proteins after consumption of the carbohydrate supply of the body. Possibly this may be explained by the idea that (very much as a Toricellian vacuum has a tendency to attract gases) the body does not permit the existence of a "sugar vacuum" in the blood but endeavors to repair the void with all the substances at its command. But in criticism of this attempt to explain the nature of phloridzin diabetes it must be recalled that, as has been previously discussed, we have no certain ground for predicating the existence of such a colloidal combination of the sugar in the blood.

There is no reason for supposing this form of diabetes to be in any way related with the glycogen function of the liver. Frank and Isaak ${ }^{9}$ were able to show that $\operatorname{dogs}_{\mathrm{s}}$ in state of starvation continue to eliminate large amounts of sugar when phloridzin is administered even after inhibition of the hepatic function (that is, after severe changes have been produced) by phosphorus poisoning.

Formation of Sugar in the Kidney.-These last authors have, in the writer's opinion, made a suggestion worth considering, that the kidney under the influence of phloridzin is not only able to separate sugar from the blood, but becomes capable of inducing synthesis of sugar and acquires the property of building up sugar from non-carbohydrate primary material. The observation that in animals with phloridzin diabetes there usually is to be found an increased quantity of sugar in the blood after some days of well marked hypoglycæmia is explained on the supposition that the blood becomes charged with sugar from the kidneys.

${ }^{9}$ E. Frank and S. Isaak, Verh. d. 17. Kongr. f. internal. Med., Wiesbaden, 1910. p. 586; Arch. f. exper. Pathol., 64, 274, 293, 1911.

10 R. Lépine, C. R. Soc. de Biol., 68, 448, 1910. 
Lépine's ${ }^{10}$ discovery that in phloridzin poisoning the blood of the renal vein contains more sugar than that of the renal artery may be regarded as in the same line. Asher, ${ }^{11}$ after stimulating the chorda tympani found such a marked increase of sugar in the blood passing from the submaxillary salivary gland that it must necessarily be assumed that under irritation sugar passes out of the glandular cells into the blood. It may be conceired that in an analogous manner the kidney under the stimulus of phloridzin becomes able to give off an excess of sugar to the blood. Frank and Isaak, however, would explain the essential character of phloridzin diabetes as consisting of an acquired inability on the part of the kidneys to fix the glucose brought to them by the blood and utilize it in their own metabolism, and as a consequence becoming permeable to the sugar and excreting it. Just as the liver in pancreatic diabetes-and with the very same failure - the kidney attempts to make good the loss by continuous reformation. The question whether the phloridzin kidney really acquires the ability to produce sugar de novo is one which apparently should receive further study.

The hypothesis that the influence of phloridzin is productive of "a general glandular diabetes with predominant involvement of the kidneys" and of a disturbance of the vital sugar fixation ${ }^{12}$ finds some support in the fact that, as proved upon a dog with a biliary fistula, after injection of phloridzin sugar is to be found not only in the urine but also in the bile. ${ }^{13}$ No constant direct influence from phloridzin upon the formation of glycogen in the liver has been successfully proved by perfusion experiments. ${ }^{14}$ It may, therefore, be conjectured that the sugar elimination in phloridzin diabetes results from activity of the glandular epithelium in much the same way as milk sugar is produced

"L. Asher and Karaulow, Biochem. Zeitschr., 25, 36, 1910.

12 E. Frank and S. Isaak, Arch. f. exper. Pathol., 64, 326, 1910.

${ }^{23}$ R. T. Woodyatt (Chicago), Jour. of Biol. Chem., 7, 133, 1910.

${ }^{14}$ B. S. Schöndorff and F. Suckrow (Bonn), Pflüger's Arch., 138, 538, 1911; opposed view, K. Grube, ibid., 128, 1909, and 139, 1911. 
in the mammary glands. It is interesting to note, too, that phloridzin has been found by observations on milk cows to increase the amount of sugar in milk, ${ }^{15}$ which may, however, perhaps be due to a relative inspissation of the milk from the effect of the increased diuresis. ${ }^{16}$ Significantly, Underhill has been able to show that hyperglycæmia will result from administration of phloridzin after excluding the renal function. ${ }^{17}$

Numerous investigations have been made upon the general metabolism in phloridzin diabetes. The same results have been obtained in the ratio between sugar elimination and nitrogen elimination in the dog with phloridzin diabetes as in the diabetic human being ( $D: N=3.6: 1$ ) in the studies of Graham Lusk and his associates. ${ }^{18}$ It is worthy of note that an injection of phosphorus, which in a normal dog is followed by a marked increase of nitrogen elimination, in the dog with phloridzin diabetes causes no greater heightening of toxic protein decomposition. ${ }^{19}$ The increase of creatinin excretion ${ }^{20}$ and of elimination of aminoacids ${ }^{21}$ seen in phloridzin diabetes may be regarded as evidence of this protein destruction.

From the investigation of G. Rosenfeld, J. Baer and others it is evident that a disturbance of the nitrogen balance, as that induced by starvation or carbohydrate-free diet, occurs in phloridzin diabetes with mobilization of fat and acidosis. The former of these features manifests itself as a fatty infiltration of the liver, the fat disappearing from other parts of the body and massing itself in the liver.

${ }^{15}$ Cornevin, Compt. Rend., 116, 263, 1893.

${ }^{10}$ C. Porcher, Compt. Rend., 188, 1475, 1908.

${ }^{17}$ F. P. Underhill (Yale Univ., New Haven), Jour. of Biol. Chem., 19, 15, 1912.

${ }^{1 s}$ G. Lusk, Ernährung und Stoffwechsel, p. 250, et seq., 1910; cf. also A. J. Ringer (Univ. of Penna.), Jour. of Biol. Chem., 12, 431, 1912.

10. E. Ray, T. S. MeDermott and Graham Lusk, Amer. Jour. of Physiol., 3, 139, 1899.

${ }^{30}$ C. G. L. Wolf and E. Osterherg (Cornell Univ., New York), Amer. Jour. of Physiol., 28, 71, 1911.

${ }^{21}$ J. Yoshikawa (Kyoto), Zeitschr. f. physiol. Chem., 78, 475, 1911. 
Fate of Phloridzin in thaBody.-In reference to this point it has been shown by a study emanating from the laboratory of $\mathrm{M}$. Cremer ${ }^{22}$ that a portion of the phloridzin is excreted in the form of a combined glycuronic acid. Another part apparently undergoes further change; after subcutaneous injection (according to investigation by $\mathrm{K}$. Glässner and E. P. Pick) phloridzin can always be found for some time in the blood and tissues of the experiment animal. In nephrectomized animals, however, after small doses the glucoside disappears, which perhaps may be interpreted by supposing that this foreign substance is destroyed with increased readiness in the body if its normal elimination is prevented. ${ }^{23}$ The real situation of affairs is, however, not clear.

Little is known of the finer mechanism of this remarkable metabolic influence of phloridzin. Offhand it is difficult to decide whether Bürcker's ${ }^{24}$ observation that phloridzin inhibits spontaneous oxidation of glucose in alkali solution, has anything to do with its effect in producing diabetes. It is worth noting, even if one cannot readily understand them, that experiments in Salkowski's laboratory have shown that aliphatic alcohols with an odd number of carbohydrate atoms in the molecule (methyl alcohol, propyl alcohol, amyl alcohol, glycerol), but not those with an even number (as ethyl alcohol and butyl alcohol) give rise to an increase of sugar excretion in phoridzin animals. ${ }^{25}$ Perhaps this may prove a loop hole through which we may approach a little nearer the secret of sugar synthesis in the phloridzin kidney.

${ }^{22}$ J. Schüller (Lab. of M. Cremer, Cologne), Zeitschr. f. Biol., 56. 274, 1911.

${ }^{23} \mathrm{~K}$. Glässner and E. P. Pick (R. Paltauf's Lab.), Hofmeister's Beitr., 10, 473, 1907; Pflüger's Arch., 133, 82, 1910; J. Schüller, l. c., p. 290; cf. also opposed view of E. Leschke, Arch. f. Anat. u. Physiol., 1910, 437; Pflüger's Arch., 132, 319, 1910; 135, 171, 1910.

${ }^{24}$ Bürcker (Tiibingen), Deutsch. Physiol. Kongr., München, 1911, Centralbl. f. Physiol., 25, 1091, 1911.

${ }^{25}$ P. Höckendorf (Pathol. Instit., Chem. Div., Berlin), Biochem. Zeitschr., $23,281,1909$. 
The capacity of glutaric acid to inhibit the glycosuria of phloridzin intoxication, discovered by E. Baer and Blum, must probably be regarded as in some way comnected with an influence of the former upon the kidneys. ${ }^{26}$

Having discussed the nature of the two most important, and as it were classical forms of experimental glycosuria, pancreatic diabetes and phloriclzin diabetes, as far as is here possible and as far as the present status of our knowledge permits, our attention may next be given to several atypical forms of glycosuria, namely, lcevulosuria, pentosuria and lactosuria.

\section{LAEVULOSURIA}

The literature devoted to lævulosuria, as may be seen in the comprehensive articles upon the subject by Neuberg, ${ }^{2 \tau}$ Magnus- Levy ${ }^{28}$ and Umber ${ }^{29}$ occupies a considerable space, - greater, probably, than the actual importance of the subject requires. Many cases in the older literature, said to be instances of lævulosuria because of their polarimetric characteristics, should be excluded for the reason that in their determination no care was taken to exclude the possibility that lævogyration might have been due to $\beta$-oxybutyric acid or combined glycuronic acids.

Detection of Lcevulose.-One should not be content in trying'to determine the existence of a lævulosuria with the recognition of disproportion between polarimetric features, grade of reducing and fermentescibility of the specimen, but should employ more direct methods. Seliwanoff's test in its various modifications, producing a red color when the specimen is boiled with resorcin and hydrochloric acid, is the most prominent. The red color changes to a yellow

${ }^{26}$ Cf. G. G. Wilenko, Ther. d. Gegenw., 1909, 227; E. Frank and S. Isaak, Verhandl. d. 27. Kongr. f. inner Med. (Senator's Clinic), Wiesbaden, 1910, p. 590.

${ }^{27}$ C. Neuberg, Handb. d. Pathol. d. Stofiwechs., 2d ed., 2, 212-219, 1907.

${ }^{28}$ A. Magnus-Levy, Handb. d. Biochem., f', 385-394, 1909.

$\approx$ F. Umber, Lehrb. d. Ernährung, pp. 249-253, 1909. 
in acetic ether when the solution is alkalinized with soda. The interpretation of the result of this reaction, however, requires considerable judgment, as the presence of nitrites in the urine can be mistaken for the presence of lævulose. ${ }^{30}$ Other color reactions are also employed for the detection of lævulose, among them the blue coloration resulting from boiling the urine with diphenylamine and hydrochloric acid. ${ }^{31}$ According to Neuberg, the asymmetrical methylphenylhydrazine, ${ }_{\mathrm{C}_{6} \mathrm{H}_{5}}^{\mathrm{CH}_{3}}>\mathrm{N}-\mathrm{NH}_{2}$, forms an osazone directly only with lævulose of the sugars which are to be considered, but with the isomeric aldehyde sugars (glucose, galactose, mannose) it constantly forms only the hydrazone. Neuberg ${ }^{32}$ regards this as an available test (contrary to objections which have been raised to the trustworthiness of the reaction). ${ }^{33}$

Transformation of Glucose into Lavulose.-In addition to the difficulty of analysis mentioned it is essential, in order to properly appreciate the statements about lævulosuria in literature, to keep prominently in mind the fact that glucose and lævulose under the influence of hydroxyl-ions may be very readily transformed one into the other both within and outside the animal body. Thus in an alkaline diabetic urine, especially after use of alkaline drinking waters a so-called "urogenous" lævulosuria can very readily appear. ${ }^{34}$ Although formerly much was said and written about lævulosuria in diabetes under the name "mixed melituria," most of the recent investigators agree that a true lævulosuria, if it ever occurs, certainly is of very great

${ }^{30}$ H. Posin, Salkowski Festschrift, eited in Jahresher. f. Tierchem., 34, 917, 1904; L. Borchardt, Zeitschr. f. physiol. Chem., 55, 241, 1908; 60, 411, 1909; H. Malfatti (Innsbruck), ibid., 58, 544, 1909; O. Adler (Prague), Pflüger's Arch., 139, 93, 1910.

${ }^{31}$ Cf. Literature: A. Jolles, Münchener med. Wochenschr., 57, 353, 1910.

${ }^{82}$ C. Neuberg, Ber. d. deutsch. chem. Ges., 37, 4616, 1904.

${ }^{32}$ R. Ofner (Prague), Ber. d. deutsch. chem. Ges., 37, 3362, 1904.

${ }^{34}$ Cf. H. Königsfeld, Zeitschr. f. klin. Med., 69, 3-4, 1909. 
rarity..$^{3.5}$ Contrary statements can be clearly explained as faults of observation. ${ }^{36}$

True Lavulosuria.-A spontaneous true lævulosuria seems to be a very rare abnormality, seen beyond question in only a very few cases, and cannot be said to be related with diabetes. It may be influenced by ingestion of lævulose or cane-sugar, but not of grape-sugar, and disappears on a carbohydrate free diet. ${ }^{37}$

The significance of presence of lævulose in the amniotic fluid and in the urine of new-born calves is unknown. ${ }^{38}$ Attention has been called with propriety to the possibility that the lævulose excreted by the calves in the first few days of their lives may have come from amniotic fluid which they swallowed. ${ }^{39}$

Alimentary Lavulosuria.-In the course of the last few years a number of observations upon alimentary lævulosuria have been collected, frequently occurring, as Strauss first pointed out, along with disturbances of the hepatic function. Thus a decrease in tolerance for lævulose has been met in cirrhosis of the liver, in marked biliary stagnation, phosphorus poisoning, and analogous conditions. ${ }^{40}$ The fact that an alimentary lævulosuria is a frequent complication of pregnancy ( $v$. sup.) may also be suggestive of a hepatic functional disturbance. Such functional faults are in sharp contrast with true diabetes, as in this latter condition, as has been seen, the tolerance for lævulose tends to be less diminished than that for dextrose.

So much for lævulosuria.

${ }^{35}$ L. Borchardt, l. c.; O. Adler, l. c. ; H. Malfatti, l. c.; H. Chr. Geelumyden (Christiania), Zeitschr. f. klin. Med., \%0, 287, 1910.

${ }^{30} \mathrm{Cf}$. criticism by Borchardt upon the work of W. Voit, Zeitschr. f. physiol. Chem., 58, 182, 1909; 60, 411, 1909, and reply thereto, ibid., 61, 92, 1909.

${ }^{37}$ Cf. Literature: F. Umber, 1. c., pp. 250-251, and Magnus-Levy, I. c., p. 391 .

${ }^{8 s}$ L. Langstein and C. Neuberg, Biochem. Zeitschr., 4, 212, 1907.

${ }^{29}$ A. Magnus-Levy, 1. c., p. 390 .

${ }^{40} \mathrm{Cf}$. Literature in F. Umber, Salkowski Festschr., 1904, and in H. Hohlweg (Giessen), Arch. f. klin. Med., 97, 443, 1909. 


\section{LACTOSURIA}

Another anomaly of metabolism of some physiological interest is lactosuria. ${ }^{41}$

The study of this condition began with a discovery by Hofmeister in 1877 of a reducing substance in the urine of lying-in women which he recognized as milk-sugar.

Since then we have framed fairly clear conceptions of the conditions under which lactose passes into the urine. We know as the ability to hydrolyse the milk-sugar and to make full use of it is missing from the blood and the tissues generally, that lactose thus entering the circulation parenterally is excreted in the urine, as above noted. It is possible that the animal economy may in a measure acquire the ability to split milk-sugar parenterally and utilize it if repeated injections of milk-sugar be given ${ }^{42}$; but at any rate this capability does not exist in the normal body.

Lactosuria of Puerperal Women.-There is nothing remarkable in the fact that if a woman in the puerperium suddenly has an interruption of suckling her infant and of thus eliminating large amounts of milk-sugar in her milk, the breasts do not at once stop producing lactose. This pent-up lactose will eventually be resorbed into the olood and thence naturally pass into the urine. Lactosuria, therefore, often appears, and has been frequently observed, as a reaction of the system to a sudden weaning; and may continue for a long time, especially in good nurses. In milk-cows lactosuria is a physiological phenomenon. ${ }^{43}$

Again, lactosuria may occur shortly before delivery, as at this time the mammary glands are beginning to assume their duty and even the colostrum contains lactose. C. v. Noorden and Zuelzer have observed even in cases of abor-

${ }^{4}$ Literature upon Lactosuria: C. Neuberg, Handb. d. Pathol. d. Stoffw., 2, 235-241, 1909; A. Magnus-Levy, Handb. d. Biochem., 4', 378-384, 1909.

${ }^{42}$ Cf. J. S. Leopold and A. v. Reuss (Pediatric Clinic, Univ. Vienna), Monatschr. f. Kinderheilk, 8, 1, 453, 1909.

${ }^{43}$ Sieg, Arch. f. Tierheilkunde, 35, 114, 1909, cited in Jahresber. f. Tierchem., \$9, 663, 1909 . 
tion, in which there could be no occasion for colostrum production normally, that the system was distinctly disposed toward elimination of milk-suger in that, after administration of large doses of dextrose, there did not occur a glycosuria but a lactosuria. Here the less readily assimilated carbohydrate was forced out of metabolism by the more easily consumed one. C. v. Noorden interpreted this as a provision in the interest of the offspring by which the economy in preparation for lactation loses its power of destroying milk-sugar. ${ }^{44}$ That the lactose appearing in the urine of nursing individuals has its origin from the mammary glands appears from observations of disappearance of the lactose from the urine of lactating guinea pigs if their mammary glands are amputated. On the other hand, however, observations of $\mathrm{P}$. Best and Porcher ${ }^{45}$ are recorded showing that removal of the nammary glands gives rise to glycosuria (not lactosuria) in lactating goats. This observation (not uncontradicted) ${ }^{46}$ was supposed to indicate that the liver is thus interrupted in furnishing to the functionating mammary glands the large amounts of glucose which may be supposed to be converted in the latter into milk-sugar. If this glucose from the liver is transferred into the circulation without the chance of its proper use because of the absence of the mammary glands, of course its excretion into the urine takes place to prevent the impending hyperglycæmia.

Lactosuria in Infants.-The lactosuria of infants at the breast is quite a different affair. It has been carefully studied by Langstein and Steinitz, ${ }^{47}$ and is referred to a pathological insufficiency of enzymic milk-sugar cleavage in

* Cf. C. Neuberg, 1. c., p. 240.

${ }^{45}$ C. Porcher, Compt. Rend., 140, 1279, 1905; 141, 73, 1905; Arch. Internat. de Physiol., 8, 356, 1909; Biochem. Zeitschr., 23, 370, 1910.

${ }^{46}$ C. Foà (Turin), Arch. di fisiol., 8, cited in Biochem. Centralbl., 8 , 1587, 1909; A. Magnus-Levy and L. Zuntz, Handb. d. Biochem., 4', 382, 1909; B. Moore and W. H. Parker (Yale Med. School, New Haven), Amer. Jour. of Physiol., 4, 239, 1900.

47 L. Langstein and F. Steinitz, Hofmeister's Beitr., 7, 575, 1906. 
the intestine. It can be readily appreciated that the lactose absorbed without preceding cleavage and in a sense a foreign substance to the tissues, cannot be utilized in the economy of the infant. It should be noted that C. v. Noorden and Zuelzer ${ }^{48}$ have also encountered appreciable amounts of lactose in the urine of children, not suffering from gastroenteric affections, in the first year of life, provided about 30 grams of milk-sugar be added to the food. A further possibility is that of the lactose which is split in the intestine before resorption the easily assimilable glucose is completely burned, while the less assimilable galactose fraction passes undecomposed to the kidneys so that in the urine the lactose is found mixed with galactose. Luzatto ${ }^{49}$ noted after free administration of milk-sugar to a dog under certain experimental conditions only galactose, but no lactose, in the urine.

Alimentary Galactosuria in Disturbances of Hepatic Function.-This brings us to the much discussed question of alimentary galactosuria. There is no doubt that the economy possesses the ability to transform galactose into grape-sugar. This is indicated in the first place by the fact that galactose is a possible source of glycogen, and in the second place by its quantitative conversion into urinary sugar in severe diabetes. The actual availability of galactose in the economy is always very much lower than that of dextrose and lævulose. This is particularly notable in the carnivora, in which even after small dosage of galactose this sugar may appear in the urine. ${ }^{50}$

In the course of the past few years alimentary galactosuria has frequently attracted the attention of clinicians, who have for a long time been seeking for means of chemical

${ }^{48}$ C. v. Noorden, Handb. d. Pathol. d. Stoff wechs., 2d ed., 2, 56, 1907.

${ }^{43}$ R. Luzatto (Schmiedeberg's Lab., Strassburg), Arch. f. exper. Pathol., $52,106,1905$.

${ }^{\circ 0}$ Literature upon Alimentary Galactosuria: A. Mangus-Levy, Handb. d. Biochem., 4', 379-381, 1909. 
diagnosis of the condition of the liver in the living patient. From the studies of R. Bauer, ${ }^{51}$ of v. Neusser's Clinic, which have met with confirmation from numerous sources, ${ }^{52}$ an alimentary galactosuria seems to always afford a limited possibility of testing the hepatic function. While a sound liver is able to handle almost all of the galactose, when from 30 to 40 grams of this sugar are administered, in certain disturbances of the hepatic function an appreciable portion of it tends to appear in the urine. Acording to Bauer the test is positive in the various cirrhoses of the liver, in catarrhal jaundice, in phosphorus poisoning, acute yellow atrophy, and the fatty liver of tuberculosis; but in passive hyperæmia of the liver, in chololithiasis, cancers, tumors, echinococcus disease and abscesses and in perihepatic affections it is said to be negative, as well as in all other affections in which the liver does not take part. However, there are exceptions to this rule. Thus alimentary galactosuria is found in occasional cases of Basedow's disease, and was met in a case of paroxysmal tachycardia recently under observation in Ortner's Clinic, which pre. sented symptoms of vagotonia and sympathicotonia. ${ }^{53}$ In cases of this sort the alimentary galactosuria is apparently associated with an alimentary glycosuria.

Bierry succeeded in inducing experimentally an alimentary galactosuria by producing severe lesions of the liver in dogs by means of chloroform injections. Milk sugar in dosage of one or two grams, easily utilized by a normal animal, caused in animals thus prepared an elimination of galactose in the urine. ${ }^{54}$

${ }^{51}$ R. Bauer, Wiener med. Wochenschr., 1906, 21, 2537; Deutsche med. Wochenschr., 1908, No. 35; Wiener klin. Wochenschr., 1912, 939-941; cf. Literature in the last.

${ }^{52} \mathrm{~V}$. Reuss, Bondi and König, Neugebauer, Jehn and Reiss and others.

${ }^{*}$ H. Politzer (Ortner's Clinic, Vienna), Wiener klin. Wochenschr., 1912, 1303; cf. also E. Reiss and W. Jehn, R. Roubitschek (Schwenkenbecher's Clinic, Frankfurt a. M.), Deutsch. Arch. f. klin. Med., 108, 187, 225, 1912.

H. Bierry, C. R. Soc. de Biol., 61, 204, 1906. 


\section{PENTOSURIA}

Another abnormality of carbohydrate metabolism, of rare occurrence it is true, but of considerable physiological interest, is pentosuria, ${ }^{55}$ which was discovered by Salkowski in 1892.

$\lambda$-xylose.-Attention has been called in a previous lecture (v. Vol. I of this series, p. 117, et seq., Chemistry of the Tissues) to the importance of the pentoses in the construction of animal and vegetable tissue. Carl Neuberg's fine researches leave no doubt that the sugar which exists so widely in the nucleoproteins of animals is $\lambda$-xylose. The discovery of Neuberg and Salkowski, who observed glycuronic acid pass over into $\lambda$-xylose in putrefaction, $\mathrm{COOH} \cdot[\mathrm{CH}(\mathrm{OH})]_{4} \cdot \mathrm{COH}-\mathrm{CO}_{2}=\mathrm{CH}_{2} \cdot \mathrm{OH} \cdot[\mathrm{CH}(\mathrm{OH})]_{3}$. $\mathrm{COH}$, has cleared up the obscurity which previously involved the origin of tissue pentoses. One cannot make any serious mistake in supposing that glucose under certain physiological circumstances can be changed by oxidation into glycuronic acid and that the latter by having $\mathrm{CO}_{2}$ split off can be transformed into tissue pentose, even though up to the present this series of changes has not been proved beyond peradventure.

Another important connection which the pentoses have with the processes of animal metabolism is seen in the fact that pentosans, the primary substances of the pentoses, occur widely in the vegetable kingdom. What their part is in the nutrition of herbivora can be easily appreciated if one considers that many types of forage contain twenty-five per cent. or more of pentosans. Although there is but little probability that the pentoses are directly changed into glucose, that is to say, into glycogen (vide supra, p. 230), and that this is conceivable only when aided by complicated

${ }^{65}$ Literature upon Pentosuria: C. Neuberg, Ergebn. d. Physiol., 3', 405-410, 1904, and v. Noorden's Handb. d. Pathol. d. Stoff wechs., 2d ed., 2, 219-224, 1907 ; A. Magnus-Levy, Handb. d. Biochem., ' ' 395-406, 1909; F. Umber, Lehrb. d. Ernähr., pp. 242-248, 1909. 
synthetical processes, it is also not very probable a priori that the pentoses are destroyed (as by fermentation in the intestine) to such an extent as to be entirely lost as sources of energy for the body. ${ }^{56}$ While herbivora are able to consume considerable quantities of pentoses, the human assimilation limit for these sugars (although man always destroys in his economy at least a part of any large amounts which have been ingested) is strikingly low; so much so, in fact, that even after ingestion of a single gram or a fraction of a gram of xylose, arabinose, rhamnose, etc., the pentose reactions may become positive in the urine.

Alimentary Pentosuria.-There is no wonder, therefore, that an alimentary pentosuria of low grade (as indicated by the studies of F. Blumenthal and others), particularly after indulgence in fruits (cherries, plums, apples) and other vegetable materials, is met with appreciable frequency.

Pentosuria in Diabetes.-It should also be easy to understand why a small amount of a pentose may be found mixed with the glucose in the urine of severe cases of human diabetes and of the dog in pancreatic diabetes, as was proved by E. Külz and J. Vogel. The nature of this sugar with five carbon atoms is apparently not well known, and in fact its optical activity never seems to have been tested. ${ }^{57}$ One would probably not be far wrong in supposing that a portion of the tissue pentoses, which are set free from the nucleoproteins in the breaking down of the tissues, can make their appearance in the urine. This idea is not contradicted by the fact that it is not possible to recognize by analysis a pentose impoverishment of the tissues in connection with pancreatic diabetes and phloridzin diabetes in animals. ${ }^{58}$

${ }^{56}$ Literature upon Pentosans as Foods: A. Magnus-Levy, 1. c., pp. 396-398.

ज C. Neuberg, Handb. d. Pathol. d. Stoffwechs., 2d ed., 2, 223, 1907; cf. also W. Voit (Sandmeyer's Sanatorium), Zeitschr. f. physiol. u. diät. Ther., $12,659,1909$.

${ }^{53}$ S. Mancini (Siena), Arch. di Farmakol., 5, 309, 1906, cited in Centralbl. f. Physiol., 20, 642, 1906; cf. also L. Caminotti, Biochem. Zeitschr., 22, 106, 1909. 
Chronic Pentosuria.-The idiopathic form of pentosuria is a complete puzzle to us.

This is a comparatively uncommon anomaly of metabolism. Some twenty cases were collected a few years ago from the general literature. Some of the cases were neuropathic individuals, cocaine and morphine habitués; in some a family disposition was recognized. The abnormality does not give rise to any special clinical symptoms. Carl Neuberg, to whom we owe much valuable progress in the chemistry and physiology of the carbohydrates, found that the sugar eliminated by the case of chronic pentosuria which he studied was directly different from the tissue pentose, $\lambda$-xylose, and was really an inactive arabinose. "It is a recognized fact," says Neuberg, ${ }^{59}$ "that all sorts of living beings produce optically active forms exclusively, and activate racemic types offered to them by consuming one of the components. The example of inactive urinary pentose is the first instance of the occurrence of a racemic body in the animal economy. By the construction of urinary pentose pentosuria is characterized as a phenomenon sui generis." While the inactive arabinose if introduced into the body of a healthy individual (as shown by Neuberg and Wohlgemuth) undergoes cleavage into its two components, one of which undergoes decomposition, the other, however, $\delta$-arabinose, appearing in the urine, we see that this cleavage power may come to be lost by the economy of the pentosuric. 0 . af Klercker ${ }^{60}$ comes to the conclusion from his own studies that in pentosuria the two complementally isomeric pentoses are excreted in very varying proportions. While they are sometimes, as in Neuberg's case, in equal amounts, the $\lambda$-component may in some instances be in excess. It is not known from what source the arabinose comes. Its excretion, according to Blumenthal and Bial, is independent

${ }^{5}$ C. Neuberg, Handb. d. Pathol. d. Stoff wechs., 2d ed., 2, 221, 1907.

${ }^{\infty} \mathrm{O}$. af Klercker (Instit. of Med. Chem., Lund), Deutsch. Arch. f. klin. Med., 108, 277, 1912. 
of the quantity of pentoses in the ingested nucleoproteids. There is just as little reason to refer it to the pentoses in combination in the tissue proteins, as the whole supply of pentoses in the human body is estimated at only about ten grams, while the amount of urinary pentose which may be excreted in a single day may reach thirty grams or more. Ingested xylose in a pentosuric (just as in a healthy person) may at least in part pass into the urine. There is no more evidence of connection between pentosuria and the metabolism of dextrose; it is not influenced by total withdrawal of carbohydrates, or by administration of phloridzin; and glycuronic acid excretion takes place in normal measure, according to Blumenthal and Bial, after administration of chloral or menthol. There is nothing left except to conclude that the pentosuric individual synthesizes his urinary pentose; where, how, or why, we do not know. Neuberg has suggested a possible connection between galactose and arabinose on the basis of their stereochemical molecular configuration :
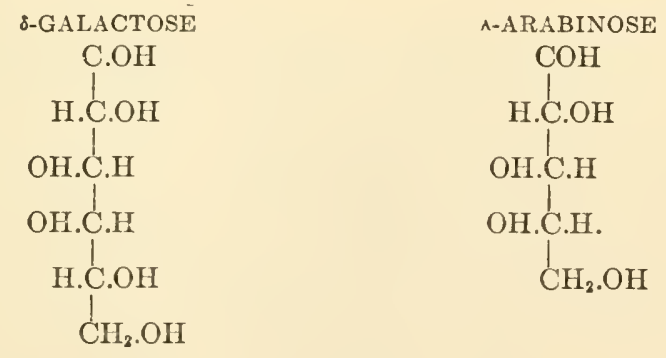

Finally, Luzzatto ${ }^{61}$ has shown in a case of pentosuria that even the exhibition of large quantities of glucose, cane-sugar or starch is incapable of modifying it in any way. If, however, galactose be given, it is in greater part decomposed, but a small portion would seem to be transformed into pentose and the amount of the five-carbon-atom sugar in-

${ }^{07}$ R. Luzzatto (Camerino), Arch. f. exper. Pathol., Schmiedeberg Festschr., 1908, 366. 
ereased. Confirmation of this work with a refined technic which will permit the possibility of quantitative differentiation between pentoses and hexoses, is very much to be desired.

Detection of Pentoses.-Most cases of pentosuria are for a time regarded as diabetics and treated as such; and yet the diagnosis of pentosuria is not a difficult one. Even with Fehling's test an attentive observer will notice that the fluid at first remains clear and only after considerable boiling is suddenly and fitfully reduced. Neuberg explains this peculiarity upon the supposition that pentose may be in the form of a ureide in the urine:

$\mathrm{CH}_{2} . \mathrm{OH}-(\mathrm{CH} . \mathrm{OH})_{3}-\mathrm{COH}+\underset{\mathrm{NH}_{2}}{\mathrm{NH}_{2}}>\mathrm{CO}=\mathrm{CH}_{2} . \mathrm{OH}-(\mathrm{CH} . \mathrm{OH})_{3}-\mathrm{CH}=\underset{\mathrm{NH}_{2}}{\mathrm{~N}}>\mathrm{CO}$ $+\mathrm{H}_{2} \mathrm{O}$.

Reduction can take place only in proportion as such a ureide is split by hydrolytic influences and the aldehyde group thus set free; for which reason it is probable that many statements as to the amount of pentose in urines are too low.

With special attention it will be found in investigating the urine of a pentosuric individual that the reducing substance of the urine is neither fermentescible nor is it optically active. The phenylhydrazine test yields beautiful yellow osazone-needles, the melting point of which is, however, distinctly lower than that of glucosazone. Transformation of arabinose into a diphenylhydrazone is, according to Neuberg and Wohlgemuth, also applicable in testing quantitatively for arabinose in the presence of other carbohydrates. Finally, the Tollens tests in their different modifications, the greenish-blue color obtained by heating with orcin and hydrochloric acid and the analogous red color with phloroglucin, and the spectroscopic behavior of the coloring matter obtained by shaking with amylalcohol, are very useful, even if they are not absolutely distinctive. Jolles recommends 
distillation of the isolated pentosazone with hydrochloric acid and subjecting the distillate, containing furfurol, to the orcin test; by which means it is said confusion of pentose with a hexose or a combined glycuronic acid may be prevented. ${ }^{62}$

Cammidge Reaction.-In concluding the consideration of pentosuria the reaction of Cammidge, which in recent years has attracted a great deal of attention, may be briefly spoken of.

Cammidge ${ }^{63}$ some years ago announced that he believed he had found a characteristic urine reaction for chronic diseases of the pancreas. The substance concerned in this reaction could be obtained by boiling the urine with hydrochloric acid, nentralizing with lead carbonate, and precipitating with alkaline lead. From the precipitate a solution can be obtained by the decomposing action of sulphuretted hydrogen, yielding the usual carbohydrate reactions and an osazone (apparently a pentosazone). Cammidge, who discovered this reaction in dogs in which a pancreatitis had been artificially produced, offered for it what was probably a correct interpretation, relating it with an excretion of sugars of five carbon atoms which were derived from the breaking down of nucleoproteins of the pancreas, which is rich in pentose. Many later investigators have much simplified the rather detailed process of Cammidge, at least to the end of satisfactorily demonstrating the presence of an osazone in an apparently sugar-free urine after hydrolysis with hydrochloric acid.

Cammidge's contribution started up a perfect flood of publications, a detailed review of which is perhaps unnecessary here. Whoever may desire to do so may easily find articles by the dozen in the last ten years of the journals devoting themselves to the publication of abstracts. The

${ }^{02}$ A. Jolles, Biochem. Zeitschr., 2, 243, 1906; Münchener med. Wochenschr., $5 \%, 353,1910$.

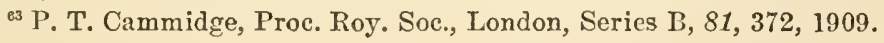


author has often wondered what factor's make particularly for the interest of the great medical public in a discovery in the field of his particular specialty. That such interest should be prominently shown for those points which may be expected to be of direct use in the practice of medicine is quite conceivable. But it is not so easy to understand why the greatest interest is so often not manifested for new facts that are clear and unambiguous and represent real advances, but by preference is turned to indefinite, vague and uncertain features in which there is no trace of really precise adaptation of chemical and physiological concepts. It is probably not wrong to believe that it is due to the fact that there are many people who at heart are glad to avoid the rather great inconveniences which a regulated course of chemical study brings with it, but who in their own interest and that of posterity are unwilling to forego having a new starlet blaze in the firmament of biochemical research. According to their experience these same people have an invincible and instinctive preference for those fields of investigation in which discovery is decidedly more easy than control of the discoveries made by others.

But to return to Cammidge's reaction, opinions generally contradict its practical utility as an aid in functional diagnosis of pancreatic affections. As to its real value it would seem from a few studies of critical character ${ }^{64}$ to be fully shown to be neither distinctive nor especially reliable. It clearly does not deal with any one single substance; the presence of any poly- or disaccharide in the urine may by cleavage give rise to an osazone-forming atomic group. Even the small amounts of polymeric carbohydrates which exist normally in the urine, particularly after a diet rich in

$\leftrightarrow$ O. Schumm and Hegler, Münchener med. Wochenschr., 56, 1878, 1909, Mitt. a. d. Hamburgischen Staatskrankenanstalten, 11, 1910, cited in Centralbl. f. d. ges. Biol., 10, No. 1933; L. Grimbert and R. Bernier, Jour. de Pharm. et de Chem., 30, 529, 1909, cited in Biochem. Centralbl., 9, No. 1643; J. E. Schmidt (Enderlen Clinic, Wïrzburg), Mitt. a. d. Grenzgebiete d. Med. u. Chir., 20, 426, 1909. 
sugar, ${ }^{6 \overline{5}}$ may give a positive result by this reaction; which may on the other hand, however, be due to excreted glycuronic acids and pentoses. It cannot possibly be regarded, therefore, as specific for pancreatic break-down, the more so because any actual nuclear decomposition in the tissues may be followed, as has been seen, by passage of pentoses into the urine. This aside, of course the particularly large amount of pentoses in the pancreas (which is said to contain five times the quantity of pentose as the liver and other glandular organs and about twenty times more than do the muscles) ${ }^{66}$ favors the passage of pentoses into the urine when this organ undergoes destructive changes. For this reason there is some value in examining the urine for pentoses as an aid to the diagnosis of pancreatic affections.

\section{EXPERIMENTAL GLYCOSURIAS OF VARIOUS KINDS}

The list of the recognized examples of this abnormality of metabolism is far from exhausted even after completing the above mentioned types of sugar excretion in the urine. We are acquainted also with a large number of possibilties of inducing experimental glycosurias by interferences of many kinds. A review of these may be considerably facilitated by dividing, as Pollak ${ }^{67}$ does; the glycosurias due primarily to renal influence from the glycosurias following hyperglycæmia.

Renal Glycosurias.-To the first of these groups, besides the phloridzin diabetes already considered, certain glycosurias caused by renal poisons are to be referred. According to Ellinger and Seelig in rabbits in a certain stage of cantharides intoxication it is impossible to induce a glycosuria by adrenin and the elimination of sugar by dogs with

${ }^{65} \mathrm{Cf}$. R. Wilhelm, 8 internat. Physiol. Kongr., Vienna, 1910. (There would appear to be a synthesis therein of mono- to polysaccharides, which pass into the urine.)

${ }^{*}$ G. Grund (Salkowski's Lab.), Zeitschr. f. physiol. Chem., 35, 111, 1902. 1909 .

${ }^{67}$ L. Pollak (Pharmakol. Instit., Vienna), Arch. f. exper. Pathol., 61, 366, 
pancreatic diabetes may be lowered by inducing renal lesions. ${ }^{68}$ In this stage of the poisoning, according to L. Pollak, ${ }^{69}$ it is possible to call out a glycosuria by superposition of uranium poisoning, although the amount of sugar in the blood is raised but little or not at all above the normal by this measure. The explanation proposed is that while cantharidin restricts the permeability of the vessels of the kidneys for sugar, uranium makes them abnormally permeable; and it is not improbable that a comparable causative mechanism obtains in chromium and bichloride of mercury glycosuria. A renal glycosuria has also been observed occasionally in human beings with chronic nephritis.

The long list of glycosurias which are accompanied by hyperglycamia includes, according to L. Pollak (exclusive of pancreatic diabetes which occupies a special position) a number of glycosurias induced by sympathetic nervous irritation. The factors producing the glycosuria are again to be grouped in two classes: first, those which (analogous to the sugar-puncture) occasion irritation of nervous centres (transmitted by sympathetic fibres, especially the splanchnics, to the liver and cause the latter to throw off its glycogen deposit); and second, those which (analogous to adrenin glycosuria) cause an irritation of the peripheral endings of the sympathetics.

Sugar Puncture.-We know enough about the essential nature of the sugar puncture of Claude Bernard to understand the parts the nerve impulses traverse which produce glycosuria after injury of the floor of the fourth ventricle of the brain. This nerve path extends from the "sugar centre" to the cervical cord, thence out through communicating branches to the lower cervical and upper thoracic

${ }^{e s}$ A. Ellinger and A. Seelig (Königsberg), Münchener med. Wochenschr.; 1905, 345, 449, and Festschr. f. M. Jaffe, p. 349, 1901.

${ }^{69}$ L. Pollak (Pharmakol. Instit., Vienna), Arch. f. exper. Pathol., 64, 415, 1911. 
sympathetic ganglia, and thence along the splanchnics to the liver. We know, too, that stimulation of the central segment of the vagus and of numerous sensory (particularly visceral) nerves will induce activity of the sugar-centre, and that a great variety of anatomical lesions of the central nervous system (from traumatism, tumors, abscesses, hemorrhages, etc.) may act in the same way. Psychic influences may also induce glycosuria. For example, in cats that have been shut up in a cage and worried for half an hour by a dog enough to have had the latter very manifestly "get on their nerves," a glycosuria may be observed..$^{70}$

We have no reason for doubting that the mechanism of the sugar puncture involves the liver and includes a process of discharging its glycogen supply; but it is not clearly understood in all points. Only recently two French investigators (Wertheimer and Battez) have called attention to the effectiveness of the sugar puncture even in animals which have been placed under the influence of atropin sufficiently to induce a paralysis of all secretory nerves ; and they, therefore, hold that the supposed connection of the sugar puncture with stimulation of glycosecretory nerves is decidedly questionable. $^{i 1}$ The possibility of a connection between the sugar puncture and the secretory activity of the adrenals will be taken up fully in the succeeding lecture, in which the relation between the "internal secretory glands" and carbohydrate metabolism will be considered.

Attention should also be called here to the occurrence of glycosuria, according to observations of Minkowski, Bedard, Pflüger and other authors, ${ }^{72}$ after a great variety of operative interferences; it is especially likely to follow irritation of the bowel and peritoneum, according to Pflüger. Zak states that even the mechanical irritation of the intestine

${ }^{70}$ W. B. Cannon, A. T. Strohl and W. S. Wright (Harvard Med. School), Amer. Jour. of Physiol., 29, 280, 1911.

${ }^{71}$ E. Wertheimer and G. Battez, Arch. internat. de Physiol., 9, 140, 363, 1910 ; C. R. Soc. de Biol., 66, 1059, 1909.

${ }^{72}$ Rose, Zak, Gaulthier, Eichler and Silbergleit, Visentini. 
occasioned by introducing a drainage tube may produce this effect. Ulrich Rose invariably found a hyperglycæmia, and sometimes, too, glycosuria, in rabbits after a simple laparotomy. And Kreidl and Winkler ${ }^{73}$ have been able to prove that after opening the peritoneal cavity in dogs and cats, but less frequently in rabbits, it is almost a regular thing to find sugar in the urine. We would probably not be far out of the way in supposing that in all procedures of this sort, comparably with Bernard's puncture, we have to deal with an effect upon the sympathetic nervous apparatus and with a discharge of glycogen from its place of storage.

Toxic Glycosurias.-L. Pollak is disposed to regard many forms of toxic glycosuria, as that in the course of caffein poisoning and strychnine poisoning, as due to a central nervous irritation analogous to that produced by the puncture. All sorts of explanations have been offered for the action of other harmful chemicals like ether, chloroform, morphine, nitrite of amyl or carbon monoxide, but thus far without any uniformity at all. ${ }^{74}$

Salt Glycosuria.-- "Salt glycosuria" is also supposed to be due to a direct irritation of the sugar centre. Injection of large amounts of a dilute (about one per cent.) solution of sodium chloride into the vascular system of an animal, is likely to occasion a glycosuria, according to M. H. Fischer, but fails to do so if the splanchnic nerves be cut. A glycosuria of much more marked intensity can be induced if the salt solution be introduced directly into the vertebral artery of the experiment animal instead of into a vein, thus insuring a direct effect upon the nervous centres. Injections of sea water, diluted to the osmotic pressure of the blood, will also give rise to glycosuria. The glycosuria produced by sodium chloride can be inhibited to some degree by injection of

${ }^{78} \mathrm{~F}$. Winkler (under direction of A. Kreidl, Vienna), Centralbl. f. Physiol., 24, No. 8, 1910; cf. therein Literature.

${ }^{7}$ Literature upon Toxic Glycosurias: K. Glässner, Wiener klin. Wochenschr., 1909, No. 26. 
potassium and calcium salts. ${ }^{75}$ Injection of concentrated salt solutions produces pronounced hyperglycæmia, but there is also induced an alteration in the renal efficiency (probably due to change of the osmotic pressure relations) and the glycosuria may fail to appear. ${ }^{76}$

Glycosuria from Chill.-."Refrigeration glycosuria" should finally be briefly mentioned, observed first by Böhm and Hoffmann and later by Araki when they reduced the body temperature of warm blooded animals to a low level by cold baths, snow packs, etc. Glässner ${ }^{77}$ was in the same way able to recognize glycosuria in individuals who had attempted suicide by jumping into cold water. Whether the coincident occurrence of lactic acid, which may be regarded as due to the combined influence of oxygen impoverishment and increased muscular activity, has any direct connection with the glycosuria, may remain undecided. Even in frogs a glycosuria may be induced by exposure to intense cold, interpreted by M. Löwit ${ }^{78}$ on the hypothesis that the oxidation processes are interfered with, and that as a result there may ensue disturbance in the consumption of sugar, alteration of the renal permeability and glycosuria.

${ }^{75}$ M. H. Fischer, Pflüger's Arch., 109, 1, 1905, and earlier contributions: O. H. Brown, Amer. Jour. of Physiol., 10, 378, 1904; T. C. Burnett (Univ. of California), Jour. of Biol. Chem., 4, 57 ; 5, 351, 1908.

${ }^{76} \mathrm{G}$. Wilenko (Lemberg), Arch. f. exper. Pathol., 66, 143, 1911.

${ }^{77} \mathrm{~K}$. Glässner, Wiener klin. Wochenschr., 1906, p. 30.

${ }^{78}$ M. Löwit, Arch. f. exper. Pathol., 60, 1908. 


\section{CHAPTER XIII}

RELATIONS OF GLANDS WITH INTERNAL SECRETION TO CARBOHYDRATE METABOLISM.

GLYCURONIC ACIDS

\section{RELATION OF THE ADRENALS TO CARBOHYDRATE METABOLISM}

In the course of a series of earlier lectures the writer attempted to present what is known of the rôle and the significance of "the glands with internal secretion," at least as far as the principal points are concerned. An important phase of this physiological problem has not, however, been systematically dealt with, the relations these puzzling organs bear to carbohydrate metabolism. In the present lecture it is proposed to fill in this hiatus and to consider the matter in an objective manner, so that it may be possible to come to some conclusion to what extent we are justified in the effort so often made in the course of the last few years to penetrate into the secrets of normal and pathological carbohydrate metabolism and to interweave these with the no less secret and obscure mysteries of the "anctless glands" into one organic whole.

Nature of Adrenal Diabetes. - The line of thought which is principally to occupy our attention in the present discussion, takes its inception from the discovery of adrenal diabetes. ${ }^{1}$

In 1901 F. Blum, in Frankfurt, a. M., made the remarkable and important discovery that injection of the substance in the adrenals which induces increase of blood pressure (known in the present stage of science by the term suprarenin or adrenin) is followed by an intense glycosuria of short duration in various experiment animals. The very great interest always manifested in the problem of diabetes

${ }^{2}$ Literature upon Adrenal Diabetes: A. Biedl, Innere Secretion, pp. 202204, 1910; R. Hirsch, Handb. d. Biochem., 3, 322-325, 1910; G. Bayer, Ergebn. d. pathol. Anat., 14, 101-105, 117-119, 1910. 
from its clinical and physiological standpoints is sufficiently explanatory of the flood of publications persisting even now which had its beginning in this discovery.

The glycosuric influence of suprarenin is appreciable only when it is introduced subcutaneously, intravenously or intraperitoneally. When given by the mouth even large doses are without effect upon the carbohydrate metabolism and the blood pressure. The glycosuria is directly related with the supply of glycogen in the liver and its liquidation. Injection of adrenin directly into a mesenteric vein acts, according to Doyen, in an almost paroxysmal manner, although in dogs with Eck's fistulas it produces neither hyperglycæmia nor glycosuria. ${ }^{2}$ Between the amount of adrenin present in the blood and that of the sugar excreted in the urine there exists within certain limits a direct ratio, according to studies made in Stranb's laboratory. The occurence of a stage of latency is clearly due to the fact that a certain amount of time is necessary to put the mechanism of sugar mobilization in motion. Straub believes, as do others, that the parts influenced by the adrenin are the same sympathetic nerve fibres whose central irritation is responsible for the effectiveness of the sugar puncture. ${ }^{3}$ As the suprarenin acts on the endings of the sympathetic fibres, one can readily appreciate why splanchnicotomy does not prevent its glycosuric effect. ${ }^{4}$ What actually takes place is that the liver under the influence of the poison passes its supply of glycogen into solution; if this supply is an abundant one (perhaps after preceding indulgence in carbohydrates) a stream of sugar will pass out from the liver into the blood. But if the store of glycogen has been used up through the

Michaud (Kiel), Verh. d. Kongr. f. innere Med., Wiesbaden, 1911.

"W. Straub, Münchener med. Wochenschr., 1909, 493; H. Ritzmann, Arch. f. exper. Pathol., 61, 231, 1909; ef. also F. P. Underhill and O. E. Closson (Yale Univ., New Haven), Amer. Jour. of Physiol., 1\%, 421, 1906.

${ }^{4}$ Cf. L. Pollak (Pharm. Instit., Vienna), Arch. f. exper. Pathol., 61, 1909; also the observations of $\mathrm{K}$. Hirayama upon the interruption of sympathetic conduction by nicotine: Zeitschr. f. exper. Pathol., 8, 649, 1911. 
influence of hunger, physical exertion, cold or earlier injections of suprarenin, phloridzin, etc., glycosuria may fail to appear. In a previous lecture occasion was taken to call attention to the fact that the economy is abundantly provided with means to maintain the sugar in the blood at constant level and that if the carbohydrate elements are used up it is in position to build sugar de novo from protein. An excellent example of this process is afforded in recent studies of L. Pollak, who has been able to show in the Pharmacological Institute in Vienna that in starving rabbits which have had their glycogen removed by strychnine convulsions, repeated administration of suprarenin in increasing dosage may induce an accumulation of glycogen in the liver, of proportions elsewhere seen only in animals fed upon carbohydrates. It is of interest to note that the muscles, which usually (as the most important physiological sites of glycogen consumption) have a tendency to attract the carbohydrate stores from the liver for their own purposes, are under these circumstances entirely or almost entirely free of glycogen. ${ }^{5}$

Dependence of Adrenin Glycosuria Upon the Renal Function.--Suprarenin diabetes should undoubtedly be classed from its essential character among the glycosurias accompanied by hyperglycæmia. Whether it is possible to actually find at a given moment after adrenin application that the level of sugar in the blood is distinctly raised, depends upon the precision and readiness with which the kidney affords passage of a surplus of sugar from the blood into the urine. Here, too, studies in the Vienna Pharmacological Institute have led to important conclusions. Thus it has been proved that in rabbits a proportion of 0.15 to 0.25 per cent. of sugar in the blood will give rise to glycosuria only in case a marked diuresis coexists (as after use of

${ }^{5}$ L. Pollak (Pharmakol. Instit., Vienna), Arch. f. exper. Pathol., 61, 166, 1909 ; ef. therein Literature: Doyen and Kareff, Gatin-Gruzewska, Agadschiananz, et al.; W. B. Drummond and D. Noël Paton, Jour. of Physiol., 31, 98, 1904. 
caffein); without the diuresis the glycosuria remains in abeyance. If the proportion of sugar in the blood exceeds 0.25 per cent. there is no longer necessity for the diuresis to put the glycosuria in operation. After repeated subcutaneous injections of adrenin, however, the kidneys may acquire a sort of tolerance, making it possible that glycosuria will not be manifested even when the proportion of sugar in the blood becomes very high. ${ }^{6} \quad$ While under certain conditions even with approximately normal proportions of sugar in the blood a glycosuria can be caused by certain nephrotoxines like chromium, uranium or corrosive sublimate ("renal diabetes"), there are other renal lesions (as temporary ligation of the renal artery), according to Ellinger and Seelig, ${ }^{7}$ which promptly inhibit the glycosuria caused by adrenalin. There is scarcely any doubt that some alteration of the renal circulation is directly concerned with the suppression of adrenin glycosuria, so often seen after injection of lymphagogues (extract of crab meat, ${ }^{8}$ hirudin, ${ }^{9}$ and Witte's peptone ${ }^{10}$ ), in infectious diseases, ${ }^{11}$ and experimentally produced fever, ${ }^{12}$ after extirpation of both adrenals, ${ }^{13}$ and other severe operative interferences, after peritoneal irritations ${ }^{14}$ (which may be produced by injection of trypsin or pancreatic juice, vide supra, p. 262), after injections of calcium chloride, ${ }^{15}$ etc.

Occasion was taken in a previous lecture to point out that it is entirely reasonable to believe that passage of adrenin from the adrenal medulla into the circulating blood takes

${ }^{6}$ L. Pollak, l. c., p. 157.

${ }^{7}$ A. Ellinger and Seelig, Münchener med. Wochenschr., 1905, No. 11.

${ }^{8}$ A. Biedl and Offer, Wiener klin. Wochenschr., 190\%, 1530.

- Mikulicich, 1. c.

${ }^{10} \mathrm{~K}$. Glässner, and E. Pick, Zeitschr. f. exper. Pathol., 6, 1909.

${ }^{11}$ G. Ghedini and G. Mascerpa, Folia Clinica, 2, H. 3, cited in Centralbl. f. d. ges. Biol., 11, No. 2508.

12 Aronsohn, Virchow's Arch., 17' 4, 383, 1903.

${ }^{13} \mathrm{~J}$. Gautrelet and L. Thomas, C. R. Soc. de Biol., 66, 798, 1909.

${ }^{14}$ O. v. Fürth and C. Schwarz, Biochem. Zeitschr., 31, 113, 1911.

${ }^{15}$ F. Schrank, Zeitschr. f. klin. Med., 6\%, 230, 1908. 
place as a physiological process. It is, therefore, not at all surprising that Herter should have succeeded in bringing on glycosuria by squeezing the normal adrenals in situ.

Hypothesis of the Regulating Influence of Adrenin Upon Normal Carbohydrate Metabolism.-It is but a step from this point to the proposition that the passage of the adrenin from the adrenals into the blood stream has normally a regulative influence upon carbohydrate metabolism. Thence it is suggested that the adrenin having entered the circulation normally from the adrenals excites the sympathetic nerve terminations in the liver (in the same way as in electric irritation of the sympathetic, in the sugar puncture, in stimulation of the central end of the vagus, in asphyxia, in the effect of carbon monoxide, caffein and many of the narcotics), ${ }^{16}$ and that such a condition of stimulation can under proper conditions give rise to a discharge of the hepatic glycogen, to hyperglycæmia and to glycosuria.

Does the Sugar Puncture Act Through the Adrenals to Cause Glycosuria? - From this point of view a line of thought has been developed, that Claude Bernard's sugar puncture may possibly not have a direct effect upon the liver, but may perhaps act indirectly by way of the adrenals, inducing primarily a massive output of adrenin from the adrenals into the blood, with production in this way of a simple adrenin glycosuria, in complete analogy to the effect of an intravenous injection of this very active substance into the circulation.

Soon after F. Blum, ${ }^{17}$ the discoverer of adrenal diabetes, published his belief that a close similarity exists between this condition and glycosuria from Bernard's puncture, the logical suggestion from which would be to investigate whether the latter does not have its influence on the liver

${ }^{16}$ E. Starkenstein (J. Pohl's Lab., Prague), Zeitschr. f. exper. Pathol., $10,1911$.

${ }^{17}$ F. Blum (Frankfurt, a. M.), Pflüger's Arch., 90, 628, 1902. 
through the adrenals, the glycosuric puncture was studied from this view point by quite a number of researchers.

Let us consider for a moment what objective facts we ought to demand in order to regard as proved such a thoroughly complicated relation as the above mentioned hypothesis assumes.

We should expect in the first place that if the adrenals were removed the glycosuric puncture would be without its customary effect. We might further very properly suppose that a massive discharge of this substance would be followed by a noticeable impoverishment in the adrenal medulla of its pressure-raising chromogen. And finally we ought to require evidence that the sugar puncture really is followed by an excessive presence of suprarenin in the blood. Closer examination may now be made as to what results experiments have afforded which may be applied to each one of these postulates.

Failure of Effect of Glycosuric Puncture After Exclusion of the Adrenals. -The first point to be made (determined coincidently by A. Meyers, E. Landau and R. H. Kahn) is that the puncture is no longer capable of producing glycosuria when the adrenals have both been extirpated. This is all the more notable in case of operated animals which survive the operation for some length of time and are in good health. In such animals, too, no hyperglycæmia is met from splanchnic irritation. ${ }^{18}$ The plausible explanation that in animals deprived of their adrenals there is simply a reduction in the glycogen supplies may hold in case of rats and dogs, ${ }^{19}$ but apparently not in case of rabbits, which may survive the bilateral removal of the adrenals for as much

${ }^{18}$ J. J. R. Macleod and R. G. Pearce, Amer. Jour. of Physiol., 29, 419, 1912 ; cf. also the diuretin experiments of M. Nishi (Pharmacol. Instit., Vienna), Arch. f. exper. Pathol., 61, 401, 1909.

10 O. Schwarz (E. Pick's Lab., Vienna), Pflüger's Arch., 134, 259, 1910 ; O. Porges (v. Noorden's Clinic, Vienna), Zeitschr. f. klin. Med., 69, 3-4, 1909 ; $\approx 0,1910$. 
as a year, take on weight, show a normal amount of glycogen, and differ from normal animals apparently only in the fact that the glycosuric puncture has no effect on them. ${ }^{20}$ It should be recalled, too, that hypoglycæmia and increased tolerance for sugar has been met in sequence to removal of the two adrenals in dogs and to Addison's disease in man. ${ }^{21}$ Considerable importance on the other hand, should be attributed to the finding that even in animals deprived of the adrenals hyperglycæmia may be caused by irritation of the central segment of the vagus nerve ${ }^{22}$; this is a positive indication that the "sugar centre" can exert its power entirely independently of the adrenals. It seems possible, too, that the failure of puncture glycosuria and other related glycosurias ${ }^{23}$ after extirpation of the adrenals, in the course of which operation it is not unlikely that lesions of the network of nerves about the kidney may have been produced (in line with what has already been said), may be explained with much probability and quite fully on the assumption of some disturbance of the renal circulation.

Chromium Affinity of the Adrenals.-An observation of Kahn is directly applicable to the second of our postulates. "If one adrenal be removed from a rabbit and glycosuric puncture be performed, and the second adrenal be extirpated some time after the appearance of glycosuria, it will be found on comparison of the two organs that the second one removed has undergone very decided alteration. The affinity for chromium is very greatly reduced, the cells are poor in granules and rich in vacuoles; the more minute vessels are for the most part distended; and its adrenin is very much 1911.

${ }^{20}$ R. H. Kahn and E. Starkenstein (Prague), Pflüger's Arch., 189, 181,

${ }^{21}$ O. Porges, 1. c.

${ }^{22}$ E. Starkenstein, l. c.

${ }^{23}$ Cf. J. J. R. Macleod and R. G. Pearce, Amer. Jour. of Physiol., 29, 419, 1912. 
reduced. Section of the corresponding splanchnic nerve protects the adrenal from these changes after glycosuric puncture." ${ }^{24}$

Question of Increase of Adrenin After Sugar Puncture. - What of the third and most important of our postulates, on which in fact the whole hypothesis stands or falls, the detection of an increased amount of suprarenin in the blood after the sugar puncture? While Watermann and Smit ${ }^{25}$ believed they had found an increase of suprarenin in the blood after sugar puncture by means of the frog's eye method, not only Kahn ${ }^{26}$ but also E. Th. von Brücke ${ }^{27}$ failed to recognize such an increase. It should be said that the latter used in determining the suprarenin in the blood serum the very delicate Trendelenburg-Läwen test, which is based on the idea that the vasoconstrictor power of a solution under examination may be tested by the variation in escape of fluid when perfused through the hind legs of a frog. Kahn ${ }^{28}$ has objected to the force of this experiment because after subcutaneous administration of suprarenin in small doses, but sufficient to cause glycosuria, it is impossible, by available methods, to recognize any accretion of this substance in the blood.

The author confesses that he is not entirely convinced of the extent to which this objection is justified. For if the suprarenin passes out from the adrenals into the circulation in sugar puncture, it does so not by a subcutaneous route but intravenously. As Kahn emphasized, adrenin-glycosuria will appear in half-grown rabbits from doses of 0.1 milligram upwards. A dose of this size given intravenously

${ }^{24}$ R. H. Kahn (Prague), Pflüger's Arch., 140, 254, 1911.

${ }^{25}$ N. Watermann and H. J. Smit, Pflüger's Arch., 124, 198, 1908.

${ }^{28}$ R. H. Kahn (Prague), Pflüger's Arch., 128, 519, 1909.

${ }^{27}$ E. Th. von Brücke (Leipzig), Münchener med. Wochenschr., 1911, No. 26 ; T. Negrin y Lopes (Physiol. Instit.. Leipzig), Pflüger's Arch., 145, 311, 1912.

${ }^{28}$ R. H. Kahn (Prague), Pflüger's Arch., 14\}, 251, 1912. 
would show a powerful vasoconstricting effect unless in injection it were spread out over a long space of time. Each one of us will necessarily value the above objection according to his own idea whether the adrenal medullary substance, from a stimulus passing along the nerve paths to it, discharges its store of suprarenin suddenly, or whether it allows it to ooze out slowly. But this is the same old story: as long as an accumulation of adrenin in the blood after the glycosuric puncture is not actually proved, we will lack authority for assuming that the puncture glycosuria is caused by such means. Here is a place in physiology where we are forced, if we are not willing to lose the ground under our feet, to hold on to things we can see, even if we are very well aware that there is plenty which we do not see. It has been well said "that the negative finding in reference to the sugar puncture proves nothing more than the impossibility of demonstrating an adrenæmia from this disturbance but in no way contradicts the possibility of its existence." $29 \mathrm{We}$ are here not after something that is possible (many things are possible), but something that is probable. The fact that a hypothesis starts up in an investigator's brain and that at the time we are not in position to fully prove its incorrectness does not force us by a great deal to accord reality to it. It does not lie at our door to bring proof that a hypothesis is incorrect; but whoever proposes a hypothesis has to bring the positive proof that it is correct. In this way and not in the reverse we hold in other exact sciences, and so, too, it should be held in physiology.

Here is a rare little verse which perhaps has occurred to some in this connection:

"Oh, learned man, 'tis thus I know you, face to face!

What you don't touch stands miles from you apace;

What you don't grasp, for you is gone for woe and weal;

${ }^{20}$ R. H. Kahn, Pflüger's Arch., 144, 271, 1912. 
What you don't see, you're sure cannot be real;

What you don't weigh, ne'er has a weight for you;

What you don't coin, you think don't count a sou."

The author will not evade the point. But for the present in biochemistry we make the most progress if we hold to the things we can see, and weigh and count.

Do the Adrenals Have a Regulating Infuence on the Normal Carbohydrate Metabolism?-Even were a positive proof obtained that the sugar-puncture acts essentially like an adrenin glycosuria, it would still be far from proving that under normal physiological conditions the internal secretion of the adrenals possesses a regulative effect on the metabolism of carbohydrates. Even if a sudden massive expulsion of suprarenin from the adrenal medulla does cause a glycosuria this might very well be a toxic glycosuria, of which there are so many examples.

Whether the minimal quantities of adrenin which in normal conditions enter the blood have anything to do with the liquidation of the glycogen stores and with the regulation of carbohydrate metabolism, remains, therefore, an open question, although many writers today regard a relation of this sort as a settled fact. Thus Falta ${ }^{30}$ thinks that every diabetic disturbance of metabolism may be looked upon as a predominance of sympathetic impulses over the autonomous ones. "If the cause of it is seen rather in some insufficiency of the pancreas it is proper to speak of a pancreatogenous diabetes; if it is rather in an excessive function of the circulatory system, to say it is an adrenalogenous one." It should be added, however, that the recognition of a hypoglycæmia and increased tolerance for carbohydrates in a few cases of Addison's disease ${ }^{31}$ is in direct contrast to

\footnotetext{
${ }^{30}$ W. Falta, Prager. med. Wochenschr., 1910, No. 7.

${ }^{21}$ O. Porges, 1. c.; H. Eppinger, W. Falta and C. Rudinger, Zeitschr. f. klin. Med., 66, 50, 1908.
} 
observations in which in rabbits with adrenals removed the amount of sugar in the blood was, as a rule, found not reduced.32 O. Schwartz, who found that the glycosuric effect of phloridzin was entirely preserved in rats deprived of their adrenals, concludes after a critical discussion of the above statements that "the assumption of a sugar-mobilizing function of adrenin, hitherto accepted without any direct experimental basis, can no longer be maintained." ${ }_{33}$ In view of the recognized antagonism between the sympathetic and autonymous nerve systems and the fact that almost always, where organs have a double innervation, this double supply is an antagonistic one, and stimulation of the sympathetic fibres produces characteristically the opposite action from that of the autonymous nerves, ${ }^{34}$ it is quite well worth observing that the glycosuria produced by adrenin is not influenced by its antagonists, cholin and pilocarpin. This certainly does not speak in favor of the assumption that sugar metabolism is subject to a delicate regulation by suprarenin through stimulation of the sympathetics. ${ }^{35}$

An idea has also been suggested that the adrenals influence sugar metabolism in some way through the pancreas. But for this view, also, there is no definite basis; in geese and ducks, in which extirpation of the pancreas does not occasion sugar excretion, suprarenin produces glycosuria even after removal of the pancreas. ${ }^{36}$ The pancreas is, of course, not responsible for the production of this effect.

So much for the relation of the adrenals to carbohydrate metabolism.

${ }^{32}$ E. Frank and S. Isaak (Wiesbaden), Zeitschr. f. exper. Pathol., $\%, 326$, 1909.

${ }^{3}$ O. Schwarz (E. Pick's Lab., Vienna), Pflüger's Arch., 134, 257, 1910 ; ef. also J. J. R. Macleod and R. G. Pearce, Amer. Jour. of Physiol., 29, 419, 1912.

ss Cf. H. H. Meyer and R. Gottlieb, Exper. Pharmacol., p. 122, 1910, and A. Fröhlich (Pharmakol. Instit., Vienna), Med. Klinik, 1911, No. 8.

w E. Frank and S. Isaak, 1. c.

${ }^{30}$ Noël Paton, Jour. of Physiol., 32, 59, 1909. 


\section{RELATIONS OF THE THYROID GLAND TO CARBOHYDRATE METABOLISM}

We next turn to a no less knotty and troublesome subject, the problem of the relation of the thyroid gland to the carbohydrate metabolism of the body.

Removal of the Thyroid and of the Parathyroids.-In order to prevent confusion it is necessary to strictly differentiate between the thyroid gland and the parathyroid bodies. From studies of cases of myxœdema ${ }^{37}$ and upon dogs after extirpation of their thyroids, a decided increase of sugar tolerance has been observed following loss of the thyroid function, and with this a marked general slowing of the transformation processes. ${ }^{38}$ Thus a dog without its thyroid can tolerate very large quantities of ingested sugar without the appearance of an alimentary glycosuria. So, too, adrenin glycosuria may fail to appear in different animals under certain conditions (although by no means always) after extirpation of the thyroid. ${ }^{39}$ Removal of the parathyroids, however, has precisely the opposite effect (as indicated in the studies of R. Hirsch, Underhill and Saiki, and of Eppinger, Falta and Rudinger). Even after extirpation of three parathyroids in dogs there may be noted, in the course of a latent tetany (which is without spasmodic twitching and is only told by a typical change in electrical excitability), an enormous lowering of the assimilation limit for grape-sugar. If there be combined with the extirpation of several of the parathyroids also extirpation of the pancreas, a marked rise in the protein exchange in fasting and

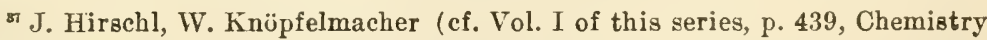
of the Tissues) and C. v. Noorden, Die Zuckerkrankheit, 5th ed., p. 47, 1910.

${ }^{28}$ Pari, Falta and Gigon, H. Eppinger, W. Falta, C. Rudinger (v. Noorden's Clinic), Zeitschr. f. klin. Med., 66, 1908; 6\%, 1909.

${ }^{30}$ Eppinger, Falta and Rudinger, 1. c.; E. P. Pick and F. Pineles, Biochem. Zeitschr., 12, 473, 1908; F. P. Underhill and W. H. Hilditch, Amer. Jour. of Physiol., 25, 66, 1909; F. P. Underhill, ibid., 27, 331, 1911; Ritzmann (Straub's Lab.). Arch. f. exper. Pathol., 61, 231, 1909; E. G. Grey and W. T. de Santelle (Johns Hopkins Univ., Baltimore), Jour. of Exper. Medicine, 11, 659, 1909; J. McCurdy, ibid., 798. 
coincidently an increase in the $\mathrm{D} / \mathrm{N}$ quotient to as much as 3.5 (as seen in the height of phloridzin diabetes). ${ }^{40}$ Possibly with these facts in view we may assume that we are justified in looking upon the thyroid and parathyroids as antagonistic in their relations to carbohydrate metabolism. However, the whole matter seems by no means thoroughly established.

Hyperthyroidism.-Hyperthyroidism lowers the assimilation limit for sugar. Transitory glycosurias have been met time after time after feeding thyroid tissue (cf. Vol. I of this series, p. 448, Chemistry of the Tissues). In special cases the occurrence of true diabetes has been noted, which may, however, be nothing more than the manifestation of a previously existing disposition toward the affection (as C. v. Noorden believes). In Basedow's disease, too, which we are for the present justified in regarding as a form of hyperthyroidism (cf. Vol. I of this series, p. 456, Chemistry of the Tissues), there may be frequently seen instances of alimentary glycosuria (first discovered by Ludwig and Kraus, and by Chvostek and confirmed by many later observers). This is to be expected, according to the observations of Eppinger in C. v. Noorden's Clinic, in those cases of Basedow's disease which show symptoms of sympathetic irritation, and is usually absent from those cases in which symptoms of vagotonia are prominent. ${ }^{41}$

Interaction of the Internal Secretory Glands.-Eppinger, Falta and Rudinger have come to very definite ideas as to the interaction of the internal secretory glands, to which they ascribe a regulative influence over normal carbohydrate metabolism. They assume that exclusion of a "blood gland" will give rise to two distinct effects, primarily direct influences from the loss of the specific secretion and secondarily indirect influences through disturbance of its interrelation with other glands.

${ }^{40}$ Eppinger, Falta and Rudinger, 1. c.; also R. Hirsch (F. Kraus's Clinic, Berlin), Zeitschr. f. exper. Pathol., 3, 393, 1906; 5, 233, 1908; Handb. d. Biochem., 3', 295, 329, 1910.

${ }^{41}$ C. v. Noorden's Die Zuckerkrankheit, 5th ed., p. 46, 1910. 
The following schema is intended to represent the mutual relations of the thyroid, adrenals and pancreas:

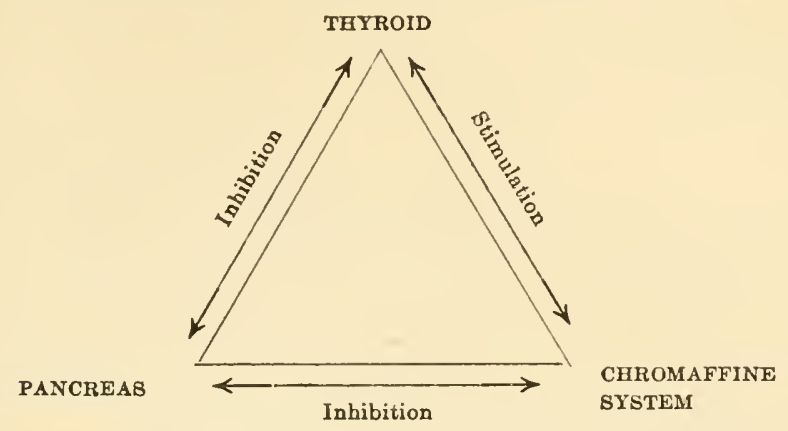

If we keep perfectly clearly before us the fact that this interrelation is of an absolutely hypothetical nature, the most of us will not be disposed to deny a heuristic value to. such schematic presentation.

It may well be that we can classify the ductless glands in two groups, one group with an accelerator, the other with a retarding functional effect upon the metabolism. The first group, whose "hormones" apparently excite sympathicotonic impulses, includes the thyroid, the chromaffine system and perhaps the hypophysis. To the second, seemingly antagonistic to the first group, belong the pancreas and the parathyroids. The first group could stimulate the basic protein destruction, carbohydrate mobilization, fat metabolism, output of water and salt, and the galvanic irritability of nerves; the second group, however, acts according to all appearance in an inhibitory manner. ${ }^{42}$ The strongest criticism, unquestionably, comes when we discriminatively examine the mutual relations of these functions. The idea that a centre in the medulla regulates the provision of sugar to the various tissues, which, as Falta supposes, "continuously mobilizes, by way of the sympathetic nerves and the adrenals, sugar in the liver, but exerts inhibitory influences

42 W. Falta, Wiener klin. Wochenschr., 1909, p. 1059; Caro, Med. Klinik, 1910, 136; W. Falta, L. H. Newburgh and E. Nobel (v. Noorden's Clinic, Vienna), Zeitschr. f. klin. Med., 7刃, 97, 1911. 
on this mobilization by the autonymous nerves and pancreas, and thus the level of sugar in the blood is kept at a constant level,' is, it is true, very plausible. But actually such interdependence is far from proven (and this should be clearly understood).

\section{RELATION OF THE HYPOPHYSIS TO CARBOHYDRATE METABOLISM}

Perhaps nothing can illustrate more clearly how extremely difficult it is to come to any definite conclusions in this field of our study than a statement of the relations of the hypophysis to carbohydrate metabolism.

As previously stated (Vol. I of this series, p. 484, Chemistry of the Tissues), Borchhardt succeeded in inducing a glycosuria in rabbits, but not in dogs, by injections of extract of the hypophysis. Later, after a careful review of the whole literature bearing upon the subject, he came to the conclusion that glycosuria is a more constantly associated feature in cases of acromegaly (in which, it may be assumed that the hypophysis is the part primarily involved) than in any other affection. ${ }^{43}$ It is very interesting in this connection that $\mathrm{B}$. Aschner, ${ }^{44}$ from recent investigations of his own carried out in R. Paltauf's Institute, holds that there exists a sugar centre in the vicinity of the hypophysis. After Kreidl and Karplus, colleagues of the writer, had succeeded in the Vienna Physiological Institute in showing a sympathetic nervous centre in immediate proximity to the tuber cinereum, Aschner found that it was possible to produce a glycosuria with absolute certainty by injuring the tuber cinereum. "If we grant," suggests Aschner, "that overactivity of the hypophysis itself, just as overactivity of the thyroid in Basedow's disease, can give rise at times to a glycosuria, it seems much more probable from the foregoing experiment (production of glycosuria from injury to the

${ }_{43}^{43}$ L. Borchhardt (Jaffe's Lab., Königsberg), Zeitschr. f. klin. Med., 66, 3-4, 1908.

* B. Aschner, Pflüger’s Arch., 146, 114, 1912. 
tuber cinereum) that the glycosuria of hypophyseal affections may be explained as depending upon an irritation of the base of the brain. This is the more likely because of the existence here of both vagus and sympathetic paths, and an irritation of the sympathetic is apparently directly capable of giving rise to glycosuria."

In this connection it seems to be of great interest that it has been found possible in R. Gottlieb's laboratory to produce a sensitization of sympathetic nerve endings by constituents of the hypophysis in the same way that this had been previously accomplished by components of the thyroid (Vol. I of this series, p. 457, Chemistry of the Tissues). Proof of sensitization of the points of attack of suprarenin was obtained both by the Läwen-Trendelenburg frog preparations and by mydriasis of the enucleated frog's eye. Emphasis has been properly laid upon the point that as long as we know nothing of an internal secretion of the constituents of the hypophysis we are really not in position to insist upon the physiological significance of this phenomenon. We cannot help, however, considering such sensitizing of the points of attack of one internal secretion by another internal secretion in trying to explain the physiological balance of the system and its disturbances. ${ }^{45}$

A rather impressive complement to the above-mentioned discoveries may be recognized in the observations of B. Aschner ${ }^{46}$ according to which in young dogs the glycosuria caused by adrenin may be markedly suppressed by extirpation of the hypophysis, possible not only in the first few days after the operation but for months. It is especially noteworthy that the skin necroses, which so often occur in case of adrenin injections, are not met in such instances at all or only rarely. This, it might be suggested, may be due to the fact that the vaso-constricting influence of the adrenin has been weakened.

\footnotetext{
${ }^{45}$ Kepinow (R. Gottlieb's Lab., Heidelberg), Arch. f. exper. Pathol., 67, $247,1912$.

${ }^{46}$ Aschner, l. c., pp. 105-106.
} 
Consistently with the failure of adrenin glycosuria in animals deprived of their hypophyses, in hypophyseal obesity (degeneratio adiposo-genitalis), which is believed to be connected with a lowered function of the hypophysis, a ligher tolerance for carbohydrates has been observed, as in myxœdema. ${ }^{47}$ As previously stated, the hypophysis may be regarded as associated with the thyroid and the chromaffine system in a group of organs with sympathetic innervation, having an accelerator influence upon metabolism, and under proper circumstances increasing the respiratory metabolism as well as the carbohydrate-, protein- and fatexchange. Aschner ${ }^{48}$ expresses this relation by the following modification of the previously presented Eppinger-Falta schema (including the ovary and the parathyroids) :

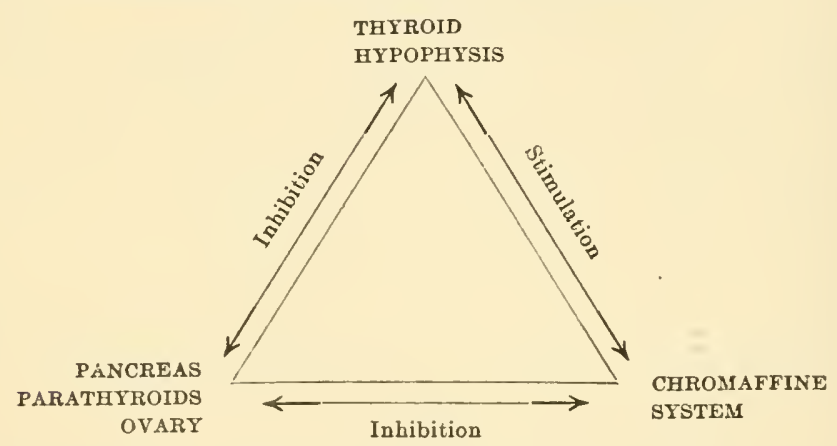

Without any desire to place any excessive provisional estimate upon the reality of all these matters, it will be well for us to follow with proper interest the further development of this modern scientific magic, in which internal secretory organs replace the planetary orbits of the ancient astrologers, with their favoring and inhibitory influences upon every phase of life.

With this, these little known subjects may be dismissed, and with them that of glycosuria, attention being directed to other matters connected with carbohydrate metabolism; of which the first to demand our interest are the glycuronic acids.

\footnotetext{
${ }^{47}$ Cf. C. v. Noorden, Die Zuckerkrankheit, 5th ed., 1910, p. 48.

"Aschner, 1. c., p. 110.
} 


\section{GLYCURONIC ACID}

Constitution.-Glycuronic acid, which was discovered as a product of metabolism in 1878 by M. Jaffe and by $\mathrm{O}$. Schmiedeberg and H. H. Meyer, contemporaneously but independently, and the constitution of which was verified by its synthetic production by Emil Fischer and Piloty, is without doubt a direct oxidation product of grape-sugar :
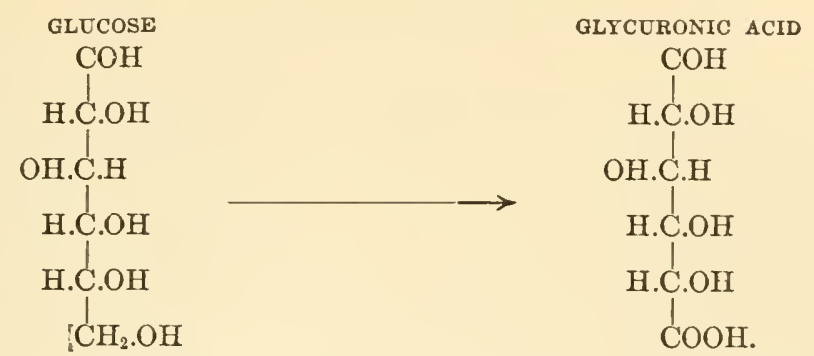

Glycuronic acid in metabolism always appears in the form of conjugated glycuronic acids which are lævorotary, an optical dextrogyration being characteristic of the free glycuronic acid.

The conjugates are in general of the nature of alcohols or phenols. According to the synthesis by Neuberg and Neimann and the discovery that glucoside-splitting ferments (like emulsin and kefirlactase) are also capable of splitting conjugated glycuronic acids, there is no room for doubt that in a general way these latter correspond to the glucoside type of Emil Fischer. Starting with the tautomeric, accessory form of glucose

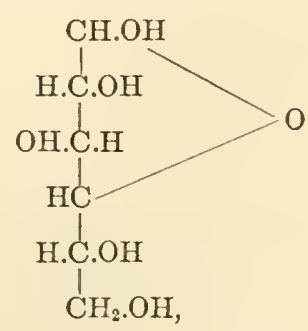

the reaction with an alcohol obviously takes place with separation of water and oxidation of the terminal $\mathrm{CH}_{2} . \mathrm{OH}$ 
group to a carboxyl, thus giving a phenol-glycuronic acid the constitution:

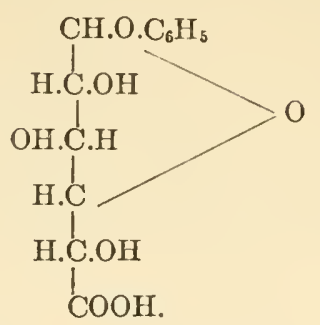

According to Emil Fischer it is very improbable that free glycuronic acid is first formed, as it cannot well be imagined why the $\mathrm{CH}_{2}(\mathrm{OH})$ group should be oxidized while the much more labile aldehyde group is preserved. However, this objection is of less force if one supposes that the aldehyde group is protected by first fixing an alcohol or a phenol group, after which the terminal $\mathrm{CH}_{2} \mathrm{OH}$ group undergoes oxidation into $\mathrm{COOH}$.

Conjugation Conditions.-Very many foreign substances when introduced into the body are finally excreted with the urine in the form of conjugate glycuronic acids. However, the alcohols and phenols alone are capable of direct conjugation. Aldehydes and acetones must first be reduced to alcohols (as chloral, $\mathrm{CCl}_{3} \cdot \mathrm{COH}$, to $\mathrm{CCl}_{3} \cdot \mathrm{CH}_{2} \cdot \mathrm{OH}$; acetone, $\mathrm{CH}_{3}$. $\mathrm{CO} . \mathrm{CH}_{3}$, to $\left.\mathrm{CH}_{3} \cdot \mathrm{CH}(\mathrm{OH}) \cdot \mathrm{CH}_{3}\right)$. Hydrocarbons of the aromatic and hydroaromatic series are hydroxylized (as benzol into phenol); and heterocyclic compounds undergo analogous hydroxylation (as indol into indoxyl). These relations have been thoroughly proved by numerous studies. by Jaffe, Neuberg, Fromm, Hildebrandt, Neubauer, Hämäläinen, and others. ${ }^{49}$

${ }^{49}$ Cf. Literature: C. Neuberg, Handb. d. Pathol. d. Stoffw., 2d ed., 2, 225, 228, 1907, and Ergebn. d. Physiol., 3, 385-390, 1904; C. Neuberg and W. Neimann, Zeitschr. f. physiol. Chem., 4h, 114 1905; E. Salkowski and C. Neuberg, Biochem. Zeitschr., 2, 307, 1906; R. Hildebrandt (Halle), Hofmeister's Beitr., 7, 438, 1906; Hämäläinen (Helsingfors), Skandin. Arch. f. Physiol., 27, 141, 1912; J. Schüller (M. Cremer's Lab., Cologne), Zeitschr. f. Biol., 56, 274, 1911; J. Saneyoshi (C. Neuberg's Lab.), Biochem. Zeitschr., 36, 22, 1911. 
In determining the amount of aromatic substances excreted in the urine it is necessary besides the conjugated sulphuric acids to also keep in mind the conjugated glycuronic acids, with possible complex interrelations. Thus Neuberg isolated ${ }^{50}$ from the urine of dogs to which cresol had been fed, the barium salt of a double combination of cresol-glycuronic acid and eresol-sulphuric acid:

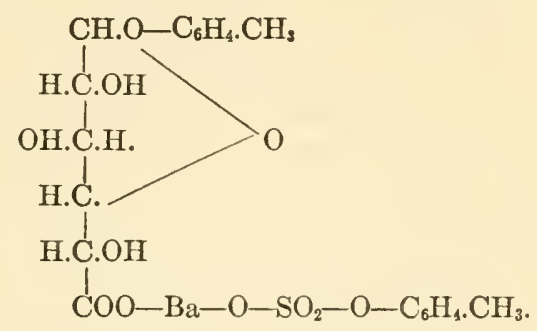

Properly considered the conjugation of foreign substances with glycuronic acid is really a detoxifying process. Apparently the economy sometimes provides a larger amount of glycuronic acid than is absolutely needed. At least $\mathrm{F}$. Blumenthal noticed in a case of lysol poisoning the formation of considerably more glycuronic acid than required for fixing the amount of cresol introduced.

Origin of Glycuronic Acid from Oxidation of Sugar.The origin of glycuronic acid from sugar by oxidation (which can be performed artificially in vitro by careful oxidation of dextrose by means of peroxide of hydrogen) ${ }^{51}$ directly explains a positive dependence of the physiological formation of this substance upon the body supply of carbohydrates. One can readily appreciate that an animal, with its glycogen reduced from long continued starvation, would react to dosage with camphor with only a slight excretion of glycuronic acid, and that this would increase progressively with exhibition of sugar. And when it is recalled that sugar may be formed from protein, there is just as little occasion

${ }^{50}$ C. Neuberg and E. Kretschmer, Biochem. Zeitschr., 36, 15, 1911; cf. also F. Stern (Kiel), Zeitschr. f. physiol. Chem., 68, 52, 1910.

${ }^{81}$ A. Jolles, Biochem. Zeitschr., 3/, 242, 1911. 
for surprise to find that a practically glycogen-free inaividual is still capable of producing some glycuronic acid. The problem of its production is to-day not so much as to its derivation from sugar (for this surely can no longer be a subject of doubt), but whether physiologically the normal catabolism of sugar proceeds through glycuronic acid. In the sense of Paul Meyer's much discussed "theory of incomplete sugar oxidation" many instances of pathological glycuronic acid excretion, not satisfactorily explicable on the assumption of an increased introduction or formation of substances able to combine with it, may be looked on as due to a primary disturbance of the normal sugar catabolism, here becoming stationary in the intermediate stage of glycuronic acid. This might be thought of in many instances of glycuronic acid excretion in respiratory disturbances, in many intoxications, in very free glycogen supply, and therefore in diabetes. Paul Meyer believes, too, that a heightened excretion of glycuronic acid without evident cause and without coincident increase of elimination of aromatic conjugates in apparently healthy individuals may be looked upon as a precedent of diabetes and as a symptom of incomplete oxidation of sugar. Neuberg very properly suggests, however, that Paul Meyer has not presented exact proof of the correctness of his theory; that it can only be looked on for the present as a simple expression of the facts observed by him and may perhaps eventually be explained in a totally different way. ${ }^{52}$ C. von Noorden, who does not favor the theory above outlined, thinks it incorrect to assign importance to increase of glycuronic acid in diabetes. ${ }^{53}$

Oxaluria.-The circumstance that free supply of sugar and glycuronic acid may lead to an increased elimination of oxalic acid and to an increased accumulation of this acid in the liver, and the fact that oxaluria and glycuronic acid ex-

${ }^{52}$ C. Neuberg, Handb. d. Pathol. d. Stoffwechs., 2d ed., 2, 233-235, 1907.

${ }^{*}$ C. von Noorden, Handb. d. Pathol. d. Stoff wechs., 2d ed., 2, 60, 1907. 
cretion are at times found associated with diabetes, has been the basis for regarding oxalic acid as an end-product of sugar catabolism:

Sugar $\longrightarrow$ Glycuronic Acid Oxalic Acid.

That oxalic acid may be an end-product of all sorts of substances has probably been the uncomfortable experience of every chemist, who after having carried out some tiresome oxidation experiment has time after time been able to obtain, instead of the product he hoped for, only the inevitable and unwelcome oxalic acid. Of course, then, it cannot be denied that sometimes sugar may also be converted into oxalic acid in the body. When and under what circumstances this is true is, however, unknown; and thus far all told there has very little of a positive nature been obtained from the many studies of the elimination of the relatively incombustible oxalic acid in physiological and pathological conditions. ${ }^{54}$

Conversion of Glycuronic Acid into $\lambda$-xylose.-A very important phase of the glycuronic acid question has been previously referred to, the conjectural relation of the acid with the tissue pentoses. From E. Salkowski's and C. Neuberg's discovery it is at least quite probable that the tissue sugar with five carbon atoms, $\lambda$-xylose, arises from glycuronic acid by cleavage of $\mathrm{CO}_{2}$, and that the latter may be thus converted into pentose by the agency of putrefactive microörganisms :

GLYCURONIC ACID

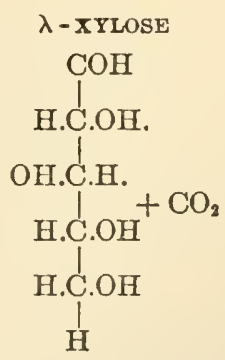

B. Literature upon Oxaluria: A. Magnus-Levy, Bd., 1, 155-159, 1906. 
Occurrence of Glycuronic Acid in the Body.-As for the occurence of compounds of glycuronic acid in the economy, this substance has been recognized by C. Neuberg and Paul Meyer and by Lépine and Boulud, as a normal constituent of the urine and of the blood, although apparently no notable amounts are apt to accumulate in the tissues generally. ${ }^{55}$ According to the opinion of the last-named authors the increment in reducing power of blood extracts after hydrolytic cleavage ("sucre virtuel") may at least partly be referred to glycuronic acid compounds supposed to be present especially in the formed elements of the blood. ${ }^{56}$

Importance of Glycuronic Acid in Diagnosis of Intestinal Disturbances and Diseases of the Liver.-Excretion of glycuronic acid in the urine apparently depends primarily upon digestive conditions and intestinal putrefaction, and thereafter upon the quantities of indol and pienol available for conjugation. According to E. Mayerhofer's studies a new reaction, originated by Guido Goldschmiedt ( $v$. infra), producing a green color from the action of $a$-naphthol and concentrated sulphuric acid upon glycuronic acid, is in general the most delicate mode of detecting the presence of intestinal disturbances in infants. While the test is invariably negative in well nourished breast-fed children, it is sufficiently delicate to give a positive result with even the slightest nutritive disturbances with an associated heightening of intestinal putrefaction, the intensity of color increasing and decreasing with the grade of the affection. In artificially fed infants, who are practically never free, as is known, from nutritive disturbances, the absence of

${ }^{65}$ Literature upon the Occurrence of Glycuronic Acid Compounds in the Body: C. Neuberg, Handb. d. Pathol. d. Stoffw., 2, 226, 1907.

R. Lépine and Boulud, Compt Rendu, 141, 453, 1905, and earlier contributions; Jour. de Physiol., 7, 775, 1905. 
glycuronic acid excretion in the urine is really an exception. ${ }^{57}$

Apparently, however, urinary glycuronic acid presents a practical clinical interest in another direction. Studies by K. v. Stejskal and Grünwald ${ }^{58}$ have indicated that, while the normal body tends to carry out the synthesis of conjugate glycuronic acid after administration of camphor with such precision that almost the whole quantity of camphorglycuronic acid, as calculated theoretically, appears in the urine in the course of twenty-four hours, in a patient suffering from hepatic cirrhosis or severe catarrhal jaundice, the process is distinctly inhibited. The expectation of possible employment of the synthetic production of this substance as the basis for a method of functional hepatic diagnosis is apparently, therefore, not entirely without reason, although there is not the least reason for referring the processes of glycuronic acid formation exclusively to the liver. It has been shown, however, in studies carried on in Hofmeister's laboratory, ${ }^{59}$ that hepatic destruction from acid infusion may be without any influence upon the synthesis of glycuronic acid after administration of chloral; and J. Poll ${ }^{60}$ has found that severe hepatic changes due to intoxication with ethylendiamine inhibit, it is true, the formation of urochloralic acid, but do not inhibit that of phenol-glycuronic acid.

Detection and Estimation of Glycuronic Acid.-In conclusion a few words may be devoted to discussion of the modes of detection and estimation of glycuronic acid.

${ }^{57}$ B. von Fenyvessy (Pharmakol. Instit., Budapesth), Arch. internat. des Pharmacodyn, 12, 407, 1903; C. Tollens and F. Stern, Zeitschr. f. physiol. Chem., 64, 39, 1910; C. Tollens, ibid., 6\%, 138, 1910; E. Mayerhofer (Franz Josef's Hospital, Vienna), Zeitschr. f. Kinderheilk., 1, 226, 1910; Zeitschr. f. physiol. Chem., 70, 391, 1910.

${ }^{s}$ K. v. Stejskal and H. Fr. Grünwald (Second Med. Clinic, Vienna), Wiener klin. Wochenschr., 1909, No. 30.

${ }^{59}$ F. Pick (Hofmeister's Lab., Prague), Arch. f. exper. Pathol., 33, 315, 1894.

${ }^{60}$ J. Pohl (Prague), Arch. f. exper. Pathol., 41, 971, 1895. 
In a general way we may suspect a given urine of containing conjugate glycuronic acid if it polarizes to the left without showing fermentescibility and reducing power, the lævogyratory power changing to dextrogyratory and coincidently a marked reducing power developing after boiling for a long time with dilute acid.

C. Neuberg recommends in the determination of glycuronic acid to first concentrate it by lead precipitation, after hydrolytic cleavage of the urine. After decomposing the lead precipitate by means of sulphuretted hydrogen or sulphuric acid one sometimes succeeds in obtaining the beautiful crystalline cinchonin salt of the acid. The p-bromphenylhydrazine compound of glycuronic acid may also prove of important service, according to Neuberg; it can be distinguished from the bromphenylosazones of sugar by its almost complete insolubility in warm alcohol, but is especially characterized by the fact that its optical rotating power in a pyridinalcoholic solution is much more marked than that of any of the analogous sugar compounds.

The brilliant colors produced in the orcin- and phloroglucin-tests may also serve for the detection of glycuronic acid. According to Neuberg, these tests are not to be attributed to the separation of furfurol, and to speak of them as "furfurol reactions" is a mistake. They are, however, not at all characteristic of glycuronic acid, but are well known reactions also of the pentoses. It seems, moreover, that they respond to any sugar with an uneven number of carbon atoms in its molecule.

The naphtho-resorcin reaction of $\mathrm{B}$. Tollens ${ }^{61}$ offers distinct advantages over these reactions. It depends on the fact that naphtho-resorcin $\left[1.3\right.$ dioxynaphthalin, $\mathrm{C}_{10} \mathrm{H}_{6}$ $(\mathrm{OH})_{2}$ ] changes the glycuronic acid, on boiling with hydro-

${ }^{*}$ B. Tollens (Göttingen), Ber. d. deutsch. chem. Ges., 41, 1783, 1908; Zeitschr. f. physiol. Chem., 56, 115, 1908; C. Tollens (Kiel), Münchener med. Wochenschr., 1909, 652; C. Neuberg and O. Schewket, Biochem. Zeitschr., 44, $502,1912$. 
chloric acid, into a coloring matter which gives a blue color in ether, and in solution gives a dark spectral band in the vicinity of the sodium lime. It is true that this reaction is also not specific for glycuronic acid; it occurs also (as shown by A. Mandel and C. Neuberg: ${ }^{62}$ with many aliphatic aldehyde- and ketonic-acids containing the group $\mathrm{CO}$
COOH' beginning with glyoxylic acid, $\begin{gathered}\mathrm{COH} \\ \mathrm{COOH}\end{gathered}$, and seems to be due to a certain combination between carboxyl and carbonyl groups. Indoxyl may also cause confusion. ${ }^{63}$ The test is suited, however, for positive differentiation of glycuronic acid from the pentoses. If glycuronic acid in a mixture of different sugars is precipitated with these as an osazone, the glycuronic acid osazone alone will give the Tollens color reaction. ${ }^{64}$

A very valuable recent reaction for glycuronic acid has been originated by Guido Goldschmiedt, as above stated; he found that glycuronic acid with a-naphthol and concentrated sulphuric acid will give an emerald green color (passing into violet and blue when diluted with water). Neither hexoses nor pentoses give this reaction, which is directly applicable in human urine only when the diet is free from nitrates (as milk, white bread and meat). The urine of dogs and rabbits is always free from nitrites, as proved by the diphenylamine reaction. ${ }^{65}$

A method of quantitative determination of glycuronic acid lias been recently proposed by Lefèvre and Tollens. It depends on the fact that if urine is precipitated by acetate of lead and ammonia, the furfurol appearing in distillation

${ }^{62}$ A. Mandel and C. Neuberg, Biochem. Zeitschr., 13, 148, 1908; C. Neuberg, ibid., 24, 436, 1910 .

a R. Bernier, Jour. d. Pharm. et de Chim., series 7, 2, 401, 1910; cited in Jahresber. f. Tierchem., 40, 301, 1910.

${ }^{64}$ C. Neuberg, and S. Saneyoshi, Biochem. Zeitschr., 36, 56, 1911.

${ }^{\text {es }}$ G. Goldschmiedt (Prague), Zeitschr. f. physiol. Chem., 65, 389, 1910; 67, 194, 1910; ef. also L. v. Udránsky, ibid., 68, 88, 1910. 
of this precipitate with acids has its actual source in glycuronic acid. A molecule of the latter breaks down into a molecule of furfurol and $\mathrm{CO}_{2}$. The former may be weighed after precipitation of the distillate with phloroglucin; and the $\mathrm{CO}_{2}$ taken up in a potash apparatus and estimated. As furfurol formation is also possible from the pentoses, but the accompanying separation of carbonic acid is entirely characteristic for glycuronic acid (from the carboxylic group of which it arises) the method serves to determine glycuronic acid in the presence of pentoses. ${ }^{66}$ It is to be expected now that we possess this method, our knowledge of the rôle and significance of glycuronic acid in the economy will advance more rapidly than has hitherto been the case.

${ }^{66}$ B. Tollens, Zeitschr. f. physiol. Chem., 61, 95, 1909; U. Lefèvre and B. Tollens, Ber. d. deutsch. chem. Ges., 40, 4513, 1908. 


\section{CHAPTER XIV}

SUGAR DESTRUCTION IN THE ECONOMY

Glycolysis.-The author feels that it is desirable to conclude the series of lectures upon the question of carbohydrate metabolism by a statement of the problem of glycolysis. Although the ground is by no means sure and we know perfectly well that whatever is to be said is far more of a negative than of positive import, the question cannot well be neglected from the list of important problems of physiological chemistry-how the economy proceeds in the catabolism of sugar.

Efforts to discover the answer of this problem reach rather far back. It is, of course, quite natural that in part these took inception in an example of glycolysis in nature, a process which has achieved a tremendous economical importance (not exactly to the best interest of human welfare), that of alcoholic fermentation of sugar by yeast fungi. It is entirely apropos to inquire whether other animal and vegetable cells may not have in some degree a power similar to that of the yeasts to split sugar into alcohol and $\mathrm{CO}_{2}$.

Distribution of Zymases in the Vegetable Kingdom.-Although Pasteur and Pfeffer had originally suggested that the first phase of the decomposition of sugar in plants consists of an anærobic formation of alcohol which then undergoes combustion into $\mathrm{CO}_{2}$ and water upon the access of oxygen, Stoklasa, of Prague, the biochemist, and his pupils deserve the credit of first having experimentally furnished support for the idea. After E. Buchner in the latter part of the nineties made the important discovery that an enzyme elaborated by the vital activity of the yeast cells, zymase, is capable of setting up fermentation of sugar into alcohol and carbonic acid, the basis was prepared for the recognition of the zymases of higher types of living beings. By employing the methods used by Buchner for recovering the zymase of 
yeast Stoklasa and his collaborators succeeded (by precipitating expressed juices by alcoholic ether and rapidly drying the precipitate) in obtaining zymases from beets, potatoes, peas and green types of plants, i.e., enzymes capable of inducing an active fermentation of sugar into alcohol and carbonic acid in complete absence of microörganisms. ${ }^{1}$ The studies of Palladin and Kostytschew mark a further step, showing that the anærobic respiration of plants is apparently at least in part an alcohol fermentation which independently of the life of the cells takes place from the influence of enzymes even after the cells have been killed by freezing. Besides the zymases, according to Stoklasa there are held to be also "lactolases" concerned in the anærobic plant respiration, which give rise to formation of lactic acid. The related older view, that a molecule of sugar is first separated into two molecules of lactic acid and these later fermented into alcohol and carbonic acid, can no longer be regarded as correct from the modern viewpoint of the fermentation theory. However, lactic acid can originate from labile intermediate products through transposition processes. In the later stages of the fermentation process the alcohol fermentation (the zymase being injured by the advancing acidity) may lag behind the lactic acid fermentation, and in still later phases the latter may in turn be limited by a butyric acid fermentation.

Supposed Occurrence of Zymases in Animal Tissues.There is thus no ground for question as to the occurrence of an alcohol fermentation in the anærobic respiration of plants. Stoklasa, however, believed his findings applicable to the field of the animal economy, and thought that he could recover zymases from all sorts of tissue (muscle, liver, pancreas, leucocytes, etc.). ${ }^{2}$ These latter discoveries, which were subjected to control tests by many authors, have, how-

${ }^{1}$ Literature upon the Zymases of Higher Plants: C. Oppenheimer, Die Fermente, 3d ed., 466-474, 1910.

${ }^{2}$ Cf. Literature: E. Abderhalden, Lehrb. d. physiol. Chem., 2d ed., 89, 1909. 
ever, been confirmed only here and there, ${ }^{3}$ but have for the most part excited opposition.

Thus Blumenthal and others found that sugar catabolism proceeds in the tissues with formation of $\mathrm{CO}_{2}$, it is true, but not with a corresponding production of alcohol. ${ }^{4}$ Small amounts of alcohol have actually been found in animal tissues by various observers, ${ }^{5}$ but Landsberg believes this can be fully explained as the result of absorption of alcohol from the gastroenteric canal, where from the influence of yeasts and bacteria upon the carbohydrates there is always opportunity given for alcohol production. Then, too, it has been shown that only the putrefaction of tissues, not their autolysis, increases their alcohol content. Battelli maintained the circulation in freshly killed animals for two hours by compressing the exposed heart, and coincidently kept up artificial hydrogen respiration through a tracheal canula; under which circumstances it was shown that in the absence of oxygen the economy of the higher animals does not form carbonic acid, that, as a matter of fact, therefore, there apparently does not exist here an "anærobic respiration." " It is certainly worth considering, too, that in the anoxybiosis of ascarides and earth worms, as shown by the studies of Weinland and Lesser, there is nothing in the way of an alcoholic fermentation of sugar (in these, however, as an important product of carbohydrate cleavage there is formed, besides carbonic, a volatile fatty acid, apparently valerianic acid). ${ }^{7} \quad$ The most weighty objection to Stoklasa's idea, however, is to be seen in the circumstance that many careful

${ }^{3}$ R. Kobert, Pflüger's Arch., 99, 176, 1909; F. Maignan, Compt. Rend., 140, 1063, 1124, 1905; F. Ransom (Cambridge), Jour. of Physiol., 40, 1, 1910.

${ }^{4}$ F. Blumenthal, Deutsch. med. Wochenschr., 1908, No. 51; J. Feinschmidt (F. Blumenthal's Lab.), Hofmeister's Beitr., 4, 511, 1904; E. Bendix (F. Blumenthal's Lab.), Zeitschr. f. physik. und diät. Ther., 2, 218, 1899.

- Ford; Rajewski; G. Landsberg, Zeitschr. f. physiol. Chem., 41, 505, 1904; Reach (A. Durig's Lab.), Biochem. Zeitschr., 3, 326, 1907.

'F. Battelli, Arch. intern. de Physiol., 1, 47, 1904.

'Literature upon Anoxybiosis: E. J. Lesser, Ergebn. d. Physiol., 8, 742796. 1909 ; Zeitschr. f. Biol., 52. 282, 190 ?. 
observers, ${ }^{8}$ in their control tests of his statements (with provision of thorough asepsis), failed to obtain any fermentation. "The fact," states Vernon,9 "that Stoklasa and his collaborators were unable to find any bacteria by their cultures does not necessarily prove that they were not present. As far as can be made out from their studies the cultures, as a rule, were placed in ærobic surroundings, although the fermentations were anærobic. The cultural conditions were, therefore, not favorable for the growth of the bacteria which occasion the alcoholic fermentation." Harden and Maclean, ${ }^{10}$ who have recently subjected the work of Stoklasa to severe criticism, found that if to solutions of glucose they add tissue juices, or sediments obtained therefrom by alcoholic ether, in the course of the first few hours a very trivial gas development takes place, the cause of which is purely physical, and which is noticeable both when there is no sugar present and when disinfectants are added. Later on, however, a gas production begins, continuously increasing in intensity, which goes on in proportion to the growth of bacteria. If toluol be added in quantities which are harmful to bacteria but which are known from experience to be without influence upon the zymases, the gas formation ceases. That the test for bacteria in Stoklasa's experiments so frequently resulted negatively, may, in the opinion of these authors, have been due to the fact that it was made at the end of the fermentation, therefore at a time when the bacteria may have been already destroyed by the concentration of their own metabolic products (alcohol, lactic acid).

However highly Stoklasa's discoveries as to the importance of zymases in the anærobic respiration of plants may be regarded, it must be said that analogous processes in the

${ }^{s}$ Battelli, Mazé, Portier, Colınheim, Embden, Arnheim and Rosenbaum, Harden and Maclean.

${ }^{9}$ H. M. Vernon, Ergebn. d. Physiol., 9, 205, 1910.

${ }^{10}$ A. Harden and H. Maclean (Lister Instit.), Jour. of Physiol., 42, 64, 1911. 
animal economy have not only not been proved but are not even probable.

The author acknowledges that this is only his own subjective impression, and desires to add that others who have gone at length into this problem have arrived at a contrary opinion. Thus Carl Oppenheimer does not look on the bacterial objection, even if it cannot be completely put aside, as the real nucleus of the question. "Stoklasa found a satisfactory reproduction of yeast fermentation in all its phases. Where are the bacteria which are carrying this on? We are aware, of course, that in bacterial fermentations alcohol occurs as a more or less insignificant by-product. Either Stoklasa's alcohol finding's are false-when there is nothing further to be said to the contrary; or they are correct-and in this case they cannot be referred to the action of bacteria. That true yeast cells are present in Stoklasa's ether-precipitated extracts of tissues no one has, to the best of my knowledge, as yet asserted. A priori it is much more probable that the investigators following Stoklasa have not had the same fortunate hand as he. . . . Other sources of error are in all probability to be apprehended in the antiseptics employed; which perhaps may have so thoroughly eliminated the bacteria so often called into question that the easily affected zymase has also been destroyed by them. We have, in fact, here one of the most curious of spectacles, one which only an exact research can afford-on one side a series of experiments published in fullest extent, with all details, which always give the same result; on the other, a list of reinvestigators who are unable to find anything and who introduce into the field unsupported contradiction of the experiments. As long as no one appears to show where the alcohol and lactic acid come from in Stoklasa's experiments his experiments are going to stand like a rocher de bronze."

Eren as objective an observer as Hammersten ${ }^{11}$ con-

${ }^{11}$ O. Hammersten, Lehrb. d. physiol. Chem., 7th ed, 382, 1910. 
cludes that the statements of Stoklasa and his collaborators have not been controverted, and believes that we cannot deny the possibility that an alcoholic fermentation can exist in animal tissues as well as in plant tissues in anærobic respiration.

Here again is an example of how differently a given situation may strike the minds of different individuals.

The same impression will be aroused when we attempt to discuss what is thought to be known of the glycolytic power of ground-up tissues and the expressed juices of tissues.

Cohnheim's Pancreas-Muscle Experiment.-In view of the importance to be attributed to the pancreas in carbohydrate metabolism since the discovery of pancreatic diabetes, it was desirable to determine whether a special extracorporeal glycolytic power is inherent to the pancreas. Otto Cohnheim believes that this may be answered affirmatively, in the sense that the muscles contain a glycolytic ferment which owes its activation to the pancreas. The "pancreatic activator" is believed to be a thermostable substance, soluble in dilute alcohol, the effect of which in increasing amounts is peculiar, first increasing and then diminishing. Cohnheim compares this last with the phenomena of complement deviation and overfixation in the combined action of amboceptor and complement. In extraction of the glycolytic enzyme of the muscle, which is very easily affected by salt solutions, an ice-cold solution of sodium oxalate is recommended. The quantity present in muscles is believed to be subject to marked variation even in physiological conditions; thus it is supposed that cat muscle is strongly active in glycolysis if the cats have been fed upon milk and sugar, but of little glycolytic power if the animals are fed on fat or fatigued from physical exercise. ${ }^{12}$

${ }^{12}$ O. Cohnheim (Heidelberg), Zeitschr. f. physiol. Chem., 39, 396, 1903; $42,402,1904 ; 43,547,1905 ; 4 \%, 253,1906$. 
Objections of Claus and Embden.-R. Claus and G. Embden ${ }^{13}$ after subjecting Cohnheim's experiments to careful control investigation, came to believe that they are dealing with an action due to contaminations, probably of bacterial nature. The apparent inerease of glycolysis on addition of pancreatic material might possibly be due to nothing more than that corpuscular elements may withdraw some of the toluol from the fluid saturated with this substance, and in this way really favor the development of bacteria. The writers named also express the opinion that toluol, as well as other antiseptics, if not added in large amounts affords no very great protection against bacteria, and that the common method of studying the action of glycolytic ferments in tissue pulp with antiseptics added is not a serviceable one and should be abandoned.

There is no doubt of the very great difficulty of entirely excluding confusion of results because of the influence of microörganisms in experiments of this sort, and this has been confirmed from another point of view. ${ }^{14}$ The conviction is borne in upon us that even if we do not employ a tissue pulp, but work with acetone-precipitates from the expressed juices, and whether toluol or chloroform be used as an antiseptic, we are by no means sure of not finding scattered bacteria in the sediment. ${ }^{15}$

However impressed the writer may be that the greatest scepticism for all the discoveries in this field is apropos, that moreover many of them are merely without objection, and that especially all estimates of the quantity of glycolytic enzyme in the tissues are apparently extremely problematical, he would not willingly be persuaded that everything which has been observed and noted here is actually nothing but the effect of bacteria.

${ }^{13}$ R. Claus and G. Embden (Frankfurt a. M.), Hofmeister's Beitr., 6, 214, $343,1905$.

${ }^{14}$ G. C. E. Simpson (Liverpool), Biochem. Jour., 5, 126, 1910.

${ }^{28}$ L. Rapoport (First Med. Clinic, Berlin), Zeitschr. f. klin. Med., 57, 208, 1905. 
No great importance can be attributed by the author to experiments with tissue pulp, ${ }^{16}$ as the technical difficulties of antiseptics with such material seem at the present, at least, not overcome. The author, however, acknowledges an impression that it may be a mistake to set aside without further consideration as "the effects of bacteria" the results of all experiments upon the glycolytic action of expressed juices provided they are conducted with necessary antiseptic precautions.

Possible Existence of Glycolytic Tissue Ferments.-One should remember, for instance, that, according to Feinschmidt, ${ }^{17}$ in the expressed juices from the pancreas, liver and muscles, even in the presence of 0.9 per cent. of sodium fluoride, appreciable glycolysis, with development of $\mathrm{CO}_{2}$ and organic acids, but with only traces of alcohol, is said to take place. It is without doubt of importance, too, that Cohnheim's work should have been confirmed by the American, Hall, ${ }^{18}$ in a very carefully conducted and critical control experiment. Hall expressed the juice from muscle and pancreas; and with these and with alcoholic extracts (by boiling) from the latter, mixed or separate, acted upon a dilute sugar solution at incubator temperature and in presence of toluol, the length of the experiment not exceeding three days. That he should have found as an average from his experiments that pancreatic juice alone destroyed only 0.3 per cent. of the amount of glucose employed, muscle juice alone only 1.6 per cent., the combination of muscle juice and pancreas 4.4 per cent., but the combination of the alcoholic extract of pancreas and muscle-juice as much as 18.3 per cent., is very remarkable. The objection that such results are entirely due to bacterial influences seems decidedly im-

${ }^{16}$ Literature: (Blumenthal, Ssobolew, Herzog, Feinschmidt, Arnheim and Rosenbaum, Sehrt, Rapoport, Braunstein, Simacek, R. Hirsch) in Rosenberg, Handb. d. Biochem., $3^{\prime}, 253,1910$.

${ }^{17}$ Feinschmidt, Hofmeister's Beitr., 4, 511, 1904.

${ }^{18}$ C. W. Hall (Harvard Medical School), Amer. Jour. of Physiol., 18, $283,1907$. 
probable. While we are coming to recognize from a growing and more and more convineing experience that even with the presence of toluol it is not at all easy to protect a tissue pulp or especially suspensions of such a material from bacterial invasion with certainty, we have no reason, as far as the writer is aware, to doubt the efficiency of toluol in a fluid medium. Hall, in addition, controlled the sterility of his tests by both ærobic and anærobic culture methods. Moreover the fact that the glycolytic power of pancreatic and muscle extracts failed to manifest itself upon solutions of fructose and lactose, and appeared only in connection with glucose, specifically contradicts any bacterial influence, bacteria being in no wise selective enough to make such a difference. ${ }^{19}$

Recently P. A. Levene, who has at his disposal the great technical facilities of the Rockefeller Institute, of New York, has investigated the glycolytic influence of various animal tissues with and without addition of "activators." The tissues as such proved in practically all cases inactive. Addition of pancreatic extract to muscle was without effect in case of canine tissues, in rabbit tissues resulted in showing a lowered reducing power of the sugar solutions (but, in the dog, for example, splenic extract in combination with other tissues seemed to be feebly active). Levene's experiments have shown, however, that we are not justified in regarding a loss in reducing power of the glucose solutions employed as due only to "glycolysis." It seems that condensation processes, converting simple sugar to higher molecular products, may be involved. The reducing power of a sugar solution which has been lowered by the combined

${ }^{19}$ Stoklasa, Zeitschr. f. physiol. Chem., 62, 35, 1909, found precisely the opposite, viz., that preparations made from pancreas juice by alcoholic ether would break up disaccharides in the absence of antiseptics, with formation of lactic acid, alcohol and carbonic acid. However, hexoses apparently ferment only when produced by fermentation hydrolysis. All these effects are decidedly interfered with by the presence of antiseptics. Here, too, may be applied the remark that bacteria do not tend to be very selective which if correct to one is fair to the other side. 
influences of muscle plasma and pancreatic extract, can be restored by boiling with weak hydrochloric acid. Levene also succeeded in recovering from such a solution the osazone of a disaccharide. ${ }^{20}$

What now, in conclusion, is the exact meaning of this long disquisition? No one doubts in the least that glycolysis takes place in the tissues and that the living tissues are able to catabolize sugar. The point in question is, however, whether we are in position to reproduce the process with dead fragments of tissue and tissue extracts, whether in such case we are justified in referring the glycolysis to the influence of ferments which can operate independently of the living cells. As far as the writer sees, the question cannot at present be either affirmed or denied with certainty; and it seems not improbable that under proper conditions ferments can be obtained from tissues which in some way chemically change the sugar, either to induce cleavage or synthesis. But that is probably all that can be said. For the assumption that this chemical cleavage is to be regarded as analogous to the vital combustion of sugar, not to say equivalent, there is in the writer's opinion not the least basis. And, too, it certainly has not been shown that the activity of Cohnheim's pancreatic activator has anything to do with the puzzling influence which the living pancreas exercises upon the metabolism of sugar. If Hall (vide sup.) found that alcoholic extract of pancreas is more efficient than the pancreas itself, and if Levene found the pancreas inactive in many cases, but did find an extract of spleen to be active, it must seem that an unprejudiced person would conclude that they are perhaps dealing with a nonspecific effect. In the course of the last few years we have heard so much about the activating influences of lipoids, and especially tissue lipoids, upon the processes of fermentation and intoxication of the most varied types, that one may well

${ }^{20}$ P. A. Levene and G. M. Meyer, Jour. of Biol. Chem., 9, 97, 1911; 11, 347, $353,1912$. 
consider the possibility of a relation with such substances of the rather inconstant effects of the activators which Cohnheim and his followers have noted.

All in all the writer believes that the expectation of nearer approach to the secret of sugar catabolism in the living body by experiments upon tissue pulp and expressed juices is at the present unfortunately decidedly depressed. It was both logical and essential in forcing the path along this way to make and perseveringly repeat the experiment. But it is quite as logical after being quite convinced of the impracticability of this route of approach to look about for other paths which lead further.

Experiments upon Surviving Tissues.-A more promising way is apparently to be found in perfusion of living organs removed from the body. Occasion has been taken in a previous lecture to state in detail the fact that in R. Gottlieb's laboratory and elsewhere it has been found possible to measure continuously the amount of sugar used by the beating mammalian heart artificially perfused. Reference has already been made, too, to the expectations we are justified in cherishing for the pancreatic problem by applying the fine perfusion methods of E. H. Starling: Opportunity may be taken here, moreover, to refer to the important experiments of the American, McGuigan, who perfused organs with blood diluted with Ringer-Locke solution and mixed with different kinds of sugar, and then calculated the amount of sugar consumed (with reference to the amount of glycogen shown before and after perfusion). His experiments show that living muscles are able to induce a rapid combustion of dextrose, lævulose and galactose, but not maltose, and that this is true to a greater degree when the muscle is in activity than when at rest. However, in perfusion experiments on dead muscles, which, of course, should always offer more natural and more favorable experimentconditions than a ground-up muscle or an expressed juice, 
scarcely any loss of sugar could be determined. ${ }^{21}$ In the last count there will be nothing left to do but to accept the same verdict in the sugar problem as we long ago arrived at in the case of the protein question; that the secret of the process is hidden within the living cells and cannot be extracted by any solvent. The hope of preparing some ferment solution and by some clever manipulation bring about the combustion of protein at $40^{\circ} \mathrm{C}$. into carbonic acid, ammonia and water has long since been abandoned. The same thing will have to be accepted in the case of the sugar problem. It is the same in science as in life; when we stop striving for the unttainable our efforts to reach the attainable are pressed forward with just so much the fresher courage.

Glycolysis in Blood.-Interesting results in relation to glycolysis may be expected from the study of sugar catabolism in blood. This is the more noteworthy because for a long time there was nothing at all promising in view from this point of investigation.

Claude Bernard observed long ago that the sugar content diminished in blood on standing for a time, and expressed the idea that this was perhaps due to a destruction of sugar with formation of lactic acid. Later blood glycolysis was made the subject of careful investigation, especially by Lépine, who framed a new, much discussed and soon abandoned theory of diabetes upon the fact that he found the phenomenon decreased in diabetics and in animals deprived of the pancreas. Lépine, and with him Arthus, referred the glycolytic process in the blood to the leucocytes; the latter was disposed to recognize it as a postmortem phenomenon related with the disintegration of the blood corpuscles. ${ }^{22}$

${ }^{21}$ McGuigan (Washington Univ., St. Louis, Mo.), Amer. Jour. of Physiol., 21, 334, 1908; H. McGuigan and C. L. von Hess (Northwestern Univ. Med. School), ibid., 30, 341, 1912.

${ }^{22} \mathrm{Cf}$. the Older Literature upon Blood-glycolysis: C. Oppenheimer, Die Fermente, 3d ed., 478, 1910. 
In recent times a series of carefully conducted investigations have afforded important results in this connection, for which we are indebted to A. Slosse, of Brussels, and his collaborators, J. de Meyer and E. Vandeput. Primarily these show that aseptic glycolysis in the blood is not an alcoholic fermentation (even the most delicate tests indicate not the slightest trace of either alcohol- or carbonic acidformation). The catabolism takes place in a much more interesting manner, one molecule of glucose separating into two of lactic acid, and the latter in turn into acetic acid and formic acid. From the formic acid very small quantities of $\mathrm{CO}$ can be produced. Sugar catabolism, therefore, according to Slosse, characteristically follows this schema:

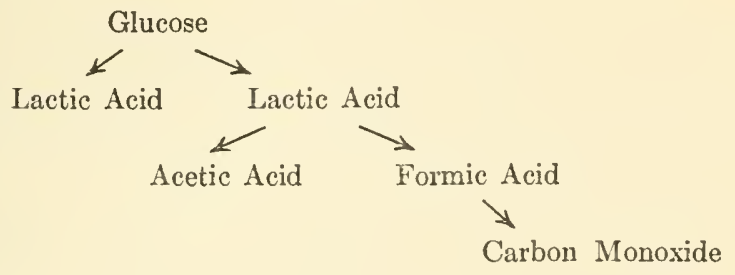

This, as will be referred to later, presents striking analogies to the mode of decomposition of sugar under the influence of alkalies. ${ }^{23}$

Importance of Leucocytes in Blood-glycolysis.- J. de Meyer ${ }^{24}$ suggests that in the formation of the glycolytic blood ferment this is secreted as a proferment by the leucocytes and that this is then activated by a substance produced by the islands of Langerhans in the pancreas (the latter, then, as a "substance sensibilatrice" or amboceptor). E. Vandeput finds, in consonance with the older statements of Lépine, that the glycolytic power of the blood of dogs is distinctly reduced after removal of the pancreas, and that

${ }^{23}$ A. Slosse (Instit. Solvay, Brussels), Arch. internat. de Physiol., 11, 153, 1911.

${ }^{24} \mathrm{~J}$. de Meyer (Brussels), Ann. de l'Instit. Pasteur, 22, 778, 1908; Arch. intern. de Physiol., 7, 317, 1909; 8, 204, 1909; Centralbl. f. Physiol., 23, No. 26, 1910 ; cf. therein Literature. 
the addition of pancreatic extract restores it. ${ }^{25}$ If with these findings we take into account the previously described observations of E. H. Starling (v. sup., p. 256), who observed a distinct increase of the amount of sugar used up by artificially perfused hearts of depancreatized animals after addition of pancreatic extract to the perfused blood, we cannot help feeling that the active manifestation of glycolytic power by the corpuscular elements of the blood is no more than an isolated example of what is really a general rule, that perhaps every living cell is capable of decomposing sugar and requires in carrying out this function the combined influence of an activator secreted into the circulation by the pancreas.

However, that the formed elements of the blood, especially the leucocytes, are directly connected with the glycolytic processes in the blood cannot well be doubted from the uniform confirmation of numerous investigators. Thus Lépine and Boulud refer glycolysis in the blood (in their estimation not only the "immediate" but the "virtuelle" hrmic sugar as well should be included) to the colorless blood cells which in this point are of decidedly more importance than the red cells. ${ }^{26}$ The observations of Nadina Sieber upon a glycolytic ferment in the blood fibrin may perhaps be related with the white corpuscles in the fibrin. ${ }^{27}$ P. Rona and A. Döblin look on the observation that even a sparing hæmolysis occasioned by addition of water will stop glycolysis (while dilution with Ringer's solution or with physiological salt solution has no influence upon it) as favoring the idea that sugar catabolism in the blood is surely not a simple oxidation process, being seen even in complete absence of oxygen, and is connected with the integrity of

${ }^{25}$ E. Vandeput (Slosse's Lab., Brussels), Arch. intern. de Physiol., 9, 293, 1910; cf. also J. Edelmann (Odessa), Biochem. Zeitschr., 40, 314, 1912.

${ }^{28}$ R. Lépine and Boulud, Jour. de Physiol., 13, 353, 1911; C. R. Soc. de Biol., 60, 901, 1906.

${ }^{27}$ N. Sieber (Petersburg), Zeitschr. f. physiol. Chem., 44, 560, 1905. 
the formed elements. ${ }^{28}$ In selum they could recognize no loss of sugar or only a very slight diminution. The recent observations of Levene, of the Rockefeller Institute, of New York, are also of special importance in this relation. The latter noted that solutions of glucose under the influence of leucocytes lose a part of their reducing power (and this is not restored by boiling with a mineral acid, and is, therefore, surely not the result of a simple molecular condensation). The fact that a neutral reaction was maintained in this experiment by means of Henderson's phosphate mixture is of special significance. If water was employed instead the effect was lost; addition of tuluol also proved deleterious. Levene, just as Slosse, found that lactic acid appears in the catabolism of sugar. ${ }^{29}$

Sugar Catabolism from the Influence of Alkali.--In reviewing the foregoing material which, in spite of the extent of literature devoted to it, is decidedly inadequate, and in trying to obtain a picture of the process of sugar decomposition in the living body, in the author's opinion the above mentioned observations of Slosse upon the catabolism of sugar in the blood stand out prominently.

Slosse very properly referred to the analogies which his observations suggested to the behavior of sugar under mild influence of caustic alkalies.

Kiliani, about the beginning of the eighties made the development of lactic acid from sugar the subject of careful investigation; Framm ${ }^{30}$ later on observed the appearance of aldehyde and of formic acid when air is passed through alkaline solutions of sugar. Still later Buchner, Meisenheimer and Schade ${ }^{31}$ noted that if they allowed a solution of sugar in dilute caustic soda to stand for some weeks or

${ }^{28} \mathrm{P}$. Rona and A. Döblin (Krankenhaus am Urban, Berlin), Biochem. Zeitschr., 32, 489, 1911.

${ }^{20}$ Levene and Meyer, Jour. of Biol. Chem., 11, 361, 1912; 12, 265, 1912.

${ }^{30}$ F. Framm (O. Nasse's Lab., Rostock), Pflüger's Arch., 64, 587, 1896.

${ }^{\text {sI }}$ Buchner, Meisenheimer, Schade, Ber. d. deutsch. chem. Ges., 38, 623, 1905 ; 39, 4217, 1906; 41, 1009, 1908; Schade, Zeitschr. f. physikal. Chem., 5\%, 1, 1906; cited in Biochem. Centralbl, 5, No. 2311. 
months, with the air excluded, half or more would be transformed into inactive lactic acid, the remainder for the most part into polyoxyacids (dioxybutyric acid, etc.), with only small amounts of formic acid, carbonic acid and alcohol appearing along with the latter. According to $\mathrm{J}$. de Meyer ${ }^{32}$ glucose breaks up in soda lye in the presence of platinum sponge with formation of lactic acid, formic acid and oxalic acid, without the appearance of alcohol and carbonic acid. However, Jolles ${ }^{33}$ saw, when he allowed the alkaline cleavage to proceed in the presence of oxidizing agents, as peroxide of hydrogen and silver oxide, at the body temperature, only formic acid develop in any important quantity.

That sugar can undergo extensive catabolism from the influence of dilute alkalies even at the temperature of the body cannot be doubted. There is a question, however, whether the degree of alkalinity of the blood and of the animal juices is high enough to permit one to seriously consider whether this mode of break-down can take place physiologically. In view of a result obtained by Michaelis and Rona ${ }^{34}$ in a fluid containing the same or somewhat higher amount of hydroxyl ions as the blood, in which practically no sugar catabolism occurred in the course of twenty-four hours at body temperature one might feel disposed to deny off-hand any importance to this factor.

Importance of Catalyzers in the Catalysis of Sugar.-As a matter of fact, however, conditions are not as simple as this would presuppose; the presence of catalyzing agents is certainly a matter which may make a complete difference. Thus Walter Löb has proved that in salt-free solutions of sugar of the same degree of alkalinity as the blood, with low concentration of hydroxyl ions (differing very slightly from

${ }^{32}$ J. de Meyer, Rev. Méd. Memoirs Lépine, 1911, 517, cited in Centralbl. f. d. Ges. Biol., 12, No. 2887.

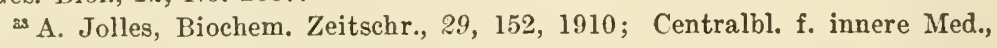
1911, No. 1 .

${ }^{14}$ L. Michaelis and P. Rona, Biochem. Zeitschr., 23, 364, 1910. 
that of pure water), glycolysis is insignificant; but if phosphates be added a very appreciable increase takes place. ${ }^{35}$ The same author also makes the very instructive statement that the iron-containing coloring matter of the blood, in spite of its unequivocal peroxidase character, is not able to affect glucose even in the presence of peroxide of hydrogen; while substances which may be obtained from an alcoholic extract of pancreas when treated with salts of iron, effect a marked cleavage of sugar in which (along with small quantities of formic acid, polyoxyacids and carbonic acid) the chief products are pentose and formaldehyde. ${ }^{36}$ Manganese and potassium are also capable of accelerating alkali-hydrolysis of sugar, according to Slosse. ${ }^{37}$ It is without question not an easy matter to properly judge the physiological value of such observations; but we cannot go far astray in assuming the association of some kind of catalyzing agencies in the processes of sugar cleavage in the economy. A wide and gratifying field of research in physical chemistry is opening in this connection.

The closely related question, how the economy, if it be capable of catabolizing sugar with such readiness, should come to have the special power of storing up large reserves of carbohydrate, may, perhaps, in the opinion of Jolles, be answered by supposing that glycogen, because it does not possess free aldehyde groups, is acted upon with much more difficulty than sugar; and that in this manner the economy protects the dextrose from the catabolizing influence of the alkali by storing it as glycogen in the liver and muscles. ${ }^{38}$

Electrolytic Cleavage of Sugar.-Walter Löb ${ }^{39}$ and, independently, Carl Neuberg, ${ }^{40}$ undoubtedly followed a valuable

${ }^{35}$ W. Löb (Virchow Krankenhaus, Berlin), Biochem. Zeitschr., 32, 43, 1911.

${ }^{36}$ W. Löb and C. Pulvermacher, Biochem. Zeitschr., 29, 316, 1910.

${ }^{3 \pi}$ A. Slosse, Bull. de la Soc. Roy. des Sciences méd., Brussels, May 5, 1911.

${ }^{38}$ A. Jolles, Wiener med. Wochenschr., 1911, No. 45.

W. Löb, Biochem. Zeitschr., 17, 132, 1909.

${ }^{10} \mathrm{C}$. Neuberg, in association with L. Scott and S. Lachmann, Biochem. Zeitschr., 17, 270, 1909; 2./, 152, 1910. 
line of thought in endeavoring, by studying the electrolysis of different sugars, to bring out analogies to the physiological destruction of sugar in the living body. Apparently formalydehyde and pentose may appear as stages of sugar cleavage and of sugar synthesis, both in the electrolytic reduction of grape-sugar and in the action of oxygen on glucose. We are probably here dealing with a change of equilibrium:

$$
\begin{aligned}
& \text { GLUCOSE } \\
& \mathrm{C}_{6} \mathrm{H}_{12} \mathrm{O}_{6} \rightleftarrows \mathrm{C}_{5} \mathrm{H}_{10} \mathrm{O}_{5}+\mathrm{CH}_{2} \mathrm{O} \text {. }
\end{aligned}
$$

W. Löb, who was able to detect in the electrolysis of grape-sugar in dilute sulphuric acid (using lead electrodes) gluconic acid, saccharic acid, arabinose, arabonic acid, trioxyglutaric acid, formaldehyde and formic acid, ${ }^{41}$ suggests the following schematic plan for the process:

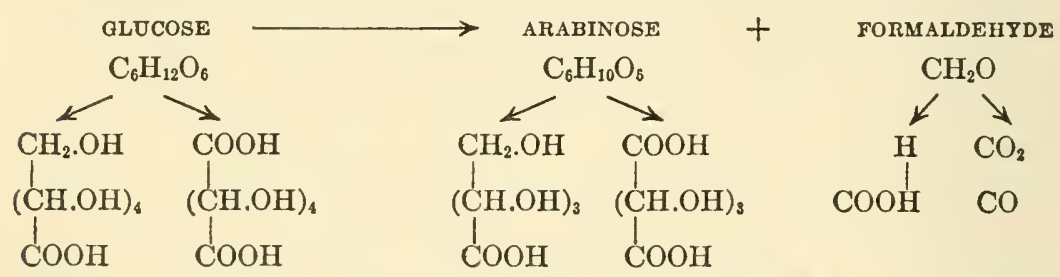

Gluconic Acid Sacchario Acid Arabonic Acid Trioxyglutaric Acić Formic Acid.

The influence of ultraviolet light rays is also followed by cleavage of sugar with formation of aldehydes and volatile acids, and if continued may lead to the appearance of formaldehyde and carbonic acid. ${ }^{22}$

Speaking in general terms it can be readily recognized that we have not progressed in the study of the catabolism of sugar in the economy much beyond the stage of hypothesis. As it is well known that everything that is printed is not for that reason true, there are a great many

${ }^{42}$ Concerning formic acid as an intermediate product in sugar cleavage in the body, cf. O. Steppuhn, and H. S'chellenbach, Zeitschr. f. pliysiol. Chem., $80,274,1912$.

${ }^{42}$ P. Meyer (Neuberg's Lab.), Biochem. Zeitschr., 32, 1, 1911; A. Jolles, \{bid., 33, 252, 1811; H. Bierry, V. Henri and Ranc, Compt. rend., 152, 1629, 1911 , and earlier contributions. 
publications on the subject which the writer gladly forbears to inflict. It may be sufficient to refer here to one of these only, ${ }^{43}$ that of Wohl: ${ }^{44}$

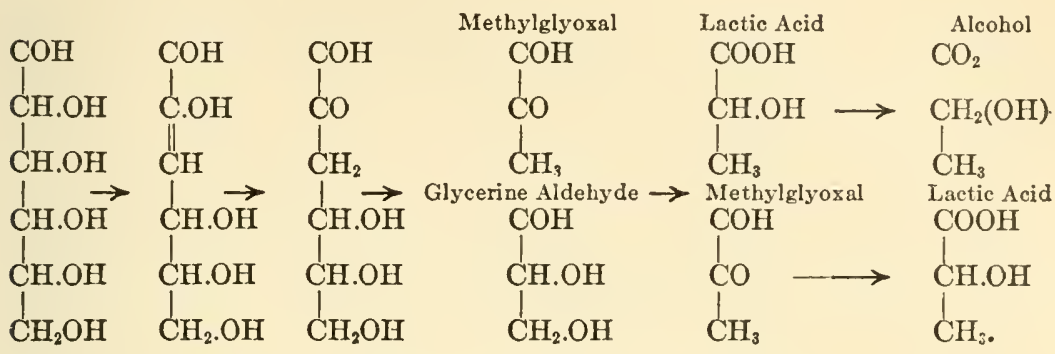

Mention may also be made here of pyroracemic acid $\left(\mathrm{CH}_{3} . \mathrm{CO} . \mathrm{COOH}\right)$, which, according to Paul Meyer, ${ }^{45}$ may be placed among the sugar-formers, and which, according to Neuberg, ${ }^{46}$ can be fermented by yeast to aldehyde and carbonic acid $\left(\mathrm{CH}_{3} \cdot \mathrm{CO} \cdot \mathrm{COOH}=\mathrm{CH}_{3} \cdot \mathrm{COH}+\mathrm{CO}_{2}\right)$, as open to consideration as a possible intermediate stage of physiological sugar catabolism.

Mechanism of Alcoholic Fermentation of Sugar.-It was originally thought that by thorough study of alcoholic fermentation of sugar we might attain definite information as to the catabolism of sugar in the animal economy. The fact, already stated, that we have no sound support for the assumption that alcohol formation is of any physiological importance in the animal body, makes the value of studies in this line of questionable worth. Then, too, it is obvious that it is impossible, in what must be merely a brief sketch of the subject of fermentation, to properly deal with a branch which in the last few decades has grown into an independent. science. The only thing which can be appropriately done here is to briefly indicate the intermediate stages, as we

${ }^{43}$ A. Wohl (Danzig), Biochem. Zeitschr., 5, 54, 1907.

"Without reference to the stereochemical configuration.

${ }^{45}$ P. Mayer (C. Neuberg's Lab.), Biochem. Zeitschr., 40, 441, 1912.

${ }^{43}$ C. Neuberg, Berlin. physiol. Ges., Nov. 1, 1912. 
know them at present, which are of the most importance in the transformation of sugar into alcohol and carbonic acid.

At first many thought that the molecule of sugar was primarily separated into two molecules of lactic acid in fermentation, and that these were thereafter broken up into alcohol and carbonic acid:

$$
\mathrm{C}_{6} \mathrm{H}_{12} \mathrm{O}_{6}=2 \mathrm{C}_{3} \mathrm{H}_{6} \mathrm{O}_{3} ; \quad \mathrm{C}_{3} \mathrm{H}_{6} \mathrm{O}_{3}=\mathrm{C}_{2} \mathrm{H}_{5} \cdot \mathrm{OH}+\mathrm{CO}_{2} \text {. }
$$

We know that lactic acid may very readily be broken down to form acetaldehyde and formic acid: $\mathrm{CH}_{3}$. $\mathrm{CHOH}$. $\mathrm{COOH}=\mathrm{CH}_{3} \cdot \mathrm{COH}+\mathrm{H} . \mathrm{COOH}$. Euler, of Stockholm, noted the appearance of alcohol and carbonic acid after subjecting lactic acid (or, instead, a mixture of equal amounts of acetaldehyde and formic acid) to the influence of the ultraviolet rays of a uviol lamp. ${ }^{47}$ However, the idea that lactic acid is an intermediary product of alcoholic fermentation was in time abandoned. Were it correct, it would be necessary to suppose the lactic acid to be as easily fermented by yeast as sugar, or even more easily. This, however, is not the case; in fact, when lactic acid is added it remains unaffected by the fermentation. ${ }^{48}$

Later on Eduard Buchner and Jacob Meisenheimer, ${ }^{49}$ two investigators who have rendered distinguished service in the elucidation of the fermentation process, were disposed

to regard dioxyacetone, isomeric to lactic acid,<smiles>O=C(CO)CO</smiles>

an intermediate product of alcoholic fermentation, because they found that this substance uniformly undergoes fermentation, not only from living yeast cells but from expressed juice of yeast as well, if juice extracted by boiling (containing the "coenzyme") be added. Recently A. Slator

${ }^{47}$ H. Euler (Stockholm), Zeitsehr. f. physiol. Chem., 71, 311, 1911.

${ }^{45}$ A. Slator, Ber. d. deutsch. chem. Gesellsch., 40, 123, 1907.

E. Buchner and J. Meisenheimer, Ber. d. deutsch. chem. Ges., 43, 1773, 1910. 
has rejected, it is true, the view that dioxyacetone is an intermediate product of alcoholic fermentation, from the fact that while, for example, a decigram of dextrose in an experiment was completely fermented by yeast in twenty minutes, a decigram of dioxyacetone in parallel experiment underwent practically no change. ${ }^{50}$ The justice of such criticism is, however, not accepted by the first-named investigators. ${ }^{51}$

Recent studies of Lebedew, Harden and Young, and of Euler seem to indicate that the phosphoric acid contained in the fermentation mixtures plays an important rôle in the fermentation, uniting with hexose to form an ester which much more readily lends itself to fermentation cleavage; perhaps, too, the possibility of an intermediate formation of a triose or triose-ester in the course of the fermentation ought to be thought of.52 At best the whole matter is at present vague and uncertain.

Butyric Acid Fermentation.-In the author's opinion there may be some interest in the observations which have been made upon the mechanism of butyric acid fermentation in their bearing upon the study of the processes of physiological catabolism of sugar. Butyric acid may be formed from hexoses as well as from lactic acid from fermentation. Buchner and Meisenheimer ${ }^{53}$ conceive of the process in this fashion: that the sugar first is split into lactic acid, and this in turn into acetaldehyde ${ }^{54}$ and formic acid, two molecules

50 A. Slator, Ber. d. deutsch. chem. Ges., 45, 43, 1912.

${ }^{51}$ E. Buchner and Meisenheimer, Ber. d. deutsch. chem. Ges., 45, 1632, 1912 ; cf. also Harden and Young, ibid., 40, 458, 1912; Chick (Lister Instit., London), Biochem. Zeitschr., 40, 479, 1912.

${ }^{32}$ A. v. Lebedew (Instit. Pasteur), Ber. d. deutsch. chem. Ges., 44, 2932, 1911 ; Biochem. Zeitschr., 36, 248, 1911; Ann. Instit. Pasteur, 25, 847, 1911; H. Euler (Stockholm), with Kullberg, Ohlsén, Fodor, Zeitschr. f. physiol. Chem., f $_{4}, 15,1911$; $\% 6,468,1911$; Biochem. Zeitschr., 36, 401, 1911.

${ }^{53}$ E. Buchner and J. Meisenheimer, Ber. d. deutsch. chem. Ges., 41, 1910, 1908.

${ }^{*}$ Cf. statements of Kostytsehew (St. Petersburg), Zeitschr. f. physiol. Chem., $\gamma 9,130,1912$, upon the formation of acetaldehyde in alcoholic fermentation of sugar. 
of the aldehyde then condensing into aldol and this finally becoming converted into its isomer, butyric acid:

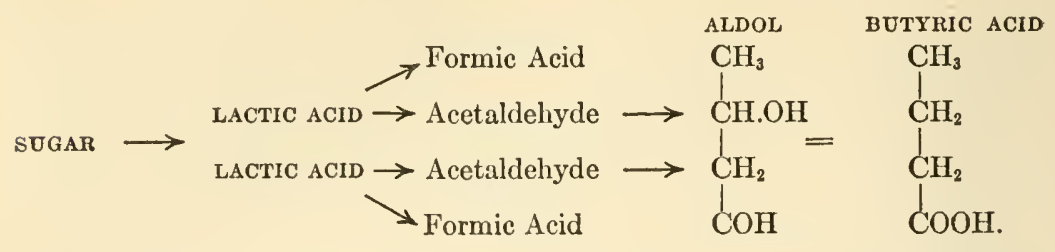

The equation for butyric acid fermentation is usually written: $\mathrm{C}_{6} \mathrm{H}_{12} \mathrm{O}_{6}=\mathrm{C}_{4} \mathrm{H}_{8} \mathrm{O}_{2}+2 \mathrm{CO}_{2}+2 \mathrm{H}_{2}$.

Citric Acid Fermentation.-In conclusion, observations upon citric acid fermentation seem to be not without some interest in connection with the question of sugar catabolism in the body, particularly because citric acid is present in the animal body as a constituent of milk. In culture of certain forms of citromycetes on appropriate media which are poor in nitrogen and contain an addiment of carbonate of lime to fix the citric acid as the relatively insoluble citrate of calcinm and thus prevent its further decomposition, the fermentation of the sugar may be governed so that actually only citric acid and carbonic acid, but neither alcohol, acetic, lactic or succinic acid, will appear. ${ }^{55}$ Obviously the branched chain of eitric acid can be explained only on the supposition of a synthesis. It is thought that it can be explained, for example, by the combination of three molecules of glycolic acid, $\mathrm{COOH}_{\mathrm{C}}^{\mathrm{C}} \mathrm{OH}_{2}$, with separation of water :

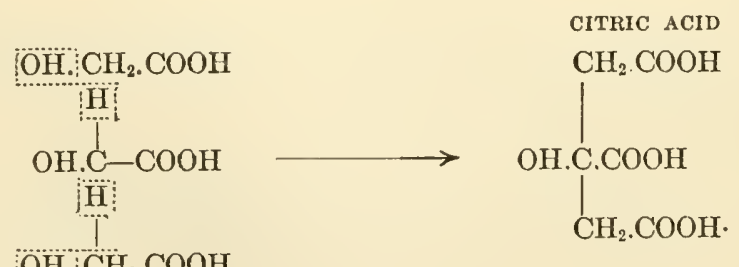

But it must be said that there is as little proof that the synthesis of citric acid actually takes place in this way, as

${ }^{55}$ E. Buchner and H. Wiistenfeld, Zeitschr. f. Biochem., 17, 395, 1909. 
there is for the statement that the hypothetical intermediate product, glycolic acid, actually is produced from sugar.

All in all there is no wonder that the real nature of sugar catabolism has remained a secret thus far, locked in the depths of the economy, when we have never been able to satisfactorily explain processes like alcoholic fermentation and the various types of acid fermentation, which have been known so long, which are completed in the greatest quantities in vitro, and which are so favorable to objective study. 


\section{CHAPTER XV}

\section{DIGESTION AND RESORPTION OF FATS}

Herewith we turn our steps to a new field, that of the biochemistry of fats. It will undoubtedly be found best to continue very much in the same way as in the discussion of protein and carbohydrate metabolism, beginuing with the introduction of the fats into the digestive tract, then dealing with their digestion and resorption, thereafter following them on their way through the chyle- and lymph-paths and through the tissues, up to where they and their cleavage products begin to sink into the depths of the intermediate metabolism and pass out of sight.

The Lipase of the Stomach.-Beginning then with consideration of the process of fat digestion, the first phase to be considered is the gastric digestion of fats. ${ }^{1}$ It is true there has been much written upon this subject, but really there is very little that can be said about it. Doubtless, according to the investigations of Volhard and others, the stomach contains a lipolytic ferment and physiologically the splitting of fat begins at this point. Thus London ${ }^{2}$ found in a dog with gastric fistula that about one-third of the fat introduced in emulsified form was split in the stomach into glycerol and fatty acids. There is probably no doubt, too, that at times some fat is resorbed in the stomach. Otto Weiss ${ }^{3}$ observed a resorption process of this sort in the stomach of ringed snakes and in the stomachs of newborn dogs and cats; in adult human beings, however, it is unquestionably insignificant. Apparently, too, the lipolytic power of pure gastric

${ }^{1}$ Literature upon Gastric Lipase: C. Oppenheimer, Die Fermente, 3d ed., 11, pp. 15-16, 1909.

2 E. S. London and M. A. Wersilowa, Zeitschr. f. phrsiol. Chem., 56, 545, 1908.

${ }^{3}$ O. Weiss (Physiol. Instit., Königsberg), Pflüger's Arch., 14ł, 510, 1912 ; cf. also IV. Lamb. Jour. of Physiol., 40, Proc. Physiol. Soc., xxiii, 1910 (Fat Resorption in the Stomach of Kittens). 
juice is distinctly less than we were formerly disposed to believe. ${ }^{4}$ From the previously mentioned investigation of Pawlow and Boldyreff we have learned that immediately after taking fatty food it is very easy to have a reflux of the duodenal contents into the stomach. The first portion of fat on entering the duodenum may in the same manner as acid give rise to a pyloric reflex; although this does not (as in case of acid stimulation) Iead to closure of the pylorus, but to an inhibition of the normal antral peristalsis. In this manner the pancreatic steapsin may gain entrance into the stomach and take part here in the cleavage of fats. ${ }^{5}$ A number of authors used to be disposed to deny for the pure gastric juice any active lipolytic function. This apparently, however, is not the case; fat cleavage in the stomach being due in part, at least, to the influence of an enzyme secreted by the gastric mucous membrane, ${ }^{6}$ the secretion of which goes on about parallel with that of the pepsin. ${ }^{\top}$ Then, too, the statement of Laqueur that the gastric lipase is not activated by bile does not bespeak an identity with the pancreatic steap$\sin ^{8}$ Nevertheless, no particular physiological importance is to be attached to the lipolytic processes in the stomach in the author's opinion.

\section{PROBLEMS OF FAT RESORPTION}

Of very different significance is the question as to the manner in which fat resorption takes place in the intestine. It is well known that, after the fat has become mixed in the small intestine with the bile and pancreatic secretion, the greater portion of it is changed into a fine emulsion. For thirty years there has been an open question whether the

${ }^{4}$ E. S. London, Zeitschr. f. physiol. Chem., 50, 125, 1906.

${ }^{5}$ Cf. S. J. Levites. (St. Petersburg), Biochem. Zeitschr., 20, 220, 1909; Zeitschr. f. physiol. Chem., 49, 273, 1906.

${ }^{6}$ Cf. S. v. Pesthy (F. Tangl's Lab., Budapesth), Biochem. Zeitschr., 34, 147, 1911.

${ }^{7}$ Heinsheimer, Deutsch. med. Wochenschr., 1906, 1194.

${ }^{8}$ E. Laqueur (R. Gottlieb's Lab., Heidelberg), Hofmeister's Beitr., 8, 281, 1906. 
emulsified fat is taken up as such by the intestinal epithelium, or whether the fat is first broken up in the intestine into glycerol and fatty acids and these components absorbed in a dissolved state, to reunite into neutral fat after the absorption is accomplished.

The writer would prefer not to enter into the detailed phases of this conflict of opinion here. ${ }^{9}$ It will perhaps be sufficient to state categorically that the view maintained by W. Kühne, J. Munk, M. Nencki, E. Pflüger, O. Frank and many others, that a process of solution must precede the resorption of the fat (at least of the bulk), has been upheld time and again. "That the great part of the fat is split before being absorbed and thereby changed into a watersoluble form," O. Colnnheim ${ }^{10}$ believes, "is certain, and there is no single ground and not a single observation to prove that this is not also true of all the fat, even though the negative proof that no known portion of the fat passes the epithelium in emulsied form has not yet been established and in fact would be difficult of establishment except by considerations of a general nature."

Probably it would be well to indicate the most important reasons which support this view.

Fat Cleavage and Solution of the Products of Cleavage.It should be clearly understood that the fat in the intestine, in by far its greatest proportion, is present, not as neutral fat, but in state of cleavage, so that, especially in the lower portions of the intestine, the neutral fat occurs in far smaller amounts than the soaps and the free fatty acids.

Moreover, one should keep in mind the important fact (known today, but not known in the early days) that, because of the presence of salts of the biliary acids, of lecithin,

${ }^{-}$Literature upon Cleavage, Resorption and Synthesis of Fat in the Intestine: J. Munk, Ergebn. d. Physiol., 1, 317-323, 1912; O. Cohnheim, Nagel's Handb. d. Physiol., 2, 555, 618-621, 1907; Physiol. d. Verd. u. Ernähr., 165169, 1908; E. H. Starling, Handb. d. Biochem., 3", 226-233, 1909.

${ }^{20} \mathrm{O}$. Colınheim, Biochem. Centralbl., 1, 174, 1903. 
and of cholesterine from the bile, physical-chemical conditions in the contents of the small intestine are determined in which the cleavage products of the fat are kept in solution no matter whether an acid or an alkaline reaction may prevail. This is true not only of the free fatty acids, but also of their relatively insoluble calcium and magnesium salts.

Synthesis of Fat in the Intestinal Wall.-The possibility of fat synthesis in the wall of the bowel is very clearly indicated from the experiments of J. Munk, and those of $O$. Frank; it has been shown that in the chyle of the thoracic duct neutral fat is present, not only after the administration of neutral fat, but also when the fatty acids, their alkaline salts and esters are ingested. Where the glycerol comes from which is necessary in such a synthetic formation is not known; it must suffice for the present to know that it can be produced apparently in unlimited amount by the intestinal wall. If this were not true it would be impossible to understand how, after the ingestion of large quantities of soaps or free fatty acids, we invariably find only the triglycerides in the lymph of the thoracic duct. The discovery that soaps are poisonous. when introduced directly into the circulation and that for this reason it would be injudicious to have them enter the circulation unchanged, is, of course, no explanation. We are here brought face to face with another unsolved puzzle. If, however, the wall of the bowel manages to carry out the synthetic formation of fat from fatty acids and glycerol even when no glycerol is provided for it, why should there be any doubt of its ability to complete the synthesis if coincidently with the fatty acids equivalent amounts of glycerol are resorbed from the lumen of the bowel?

From recent experiments of O. Frank ${ }^{11}$ it appears that ingested monoglycerides do not enter the chyle as such but

${ }^{11}$ A. Argyris and O. Frank (Munich), Zeitsch. f. Biol., 59, 143, 1912. 
are changed into triglycerides. The fatty acids essential for this synthesis requisite to completely transform the monoglyceride into triglyceride must first, however, be obtained from cleavage of the former. The inference that any extensive cleavage of ingested fat must occur is not to be made, however, from this point.

Behavior of Non-saponifiable Emulsions.-The clearest indication that the intestine does not take up the fat exclusively in the form of an emulsion, but at least partly in a dissolved state, may be seen, to the author's mind, in the fact that even the finest emulsion of lanolin, ${ }^{12}$ petroleum or paraffin (material which from its chemical peculiarities cannot be converted into a dissolved form in the intestine) is not open to absorption. If neutral fat be incorporated with soft paraffin by melting them together and the mixture introduced into the intestine in finely emulsified form, the bowel wall takes up only the fat, but rejects the paraffin. ${ }^{13}$ The writer is disposed to regard this as a thoroughly crucial experiment. The statement of Hofbauer and S. Exner, ${ }^{14}$ subsequently confirmed by Lafayette Mendel, that fat colored with suitable staining reagents can pass into the chyle ducts as stained fat has no further reference to the method of resorption in the opinion of Pflüger, and, too, of L. B. Mendel, than to indicate that these staining substances are soluble in free fatty acids or in a biliary solution of fatty acids and soaps, the latter being quite capable of acting as a vehicle to aid the passage of the staining substances through the wall of the intestine into the chyle ducts. ${ }^{15}$

${ }^{12}$ W. Connstein, Arch. f. Anat. u. Physiol., 1899, 30; A. v. Fekete (Physiol. Instit., Budapesth), Pflüger's Arch., 139, 211, 1911.

${ }^{13} \mathrm{~V}$. Henriques and C. Hansen, Centralbl. f. Physiol., 14, 313, 1900.

${ }^{14}$ L. Hofbauer (S. Exner's Lab., Vienna), Pflüger's Arch., 81, 263, 1900 ; 84, 619, 1901 ; Zeitschr. f. klin. Med., 47, 475, 1902; S. Exner, Pflüger's Arch., 84, 628, 1901; L. B. Mendel (Yale Univ.), Amer. Jour. of Physiol., 24, 493, 1909.

${ }^{25}$ E. Pflüger, Pflüger's Arch., 81, 375, 1900; 85, 1, 1901; I. B. Mendel, 1. c.; cf. also L. B. Mendel and A. L. Daniels (Yale Univ.), Jour. of Biol. Chem., 13, 71, 1912. 
Finally, as O. Cohnheim believes, the very existence in the intestine of fat splitting ferments seemingly would be inexplicable and superfluous, if it were true that the resorption is exclusively that of fat in emulsion.

Histological Observations Bearing Upon Fat Resorption. -To Pflüger's objections, however, Sigmund Exner ${ }^{16}$ suggests that histological examination always has made it look as though a part of the fat is resorbed without being split. "I have always regarded it as probable," says Exner, "that fat is absorbed in part unsaponified, having followed since the sixties a number of investigations conducted in the Vienna Physiological Institute bearing upon the path of resorption, ${ }^{17}$ and having invariably found features which upheld this idea. . . . As the hypothesis that all fat is changed into a soluble form before absorption and is reformed after absorption gained more and more adherence I was forced to say to myself: If in the first place we see the fat droplets (possibly, too, droplets of fatty acids) in the contents of the intestine, in the rodded border of the cells, in the protoplasm of the epithelial cells, and finally in the chyle vessels, is it not more likely that all these droplets are of essentially identical origin and that we are catching them first before absorption and then step by step in their progress, than that the droplets which we find within the intestinal lumen are as yet to undergo solution, and that those right alongside of them in the rodded cell border or in the cell protoplasm have already reseparated from such a solution, that is to say, have been regenerated?

Solutions go through all forms of epithelium; fat in any important amount especially through that of the small intestine; is it purely a matter of chance that no other epithelium but that lining the small intestine is provided with that peculiar border which in its construction from parallel rods arranged in palisade manner cannot help

${ }^{16}$ S. Exner, Pflüger's Arch., 84, 628, 1901.

${ }^{17} \mathrm{E}$. Brücke, S. v. Basch, F. v. Winiwarter. 
suggesting a sieve-like purpose? . . . I am well aware that this is all based on probabilities, and would not care to bring it forward if there were clear proof evident on the other side. But there, too, I recognize nothing but arguments based upon probability. For even if anyone had proved that in this or that particular instance all the fat had undergone cleavage or saponification before being absorbed, it would be far from proving that invariably this is the case or even usually true."

Many histological studies have been made to come nearer the solution of the secrets of fat resorption. The synthetic production of fat from soaps and glycerol formerly maintained by many has as a fact not been confirmed by experiments upon excised living intestinal mucosa ${ }^{18}$ studies from Fano's laboratory in Florence ${ }^{19}$ have, on the contrary, shown that the epithelial cells of the intestinal mucosa when brought in contact with oleic acid or a solution of sodium oleate become loaded with fatty acid which can be demonstrated by staining with osmic acid; neutral fat, however, is not taken up. We are in this case undoubtedly dealing with a true physical solution phenomenon, one not manifested by the epithelium of the cosophagus and stomach, but which can be demonstrated with intestinal mucosa even when hardened in formol, and which is probably due to some solvent which the cells contain for oleic acid.

Formerly a great deal of importance was ascribed to tracing the fat droplets in their passage through the epithelial cells of the intestine. For example, observations like those of Cuénot upon the intestine of crustacea, in which the fat globules are apparent only in the portion of intestinal epithelium exposed to the lumen, were regarded as particularly valuable. Since we have come to realize that fats may be masked in the presence of proteins so that they are no

${ }^{18}$ O. Frank and A. Ritter (Physiol. Instit., Munich), Zeitschr. f. Biol., 4\%, 251, 1906; Moore, Proc. Roy. Soc., 72, 134, 1903.

${ }^{19} \mathrm{G}$. Rossi, Arch. di Fisiol., 5, 381, 1908. 
longer demonstrable by means of osmic acid, ${ }^{20}$ the interest in these and similar observations has perceptibly diminished.

According to the studies of Noll and those of many of the older observers, a portion of the fat taken up by the intestinal epithelium leaves the latter immediately; another portion first runs together into larger droplets, these then gradually passing out into the chyle vessels. ${ }^{21}$ Step by step the process first shows the fat granules in the lymph clefts of the villus; passing thence with the lymph which transudes from the capillaries into the central chyle vessel, and finally along the mesenteric lymph passages into the thoracic duct, the contraction of the musculature of the villi acting as the propelling force. When fat resorption is in active process the exposed intestine shows the chyle passages filled with milky fluid.

Resorption of Soaps.-As to the further question in what form the iat is most readily resorbed, it was formerly the tendency to assume that soap solutions introduced into an intestinal loop are particularly suited for resorption. However, experiments made in the Zuntz Institute ${ }^{22}$ have shown that in dogs with Thiry-Vella fistulas of the upper portions of the intestine where a prompt resorption of fat emulsions takes place, soap solutions are not resorbed even after bile and pancreatic juice are added. (On the other hand, in case of fistulas of the lower parts of the bowel soaps were readily absorbed.) The author, in collaboration with J. Schütz ${ }^{23}$ and with Bleibtreu, ${ }^{24}$ has also noted a poor resorption of soap solutions from isolated intestinal loops.

${ }^{20}$ G. Rossi, Arch. di Fisiol., 4, 429, 1909.

${ }^{21}$ A. Noll (Physiol. Instit. Jena), Arch. f. Anat. u. Physiol., 1907, 349; Physiologentag Würzburg, 1909; Centralbl. f. Physiol., 23, 290, 1909 ; Pflüger's Arch., 186, 208, 1910; cf. also Literature: E. H. Starling, Handb. d. Biochem.. 3", 226-228, 1909.

22 W. Croner (Lab. of N. Zuntz, Berlin), Biochem. Zeitschr., 23, 97, 1909.

${ }^{23}$ O. v. Fürth and J. Schütz, Hofmeister's Beitr., 10, 462, 1907.

${ }^{24}$ M. Bleibtreu, Deutsch. med. Wochenschr., 1906, 1233. 
One might be disposed, perhaps, to use this as an argument against the above stated theory of hydrolytic fat cleavage in the intestine. But from the present status of the general question the author would prefer to interpret these observations as indicating that it makes a distinct difference whether the neutral fat is hydrolyzed little by little and immediately elaborated, or whether the intestine is flooded beyond physiological possibilities by large and presumably not indifferent quantities of soaps.

For the rest, mixtures of fatty acids are apparently at times absorbed with more difficulty than their corresponding sodium salts. ${ }^{25}$

The rapidity of resorption of neutral fats depends in large measure upon the melting point of the fat concerned, the fats with high melting points (as tallows) being taken up more slowly and less fully, than oily and lard-like fats, this explaining to some degree why the fats passed with fecal matter show a higher melting point than the corresponding fats in the food. ${ }^{26}$

Method of Study With Isolated Intestinal Loops.-Before proceeding further, some reference should be introduced here upon the methods applicable in experiments upon fat absorption. Some years ago we were accustomed to regard the method of the "isolated intestinal loops" very highly in all sorts of absorption experiments, and fancied that we were working under precise "physiological" conditions when employing this method. When, several years ago, the author, in association with Julius Schütz, ${ }^{27}$ undertook to study fat resorption from isolated loops high hopes were centred in the experiments, particularly because the technic employed was a very distinct improvement upon that

${ }^{25}$ S. Levites (Instit. of Exper. Med., St. Petersburg), Zeitschr. f. physiol. Chem., 53, 349, 1907.

${ }^{26} \mathrm{~J}$. Munk, F. Müller, Aruschnik, Levites (1. c.), F. Tangl and A. Erdélyi (Budapesth), Biochem. Zeitschr., 34, 94, 1911.

${ }^{2} \mathrm{O}$. von Fürth and J. Schïtz, l. c. 
of their predecessors. ${ }^{28}$ In order to diminish, as far as possible, the untoward effects of chilling which is unavoidable in intestinal operations, the experimenters made use of a warm operating table made of a large tin box provided with a heating coil, this enclosing the whole narcotized animal (cat); the exposed intestine was spread out on compresses wet with warm physiological salt solution, kept moist with the latter, and replaced immediately after application of the ligatures and injection of the fluid under investigation, with the usual further steps. In spite of all their effort and care the resorptive efficiency of an intestinal loop thus prepared was so low in comparison with the physiological effectiveness of the normal intestine, that the writer has lost all confidence in studies based on the method of tying off intestinal loops, and can only regret the hecatombs of animals which the method has cost and, in spite of this warning, is likely to cost in the future. To-day, now that Pawlow and London have shown us how we can arrange our resorption experiments under practically physiological conditions by means of the polyfistula method, this pseudophysiological procedure has lost all justification for its continuance, in the opinion of the writer.

\section{INFLUENCE OF THE PANCREATIC JUICE AND THE BILE UPON FAT DIGESTION}

We come now to the presentation of the important question of the part taken by the biliary and pancreatic secretions in fat digestion. That these two secretions are actually concerned in the process was proved as early as 1852 by Bidder and Schmidt, and is further indicated from the observations of Claude Bernard, who found in rabbits (in which the pancreatic duct opens some distance below the common biliary duct in the small intestine) that after a diet

${ }^{28}$ H. J. Hamburger, Arch. f. Anat. u. Physiol., 1900, 433; H. von Tappeiner, Zeitschr. f. Biol., 45, 222, 1908; T. Hattori, F. Hercher (Bleibtreu's Lab.), Inaug. Dissert., Greifswald, 1305, 1907. 
rich in fat the lymph vessels begin to show injection with the milk-white chyle from that level of the bowel where these two secretions become mixed with the intestinal content. Dastre made a very similar observation in the dog, in which animal he ligated the bile duct and opened the gall bladder by a fistula into the middle of the small intestine, below which point mixture of the chyme first took place with the bile, the commingling of the pancreatic secretion occurring, of course, normally. A long series of observations on animals and man, in which after exclusion of one of the two secretions or of both the utilization of fat was manifestly reduced, proved the fact that normal digestion of fat presupposes the combined effect of both secretions. ${ }^{29}$ According to the clinical observations of T. Brugsch acute or chronic degenerative pathological processes in the pancreas of man impair the fat absorption to a very considerable degree (50-60 per cent.); but if in addition to the disturbance of the pancreatic secretion there is associated a cessation of the normal biliary flow the loss of fat may amount to as much as 80 to 90 per cent.- that is to say, the bulk of the fat leaves the intestine unabsorbed. It may be readily understood why by artificially furnishing bile and pancreatic juice one may succeed in favorably influencing disturbances occasioned by the loss of these secretions. So, too, the addition of bits of pancreas to the food may appreciably improve the utilization of fat, according to the statements of Sandmeyer. ${ }^{30}$

${ }^{20}$ C. Voit, 1882; F. Röhmann, 1882; F. Müller, 1887; J. Munk, 1890; Minkowski and Abelmann, 1890; A. Dastre, 1891; Sandmeyer, 1894; Harley, 1895; Hédon and Ville, 1897; Rosenberg, 1898; Albu, 1900; A. Schmidt, 1905; F. Umber and T. Brugsch, Arch. f. exper. Pathol., 55, 164, 1906; T. Brugsch (Umber's Clinic), Zeitschr. f. klin. Med., 58, 518, 1906. Literature upon the Importance of the Bile and Pancreatic Secretion for Fat Digestion: J. Munk, Ergebn. d. Physiol., 1, 323-325, 1902; O. Prym, Handb. d. Biochem., 3", 116118, 1909; E. H. Starling, ibid., pp. 228-230; A. Magnus-Levy, Handb. d. Pathol. d. Stoffwechsels, 2d., 1, 32-39, 1906.

${ }^{80} \mathrm{~W}$. S'andmeyer (Physiol. Instit., Marburg), Zeitschr. f. Biol., 31, 12, 1895; Inouye and T. J. Sato, Arch. f. Verdauungskr., 17, 185, 1911; M. Adler (Senator's Clinic), Zeitschr. f. klin. Med., 66, 302, 1908. 
Influence of Extirpation of the Pancreas Upon Fat Resorption.-Taking up here the question of the mode of action exercised by the bile and pancreatic secretion on fat resorption, brief reference may be appropriately made first to the ideas which $U$. Lombroso has evolved as to the influence of the pancreas. These rest upon the statement made by a number of authorities, that it is by no means the same thing for proper utilization of the fat whether we merely ligate the pancreatic ducts or completely extirpate the whole gland. Thus Rosenberg after the first procedure noted no striking disturbance of fat utilization in dogs; but as soon as he entirely ablated the gland (already markedly degenerated in sequence to the ligation), marked disturbance ensued. ${ }^{31}$ Observations of the same sort were repeatedly made by U. Lombroso, ${ }^{32}$ R. Fleckseder ${ }^{33}$ and P. C. P. Jansen. ${ }^{34}$ The first of these suggested the theory (with reference to the fact that after total extirpation of the pancreas there may at times be observed fatty degeneration, crowding of the fat depots of the body and even fat secretion into the intestine) that the pancreas may be involved in interruption of the natural process of fat metabolism not only by loss of the mixture of its external secretion with the intestinal contents, but also by an internal secretion which is given off into the circulating blood and by which it governs the fat transformation in the same way that it regulates the carbohydrate metabolism. ${ }^{35}$ To properly interpret this idea one should keep especially in mind that total pancreatic ex-

${ }^{31}$ S. Rosenberg, Pflüger's Arch., $70,371,1898$.

${ }^{82}$ U. Lombroso (Turin), Arch. Ital. de Biol., 42, 336, 1904; Pflüger's Arch., 112, 531, 1906; Arch. f. exper. Pathol., 56, 357, 1907; 60, 99, 1908; Arch. di Fisiol., 8, 209, 1910.

${ }^{33}$ R. Fleckseder (H. H. Meyer's Lab., Vienna), Arch. f. exper. Pathol., 59, $407,1908$.

${ }^{34}$ P. C. P. Jansen (Physiol. Instit., Amsterdam), Zeitschr. f. physiol. Chem., 72, 158, 1911.

${ }^{25}$ O. Gross (Steyrer's Clinic, Greifswald), Deutsch. Arch. f. klin. Med., $108,106,1912$, has also recently accepted with Lombroso that the steatorrhœa met in pancreatic affections is due to a loss of the internal secretion of the pancreas. 
tirpation is a very serious interference which results in an inexpressible wasting of the body. It might be asked very properly whether, when "everything is upset" in metabolism in sequence, it really is a matter of much wonder that the fat digestion should also become disordered. Minkowski noted in dogs with only a remnant of pancreatic tissue transplanted under the skin of the abdomen, the secretion of which escaped externally, that the resorption of fat was not materially reduced provided the dog could lick up the secretion; when the secretion, however, was withheld, interference with resorption at once manifested itself. ${ }^{36}$ Off-hand there does not seem to be any insistent reason for ascribing to the internal secretion of the pancreas, besides its dominant part in the metabolism of sugar, a second analogous cardinal function in relation to the metabolism of fats. Disturbances of the latter process, after complete pancreatic extirpation, can be fully explained in the first place on the basis of the failure of its external secretion, and in the second place by the general disturbance of the economy which severe pancreatic diabetes brings with it.

There will probably be noted a contradiction in the author's first statement that the combined influence of the pancreas and the bile is essential to the proper procedure of fat digestion and the subsequent point to the effect that ligation of the pancreatic ducts need not necessarily give rise to any very important disturbance of fat resorption. This is, however, probably only a superficial contradiction. If under normal conditions the bile and the pancreas cooperate in connection with the resorption of fat (which is undoubtedly the case from the decisive observations of Claude Bernard and Dastre upon the chyle), this does not preclude the possibility of the economy taking advantage of vicarious means of compensating in some measure for the loss of pancreatic secretion. We know, for instance, that

${ }^{28}$ G. Burkhardt (Minkowski's Clinic, Greifswald), Arch. d. exper. Pathol., $58,252,1908$; cf. also the observations of Abelmann and others. 
fat cleavage in the digestive tract is not accomplished exclusively by the pancreatic steapsin, but that in addition lipases of the gastric juice, of the intestinal secretion and of the vast numbers of microörganisms in the intestine are also concerned in the process.

Activation of the Pancreatic Steapsin by the Salts of the Biliary Acids.-In further effort to properly appreciate the manner in which the pancreatic secretion and the bile influence the digestion of fat, we at once are met by the important fact that the fat-splitting ferment of the pancreas is greatly augmented in its effectiveness by the bile.

The first statements bearing upon the reinforcing influence of the bile upon the pancreatic steapsin are probably to be ascribed to M. Nencki. These were confirmed later by a number of observers. ${ }^{3 i}$ The general fact in itself thus seemed settled; but until recently it was not known to which of the components of the bile this characteristic and (for the physiological action of the bile) undoubtedly important property was to be referred. Contrary to the statements of Hewlett, who believed he was in position to ascribe its most important rôle in fat cleavage to the lecithin of the bile, the author, in collaboration with Julius Schïtz, was able to show that the effect (at least for the most part) is due to the salts of the bile acids (glycocholic and taurocholic acids). Although these results were regarded as entirely conclusive, it was unquestionably a matter of satisfaction that R. Magnus ${ }^{38}$ determined further that the sodium salts of synthetically formed biliary acids are also capable of acting as powerful activating agents. "In the synthetic production of the two biliary acids," says Magnus, "which was done by starting with cholalic acid and producing successively the ethylester, the hydrazid and the azid of this

${ }^{37}$ Dastre, 1891; Knauthe, 1898; G. C. Bruno, 1899; Babkin, 1903; K. Glässner, 1904; A. W. Hewlett, 1906; cf. Literature: O. v. Fürth and J. Schütz, Hofmeister's Beitr., 9, 28, 1906.

${ }^{38}$ R. Magnus, Zeitschr. f. physiol. Chem., 48, 376, 1906; cf. also E. F. Teorrine (Lab. of the College of France), Biochem. Zeitschr., 23, 440, 1910. 
acid, there were so many and such interfering procedures (prolonged boiling with acids and alkalies, treatment with hydrazine hydrate, sodium nitrite, etc.) required that it seemed quite impossible that any substance active in small amounts could remain intact and maintain itself in practically unchanged quantity through all these processes. - . The augmenting influence of the bile upon fat cleavage by the pancreatic juice depends upon its containing biliary salts of alkalies. The economy in this respect works with precisely the same means as the technical chemist, who splits fats today with ferments and activates the latter by small quantities of manganese sulphate."

Question of the Complex Nature of the Pancreatic Steapsin.-Here arises the further question of just how this powerful effect (for the fat splitting action of the pancreatic steapsin can be increased more than tenfold at times by the addition of small amounts of bile) is to be interpreted. The author's pupil, Hedwig Donath, whom he induced to take up this question seriously, answers it by supposing that we are here dealing with the conversion of an inactive zymogen or proferment into an efficient enzyme, a slow transformation being also possible "spontaneously," but greatly accelerated by the catalytic action of the bile salts. From this it is apparently easy to appreciate why steapsin preparations may spontaneously undergo changes of such a character that add to their direct effectiveness but diminish their capacity for activation by cholic acid. Activation of the pancreatic ferment by cholates results in increasing the ferment activity only within certain limits in proportion to the quantity of cholic acid employed; from this limit forward further addition of cholic acid is not followed by any increase in efficiency. ${ }^{39}$ This discovery is of general interest from the fact that in many ways it suggests certain analogies which

so H. Donath, Hofmeister's Beitr., 10, 390, 1907, conducted under direction of O. v. Fürth; cf. also O. Rosenheim, Jour. of Physiol., 40, Proc. Physiol. Soc., 1910-Separation of the Pancreatic Lipase from Its Coenzyme. 
ferments present with toxines. It has been especially suggested, too, that enzymes, just as toxines, are perhaps composed of two parts, one a thermostable "amboceptor" and the other a thermolabile "complement." Observations like those of $\mathrm{H}$. Donath, of the possibility of partially reactivating pancreatic steapsin which had been inactivated by exposure to a temperature of about $60^{\circ} \mathrm{C}$. by a thermolabile agent present in normal horse serum, invariably make it seem very likely that the pancreatic steapsin is of a complex nature. It should be added, too, that appearances of this and similar nature fall in very well with the ideas of Victor Henri, who, on the basis of ultramicroscopic observations, has brought into the reach of possibility an explanation of "complement effects" from purely physical factors. ${ }^{40}$

Synthetic Production of Fat by Reverse Ferment Action of Lipase.-The fermentative kinetics of pancreatic lipase has been closely studied from a number of standpoints ${ }^{41}$; but it is impossible here to enter into the details of this phase of the subject, which belong properly to the sphere of physical chemistry. Reference may be made merely to one point, because of its special physiological interest, that is, the fact that the lipases concerned in digestion, coming from the pancreatic and intestinal secretions, are not only capable of separating fat into glycerol and fatty acids, but also of bringing about in a reverse way a synthetic production of fat from its components. We are concerned here with a true reversible enzyme action,

$$
\text { Gylcerol + Fatty acids } \longleftrightarrow \text { Neutral fat, }
$$

which, according to conditions, can take place in either direction, and which brings somewhat closer to our under-

${ }^{40}$ V. Henri, Congress of Physiologists, Heidelberg, Aug., 1907, Centralbl. f. Physiol., 21, 477, 1907.

${ }^{41}$ Kastle and Löwenhart, H. Engel, J. Lewkowitsch and J. J. R. Macleod, Taylor, A. Kanitz, Zeitschr. f. physiol. Chem., 46, 482, 1905; E. F. Terroine, Biochem. Zeitschr., 2s, 404, 1910, and others. Cf. therein the Literature. Cf. also O. Rosenheim and collaborators, Jour. of Physiol., 40, Proc. Physiol. Soc., 1910. 
standing the fact that fat which has undergone cleavage in the lumen of the intestine is regenerated synthetically in the wall of the bowel. ${ }^{2}$ Just as fat cleavage is activated by the salts of the biliary acids, so, too, is the fermentative synthesis of fat. ${ }^{43}$

Cleavage of Fat in the Intestine in the Absence of Pancretic Secretion.- Since, as above pointed out, the absorption of fat, at least for the greater part, can be completed only after complete cleavage according to the more recent views, and the latter is very much augmented by the influence of the bile, disturbance of fat resorption might at first glance seem to be thoroughly explained after loss of the bile and panereatic secretion. On closer consideration, however, this explanation is seemingly subverted by the fact that even in a case of this sort the fat which appears in considerable quantities in the frees is not (as might have been expected) an intact neutral fat, but, on the contrary, seems to be practically all split up into its components. This has confused our conceptions of the true nature of fat resorption all the more, because, as E. H. Starling ${ }^{44}$ very properly remarks, we overlooked the point that we should know not only whether the fat has been split in the digestive tract at all, but whether the cleavage occurred at the right place, that is, in the upper portion of the intestine. It may take place (probably true in case of diminutions of the pancreatic secretion) through the agency of microörganisms only in the lower parts of the intestine, where it is apparently too late, and where the intestine is unable to deal with the products of cleavage.

In view of the fact that resorption of fat is apparently much more seriously interfered with when the flow of bile is stopped along with that of the pancreatic fluid, than when

${ }^{43}$ Hanriot, J. H. Kastle and A. S. Löwenhart, O. Mohr, H. Pottevin, Ann. Instit. Pasteur, 22, 901, 1906; H. Donath, 1. c.; A. E. Taylor, Jour. of Biol. Chem., 2, 87, 1906-1907; W. Dietz, Zeitschr. f. physiol. Chem., 52, 279, 1907.

${ }^{43}$ A. Hamsik (Čech. Univ., Prague), Zeitschr. f. physiol. Chem., 59, 1, 1909 ; $65,232,1910 ; \% 1,238,1911$.

${ }^{44}$ E. H. Starling, Handb. d. Biochem., $3^{\prime \prime}, 230,1909$. 
the latter alone is stopped, it is important to call attention to the point that the bile acts as an important activator not only upon the lipase of the pancreatic secretion but also upon that of the unmixed intestinal juice.

Solvent Power of the Bile.--Since, following what has been said above, the generally acknowledged powerful effect of the bile on fat digestion does not seem thoroughly explained by its influenceupon fat cleavage, earnest efforts have been made to discover other explanatory possibilities. One suggestion has brought into prominence the solvent power of the bile for the higher fatty acids, and lipoids of all sorts. If, for example, an opaque, milky suspension of lecithin be treated with a solution of the biliary salts, the fluid becomes clear at once, and in the ultramicroscopic field the suspended particles may be watched disappearing from sight. ${ }^{45}$ The combination of salts of the biliary acids, lecithin, cholesterine and mucin in the bile form with the soaps a physical-chemical system in which (as we have learned from the studies of Moore and Rockwood, Pflüger and Rossi ${ }^{46}$ ) fatty acids are soluble to so great an extent that, as a matter of fact, the largest amounts which could possibly be regarded as within bound of physiological occurrence are converted to a water soluble form. This is the more important, as soaps in the intestinal contents very readily undergo hydrolytic dissociation from the influence of carbonic acid, fatty acids being observable as a consequence in free state even in the presence of notable amounts of sodium carbonate. ${ }^{47}$ Whether, in addition to this important point, the favoring influence (at one time looked upon as important) of the alkali contained in the bile upon emulsification of fat, and the reduction of the surface tension of the intestinal contents by the salts of the biliary

\footnotetext{
${ }^{4}$ L. Kalaboukoff and E. F. Terroine, C. R. Soc. de Biol., 66, 176, 1909.

${ }^{46}$ G. Rossi (G. Fano's Lab., Florence), Arch. di Fisiol., 4, 429, 1907, cited in Centralbl. f. Physiol., 21, 811, 1907.

${ }^{47}$ G. Rossi, l. c.
} 
acids, ${ }^{48}$ or whether finally an increase of the absorbing activity of the intestinal epithelial cells caused by the bile, should be taken into consideration, may remain where they are.

\section{LIPEEMIA}

Passing a step further, we may next consider the route by which the fat passes into the blood stream, and the form which the fat taken up out of the intestine assumes in the blood.

Resorption Path of the Fat.- That a part of the fat finds its way by the lymph paths and thoracic duct may be seen by direct anatomical study of an animal killed after a meal rich in fatty substances. Many observations, as those of Munk and Rosenstein on a girl with a thoracic duct fistula, indicate that at times the bulk of the fat follows this route. Without question, however, a portion of the fat goes directly into the blood stream. J. Munk and Friedenthal observed after ligating the thoracic duct and feeding freely on food rich in fat (cream) that the blood sometimes contained upwards of six times the normal amount of fat, so that, after preventing coagulation by the addition of ammonium oxalate, the blood on sedimentation became covered with a thick layer of cream. ${ }^{49}$ In the writer's opinion a study which has attracted but little notice, made in Bottazzi's laboratory in Naples, ${ }^{50}$ should be regarded as of special importance to the question of the route of fat resorption. From animals during fat digestion two blood specimens are taken at the same time, one from the portal vein and one from the jugular vein; and these are compared for their fat content. Did the principal stream of fat pass from the thoracic duct into the jugular vein obviously one should always expect that the amount of fat in the blood of the latter would exceed that of the portal blood; actually, however, the opposite was

${ }^{48}$ Cf. G. Billard, C. R. Soc. de Biol., 61, 323, 1906.

4 J. Munk and H. Friedenthal, Centralbl. f. Physiol., 15, 297, 1901.

${ }^{6}$ G. d'Errico (Bottazzi's Lab.), Arch. di Fisiol., 4, 1908. 
found to be the case. It has not been possible to recover from the lymph of the thoracic duct, collected during the period of resorption of a known amount of fat, more than sixty per cent. of the fat which disappeared from the intestine. H. J. Hamburger ${ }^{51}$ has satisfied himself that the resorption of soaps from loops of the small intestine of the dog continues even after the recognizable lymph vessels have been ligated.

Hamoconiosis.-In what form does the resorbed fat appear in the blood? After free fat diet the plasma, and, too, the serum expressed from the clotted blood, looks milky; and on standing a cream-like layer may be formed on the surface by the collection of the fat globules. Kreidl and Neumann ${ }^{52}$ have observed in ultramicroscopic study of the blood at time of fat resorption the appearance in the dark field of great numbers of shining, very minute granules ("hæmoconiæ") which are not seen in the blood of the fasting human being or of one on fat-free diet. If such examinations of the blood are repeated at short intervals after the ingestion of a meal rich in fat, and the quantity of the particles visible in the field be estimated each time, one can recognize a gradual accession of the fatty particles, and after a maximum has been reached a gradual recession succeeding. About twelve hours after the last meal the serum of healthy human beings is clear and free from hæmoconiæ. In cats and rabbits the highest point of resorption is reached in about four hours, in man in about six hours. ${ }^{53}$ These blood-dust particles seem to belong exclusively to that part of the fat which reached the blood by way of the thoracic duct. Solution in the blood cannot be said to take place. The particles seem to disappear from the blood vessels

${ }^{51}$ H. J. Hamburger, Arch. f. Anat. u. Physiol., 1900, 554.

${ }^{82}$ A. Neumann, Centralbl. f. Physiol., 21, 1907; Wiener klin. Wochenschr., 1907; A. Kreidl and A. Neumann, Sitzungsber. der Wiener Akad. Mathem. Naturw. Kl., 120, III, February, 1911.

${ }^{s}$ A. Kreidl and A. Neumann, l. c.; E. Neisser and H. Bräuning (Stettin), Zeitschr. f. exper. Pathol., 4, 747, 1907. 
by traversing the capillary wall and are taken up in corpuscular form, as are other suspended particles in certain cell groups, by the tissues, especially the liver, spleen and bone-marrow. ${ }^{54}$

\section{Masking of the Fat in the Blood.-Information obtained} in another way indicates, however, that in the disappearance of the fat from the blood that there are processes of a very different character which we must also consider. W. Connstein and Michaelis came to the conclusion that there exists a lipolytic function of the blood. If, to be specific, an emulsion of fat be mixed with blood and air conducted through it, one will notice an appreciable loss in the ethereal extract. That an ester-splitting ferment discovered by Hanriot in the blood has no part at all in the disappearance of the fat from the blood was shown by careful studies long ago by Arthus, and also by Doyon and Morel. The latter authors were able to show that the reduction in the ethereal extract obtained from blood containing fat does not coincide in the least with cleavage of the fat into fatty acids and glycerol..$^{55}$

Recent investigations, among which those of Mansfeld, ${ }^{56}$ of Budapesth, are prominent, have shown the unexpected fact that in this puzzling disappearance of the fat from the blood (aside from the above mentioned escape of the blood dust particles from the blood vessels through the walls of the capillaries into the cells) we are not dealing with either a cleavage process or with one of destruction, but rather with a process of masking. It was mentioned above that fat in contact with albumin (as shown in Fano's laboratory)

${ }^{54} \mathrm{~S}$. Biondi and A. Neumann, Wiener klin. Wochenschr., 1910, 734; E. Nobel (S. Exner's Lab., Vienna), Pflïger's Arch., 134, 436, 1910; J. Leva (Berlin), Berliner klin. Wochenschr., 1909, 961.

${ }^{55}$ Connstein and Michaelis, Hamburger, Weigert, Arthus, Doyon and Morel; cf. the Literature: W. Connstein, Ergeln. d. Physiol., 3', 210-223, 1904; cf. also the statements of P. Rona and L. Michaelis, Biochem. Zeitschr., 31, 345, 1910, as to the existence of a tributyrin-splitting ferment in the blood.

${ }^{56}$ G. Mansfeld (Pharmacol. Instit., Budapesth), Magyar Orvosi Arch., 9, cited in Jahresber. f. Tierchem., 1908, 84; Pfliiger's Arch., 129, 46, 63, 1909. 
may escape detection by osmic acid staining. From Mansfeld's studies it would appear that the resorbed fat enters in part into some sort of combination with the protein in the blood, and thus becomes insoluble in ether. We are compelled, therefore, to distinguish in the blood between the free fat and the combined fat. Only the free fat can be supposed capable of passing through the capillary walls and entering the tissues. Possibly, too, changes of lipoids may play some part in the apparent disappearance of fat in the blood. ${ }^{57}$

Relation of the Masking of Fat to Fatty Degeneration.-That crude interferences like heat coagulation, the influence of alcohol or peptic digestion are capable of breaking the delicate combinations between fat and protein (at first supposed necessarily to be physical but later regarded as chemical in character) ${ }^{58}$ is entirely obvious. Mansfeld is, however, of the opinion that changes of a more intricate type are also capable of destroying this union and that fatty degeneration and fat metastasis in pathological conditions (as in phosphorus- and acid-poisoning, starvation, etc.) are closely connected with the process. Since infusion of dilute lactic acid under proper conditions sets free the fat in combination with protein in the blood and enables it to pass out through the capillary wall, Mansfeld regards it probable that the fatty degeneration of phosphorus poisoning is related with the accumulation of lactic acid in the blood. Such an assumption would, however, seem justified only after proof by careful quantitative experiments that the amounts of lactic acid which appear in the blood in phosphorus poisoning

${ }^{87}$ L. Berczeller (F. Tangl's Lab., Budapesth), Biochem. Zeitschr., 44, 193, 1912.

${ }^{5 s}$ Boggs and Morris, Jour. of Exper. Med., 11, 563, 1909, who have observed a distinct lipæmia in animals after repeated bleeding, found that the milky serum is not cleared up by shaking with ether, but is readily cleared after adding ammonium oxalate. It would require special study to determine whether the removal of calcium is the essenial point in this procedure and whether we are not rather dealing with some kind of disturbance of the pliysicalchemical equilibrium. 
are capable of breaking up the combinations between fat and protein in the blood, although subject to instant neutralization by the blood alkali. As long as we lack this proof the fact that in phosphorus poisoning the relation between free and combined fat in the blood is altered so that the former predominates, is open to a number of other interpretations.

Pathological Lipcemias.-Coming to the pathological lipæmias, ${ }^{59}$ quite a number of pathological conditions are known in which an abnormal accumulation of fat often occurs in the blood. This is true especially of starvation, of the various forms of anæmias and cachexias, of diabetes (both the severe human type and experimentally produced pancreatic and phloridzin diabetes), of chronic alcoholism and long continued narcoses, of phosphorus poisoning and a number of other toxic conditions.

It is scarcely possible, in the present state of our knowledge, to consider these different lipæmias from a single standpoint. But one may at least endeavor to clear up a group of physiological factors which are open to consideration in this connection.

Lipæmia from Mobilization of Fat Deposits.-As a very important element in many of these lipæmias we may safely consider a compensatory regulative effort on the part of the economy enabling it to mobilize its supply of fat in case of need, as in starvation. The importance of this fat mobilization, which manifests itself anatomically in the loss of the fat accumulations in various positions, may be at once appreciated, if we recall that the body in long-continued starvation, as soon as its glycogen has been used up, calls upon fat combustion to cover at least nine-tenths of its demand for energy. That this may become possible, however, the fat must lend itself to ready movement. The liver is apparently frequently the first objective point, and may in many pathological states be found the seat of an excess of fat (as, typically, in dogs with pancreatic diabetes). Here

${ }^{69}$ Literature on Lipæmias: A. Magnus-Levy and L. F. Meyer, Handb. d. Biochem., 4', 459-470, 1909. 
there may be manifested a certain antagonism between glycogen and fat, the site left vacant by the disappearance of the glycogen coming to be occupied by the fat (not so much in the anatomical sense as functionally, in the view taken by G. Rosenfeld). This point will be again taken up in connection with fatty degeneration. The classical example of this type of fat mobilization is seen in the lipremia of the Rhine salmon (during their migration without food) observed by Miescher. In starving mammals the time of lipæmic occurrence perhaps may be regarded as corresponding with the time when the supply of carbohydrate has become completely exhausted. ${ }^{60}$

Diabetic Lipcemia.-It is not easy to see why a mobilization of fats should not be assumed also for the lipæmia in phloridzin diabetes, in that due to removal of the pancreas, ${ }^{61}$ and in protracted diabetic coma. ${ }^{62}$ Diabetic coma seems in the vast majority of cases to be associated with lipæmia, in which the amount of fat in the biood may reach an enormous grade of twenty per cent. or more; the blood assuming an appearance not unlike cream and chocolate, and on ophthalmoscopic examination the retina showing directly a milky turbidity. According to G. Klemperer in such cases we are really dealing with a lipoidæmia rather than a lipæmia, the bulk of the ethereal extract consisting, not of fat, but of cholesterine and lecithin. For this reason he would interpret diabetic lipxmia not so much as a phenomenon of mobilization of fat deposit as of the cellular lipoids and as evidence of increased cellular disintegration. ${ }^{63}$ Other observers do not express themselves upon this point in by any means as dogmatic a manner. Thus an examination of the blood in a case of pancreatic diabetes showed that the

${ }^{60}$ F. N. Schulz, Pflüger's Arch., 65, 299, 1897; IV. Daddi (IV. Aducco's Lab.) , Lo Sperimentale, 52, 43, 1898.

${ }^{61}$ L. Lattes (Turin), Arch. f. exper. Pathol., 66, 132, 1911, and earlier investigators.

${ }^{62}$ L. Schwarz (Prague), Deutsch. Arch. f. klin. Med., 76, 233, 1903; G. Klemperer and H. Umber, Zeitschr. f. klin. Med., 61, 145, 1907; 65, 340, 1908.

${ }^{63}$ G. Kllemperer, Deutsch. med. Wochenschr., 1910, 2373. 
lecithin was, as a rule, increased, but the amount of cholesterine was variable; ${ }^{64}$ another observer on the contrary believes that in the lipæmia of human diabetes we are dealing more with a cholesterinæmia than with a lecithinæmia. ${ }^{65}$ The writer, too, regards it as more than doubtful whether an accumulation of as much as half a kilogram or more, as estimated by Magnus-Levy, ${ }^{66}$ in the circulating blood in numerous coma cases, can be properly referred to the lipoids arising from cellular disintegration. As there is every reason to regard the acetone bodies to be due to changes in the neutral fat, it would appear not at all inappropriate to refer the coincident lipæmia to the same basic cause. That tissue cells do undergo distintegration and that their lipoids gain access to the circulating blood under such circumstances should not, it seems, be a matter of doubt.

Lipamia from Narcosis.-Reicher's suggestion that in the lipæmia which is sometimes seen in long continued anæsthetization we are dealing with an escape of lipoids from the cells (due to entrance of fat solvents in the blood) is contradicted by the fact that lipæmia is sometimes also seen in morphine narcosis where such an outpouring cannot be considered. ${ }^{67}$

On reflection, moreover, it must be confessed that increased passage of fat into the blood stream does not entirely explain the pathological lipæmias. It should be recalled that even the greatest concentration of fat in the blood, as that which takes place after ingestion of fatty food, disappears under normal circumstances in the course of a few hours, the fat leaving the blood stream. It was formerly believed to be due to the tissue cells taking up the hæmoconial particles; yet it may be presumed that at least in part the fat passes through the capillary walls in dis$1,1909$.

J. Seo (Minkowski's Clinic, Greifswald), Arch. f. exper. Pathol., 61,

${ }^{65}$ M. Adler (Univ. Polyclinic, Berlin), Berliner klin. Wochenschr., 1909, 1453.

${ }_{68}^{6}$ A. Magnus-Levy and L. F. Meyer, 1. c., p. 464.

${ }^{67}$ Cf. A. Magnus-Levy and L. F. Meyer, l. c., p. 463. 
solved state. The liver undoubtedly performs an important rôle in working up the fat which passes out of the circulating blood. ${ }^{\circ 8}$ Observations of K. Glässner and G. Singer on animals with biliary fistulas indicate that the fat of the food passes to the liver by way of the blood, is fixed there for a brief period and may also be in part excreted in the bile. ${ }^{69}$

Passage of the Fat Out of the Blood Stream.-But when it is realized that in pathological lipæmia large quantities of fat continue in concentration in the blood, the logical conclusion must necessarily be that for some reason or other the fat must be hindered in its passage out of the circulating blood. There is not the least basis for accepting the idea that the parenchymatous tissues because of loss of oxidizing power have been deprived of their ability to consume fat in their normal manner. As Magnus-Levy properly suggests, it is impossible to consider anything except solie added difficulty of passage of the fat out of the capillaries, either from change in the permeability of the capillary walls or from delay in the occurrence of the changes which are necessary in the fat itself in order to enable it to pass through the capillary wall. ${ }^{70}$ What the nature of such changes is it is impossible to say at present.

Brief reference may here be made to the question as to what conditions are required for the passage of the fat from the blood into the urine. There is no doubt that in conditions of concentration of fat in the blood small amounts of the former may pass over into the urine. ${ }^{71}$ Both lipuria and albuminuria have been induced coincidently by infusion of cream intravenously in the dog, the fat appearing in the urine as a persistent cloud-like emulsion. ${ }^{22}$ Massive occur-

${ }^{6 s}$ F. Ramond, Jour. de Physiol., 7, 245, 1905.

${ }^{\oplus}$ K. Glässner and G. Singer (E. Freund's Lab., Vienna), Med. Klinik, 1909, No. 51.

${ }^{70}$ A. Magnus-Levy and L. F. Meyer, 1. c., p. 465.

${ }^{71}$ B. Schöndorff (Physiol. Instit., Bonn), Pflüger's Arch., 117, 291, 1907 ; cf. therein the Literature.

'2. Magnus-Levy and L. F. Meyer, 1. c., p. 469. 
rence of fat in the urine ("chyluria") is only observed, as indicated beyond doubt by recent studies, ${ }^{73}$ when there happens to be an abnormal communication between the chyle vessels and the urinary passages.

Fetal Lipcemia.-An interesting form of lipæmia has been observed in fetal guinea pigs by A. Kreidl and his collaborators. It seems that the blood of developed guinea pig fœtuses is crowded with ultramicroscopic particles of fat. Their presence is in no way due to corpuscular fat contained in the maternal blood; the placenta prevents the corpuscular fat in the maternal circulation from passing to the fœtus, and vice versa. In the end, of course, the fotus obtains its required fat from the mother animal, and it must be assumed, therefore, that the component fatty acids and glycerol are taken from the maternal blood, synthesized by the placenta into fat and transmitted as such to the fotus. The placenta in this matter seems to fulfil a function similar to that which belongs to the secreting mammary gland ${ }^{74}$ ( $v$. infra, Chapter XVII). In human beings during pregnancy the blood becomes richer in fatty substances (especially cholesterine compounds and neutral fat). ${ }^{75}$ The proportion of lipoids in the placenta is maximal in the early stages of pregnancy and diminishes during the course of the period..$^{76}$

Peculiar features in the migration of fat may be met in many fish, as in the torpedo, the female of which, according to Reach, does not take food during her pregnancy, her rich supply of hepatic fat passing into the yolks to serve as the most important source of energy for the embryos. ${ }^{77}$

${ }^{23}$ Carter, Franz and Steyskal, Magnus-Levy; Literature: A. Magnus-Levy and L. F. Meyer, I. c., 469-470.

${ }^{74}$ Oshima (under direction of A. Kreidl, Vienna), Centralbl. f. Physiol., 21, No. 10, 1907; A. Kreidl and H. Donath, ibid., 24, No. 1, 1910.

${ }^{75}$ E. Herrmann and J. Neumann (S. Fränkel's Lab., Vienna), Wiener klin. Wochenschr., 1912, No. 12, and Biochem. Zeitschr., 43, 47, 1912.

${ }^{76}$ B. Bienenfeld (S. Fränkel's Lab. and F. Schauta's Clinic, Vienna), Biochem. Zeitschr., 43, 245, 1912, and Monatschr. f. Geburtsh., 36, 158, 1912.

7 F. Reach, in collaboration with V. Widakowich (A. Durig's Lab., Vienna), Biochem. Zeitschr., 40, 128, 1912. 
Diet Lipamia.-In detailing the different forms of lipæmia mention must finally be made of mastlipæmia, seen, for instance, in geese sometimes after forced carbohydrate feeding and after fatty diet. ${ }^{78}$ It may, perhaps, be imagined that when there is too great a transformation of carbohydrates into fat, the fat depots become overfilled to such an extent that finally they can no longer accommodate it, and that then it accumulates in the blood. It may be, too, that the lipæmia of many obese alcoholics can be referred to a similar mode of causation ( $v$. infra, p. 387).

Pavy's Theory.-Pavy ${ }^{79}$ observed that if rabbits are fed upon material rich in carbohydrates but poor in fat, as oats, the intestinal chyle vessels afterwards become prominent from their milk-white injection. On this fact he based his theory (diametrically opposed to all of our views) that the intestinal villi are able to change carbohydrate into fat, and that this happens with the most of the resorbed carbohydrates so that they do not enter the blood as sugar. G. von Bergmann and K. Reicher were, however, able to prove that, on feeding with oats from which the fat had been carefully extracted, no fat appears either in the intestinal villi or in the lymph vessels, and that therefore Pavy's hypothesis is not correct. ${ }^{80}$

The path to knowledge is paved with mistakes; this has always been so and always will be. Whoever has devoted himself for any time to experimental study learns from his own failures to be lenient toward the failures of others. And yet one cannot help feeling depressed to see, as in this instance, some new theory brought before the world which upsets all existing opinions and brings about a lot of confusion, when even a simple and obvious control examination would have been sufficient to prevent its birth.

${ }^{78}$ Bleibtreu, Pflïger's Arch., 85, 345, 1901.

F. W. Pavy, Ueber den Kohlehydratstoffwechsel, Leipzig, Engelmann, 1907.

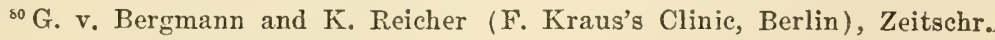
f. exper. Pathol., 5, 760, 1909. 


\section{CHAPTER XVI}

\section{FAT METABOLISM. OBESITY}

Having discussed the manner in which the food fat is taken up from the intestine, how it enters the blood and is distributed with the latter in the body, we may next endeavor to gain some insight into the methods by which, having accumulated in the economy, it is transformed in metabolism.

We should start with the fact that fat serves as an important source of energy and is a substance well suited to limit the demand upon other materials. In contrast to protein it is strikingly distinguished by its capacity for being stored as a reserve substance in times of abundant supply; while, as is well known, we are not directly in position to insure a new formation of organized body-protein by an abundant proteid food supply.

Dependence of Protein Destruction Upon Supply of Fat. -When protein and fat are ingested at the same time the amount of protein required can be kept down by the latter. While (following the teachings of the Voit school) in a dog fed on proteid material alone the nitrogen balance can be maintained only by supplying three and one-half times the amount of protein exchanged in inanition, the nitrogen balance may be successfully maintained, if fat be also exhibited, with but one and a half or two times the amount of protein metabolized in starvation. At first glance the statement based on Voit's authority that in a starving dog, whose fat deposits have not as yet been consumed, administration of several hundred grams of fat scarcely influences the protein exchange at all, seems surprising. The explanation of this rather remarkable peculiarity is simply that in starvation fat is in demand also; as already stated, the starving body draws mainly upon fat to supply its requirements for production of energy. If, therefore, a starving organism, which still has a supply of fat, be flooded with fat, this added fat will be surely burned in place of the tissue fat, but will 
not otherwise make much change in the relative transformation processes. Above all, however, the wear on the corporeal mechanism will be manifest in a nearly constant nitrogenous output. ${ }^{1}$

Importance of Lipoids in Nutrition.-Is fat a vitally necessary food? We formerly were disposed to deny this question without hesitation, because it was well known that dogs can be readily kept alive and strong for a long time on meat diet alone. However, recently W. Stepp, in investigations, undertaken under direction of Franz Hofmeister, has brought out the remarkable fact that mice invariably die if their appropriate food be freed of all fatty substances by thorough alcohol-ether extraction. If pure neutral fat (tripalmitin, tristearin or triolein), or lecithin or cholesterol or even butter, be added to the degreased food, the animals continue to die; apparently it is not the well-defined fats but certain "lipoids" which are essential for maintenance of life. This is only another example of the peculiar things which one is sure to encounter in the course of metabolism studies. ${ }^{2}$

Parenteral Fat Absorption.-If it is desired to introduce large amounts of fat into the body apparently the only way is by the bowel, and, perhaps, too, by intraperitoneal introduction. Experimental subcutaneous injection of olive oil, and, similarly, stained and iodized fat, has invariably shown that only very small amounts of such substances (at best no more than a few grams per diem) can be absorbed from the subcutaneous tissue, the bulk otherwise remaining unchanged in situ. On reflection it may be readily appreciated that the injected fat in all likelihood (just as the fat of the organized depots) can be absorbed only after it has been changed to a soluble form by some lipolytic ferment. However, a large

${ }^{1}$ Literature: Grabam Lusk, Ernährung and Stoffwechsel, 2d ed. (German Translation by L. Hess), pp. 149-154, 1910.

${ }^{2}$ W. Stepp (Hofmeister's Lab., Strassburg), Biochem. Zeitschr., 22, 452, 1909; Zeitschr.f. Biol., 57, 135, 1911. Cf. also W. Stepp (Med. Clinic, Giessen, Voit), XXIX Kongr. f. innere Med., Wiesbaden, 1912, p. 610. 
amount of fat injected under the skin presents, of course, a relatively small surface for attack by such ferments, and for this reason it seems possible to very materially improve the resorption by introducing the fat in the form of a fixed emulsion. In spite of the fact that in occasional experiments it has seemed possible to distinctly prolong the life of starving animals by subcutaneous injections of fat, the hopes which were entertained by clinicians of being able to feed by subcutaneous injection of fat, because fat contains in the smallest volume the largest amount of energy (measured in calories), have for the present at least entirely failed of realization $^{2 a}$ ( $v$. infra, Chapter XX).

Fat Storage in the Body.-The amount of fat stored in the economy is very considerable even under normal conditions. In a healthy human being it has been estimated at about 18 per cent. of the body-weight. The importance of the energy thus accumulated can be readily appreciated when one thinks of the long periods of fasting and the diseases which can be endured in which the intake of food seems to be reduced to a minimum. A study made in Pflüger's laboratory ${ }^{3}$ showed in a well nourished dog a fat content equivalent to more than one-fourth of its body weight; about one-half of the fat was obtained from the skin and subcutaneous tissue, and onethird from the musculature, so that only a comparatively small proportion was distributed in the other tissues. In a fattened animal as much as a third or even a half of the live weight may be represented by fat. The large quantities of glycogen which the liver ordinarily contains during full carbohydrate diet, are supplanted by fat in case of forced feeding with the latter, thus bringing out the antagonism

${ }^{2}$ a IV. v. Leube, 1895 ; E. Koll, 1898; Hofbauer, 1903; H. Winternitz, 1903 and 1906. Literature: A. Magnus-Levy and L. F. Meyer, Handb. d. Biochem., 4', 448-449, 1909; and E. Heilner (Munich), Zeitschr. f. Biol., 5/, 54, 1910. J. Henderson and E. F. Crofutt (Yale Med. School), Amer. Jour. of Physiol., 14, 193, 1905.

${ }^{3}$ K. Möckel, Pflüger's Arch., 108, 189, 1905. 
which was above mentioned between glyeogen and fat. Pflüger found in a dog which had been fed solely upon large quantities of fat for a month, that all of the glycogen had been replaced in the liver by fat, which comprised almost half of the dried hepatic substance. ${ }^{5}$ From the readiness with which the economy is able to draw upon its fat supply in case of need, it is remarkable with what tenacity a residuum of the fat is retained. According to F. N. Schulz ${ }^{6}$ the external appearance alone of a starved dog affords no basis for judging the amount of fat in its economy, and mere long continuance of starvation is not sufficient to actually make an animal free of fat.

Deposit of Foreign Fat.-We may now take up more fully the question of the manner in which the economy makes use of the food fat.

A long series of experiments have proved that the body can lay down foreign types of fat in its own depots. It has been shown that oil of rape, linseed oil, oil of sesame, mutton suet and cow's butter are not only deposited in the system, but that foreign types of fat may also find their way into milk, eggs and the coccygeal secretion of birds. ${ }^{7}$ Iodized and bromized fats can also be laid down in the body, as shown by the studies of Winternitz, Coronedi and others. ${ }^{s}$

For a long time no more doubt has been entertained as

4. Magnus-Levy, Noorden's Handb. d. Path. d. Stoffw., 2d ed., 1, 177, 1906 , regards the antagonism between glycogen and fat accumulation in the liver as not an absolute one; he states that he has frequently found in typical examples of fois gras of Strassburg geese very large deposits of glycogen along with enormous quantities of fat.

${ }^{5}$ Cf. also Pflïger and E. Junkersdorf, ibid., 131, 225, 1910.

${ }^{8}$ F. N. Schulz (Pflüger's Lab.), Pflüger's Arch, 66, 145, 1897.

${ }^{7}$ Radziejewski, Lebedeff, J. Munk, Leube, G. Rosenfeld, Winternitz, Caspari, Zaitschek, Röhmann, Henriques and Hansen; Literature: G. Rosenfeld, Ergebn. d. Physiol., 1", 673-678, 1902; A. Magnus-Levy, Noorden's Handb. d. Pathol. d. Stoffw., 2d ed., 1, 178, 1906.

${ }^{8}$ G. Coronedi and R. Luzzatto, Arch. di Farmacol., 12, 343, cited in Centralbl. f. Physiol., 21, 122, 1907; cf. G. Coronedi (Parma), VIII Intern. Physiol. Congr, Vienna, Sept., 1910; G. Coronedi and F. Dematheis, Boll. della Societa med. di Parma., July, 1911. 
to the reality of assimilation of foreign fats. However, it is not well known even at present to what degree the body changes this acquired fat, and, as it were, impresses upon it the stamp of its own individuality. We know, it is true, that the fats of different genera of animals present nearly constant characteristics. As far as the fat which is formed within the body (probably from carbohydrates) is concerned, there is nothing remarkable in this. But in case of the fat which is acquired directly from the food, this would demand a constancy in the food which certainly does not always obtain (providing the fat does not undergo secondary changes). G. Rosenfeld found, as a matter of fact, that a dog which had been stuffed with mutton suet continued a month after interrupting the fat diet to show a pure mutton fat in his tissues; and he was of the opinion that a panther, for instance, if he would devour nothing but sheep would necessarily put on sheep fat. He found, too, that gold fish and carp when fed mutton suet deposit this form of fat; and comparison of the fats of various marine forms with the fats of their customary foods showed a widespread similarity between them. The same seems to be true, too, for vegetarian animals, although in these, besides the fats contained in the food, there is also that which is formed in the economy from carbohydrates. "Thus we find," says G. Rosenfeld," "that the herbivorous animals have a firm fat, poor in oleic acid, while the graminivora have a soft fat. The fat of the food shows almost precisely the same characteristics; green food has a firm fat, seeds contain a soft oil. If a horse becomes fat from feeding on oats, his fat will be fluid; if he has been fattened on hay, his fat is much firmer. The similarity of the tallow from the ox, sheep, roe and hart is referable to the similarity of food, i.e., grasses."

Transformation of Fat in the Body.-Be these discoveries as illuminating as they may, we have, however, no substantial reason for doubting the ability of the body to adapt

'1. c., p. 676. 
the acquired fats to its own requirements by certain changes. Such changes may include more rapid absorption of oleic acid, elimination of volatile fatty acids, change of saturated into unsaturated fatty acids or the reverse, or of the latter into oxyacids, or separation of the long carbon chains into shorter groups, etc.

Thus, for example, after cramming a dog with butter which is characterized by its high proportion of volatile fatty acids, the Reichert-Meiszl figure (which is indicative of the amount of the latter substances) was not found higher in the fat of the animal than under normal conditions. ${ }^{10}$

As an example of such an adaptation process may perhaps be pointed out that in infancy the proportion of oleic acid in the dermal fat, as stated by Knöpfelmacher and Lehndorff, ${ }^{11}$ increases from month to month, and that the buccal fat (which acts as a support to the buccinator muscle and prevents aspiration of the poorly developed muscle between the jaws in the oral negative pressure in suction) seemingly is poorer in oleic acid, and therefore more resistant than the general subcutaneous fat tissue of the same individual. The skin fat of children fed upon human milk is always richer in unsaturated fatty acids, than that of artificially fed infants. When an infant undergoes emaciation the proportion of oleic acid of its fat decreases, and it appears, according to Knöpfelmacher's studies, that the inflexibility of the fat tissue thus induced, which is poor in oleic acid, is related with the condition which is well known by pædiatrists under the name sclerema neonatorum..$^{12}$

Comparing the iodine combining power of yolk fat and that of the fat of the embryo chick in course of development

${ }^{10}$ W. v. Leube, Verhandl. d. Kongr. f. innere Med., 13, 424, 1895.

${ }^{11} \mathrm{~W}$. Knöpfelmacher and H. Lehndorff, Zeitschr. f. exper. Path., 2, 133, 1906; H. Lehndorff (Abt. Knöpfelmacher), Jahrb. f. Kinderheilkunde, 66, 286, 1907.

12 Literature upon Sclerema: Cf. F. Luithlen, Die Zellgewebsverhärtung der Neugeborenen, Vienna, Alfred Hölder, 1912; G. Rommel, in Hand. d. Kinderheilk., 1, 423-425, 1910. 
within the egg, the fact has been noted that the former gradually grows poor in unsaturated acids, corresponding with the greater mobility and resorption of oleic acid (in contrast to stearic and palmitic acids). On the other hand, the gradual increase in the iodine value of the organized fat of the embryo chick indicate that saturated acids in the embryo are undergoing conversion into unsaturated acids (v. inf.). ${ }^{13}$

Depot Fat and Cell Fat.-According to studies of Abderhalden and Brahm it would be well in the study of fat metabolism to distinguish between depot-fat and cell-fat. In order to determine whether not only the former but also the fat directly involved in the construction of the body cells is dependent upon the character of the food fat ingested, dogs were fed for a long time with mutton suet or with rape-seed oil and then killed. The readily extracted depot-fat is then removed by ether. In order to make it possible to extract the cell-fat, however, the tissue to be subjected to ether is digested or broken up by dilute hydrochloric acid. It is interesting to note from this procedure that the proper cell-fat in contrast to the depot-fat is independent of the character of the ingested food. ${ }^{14}$

This difference between depot-fat and cell-fat acquires special significance when it is recognized that a considerable fraction of the ethereal extract from the liver, heart, kidneys and other tissues does not consist of ordinary neutral fat but of phosphatides of many types (v. Vol. I of this series, pp. 171-172, Chemistry of the Tissues), which contain besides the typical high fatty acids even a higher proportion of unsaturated fatty acids of the linseed oil and linolic acid series. ${ }^{15}$ There is perhaps some connection between the fact

${ }^{13}$ E. C. Eaves (Instit. of Physiol., Univ. College, London), Jour. of Physiol., 40, No. 6, 1910.

${ }^{14}$ E. Abderhalden and C. Brahm, Zeitschr. f. physiol. Chem., 65, 330, 1909.

${ }^{15}$ Rubow, Heffter, Henriques and Hansen, Erlandsen, Hartley, Leathes and Kennaway and others. Literature: J. B. Leathes, Ergebn. d. Physiol., 8, 366-370, 1909. 
that these acids undergo oxidation very readily in the air with loss of iodine-binding power and the further fact that Röhmann ${ }^{16}$ and his collaborators found the acetyl proportions of the mixture of fatty acids obtained from the liver extracts distinctly higher than those of the fat from adipose tissue; the acetyl figure (the number of milligrams of potassium hydrate which are combined with the amount of acetic acid in one gram of acetylized fat after saponification with alcoholic solution of potassium hydrate) is a well-known measure for the amount of free hydroxyl groups in a fat. It seems that unsaturated acids are to be found in tissues not only in the form of lecithids and phosphatids but also in the form of simple glycerides.

Oxidative Function of the Liver in the Catabolism of Higher Fatty Acids.-These results acquire special significance from the observations of G. Joannovics and E. P. Pick, and, too, of Leathes and Hartley, indicating that the liver upon access of fat with the food subjects it to an oxidation catabolism with formation of high unsaturated acids. The first mentioned investigators were able to reduce this oxidation power in the living animal by narcotics. It might well be imagined, perhaps, that by the introduction of new double combinations into the long carbon chain the fatty acids would be prepared for their oxidative destruction, these double combinations forming points of lessened resistance at which the chains may be separated into shorter fragments, the latter then in turn undergoing further disintegration. ${ }^{17}$ The essential features of the subject are not proven, however, as yet. In this connection the passage of fat to the liver might from one standpoint be interpreted on the supposition that

${ }^{16}$ F. Röhmann, with IV. Lummert, Y. Nukada, Pfliger's Arch., 71, 176, 1898; Biochem. Zeitschr., 14, 419, 1908.

${ }^{17} \mathrm{G}$. Joannovics and E. P. Pick (Instit. Paltauf, Vienna), Wiener klin. Wochenschr., 1910, 573; Pflïger's Arch., 140, 327, 1911 ; J. B. Leathes, 1. c.; J. B. Leathes and L. Meyer-Wedell, Journ. of Physiol., 38, Proc. Physiol Soc. XXXVIII, 1909; P. Hartley (Lab. of J. B. Leathes), Jour. of Physiol., 38, 353, 1909; H. Mottram, Jour. of Physiol., 3S, 2S1, 1909. 
the higher fatty acids (as Nasse has suggested) are there prepared for further elaboration; on the other hand, as Magnus-Levy believes, the accumulation of fat in the liver may be an expression of a duty ascribed to this organ of holding in readiness reserve material available for any suddenly introduced increase of metabolic exchange. "It is evident that finely divided fat can be passed when needed into the blood much more readily and quickly from the liver with its full vascular arrangement, than from the fat globules of the adipose cells of the subcutaneous tissue, which present so small a surface in proportion to their contents. According to this view the liver with its deposits both of glycogen and of fat would have the office of providing material for combustion for the body at any time when there is a sudden increase of demand put upon it." 18

Formation of Fat from Sugar.-A matter of much importance to the physiological procedure of metabolism is the formation of fat from sugar. This subject may now be somewhat more fully considered as the reverse process, the formation of sugar from fat, has been discussed above (v. supra, p. 240).

The fact that carbohydrate is converted into fat in the economy seems today quite axiomatic to us; it is in fact one of the few scientific points in physiological chemistry which has passed into popular knowledge. Every layman realizes in these days that people who want to avoid becoming too obese must guard against eating too much bread and made dishes. And yet it was at the expense of long continued and difficult metabolic study that the fact of the formation of fat from sugar was finally removed from any doubt. ${ }^{19}$ The

${ }^{18}$ A Magnus-Levy, Noorden's Handb. d. Pathol. d. Stoffwechs., 2d ed., 1, 177-178, 1906.

${ }^{19}$ Literature upon Fat Formation from Carbohydrates: G. Rosenfeld, Ergebn. d. Physiol., 1, 666-671, 1902; R. Tigerstedt, Nagel's Handb. d. Physiol. 1, 513-516, 1905; A. Magnus-Levy, Noorden's Handb. d. Pathol. d. Stoffwechs., $2 d$ ed., 1, 165-168, 1906; A. Magnus-Levy and L. F. Meyer, Handb. d. Biochem., 4, 449-450, 455-456, 472-474, 1909. 
absolute proof was attained by forced feeding of various experiment animals, like pigs, sheep, dogs, and geese, on fatfree food, poor in protein but rich in carbohydrates, after a previous fasting. Careful equilibrium experiments showed that large amounts of carbon are retained in the body. That this was not retained in the form of protein carbon was proved by calculating the retained nitrogen. Even granting that a high proportion of glycogen could be accepted as accumulated by the process, there still remained a large overplus of carbon which could not be accounted for save as representing new-formed fat.

The conversion of carbohydrate into fat is shown in respiration experiments by a marked rise of the respiratory quotient. Sugar being rich in oxygen and fat poor in oxygen, transformation of the former into the latter will set free considerable oxygen which may be used to burn carbon into carbonic acid. This will lead to an increase in the numerator of the ratio between the exhaled carbonic acid and the inhaled oxygen, $\frac{\mathrm{CO}_{2}}{\mathrm{O}_{2}}$; the amount of $\mathrm{CO}_{2}$ eliminated increases without increase of the oxygen inhaled. Thus Bleibtreu noted, in case of geese stuffed with carbohydrates, and Pembrey in marmots, which were preparing for hibernation and taking on a large supply of fat by gorging with carbohydrates, in order to enable themselves to pass the winter a respiratory coefficient which reached nearly 1.4. This amounts to almost double the proportion to be met in a normally fed individual.

Transformation of Fat into Carbohydrate in the Vegetable Economy.-For the most part in these lectures it is unfortunately impossible to bring forward the analogies which exist between the metabolism of animals and plants. In the present connection, however, attention should be called to the fact that the plant economy is likewise able to change carbohydrate into fat and vice versa. While, for example, unripe oily seeds contain much starch and mannite, as they ripen the carbohydrate is converted into oil. However, the 
reverse takes place when oil-bearing seeds come to sprout, ${ }^{20}$ the oil being converted in greater part into carbohydate, going directly as it disappears from the reserve stock into the formation of material from which the cell walls of the young plants are constructed. Many bulbs and, too, ever-green leaves, and even wood, may contain reserve fats. In many trees starch disappears from the wood in winter, considerable amounts of fat taking its place; in the spring there is a return of the fat into carbohydrate, and the process may be to a certain degree reversed by artificial chilling.

Characteristics of Fat which is Formed de novo from Carbohydrates. - The fat formed de novo in the animal body from carbohydrate is characterized by its low proportion of oleic acid and its peculiar firmness. G. Rosenfeld found that nine-tenths of the fat of fasting geese consisted of oil, with only a trace of solid fat in it; the fat of geese which had been fed freely on potatoes was, however, of a distinctly firmer consistence (very like lard), which did not become soft at full summer heat and when tried out consisted for the most part of crystals of palmitic acid and stearic acid glycerides, with which only a small amount of fluid fat was mixed. In mirror carp, too, which were freely fed on seeds in a bowl, the engorgement with carbohydrate led to a fat poor in oleic acid. ${ }^{21}$ If the same conditions obtain in man, there ought to be a distinct difference observable between the adipose layer of Esquimaux, who assimilate the fluid fat of the north polar animals, and that of a negro or Chinaman in whom free rice diet has helped to produce a well developed panniculus adiposus; and this may well have some physiological significance. For instance, it may be readily thought that an individual with fat containing considerable oleic acid would be in position to more rapidly mobilize his fat supply than one in whom the firm fats prevail. Perhaps there is some difference whether a child as-

${ }^{20}$ Literature: O. v. Fürth, Hofmeister's Beitr., 4, 430, 1903.

${ }^{2}$ G. Rosenfeld, Ergebn. d. Physiol., 1', 670, 1902. 
similates the fluid fat of codliver oil or the firm fat of cow's butter. We have little positive information on these points; but it would undoubtedly be worth while for the pædiatrists especially to devote some attention to the subject. Reference has already been made to the observation that the wasting of young individuals leads to an impoverishment of the subcutaneous fat in oleic acid. May not the wellproved favorable influence of codliver oil, aside from its very real food value, be possibly dependent upon the fact that it, in the absence of fat depots, serves to supply fluid and easily absorbed fatty acids?

Place of Origin of the Fat from Carbohydrates.-Another important question is, in what tissues is the fat formed from carbohydrates. One is, of course, first likely to think of the liver. G. Rosenfeld, however, concludes from results obtained by Bleibtreu with geese stuffed with carbohydrate food, in some of which the blood remained poor in fat, that if the carbohydrate fat is actually formed in the liver and thence worked into the subcutaneous depot the migration of the fat would necessarily always be recognizable by an increase in the amount of fat in the blood. Arguing in this wise Rosenfeld finds himself forced to the hypothesis that fat is constructed from carbohydrate at the place of its deposit, therefore especially in the fat cells of the subcutaneous tissue. ${ }^{22}$ While normally the adipose tissue of rabbits is free from glycogen, it has been shown that after free carbohydrate nutrition microscopic examination will reveal a marked amount of glycogen in this situation; but after continued forced feeding of carbohydrates the glycogen after a time disappears from the fat cells. ${ }^{23}$ MagnusLevy believes that the interpretation that this is an evidence

\footnotetext{
${ }^{22}$ G. Rosenfeld, 1. c., p. 671.

${ }^{23}$ Gierke (Freiburg), Verh. d. Pathol. Gesellsch., 1906, 182; Best, ibid.,
} 184. 
of formation of fat from carbohydrate is probably correct, even though further study is necessary. ${ }^{24}$

Chemistry of Fat Formation from Sugar.-The problem of the chemical transformations by which sugar is converted into fat has as yet not passed beyond the hypothetical stage. The fact that the high fatty acids concerned in the synthetic production of fat show an even number of carbon atoms suggests the idea that groups, each containing two carbon atoms, may, perhaps, be concerned in the construction of the long chains. In review of hypotheses of Nencki and HoppeSeyler, Magnus-Levy suggests ${ }^{25}$ that the formation of fat from sugar may take place along the same lines as (v. supra., p. 347 ) the bacterial butyric acid fermentation, that is, by way of lactic acid and acetaldehyde. ${ }^{26} \mathrm{As}$ is well known, two molecules of lactic acid may be derived from one molecule of sugar, $\mathrm{C}_{6} \mathrm{H}_{12} \mathrm{O}_{6}=2 \mathrm{C}_{3} \mathrm{H}_{6} \mathrm{O}_{3}$; the latter, then, by oxidation gives rise to acetaldehyde, $\stackrel{\stackrel{\mathrm{CH}_{3}}{\dot{\mathrm{C}}} \cdot \mathrm{OH}}{\dot{\mathrm{COOH}}}+\mathrm{O}=\stackrel{\stackrel{\mathrm{CH}_{3}}{\dot{\mathrm{COH}}}}{+}+\mathrm{CO}_{2}+\mathrm{H}_{2} \mathrm{O}$.

This under certain condensation conditions is changed into

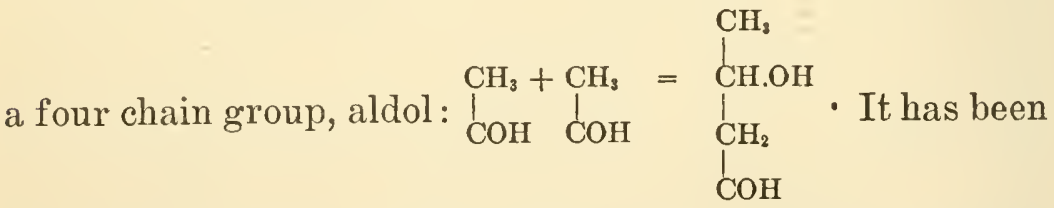
proved, moreover, that two molecules of this latter substance may be condensed in vitro into an eight-carbon atom group:

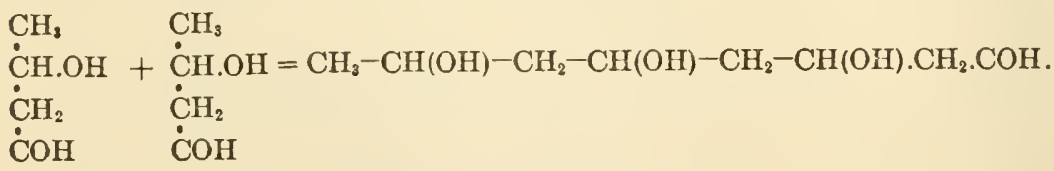
The conversion of this last in the laboratory into n. octylic acid, $\mathrm{CH}_{3} \cdot \mathrm{CH}_{2} \cdot \mathrm{CH}_{2} \cdot \mathrm{CH}_{2} \cdot \mathrm{CH}_{2} \cdot \mathrm{CH}_{2} \cdot \mathrm{CH}_{2} \cdot \mathrm{COOH}$, is easily ac-

${ }^{24}$ A. Magnus-Levy and L. F. Meyer, l. c., p. 456.

${ }^{25}$ A. Magnus-Levy and L. F. Meyer, l. c., pp. 472-474.

${ }^{26}$ A. Magnus-Levy, Verhandl. d. physiol. Ges., Berlin, March 15, 1902, etc. 
complished. ${ }^{2 \tau}$ Finally it is undoubtedly rational to suppose that the aldol by taking up one atom of oxygen may change

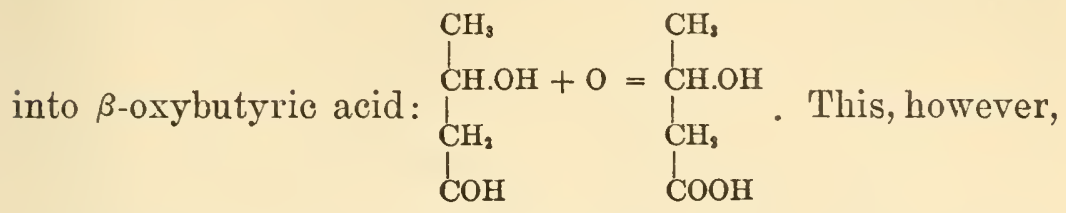
undoubtedly plays an important rôle in the physiological chemistry of the fatty acids, to which further reference will be made in a succeeding lecture. However, it may well be that the route from sugar to fat may be quite different, and may not lead through lactic acid and aldehyde. Even today it is still impossible to speak at all positively in this connection.

In precisely the same way as the upbuilding of the long carbon chain of the fatty acid molecule is shrouded in darkness, so, too, is its catabolism unknown. As no opportunity seems open in the study of animal metabolism to solve this mystery the writer has endeavored by two experiments in the field of plant physiology to force an access.

Experiments upon the Disintegration of Fat by Plants.In the first place the writer, at the suggestion of his teacher, Franz Hofmeister, took up the behavior of the fat of oilbearing seeds at time of sprouting ( $v$. supra, p. 387) in order, if possible, to obtain from the study of their fat catabolism some basic information applicable to the chemistry of the conversion of fat in the animal body. In spite of all the care with which large numbers of sun-flower and castor-bean seedlings were reared in the basement of the Strassburg Institute, it was impossible to find in them any trace of intermediate products between fat and sugar, or to determine in a single instance the new formation of unsaturated acids or oxy-acids of the fatty acid series. ${ }^{28}$

${ }^{2 \pi}$ Raper, Jour. Chem. Soc., 91, 1831, 1907; Proc. Chem. Soc., 23, 235, 1907, cited in Chem. Centralbl., 1908', 223.

${ }^{2 s}$ O. v. Fürth (F. Hofmeister's Lab.), Hofmeister's Beitr., 4, 430, 1903. 
There was not much more success when later with his friend, Carl Schwarz, the writer undertook to study the disintegration of fat by low forms of plant life (mouldfungi, bacillus fluorescens liquefaciens, proteus). ${ }^{29}$ The microörganisms were watched in their growth and development upon inorganic media containing as their sole organic substance high fatty acids, and in their abstraction of their carbon requirements from these fatty acids; but the investigator's never succeeded in obtaining any catabolic product. The only point that was learned was that this type of fat catabolism cannot be regarded, as is occasionally done, as parallel to any of the known fermentation processes. To all appearances it is rather an intracellular oxidation process.

Catabolism of the Fatty Acids in the Animal Body.-The most available points of attack for the type of catabolism of the higher fatty acids which occurs in the economy are presented from the studies of F. Knoop ${ }^{30}$ on the one hand, and by those of G. Embden ${ }^{31}$ and his associates on the other, somewhat as follows: The catabolism of the saturated aliphatic fatty acids takes place by oxidation at the $\beta$-carbon atom with cleavage of the two carbon atoms from the carboxyl end :

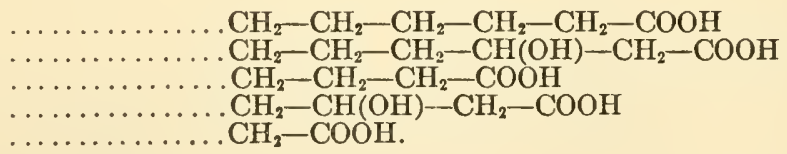

Embden held that, in case the process actually takes place in the manner depicted, it would be necessary to expect that eventually from the higher fatty acids, after the long carbon atom chain is again and again shortened by throwing off two

O O. v. Fürth and C. Schwarz (Festschr. f. Giulio Fano), Archivio di Fisiol., 7, 441, 1909.

${ }^{30}$ F. Knoop, Hofmeister's Beitr., 6, 150, 1905.

${ }^{3 x}$ G. Embden, H. Salomon and Fr. S'chmidt, Hofmeister's Beitr., 8, 129, 1906; G. Embden and A. Marx, Hofmeister's Beitr., 9, 318, 1908. 
carbon atoms, we would obtain butyric acid and from this $\beta$-oxybutyric acid, diacetic acid and acetone:

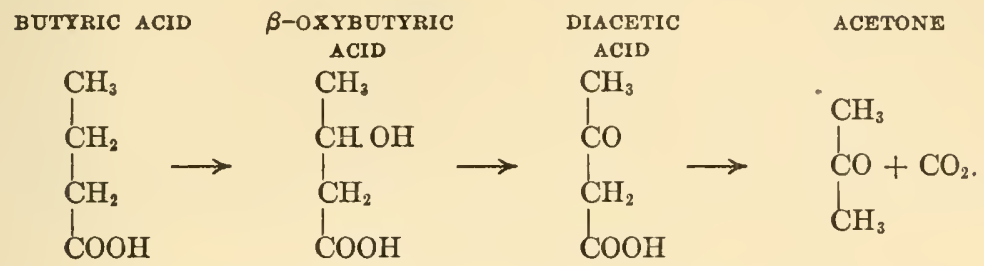

There follows now the very interesting fact that if various acids are added to the blood perfused through the living excised liver of a dog, the acids with even number of carbon atoms (butyric acid, $\mathrm{C}_{4}$; caproic acid, $\mathrm{C}_{6}$; caprylic acid, $\mathrm{C}_{8}$; capric acid, $\mathrm{C}_{10}$ ) give rise to a notable acetone formation; while in case of the acids with uneven number of carbon atoms the amounts of acetone formed are no greater than when the liver is perfused with normal blood. Embden ${ }^{32}$ properly says that the supposition that fatty acid catabolism takes place in the manner described has been made much more probable by these experiments. It should be definitely understood that, provided the oxidation of a carbon chain in the body takes place at the $\beta$-carbon atom (as we have every reason for assuming, following Knoop) we can never obtain from a normal fatty acid with an uneven number of carbon atoms $\beta$-oxybutyric acid and acetone; for example:

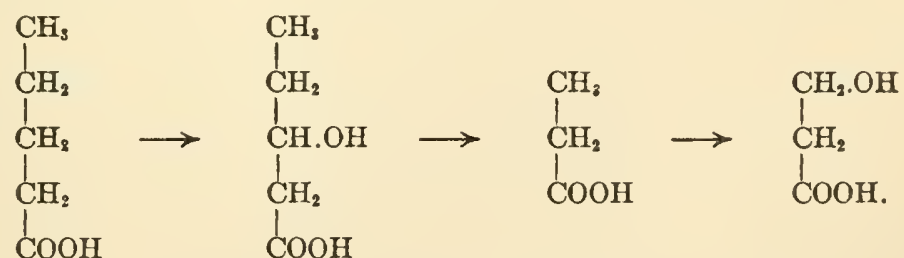

Reference will again be made to these points, which argue a direct relation between the acetone bodies and fat disintegration in the economy, when the former are discussed. Consideration of the occurrence of the lower fatty acids in milk

G. Embden and A. Marx, 1. c. 
will also give occasion to take up the matter of fatty acid catabolism. It should only be added that Dakin, ${ }^{33}$ who hoped to imitate the oxidation reactions in the body by the action of hydrogen peroxide, observed besides the oxidation at the $\beta$-carbon atom the same thing at the $\alpha$-atom and the catabolism of the $\beta$-oxybutyric acid into not only diacetic acid and acetone but also into acetic acid and formic acid:

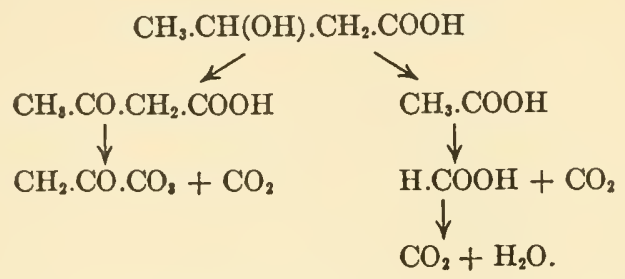

Whether an analogous disintegration, as this just described, is also to be thought of as physiological, is, however, at present not known.

Nature of Obesity.-Here may be taken up briefly what is known from the standpoint of the biochemist of the nature of obesity.

Common experience indicates that many persons who are "disposed" toward corpulence accumulate fat even though they do not ingest any more food apparently than do other individuals; in such cases one might suspect that there exists a lowering of material exchange. A whole series of studies upon metabolism in obesity are now at our disposal for consideration. ${ }^{34}$ Many authorities, as Jaquet and Svenson, found, as a matter of fact, in corpulent persons a distinctly lower increase in gas-interchange after ingestion of food

${ }^{23}$ H. D. Dakin (C. A. Herter's Lab., New York), Jour. of biol. Chem., 4, $77,91,227,1908$.

84 Thiele and Nehring, 1896; Stuve, 1896; A. Magnus-Levy, 1897; C. von Noorden, 1900; Jaquet and Svenson, 1900; Rubner, 1902; Reach, 1904; E. A. v. Willebrandt, 1908; R. Stähelin, 1909; G. v. Bergmann, 1909; F. Umber, 1909. Literature on Metabolism in Obesity: C. v. Noorden, Die Fettsucht, Nothnagel's Handb., Part 7, 1900; v. Noorden's Handb. d. Pathol. d. Stoffw., 2d ed., 2, 189-211, 1907; A. Jaquet, Ergebn. d. Physiol., 2', 553-554, 1903; F. Umber, Lehrb. d. Ernäbr. u. d. Stoffwechselkr., 73-117, 1909; G. von Bergmann, Handb. d. Biochem., 4" 208-237, 1910. 
than in normal individuals; the reaction, too, was of abnormally short duration, the gas interchange sinking to normal within two or three hours after taking food. They regarded the conclusion justifiable that the obese individual must necessarily as a result of diminished interchange be storing his combustible material. Observation of Reach, Stähelin and G. v. Bergmann also indicated that at least many corpulent persons differ from normal persons particularly in that their curve of interchange does not rise as high and descends less sharply to a level after intake of food, in such manner that a "trailing out of metabolism" is suggested. However, these positive statements are completely contradicted by those of other authorities. Thus Rubner ${ }^{35}$ compared with the greatest care the metabolism of two brothers, both children and differing only a single year in age, one of whom was corpulent, the other spare. Calculated according to the square surface, the exchange in the two was exactly the same, and there could not be considered any specific diminution of metabolism. We cannot off hand, therefore, ascribe to all obese persons a diminished protoplasmic disintegration energy; on the contrary we may be forced to assume, following Rubner, apparently for the majority of them just as much utilization of energy in relation to their body mass as would correspond to an equivalent normal individual. ${ }^{36}$ A. Loewy and F. Hirschfeld also find that there are normal, in fact lean, persons in whom the maintenance exchange is so low that it may be of the same level at least as the interchange determined in individual cases of obesity. Perhaps it would be best to foresee, if the expression may be permitted, that the methods of investigation now at our command are not good enough to allow us to say that there is a true and constant abnormality in the metabolism of all obese individuals; which does not say, however, that such fault does not exist.

${ }^{35}$ Rubner, Beiträge zur Ernähr. im Kindesalter, Berlin, 1902.

${ }^{38}$ Cf. F. Umber, l. c., pp. 78 and 84. 
Corpulence and Overfeeding.-For the rest, it should be understood that we can explain very well (even in persons who are not customarily large eaters) an accumulation of fat by the summation of very small amounts of food beyond the maintenance requirements. Carl von Noorden ${ }^{37}$ illustrates this point by the following proposition: A healthy man weighing 70 kilograms, who uses 40 calories for each kilogram per diem, in all, therefore, 2,800 calories, will generally regulate his intake of food involuntarily according to the actual requirements of his body; and is able thus, even with entirely free choice of food, to keep himself in average state of nutrition for many years. A small daily excess of food of only 200 calories will result, if we presume that it is converted into fat and deposited as such, in a yearly gain in weight of eleven kilograms. One would be surprised to learn to how small a quantity of food these 200 calories correspond: $1 / 3$ liter of milk, or 4/10 liter of light beer, or 90 grams of rye bread, or 25 grams of butter, or 100 grams of fat meat. What fat man would dare then to disclaim the possibility with quiet conscience that at least at times he has not been guilty of overeating?

Moreover, if this is to be properly appreciated, we must also take into account the relation between "ballast" and "live substance" in the body. "The relation between ballast and live substance," says H. Friedländer, "is variable in individuals at different periods of age. . . Abnormally fat animals, like whales and seals, as well as abnormally fat men, contain to the unit of weight less active substance than lean animals of the same age period; the complaint of many fat persons can be understood when they declare that they continue to put on weight with an absolutely lower ingestion of food. In ratio to their small proportion of live substance the ingested food is frequently not small, and a portion of it is still available for weight increment." 38

${ }^{37}$ C. von Noorden, Handb. d. Pathol. d. Stoffw., 2d ed., 2, 190, 1907.

${ }^{38}$ H. Friedenthal (Nicholas Lake in Berlin), Centralbl. f. Physiol., 23, 437, 1909. 
Antifat Treatments.-It is impossible to enter into the various antifat treatments ${ }^{39}$ beyond mentioning that in the majority of cases they are essentially fasting treatments, with different variations. Thus in the so-called Banting treatment there are given, mostly in form of meat, only about 1100 calories to a person instead of the 2800 calories due him; the Ebstein bill of fare with about 1300 calories gives preference to fat; that the intermittent restricted milk diet in limited amounts is equivalent to actual fasting goes without saying. The same thing is true of the Rosenfeld potato treatment (with about 1200 calories). Oertel's treatment is based on the restriction not only of the number of calories but also of the amount of fluid allowed; but it should be remarked that the losses in weight obtained with this last method, for which the patient must pay with the torments of thirst, are partly only apparent and are due to the loss of water. We have learned to realize, too, that the patient should not be allowed to be weakened in the course of an antifat treatment. It is important that modern methods of dietetic reduction of fat be so planned, like that of G. Gärtner, that the subjective sensation of hunger be kept down by full use of bulky food rich in cellulose, of low ealoric value, like green vegetables and fruits. It is of value, too, to further the process of reduction by increasing the muscular activity. Employment of mineral waters containing sodium sulphate (Marienbad, Karlsbad, Neuenahr, Tarasp) often is of service by lowering the complete utilization of the food. "The combined action of all the factors favoring the reduction of fat in special baths," says F. Umber, "the regulation of diet (which is frequently, for example in Marienbad, in Kisch's regulations, administered in a bill of fare similar to that of the Banting system), the drink treatments, the bath treatments, the systematic muscular exercise, and not the least the removal of the patients from their

${ }^{39}$ For details cf. E. H. Kisch, Entfettungskuren, Berlin, 1901; F. Umber, Lehrb. d. Ernährung u. Stoffwechselkr., 1909, pp. 94-114. 
every-day surroundings, all these are elements which make for success in such an establishment for the cure of the obese. First and foremost the result is that these obese people, who either are unwilling or cannot use the necessary energy and precaution at home to deal with their trouble, amuse themselves with the annual outcome of their Marienbad or Kissingen sojourn and make excuses for their persistent failings."

The thyroid gland medication in the obese depends upon an entirely different principle. G. von Bergmann ${ }^{40}$ holds that an increase of calory-exchange of from 25 to 50 per cent. can be obtained by administration of thyroid substance, with protection of the protein store; and believes that (if we exclude direct or indirect toxic influences, especially upon the nervous system, which may give rise to contraindication for this method of treatment) thyroid gland substance is "from a purely metabolic standpoint the ideal means of reducing fat." As has been previously stated (Vol. I of this series, p. 450, Chemistry of the Tissues), we cannot fully share this view, and are more likely to accept the idea (on the basis of the statements of Magnus-Levy, Ebstein, v. Noorden, Umber and others) that the antifat treatments by administration of thyroid not only are wanting in every practical but also every physiological justification.

Fattening.-In conclusion of the present discussion we may point out what principles are involved if the opposite of the above depicted effect is sought to be obtained, namely, putting on fat. Probably nothing better can be done than to follow herein the lines of thought which C. von Noorden has developed in his remarkable monograph concerning hypernutrition. ${ }^{41}$

${ }^{40}$ G. v. Bergmann, Handb. d. Biochem., f", 230-237, 1910.

${ }^{41}$ C. von Noorden, "Die Ueberernährung," Handb. d. Pathol. des Stoffw., 2d ed., 1, 548-577, 1906. 
A sharp difference must be drawn between fattening and putting on flesh.

There are undoubtedly cases in which a true protein upbuilding takes place; this is seen, for example, in the period of growth, during pregnancy, in functional hypertrophy of the muscles from exercise, and above all in convalescence after sickness and undernutrition. In correspondence to an increased intake of food, which (in contrast to the normal of 40 calories per diem for each kilogram of body weight) may reach as much as 70 calories in the first weeks, the energy exchange, for example, in a convalescent from typhoid fever may be found tremendously exaggerated ( 30 to 50 per cent.). The respiratory quotient remains generally in the neighborhood of 1 , as the energy expenditure is chiefly made good by combustion of carbohydrates, while the fat and protein are not burned but accumulate in the economy.

The usual fattening, as, for instance, that which is practised in such large measures by animal raisers, is truly a putting on of fat. The production of well-muscled animals with large amount of meat is not possible by forced feeding, but only by selective breeding (a proposition which has suffered scarcely any check from occasional observations which have been made upon nitrogen retention after feeding abnormally large amounts of protein). Besides fat, water may also contribute to an important degree to the on-put of weight of fattened individuals. This is observed, for example, in the very marked increase of weight seen at first in forced feeding, followed, however, by a pause; at first in such cases there is a marked accumulation of water in the tissues, which is thereafter gradually, with rise of diuresis, replaced by fat.

If we ask, further, what type of food may be expected to be followed most quickly by increase of fat, the answer would be that protein seems least suited, as an excess of calories provided in protein form is usually not fixed.

The carbohydrates are much more favorable; there is 
always lost about one-fourth of their energy value in passing from the intestine to the fat depots, in which, according to the findings of $\mathrm{N}$. Zuntz and Rubner, not only the work of digestion but also the heat abstraction which takes place in the passage of carbohydrate into fat, are included.

"The most favorable substance is fat" says Carl von Noorden. "This requires but little expenditure of force on the part of the digestive organs and is deposited as fat with almost no loss of energy. Practical medicine still hesitates to make effective use of fat as a fattening medium, and generally gives preference to the carbohydrates. I have often pointed out that this should be abandoned, and that large, and even enormous amounts of fat (neglecting here certain pathological changes of the stomach and intestines) are excellently borne, and bring about results which can scarcely be equalled, not to say surpassed, by extra administration of carbohydrates."

Alcohol, too, may find a place among the adjuvants in fattening, because of the large energy-value it possesses, and because its combustion serves to protect other material. However, because of its toxic features it can be considered only in very limited sense as a food material; and is, of course, in no wise indispensable (as has been thoroughly established). The writer is, however, not so naïve as to fancy that the many fellow beings whom alcohol serves as a fattening agent in an empiric way not worthy of imitation will allow themselves to be at all disturbed in the use of this substance by considerations of a physiological-chemical nature.

Now and then we realize to our surprise that practice does not always direct its measures as theory believes is right.

This holds good, unfortumately, not only for alcohol, but also for many other measures looking to the advance of human culture. 


\section{CHAPTER XVII}

FAT-SPLITTING TISSUE FERMENTS. FAT FORMATION FROM PROTEIN. FATTY INFILTRATION AND FATTY DEGENERATION. ORIGIN OF MILK-FAT.

\section{FAT-SPLITTING TISSUE FERMENTS}

Frow the general knowledge we possess as to the fate of fat in the living body there is no doubt that even outside the intestinal tract a voluminous catabolism of neutral fat takes place. We see a flood of fat pouring into the blood after ingestion of fat-bearing food, and after a time disappearing; we see that in wasting processes the fat disappears from its depots in cells and tissues; we notice in the processes of fat-migration of every type how the fat is mobilized in the compass of the large depots. There is certainly probability in the assumption of a close relation between fat mobilization and fat cleavage and in the belief that, just as the stable glycogen passes into solution as soon as the economy requires it, the same is true of fat. From what has been said it might be supposed that the fat, which according to Pflüger's opinion can pass from the intestine only after cleavage, can also only pass through the wall of the blood capillaries when in fully split state, as soap. Many authorities have earnestly tried to attribute it to the cleavage of fat in the blood and the tissues. ${ }^{1}$

Cleavage of Fat in the Blood.-We next ask ourselves what is there in the proposition of fat cleavage in the blood. It has been previously stated that Hanriot, when engaged upon the subject, came to the conclusion that there exists in the blood a lipolytic ferment; while the opponents of this view ${ }^{2}$ were of the opinion that at most there is an

${ }^{1}$ Literature upon Fat-splitting Tissue Ferments: W. Connstein, Ergebn. d. Physiol., 3, 223-226, 1904; H. M. Vernon, Intracellular Enzymes, London, Jolin Murray, pp. 53-60, 1908; C. Oppenheimer, Die Fermente, 3d ed., 5-24, 1909; F. Samuely, Handb. d. Biochem., 533-537, 1909; A. Magnus-Levy and L. F. Meyer, ibid., 4', 457, 1909.

2 Arthus, Doyen and Morel. 
estersplitting ferment present, but no lipase. We have already seen, too, that the apparent disappearance of fat from the blood, as may be observed in vitro (v. supra, p. 370), is due to a masking of the fat but not to a lipolysis. In the course of the last few years P. Rona and L. Michaelis ${ }^{3}$ have reverted to the question of cleavage of esters and fat in the blood. They start out from the fact that observation of the surface tension of aqueous solutions of glycerol esters permits one to follow the cleavage of these substances with unusually marked clearness; the glycerolesters of the lower fatty acids (in contrast to their cleavage products) belong to the substances having very marked surface activity which sharply lower the tension of water. They were able to recognize, using Traube's drop counter, the presence not only of Hanriot's monobutyrin-splitting ferment but also of a tributyrin splitting ferment in the blood. The velocity of ester cleavage was approximately in proportion to the quantity of ferment." The authors named speak of the tributyrin-splitting ferment as a "true lipase," a statement which is perhaps entirely correct from the standpoint of physical chemistry. Whether, however, this lipase is of importance from a physiological point of view, and whether it is actually to be considered as involved in the cleavage of true fat can scarcely be regarded as proved. An observation of Abderhalden and Rona is of interest here, indicating that after feeding large amounts of specifically foreign fat and, too, in starvation, an exaggeration of the ester-splitting power becomes noticeable in the blood of dogs. ${ }^{5}$ That the serum lipase cannot be held to be simply resorbed pancreatic lipase is shown by the points that it is not materially influenced by removal of the pancreas, and that it does not seem to be at

${ }^{8} \mathrm{P}$. Rona and L. Michaelis (Hospital at Urban, Berlin), Biochem. Zeitschr., $31,345,1911$.

${ }^{4}$ P. Rona, Biochem. Zeitschr., 33, 413, 1911; P. Rona and J. Ebsen, ibid., $\$ 9,20,1912$.

${ }^{5}$ E. Abderhalden and P. Rona, Zeitschr. f. physiol. Chem., 75, 30, 1911; E. Abderhalden and A. E. Lampé, ibid., 78, 396, 1912. 
all activated, as the pancreatic lipase is, by the salts of the biliary acids. ${ }^{6}$

Lipase of the Leucocytes.-In the cellular elements of the blood, too, the existence of a lypolytic ferment has been demonstrated, not only by ester-splitting but also by a plate method, somewhat like the Müller-Jochmann method. Just as in the latter method the tryptic power of cells is recognized by the formation of depressions in a gelatine plate, in this case the formation of delles in a wax plate is observed. Preparations, consisting mainly of lymphocytes, especially tuberculous pus, show fine examples of delleformation dependent upon fat-cleavage. Myeloid cells apparently do not contain a lipase. If capillary tubes filled with yellow wax be introduced aseptically into the peritoneal cavity of living animals examination will show after one or two days that at the open ends of the tubes the wax will have disappeared, and will have been replaced by a whitish material consisting principally of mononuclear white blood corpuscles. ${ }^{7}$

In this connection it is vely suggestive that, according to observations of Edmund Nirenstein, infusoria (paramœcia) are not only capable of ingesting large amounts of fat from an emulsion of oil, but also of digesting it within the food vacuoles (that is, decomposing it into components soluble in water). 8

Cleavage of Esters in the Tissues.-As far as the existence of lipolytic ferments in tissues is concerned, a number of statements are to be found in the literature concerning the cleavage of different esters (as monacetin, monobutyrin, ethylbutyrate, tribenzoin and amylsalicylate). P. Saxl, who 1911.

${ }^{6}$ C. L. von Hess (Carlson's Lab., Chicago), Jour. of Biol. Chem., 10, 381,

'S. Bergel (Surgical Clin., Berlin), Münchener med. Wochenschr., 1909, H. 2; N. Fiessinger and P. L. Marie, C. R. Soc. de Biol., 67, 1909.

${ }^{8}$ E. Nirenstein (II Zoöl. Instit., Vienna), Zeitschr. f. allgemein. Physiol., $10,137,1909$; cf. on the contrary the different interpretation of W. Staniewicz, Bull. de l'Acad. de Cracovie, 1910, 199, cited in Centralbl. f. Physiol., 24, 855, 1910. 
tried out these statements at the request of the author, found that the first three esters above named are split in only very slight but always measurable degree by short exposure (an hour at room temperature) to the influence of minced tissues (but salicylic acid amylester was split by almost all the tissues studied). On longer exposure to the same influence usually a marked access of acidity could be recognized titrimetrically, brought about not only by the cleavage of the esters but also by formation of acid by autolysis of the tissues. Saxl came to the conclusion that none of the recommended methods is adapted to quantitative study of ester cleavage, and that all the statements dealing with quantitative variations of lipase in the tissues are without proper foundation. ${ }^{9} \quad$ P. Rona has shown that tracing the change in surface tension of a solution of monobutyrin or tributyrin may also be employed in the recognition of ester-splitting ferments in aqueous extracts of tissues. ${ }^{10}$ But this method has not been properly elaborated as a quantitative one any more than the rest. The greatest problem in this connection not as yet solved, and perhaps not capable of solution, is that of quantitative extraction of the lipases from a tissue. Studies upon animal and plant lipases especially have raised reasonable doubt as to whether the lipases are at all soluble in water and whether they are separable from organized cytoplasm.11 With this should be associated the striking observation that the ester-splitting power of freshly prepared tissue extracts becomes enormonsly augmented when they are preserved on ice. ${ }^{12}$ All in all, this matter is

-P. Saxl (under direction of O. v. Fürth), Biochem. Zeitschr., 12, 343, 1908; consult therein the older Literature: Hanriot, P. Th. Miiller, Kastle and Loevenhart, R. Magnus, N. Sieber; cf. also L. B. Mendel and Leavenworth, Amer. Jour. of Physiol., 21, 95, 1908.

${ }^{10}$ P. Rona, Biochem. Zeitschr., 32, 482, 1911.

"Astrid and Euler, Hoyer, Armstrong, Nicloux, cited in H. M. Vernon, 1. c., p. 60 ; L. Breczeller (Tangl's Lab.), Biochem. Zeitschr., 34, 170, 1911.

${ }_{12}$ M. C. Winternitz and R. Meloy (Johns Hopkins Univ.), Jour. Med. Research, 22, 107, 1910. 
by no means, to the writer's way of thinking, satisfactorily removed from the plane of uncertainty.

Fat-splitting Tissue Ferments.-This feeling of uncertainty grows when we come to consider the true lipases, that is, those tissue ferments which bring about cleavage of neutral fats into their components. There are a few references in literature to this type of ferments. ${ }^{13}$ P. Saxl, ${ }^{14}$ in following these up in control tests, obtained results indicating that neutral fat, both that contained in the tissues and that added thereto undergoes but a slight degree of cleavage during postmortem autolysis (excluding action of bacteria). The author's usual contention, however, here applied to Saxl's negative findings, would rank them as of less relative value than the positive results of other authors, who, like Umber and Brugsch, ${ }^{15}$ Pagenstecher ${ }^{16}$, and Berezeller, ${ }^{17}$ conducted their experiments carefully and added the fat in the form of an emulsion to the tissue pulp. In experiments of this sort it is likely, too, that activation of zymogens plays an important rôle. Thus in the adipose tissue of freshly killed hens practically no lypolytic power can be detected; but it appears after they are kept for a long time. ${ }^{18}$ It is impossible her'e to enter in detail into the ferment-kineties of the lipases; only a few more features seemingly essential to a sketch of their characteristics, may be briefly mentioned.

${ }^{13}$ Lüdy ; Ramond (1889), j904; N. Sieber, Zeitschr. f. physiol. Chemie., 55, $177,1908$.

${ }^{14}$ P. Saxl, 1. c.; cf. also G. Comessati, Clin. Med. Ital., 46, 417, cited in Jahresber. f. Tierchem., 38, 179, 1908.

${ }^{15}$ F. Umber and Th. Brugsch, Arch. f. exper. Pathol., 55, 164, 1906.

${ }^{16}$ A. Pagenstecher (Heidelberg), Biochem. Zeitschr., 18, 285, 1908; ef. also A. Juschtschenko (St. Petersburg), Biochem. Zeitschr., 25, 49, 1910; G. Izar (Catania), ibid., 40, 390, 1912.

${ }^{17}$ L. Berczeller (F. Tangl's Lab., Budapesth), Biochem. Zeitschr., 44, 185, 1912.

${ }^{13}$ M. E. Penuington and J. S. Hepburn, Jour. Amer. Chem. Soc., 34, 210, 1912 ; United States Dept. of Agriculture, Bureau of Chem., Circular No. 75, 1911, cited in Centralbl. f. d. ges. Biol., 13, No. 5, and 156, 1912. 
Dakin's observation that the racemic esters of mandelic acid, $\stackrel{\mathrm{CH}}{\mathrm{C}}(\mathrm{OH}) . \mathrm{HOOH}_{5}$, are asymmetrically split by the lipase from hog's liver has been interpreted to mean that the enzyme itself is an optically active substance. ${ }^{19}$

It is worth noting, too, that the tissue lipases, just as the pancreatic lipase, may be activated by biliary salts. ${ }^{20}$ Moreover, the fact that minute amounts of acid serve to activate a tissue lipase of vegetable nature, the lipase of ricinus, has proved of very wide practical value in industrial fat cleavage, based on the studies of Connstein, Hoyer and Waterberg. ${ }^{21}$ The same ferment, which brings about cleavage of neutral fat in the presence of an excess of water, works in the reverse fashion, that is, to cause synthetic formation of neutral fat, when allowed to act upon a mixture of fatty acids and glycerol in a medium poor in water. ${ }^{22}$

\section{FORMATION OF FAT FROM PROTEIN. FATTY DEGENERA- TION AND FATTY INFILTRATION}

At this point we turn to a difficult and complicated problem which has had a prime position for the past half century in the interest of metabolic physiologists and pathologists, the question of formation of fat from protein.

The doctrine of a metamorphosis of protein into fat takes its starting-point on the one hand from $\mathrm{R}$. Virchow's microscopic observations upon fatty degeneration of tissues, and on the other from metabolic investigations. ${ }^{23}$

In the years from 1862 to 1871 Carl Voit in association

${ }^{19}$ Dakin, Jour. of Physiol., 32, 199, 1905.

${ }^{20}$ A. S. Loevenhart (Johns Hopkins Univ.), Jour. of Biol. Chem., 2, 391, $415,1907$.

${ }^{21}$ E. Hoyer, Zeitschr. f. physiol. Chemie, 50, 414, 1907.

${ }^{22}$ Cf. A. Welter, Zeitschr. f. angew. Chem., 24, 385, 1911, cited in Chem. Centralbl., 1911', 1258.

${ }^{2}$ Literature upon Fat Formation from Protein in Metabolism: G. Rosenfeld, Ergebn. d. Physiol., 1, 655-699, 1902; R. Tigerstedt, Nagel's Handb. d. Physiol., 1, 511-512, 1905; A. Magnus-Levy and L. F. Meyer, Handb. d. Biochem., 4', 451-453, 1909. 
with Pettenkofer in a series of extensive studies developed the theory that protein is the principal source of fat in the living body. For decades metabolic physiology remained under the domination of this doctrine, supported as it was by the great authority of its founders, until it was overthrown by the ponderous opposition of E. Pflüger. "These celebrated experiments of Voit and Pettenkofer," wrote Pflüger at the beginning of the nineties, "prove nothing for the formation of fat from protein. For the computations of these investigators, as here involved, are really the result of a mistaken assumption as to the elementary composition of lean meat, which Voit adopted, not after analysis, but from his personal judgment, in contravention of analyses of other investigators generally regarded as reliable, and in fact contrary to the results of his own analyses. It is on such a foundation that the modern superstructure of metabolism rests for the majority of physiologists.' In answer to these ideas the Voit school set about energetically to defend itself; and in particular E. Voit, M. Cremer and M. Gruber brought forward new arguments for the retention of a carbon residium after meat consumption which did not seem covered by the carbohydrate in the food, and which, therefore, was held to indicate a formation of fat from protein. Pflüger invariably returned to the fray with new objections, of the correctness of which different opinions might be, and in fact were held. To-day the whole question has shifted; since, as has been stated, we must necessarily accept the formation of sugar from protein as a settled fact, and cannot possibly doubt that fat is formed from sugar. The logical conclusion, therefore, follows that it must be granted that in the living body fat may be formed from protein. It is another question, of course, whether under practical conditions this possibility becomes an actuality. When very large amounts of protein are fed one would probably always contemplate such a result. Magnus-Levy, as well-informed in the fundamental points as he is an objective observer in the subject of 
metabolism, believes that really the formation of fat from protein does not occur to any important amount, although the possibility of such process must be maintained. Nor is it absolutely essential that the route should be throngh a fully formed sugar; for if we may presume that groups of six carbon atoms, combined from the "building stones" of the protein molecule, unite to the formation of the sugar molecule, we have as much right to fancy that eight or nine such groups, if need be, can enter into the construction of the long fatty acid chains. When, however, would this be needed? "When carbohydrates and fat are available in metabolism there is no occasion for further production from protein. Whenever, in case of deficiency of carbohydrate, important amounts of sugar are formed from protein, it seems to be required for the immediate needs of the body, unless, as in diabetics, it is excreted. As we cannot recognize in animal experiments that in case of exclusive protein diet any extensive formation of fat takes place, so there is no reason for holding that the process plays any important part under natural conditions of life in the carnivorous individual." 24 On the contrary, only recently E. A. Bogdanow has concluded from his studies on the fattening of pigs that fat formation from protein is at least probable. ${ }^{25}$

Tangl and Farkas ${ }^{26}$ have found an increase in fat content of trout-eggs in the course of development which was held to be due to transformation of protein into fat because the undeveloped egg does not contain any important supply of either glycogen or sugar; although the possibility of glycoproteid with its carbohydrate group in combination in protein, should be considered.

It is the same old story: the great conflict over the formation of fat from protein in metabolism has, if the expres-

24 A. Magnus-Levy and L. F. Meyer, 1. c., p. 453.

${ }^{25}$ E. A. Bogdanow (Moscow, 1909), cited from the Russian in Jahresber. f. Tierchem., 39, 585, 1909.

${ }^{26} \mathrm{~F}$. Tangl and Farkas (Budapesth), Pflüger's Arch., 10\%, 624, 1904. 
sion be allowed, stalled in the sand-more exactly stated, has found its own natural solution. It would be difficult to forego the opportunity to add here a moral reflection that, although in the determination of private differences it is not always possible to get along without disturbances of temper, it should always be a rule to deal with differences of scientific opinion with equanimity and without feeling; in confidence that, with the progress of knowledge, that which is right is bound to win recognition entirely of its own strength. The writer might, however, in an objective manner equally add that here, as well as elsewhere, it is much easier and more convenient to give good advice to others than to practice it personally.

Thus far, we have, however, been dealing with but one side of the problem of formation of fat from protein, that which is manifest to us in metabolic experimentation. The question, however, has many other sides for consideration in turn. A historical development of the question from the beginning may be dispensed with, the writer contenting himself with an explanation of its present status.

Fat Phanerosis in Autolysis.-Probably it will be best to consider first the simpler phenomena and then pass on to the more complicated, taking up first the subject of "fatty degeneration" of tissues occurring in extracorporeal autolysis. Here there is at no time a possibility of the fat being introduced by the blood stream and deposited as an infiltration. Since, as has been noted by numerous authors, ${ }^{27}$ in tissue autolysis there are histological pictures reminding one fully of fatty degeneration, two possibilities are here presented: either fat is being formed de novo through fermentative changes or else fat which was previously present, but which was not directly visible and was not demonstrable by the usual methods of staining, is being made appreciable to us by the autolytic process. This last has recently been ex-

${ }^{27} \mathrm{Cf}$. the older Literature upon Fatty Degeneration in Autolysis: G. Rosenfeld, Ergebn. d. Physiol., 2, 89-94, 1903. 
pressed by the very appropriate term "fat phanerosis." A large number of careful investigations, especially those (conducted under direction of $F$. Hofmeister) of F. Kraus ${ }^{2}$ and of F. Siegert, ${ }^{29}$ as well as those of G. Rosenfeld, ${ }^{30}$ and A. Slosse ${ }^{31}$ and a number from the Medical-chemical Institute in Tokio, ${ }^{32}$ have shown that the formation de novo of the higher fatty acids is impossible in autolysis without bacterial contamination. A few statements adverse ${ }^{33}$ to this view, in the author's opinion, prove absolutely nothing, as the technique involved is by no means above objection. It is especially unfair to account, for such purpose, only the bare ethereal extract as fat; the tissues must be completely broken down by an intense saponifying process (as in the methods of Liebermann and of Kumagawa and Suto) ${ }^{34}$ and their higher fatty acids, poorly soluble in water, estimated as fat as well. There is not the least contribution to the solution of the situation in the attitude of Waldvogel, who instead of simplifying the problem by reverting to the isolated higher fatty acids introduced into the question "hepatic protagon" and "jecorin" (more than problematic in its chemical individuality), and tried to make the latter an intermediate product between protein and fat, for which assumption there was not even the shadow of proof.

From the fact that in prevailing opinions, as will be discussed later, we are, in the production of a fatty liver from

${ }^{28}$ F. Kraus (F. Hofmeister's Lab., Prague), Arch. f. exper. Pathol., 22, $174,1897$.

${ }^{20}$ F. Siegert (F. Hofmeister's Lab., Strassburg), Hofmeister's Beiträge, 1, 114, 1902 .

${ }^{20}$ G. Rosenfeld, Ergebn. d. Physiol., 2, 90, 1903.

${ }^{51}$ A. Slosse (Brussels), Arch. internat. de Physiol., 1, 384, cited in Biochem. Centralbl., 3, No. 711, 1904.

${ }^{32}$ Kohshi Ota, Biochem. Zeitschr., 29, 1, 1910; N. Shibata, ibid., 31, 321, 1911.

${ }^{33}$ Kotsowski, Waldvogel, Leathes; cf, the criticism of J. Meinertz (Thierfelder's Lab.), Zeitschr. f. physiol. Chem., 44, 371, 1905.

${ }^{34}$ In reference to the Literature upon the more modern Methods of Fat Analysis: Cf. the articles by Röhmann, Rosenfeld, and by Kumagawa and Suto, in Abderhalden's Handb. d. biochem. Arbeitsmethoden, 5', 477-488, 1911. 
phosphorus poisoning, dealing with an immigration of fat from the blood stream, that is, with a fatty infiltration, one must necessarily be intensely interested in the statement of Mavrakis ${ }^{35}$ that there may be found the well-known histological appearance of fatty degeneration in specimens when an aqueous suspension of yellow phosphorus has been injected into a branch of the portal vein of a liver which has been excluded from the circulation and then left otherwise unmolested. Under the author's direction his student, P. Saxl, ${ }^{36}$ has repeated this experiment. He was able to fully convince himself that under the experimental conditions named tissue changes may be produced which are histologically entirely comparable to the picture of fatty degeneration. Exact analyses, however, indicated that even in this case there is no actual new formation of fat by conversion of the protein of the cellular protoplasm, but that because of the increased tissue autolysis there is a histological manifestation of fat previously present but invisible. Here, too, should be mentioned the experiments of Ernst Weinland, in the course of which he believed he found evidence of an autolytic new formation of higher fatty acids "absolutely in minute but relatively in large amount"' in the expressed juice of the larvæ of certain flies (calliphora); which new formation, following the Voit traditions, he interpreted as a formation of fat from protein. As a matter of fact, however, with general recognition of the care involved in these studies, it seems probable to the author that only the more recent experiments of Weinland ${ }^{37}$ have been conducted with a reliable method of estimating fatty acids, and that his absolute results are quite too small and variable to permit one to recognize them as proving the position (fat disintegra-

${ }^{\approx}$ C. Mavrakis (Athens), Arch. f. Anat. u. Physiol., 1904, 94.

${ }^{35} \mathrm{P}$. Saxl (under direction of O. v. Fürth), Hofmeister's Beitr., 10, 447,1907 ; L. Hess and P. Saxl (v. Noorden's Clinic, Vienna), Virchow's Arch., 202, 148, 1910; cf. also A. Krontowski (Kiev), Zeitschr. f. Biol., 54, 479, 1908.

${ }^{37}$ E. Weinland (Munjch), Zeitschr. f. Biol., 52, 1909; cf. also Biol. Centralbl., 29, 565, 1909. 
tion also takes place in the larval pulp, and there is even said to be a periodicity between increase and loss of fat in the ground-up maggots). We may conclude, then, that there is no proof of the new formation of higher fatty acids from protein in autolysis, that in fact this is highly improbable, and that all of the microscopic observations which apply here may be interpreted very satisfactorily as instances of "fat phanerosis."

Nature of Fat Phanerosis.-Are we actually in position to offer a precise chemical interpretation of the phenomenon of fat phanerosis? In the first place, are we dealing here with a process of a chemical or of a physical nature? In the writer's opinion it partakes of both. It is essential that we conceive of the fat substances in the cells of the tissue for the most part, not as neutral fat, but as made up of a variety of phosphatids. We are, moreover, undoubtedly fully justified in supposing, as Friedrich v. Müller suggested years ago, that changes which involve these phosphatids in the course of autolysis are connected with fat phanerosis. Yet even without such an assumption it is possible to fancy that the cells, as the result of autolytic processes, have lost their ability of maintaining fat in a state of solution, ${ }^{38}$ as perhaps in comnection with cellular swelling, coagulation and acid changes. Then, too, we may think that possibly true chemical combinations between fatty acids and proteid bodies ("lipoproteids") exist, which may undergo cleavage in the autolytic process.

In this aspect it is of interest to recall that amido-combinations between high fatty acids and aminoacids (as those synthetically reconstructed in the first place by Bondi ${ }^{39}$ and again by Abderhalden, ${ }^{40}$ and their co-workers) in contrast to free fatty acids are not soluble in ether, do not take up the

\footnotetext{
${ }^{38}$ Cf. V. Rubow (Copenhagen), Arch. f. exper. Pathol., 52, 174, 1905.

${ }^{3} \mathrm{~S}$. Bondi, in association with T. Frankl and F. Eissler (J. Mauthner's Lab., Vienna), Biochem. Zeitschr., 1\%, 1909, and 23, 1910.

${ }^{40}$ E. Abderhalden and C. Funk, Zeitschr. f. physiol. Chem., 65, 61, 1910.
} 
fat-staining reagents, and are split into their components by the ferment action of autolyzing tissue (but not by trypsin).

Having in some degree come to an appreciation of these points, a further step may be taken and attention given to other examples of the supposed formation of fat from protein.

Formation of Higher Fatty Acids by Microörganisms.We at once encounter here the fact, of importance to appreciation of the general problem, that we must acknowledge without question the power of forming fat from protein as belonging to the lower vegetable organisms (a power which, as far as the animal organism is concerned, if not absolutely contested, can be recognized only conditionally and with much reservation with the preformation of sugar from protein in mind). A long time ago Emmerling concluded that higher fatty acids are produced in culture of staphylococcus pyogenes aureus on egg albumin. The experiments of several American authors (Beebe and Buxton) ${ }^{41}$ seem particularly significant in this connection. They have shown that if bacillus pyocyaneus be cultivated on media free from sugar and from fat, such quantities of fatty substances are formed that they become evident on the culture surface in the form of microscopic needle-shaped crystals.

Hoffmann's Experiment with Fly-maggots.-The ability of microörganisms to construct fat out of protein explains other points; particularly the famous maggot experiment made by Franz Hoffmann in the early seventies. This investigator determined the fat-content of a portion of a number of fly-eggs and then allowed the remainder to develop upon defibrinated blood. It was proved at the close of the experiment that the fat-content of the larva exceeded by tenfold the sum of the egg-fat and of the fat in the blood. Long ago Pflüger's acumen suggested the apparently pertinent interpretation for this experiment, which was later

${ }^{41}$ S. P. Beebe and B. H. Buxton (Cornell Univ., New York), Amer. Jour. of Physiol., 12, 466, 1905. 
repeated with unsatisfactory result by Otto Frank, that the enormous numbers of bacteria present in the cultures were to be suspected of bringing about the trick of building up fatty acids from protein.

Adipocere.-Another puzzling natural phenomenon, which is constantly used as an example of the formation of fat from protein in the animal economy is that of the production of cadaveric wax. ${ }^{42} \mathrm{As}$ is well known adipocere is formed when corpses or parts of corpses are buried in moist places or are kept in contact with water, the muscles and soft parts being replaced by a mass made up of a mixture of free fatty acids along with palmitates and stearates of magnesium, calcium and ammonium. There was formerly a common disposition to regard the process as one of a direct production of fat from protein. We are at present inclined to assume that we are dealing only with the fatty acids which were previously present in the structures; that through the influence of lipases and putrefying bacteria the neutral fats are split into their components, the fatty acids rendered soluble by combining with the ammonia produced by putrefaction, and the soap solution then permeating and percolating through the soft parts; that thereafter by replacement of the ammonia of the soaps by calcium and magnesium salts there results the formation of relatively insoluble precipitates. There are, however, statements to the effect that the total quantity of fatty acids in the formation of adipocere undergoes a definite increase. In view of the gross technical errors involved in the older analyses it is very difficult to properly evaluate this contention. It would appear, however, that even if an actual formation de novo of the higher fatty acids be recognized when adipocere is formed, the agency of bacteria may be looked upon as largely explanatory.

s2 Literature upon Adipocere: G. Rosenfeld, Ergebn. d. Physiol., 1', 659664, 1902; H. G. Wells, Chemical Pathology, lst ed., 342-343, 1907; cf. therein the work of Kratter, Ermann, Zillner, E. Voit, Lehmann, Salkowski; cf. also C. Ipsen (Innsbruck), Ber. der Univ., 1909, cited in Jahresber. f. Tierchem., 1910,891 . 
Formation of Fat in the Ripening of Cheese.-Precisely the same is true in case of the old problem of the formation of fat in the ripening of cheese..$^{43}$ It may be accepted as proved that there actually is an increase in the ethereal extract when cheese is ripened. Yet recently M. Nierenstein ${ }^{44}$ has called attention to the point that this increase need not necessarily be referred to an increase in fat alone, as in the ethereal extract in addition to fat and cholesterol there are also present putrescine, cadaverine, etc. But where actual new formation of higher fatty acids is taking place (and there is scarcely basis for doubting this) there is reason to at least suspect it to be due to the activity of microorganisms.

Accumulation of Fat in the Liver in Phosphorus Poisoning.-Having progressed with reasonable assurance thus far, we may venture with confidence upon a question which in a certain measure is the central point of the whole problem, namely, that of intravital fatty change of the tissues. ${ }^{45}$

"Fatty degeneration of the liver" in phosphorus poisoning has been held up as a classical example of such change for the longest time; for this reason the process should be considered next in turn, the more so because its essential nature seems at present to be satisfactorily understood. While the older pathclogists permitted themselves to be so much impressed by the microscopic picture of the fatty degenerated liver as to have no doubt whatever as to the occurrence here of a transformation of protein into fat, we know to-day that the bulk of the fat in a phosphorus liver has really come as a fatty infiltration into the organ. This has been proved with thoroughly satisfactory exactness.

In the first place, contrary to the older statements to the

${ }^{43}$ Literature upon Fat Formation in the Ripening of Cheese: G. Rosenfeld, Ergebn. d. Physiol., 1', 663-664, 1902.

${ }^{44}$ M. Nierenstein (Bristol), Proc. Roy. Soc., Series B, 83, 301, 1911, cited in Centralbl. f. d. ges. Biol., 1911, No. 2087.

${ }^{45}$ Literature upon Vital Fatty Degeneration of Tissues: G. Rosenfeld, Ergebn. d. Physiol., 2, 64-86, 1903; R. Tigerstedt, Nagel's Handb. d. Physiol., $1,510-511,1905$. 
opposite, ${ }^{46}$ complete proof has been furnished by a series of studies ${ }^{47}$ showing that the total amount of fat in animals poisoned by phosphorus does not undergo any increase; there is merely a change in the fat distribution, in consequence of which there is more fat accumulated in a number of tissues, above all in the liver.

Besides, this has been very strikingly confirmed by the recognition that the fat of the phosphorus liver corresponds in its composition with depot-fat, and that if the fat storagesites be filled with fat of a type foreign to the body and phosphorus poisoning is then induced, this foreign form of fat will accumulate in the liver. This was shown first by Lebedeff, employing linseed oil, then by G. Rosenfeld, who used mutton-fat and cocoa-butter. Similar experiments carried out with iodized fat by Gideon Wells ${ }^{48}$ gave an uncertain result; while the same experiment by Schwalbe ${ }^{49}$ resulted positively.

Finally G. Rosenfeld, undertook another crucial experiment, and showed that the fatty change does not occur in phosphorus poisoning if animals which are very poor in fat be used. The outcome of this experiment proves how fatty change comes to involve the liver in phosphorus poisoning: were we to assume that it is due to a breaking down of protein into fat, then necessarily phosphorus should invariably produce a fatty liver, because the assumed mother substance of the fat, protein, is always present. If the change, however, is the result of a passage of the depot-fat into the liver, the condition must fail to appear if no depot-fat is available for immigration. ${ }^{50}$ Actually, too, under these circumstances, it does not appear.

${ }^{46}$ Leo, Polimanti.

${ }^{47}$ Athanasiu (E. Pflüger's Lab.), Taylor, 1899; F. Kraus and Sommer, 1902; J. Barro, Jahresber. f. Tierchem., 31, 75, 1902; Boruttau, Arch. de Fisiol., 2, 26, 1904; Shibatu Negamachi, Biochem. Zeitschr., 37, 345.

${ }^{45}$ H. G. Wells (Chicago), Zeitschr. f. physiol. Chem., 45, 412, 1905.

4 Schwalbe (Heidelberg), Verh. d. deutsch. pathol. Gesellsch., Kassel, 1903, 71 .

${ }^{\circ 0}$ G. Rosenfeld, Ergebn. d. Physiol., 2', 68, 1903. 
Fatty Infiltration in Other Pathological Conditions.Whatever is true of the origin of the fatty liver in phosphorus poisoning seems, from all we know thereof, to be also applicable in case of the fatty livers which follow poisoning from arsenic, antimony, chloroform, alcohol and many other poisons. There are many other pathological conditions in which at times a typical fatty liver is met, as for example, starvation, phloridzin diabetes and pancreatic diabetes ${ }^{51}$ and overheating. (It was customary for a long time in France in producing fatty livers in geese to confine them in small, warm coops.) We have no substantial reason for doubting that in such instances, as well as in the so-called "liver of pregnancy," of typical fatty infiltration.

Rosenfeld's Theory.-Are we able to offer any explanation for the fact that the same process, fatty infiltration of the liver, is common to pathological conditions of the most diverse type? G. Rosenfeld, basing his views upon the fact that in the different fatty livers due to intoxications the organ is generally devoid of glycogen and that, for example, in phloridzin intoxication the production of a fatty liver may be inhibited by free administration of sugar, meat ${ }^{53}$ and other substances which go to form glycogen, has formulated the following line of thought: "If cells are brought under the influence of any sort of noxious agent . . . they increase their resistive power by oxidation of every bit of carbohydrate of which they may be possessed (for which reason the liver of the animal with phosphorus poisoning is free of glycogen). . . . If there is no reserve material or an amount insufficient to protect the cellular protein, the cells take recourse to their last adjuvant; they attempt to restore their supplies for production of resistive power by

${ }^{51}$ H. Lattes, Arch. Scienze med. Torino, 38, cited in Jahresber. f. Tierchem., 40, 816, 1910 .

${ }_{52}$ J. Hofbauer (Königsberg), Arch. f. Gynäkol, 93, 405, 1909.

${ }^{5}$ G. Rosenfeld (Breslau), Berliner klin. Wochenschr., 4\%, 1268, 1910. 
taking up an increased amount of fat. Res redit ad triarios: the last reserves enter the fray if the legionaries are destroyed. If the cell then succeeds in mastering the poison, the victory is through the aid of a fatty regeneration; if even this be of no service, the cell dies the death of a hero; in spite of the fatty infiltration degeneration ensues." "54

Association of Fat Phanerosis in the Phenomena of Fatty Degeneration.-Probably, however, it is not correct to end the matter by attributing solely to fatty infiltration all of the appearances which the older pathologists recogunder the name "fatty degeneration." To the author's mind it is entirely logical to assume as well a superimposition of the process of fat phanerosis. We have had under discussion the fact that when phosphorus is injected into the portal vein the picture of a fatty degeneration may be produced even in a liver removed from the body. Besides in case of the isolated, artificially perfused hearts of warm-blooded animals it has been shown that the same noxious factors (as incomplete nutrition and poisons) which cause fatty degeneration in the living body, give rise to "fatty change" also of the isolated heart, in which there can be no suspicion of the entrance of fat from any of the fat depots. ${ }^{55}$ Di Christina, for example, ascribed to phosporus two entirely distinct influences, one a necrosing, the other a steatogenous action (the latter in the sense of a mobilization of fat in the depots). ${ }^{56}$ We have, too, every reason for assuming that an intoxication, such as phosphorus poisoning, does not leave the protein material of the liver undisturbed; according to a study made in Kossel's laboratory ${ }^{57}$ catabolism of the protein molecule is likely to result in a spliting off of compounds rich in bases with a residue of material poor in bases and nitrogen. That such a process of disintegration cannot be

${ }^{54}$ G. Rosenfeld, l. c., p. 84.

${ }^{66}$ A. Cesaris-Demel (Pisa), Arch. ital. de Biol., 51, 197, 1908.

${ }^{50}$ Di Christina, Virchow's Arch., 181, 509, 1905.

${ }^{\text {" }}$ A. J. Wakeman (A. Kossel's Lab., Heidelberg), Zeitschr. f. physiol. Chem., 44, 335, 1905. 
thought of as unattended by serious change of the physical and chemical characters of the hepatic proteins, goes without saying. The view indicated by Mansfield therefore is decidedly plausible, this writer from his observations upon fat combination ( $v$. supra, p. 370) believing it quite characteristic of phosphorus poisoning that there should exist a loss in the power of the hæmic and tissue proteins to fix fat. ${ }^{58}$ The author would readily believe that the assumption of such a change in the ability to fix fat would make it possible to regard the features of fat phanerosis and those of fat migration from a common point of view. The fundamental cause which destroys the union between the fats and the cells of the fat depots, and brings about mobilization of the latter as well as fatty infiltration of the liver, may very well be the same as that which breaks up the bond between the tissuefat and the tissue-cells, and which in this way induces fat phanerosis (that is, brings into view fat which was previously invisible). In this sense we may, therefore, perhaps look upon fatty infiltration and fat phanerosis as different phases of one and the same process.

"Fatty degeneration" is by no means necessarily confined to the liver, but may involve other structures as well, as the cardiac and skeletal musculature, the kidneys, the lungs and the epithelium of the intestinal tract. ${ }^{59}$

Fatty Change of the Kidney.--A few remarks at this point in reference to fatty change of the kidneys may not be inappropriate.

Rosenfeld and several other investigators had concluded that the histological observations of a fatty change of a kidney could not be regarded as having any real reference to the actual amount of fat in the organ; that, although a kidney may appear to be "fatty degenerated," actually its fat

${ }^{58}$ G. Mansfeld (in collaboration with E. Hamburger and F. Verzár, Pharmacolog. Instit., Budapesth), Pflüger's Arch., 129, 46, 1909.

". . and S. Bondi (v. Noorden's Clinic and R. Paltauf's Lab., Vienna), Zeitschr. f. exper. Pathol., 6, 254, 1909. 
content may be decidedly less than normally. ${ }^{60}$ In opposition to this idea K. Landsteiner and V. Mucha ${ }^{61}$ have applied themselves with great confidence. As a matter of fact if the whole kidney is not analyzed but the cortex only be used (thus excluding the fat situated about the renal pelvis, which has nothing whatever to do with pathological processes), the microscopic determination and chemical analysis apparently agree fairly well. Precise analyses conducted in E. Ludwig's laboratory indicate that while the cortical substance of the kidney may normally contain at most as much as eleven per cent. of fat, this proportion may be much increased in phosphorus poisoning. According to Landsteiner it is possible to distinguish two types of renal fatty change, the one a true fatty infiltration (as in the diabetic kidney), and another form in which the fat deposit is associated with distinct cellular destruction. This brings into prominence again the old distinction between fatty infiltration and fatty degeneration. With G. Klemperer ${ }^{62}$ one may believe that in the latter process fat phanerosis may also be granted a part. However, sufficient has probably been said to indicate that there is no room left in modern thought for the old acceptation of fatty degeneration, that is, that it involves a direct conversion of cellular protein into fat.

The ability of the kidney to construct fat from its components, it may be remarked in passing, has been proved by Fischler in the Heidelberg Pathological Institute. He perfused a living kidney with blood to which soap and glycerine were added, with the production of typical pictures of fatty change of the renal epithelium. ${ }^{63}$

${ }^{60}$ G. Rosenfeld, 1. c., pp. 78-81; A. Orgler (Salkowski's Lab.), ibid., 176, 413, 1904; E. Kuznitsky (Ribbert's Lab.); Baum and Rosenfeld (Breslau), Berliner klin. Wochenschr., 1909, 629.

${ }^{62} \mathrm{~K}$. Landsteiner and V. Mucha (Lab. of Weichselbaum and E. Ludwig, Vienna), Centralbl. f. allgem. Pathol. u. pathol. Anat., 15, 18, 1904.

${ }^{62}$ G. Klemperer (Moabite Hosp., Berlin), Deutsche med. Wochenschr., 1909, 89; cf. also Löhlein (Pathol. Instit., Leipzig), Virchow's Arch., 180, 1, 1909.

${ }^{\bullet 3}$ F. Fischler (Arnold's Lab., Heidelberg), Virchow's Arch., 174, 338, 1903. 
Cholesterol-ester Steatosis.-The problem of the process of fatty change would be incompletely dealt with were the author not to mention an entirely new phase, that of cholesterol-ester steatosis.

As previously stated (v. Vol. I of this series, p. 324, Chemistry of the Tissues) the esters of cholesterol with the higher fatty acids are of interest both from a physiological and a pathological point of view. These esters have been demonstrated in wool fat, in epidermal scales by Salkowski, ${ }^{64}$ in the cutaneous fat by Unna, ${ }^{65}$ and in the blood serum by Hürthle. ${ }^{66}$ It has been shown in Röhmann's laboratory ${ }^{67}$ that in the acetic-ether extract of the liver, along with free cholesterol, a certain amount of cholesterol esters is present, and that the liver also contains an enzyme capable of splitting these esters. What is of especial interest to us, however, is the fact that a crystalline, doubly refractive substance found in fatty kidneys has been determined by Panzer, ${ }^{6 s}$ in Ernst Ludwig's laboratory, as an ester of cholesterol with an unsaturated higher fatty acid. This discovery has been fully confirmed by Windaus ${ }^{69}$ by his digitonin method of determining cholesterol; and we are justified in assuming that the cholesterol esters actually take an important part in the formation of doubly refractive substances in fatty tissues. The pathologist Aschoff has in fact seen fit to regard cholesterol-ester fatty change as being a form of fat metabolism of at least equal importance and of equivalent origin to glycerol-ester fatty change; and he intrusted his pupil,

* E. Salkowski, Arb. a. d. Pathol. Instit., Berlin, A. Hirschwald, 1906; Biochem. Zeitschr., 2\$, 362, 1910.

${ }^{c 5}$ Unna and Golodetz, Biochem. Zeitschr., 20, 469, 1909.

${ }^{66}$ Hürthle, Zeitschr. f. physiol. Chem., 21, 331, 1895.

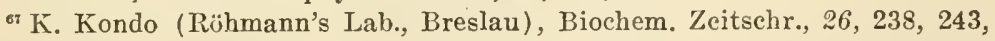
$252,427,437,1910$.

${ }^{63}$ T. Panzer (E. Ludwig's Lab., Vienna), Zeitschr. f. physiol. Cliem., 48, 519,$1906 ; 54,239,1907$.

${ }^{\circ}$ A. Windaus (Freiburg), Zeitschr. f. physiol. Chem., 65, 110, 1910; cf. also J. Pringsheim, Biochem. Zeitschr., 15, 52, 1907. 
Kawamura, ${ }^{70}$ with the task of determining by means of a great number of morphological methods (determination of their behavior with neutral red, nile-blue, and a number of other staining reagents, their refraction in glycerol, etc.) whether the cholesterol-ester's can be definitely distinguished from the glycerolesters and the other lipoids. The author contrasts (unnecessarily introducing new terms for previously known conditions) steatosis (fatty infiltration) with myelinosis (fat phanerosis), and divides the former into glycerol-steatosis, cholesterol-steatosis and lipoid steatosis. It is very clear that only thorough chemical studies in close coördination with morphological observations could possibly determine the value of such classifications. It is, however, quite a matter for congratulation that morphologists are also largely being brought to recognize that differentiation by staining methods is really nothing more than a very special form of chemical or physical-chemical reaction, and that it is really desirable that they supplement this by other and better defined chemical methods. The tremendous enlargement of the sum total of scientific knowledge is constantly leading to the rise of new specializations and changes of limitations. Unfortunately in view of the limited receptive power of the human brain this cannot be avoided. Yet the chemist, idling between his tubes and his jars, and ignoring designedly and stubbornly everything which he cannot boil, extract and distill, fits just as sadly in the field of modern science as does the morphologist, to whom nothing else seems worth bothering about, and who regards nothing as important as his stained sections. Freer vision will come only to the appointed, to him for whom the thickets of the lowland are too confined and who strives upward to the heights.

${ }^{70}$ R. Kawamura, Die Cholesterinesterverfettung (Pathol. Instit., Freiburg, i. B.), Jena, G. Fischer, 1911; cf. also F. M. Hanes (Columbia Univ., New York), Johns Hopkins Hosp. Bull., 23, 77, 1912. 
ORIGIN OF MILK FAT

As the final subject of this section of our study of fat metabolism, the origin of the fat in milk may be presented for consideration. ${ }^{71}$ In bringing this subject forward in direct connection with the chapter upon the processes of fatty change, a historical rather than a logical relation is being followed.

The older pathologists looked upon the origin of the milk fat as an example of supposed conversion of protein into fat. Virchow was fully convinced that both the fat globules and the other constituents of milk arise from a fatty degeneration and disintegration of the cells of the mammary gland. Then, later, Haidenhain modified this view by supposing that only that part of the gland cell next to the lumen sets free the fat droplets as it undergoes disintegration. C. Voit, in connection with his above mentioned doctrines, advocated the idea that protein breaks down in nursing animals in such manner that its nitrogen is excreted as urea and the residue, rich in carbon, is secreted as fat with the milk. That the doctrine of the protein origin of the milk fat was firmly impressed by the weight of the great and overpowering authority of these men upon the minds of physiologists is, of course, not in the least remarkable; and it has required a great deal of labor to evict it. Among others, the noted Heidelberg pathologist, J. Arnold (to whom I refer as one of my teachers with special appreciation), not long ago undertook to reinvestigate the subject by a thorough histological study of the mammary glands of women and female animals. He came to the conclusion that, contrary to the assumption of Virchow, even the freest secretion of milk may take place without any degeneration of the cells of the mammary glands. The fat appears in the interior of the cells, especially in the basal portion of the cytoplasm, that away from the lumen of the gland, and

${ }^{71}$ Literature upon Milk Fat: K. Basch, Ergebn. d. Physiol., 2', 366-373, 1903; R. W. Raudnitz, ibid., 259-264. 1903; A. Magnus-Levy and L. F. Meyer, Hand. d. Biochem., ' $\ell^{\prime}$, 468, 1909; L. Kalabaukoff, Biologie médicale, Jan., 1909. 
no fat is to be seen in the neighborhood of the secretory cells. Arnold concludes from what he saw and with the prevailing status of metabolism in mind, that the component parts of the fat are brought to the lactating cells from without in a water-soluble form, and that the fat is newly constructed from such material within the cellular protoplasm by functionating vital processes.

What then do we really know of the origin of the fat in milk? In the author's opinion it is necessary to recognize a three-fold origin. It arises in part from the fats of the food, in part from those of the fat depots of the body, and in part, finally, from the carbohydrates which are undergoing transformation in the economy into fat.

Passage of the Fat of the Food into the Milk.-As far as concerns the subject of passage of the fat of the food into the milk, a large number of investigations ${ }^{72}$ should be noted, in which studies were made with all sorts of extraneous fats (as cottonseed oil, sun-flower oil, peanut oil, cocoa butter, lindseed oil, oil of sesame, almond oil, palm oil, goose fat, mutton suet, iodized and brominized fats) and which have removed all doubt from the subject. The question is of interest not only from a general scientific viewpoint, but has, too, a very decided bearing upon medical practice. The general composition of the milk-fat of a nurse, as pointed out by Engel ${ }^{3}$ from systematic studies in the Dresden Infants' Home, depends upon the character of the fats of the food ingested. The importance of the details of diet for maintenance of health of the normal human being has unquestionably been very greatly exaggerated by the laity generally; and it is of more immediate importance to

¿2 Willy, 1889; Stellwag, 1890; Heinrich, 1891; Klien, 1892; Lehmann, 1896; Winternitz, 1897; Rosenfeld, 1895; Baumert and Falke, 1898; Henriques and Hansen, 1899; Caspari, 1899; Engel, 1906; Gogitidse, Zeitschr. f. Biol., 45, 353, 1904; $16,403,1905$; $4 \tilde{\gamma}, 475,1906$; W. Caspari and H. Winternitz, Zeitschr. f. Biol., 49, 558, 1907 ; cf. Literature in K. Basch, 1. c., and A. Magnus-Lery and L. F. Meyer, 1. c., p. 468.

${ }^{73}$ Engel (S'chlossmann's Clinic), Arch. f. Kinderheilk., 43, 194, 1906; Zeitschr. f. physiol. Chem., 4', 352, 1905. 
the healthy adult individual that he should really have something to eat (a postulate which unfortunately in this best of all worlds is apparently very incompletely satisfied) than that the food, provided in a general way it is palatable, should have any particular fixed composition. How often has the author been amazed at the patience shown by his colleagues in active medical practice toward the very silly questions about diet with which old ladies of both sexes are in the habit of plying them in their anxiety for their relatives or from pure love of asking questions. But it is a very different matter when we are dealing with the feeding of infants. Here there is room for the most painstaking care and attention from a practical standpoint. And it is particularly important that the physician keep constantly before him the fact that the infant's supply of fat is directly dependent upon the food which is ingested by the nurse and upon the character of her fat deposits. This is no "nursery tale"; it is a scientifically proved fact. Thus, often the trouble met in changing wet nurses may in the last count be connected with the biochemistry of fat; and there is justice in the demand that in the first place the milk of nursing women be kept constant by selection of an appropriate fatmixture, and again that by proper feeding of cows a milk be produced with fat similar to the fat of human milk. ${ }^{74}$ In spite of the enormous extent of milk literature, the details of which cannot possibly be entered into here, a great deal of work remains to be done before we can clearly appreciate how far race, heredity, mode of nutrition, sexual activity, season, calory-requirements of the growing body, etc., affect the composition of milk..$^{75}$

Origin of Milk Fat from the Carbohydrates of Food.A portion of the fat in milk doubtless comes from the carbohydrates of food. Thus an experiment upon a cow fed for three months on material poor in fat (hay and grain-food

${ }^{74}$ Engel and Plaut, Wiener klin. Wochenschr., 1906, No. 898.

${ }^{75}$ Cf. G. von Wendt, Skandin. Arch. f. Physiol., 21, 89, 1909. 
from which the oil had been removed) showed that in this period the animal produced in her milk about fifty pounds more fat than she consumed with her food. And yet the cow had become much fatter; the actual amount of newly formed fat must, therefore, have been much more than this. The extent of protein decomposition, determined by the nitrogen output, was at the same time far from being sufficient to explain in any degree the new formation of fat. The bulk of the latter was certainly derived, therefore, from the carbohydrates of the food. ${ }^{76}$

Lower Fatty Acids in Milk.-Besides the typical higher fatty acids (palmitic, stearic and oleic acid) there are also small quantities of the lower fatty acids in milk, the presence of which is the more interesting because it offers a very important and, as far as the author knows, hitherto little considered suggestion as to the nature and the method actually followed by physiological catabolism of the higher fatty acids in the economy. It is certainly not a matter of accident that only normal fatty acids with unbranched chains and an even number of carbon atoms are to be found along with the higher fatty acids in milk, namely, myristic acid, $\mathrm{C}_{14}$; lauric acid, $\mathrm{C}_{12}$; capric acid, $\mathrm{C}_{10}$; caprylic acid, $\mathrm{C}_{8}$; caproic acid, $\mathrm{C}_{6}$, and butyric acid, $\mathrm{C}_{4} \cdot{ }^{77}$ Elsewhere, too, we find precisely these same normal fatty acids with paired carbon atoms (considering here the acids with more than three carbon atoms) emerging in all sorts of places from the sea of metabolism. Thatwe once in a whilemeet with isobutyric acid, $\stackrel{\mathrm{CH}_{2}}{\mathrm{CH}_{3}}>\mathrm{CH}-\mathrm{COOH}$, and isovalerianic acid, ${ }_{\mathrm{CH}_{2}}^{\mathrm{CH}_{3}}>\mathrm{CH}-\mathrm{CH}_{2}-\mathrm{COOH}$, is not of any special moment, because these may be regarded

${ }^{76}$ W. Jordan and C. G. Jenter, New York Agric. Exp. Station Bulletin, 1897.

${ }^{77}$ The only secming exception to this rule known to the author, a statement of Chevreul as to the occurrence of isobutylacetic acid, $\mathrm{CH}_{3}>\mathrm{CH}-\mathrm{CH}_{2}-$ $\mathrm{CH}_{2}-\mathrm{COOH}$, and of isovalerianic acid in cow's butter, may not be held as of very great importance when we remember the great age of the observation, almost a century. Cf. W. R. Raudnitz, l. c., p. 260. 
as protein derivatives (from the branched chain of leucin, $\left.\mathrm{CH}^{3}>\mathrm{CH}-\mathrm{CH}_{2}-\mathrm{CH} . \mathrm{NH}_{2}-\mathrm{COOH}\right){ }^{.8}$ In the author's opinion the occurrence of the normal acids, $\mathrm{C}_{4}, \mathrm{C}_{6}, \mathrm{C}_{8}, \mathrm{C}_{10}, \mathrm{C}_{12}, \mathrm{C}_{14}$, in the milk is very suggestive of the possibility that they may be due to an oxidation reduction from the typical higher fatty acids, the long chain of the latter being gradually shortened, each time by two carbon atoms by oxidation at the $\beta$-position, following Knoop's idea (vide supra, p. 392):

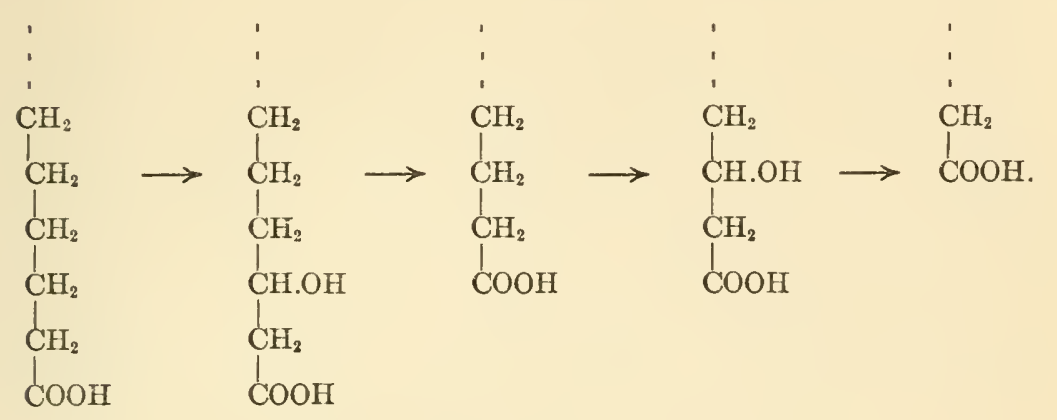

Sebaceous Glands and Coccygeal Gland.-In attempting to understand the function of the mammary glands the idea that they are really modified sebaceous glands is not without significance. A number of the lower mammals (as the monotremes) have instead of the mammary glands a large number of small dermal glands and the offspring lick the surface of the abdomen instead of sucking. It is interesting, too, to know that in the material secreted by ordinary sebaceous glands casein has been recognized.

The coccygeal gland of water fowl corresponds, too, in its development, structure and function, to a modified sebaceous gland. Its fatty secretion, however, according to Röhmann, is not ordinary neutral fat, but consists for the most part of esters, combinations of fatty acids with octadecylalcohol (derived by oxidation from oleic acid and stearic acid). Fats

${ }^{r 8}$ Literature upon The Occurrence of Fatty Acids in the Body: W. Glikin, Handb. d. Biochem., 1, 95-102, 1909. 
foreign to the birds' economy may, just as in milk, pass into the secretion of the coccygeal gland. ${ }^{79}$

Haptogenic Membranes.-In conclusion a few words may be devoted to the old question as to the form in which the fat exists in milk and the nature of the much discussed haptogenic membranes which surround the fat globules. The contention on this subject took its inception in the observations of Ascherson in 1840; and it is not settled today. The physicist Quincke took the position that the covering of the fat globules consisted merely of a layer of protein condensed about the globules by surface tension; V. Storch and a number of other observers (as, recently, W. Völtz ${ }^{80}$ and $H$. Bauer ${ }^{81}$ ) held that the haptogenic membrane is of a gelatinous, relatively firm character, often compared to the stroma of red blood cells. Völtz refers with emphasis to the fact that if milk globules passed through a column of water are skimmed off from the surface of the water and centrifugated, invariably in a short time the coverings of the milk globules are largely precipitated and collect as a firm (not a gelatinous) substance at the bottom. When the fat is removed by use of a Soxhlet apparatus the haptogenic membranes remain behind. Under the microscope the isolated coverings show very irregular appearances. Analysis and hydrolysis (a few decigrams may be obtained from a liter of milk) show that they contain a very large proportion of ash along with protein, and consist not only of casein but also of calcium salts of the fatty acids. ${ }^{2}$ All this does not in the author's opinion prove that they are organized, preformed structures in the milk. It may easily be fancied that a layer

i̊ F. Röhmann (Breslau), Hofmeister's Beitr., 5, 110, 1904.

${ }^{\text {so }}$ W. Völtz (Zoötech. Instit., Agric. High School, Berlin), Pflüger's Arch., 102, 373, 1904; Handb. d. Biochem., 3', 394, 1910.

${ }^{81}$ H. Bauer (Instit. of Dairying, Agric. High School, Vienna), Biochem. Zeitschr., 32, 362, 1911.

${ }^{82}$ E. Abderhalden, and W. Völtz, Zeitschr. f. physiol. Chem., 59, 13, 1909; Bredenberg (N. Zuntz's Lab.), Abhandl. d. Agrikulturwissenschaftl. Ges. in Finnland, H. 4, Helsingfors, 1912, cited in Centralbl. f. d. ges. Biol., 1912, No. 2011. 
of protein, condensed about a fat globule by surface tension, may become still more condensed by these very processes of separation (passing through a layer of water, centrifugation), rendering it a firm and separable structure. That coagulative phenomena may take place in the adsorbed surface layer of a colloidal solution has been repeatedly emphasized, and by Kreidl and Lenk for milk especially. ${ }^{83}$

These latter writers have, too, proposed a very simple experiment, which in the author's opinion distinctly contradicts the idea of an organized nature for the haptogenic membranes. It is well known that the theory of the haptogenic membrane is based on the fact that fat is not separable from cow's milk by merely shaking with ether, but can be accomplished only after first treating the milk with potassium hydrate solution. This has been interpreted as indicating that the potash solution dissolves the "membrane" which encloses the fat globule and protects it from the penetration of the ether. Kreidl and Lenk, ${ }^{8+}$ however, have found that when a drop of milk is placed on Lösch carton it divides into three concentric zones as the result of capillary adsorption; in the central zone the suspended fat remains behind, in the middle zone the imperfectly dissolved casein, while the water and fully dissolved materials (as sugar) pass furthest and are to be found in the outer ring. If the milk be rich in fat there remains in the centre a large proportion of a butterlike material, which is readily soluble in ether (particularly apropos to the matter in hand). To the writer's mind this seems altogether at variance with the assumption of an organized nature of "milk-stromata" or "haptogenic membranes." It would be impossible to think that they are stripped away from the individual fat globules in the course of distribution of the milk in the Lösch paper. The facts probably are that the insolubility of the milk fat in ether is connected with the presence of ultra microscopic particles of

${ }^{83}$ A. Kreidl and E. Lenk (Vienna), Pflüger's Arch., 141, 558, 1911.

${ }^{8 \pm}$ L. c., pp. $543-549$. 
casein in the milk. According to R. Liesegang the addition of the ether, by precipitating the casein emulsion, produces the formation of the membrane as an artefact. When potash solution is added the ether does not meet an emulsion of casein, but a solution of casein, and therefore cannot induce membrane formation. It has been long known that the fat of human milk, in contrast to that of cow's milk, is directly soluble in ether; this, according to Kreidl and Lenk, ${ }^{85}$ depends on the fact that casein is not present in human milk in the form of ultramicroscopically demonstrable particles, but in solution.

${ }^{85}$ A. Kreidl and E. Lenk (Verhandl. d. morpholog-physiol. Ges., Wien), Centralbl. f. Physiol., 25, No. 12, 1911. 


\section{CHAPTER XVIII}

\section{ACETONE BODIES}

THAT the acetone bodies are introduced here in immediate connection with our studies of fat metabolism is because of the fact that these mysterious substances, which appear in an apparently unregulated way, now here, now there, upon the surface of the tide of metabolism, and which at one or other time were referred now to one, now to another of the principal types of foods, must, in consonance with the present status of science, be regarded, at least principally, as catabolic products of fat.

In the group of acetone bodies we recognize, as is well known, $\beta$-oxybutyric acid, acetoacetic acid and acetone, the relative chemical connection of which seems to be that indicated in the following schema:

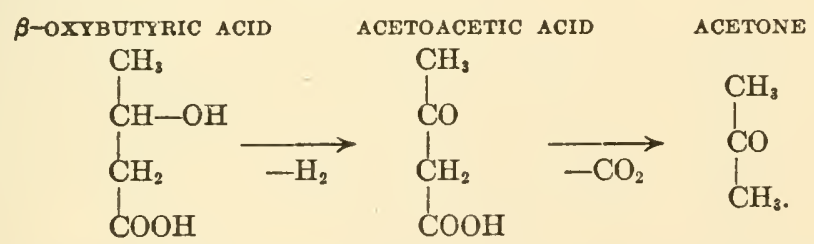

These accumulate in the body in eertain pathological conditions, notably in diabetic coma.

Without entering into the historical development of the subject of the acetone bodies, the author may with propriety in introduction briefly outline the basis for assuming that there is a connection between them and the breaking down of the higher fatty acids in the body. ${ }^{1}$

Relation of the Formation of Acetone Bodies to the Corporeal $F$ at and to that of the Food.-It may be stated first

${ }^{1}$ Literature upon the Relation of the Acetone Bodies to Fat Destruction in the Economy: A. Magnus-Levy, Noorden's Handb. d. Pathol. d. Stoffw., 2d ed., 1, 184-188, 1906; A. Magnus-Levy and L. F. Meyer, Handb. d. Biochem., 4, 483-484, 1909; O. Porges, Ergebn. d. Physiol., 10, 8-11, 1910; C. Oppenheimer and L. Pincussohn, Handb. d. Biochem., 4, 697-702, 1911. 
that no parallelism has been recognized between the excretion of acetone bodies and the reduction of the body protein (reckoned from the nitrogen output), but that such parallelism has been noted in case of reduction of the body-fat in starvation, diabetes, cancer, phosphorus poisoning, and other pathological conditions. Thus Brugsch observed abundant excretion of acetone bodies in case of a professional faster who in spite of the low nutrition to be expected in his calling, had a magnificent fatty panniculus; whereas in a woman in extreme emaciation, who had not the slightest visible trace of body fat left, no evidence of " acidosis" could be noted. ${ }^{2}$ The striking inhibitory influence manifested upon the excretion of acetone bodies by exhibition of carbohydrates is naturally explained by the consequent diminution of the destruction of the body fat. Magnus-Levy noted in a case of diabetic coma the excretion of such large amounts of acetone bodies (more than one-third of a kilogram estimated as oxybutyric acid, in the course of three days) that even if the total carbon of the coincident protein destruction were converted into oxybutyric acid (which naturally was not the case) it would not have been equivalent. This observation alone would permit scarcely any other interpretation than that the acetone bodies originate from the fat. ${ }^{3}$

Another and for us an important fact is that frequently the pathological excretion of acetone bodies is associated with a high grade of lipæmia, in evidence of mobilization of the fat from the depots. It was pointed out above that the blood may be so rich in fat in diabetic coma as to look like chocolate and cream.

Origin of the Acetone Bodies from the Lower Fatty Acids with Even Carbon Atom Chain.-There are a number of observations of an increased excretion of acetone bodies

${ }^{2}$ Brugsch, Zeitschr. f. exper. Pathol., 1, 426, 1905.

\& A. Magnus-Levy, l. c., p. 184. 
after ingestion of dietary fat. ${ }^{4}$ That this sequence does not evince itself in a more striking manner is, in the author's opinion, due to the fact that we are not always able to insure an increased utilization of fat by increasing the ingestion of fat, as the excess is generally simply deposited. Twice in the course of these lectures (Chapter XVI, p. 392 and Chapter XVII, p. 427) occasion has been taken to refer to the important discoveries of F. Knoop and G. Embden which indicate (with great probability, in the author's opinion) that the catabolism of the normal fatty acids proceeds with a two-by-two loss of carbon atoms from the carboxyl end. It has been pointed out above that there are no essential difficulties in the belief that, beginning with the higher fatty acids, by a continuous shortening of the carbon chain we finally obtain butyric acid, from which we get oxybutyric acid, and from this then diacetic acid and acetone.

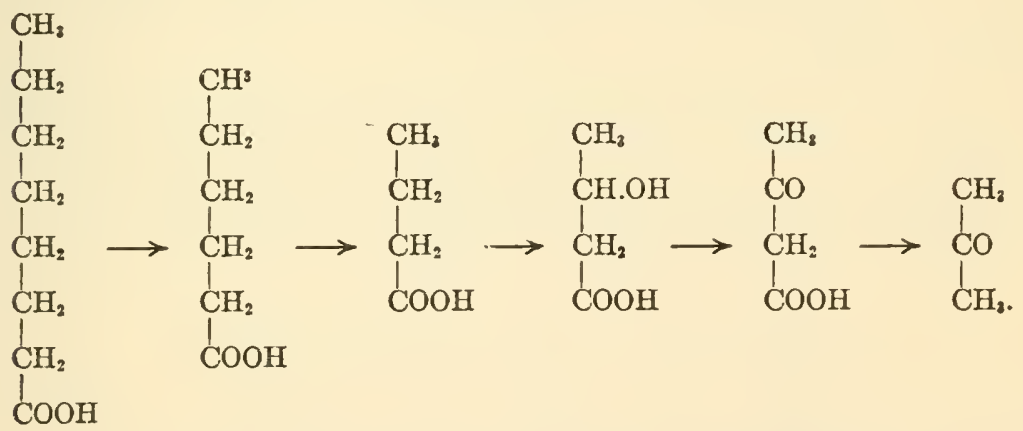

It is very well worth noting and is established by many observations on diabetic human beings and animals ${ }^{5}$ that administration of butyric acid $\left(\mathrm{C}_{4}\right)$ and caproic acid $\left(\mathrm{C}_{6}\right)$

"Geelmuyden; L. Schwarz; E. P. Joslin (Harvard Univ., Boston), Jour. of Med. Research, 12, 433, cited in Biochem. Centralbl., 3, No. 828, 1904; E. Allard (Minkowski's Clinic, Greifswald), Arch. f. exper. Pathol., 5\%, 1, 1907; F. Steinitz, Centralbl. f. innere Med., 25, 81, 1904; Forssner (Stockholm), Skandin. Arch., 23, 305, 1910; sf. therein the older Literature.

${ }^{5}$ Geelmuyden, Rumpf, L. Schwarz, Löb, Strauss and Philippsohn; cf. Magnus-Levy, l. c., p. 185; L. Schwarz (Prague), Deutsch. Arch. f. klin. Med., テ6, 233, 1903; J. Bär and L. Blum (Strassburg), Arch. f. exper. Pathol., 55, 89, 1906 ; $59,321,1908 ; 62,129,1910$. 
appreciably increase the elimination of acetone bodies, and, too, in greater proportion than the exhibition of the higher fatty acids. A. Löwy and R. Ehrmann saw a deep and persistent coma occur in butyric acid poisoning, while in poisoning with isobutyric acid, $\begin{aligned} & \mathrm{CH}_{3} \\ & \mathrm{CH}_{3}\end{aligned}>\mathrm{CH}-\mathrm{COOH}$ (the branched chain of which is unable to pass over into $\beta$-oxybutyric acid), nothing in the least comparable was noted. ${ }^{6}$

C. von Noorden recommends that the butter intended for diabetics be thoroughly worked with water in order to remove the butyric acid.

In close consonance with the above conception of fatty acid catabolism is the fact that only the normal fatty acids with an even number of carbon atoms are productive of acetone bodies, as Embden found experimentally by perfusion of the liver, and Bär and Blum found in diabetics (vide supra, p. 393).

As $\alpha$-aminoacids in catabolism are first deprived of one member it can be easily understood why $\alpha$-aminovalerianic acid (but not $\alpha$-aminobutyric acid or normal $\alpha$-aminocaproic acid) may be classed with the acetone producers : ${ }^{7}$

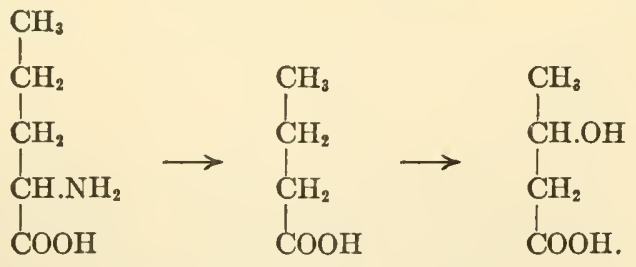

Possibility of Disintegration of the Longer Fatty Acid Chains into Short Parts. - The above presented mode of formation of oxybutyric acid from higher fatty acids indicates one possibility of this connection, but not the only one

B A. Löwy, Berliner physicl. Ges., Dec. 16, 1910; A. Löwy, together with R. Ehrmann and P. Esser, Zeitschr. f. klin. Med., 广2, 496, 500, 502, 1911.

${ }^{7}$ G. Embden and A. Marx, Hofmeister's Beitr., 11, 318, 1908; J. Bär and L. Blum, l. c. 
by any means. It is stated that in severe diabetes sometimes there are excreted a greater number of molecules of oxybutyric acid than can be accounted for by the number of molecules of fatty acids which are in course of decomposition. As a matter of fact it is very difficult, if at all possible, to estimate correctly the number of the latter in our calculations in metabolic experiments. However, were this the case it would strongly indicate that the long fatty acid chains are not reduced step by step until they come to the four carbon atom stage and are changed into butyric acid; we would have to assume that the chain is first broken into a number of segments, each of which is transformed into butyric acid. ${ }^{8}$ Ernst Friedmann ${ }^{9}$ found in F. Hofmeister's laboratory that (of a number of substances with two-armed carbon chain subjected to investigation) acetaldehyde alone was synthesized into diacetic acid in perfusion of the liver. As two molecules of acetaldehyde are very readily condensed into aldol and this in perfusion experiments is capable of transformation into diacetic acid, it is not unlikely (following the conceptions of Magnus-Levy ${ }^{10}$ and Spiro) that the reactions may be represented by the following formulæ:

ACETALDEHYDE

ALDOL

$\mathrm{CH}_{2} \cdot \mathrm{COH}+\mathrm{CH}_{3} \cdot \mathrm{COH}=\mathrm{CH}_{3} \cdot \mathrm{CH}(\mathrm{OH}) \cdot \mathrm{CH}_{2} \cdot \mathrm{COH}$

ALDOL

B-OXYBUTYRIC ACID

$\mathrm{CH}_{2} \cdot \mathrm{CH}(\mathrm{OH}) \cdot \mathrm{CH}_{2} \mathrm{COH}+\mathrm{O}=\mathrm{CH}_{3} \cdot \mathrm{CH} \cdot \mathrm{OH} \cdot \mathrm{CH}_{2} \cdot \mathrm{COOH}$.

It might also be imagined that the fatty acid chains are primarily broken up into links with only two carbon atoms each, and that these then become synthesized by way of acetaldehyde into $\beta$-oxybutyric acid.

\footnotetext{
${ }^{8}$ A. Magnus-Levy, Arch. f. exper. Pathol., 45, 433, 1901.

'L. Friedmann (F. Hofmeister's Lab., Strassburg), Hofmeister's Beitr., $11,202,1908$.

${ }^{10}$ A. Magnus-Levy, Die Oxybutyrsäure und ihre Beziehungen zum Coma diabeticum, Leipzig, F. C. W. Vogel, 1899, p. 78.
} 
Again, ethyl alcohol may give rise to diacetic acid in experimental perfusion of the liver (probably by way of acetaldehyde). ${ }^{11}$

Is $\beta$-oxybutyric Acid a Product of Normal Metabolism?Another important question, which for the present must be accepted as an open one, is whether $\beta$-oxybutyric acid is to be regarded as distinctly a product of normal or only of pathological metabolism. The author's early deceased friend, Leo Schwarz, who insured for himself a lasting place in science by his investigations upon diabetes, long since satisfied himself that ingested $\beta$-oxybutyric acid is metabolized with more difficulty by diabetics than by normal human beings (whereas ingested acetone is apparently attacked with equal difficulty by the normal and by the diabetic economy). Therefore it can scarcely be thought that acetone plays any important rôle in normal metabolism, as it would otherwise necessarily appear also normally. But one cannot exclude the possibility, in case of $\beta$-oxybutyric acid, of its occurrence as an intermediate product of physiological metabolism. If this be true, then an increased excretion of this substance should be due to the fact that its destruction in the economy is diminished under pathological conditions. It might be, too, that in pathological conditions the fault lies in an increased formation of the acetone bodies. Embden found in his perfusion experiments that the liver of the dog with pancreatic diabetes undergoes a change in its normal function of forming diacetic acid, in the form of a decided exaggeration. ${ }^{12}$ As he further found that the ability of the surviving liver to induce disappearance of diacetic

${ }^{11}$ N. Masuda (G. Embden's Lab.), Biochem. Zeitschr., 45, 140, 1912. From another standpoint alcohol is to be classed with the antiketogens along with other substances, as tartaric acid and glycerol-aldehyde, which, according to experimental conditions, can either serve as a source for the acetone bodies or act to inhibit the formation of acetone. (Cf. G. Embden and K. Ohta, Biochem. Zeitschr., 45, 170, 1912; R. T. Woodyatt, Jour. Amer. Med. Assoc., 55, 2109, cited in Jahresber. f. Tierchem., 40, 818, 1912.)

${ }^{12}$ G. Embden, and L. Lattes, Hofmeister's Beitr., 11, 327, 1908. 
acid is not abnormally diminished for the depancreatized dog, he thought that the increased excretion of acetone bodies in case of the diabetic individual is not due to a diminished catabolism of these substances but more likely to their increased formation. This result, however, cannot be accepted as definitive, as it is not as yet proved that the loss of diacetic acid noted in experiments with the ground-up hepatic tissue, is consistent with the intravital catabolism of diacetic acid. ${ }^{14}$

Derivation of Acetone Bodies from Compounds with Branched and Cyclical Chains.-Thus far we have been considering only the relations of the acetone bodies to the normal fatty acids. However, the acetone bodies have also been traced back to compounds with branched and cyclic nuclei, like leucin, tyrosin and phenylalanin; and the question naturally arises whether these cleavage products of the protein molecule can also serve as a source of the acetone bodies in the living body. The author will attempt to present the existing status of the problem, which, thanks to the studies of Embden, ${ }^{14}$ Bär and Blum, ${ }^{15}$ Borchhardt and Lange, ${ }^{16}$ Friedmann, ${ }^{17}$ and other authors ${ }^{18}$ has been considerably clarified, as well as he understands it, and requests special attention to the points involved that confusion may be avoided.

${ }^{13}$ G. Embden and L. Michaud, Hofmeister's Beitr., 11, 331, 1908, and Biochem. Zeitschr., 19, 262, 1908; cf. also E. Allard (Minkowski's Clinic, Greifswald), Arch. f. exper. Pathol., 59, 380, 1908.

${ }^{14}$ G. Embden, in collaboration with Almagia, Kalberlah, MIarx, Salomon, Schmidt, Engel, Wirth and Sachs, Hofmeister's Beitr., 8, 129, 1906; 11, 323, 847, 1908; Biochem. Zeitschr., 27, 20, 27, 1910.

${ }^{15} \mathrm{~J}$. Bär and Blum, l. c.

Is Borchhardt and Lange (Weintraud's Clinic), Hofmeister's Beitr. 9, 116, 1907.

${ }^{17}$ E. Friedmanu (Berlin), Hofmeister's Beitr., 11, 365, 37 1, 1908.

${ }^{1 s}$ A. Baumgartner and H. Popper (E. Freund's Lab., Vienna), Centralbl. f. Physiol., 20, No. 12, 1906; G. Forssner (Stockholm), Skandin. Arch. f. Physiol., 25, 338, 1911 ; E. M. Fittipaldi (Naples), Centralbl. f. Stoffw., 5, 161, 1910 ; cf. also Literature: O. Porges, Ergebn. d. Physiol., 10, 17, et seq., 1910. 
The fact of the matter is that leucin is recognized as capable of serving in the economy as a source of acetone bodies. As long as it was known only that acetone could be produced from it by perfusion through the liver it could be supposed that this occurred by the separation of the leucin nucleus at the position of branching and the entrance of an atom of oxygen at this point:

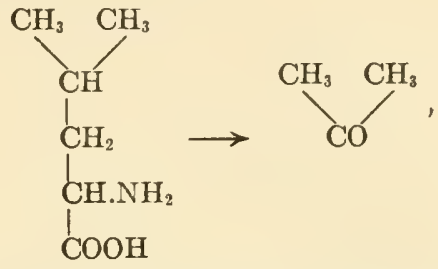

precisely as we suppose that acetone is formed in oxidation of proteins with peroxide of hydrogen (Vol. I of this series, p. 23, Chemistry of the Tissues). This view, however, was seen to be incorrect after it was recognized that diacetic acid in this case also serves as a forerunner of acetone. It is now held that isoamylamine, ${ }_{\mathrm{CH}_{3}}^{\mathrm{CH}_{3}}>\mathrm{CH}-\mathrm{CH}_{2}-\mathrm{CH}_{2} \cdot \mathrm{NH}_{2}$, isovaleraldeyde, $\quad \begin{aligned} & \mathrm{CH}_{3} \\ & \mathrm{CH}_{3}\end{aligned}>\mathrm{CH}-\mathrm{CH}_{2}-\mathrm{COH}, \quad$ and isovalerianic acid, ${ }_{\mathrm{CH}_{2}}^{\mathrm{CH}_{2}}>\mathrm{CH}-\mathrm{CH}_{2}-\mathrm{COOH}$, can contribute to the formation of acetone bodies in the economy, as well as ethylbutyric acid, $\mathrm{C}_{2} \mathrm{H}_{5}>\mathrm{CH}-\mathrm{CH}_{2}-\mathrm{COOH}, \beta$-oxyisovalerianic acid, ${ }_{\mathrm{CH}_{3}}^{\mathrm{CH}_{2}}>\mathrm{C}(\mathrm{OH})-\mathrm{CH}_{2}$ - $\mathrm{COOH}$, dimethylacrylic acid, ${ }_{\mathrm{CH}_{3}}^{\mathrm{CH}_{3}}>\mathrm{C}=\mathrm{CH}-\mathrm{COOH}$, and crotonic acid, $\mathrm{CH}_{3}-\mathrm{CH}=\mathrm{CH}-\mathrm{COOH}$. In the first mentioned instances a possible arrangement might be made by which one of the alkyl groups above the position of branching is thrown off and replaced by a hydroxyl radicle:

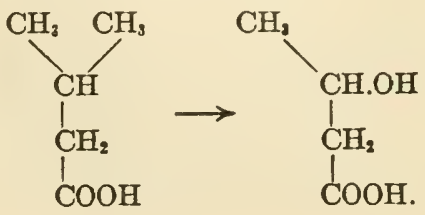


This possible mode of explanation, unless forced, fails, however, in case of $\alpha$-methylbutyric acid,<smiles>CCC(C)C(=O)OO</smiles>
from which by analogous procedure $\alpha$-oxybutyric acid should arise. There is particularly no possibility of explaining by this means the fact that a tricarbon complex like glycerol ${ }^{19}$ and that certain benzol derivatives, whose ring is subject to disintegration in the animal body, like phenylalanin, $\mathrm{C}_{6} \mathrm{H}_{5}-$ $\mathrm{CH}_{2}-\mathrm{CH} . \mathrm{NH}_{2}-\mathrm{COOH}$, and tyrosin,

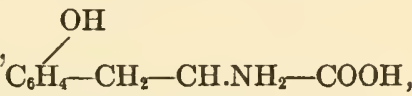
must be classed among acetone forming substances. And as the formation of acetone bodies from these latter can be conceived synthetically possible only from groups containing but few carbon atoms, the question at once arises whether in case of the formation of $\beta$-oxybutyric acid from normal higher fatty acids the process may not follow pretty much the line of explanation proposed by Friedmann. This in the author's opinion can be made to fit in, too, with Embden's observation upon the contrast between acids with even and with odd numbers of carbon atoms. It is, however, quite as likely that the development of $\beta$-oxybutyric acid in the economy takes place in different ways : that it may be formed from stearic acid, for example, by "two-atom shortening of the chain," but from tyrosin by way of synthesis of twocarbon-atom compounds.

Carbohydrate Deficiency and Acidosis.--In what relation, next, does the appearance of the acetone bodies stand to the carbohydrate exchange in the economy? Allusion has been made above to the distinct "antiketogenic" influence of carbohydrates, along with the statement that this may be fully explained on the basis of an inhibition of fat decomposition because of the combustible material thus introduced into the body. To the author's way of thinking, this makes all other complicated theories entirely superfluous, espe-

${ }^{19}$ F. Reach (A. Durig's Lab., Vienna), Biochem. Zeitschr., 14, 279, 1908. 
cially such theories as that of Geelmuyden, who first urged the idea that carbohydrates and acetone bodies unite synthetically to form a combination which is essential for the further exchange of the acetone bodies, and then undertook to show that acetone bodies are convertible in the body into carbohydrates, and that they constitute a transition stage in the supposed transformatiois of fat into carbohydrates. It seems more likely that the observed fact that subcutaneous injection of diacetic acid or $\beta$-oxybutyric acid in animals poisoned with phloridzin increases the output of sugar in the urine, is explicable on the supposition of a toxic increase of protein decomposition, rather than upon the assumption of Geelmuyden that there occurs a sugar synthesis from acetone bodies. ${ }^{20}$

According to J. Bär simple withdrawal of carbohydrates is followed in normal human beings accustomed to a mixed diet, and also in apes, by an acidosis, that is, by an excretion of acetone, diacetic and oxybutyric acids, along with coincident increase in the ammonia elimination. In the dog, goat and pig acidosis does not show upon mere reduction of carbohydrate, but is induced by combining phloridzin intoxication with fasting. ${ }^{21}$

Diabetic Coma.-As is well known diabetic coma, a symptom complex clearly described many years ago by Kussmaul, has been recognized, especially from the investigations of Stadelmann and the Naunyn school, as an acid intoxication caused by an accumulation in the system of acetone bodies. ${ }^{22}$ Magnus-Levy, ${ }^{23}$ who took a prominent part in these investigations, showed that oxybutyric acid appears in the urine of all severe cases of diabetes, even apart from the coma,

${ }^{20}$ H. C. Geelmuyden (Christiania), Zeitschr. f. physiol. Chem., 41, 128, $1904 ; \% 3,176,1911$.

${ }^{21}$ J. Bär (Med. Clinic, Strassburg), Arch. f. exper. Pathol., 54, 153, 1905.

${ }^{22}$ Literature upon Acetone Bodies in Diabetic Coma: C. v. Noorden, Handb. d. Pathol. d. Stoffw., 2d ed., 2, 69-S6, 1907.

${ }^{23}$ A. Magnus-Levy, 1. c.; Arch. f. exper. Pathol., 41 and 4.5. 
in very large amounts (twenty to thirty grams in the course of twenty-four hours). In cases of coma the formation of this acid rises to an abnormal level, and coincidently there is a lowering of its combustion. Under such circumstances enormous quantities of the substance may appear in the urine (as much as 160 grams in twenty-four hours). In the body of subjects dead from diabetic coma one or two hundred grams of the acid may be found. The coma is regarded as an acid intoxication, in which, it would seem, all the individual phenomena are dependent either directly or indirectly upon the accumulation of acid. As the supply of alkali which the system keeps ready for the neutralization of the acids permeating it is not large, these acids (oxybutyric acid, diacetic acid) are for the most part neutralized by ammonia, which is thus withdrawn from urea formation. In these cases, therefore, the urinary ammoniacal elimination serves as an approximate index of the acid excretion. ${ }^{24}$

Alkaline Treatment of Diabetic Coma.-Oxybutyric acid, the sites of production of which may be looked upon as the liver and muscles and perhaps other tissues as well, produces in case of diabetic coma, as indicated by the observations of Minkowski, F. Kraus and others, a lowering of the alkalescence of the blood and of the amount of carbonic acid fixed thereby in the blood. ${ }^{25}$ For this reason it is altogether logical that in the coma, which in Frerich's opinion is the most serious menace to the life of the diabetic subject (aside from pulmonary phthisis), efforts be made to anticipate it by a prophylactic alkaline treatment. Umber believes that in those cases of diabetes in which persistence of diacetic acid in the urine can be recognized by the ferric chloride reaction, enough alkali should be given daily to give the urine an amplioteric reaction. "This frequently

${ }^{24}$ A. Magnus-Levy, Die Oxybuttersäure und ihre Beziehungen zum Coma diabeticum, Leipzig, J. C. Vogel., 1899, p. 83.

${ }^{25}$ G. Embden and L. Lattes (Frankfurt a. M.), Hofmeister's Beitr., 11, 327, 1908; H. C. Geelmuyden (Christiania), Zeitschr. f. physiol. Chem., 58, 253, 1909 . 
requires comparatively large amounts, which the patient often can scarcely master . . . fifteen to one hundred, up to two hundred grams or more, of sodium bicarbonate may be necessary to accomplish the desired end. . . . I have never seen any more effect from intravenous administration of alkali (usually given in the form of three or four per cent. sodasolutions) than from subcutaneous infiltrations of isotonic sodium chloride solutions; and for this reason, like Naunyn, I have long ago given up the former method. There is no question as to our ability to save severe cases of diabetes by alkaline treatment in the face of an acidosis of years' duration, although without this method of treatment this would be a matter of impossibility. When coma is fully developed in adults all effort to stop it is in vain; but in children now and then therapeutic results may be obtained. ${ }^{26}$

C. v. Noorden ${ }^{2 \pi}$ is in the habit of saying of these influsions, because of his own rich experience, that any one who has ever witnessed a single time the wonderful result produced by the infusion of a soda solution upon a comatose diabetic subject is bound to accept as a certainty the effectiveness of the alkaline treatment. Time and again the patient is seen waking up from the deepest coma while the infusion is being administered. There is no other agency which will do the same thing.

Antiketogenic Substances.-In view of the antiketogenic influence of carbohydrates, one should seek in those cases in which acidosis arises after the withdrawal of carbohydrates to give some form of these substances adapted to the diabetic patient. In Umber's opinion these are the cases which should be placed upon $\nabla$. Noorden's oatmeal treatment, by which not infrequently it is possible to restore tolerance and remove the impending danger of coma. ${ }^{28}$

${ }^{\Re}$ F. Umber, Lehrbuch d. Ernähr. u. d. Stoff wechselkr., p. 231, 1909.

${ }^{27}$ C. von Noorden, 1. c., p. 85.

${ }^{28}$ F. Umber, l. c., p. 229. 
Other substances which are easily combustible in the economy also have an antiketogenic action, in the same way as carbohydrates. According to Embden it is also possible, in experimental perfusion of the liver, to inhibit the formation of acetone bodies by adding easily oxidizable substances to the perfusion fluid. For example, we may prevent the production of diacetic acid from caproic acid by introducing into the liver valerianic acid (which is not a source of acetone bodies, because of the uneven number of its carbon atoms).$^{29}$ It is conceivable that substances of very varied character (as xylose, gluconic acid, mannite, glycerol, alcohol, tartaric acid, lactic acid, propionic acid, citric acid, glycocoll, alanin, glutaminic acid) which readily undergo combustion in the living body, may at times manifest an antiketogenic power. ${ }^{30}$ An especially marked antiketogenic influence is ascribed by J. Baer and L. Blum (from their observations in phoridzin

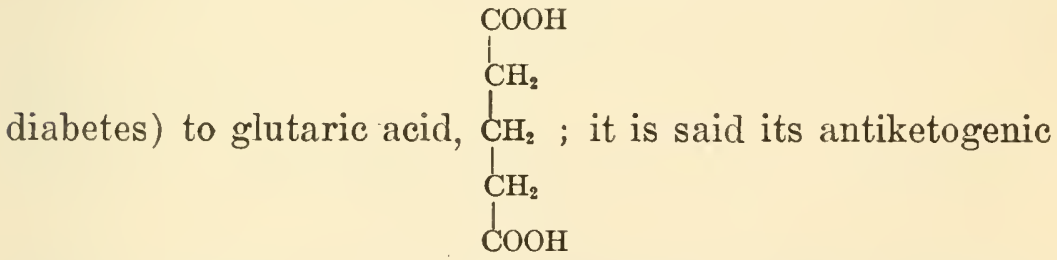

influence is all the more definite, the more marked the sugar excretion and the more severe the disturbance of metabolism which manifests itself in the acidosis. In severe acidosis and high grade glycosuria after phloridzin administration the authors mentioned have observed a complete disappearance of sugar and of oxybutyric acid, along with marked reduction in the nitrogen elimination. A similar influence is ascribed also to the homologous dicarbooxylic acids with five to ten carbon atoms in their chains, the influence decreas-

${ }^{20}$ G. Embden and S. Wirth, Biochem. Zeitschr., 27, 1, 1910.

${ }^{30}$ Cf. Literature: A. Magnus-Levy, Noorden's Handb. d. Pathol. d. Stoffw., 2d ed., 1, 184, 1906; G. Satta (Frankfurt a. M.), Hofmeister's Beitr., 6, 376, 1905; J. Bär and L. Blum (Strassburg), Hofmeister's Beitr., 10, 90, 1907; 11, 101, 1908; Arch. f. exper. Pathol., 65, 1, 1911; O. Neubauer, Münchener med. Wochenschr., 1906, 791. 
ing as the number of carbon atoms increases. A. J. Ringer has very recently occasioned a great deal of surprise by reporting that in control experiments, conducted under direction of Graham Lusk, he was unable to confirm these findings, and by attributing the above results to fault in the experimental technic of his predecessors. ${ }^{31}$ In the author's opinion liowever, the oft-repeated results of Baer and Blum, assembled with so much care, are not to be put aside in such summary manner; it would seem rather to be an objective requirement to follow up the particular factors which are the ultimate cause of this contradiction.

Ammonia Elimination and Acidosis.-As already stated the proportion of ammonia in the urine affords an approximate evaluation of the elimination of oxybutyric acid. However, the ammonia, even if a large quantity is excreted, does not, according to C. von Noorden, ordinarily represent more than twenty to twenty-five per cent. of the total urinary nitrogen. In a case of diabetic coma we may, it is true, meet with not less than forty-five per cent. of the total nitrogen as ammonia. ${ }^{32}$ Yet it would be a decided misuse of words to identiiy, as is often done, two different phenomena like increased elimination of acetone bodies and of ammonia, which, of course, often run along parallel, under the collective term "acidosis." There are conceivable cases in which an increased ammonia excretion is due to altogether different causes. Disturbances of the synthesis of urea in the liver may be such a cause, as was pointed out above. According to W. Schlesinger ${ }^{33}$ an abnormally increased fat cleavage in the intestine and an abnormally high loss of calcium in the frees, from the formation of relatively insoluble lime soaps, may give rise to alkali impoverishment and to a compensatory increase of excretion of ammonia. Then, too, a notable

${ }^{31}$ A. J. Ringer (Univ. of Pennsylvania), Jour. of Biol. Chem., 12, 223, 1912.

${ }^{32}$ C. von Noorden, Handb. d. Pathol. d. Stoffw., $2 d$ ed., 2, 82, 1907 ; ef. also IV. Camerer, Zeitschr. f. Biol., 44, 22, 1903.

${ }^{33}$ W. Schlesinger (Vienna), Zeitschr. f. klin. Med., 5ł, 14, 1904. 
increase of the lower fatty acids in the intestine doubtless calls out a lowering of the alkalinity of the body, as the acids appear in the fæces in a practically entirely neutralized condition. ${ }^{34}$

Interrelation of the Acetone Bodies.-This discussion of the acetone body problem would be incomplete were there no attempt made to explain the mutual relations of these substances.

Formerly this relationship was supposed to consist of a transition of the $\beta$-oxybutyric acid in the economy into diacetic acid, which then under normal conditions was supposed to undergo combustion (without forming acetone by cleavage of carbonic acid). It was presumed, moreover, that in severe diabetes this transformation was so disturbed that the oxybutyric acid and diacetic acid were passed off as excretions.

This conception must be modified, to be in harmony with modern investigations. Otto Neubauer ${ }^{35}$ proposes the following schema:

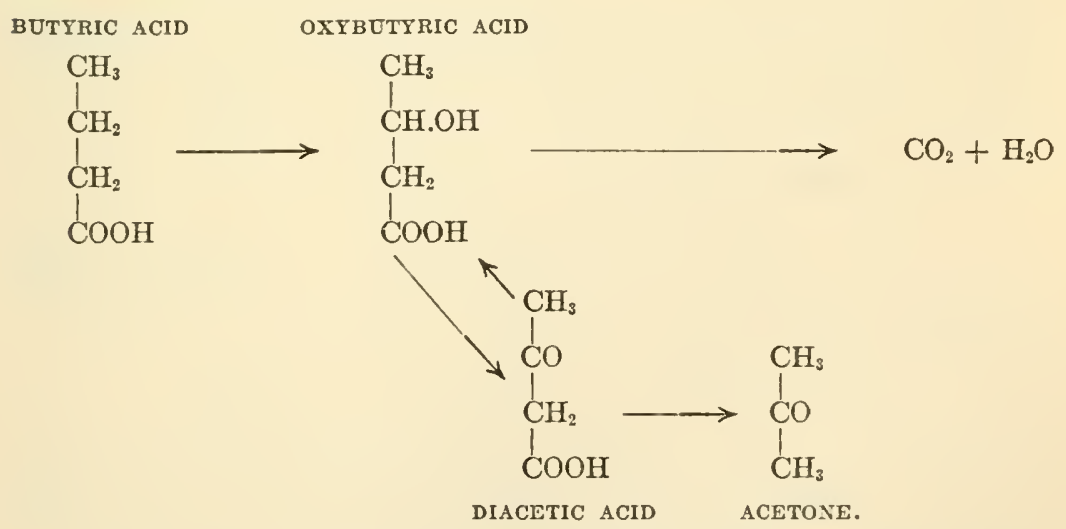

According to this the oxybutyric acid, but not the acetoacetic acid, would be a normal intermediate metabolic prod-

${ }^{34}$ Cf. also A. Schittenhelm and A. Katzenstein (Göttingen). Zeitschr. f. exper. Pathol., 2, 542, 1906 ; L. F. Meyer and L. Langstein (Berlin), Jahrb. f. Kinderheilk., 63, 30, 1906.

${ }^{25} \mathrm{O}$. Neubauer, 27 th Internat. Kongr., Wiesbaden, 1910, 566. 
uct. In healthy individuals the oxybutyric acid would be converted by oxidation into carbonic acid and water, the diacetic acid not appearing as an intermediary product. In case of interference with the normal catabolism of oxybutyric acid, however, a false route would be interposed: oxidation into diacetic acid, and then formation of acetone by splitting off carbon dioxide. It may be thus conceived why in a healthy individual (as contrasted with the diabetic subject) even large quantities of oxybutyric acid do not give rise to diacetic acid production, ${ }^{36}$ and why in perfusion experiments on the normal liver (in contrast to a phloridzin liver) the amounts of oxybutyric acid decomposed are in absolute disproportion to the newly formed diacetic acid. ${ }^{37}$

An example of the saying that when the proper time arrives for a truth it falls like a ripe fruit from the tree of knowledge, is to be seen in the fact that by chance E. Friedmann in Berlin, O. Neubauer in Munich, H. D. Dakin in New York, and L. Blum in Strassburg, all recognized at the very same time that the passage of oxybutyric acid into diacetic acid is a reversible process, and that the economy is not only able to oxidize the former into the latter, but may in reverse manner reduce diacetic acid into oxybutyric acid:

$\mathrm{CH}_{3} \cdot \mathrm{CH}(\mathrm{OH}) \cdot \mathrm{CH}_{2} \cdot \mathrm{COOH} \rightleftarrows \mathrm{CH}_{3} \cdot \mathrm{CO} \cdot \mathrm{CH}_{2} \cdot \mathrm{COOH} \cdot{ }^{38}$

How the $\beta$-oxybutyric acid undergoes combustion in the normal body is unknown; it might be supposed that it breaks down into acetic acid:

$$
\mathrm{CH}_{3}-\mathrm{CH}(\mathrm{OH})-\mathrm{CH}_{2}-\mathrm{COOH}+\mathrm{O}=2 \mathrm{CH}_{3} \cdot \mathrm{COOH} \text {; }
$$

but it is by no means certain that it is entirely consumed. It is not impossible that the oxybutyric acid may enter into

${ }^{36} \mathrm{~L}$. Schwarz, Zeehuyzen, Araki and others.

${ }^{27}$ B. O. Przibram (F. Kraus's Clinic), Zeitschr. f. exper. Pathol., 10, 1912.

${ }^{38}$ E. Friedmann and Maase (Berlin), Münchener med. Wochenschr., 1910, No. 34; Biochem. Zeitschr., 27, 474, 1910 ; O. Neubauer, 1. c.; L. Blum, Intern. Kongr., 1910, Münchener med. Wochenschr., 57, 1910; H. D. Dakin (New York), Jour. of Biol. Chem., 8, 97, 1910; A. J. Wakeman and H. D. Dakin, ibid., 105. 
further synthetic changes. A number of authorities, as Minkowski and von Noorden, have thought that it may perhaps be looked upon as an intermediate link between fat and sugar. ${ }^{39}$ The statement has been made above that there is at present no convincing basis for Geelmuyden's view that the acetone bodies should be regarded as transition stages in the supposed formation of sugar from fat. There are many arguments against the idea that oxybutyric acid can be in any way concerned with the synthetic formation of fatty acids from carbohydrates. Embden, in his last publications, expresses the belief that the route from sugar to the fatty acids may, perhaps, lie through lactic acid, acetaldehyde and diacetic acid. "Acetaldehyde, as E. Friedmann first showed, in the experimentally perfused liver forms diacetic acid. If acetaldehyde, as would appear, is a product of carbohydrate catabolism which develops in very large amounts, we may perhaps regard this substance, as earlier authors have suggested, as the point of attack in the synthetic production of fatty acids from carbohydrates." 40 Should this line of thought prove correct an interesting relation would be established between the acetone bodies with both the anabolism and catabolism of the higher fatty acids. Thus far, however, the connection of these substances with fat decomposition in the economy constitutes the best based phase of the whole problem.

The fact that enzymic catalysers are known to exist in the tissues, which are capable of oxidizing oxybutyric acid to form diacetic acid, ${ }^{41}$ and of converting the latter into acetone by splitting off carbon dioxide, ${ }^{42}$ is no proof that this is a process which takes place physiologically.

It is impossible to say at present what factors determine

${ }^{2}$ Cf. B. O. Przibram, l. c.

${ }^{40}$ G. Embden and M. Oppenheimer, Biochem. Zeitschr., 45, 202-203, 1912.

${ }^{41}$ A. F. Wakeman and H. D. Dakin, Jour. of Biol. Chem., 6, 373, 1909.

${ }^{42}$ L. Pollak (R. Paltauf's Instit., Vienna), Hofmeister's Beitr. 10, 232, 1907. 
whether the diacetic acid arising in metabolism is to be excreted unchanged or as acetone. According to Lüthje ${ }^{43}$ a portion of the diacetic acid may perhaps be excreted by the kidneys as an alkaline salt, provided sufficient supply of alkali be available; this portion otherwise appearing as acetone.

Determination of Acetone and Diacetic Acid.-In conclusion a few remarks upon the quantitative determination of the acetone bodies are desirable. ${ }^{44}$

In the determination of acetone, precedence is still given to the long approved Messinger-Huppert method. This consists in distillation of the acetone from the urine, transforming it into iodoform by means of iodide of potassium in an alkaline solution, and determining by titration the amount of iodine used in the formation of iodoform. Acetone can also be separated from the distillate by.nitrophynylhydrazine (according to Eckenstein and Blancksma) as a bright yellow crystalline sediment, and weighed. ${ }^{45}$ It may, too, be precipitated by an alkaline solution of mercuric cyanide, the acetone-mercurial precipitate broken up by acids, and the mercury determined by titration (verylikeVollhard's method of determining silver). ${ }^{46}$ Finally the fixation of sodium bisulphite by acetone may be used for iodometric estimation, provided a very long period of reaction is given ${ }^{47}$ while in experiments of short duration hydrolytic dissociation is so marked that besides the fixed sulphurous acid there is always present a considerable fraction in free state. ${ }^{48}$ In the de-

${ }^{43}$ H. J. Lüthje (Kiel), Therap. d. Gegenw., 51, 8, 1910.

${ }^{45}$ Literature upon the Quantitative Determination of the Acetone Bodies: G. Embden and G. Schmitz, Handb. d. Biochem., 3, 906-939, 1910; E. Letsche, ibid., 5, 1, 197-199, 1911; cf. also G. Embden and L. Michaud, Biochem. Zeitschr., 13, 262, 1908; Hofmeister's Beitr., 11, 332, 1908.

${ }^{45}$ S. Möller (v. Leyden's Clinic), Zeitschr. f. klin. Med., 6/, 207, 1907; IV. C. de Graaff, Pharmac. Weekbl., 4/, 555; Jahresber. f. Tierchem., 37, 356, 1907.

${ }^{46}$ H. Scott Wilson (Oxford), Jour. of Physiol., 12, 444, 1911.

${ }^{47}$ A. Jolles, Ber. d. deutsch. chem. Ges., 39, 1306, 1906.

* J. Mondschein (under direction of O. v. Fürth), Biochem. Zeitschr., 位, 95-97, 1912. 
termination of acetone, if glucose be present in the urine, special care should be taken, because in heating sugar-containing solutions substances of the nature of ketones and aldehydes are easily produced which may be confused sometimes with acetone. ${ }^{49}$

Separation of acetone and diacetic acid, as elaborated by Embden and Schliep ${ }^{50}$ and by Folin, ${ }^{51}$ is performed by driving over the preformed acetone in a given amount of urine by careful distillation at very low pressure and temperature (not above $35^{\circ} \mathrm{C}$.), or by an air current, and estimating it. Another portion of urine is subjected to the Messinger method, after boiling with phosphoric acid, the diacetic acid being thus converted into acetone; by which measure the total of acetone and diacetic acid is obtained. Rowald 52 recommends a combination of Embden's vacuum distillation with the method of precipitation by nitrophenylhydrazine as the most practicable means of separate determination of acetone and diacetic acid.

Quantitative Determination of Oxybutyric Acid.-There are essentially four methods available for quantitative determination of oxybutyric acid: polarimetric estimation, conversion into crotonic acid, into diacetic acid and into acetone.

The polarimetric method worked out by Magnus-Levy, depending upon the optical activity of oxybutyric acid and yielding excellent results when large amounts are present, is not reliable when one is dealing with small quantities, because of laevogyrating substances which can be obtained even from normal urine in ether extraction, and because the specific rotating power of $\beta$-oxybutyric acid is not high. ${ }^{53}$

Darmstädter proposed a method by which the oxy-

${ }^{49}$ Borchhardt (Wiesbaden), Hofmeister's Beitr., 8, 62, 1906.

${ }^{50}$ L. Schliep (Embden's Lab.), Centralbl. f. Stoffw., No. 2, 250, 289, 1907.

${ }^{61}$ O. Folin, Jour. of Biol. Chem., 3, 177, 1907; J. S. Hart, Jour. of Biol. Chem., 4, 473, 1908.

${ }^{52} \mathrm{~J}$. Rowald, Inaug. Dissert., Giessen, 1908.

${ }^{63}$ Embden and Schmitz, Geelmuyden, B. O. Przibram, Zeitschr. f. exper. Pathol., 10, 279, 1912. 
butyric acid is converted into crotonic acid by distillation with sulphuric acid, with separation of water, and the crotonic acid then determined by alkalimetry. This method, however, has proved to be rather inexact in control tests $;^{54}$ but apparently excellent results are obtained, according to Ryffel ${ }^{55}$ and B. O. Przibram, ${ }^{56}$ by determining the crotonic acid, not by alkalimetry, but by taking advantage of its ability to fix bromine:
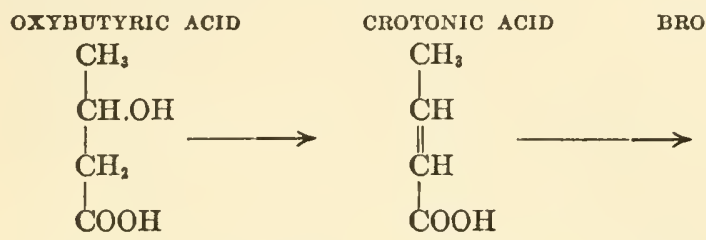

BROMINE ADDITION PRODUCT

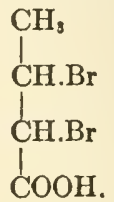

The bromine is added in excess; the excess of bromine, on the addition of potassium iodide, sets free an equivalent amount of iodine which is estimated by titration with thiosulphate. It is recommended that the urine be not subjected to direct sulphuric acid distillation, but that, saturated with ammonium sulphate and acidulated with sulphuric acid, it be first extracted for twenty-four hours with ether in Lindt's apparatus and the ethereal extract further employed.

A colorimetric method of estimating oxybutyric acid has been proposed, depending upon transformation of oxybutyric acid into diacetic acid by hydrogen peroxide, and subsequent estimation of the latter optically by the beautiful red color which it yields on addition of ferric chloride. ${ }^{57}$ In view of the instability of diacetic acid, however, it is impossible to restrain a feeling of distrust for this method.

An excellent mode of determination, however, is afforded in Schaffer's method, ${ }^{58}$ which consists of heating to boiling the fluid containing the oxybutyric acid, in the presence of

\footnotetext{
${ }^{54}$ Embden and Schmitz, B. O. Przibram, 1. c.

${ }^{65}$ Ryffel, Jour. of Physiol., 32, Proc. Physiol. Soc., LVI, May 20, 1905.

${ }^{68}$ O. F. Black, Jour. of Biol. Chem., 5, 207, 1908.

${ }^{57}$ B. O. Przibram, 1. c.

${ }^{58}$ P. A. Schaffer, Jour. of Biol. Chem., 5, 211, 1908.
} 
dilute sulphuric acid, and then decomposing it by adding drop by drop a solution of potassium bichromate. The oxybutyric acid undergoes decomposition according to the following formula, into diacetic acid, then into acetone, carbon dioxide and water:

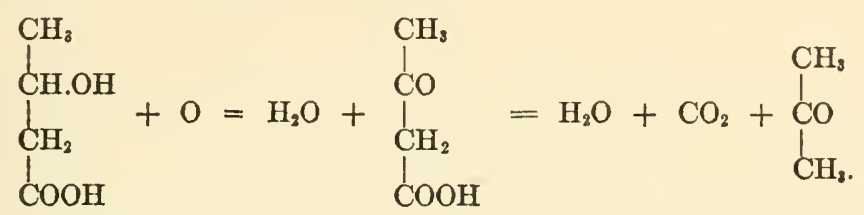

The acetone distilled over is taken up in water and the proportion determined by Messinger's method with iodine and thiosulphate. J. Mondschein, ${ }^{59}$ who worked out a method in the author's laboratory by which the quantitative estimation of oxybutyric and lactic acids is possible together (vide infra), was able to fully satisfy himself of the delicacy of Schaffer's method.

So much may be said of the acetone bodies and their physiological significance.

${ }^{59} \mathrm{~J}$. Mondschein, 1. c. 


\section{CHAPTER XIX}

\section{LACTIC ACID. FATE OF BODY-FOREIGN SUBSTANCES}

IN THE ECONOMY

\section{LACTIC ACID}

As an addendum to the acetone bodies it seems desirable at this place to examine into the problem of lactic acid, which is of the greatest importance to the comprehension of the metabolic processes. This is one of those questions which are always of special stimulative interest to the writer, not so much because of the wealth of knowledge which comes immediately from them (for this for the present can satisfy only very modest demands) but rather because of the feeling that here we are before the entrance to a steep and laborious mountain trail which may lead one, if he be able to surmount its difficulties, to a broad and as yet unknown plateau.

Quantitative Estimation of Lactic Acid by the Method of Fürth and Charnass.-The reason that the lactic acid problem has not advanced more rapidly is primarily due to the fact that it has been only recently that a successful method of overcoming the difficulties of exact lactic acid estimation has been attained. The older authors conducted their determinations of lactic acid as a rule by extracting it by simply shaking it for a time with ether in a separatory funnel, then forming the relatively insoluble zinc or lithium salt of lactic acid and weighing it. As lactic acid is by no means readily taken up by ether from water, and as quantitative extraction is seemingly possible only by long continued treatment in some such elaborate apparatus as Lindt's rotating extraction apparatus, as, too, the above mentioned salts are not entirely insoluble in their mother fluids, and impurities can be removed only by repeated crystallization, it must be evident that the older methods of estimating lactic acid were attended by very serious faults and that 
the results from such methods seem extremely unreliable.

Boas had originally recommended that in qualitative determination of lactic acid (as in gastric juice) the fluid under examination be distilled with manganese and sulphuric acid and the acetaldehyde, formed according to the equation:

$$
\begin{aligned}
& \mathrm{CH}_{3} \\
& \underset{\mathrm{COOH}}{\mathrm{CH}} \mathrm{OH}
\end{aligned}+\mathrm{O}=\underset{\mathrm{COH}}{\mathrm{CH}_{3}}+\mathrm{CO}_{2}+\mathrm{H}_{2} \mathrm{O} \text {, }
$$

be determined by transforming it into iodoform with an alkaline solution of iodine. E. Jerusalem having shown in the author's laboratory that oxidation of lactic acid in hot sulphuric acid solution by the addition of drop after drop of permanganate solution may be employed for the purpose of quantitative determination, ${ }^{1}$ the author, in collaboration with D. Charnass, ${ }^{2}$ worked out a reliable method based upon this principle for its quantitative estimation. They were able to show that oxidation cleavage of aldehyde from lactic acid occurs when certain experimental conditions are maintained, even if not absolutely quantitatively, at least with such a degree of uniformity that a quantitative method can very well be based upon this process as a foundation. Titrimetric estimation of aldehyde by the iodoform method gives reliable results only when very exact experimental conditions are maintained. It is very inferior in practice to the iodometric method of Ripper based on the addition of bisulphite :

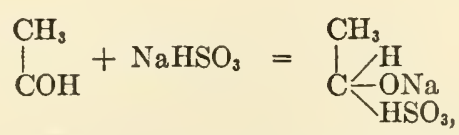

as the latter yields almost theoretically correct results. ${ }^{3}$ The

${ }^{1}$ E. Jerusalem (under direction of O. v. Fïrth), Biochem. Zeitschr., 12, $361,379,1908$; O. v. Fürth, Emendation to article of E. Jerusalem, ibid., 24, $266,1910$.

${ }^{2}$ O. v. Fürth and D. Charnass, Biochem. Zeitschr., 26, 199, 1910.

${ }^{3} \mathrm{Cf}$. also W. Sobolowa and J. Zaleski (St. Petersburg), Zeitschr. f. physiol. Chem., 69, 441, 1910. 
amount of aldehyde obtained from lactic acid in the v. Fürth and Charnass tests averaged eighty-nine per cent. of the theoretical value; and the constant error is taken into account by introducing a correction factor. In Embden's laboratory ${ }^{4}$ several improvements have recently been made in the method, which make it satisfy even far reaching requirements. The aldehyde recovery of the original method particularly can be increased by using a very dilute solution of permanganate ( $n / 100$ instead of $n / 10$ solution) for oxidizing purposes.

Observations in Embden's laboratory show the need which existed for replacing the weighing of the zinc lactate by another and better method. This is done by extracting the lactic acid for about twenty-four hours in the Lindt rotary apparatus (which forces a whirl of very fine ether bubbles through the fluid) and removing the lactic acid from the etheral extract for weighing as zinc lactate. Control experiments by the author's method show that in determinations of lactic acid from tissue extracts made by weighing the lactate of zinc, the zinc salts contain so many impurities at times that no fixed conclusions can be drawn as to the amounts of lactic acid present by mere weighing. ${ }^{5}$

A source of error until recently entirely overlooked in the determination of lactic acid in tissues may arise from the fixation of the free lactic acid by the tissue proteins. J. Mondschein, ${ }^{6}$ for example, has determined in the author's laboratory that the previously existing statements as to the amount of lactic acid in muscle are too low, as about onethird of the lactic acid present (which, if the tissue is well boiled, remains fixed in the coagulum because of combinations with proteins) escapes estimation. However, the

${ }^{4}$ G. Embden, Handb. d. biochem. Arbeitsmeth., 5, 1255-1259, 1912.

${ }^{5} \mathrm{~S}$. Oppenheimer (Embden's Lab.), Biochem. Zeitschr., 45, 30, 1912.

${ }^{6} \mathrm{~J}$. Mondschein (under direction of O. v. Fürth), Biochemic. Zeitschr., 42, $105,1912$. 
lactic acid in the extract obtained by boiling muscle can be determined with great accuracy by titration (using phenolphthalein as indicator), because all the recognizable lactic acid is present in free form, and the amount of other acid products is of no practical importance; and the fraction of lactic acid in the proteid coagulum can be released for determination by liquefying the coagulum by heating with caustic alkali, the albuminous fluid freed of its protein by addition of saturated salt solution, and finally the lactic acid determined by the method proposed by the author and Charnass in the protein-free filtrate.

Determination of Lactic Acid and $\beta$-oxybutyric Acids Together.-Recourse should also be had to a special method for determination of lactic acid in case fluids containing both lactic acid and $\beta$-oxybutyric acids are to be dealt with. In separate portions the two acids may be determined, respectively, as aldehyde or acetone ( $v$. sup.), after oxidation with permanganate or with bichromate in a sulphuric acid solution. As in both cases, however, a mixture of aldehyde and acetone distills over, separation of the two substances is requisite. In estimating the lactic acid a modification is introduced, whereby in an aliquot portion of the distillate the readily destroyed aldehyde is decomposed by boiling with hydrogen peroxide and potassium hydrate, the acetone redistilled and titrated according to Ripper. In estimating the butyric acid the distillate (containing acetone and aldehyde) is freed of its aldehyde by boiling with hydrogen peroxide and caustic potash; the acetone is redistilled and determined by titration according to Messinger's method. ${ }^{7}$

Ryffel's Method of Lactic Acid Determination.-Ryffel proposed a method of lactic acid determination which depends upon a somewhat different principle. In this the lactic acid in the urine is broken up directly into acetaldehyde

${ }^{7} \mathrm{~J}$. Mondschein (under direction of O. v. Fïrth), Biochem. Zeitschr., 42, $91,1912$. 
and formic acid by distillation with fifty per cent. sulphuric acid:

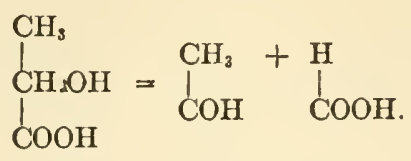

The aldehyde is then estimated colorimetrically by the handsome red color which it strikes with a rosaniline solution decolorized with sulphurous acid. ${ }^{8}$

Postmortem Formation of Lactic Acid.-We may at this point take up again the striking features of the present status of the lactic acid problem.

It should be definitely understood that as sources of lactic acid we must keep in mind carbohydrates, proteins, and, too, a substance of unknown nature, which may be characterized, following the suggestion of Embden, as lactacidogen. The chemical relation with carbohydrates may be seen in the very readily occurring decomposition of one molecule of sugar into two molecules of lactic acid: $\mathrm{C}_{6} \mathrm{H}_{12} \mathrm{O}_{6}=2 \mathrm{C}_{3} \mathrm{H}_{6} \mathrm{O}_{3}$; and for the relation with proteins we may at once refer to the deamidization of alanin: $\mathrm{CH}_{3} \cdot \mathrm{CH}\left(\mathrm{NH}_{2}\right) \cdot \mathrm{COOH}+$ $\mathrm{H}_{2} \mathrm{O}=\mathrm{NH}_{3}+\mathrm{CH}_{3} \cdot \mathrm{CH}(\mathrm{OH}) \cdot \mathrm{COOH}$. (The possibility of an actual intracorporeal transformation of alanin into lactic acid has been demonstrated by the experiments of Neuberg and Langstein upon animals deprived of glycogen.)

We may first take up for consideration the postmortem acid change of the tissues. The fact has been known a very long time that this is due to formation of lactic acid, and that the much studied postmortem production of acid in muscle (Vol. I of this series, pp. 145-147, Chemistry of the Tissues) is nothing more than a particular instance of a process equally likely to occur in all the tissues. This acid change is at present regarded as a continuation of an intravital process. A great number of investigations have been devoted to the subject of acid production in aseptic and anti-

${ }^{8}$ J. H. Ryffel, Jour. of Physiol., 39. Proc. Physiol. Soc., V, 1909. 
septic autolysis, which leave no doubt of the enzymatic nature of the process. The acid met with may be said to be $\delta$-lactic acid. (The observations indicating the occurrence of inactive fermentative lactic acid in autolysis may be fully explained, in the writer's opinion, by the associated influence of microörganisms.) ${ }^{9}$ When it is recalled that the amount of lactic acid in a specimen of tissue pulp for a time increases until it reaches a maximum, and thereafter undergoes diminution, and that this decrease (as recently shown among others, by Ssobolew, ${ }^{10}$ in the Vienna Physiological Institute) also takes place under experimental conditions surely exclusive of bacterial influence, we seem justified in assuming the existence of enzymes which decompose lactic acid, as well as of those which cause the formation of this substance. When a tissue juice contains an insufficient proportion of alkali lactic acid formation ceases, apparently at a certain degree of concentration of hydrogen ions, by autoinhibition. ${ }^{11}$ Although even earlier investigations ${ }^{12}$ indicated the improbability of a direct connection between the amount of glycogen of a tissue (especially of muscle) and postmortem acid change, the author's pupil, R. Türkel, ${ }^{13}$ recently deceased, was able to prove that a liver, even if practically free from glycogen and sugar, is capable of forming lactic acid in the course of autolysis, and that, too, in proportions not materially less than is a liver with normal carbohydrate con-

${ }^{9}$ Mochizuki and Arima, Kikkoji, Inouye and Kondo; cf. Literature: C. Oppenheimer, Die Fermente, 3d ed., 475, 1909; E. Salkowski, Zeitschr. f. physiol. Chemie., 63, 237, 1909 ; R. S. Frew (Salkowski's Lab.), ibid., 60, 15, 1909 ; T. Saito and J. Yoshikawa, ibid., 62, 107, 1909; T. Saiki, Jour. of Biol. Chem., 7, 17, 1910; G. v. Stein, Inaug. Dissert., Berlin, 1911; Biochem. Zeitschr., 40, 186, 1912: H. Youssouf (Salkowski's Lab.), Virchow's Arch., $20 \%, 374,1912$.

${ }^{10} \mathrm{~N}$. Ssobolew (under direction of O. v. Fürth), Biochem. Zeitschr., 47, $367,1912$.

${ }^{11}$ K. Kondo (G. Embden's Lab., Frankfurt a. M.), Biochem. Zeitschr., 45, 63,1912 .

${ }^{12}$ Cf. Literature: O. v. Fürth, Ergebn. d. Physiol., 2', 594-600, 1903.

${ }^{13}$ R. Türkel (under direction of O. v. Fürth), Biochem. Zeitschr., 20, 431, 1909. 
tent. As, moreover, introduction of alanin and inosite gave no definite result, the conclusions reached were in consonance with the important observations of Embden ${ }^{14}$ with carbohydrate-free expressed muscle juices, and those of Fletcher ${ }^{15}$ with ground muscle, that postmortem formation of lactic acid takes place not at the expense of carbohydrates, or of inosite or alanin, but at the expense of some unknown predecessor, Embden's "lactacidogen," which may possibly be thought of as related with the hypothetic phosphosarcous acid of Siegfried (v. Vol. I of this series, p. 148, Chemistry of the Tissues).

The observations upon muscle autolysis thus gave no basis for assuming a connection between lactic acid and the carbohydrates. And as no increase of lactic acid production was obtained by perfusing the posterior extremities of dogs with sugar added to the blood, Asher and Jackson were disposed to accept the idea that the lactic acid does not arise from carbohydrates but from the decomposition of protein. ${ }^{16}$

Origin of Lactic Acid from Sugar.-Much more certain evidence of the origin of lactic acid from carbohydrates may be met, however, in the liver perfusion experiments of Embden and his associates. ${ }^{17}$ These indicated that in perfusing a dog's liver, free of glycogen, with bovine blood no lactic acid is formed de novo; although in perfusing a liver rich in glycogen under similar experimental conditions there could always be observed a very marked new formation of s-lactic acid. A result of the same kind could be obtained, although the amount of acid was somewhat less, when glucose was added to the fluid used in perfusing a liver free of glycogen. Alanin also proved to be a lactic acid former. Embden

${ }^{14}$ G. Embden and F. Kraus, 26 Kongr. f. innere Med., 1909, 351; G. Embden, F. Kalberlah and H. Engel, Biochem. Zeitschr., 45, 58, 1912.

${ }^{25}$ W. M. Fletcher (Cambridge), Jour. of Physiol., 43, 286, 1911.

${ }^{16}$ L. Asher and H. C. Jackson, Zeitschr. f. Biol., 41, 393, 1901.

${ }^{17}$ G. Embden with M. Almagia, Centralbl. f. Physiol., 18, 832, 1905 ; v. Noorden and Embden, Centralbl. f. Stoffw., n. s., 1, 1, 1906; G. Embden and F. Kraus, Biochem. Zeitschr., 45, 1, 1912. 
came to the conclusion from these results that both the carbohydrates and the proteins are to be regarded as contributing to the formation of lactic acid, the former, it is true, apparently in much the greater proportion. This harmonizes closely with the latest researches upon the nature of glycolysis, dealt with above (vide supra, p. 338). Just as sugar by the isolated influence of alkali is broken down with extreme readiness into lactic acid, we have every reason for assuming that physiologically also glycolysis gives rise to lactic acid, ${ }^{18}$ and that the formation of lactic acid observed by J. Müller in the surviving cat's heart, for example, is due to direct cleavage of grape sugar. Apparently a portion of the lactic acid coming from sugar cleavage in the economy is changed into "lactacidogen," which later under certain conditions, as in postmortem acid change, again gives rise to lactic acid. "Apparently," says Embden,19 "the principal route of carbohydrate catabolism in the economy is by way of lactic acid; and in lactic acid the greater part of the chemical energy which was in the glucose is still present.

The very fact that a predecessor of lactic acid, which is very easily convertible into lactic acid, is at the disposal of the musculature, permits one to surmise that lactic acid is the most substantial source of muscular power. . . . It should be recalled that the older and particularly, too, recent authors regard it as very probable that a definitely local lactic acid production within the muscle is concerned with the relaxation of contracted muscle. For the purpose of rapid production of lactic acid this predecessor of lactic acid, which is apparently not of acid nature or at least less acid than the lactic acid, may, perhaps, have an important part." The author's ideas based upon his personal studies as to the rôle of lactic acid in bringing about and relaxing rigor mortis have been discussed in a previous lecture ( $\nabla$. Vol. I of this series, p. 135-147, Chemistry of the Tissues).

${ }^{19}$ Cf. J. H. Ryffel, Jour. of Physiol., 40, Proc. Physiol. Soc., LI, 1910.

${ }^{10}$ G. Embden, F. Kalberlah and H. Engel, Biochem. Zeitschr., 45, 45, 1912. 
Embden's Schema of Sugar Catabolism in the Living Body.-Thanks to a long series of remarkable studies carried on by Gustav Embden ${ }^{20}$ in the Frankfurt Institute of Physiological Chemistry in collaboration with a number of associates, we are able today to frame very exact ideas as to the decomposition of sugar into lactic acid and the further catabolism of the latter. Embden ${ }^{21}$ condenses these points in the following schema:

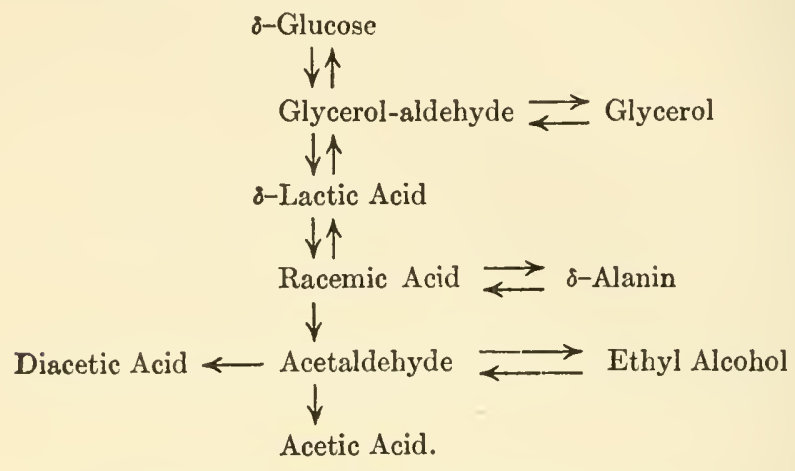

If we consider this schema somewhat more fully, in accordance with it we may suppose that physiologically sugar catabolism would follow the course below indicated:

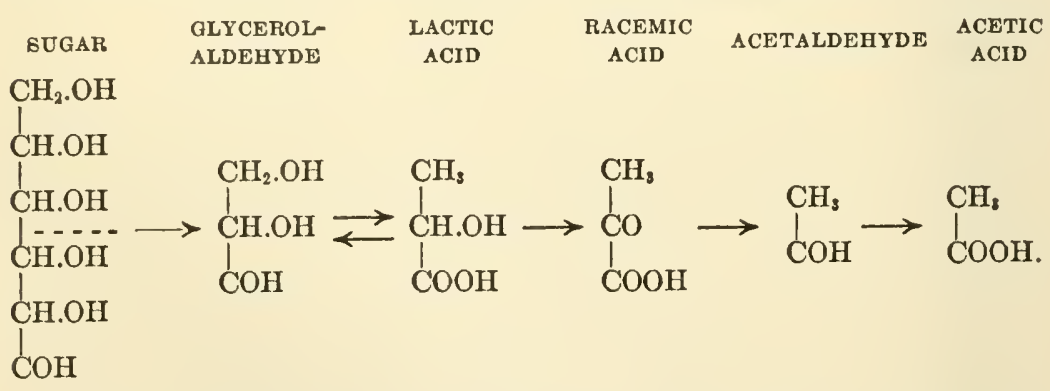

Glycerol-aldehyde as an Intermediate Product Between Sugar and Lactic Acid.-The assumption that glycerolaldehyde is an intermediate product between glucose and

${ }^{20} \mathrm{G}$. Embden and associates, Biochem. Zeitschr., 45, 1-206, 1912, and their earlier studies; cf. therein Literature.

${ }^{21}$ G. Embden and M. Oppenheimer, Biochem. Zeitschr., 45, 202, 1912. 
lactic acid is based on the fact that it (in contrast to the $\mathrm{CH} . \mathrm{OH}$

isomeric dioxyacetone, $\underset{\mathrm{CH}_{2} . \mathrm{OH}}{\mathrm{CO}}$, which according to Buchner

and Meisenheimer is an intermediate product of yeast fermentation) has proved to be a lactic acid producer of very exceptional strength. Embden suspects that, just as glycerolaldehyde is an important source for $\delta$-lactic acid, dioxyacetone may be considered as the chief source of inactive fermentative lactic acid, and expresses the idea that in transition of the glycerolaldehyde into lactic acid

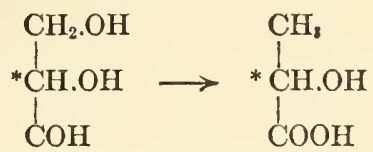

the middle carbon atom continues to retain its asymmetrical character.

The belief that glycerol formation in the economy also proceeds through the intermediate stage of glycerolaldehyde, and that by this route sugar may pass into glycerol, and, vice versa, glycerol into sugar, is not incredible.

It may be thought, too, that not only does sugar undergo transition into lactic acid, but that the reverse, the transition of lactic acid into sugar, is also possible. Embden and Salomon ${ }^{22}$ have convinced themselves that lactic acid is a sugar former in depancreatized dogs ; Mandel and Graham Lusk, ${ }^{23}$ in phloridzinized animals.

According to Parnas and Bär ${ }^{24}$ the route from lactic acid to glucose leads through glyceric acid and glycolaldehyde:

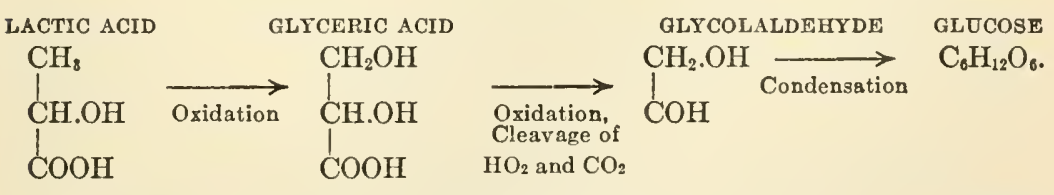

${ }^{22}$ G. Embden and Salomon, Hofmeister's Beitr., 5, 507, 1904

${ }^{23}$ A. Mandel and G. Lusk, Amer. Jour. of Physiol., 16, 129, 1906.

${ }^{24}$ Cf. also J. Parnas and J. Bär (Hofmeister's Lab., Strassburg), Biochem. Zeitschr., 41, 3S6, 1912. 
These authors also look upon the route from glucose through lactic acid to glyceric acid and glycolaldehyde as the principal mode of carbohydrate catabolism in active metabolism of the animal economy.

Racemic Acid as an Intermediate Product.-While Parnas and Bär are willing to accept the formation of racemic acid as at most a by-path in the formation of lactic acid, Embden regards it as the normal catabolic product of lactic acid and as an intermediate product of the transition of alanin into lactic acid and vice versa; a view which is in harmony with the assumption of $\mathrm{O}$. Neubauer that catabolism of $\alpha$-aminoacids takes place through $\alpha$-ketonic acids.

Paul Mayer, ${ }^{25}$ in Neuberg's laboratory, has seen after administration of racemic acid to rabbits both lactic acid and sugar in the urine. It might well be conceived, therefore, that the route from glucose, through lactic acid, to racemic acid may also be traversed in the reverse way:

\section{Sugar $\longleftrightarrow$ Lactic Acid $\rightleftarrows$ Racemic Acid.}

Finally it should be noted that the route indicated in Embden's schema:

Glucose $\longrightarrow$ Lactic Acid $\longrightarrow$ Racemic Acid $\longrightarrow$ Acetaldehyde $\longrightarrow$ Diacetic Acid ${ }^{26}$ is possibly the one, too, which may be taken by the carbohydrates in the synthetic production of higher fatty acids in the body. Possibly this line of thought may prove fruitful also in clearing up the mysterious processes of fat formation in the economy.

Appearance of Lactic Acid in the Urine.-What do we know, finally, of the excretion conditions of lactic acid? Small amounts are always present in the blood. ${ }^{27}$ In rabbits, in-

${ }^{25}$ P. Mayer (Neuberg's Lab.), Biochem. Zeitschr., 40, 441, 1912.

${ }^{28}$ According to Neuberg (Berliner physiol. Gesel., 19i2) racemic acid is fermented by yeast very readily into acetaldehyde and carbonic acid:

$$
\mathrm{CH}_{3} \cdot \mathrm{CO} \cdot \mathrm{COOH}=\mathrm{CO}_{2}+\stackrel{\mathrm{COH}}{\mathrm{CH}_{3}}
$$

${ }^{27}$ A. Fries (G. Embden's Lab.), Biochem. Zeitschr., 35, 368, 1911. 
troduced dextrorotary lactic acid, even when administered in large amounts, is almost completely consumed, according to observations by J. Parnas ${ }^{28}$ in Hofmeister's laboratory. Lævo-rotary lactic acid is partly changed, partly excreted unchanged; after introduction of racemic lactic acid an excess of lævo-rotary acid is eliminated. From observations made in the Vienna Pharmacological Institute it seems that the unconsumed fraction of lactic acid is excreted partly as such, partly, however, in the form of other ether-soluble acids. ${ }^{29}$

Passage of lactic acid into the urine is observed especially after severe muscular efforts, in epilepsy and eclampsia, in hepatic affections (acute yellow atrophy, phosphorus poisoning, etc.), in oxygen deficiency, and, too, in geese after extirpation of the liver. ${ }^{30}$ The fact that uric acid contains a tricarbon nucleus by no means justifies the assumption that the lactic acid excreted in the last instance is a substance which would have been transformed into uric acid under normal conditions.31 The general impression is given that lactic acid appears in the urine in conditions in which its normal combustion is lowered. However, it is impossible as yet to definitely formulate how, where and why this is the case; and from appearances it is likely that considerable time will elapse before this is possible.

\section{FATE OF BODY-FOREIGN SUBSTANCES IN THE ECONOMY}

Having in the course of the preceding lectures attempted in one way or another to discuss in detail the fates of the most important foodstuffs, proteins, carbohydrates and fats, it may be well to round out our knowledge by endeavoring

${ }^{29}$ J. Parnas (F. Hofmeister's Lab., Strassburg), Biochem. Zeitschr., 38, $53,1912$.

$\approx$ E. Neubauer (Vienna Pharmacological Institute), Arch. f. exper. Pathol., $61,387,1909$.

${ }^{30}$ Literature upon Lactic Acid Excretion: A. Ellinger, Handb. d. Biochem., $3^{\prime}, 651-653,1910$.

${ }^{31}$ Cf. J. B. Leathes, Ergebn. d. Physiol., 8, 360, 1909. 
to trace the fate of a few body-foreign substances in the intermediate metabolism..$^{32}$

Decomposition of Fatty Acids and Aliphatic Sidechains. -In taking up first the fatty acids and aliphatic sidechains we keep in direct connection with the information gained in the course of the last few lectures as to the catabolism of fats and the origin of the acetone bodies. It was pointed out that the investigations of Knoop and Embden particularly have led to the recognition that in the disintegration of the normal fatty acids in the animal body $\beta$-oxidation plays an important part, and that as a mode of oxidation we can picture: $\mathrm{R} \cdot \mathrm{CH}_{2} \cdot \mathrm{CH}_{2} \cdot \mathrm{COOH} \longrightarrow \mathrm{R} \cdot \mathrm{CH}(\mathrm{OH}) \cdot \mathrm{CH}_{2} \cdot \mathrm{COOH} \longrightarrow$ R.CO.CH ${ }_{2} \cdot \mathrm{COOH} \rightarrow$. R.COOH ; in which a normal fatty acid passes first into a $\beta$-oxyacid by $\beta$-hydroxylation, and this then through the corresponding $\beta$-ketonic acid into an acid with two less carbon atoms.

A long series of careful studies conducted in the past few years, requiring much chemical scientific knowledge and skill, especially by E. Friedmann, F. Knoop, H. D. Dakin and O. Neubauer, ${ }^{33}$ have been devoted to tracing out the fate of many phenyl, halogenphenyl, furfuryl and similar substitutions in fatty acids, oxyacids, ketonic acids and aminoacids in the conrse of metabolism. These studies, the details of which camnot be entered into here, have shown that the above mentioned simple schema of $\beta$-oxidation cannot be accepted as of general applicability, and that oxidation of fatty acids

${ }^{82}$ Literature upon the Excretion of Body-foreign Organic Substances: A. Heffter, Ergebn. d. Physiol., 4, 184-306, 1905.

${ }^{23}$ F. Innoop, Der Abbau aromatischer Fettsäuren im Tierkörper, Freiburg i. B., 1904; Hofmeister's Beitr., 11, 1908, and later works; E. Friedmann, Hofmeister's Beitr., 11, 151, 1908; E. Friedmann and C. Maase, Biöchem. Zeitschr., 27, 97, 113, 1910; E. Friedmann, ibid., 27, 119, 1910; 35, 40, 1911 ; Med. Klinik, 1909, Nos. 36 and 37, and 1911, No. 28; T. Sasaki (E. Friedmann's Lab.), ibid., 25, 272, 1910; H. D. Dakin (New York), Jour. of Biol. Chem., $4-6,1908-09 ; 8,35,1910 ; 9,123,1911 ;$ O. Neubauer, with IV. Gross, H. Fischer, K. Fromherz, Zeitschr. f. physiol. Chem., 67, 219, 230, 1910; 70, 326, 1911; Literature upon the Catabolism of Fatty Acids and Aliphatic Side Chains: O. Porges, Ergebn. d. Physiol., 10, 1-46, 1910; C. Oppenheimer and Pincussohn, ibid., 4', 699-700, 706-709, 1911. 
and aliphatic side chains takes place in much more complicated ways which Friedmann and Dakin ${ }^{34}$ would outline schematically somewhat as follows:

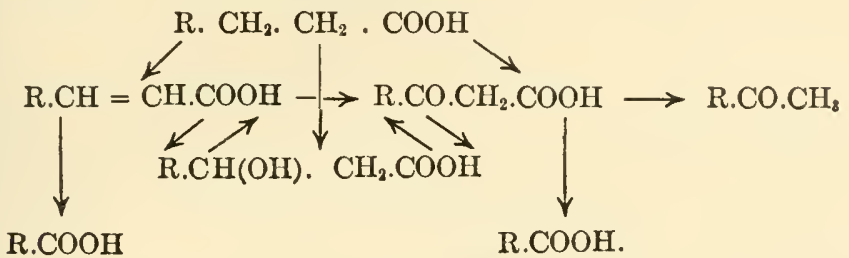

If this schema be applied, for illustration, to the individual case of phenylpropionic acid $\left(\mathrm{C}_{6} \mathrm{H}_{5} \cdot \mathrm{CH}_{2} \cdot \mathrm{CH}_{2} \cdot \mathrm{COOH}\right)$, it will be seen that it can pass into either (by $\beta$-oxidation) phenyl- $\beta$-oxypropionic acid (R.CH $\left.(\mathrm{OH}), \mathrm{CH}_{2} . \mathrm{COOH}\right)$, or into benzoylacetic acid $\left(\mathrm{C}_{6} \mathrm{H}_{5} . \mathrm{CO} \cdot \mathrm{CH}_{2} \cdot \mathrm{COOH}\right)$ or, finally, into cinnamic acid $\left(\mathrm{C}_{6} \mathrm{H}_{5} \cdot \mathrm{CH}=\mathrm{CH} \cdot \mathrm{COOH}\right)$. The last two may then be further catabolized into benzoic acid $\left(\mathrm{C}_{6} \mathrm{H}_{5}\right.$. $\mathrm{COOH})$. Benzoylacetic acid can by loss of $\mathrm{CO}_{2}$ pass into acetophenone $\left(\mathrm{C}_{6} \mathrm{H}_{5}\right.$. CO. $\left.\mathrm{CH}_{3}\right)$, or by reduction into phenyl$\beta$-oxypropionic acid.

Transition of this last, shown by the two pairs of arrows, into benzoylacetic acid and cinnamic acid is fully analogous to the previously mentioned equation between $\beta$-oxybutyric acid, diacetic acid and crotonic acid:

CROTONIC ACID OXYBUTYRIC ACID DIACETIC ACID

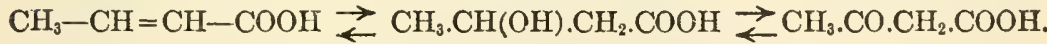

The catabolism of the fatty acids, therefore, in line with this schema, is not confined to simple oxidation processes; these latter have asscciated with them processes of reduction and of water-and $\mathrm{CO}_{2}$-cleavage. It may be said in passing that the previously mentioned ( $\mathrm{p} .385)$ discoveries of $\mathrm{E}$. Pick and Joannovies as to the conversion in the liver of sa-

${ }^{34}$ E. Friedmann, Med. Klinik, 1911, No. 28; H. D. Dakin, Jour. of Biol. Chem., 9, 123, 1911. 
turated higher fatty acids into unsaturated acids acquire special interest in this connection.

No one knows how the last phases of the combustion of an aliphatic chain take place, and how in particular acetic acid is converted. O. Porges believes that while a small fraction of acetic acid and its derivatives are oxidized through oxalic acid, the greater part is probably not oxidized but undergoes further synthetic elaboration. ${ }^{35}$ However, nothing definite is known in this connection.

Catabolism of the a-aminoacids.-It is generally held that in the decomposition of the physiologically important acids amidized in the $\alpha$-position, these are catabolized through a stage of an $\alpha$-ketonic acid with $\mathrm{CO}_{2}$ cleavage into the acid of the same group with one less carbon atom (v. Vol. I of this series, pp. 49-51, Chemistry of the Tissues) in which process apparently aldehyde may enter as an intermediate product:

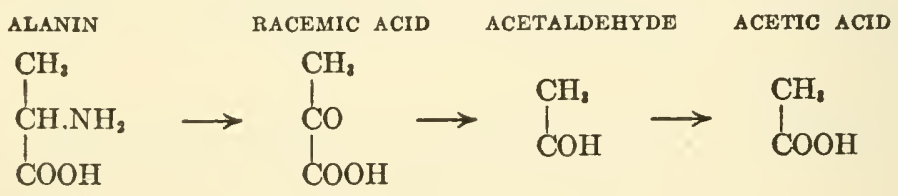

LEUCIN

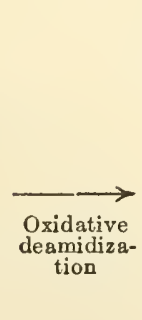<smiles>CC(C)CC(=O)O</smiles>

ISOVALERIANIC<smiles>CC(C)CC(N)C(=O)O</smiles>
ACID

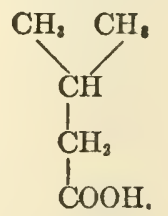

This harmonizes with the schema proposed by $\mathrm{O}$. Neubauer ${ }^{36}$ for the catabolism of aminoacids by yeast fermentation:

${ }^{35}$ O. Porges, Ergebn. d. Physiol., 10, 32, 1910.

${ }^{36} \mathrm{O}$. Neubauer and K. Fromherz (F. v. Müller's Clinic, Munich), Zeitschr. f. physiol. Chem., \%0, 348, 1911 . 


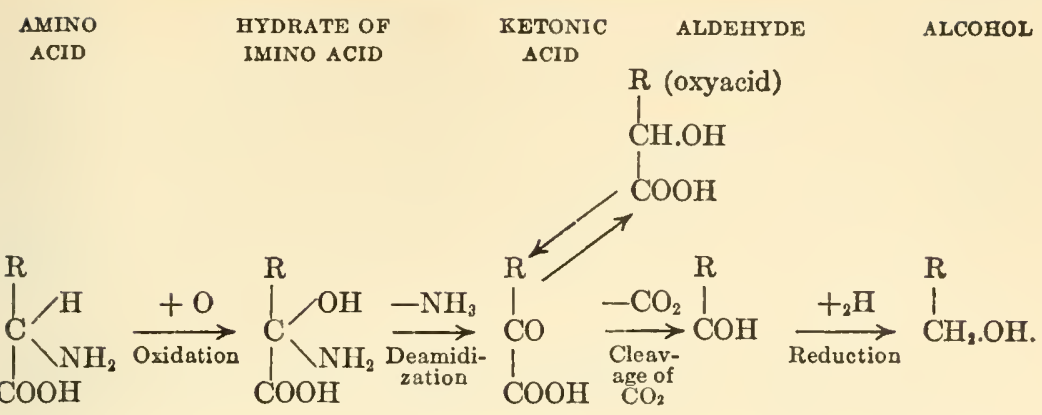

It might well be conceived, too, that the route from leucin to isovalerianic acid may pass through isoamylamine and isoamylic alcohol: ${ }^{37}$

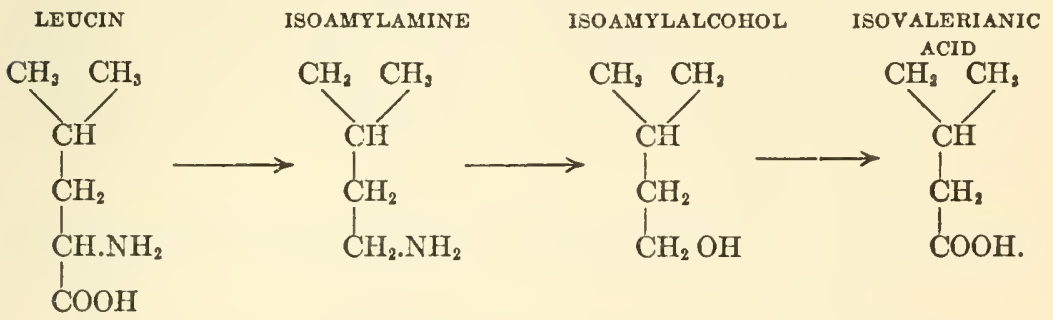

In experiments of Friedmann ${ }^{38}$ (conducted in Hofmeisters' laboratory) of the homologues of glycocoll the lower members were better utilized by the economy than the higher.

The catabolism of tyrosin and phenylalanin has been previously dealt with (Vol. I of this series, pp. 46-55, Chemistry of the Tissues). In this connection it should be stated that parahydroxyphenylethylamine may undergo transition in the economy into paranydroxyphenylacetic acid: ${ }^{39}$
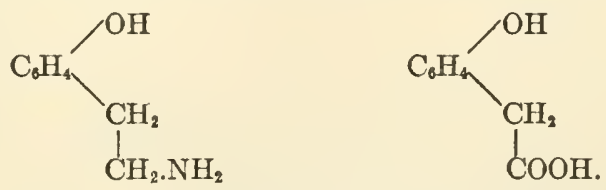

${ }^{37}$ C. Oppenheimer and Pincussohn, 1. c., p. 707; F. Sachs (G. Embden's Lab., Frankfurt), Biochem. Zeitschr., 27, 27, 1910.

${ }^{3 s}$ E. Friedmann, Hofmeister's Beitr., 11, 151, 1908.

${ }^{9}$ A. J. Ewins and P. P. Laidlow, Jour. of Physiol., 12, 78, 1910. 
Oxidation of $C y c l i c N u c l e i$.-Taking up the question as to the extent an oxidation or disruption of cyclic groups can take place in the economy, ${ }^{40}$ there is no doubt that these cyclic compounds frequently effectively withstand eren the oxidation powers of the system, and at times may be either excreted entirely unchanged (as is the case with phthalic acid, $\mathrm{C}_{6} \mathrm{H}_{4}\left\langle{ }_{\mathrm{COOH}}^{\mathrm{COOH}}\right.$, when introduced parenterally in rabbits) ${ }^{41}$ or undergo merely hydroxylation. Thus, to take up a few examples, benzol $\mathrm{C}_{6} \mathrm{H}_{6}$ may pass into phenol $\mathrm{C}_{6} \mathrm{H}_{5}(\mathrm{OH})$, aniline $\mathrm{C}_{6} \mathrm{H}_{5} \cdot \mathrm{NH}_{2}$ into paraamidophenol $\mathrm{C}_{6} \mathrm{H}_{4}<{ }_{\mathrm{NH}_{2}}^{\mathrm{OH}}$, phenol $\mathrm{C}_{6} \mathrm{H}_{5}(\mathrm{OH})$ into hydrochinon $\mathrm{C}_{6} \mathrm{H}_{6}<\frac{\mathrm{OH}}{\mathrm{OH}}$, indol

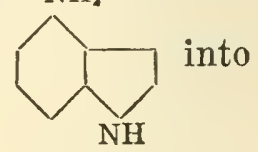
indoxyl<smiles>CNC1CCCCC1O</smiles>
naphthaline<smiles>C1CCC2CCCCC2C1</smiles>
into naphthol, etc.

The views as to the movement of the hydroxyls observed in this process of oxidation now and again observed, as in the transition of tyrosin,

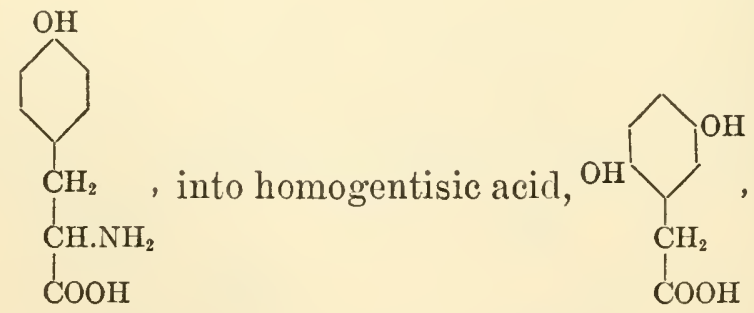

have been stated in a previous lecture (Vol. I of this series, pp. 51-52, Chemistry of the Tissues).

${ }^{40}$ Literature upon the Behavior of Benzol Derivatives in the Economy: S. Fränkel, Dynamische Biochemie, Wiesbaden, 1911, pp. 53-66.

${ }^{41}$ E. Przibram, Arch. f. exper. Pathol., 51, 372, 1904; J. Pohl, Biochem. Zeitschr., 16, 68, 1909. 
In many cases, again, oxidation takes place in the nuclear ring, with change of $-\mathrm{CH}=$ groups into $-\mathrm{CO}-$. Thus, according to Fühner, ${ }^{42}$ quinolin<smiles>C1CCC2CCCCC2C1</smiles>
passes into quinolinquinon,

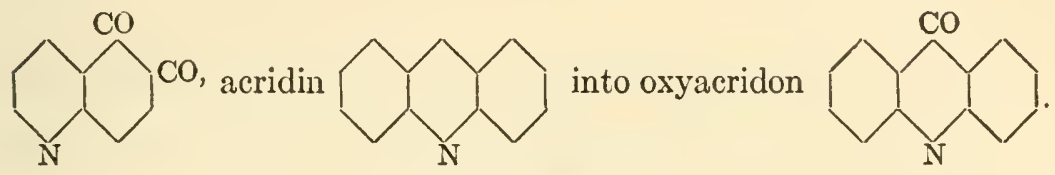

As an example of a dehydration of hydroaromatic compounds in the body may be mentioned the long known transition of quinic acid (tetraoxycyclohexancarboxylic acid) into benzoic acid, and the change of hexahydrobenzoic acid, as observed by E. Friedmann, ${ }^{43}$ into benzoic acid,
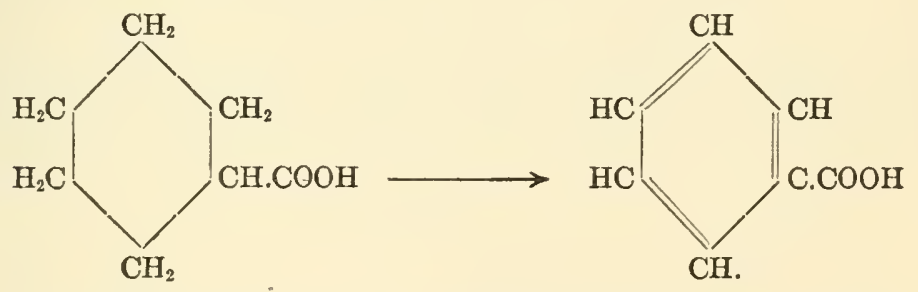

Nor is there any dearth of examples of nuclear disruption in the body. Here may be classed the excellent observation of $J_{a f f e}{ }^{44}$ upon the occurrence of muconic acid in the urine after administration by mouth of benzol,

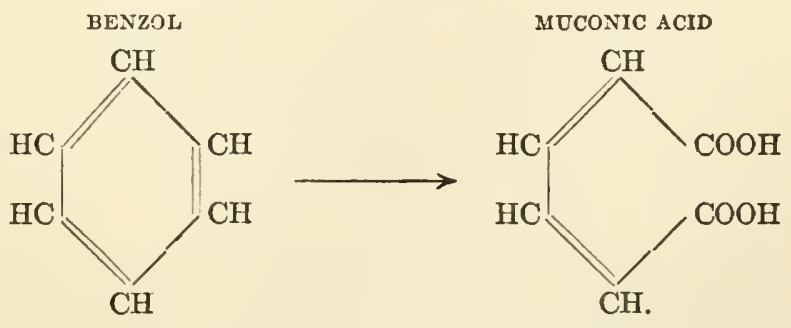

${ }^{42}$ H. Fühner, Arch. f. exper. Pathol., 51, 391, 1904; 55, 27, 1906.

${ }^{43}$ E. Friedmann, Biochem. Zeitschr., 35, 49, 1911.

44. Jaffe, Zeitschr. f. physiol. Chem., 62, 57, 1909. 
The observation in E. Friedmann's laboratory ${ }^{45}$ of rupture of the naphthalin nucleus when naphthalanin and naphthyl-racemic acid pass into benzoic acid may be noted here,
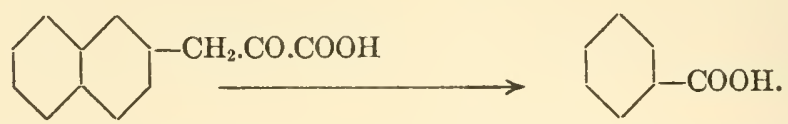

It is known, too, that tyrosin and probably phenylalanin undergo advanced disintegration in the normal body; but on the other hand an individual with alcaptonuria (v. Vol. I of this series, p. 47, et seq., Chemistry of the Tissues) brings this nucleus in hydroxylized form in the shape of homogentisic acid, $\mathrm{HO} \mathrm{CH}_{-\mathrm{CH}_{2}-\mathrm{COOH}}$, to the surface of metabolism. The fact that homogentisic acid and its mother substances in the body may undergo transition into aceto-acetic acid, or into $\beta$-oxybutyric acid, ${ }^{46}$ may perhaps be interpreted as indicating that homogentisic acid is split off as in the schema, ${ }^{47}$

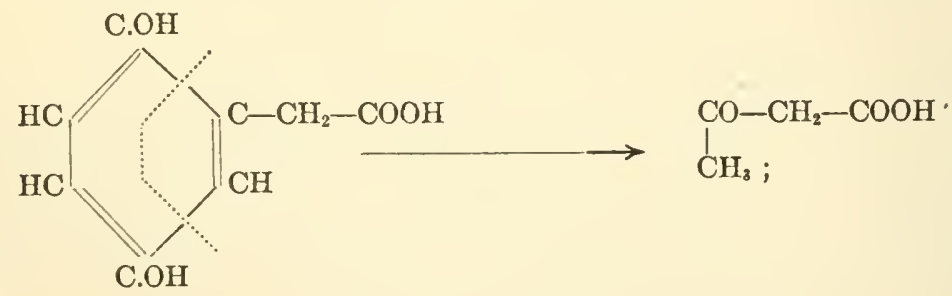

yet, according to what has been previously said in reference to the formation of acetone bodies, it would appear at least quite as plausible that homogentisic acid would break down into a bicarbon complex, and $\beta$-oxybutyric acid be formed by way of acetaldehyde and aldol synthesis.

${ }^{45}$ F. Kikkoji (First Med. Clinic, Berlin), Biochem. Zeitschr., 35, 57, 1911.

${ }^{46}$ G. Embden, H. Salomon and F. Schmidt (Frankfurt a. M.), Hofmeister's Beitr., 8, 129, 1906; G. Embden and H. Engel (Frankfurt a. M.), Hofmeister's Beitr., 11, 323, 1908; J. Bär and L. Blum, Arch. f. exper. Pathol., $56,92,1907$.

${ }^{47}$ T. Kikkoji, l. c., p. 63. 
Reduction Processes in the Economy.-Besides oxidation processes there undoubtedly take place reduction processes in the body; as examples may be mentioned the transition of chloral, $\underset{\mathrm{COH}}{\mathrm{CCl}_{3}}$, into trichlorethyl alcohol, ${ }_{\mathrm{CH}_{2} . \mathrm{OH}}^{\mathrm{CCl}_{3}}$, of nitrobenzol, $\mathrm{C}_{6} \mathrm{H}_{4} \cdot \mathrm{NO}_{2}$, into aminophenol, $\mathrm{C}_{6} \mathrm{H}_{4}{ }_{\mathrm{OH}} \mathrm{NH}_{2}$, of picric acid, $\mathrm{C}_{6} \mathrm{H}_{4}\left(\mathrm{NO}_{2}\right)_{3}(\mathrm{OH})$, into picraminic acid, $\mathrm{C}_{6} \mathrm{H}_{2}\left(\mathrm{NO}_{2}\right)_{2}$ $\left(\mathrm{NH}_{2}\right)(\mathrm{OH})$, and of nitrobenzaldehyde, $\mathrm{C}_{6} \mathrm{H}_{4}<{ }_{\mathrm{COH}} \mathrm{NO}_{2}$, into acetyl-

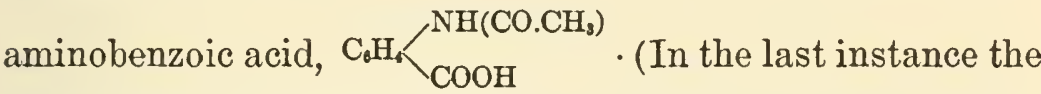
reduction of the nitrous group into the amino group takes place with acetyl combination with the latter and with oxidation of the aldehyde group to carboxyl.)" The "reducing ferments" will be considered later.

Deaminization.-Processes of deaminization are of considerable importance in the economy, being indispensable to the elaboration of the aminoacids which go to form the protein molecule. An excellent example of intravital deaminization is seen in the transition of diaminopropionic

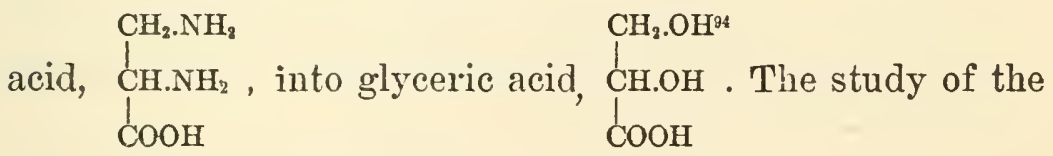
elaboration of aminoacids by low forms of vegetable life affords very instructive analogies to deaminization processes in the animal economy. Reference has previously been made to the views at present held upon the action of fermentative yeasts on the elaboration of aminoacids. By mould fungi (according to the studies of Felix Ehrlich) aminoacids are catabolized typically following the equation:

${ }^{48}$ Literature upon Reduction Processes in the Body: S. Fränkel, Dynamische Biochemie, Wiesbaden, 1911, pp. 71-75; E. Meyer (F. v. Múller's Clinic, Munich), Zeitschr. f. physiol. Chem., 46, 497, 1905.

w P. Mayer (Salkowski's Lab.), Zeitschr. f. physiol. Chem., 42, 59, 1904. 
R. $\mathrm{CH}\left(\mathrm{NH}_{2}\right) \cdot \mathrm{COOH}+\mathrm{H}_{2} \mathrm{O}=\mathrm{R} \cdot \mathrm{CH}(\mathrm{OH}) \cdot \mathrm{COOH}+\mathrm{NH}_{3}$, it being easy in this way to obtain many aminoacids, with difficulty produced hitherto in optically-active form. Thus from

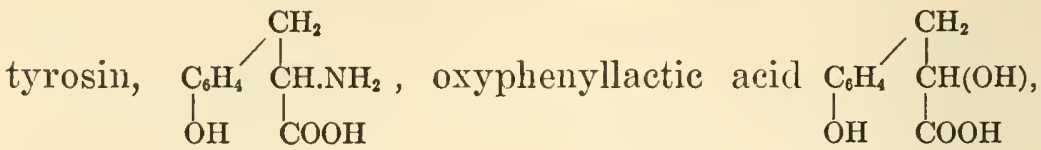
may be obtained; and from phenylalanin and tryptophane their corresponding oxyacids. ${ }^{50}$

Synthetic Formation of Aminoacids in the Animal Body. -Our ideas about deaminization processes have been materially extended by Knoop's discovery of a synthetic formation of aminoacids in the animal body.

Knoop ${ }^{51}$ in the first place succeeded, after feeding phenyl- $\alpha$-aminobutyric acid, ${\stackrel{\mathrm{CH}}{6} \mathrm{H}_{5} \cdot \mathrm{CH}_{2} \cdot \mathrm{CH}\left(\mathrm{NH}_{2}\right) \cdot \mathrm{COOH}}_{\mathrm{C}^{2}}$, in isolat-

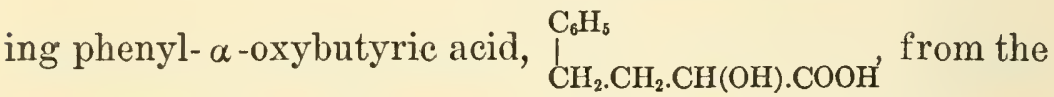
urine; but after feeding phenyl- $\alpha$-ketobutyric acid, $\mathrm{C}_{6} \mathrm{H}_{5}$ ${ }_{\mathrm{CH}_{2}} \cdot \mathrm{CH}_{2} \cdot \mathrm{CO} \cdot \mathrm{COOH}$, the acetyl compound of phenyl- $\alpha$-aminobutyric acid. From these observations he proposed the idea that the first phase of oxidation catabolism of aminoacids is a reversible one:

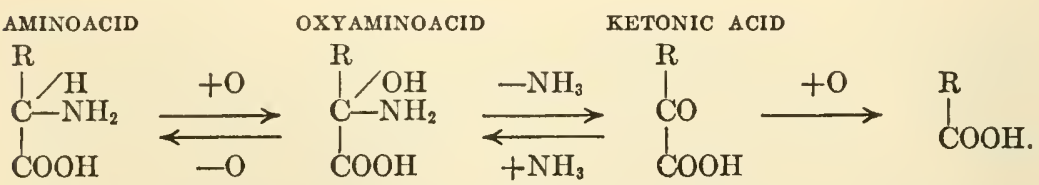

According to this view it would be necessary to assume the formation of a hypothetical oxyaminoacid, arising possibly on the one hand from the aminoacid by the introduction

${ }^{50}$ F. Ebrlich and K. A. Jacobsen (Breslau), Ber. d. deutsch. chem. Ges., 44, $888,1911$.

${ }^{81}$ F. Innoop (Freiburg i. B.), Zeitschr. f. physiol. Chem., 67, 489, 1910; F. Knoop and E. Kertess, ibid., 71, 251, 1911. 
of an atom of oxygen, on the other hand from the ketonic acid by the addition of a molecule of ammonia. This acid would, if conditions are favorable for oxidation, catabolize to ketonic acid by the cleavage of ammonia and thereafter by the introduction of an atom of oxygen to the next lower acid; if, however, conditions favorable for reduction prevail, would be reduced to aminoacid. We know already, however, that an aminoacid can be converted into an oxyacid by a typical hydrolytic deaminizing process.

Following this line of thought recently Embden has succeeded, ${ }^{52}$ by experimentally perfusing the liver of the dog with blood to which ammonia salts of various $\alpha$-ketonic acids have been added, in obtaining their corresponding $\alpha$-aminoacids :

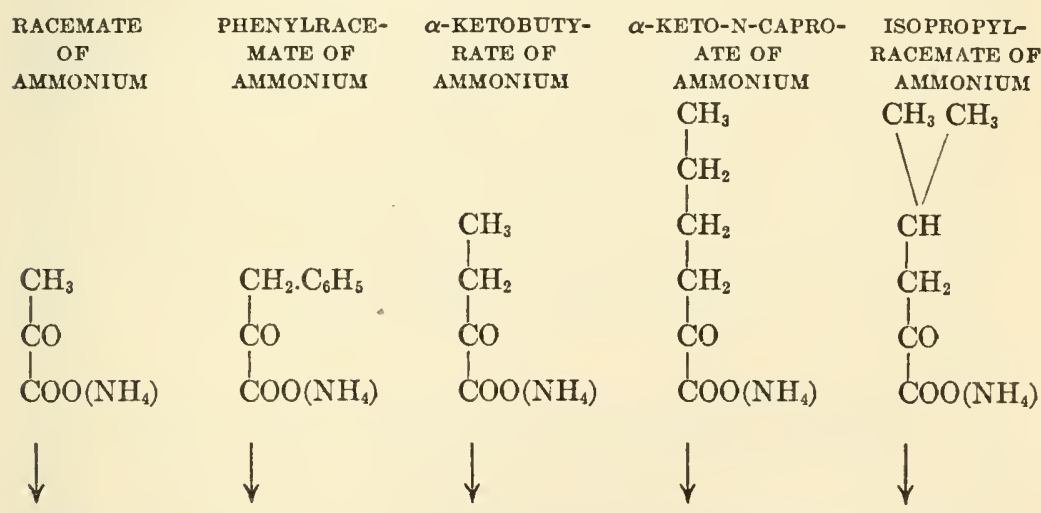

ALANIN PHENYLALANIN $\alpha$-AMINO-BUTY- AMINO-N-CAPROIC LEUCIN RIC ACID
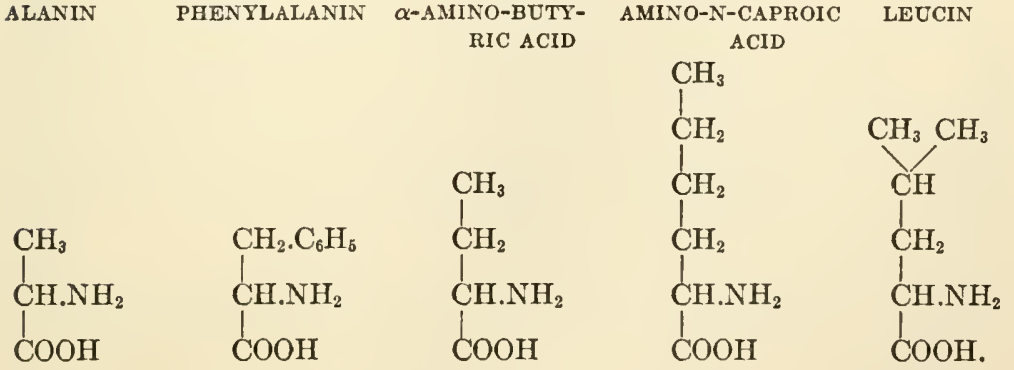

${ }^{32}$ G. Embden with E. Schmitz and K. Kondo (Frankfurt a. M.), Biochem. Zeitschr., 29, 423, 1910; 38, 393, 407, 1912. 
These findings are the more significant as they suggest the route traversed from the non-nitrogenous products of intermediate metabolism to the "building stones" of the protein molecule. For instance, it may easily be imagined that sugar is decomposed into lactic acid in the system, that this is then oxidized to racemic acid and that the latter is changed to alanin by taking up ammonia :

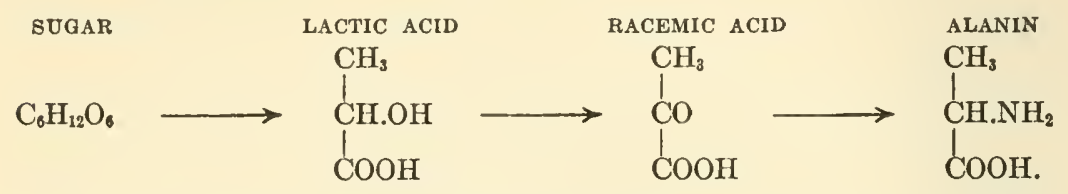

It has been actually shown in Embden's laboratory that alanin can be found to appear in a liver rich in glycogen (but not in one which is free of glycogen) in perfusion experiments; if ammonia be added to the perfusing blood in the experiment upon the glycogen-free liver, here, too, the recognition of alanin-formation is possible. "This is the first time positive proof has been obtained that in intermediate metabolism in the mammal carbohydrate can be transformed into an aminoacid by taking up nitrogen, i.e., can be converted into a characteristic component of the protein molecule." 53

Acetylizing Processes in the Animal Body.-It has been shown, moreover, that the processes of anabolism and catabolism of the aminoacids in intermediate metabolism are apparently closely connected with acetylization processes. Examples of the attachment of an acetic acid rest to organic substances in metabolism have been known for a long time. Thus furfurol combines in the body with acetic acid to form furfuracrylic acid : ${ }^{54}$

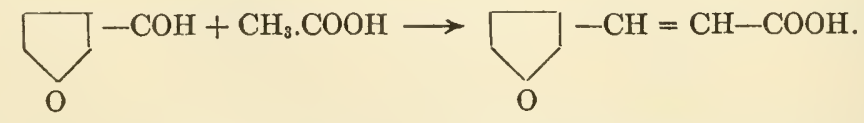

"Hanni Fellner (G. Embden's Lab.), Biochem. Zeitschr., 38, 414, 1912.

ss According to Jaffe and R. Cohn. 
Fixation of acetic acid to aminobenzoic-acid,<smiles>CC(=O)NC(CC(=O)O)C(=O)O</smiles>

has been previously mentioned. It seems too that the mercapturic acids (studied by Baumann and by E. Friedmann), which are met in the urine of dogs to which iodobenzol or bromobenzol has been administered, owe their origin to the simultaneous combination of cystein with halogenbenzol and with acetic acid: 55

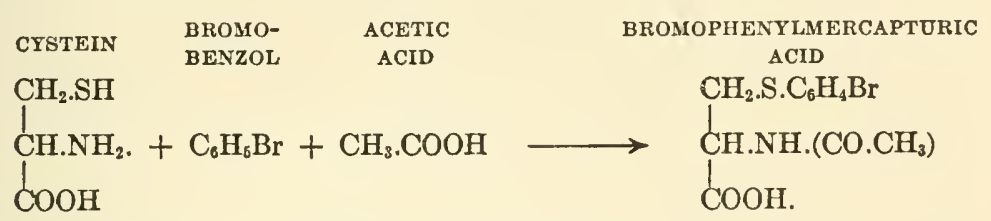

In addition, $O$. Neubauer ${ }^{56}$ and his collaborators have obtained both in the artificially perfused liver of the dog, and, too, under the influence of fermenting yeasts from phenylaminoacetic acid, $\underset{\mathrm{N}_{0} \mathrm{H}_{5}-\mathrm{CH} . \mathrm{COOH}}{\stackrel{\mathrm{H}}{\mathrm{H}_{2}}}$ (besides phenylgly-

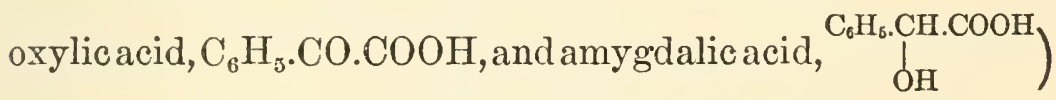
acetylphenylaminoacetic acid, $\mathrm{C}_{6} \mathrm{H}_{5}-\mathrm{CH} . \mathrm{COOH}$ too, found that a portion of phenylaminobutyric acid, $\mathrm{CH}_{2} \mathrm{C}_{6} \mathrm{CH}_{5} \cdot \mathrm{CH}\left(\mathrm{NH}_{2}\right) \cdot \mathrm{COOH}$, introduced into the system is excreted as acetyl-derivative. It seems, therefore, that a rather wide distribution is to be recognized for acetylization in the economy. Knoop points out a very striking coincidence between this process and the catabolism of aminoacids from the point of view of a transposition described by the younger Erlenmeyer and van de Jong, in which two molecules of racemic

${ }^{*}$ E. Friedmann (F. Hofmeister's Lab.), Hofmeister's Beitr., 4, 486, 1903.

${ }^{56} \mathrm{O}$. Neubauer, in association with $\mathrm{O}$. Warburg and K. Fromherz (F. $\nabla$. Müller's Clinic, Munich), Zeitschr. f. physiol. Chem., 70, 252, 325, 1911.

${ }^{s 7}$ F. Knoop and E. Kertess, 1. c. 
acid may, if brought into contact at room temperature with ammonium carbonate, form, when heat is applied, a molecule of acetalanin :

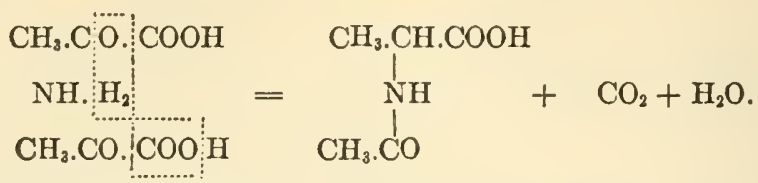

Alkylation-Finally it should be recalled (vide supra, p. 132) that the body is able to bring about a simple alkylation. Thus after introduction of selenic or telluric acid into the body, according to F. Hofmeister, selenium-methyl or tellurium-methyl seems to appear; and, according to $\mathrm{J}$. Pohl, 58 thiourea, $\mathrm{CS}_{\mathrm{NH}_{2}}\left\langle_{\mathrm{NH}_{2}}\right.$, may be partly changed into ethyl sulphide, $\mathrm{S}_{\mathrm{C}_{2} \mathrm{H}_{5}}^{\mathrm{C}_{2} \mathrm{H}_{5}}$. On the other hand, the transformation, observed by His, of pyridin, ammonium-hydroxide, 59 certained. We are apparently dealing with a methylation process, too, in the change, described by Neuberg, ${ }^{60}$ of ethyl sulphide into the diethylmethylsulphinium base,

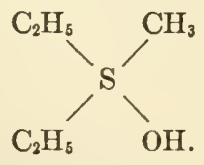

${ }^{5 x}$ J. Pohl (Prague), Arch. f. exper. Pathol., 51, 341, 1904.

${ }^{c 9}$ Cf. E. Abderhalden, C. Brahm and A. Schittenhelm, Zeitschr. f. physiol. Chem., 59, 32, 1909.

${ }^{60}$ C. Neuberg and Grosser, Deutsche phys. Ges., 1905, Centralbl. f. Physiol., $19,316,1905$. 
Detoxification by Sulphuric Acid and Sulphur-containing Rests. -There still remain a group of conjugation processes possible to the system to be rapidly reviewed.

First may be mentioned the conjugation of phenols with sulphuric acid, discovered by Baumann, which follows the schema : $\mathrm{C}_{6} \mathrm{H}_{5} \mathrm{OH}+\mathrm{KHSO}_{4}=\mathrm{SO}_{4}<{ }_{\mathrm{C}_{6} \mathrm{H}_{6}}^{\mathrm{K}}+\mathrm{H}_{2} \mathrm{O}$; which is applicable also to dioxyphenol, trioxyphenol, halogen-phenols, nitrophenols, aminophenols, cresols, thymols, many substitution benzoic acids, ete. In the combination of sulphuric acid (doubtless originating principally from oxidized protein-sulphur) with phenols we undoubtedly possess a method of detoxifying. After Marfori had discovered that intravenous injection of ammonium sulphate is capable of detoxifying a certain amount of phenol, it was shown from a study in F. Hofmeister's laboratory ${ }^{61}$ that the sulphates are decidedly less efficient as detoxifying agents than the salts of sulphurous acid. The most efficient antidote for phenol poisoning is apparently, however, the salts of persulphurie acid, ${ }^{62}$ $\mathrm{H}_{2} \mathrm{~S}_{2} \mathrm{O}_{8}$. Rabbits which have received a subcutaneous injection of "persodin" (a mixture of sodium- and ammoniumpersulphate) can withstand far more than the maximal dose of phenol, sometimes without manifesting the least symptoms of poisoning.

An interesting antitoxic process may be seen, too, in the combination of hydrocyanic acid and nitriles to form sulphocyanides ( $\mathrm{KCN}+\mathrm{S}=\mathrm{KCNS}$ ) and the hastening of this synthesis by the introduction of thiosulphates, discovered by Sigmund Lang in F. Hofmeister's laboratory. In spite of the rapid action of hydrocyanic acid several times the lethal dosage may be robbed of its effect by supplementary intravenous exhibition of the thiosulphate. ${ }^{63}$

${ }^{61}$ S. Tauber (F. Hofmeister's Lab.), Arch. f. exper. Pathol., 36, 196, 1895.

62 G. Bufalini, Arch. ital. de Biol., 40, 131, 1904.

${ }^{83}$ S. Lang (F. Hofmeister's Lab., Prague), Arch. f. exper. Pathol., 36, 75, 1894. 
According to L. Lewin ${ }^{64}$ the poisonous condensation products of acetone, mesityl oxide and phorone, in the body enter into combination with sulphhydryl and are excreted in the urine as thioketones.

Conjugation with Glycocoll and Ornithin.-The conjugation of benzoic acid and its homologues with glycocoll will not be dealt with here any further, as hippuric acid has already been considered. It is well known that in the economy all substances which are catabolized to benzoic acid lend themselves to synthesis of hippuric acid. A number of related acids, too, as oxy-, nitro-, halogen-benzoic acids, toluic acid,

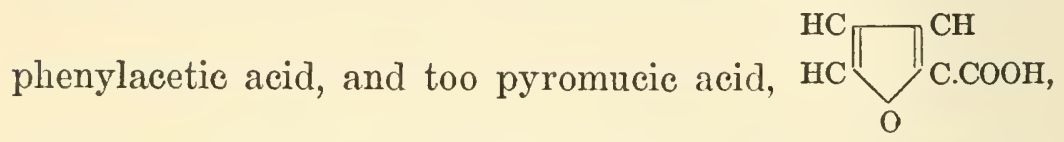
unite with glycocoll according to the equation: $\mathrm{R} . \mathrm{COOH}+$ $\mathrm{NH}_{2} \cdot \mathrm{CH}_{2} \cdot \mathrm{COOH}=\mathrm{R} \cdot \mathrm{CO}-\mathrm{NH} \cdot \mathrm{CH}_{2} \cdot \mathrm{COOH}+\mathrm{H}_{2} \mathrm{O}$. In the economy of birds benzoic acid (as discovered by Jaffe), instead of uniting with glycocoll, combines with another protein derivative, ornithin (Vol. I of this series, p. 10, Chemistry of the Tissues) to form ornithuric acid:

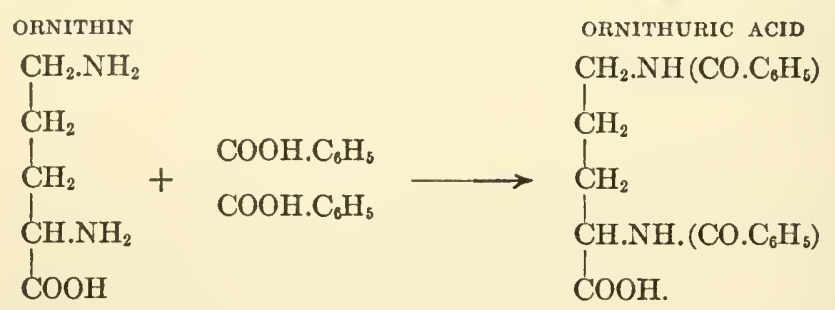

In the avian economy pyromucic acid and phenylacetic acid, $\mathrm{C}_{6} \mathrm{H}_{5}-\mathrm{CH}_{2} . \mathrm{COOH}$, may also enter into an analogous synthesis. ${ }^{65}$

Uraminoacids.-There are quite a large number of statements in literature that aminoacids in the intermediate

\footnotetext{
${ }^{64}$ L. Lewin (Berlin), Arch. f. exper. Pathol., 56, 346, 1907.

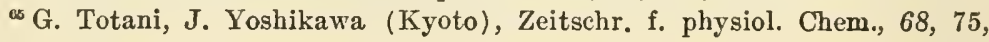
1910.
} 
metabolism supposedly unite with urea rests. For example, taurin, $\mathrm{C}_{2} \mathrm{H}_{4}<\frac{\mathrm{NH}_{2}}{\mathrm{HSO}_{8}}$, according to Salkowski appears as taurocarbaminic acid, $\mathrm{C}_{2} \mathrm{H}_{4}<{ }_{\mathrm{HSO}_{3}}^{\mathrm{NH}\left(\mathrm{CO} \cdot \mathrm{NH}_{2}\right)}$. Analogous statements ale made of sulphanilic acid, ethylamine, sarcosin, tyrosin and phenylalanin. However, from the observations of Dakin upon tyrosinhydantoin (Vol. I of this series, pp. 16 and 47, Chemistry of the Tissues) and those of Weiland ${ }^{66}$ it appears that not only on boiling a urine after the addition of an aminoacid, but on merely steaming it over a water bath, or even on concentrating a neutral aqueous solution containing urea and an aminoacid at a temperature of the water bath not above $45^{\circ} \mathrm{C}$. uraminoacids are formed. We are not at present in position to make any assertions as to the physiological significance of these acids. It is quite possible that they are altogether artificial products of extracorporeal development (vide supra, p. 98).

Combinations of glycuronic acid will not be dealt with here, as they have been considered previously.

Behavior of Stereoisomeric Substances in the Body.These considerations of the behavior of body-foreign substances in intermediate metabolism may be concluded by directing attention to the importance of the stereochemic configuration of such substances from this point of view.

The recognition of this significance goes back to the classical studies of Pasteur upon the influence of moulds upon paratartaric acid and those of Emil Fischer upon the variations in the behavior of stereoisomeric methylglucosides toward invertin and emulsin. Since then a number of other comparable observations have been collected. For example, studies upon asymmetric cleavage of racemic mandelic acid methylester, and brominated stearic acid glyceride

${ }^{\infty}$ W. Weiland (G. Embden's Lab., Frankfurt a. M.), Biochem. Zeitschr., $38,385,1912$. 
by lipases ${ }^{67}$ may be classed here. Observations upon the behavior of stereoisomeric substances in metabolism have been made in case of tartaric acids, ${ }^{68}$ arabinoses, ${ }^{69}$, mannoses, ${ }^{70}$ methylglucosides, ${ }^{71}$ and monoaminoacids. ${ }^{72}$ Particularly in the case of these last (as leucin, tyrosin, asparaginic acid and glutaminic acid) the important point was developed that after introduction of these racemic compounds the particular components which occur naturally in animal protein readily underwent combustion, while the bodyforeign components almost completely passed out into the urine of the experiment animal. Even the two stereoisomeric methylglucosides behave very differently in the body; and the same is true of isomeric forms of sugar (it may be recalled how much more readily glucose is assimilated than galactose). On the other hand, there is no apparent difference between $\delta$ - and $\lambda$-tartaric acid; in both cases racemic acid is eliminated in the urine in unchanged, inactive form. That the system is also able to bring about changes in stereochemic configuration is evidenced by the couversion of lævulose into dextrose by the diabetic subject, and by the transformation of dextrose into galactose in the mammary gland. The name "stereokinases" has been proposed for the hypothetical ferments supposed to bring such conversions about.

Here, then, is the end of today's discussion; and this is probably well, as the author cannot but fear that the concentration of so many formulæ and dry chemical facts in such brief outline must decidedly test his hearer's patience. It is indeed a rigid and peculiar material with which this lecture has had to deal, and yet it is well adapted to be shaped into beautiful plastic forms by the hands of one who applies him-

${ }^{67}$ Dakin, Neuberg and Rosenberg.

${ }^{68}$ Brion (Hofmeister's Lab.), Zeitschr. f. physiol. Chem., 25, 282, 1898;

Neuberg and Saneyoshi, Biochem. Zeitschr., 36, 32, 1911.

${ }^{69}$ C. Neuberg and Wohlgemuth, Zeitschr. f. physiol. Chem., 35, 41, 1902.

${ }^{70}$ C. Neuberg and P. Mayer, Zeitschr. f. physiol. Chem., 37, 530, 1903.

${ }^{71}$ S. Lang, Zeitschr. f. klin. Med., 55, 1904.

${ }^{72}$ J. Wohlgemuth, Ber. d. deutsch. chem. Ges., 38, 2064, 1905. 
self with the fire of true zeal for research. But in this sculptor's studio there is need of dextrous, trained and diligent hands. The crowd of tyros in our science, who it is true are making biochemical investigations, but who are not willing to learn chemistry, invariably keep away with proper awe from this workshop, through whose window flows a broad stream of bright light and in which no lack of mental clarity and confusion are tolerated. But within the confines of biochemistry there still remain plenty of broad stretches of the primæval forest where they are entirely safe from this light, where they may meddle about undisturbed in the construction of their papers upon subjects of temporary popularity. 


\section{CHAPTER XX}

\section{NUTRITIONAL REQUIREMENTS. FASTING. PARENTERAL NUTRITION}

\section{NUTRITIONAL REQUIREMENTS}

THе streams of nutritive material which are poured into the body have been followed from the very start, not without interruption to their exit, but up to the point where they disappear in intermediate metabolism, somewhat like waterways whose courses are suddenly interrupted and lost in the depths of a labyrinth of underground caves and passages. At this time it is desirable to deal more fully not so much with the individual types of food as such, but rather in a sense with their effects. The present lecture, therefore, may properly be devoted to the problems of nutritional requirement, of inanition, and of restricted diet. We enter here directly into a field of study looked upon by the older

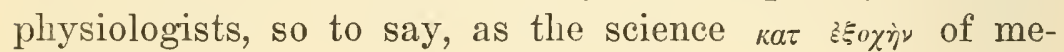
tabolism.

A mount of Food.-In calculating the normal nutritional requirements of an individual, for a long time "Voit's dietetic allowance" was used as a basis. According to this 118 grams of protein, 56 grams of fat and 500 grams of carbohydrate were regarded as the proper requirement of a healthy human being of about seventy kilograms weight. Taking Rubner's standard figures, according to which one gram of protein yields 4.1 calories, one gram of either starch, glycogen or sugar 4.1 calories, but one gram of fat 9.3 calories, the total calory requirement foots up in round numbers three thousand calories. A long list of studies, among which may be especially mentioned those of Rubner, Zuntz, Tigerstedt, Atwater and Benedict, and Chittenden, ${ }^{1}$ have

${ }^{1}$ Literature upon the Amount of Normal Food Requirement: A. MagnusLevy, v. Noorden's Handb. d. Pathol. d. Stoffw., 2d ed., 1, 319-330, 1906; O. Cohnheim, Physiologie der Verdauung und Ernährung, pp. 400-460, 1908. 
proved that the idea of a "normal dietary allowance", is decidedly misleading, as the amount of food which a man needs depends primarily upon the amount of muscular labor which he has to perform. ${ }^{2}$ Rubner, for instance, divides his human observation material into four classes according to the type of occupation. To the first class belong persons with sedentary occupation (as brokers, the learned professions, merchants, writers, textile workers and those who attend machines); such individuals require about 2400 calories. To the second group he refers workers who either work standing, or engage in rather severe labor in sitting position; these need about 3000 calories. The third class includes individuals whose labor demands more physical strength (masons, smiths, soldiers in forced marches) ; these requiring accordingly a larger amount of food, about 3400 calories. In the fourth class finally, individuals are placed who are required to perform especially heavy labor (as farmers, porters and persons who undertake heavy athletic feats); in these a calory requirement of from 4000 to 5000 commonly is met. Even this does not cover the extreme demands. Atwater has met American woodsmen who easily required 7000 to 8000 calories; and there is record of a man who rode a bicycle for sixteen hours with the imposing record of 9000 calories.

Metabolic Minimum.-What is the metabolic minimum for man? Recent studies by Zuntz and Tigerstedt ${ }^{3}$ show the metabolic minimum of the adult individual as about one calory pro kilogram per hour. This would mean about 1700 calories for an individual of seventy kilograms weight. This estimate tallies fairly with the direct results of respiration studies conducted by Sondén and Tigerstedt upon individuals in sound sleep, and by Zuntz and Lehmann upon

${ }^{2}$ Cf. also A. Slosse and E. Waxweiler (Instit. Solvay, Brussels; Travaux de l'Instit. de Sociol.). Observations upon the nutrition of more than 1000 Belgian laborers.

${ }^{3}$ R. Tigerstedt (Helsingfors), Skandin. Arch. f. Physiol., 23, 302, 1910; E. Koch (Tigerstedt's Lab.), ibid., 25, 315, 1911. 
professional fasters. Among bedridden inmates of asylums for the aged and of insane asylums a calory requirement below 2000 has often been observed, and individual eases have shown 1400 and less. ${ }^{4} \quad$ The really small significance of such figures may perhaps be appreciated by stating that this corresponds, according to O. Cohnheim's estimation, to only one liter of milk, eight lumps of sugar and four wheat-rolls a day.

Protein Minimum.-A question, which because of its economic and hygienic importance has aroused considerable discussion, is-what is the smallest amount of protein with which a normal person can actually get along? The distinguished American physiologist, Chittenden, has endeavored in an extensive series of experiments to prove that Voit's diet, with its 118 grams of protein and 3000 calories, is much too high; and that a healthy human being can get on with much less. From Chittenden's experiments, which were performed on educated persons, volunteers of the military sanitary service and on trained student athletes, the results would show, to the author's mind, a requirement of from 1900 to 2500 calories, about 0.10 to 0.12 protein nitrogen to the kilogram of body weight (i.e., 43 to 53 grams of protein for a body weight of 70 kilograms) to be satisfactory. Chittenden came to the conclusion that, without necessarily raising the consumption of non-nitrogenous foods, it is possible to maintain nitrogen equilibrium by amounts of protein fully fifty per cent. less than usually considered necessary. ${ }^{5}$ O. Cohnheim calls attention to the point that in case of many foodstuffs relatively low in nitrogen, particularly legumes and bread, utilization is distinctly poorer than for substances commonly employed in metabolic studies, and that of the 118 grams of crude protein of Voit's meal actually only about 100 grams are to be regarded as digestible. The difference between this latter and Chittenden's results is therefore by

${ }^{4} \mathrm{Cf}$. the instructive collection of data by O. Cohnheim, 1. c.

${ }^{\circ}$ Cf. I. B. Mendel, Ergebn. d. Physiol., 11, 499, 1911. 
no means as great as would appear at first glance. However, the exact proof that an individual can increase his bodily strength on a moderately restricted diet is a matter of lasting practical value. "The laudation of temperance," says Magnus-Levy, “is sounded in Chittenden's book, it is true, less philosophically and rsthetically than in the pages of a Ludovico Cornaro and a Hufeland, but certainly with no less enthusiasm and impressiveness. . . . If Chittenden's followers feel so much better in their new mode of life than formerly, there should be considered many other factors besides the reduction of protein in their diet in explanation. The great regularity of their plan of living, perhaps the different distribution of their hours of eating, the almost complete abstention from alcohol, condiments and other irritative agents, must also be considered. . . . Special prominence is due, too, to the return to the simple life, or as it is often spoken of, 'back to nature,' in bringing about what is almost a new birth to Chittenden and some of his young men. Vegetarianism, natural methods of treatment and other modes of nonscientific therapy are indebted to them, too, for their actual and apparent results." 6

For the other points upon the theories of protein metabolism and the questions of protein minimum and protein requirement it seems best to make reference to the recent clear and well directed monographs by W. Caspari ${ }^{7}$ and the American physiologist, Lafayette B. Mendel. ${ }^{8}$ In these publications there may be found full presentations of the views held upon this difficult subject by the authors and other experts in this field. These are matters which to-day cannot be put aside with a brief statement without sinning against the law of objectivity. A glance at Caspari's reference list,

${ }^{6}$ A. Magnus-Levy, 1. c., pp. 326-330.

' IV. Caspari, Handb. d. Biochem., 4', 722-825, 1911.

${ }^{8}$ L. B. Mendel (New Haven), Ergebn. d. Physiol., 11, 418-525, 1911; ef. also K. Thomas, Arch. f. Anat. u. Physiol., 1910, Spplbd., 249, 1911; M. Rubner, ibid., 1911, 39-61, 67 . 
which contains more than five hundred papers, will show the propriety of so doing.

RelationBetween Protein Requirement and Total Energy Requirement.-How large a part of the energy requirement must be furnished the economy in the form of protein? That depends entirely upon the kind of nutrition. Thus F. Siegert ${ }^{9}$ found that a fairly favorable nutrition for the growing child can be attained if the protein calories represent nine or ten per cent. of the quantity of food appropriate to the subject. In an investigation made in Tigerstedt's laboratory ${ }^{10}$ the result indicated that of the 4000 calories of the food of a Finnish farmer or of students, about 15 per cent. are ingested in the form of protein. Rubner found that a physician, whose energy requirement he had controlled, ordinarily covered twenty per cent. with protein; in a Bavarian woodsman, however, only eight to nine per cent. It might, of course, be that accidentally both the physician and the woodsman were using the same daily amount of about one hundred grams of protein, but while the physician had an energy requirement of about 2400 calories, the woodsman was by chance using twice this amount. Persons who do but little muscular work must, of course, ingest the same protein proportion in a smaller general quantity of food. The amount of protein in human diet is, as O. Cohnheim believes, ${ }^{11}$ nearly the same in all peoples who have been studied, Germans, Scandinavians, Italians, Transylvanians, Americans, Japanese and Malays. Independently of race, climate and occupation the figures for crude protein are said to be everywhere from 100 to 130 grams, for pure protein

- F. Siegert (Cologne), Arch. f. exper. Pathol., Schmiedeberg Festschr., 489,1908 ; cf. statements as to energy determinations of nutritional requiremen in the infant, by $\mathrm{O}$. and $\mathrm{W}$. Heubner, Jahrb. f. Kinderheilk., $72,121,1910$; A. Schlossmann and H. Murschhauser (Düsseldorf), Biochem. Zeitschr., 26, 14,1910 .

${ }^{10} \mathrm{~S}$. Sundström (Tigerstedt's Lab., Helsingfors), Dissert., Helsingfors, 1908, Skandin. Arch. f. Physiol., 19, 78, 1907.

״ 0 . Cohnheim, 1. c., p. 452 , et seq. 
90 to 120 grams. It may be added that Oshima, ${ }^{12}$ in an interesting but little known paper upon Japanese diet, concludes that it is apparently fair to say that the amount of protein " in the food of those classes who live mainly on vegetable material (and these constitute a large part of the population) is not far from 60 grams daily.', This would be less, even if we take in consideration the much smaller average weight of the Japanese, than the above figures regarded as standard for an individual of seventy kilograms average weight. Doubtless Cohnheim was entirely correct in suggesting that Italian laborers and Chinese coolies do not live on maize, rice and bread primarily because they have any special freedom from requirements or because a hot climate in itself produces a lessened requirement for food (according to Hans Aron ${ }^{13}$ an average man of 50 to 55 kilograms weight in the tropical climate of the Philippines consumes 2500 to 2600 calories, not less therefore than an individual of equal weight in temperate climates), but simply because, having especially heavy labor to perform, they eat a correspondingly large amount; and the result is that they obtain the necessary amounts of protein from the large quantities of food ingested even if it be poor in protein. For hardworking country-people, therefore, a preponderating vegetarian diet is possible. For persons with a predominatingly sitting or standing habit of life Cohnheim would hold this to be a mistake, however, and he would not regard the craving of the industrial worker for a full meat diet as nothing more than a "sensual craving", (as many concerned with public welfare, belonging to the ruling classes, are disposed to look upon it), but an entirely proper demand based upon physiological reasons. This shows that the deplorable opposition to the importation of cheap foreign meat is doubly objectionable, and, too, more fortunately, as entirely without

\footnotetext{
${ }^{12}$ Oshima, cited by L. Mendel, Ergebn. d. Physiol., 11, 485, 1911.

${ }^{13}$ H. Aron (Manila), Philippine Jour. of Science, 4, 195, 1909, cited in Biochem. Centralbl., 1909.
} 
fore-sight. It makes little difference how little influence physiologists may individually possess; physiology is nevertheless a powerful mistress. When man has found something nature requires for life, he has thus far at least generally known a way to procure it.

Vegetarianism.-This, then, brings us to the consideration of the important subject of vegetarianism.

There is no question, of course, but that human beings are capable of continuously maintaining their bodily and mental ability even on unmixed vegetable diet. A Japanese author has shown, from collective inquiry of two hundred persons who have all exceeded a century of life, that about one-third lived mainly upon vegetarian food (had scarcely once a week eaten even fish) ; about half were, however, for years strict vegetarians, who refused eggs, milk and animal fat. Among the Japanese Buddhists of strict sect there seem to be individuals who manage to get on with a remarkably small amount of food (consisting of rice, radishes and various greens), and who acquire a condition in which they can very readily handle vegetables, but for whom a sudden change to animal food is decidedly harmfu]. ${ }^{14}$ (According to statements of various authors 0.6 gram of protein pro kilogram a day may be regarded as the low limit of protein requirement.) ${ }^{15}$

Generally, however, investigations of recent years are not favorable to vegetarianism. Thus Caspari ${ }^{16}$ from his intensive studies regards a pure vegetable diet, because of the difficulty of utilizing it in the body, its insipidity and its large volume, as injudicious and its merits (low amount of uric acid forming substances, etc.) as doubtful. Individual

${ }^{14}$ G. Yukawa (Osaka), Arch. d. Verdauungskr., 15, 471, 740, 1909; cf. also W. G. Little and Charles E. Harris (Liverpool), Biochem. Jour., 2, 230, 1907.

${ }^{15}$ C. von Noorden, E. Voit and Constantinidi, Caspari; ef. Hammersten's Lehrb., p. 858, 1910.

${ }^{16}$ W. Caspari, Pfliger's Arch., 109, 473, 1905; cf. also the Literature in Stiihelin (Basel), Zeitschr. f. Biol., 49, 199, 1907. 
attempts to give vegetarianism a dynamic basis seem to be misplaced. ${ }^{17}$ Albertoni and Rossi ${ }^{18}$ have conducted exhaustive metabolic investigations upon Italian country people from the Abruzzi, who (at a food-cost of about fifteen centimes a day for each) live their whole lives upon vegetable food, eating perhaps a little pork three or four times a year. The Italian investigators were able to satisfy themselves that this mode of living has an unfavorable influence upon development, and that the addition of meat results in an improvement in the general health, in the utilization of the food, improvement in weight and strength, and raising the hæmoglobin. It is, of course, impossible to exclude the chance that a corresponding improvement of the food of strictly vegetable type might perhaps exert a similarly favorable effect.

The observations made by the American physiologist, Slonaker, ${ }^{19}$ seem of even greater importance. This investigator separated a number of young rats of the same age into two groups and reared them under the same conditions, with this difference, that those of one group were fed exclusively upon vegetables, those of the other upon the same materials with the addition of meat. As a result it appeared that the growth of the vegetarian animals was decidedly retarded, the animals were weakly and much more apathetic than their omnivorous comrades; they became senile much earlier, and their average length of life was only about half that of the second group. Collectively the omnivorous rats lived longer than even those individuals of the other group which attained the greatest age. These results are of such a character that the experience gained upon rats may be directly applied, if we wish to protect man from such effects, to human beings.

${ }^{17}$ M. Bircher-Benner, Grundzüge der Ernährungstherapie, 3d ed., Berlin, O. Salle, 1909 ; cf. references of N. Zuntz, Biochem. Centralbl.. 8, No. $2178,1909$.

${ }^{18}$ P. Albertoni and Rossi (Bologne), Arch. f. exper. Pathol., Schmiedeberg Festschr., 29, 1908, and 64, 439, 1911.

18 J. R. Slonaker, Stanford University Publications, 1912. 
Doubtless much depends upon the quality of the vegetable food. It is well known that the occurrence of pellagra has by many been attributed to an almost exclusive maize diet; it is worth noting that zein (a protein substance which represents the bulk of the proteid material in the maize grain, and which is distinguished by the absence of the tryptophane group, of glycocoll and lysin) has been proved to be badly suited as a continuous food for guinea pigs and mice. ${ }^{20}$

Mechanical Preparation of Vegetable Food.-Hans Friedenthal has recently directed attention to a new side of the vegetarian problem, which, to the author, seems to present a phase of great interest. In a general way, we are only able to get the good out of those parts of plants which are stocked with reserve substances (like fruit, roots and tubers); while those very parts of plants which are richest in protein, the leaves, cannot be utilized either in the raw or after cooking. It seems, however, that it is possible by a method of very fine mechanical comminution to pulverize dried green plants in such a way that the greater part of the cell walls are broken up and the cell contents made available for the action of the digestive juices. By this method we can obtain the green plants in the form of a fine powder, which, in passing through the intestine, does not induce an increased peristalsis as the ordinarily ingested gross vegetable structures regularly do, and which is digested with the greatest ease. Infants less than six months of age, to whom hitherto greens could not be given in any way, have been allowed to drink spinach-powder or carrot-powder with the milk from a bottle, without the least manifestation of digestive disturbances. It certainly is a matter of considerable importance to be able, with a spoonful of the powder dis-

${ }^{20}$ S. Baglioni, Rend. Accad. Lincei, $1 \gamma^{\prime}, 609$, cited in Centralbl. f. Physiol., 22, 782, 1908; V. Henriques (Copenhagen), Zeitschr. f. physiol. Chem., 60, 105, 1909; E. Abderhalden and C. Funk, Zeitschr. f. physiol. Chem., 60, 418, 1909. 
solved in the milk, to administer to an infant iron, inorganic salts, nucleins and lipoids. Possibly, however, the matter has even a greater significance, as there seems to be here a hint of possibility of utilizing wide stretches of land, hitherto serviceable to man's nutrition only by way of the cattle industry, in a much more direct and rational manner. ${ }^{21}$ The proposal to make human beings become grass- and leafeaters may, perhaps, at first thought seem very ridiculous. It should not be forgotten, however, that it has not always been the poorest acquisitions of mankind which at the outstart have been recognized by the majority of their contemporaries in their humorous aspect alone (witness steam machinery, illuminating gas, and electricity). Perhaps here, too, we are confronting one of those possibilities destined to take form more easily for later generations than for the one now in existence.

Nitrogen Balance.-Before we can properly coördinate the phenomena of metabolism in fasting it is necessary that we briefly (for it is impossible in the course of these lectures to deal with detail) take up some of the points in relation to protein metabolism.

First the matter of nitrogen balance: It is well known to all that a meat eater who has been accustomed to a fixed meat ration, reacts to an increased or a diminished amount of meat ingested by a heightened or lowered nitrogen elimination, and that after a time there gradually comes to be maintained an equilibrium between the total amount of intaken protein-nitrogen and of the eliminated urinarynitrogen.

Tissue Protein and Circulating Protein.-This peculiarity of the animal economy, which is in effect that the amount of protein disintegration is primarily determined by the amount of protein introduced, led Voit to physiologically differentiate between tissue-protein and circulating-protein.

${ }^{2}$ H. Friedenthal (Nikolas Lake in Berlin), Pflüger's Arch., 144, 152, 1912 ; Umschau, 1912, 649. 
For decades the propriety of this differentiation has been a matter of contention. Pflüger in particular has most violently assailed it. The author frankly confesses that he has never fully appreciated the importance of this contention. Is there anything so remarkable in the point that constituents of the body, so distinct from an anatomical standpoint as blood-proteins and tissue-proteins, should from many aspects also present distinctive physiological features? Is it to be assumed as a fact that every protein which a few hours after a meal occasions an increased nitrogen elimination had previously become "organized"? Investigations in recent years have clearly shown that a differentiation between endogenous and exogenous tissue-metabolism is thoroughly justified; while the urea elimination seems primarily dependent upon the protein which is introduced we realize that the excretion of other urinary constituents, as the oxyproteic acids, urochrome, creatinin and uric acid, is determined essentially by the break-down of tissue. ${ }^{22}$ It may be that the author is not enough of an expert to be able to thoroughly comprehend fine points of distinction; but he cannot rid himself of the feeling that in the endless disputations over these and many related ideas there is a trace of the scholasticism of the Middle Ages.

Specific-dynamic Action of Protein.-While the introduction of fat and of carbolydrates in the food leads to an increase in the body stores, increase of the proteins of the food gives rise merely to an increased protein exchange. According to Rubner's theoretical views the protein undergoes a cleavage into a nitrogenous and a non-nitrogenous fraction. To the latter, along with the carbohydrates and fats, falls the rôle of providing for the energy requirements of the economy; continuous combustion of the nitrogenous moiety, in as far as it cannot be made of use for purposes of temperature regulation, leads to a loss of energy. ${ }^{23}$ Increase of

${ }^{22}$ Cf. O. Hammersten's Lehrb., 7th ed., 851, et seq., 1910.

${ }^{28}$ Cf. O. Hammersten, 1. c., p. 859 . 
protein ingestion is not an unmixed good to the adult body; aside from the fact that it forces upon the kidneys an increased functional demand, it also makes increased demands upon the provisions for temperature regulation. Later on, in connection with the subject of heat production in the body, this particular point in protein metabolism, for which Rubner has introduced the term "'specific-dynamic action," will be again taken up.

Physiological Value of Different Proteins. Heterospecific and Homospecific Proteins.-The question may here be taken up, whether the different proteins are to be considered, as far as their nutritive value is concerned, as physiologically equivalent. It is obvious that the organism, in order to construct the proteins peculiar to its tissues, makes use of "building stones," particularly aminoacids, in the same proportion in which they exist in the tissues. That the construction of the body is largely independent of the character of the food has been shown by Abderhalden and Samuely: ${ }^{24}$ the serum proteins contain eight to nine per cent. of glutaminic acid, while a vegetable protein, gliadin, is made up of about half (according to T. B. Osborne, 43 per cent.) of this latter. It has been shown that the constitution of the serum proteins of the horse is in no wise disturbed by gliadin feeding.

There is a question here which forces itself upon every one who reflects upon protein metabolism-how it happens that the same amount of protein which is broken down in the course of fasting is not sufficient to maintain the body in nitrogen equilibrium when ingested. C. Voit long since recognized that if we seek to maintain this, a multiple of the nitrogen which appears in the urine in protracted fasting must be given in the form of protein. Michaud ${ }^{25}$ (in Lüthje's Clinic) has raised the question whether it may not perhaps be

${ }^{24}$ E. Abderhalden and F. Samuely, Zeitschr. f. physiol. Chem., 46, 193, 1905.

${ }^{25}$ L. Michaud (Lüthje's Clinic, Frankfurt a. M.), Zeitschr. f. pliysiol. Chem., 59, 405, 1909. 
that the economy, in the introduction of heterospecific protein containing the protein "building stones" in different quantitative proportions than those characterizing the protein of the body, must not exert a selective activity between these components, throwing out the aminoacids that are in excess and concentrating others. "The process of transforming heterologous into homologous protein, as Abderhalden depicts it, might well explain why an animal with a supply of barely the minimum of protein of fasting cannot be brought into nitrogen balance. If this idea be followed, it must be theoretically possible to restore the nitrogen balance by limiting as far as possible this necessity for selection in regeneration, and by putting at the disposal of the economy the 'building stones' in the same concentration in which they exist in the homologous protein, none of the aminoacids or peptids either in extra or in deficient proportions. In other words, we should give an animal a protein mixture of its own body, that is, a mixture in which the individual tissue proteins are represented in exactly the same proportions as they show in their breaking down in fasting." Attempts to follow this idea have been made, by feeding dogs after a period of fasting, in some instances with heterologous proteins (gliadin, casein, nutrose), in others with a broth made up of dog muscle, various canine tissues and canine serum. The result showed (as, too, in similar experiments carried out by Hösslin and Lesser) ${ }^{26}$ that in a general way it is impossible to maintain an animal in nitrogen equilibrium by giving it no more than the equivalent of protein lost in fasting; that, however, invariably smaller amounts of homologous protein are required to restore this balance than would be required of heterologous protein. The statements of French authors ${ }^{27}$ are in harmony with this view, in that the protein

${ }^{28}$ H. v. Hösslin and Lesser (Halle und Mannheim), Zeitschr. f. physiol. Chem., $73,345,1911$; ef. also F. Frank and A. Schittenhelm, ibid., $70,99,1910$; \%马, 157, 1911.

${ }^{27}$ H. Busquet, Jour. de Physiol., 11, 399, 1909; G. Billard (ClermontFerrand), C. R. Soc. de Biol., 68, 1103, 1910. 
supply of frogs is more easily maintained by feeding with frog-meat than with the flesh of mammals; tadpoles fed in some instances with frog-liver, in others with calf-liver, are said to thrive better in the former case.

The idea that proteins of different origin are not physiologically equivalent is by no means new. Some reference to this point has been made above, in connection with the subject of the processes of resorption in the intestine; and the statement was made, too, that it has not been found possible to maintain the nutrition of an animal on gelatin as the sole source of nitrogen. Casein, gliadin and, too, zein (to be thought of in connection with its relation to pellagra) may also be regarded as examples of proteins which do not contain certain characteristic "building stones." There are a number of comparative studies upon the physiological value of different proteins, among which may be especially mentioned those of Röhmann, Thomas, ${ }^{28} \mathrm{E}$. Voit and Zisterer, ${ }^{29}$ and, too, those of Osborne and L. B. Mendel. ${ }^{30}$ The last named writer believes that at present it is too early to come to final conclusions upon this subject; that the factors of variation are too numerous to be mastered in a few simple equilibrium experiments of short duration.

Food Composed of Simple Substances.-In concluding, the interesting question of feeding animals on a diet artificially constructed of elementary foodstuffs may be properly discussed here.

The basic principle of maintaining animal life by a mixture of simple nutrient substances was long since brought forward by studies by Zadik, Abderhalden and Rona, and by Henriques and Hansen. Abderhalden's recent investigations, which have been presented above (p. 64), indicating the possibility of nourishing animals on a mixture of the

${ }^{28}$ K. Thomas, Arch. f. Anat. u. Physiol., 1909, 219.

${ }^{29}$ E. Voit and J. Zisterer. Zeitschr. f. Biol.. 53, 157. 457, 1909.

${ }^{30}$ T. B. Osborne and L. B. Mendel, Carnegie Institution of Washington, Publication, No. 156, I and IV, 1911 ; ef. Literature: L. B. Mendel, Ergebn. d. Physiol., 11, 482, 1911. 
products of hydrolytic cleavage of simple food substances, as a mixture of simple sugars, higher fatty acids, aminoacids and salts, make any further brain-racking efforts in this line superfluous. This is, however, not to say that such artificially constructed food is fully equivalent to natural food; this is certainly not true. There are still a great many imperfectly studied factors involved which are to be taken into consideration. For example, although it has not been found possible thus far to indefinitely maintain the lives of pigeons upon a mixture of simple food substances, this is apparently due, as shown by studies in the Munich Physiological Institute, ${ }^{31}$ simply to the physical character of the nutrient material, which occasions severe inflammatory processes in the crop of the birds. Contrary to divergent findings, ${ }^{32} \mathrm{~F}$. Röhmann has shown that mice can be kept alive very well on a nutrient mixture of protein material, fats, carbohydrates and salts. $^{33}$ What complicating factors are likely to enter into this type of experiments is evident in the already presented experiments of Stepp, ${ }^{34}$ who found that mice would invariably die in the course of a few weeks on a diet, otherwise entirely sufficient, from which the contained lipoids had been removed by means of alcohol and ether.

A valuable recent study by T. B. Osborne and L. B. Mendel ${ }^{35}$ has been submitted in reference to rats, showing that white rats serve as very suitable subjects for such investigations. The normal length of life of these animals is about three years; studies extending over the period of a year therefore include a very considerable part of their term of

${ }^{31}$ L. Jakob (O. Frank's Lab., Munich), Zeitschr. f. Biol., 48, 19, 1906.

${ }^{82}$ W. Falta and C. T. Noegerath (W. His's Clinic, Basel), Hofmeister's Beitr., \%, 313, 1905; P. Knapp (Basel), Zeitschr. f. exper. Pathol., 5, 147, 1908.

${ }^{33}$ F. Röhmann (Breslau), Allgem. med. Centralztg., 1908, No. 9, cited in Jahresber. f. Tierchem., 38, 659 .

${ }^{34}$ IV. Stepp (F. Hofmeister's Lab., Strassburg, and Medical Clinic, Giessen), Biochem. Zeitschr., 22, 452, 1909, and Zeitschr. f. Biol., 57, 135, 1911.

${ }^{35}$ T. B. Osborne and L. B. Mendel, 1. c., and Science, n. S., 34, 722, 1911; Jour. of Biol. Chem., 12, 473, 1912 ; Zeitsclir. f. physiol. Chem., 80, 307, 1912. 
existence. With favorable hygienic conditions and careful attention made possible in the study by the assistance of the Carnegie Institution, they succeeded in keeping rats on artificial diet for a great part of their lives. A diet of the type in mind was made up of a mixture of milk powder, starch, pork fat and salts. If milk was freed of its proteins, and the remainder concentrated, it proved to be a suitable supplement for different forms of protein diet, to such a degree in fact that, even when they fed isolated proteins, marked growth of young animals was induced. By this method the possibility of making comparisons between different proteins was afforded. Casein, lactalbumin, crystallized eggalbumin and edestin, and the glutein from wheat and glycinin from the soya bean proved to be of full value. Gliadin (from wheat) and hordein (from barley), in the catabolism of which glycocoll and lysin enter but little, proved to at least have the power of keeping the bodies of the rats in statu quo, although without growth; and zein, the tryptophan-, lysinand glycocoll-free protein of maize, as also gelatine, were found insufficient even for this last purpose. It was repeatedly noted that proteins devoid of the cyclical molecules of tyrosin and tryptophane were apparently not suitable for satisfying the requirements of growth. With this in mind Osborne suggested the hypothesis that "cyclopoiesis" (that is, ability to build up certain cyclical molecules) is a characteristic of the vegetable cell, and that for this reason the animal body may be supposed to be dependent for certain types of its nutriment upon vegetable life.

Investigations along similar lines have very recently been made in Cambridge by Hopkins: Rats were fed in parallel experiments on mixtures of casein, fat, carbohydrates and salt, with and without addition of a minimal quantity of fresh milk. Although this last addendum formed scarcely four per cent. of the total food in its dried state, it made possible a normal and continued growth; while the rats fed on the 
milk-free mixture remained stationary in their development. ${ }^{36}$

Velocity of Protein Catabolism in Metabolism.-Another problem of metabolism which has received much attention is that involving the rapidity of protein break-down in metabolism. A very large number of studies ${ }^{37}$ may be interpreted somewhat as follows: The velocity of decomposition of ingested proteins depends upon the state of nutrition and is the more marked the longer a preceding period of hunger has existed. Postcoenal urea elimination in normal human beings shows a maximum reached in from the fourth to the fifth hour ; ${ }^{38}$ if, however, the nitrogen-bearing nutrient matter is given in the form of protein in advanced cleavage the maximum urea-elimination appears earlier (in the course of the first hour). Elimination of nitrogen and that of sulphur often, but not invariably, proceed in parallel lines; in many instances the sulphur fraction appears to be the first to be attacked in the cleavage of the protein molecule, and the elimination of sulphur, as a sulphate, precedes the formation of urea. ${ }^{39}$ The output of ammonia takes place with greater velocity and at times reaches its maximum in advance of the nitrogen and sulphur. ${ }^{40}$ When the protein cleavage occurs with formation of sugar (as in phloridzin diabetes) glucose is excreted before the nitrogen. ${ }^{41}$ The carbon coming from the protein is eliminated by the lungs (according to Frank

${ }^{36}$ F. Gowland Hopkins (Physiol. Lab., Cambridge), Jour. of Physiol., 44, $425,1912$.

${ }^{\Im}$ C. Voit, C. Ludwig, Panum, Falck, Feder, Sondén and Tigerstedt, Landergren, Reilly, Nolan and Lusk, Sherman and Hawk, Slosse, Frank and Trommsdorf, Vogt, Falta, Gigon and Pari, Marriott and Wolf, Camerer, Asher and Haas, Levene, Stauber, Wolf and Österberg, and others. Cf. Literature: R. Tigerstedt, Nagel's Handb. d. Physiol., 1, 392, 412-1905; A Stauber (E. Freund's Lab., Vienna), Biochem. Zeitschr., 25, 187, 1910; C. G. L. Wolf (Cornell Univ., New York), ibid., 40, 194, 1912; 41, 111, 1912.

${ }^{38}$ According to Asher and Haas and to A. Stauber.

${ }^{30}$ Cf. J. Hämäläinen and W. Helme (Helsingfors), Skandin. Arch. f. Physiol., 19, 182, 1907.

${ }^{40}$ C. G. L. Wolff, 1. c.

${ }^{41}$ Lusk and his collaborators. 
and Trommsdorf) more quickly than by the kidneys. An important point determined in these studies is the fact that excretion of creatinin, uric acid, and oxyproteic acids is not influenced in any material degree by protein ingestion.

Ernest Heilner's observation is of considerable interest in this connection, showing that urea introduced subcutaneously has a stimulative effect on protein metabolism, thus suggesting the possibility of urea itself being a factor in the special mechanism regulative of the course of intracorporeal protein disintegration. ${ }^{42}$

\section{METABOLISM IN FASTING}

We may now proceed to outline the information we possess relative to metabolism in fasting: ${ }^{43}$ It is the author's purpose to set forth only the most interesting points which have appeared in the extensive literature concerning this subject. It has been so often stated that these discussions make no pretense to completeness, that it is decidedly superfluous to repeat it.

How Long May Hunger and Thirst Be Endured?What is the longest possible period of endurance of absolnte withdrawal of food? The professional faster, Succi, fasted for thirty days; the American physician, Dr. Tanner, for forty days; and Merlatti in Paris for as much as fifty daysalthough it must be noted that the last drank water and that Succi took large doses of opium to allay his gastralgia. Adult dogs can be kept alive certainly as much as sixty days in a state of absolute carency. The author would not grant any very great importance to the isolated observation of Kumagawa, whose experiment animal died on the ninety-eighth day

${ }^{42}$ E. Heilner (Physiol. Instit., Munich), Zeitschr. f. Biol., 52, 216, 1909.

${ }^{43}$ Literature upon Metabolism in Fasting: S. Weber, Ergeb. d. Physiol., 1', 701-746, 1902; R. Tigerstedt, Nagel's Handb. d. Physiol., 1, 375-391, 1905; A. Magnus-Lery, Handb. d. Pathol. d. Stoffw., 2d ed., 1, 310-315, 1906; C. ron Noorden, ibid., 1, 480-547, 1906; Benedict, Metabolism in Inanition, Carnegie Institution, Washington, 1907; T. Brugsch, Handb. d. Biochem., 4', 284-306, 1908; R. Tigerstedt, ibid., 4", 55-66, 1910; Graham Lusk, Ernährung u. Stoffw., $38-70,1910$. 
of fasting, with a loss in weight from the original seventeen kilograms down to six kilograms; as experimental faults, such as an occasional clandestine feeding by some compassionate hand, can scarcely be entirely excluded in practice. American authors have recently obtained information for publication of a dog which withstood one hundred and seventeen days of hunger and a loss of sixty-three per cent. in weight. ${ }^{44}$

When water is withdrawn at the same time hunger cannot be withstood for nearly the same length of time. In this case the water required for solution of the urea is abstracted from the tissues. Straub observed in his thirsting dogs, fed on dried meat and fat, a loss of one-fifth of the water contained in the muscles; yet in these cases the mode of feeding could not be continued very long because of intestinal disturbances and vomiting of the ingested food. According to Rubner pigeons die after four or five days if allowed to hunger and thirst, but can be kept alive for twelve days if given water. As a rule, fasting luman beings do not drink a great deal of water, as water is produced in the course of combustion of the tissues and the amount of digestive juices secreted is very small.

Loss of Weight of the Organs.-Death of animals in inanition occurs after at least from one-third to one-half of their weight has been lost. If one considers, however, the total amount of consumable material only, the loss at time of death may amount to as much as seventy per cent. The loss of weight in starved animals is distributed (as indicated by the studies of Chossat, Voit, Kumagawa, Sedlmair and others) unevenly; the adipose tissue being seriously involved, a loss of ninety per cent. or more of this being possible. The muscles, the large glands and the blood may lose as much as half their substance; while the central nervous system remains almost unchanged in weight. The skeletal

${ }^{4}$ P. E. Howe, H. A. Matill and P. B. Hawk (Univ, of Illinois), Jour. of Biol. Chem., 11, 103, 1912. 
muscles are affected in a higher degree than the heart; Voit calculated in case of the cat that while the muscles had lost thirty per cent. in weight, the heart had been reduced only three per cent. However, the statements recorded in reference to this point in literature are contradictory.

As far as the blood is concerned, the most constant change seems to be a relative increase of its globulins as contrasted with the albumins (as observed by Burckhardt, Githens, Wallerstein and others). This is accounted for in different ways, in the first place as due to a passing of the globulins out of the tissues, and in the second place on the ground that albumin principally is derived from the food; howerer, the connection is not clear. Sometimes, too, it is said that there is a "thickening," or, on the other hand, that there is an "atrophy" of the blood (where it is held there is a loss of its formed elements proportionate to the body mass). The increased amount of fat in the blood in inanition is striking (vide infra). Some have regarded observations of Landois upon artificial plethora by injection of blood, in which condition the excess of serum proteins as circulating protein is easily used, but the "tissue protein" of the red blood cells is much more slowly broken down, as of importance to our conception of the condition of the blood in inanition; however, there has not been any important conclusion from it. Benedict has noted in fasting human beings a progressive loss of lencocytes, erythrocytes and hæmoglobin.

Total Metabolism in Inanition.-What then of the general exchange in fasting? ${ }^{45}$ It might be expected in the first place that the fasting individual would lower his requirement. This, however, is not the case; in spite of expenditure of the body substance proper, the organism is unable to materially lower its exchange below that of normal nutrition. It is true the energy consumption is lowered from day to day, but at the same time the body weight also is diminished. If

${ }^{45}$ Cf. Literature upon Energy Exchange in Inanition: R. Tigerstedt, Handb. d. Biochem., -4" 55-66, 1910. 
the energy consumption be determined in proportion to the kilogram of body weight a striking uniformity becomes evident, about 28 to 32 calories pro kilogram for the twentyfour hours. In case of rest in bed the minimal requirement of a liuman being was determined as somewhat less by Tigerstedt and by Johansson, twenty-two to twenty-five calories daily pro kilogram. Atwater and Benedict found in fasting human beings resting in bed an energy consumption of twenty to twenty-one calories by direct calorimetry; Zuntz, in case of an individual accustomed to a diet very low in protein (consisting of potatoes and butter), at absolute rest and fasting, met with a twenty-four hour energy consumption of only about nineteen calories pro kilogram. ${ }^{46} \mathrm{Ob}-$ servations of the respiratory metabolism and nitrogen output have shown, further, that not only the total expenditure of energy but also the amount of protein and fat, which provides the latter, are fairly constant in the body. It should be noted, too, that the economy begins its actual fasting state only after the lapse of several days, after the greater glycogen deposits have been consumed. The constancy of the exchange in inanition is, however, not confined merely to human beings. E. Voit found in case of all warm blooded animals studied a relative uniformity of energy requirement in inanition if it be determined for the unit of surface. " "I conclude directly," says Rubner, "that the developing animal in its growth manifests a very varying intensity of general metabolism in inanition, but that invariably the intensity

${ }^{40}$ N. Zuntz, Centralbl. f. Physiol., 26, 725, 1912.

${ }_{4 \pi}^{4}$ Note: "The minimal maintenance work of the fattened and the nonfattened growing animal," says Tangl, in a study of the minimal maintenance effort of the hog (Biochem. Zeitschr., 44, 278, 1912), "show scarcely any difference, when calculated on the basis of the surface extent of the body; calculated on the basis of body weight it is greater for the growing unfattened animal. As an average it is for the fattened, pro kilogram 19.6 calories, pro square metre 1060 calories; for the unfattened, pro kilogram 27.2 calories, pro square metre 1100 calories. It is in each instance noteworthy that in spite of the difference in the amount of fat in the fattened and unfattened animals the maintenance work determined on the basis of a unit of body surface is the same . . ." 
is, under similar conditions, only an expression of the relative surface development." 48 Reference will hereafter be made to the objections to this view. That active effort in the state of inanition must necessarily raise the energy requirement, is obvious; Pettenkofer and Voit in such case were always able to show a greatly increased fat break-down.

Protein Economics in Inanition.-The curve of nitrogen elimination presents a fairly characteristic course for the protein management in fasting: ${ }^{49}$ During the first days of fasting it seems to be influenced by the previously ingested food ${ }^{50}$ until the supplies of "labile protein" and glycogen in the system have been consumed. The consumption of the latter substance especially, according to Prausnitz and Landergren, is usually followed by an increase in the protein exchange after the course of the first few days. Then, however, the protein exchange gradually falls in the further continuation of starvation. By far the greatest proportion of energy used in inanition, about ninety per cent. as an average in man, is accomplished at the expense of the diminishing fat supply. Only at the close, after the stored fat has been reduced to small residua, does an antemortem nitrogen-increase make its appearance. This is usually regarded as due to the impoverishment in fat making itself felt. There is no question but that a fat animal will withstand starvation longer than one poor in fat. F. N. Schulz believes that the antemortem rise in nitrogen elimination is determined not so much by a lack of fat as by a sudden necrosis of numerous badly involved cells; but this suggestion is contradicted by the Voit school. Tigerstedt thinks that perhaps it may be due to some kind of intoxication. The fact that residual fatty tissue is to be found in starved animals cannot, in the writer's opinion, be accepted as proof against the view

${ }^{48}$ Cf. Th. Brugsch, l. c., p. 288.

Literature upon Protein Conservation in Inanition: A. Magnus-Levy, Handb. d. Pathol. d. Stoffw., 2d ed., 310-315, 1908.

${ }^{50}$ Cf. G. Kinberg (Stockholm), Skandin. Arch. f. Physiol., 25, 291, 1911. 
that the antemortem nitrogen rise is brought on by the lack of fat; it might easily be conceived that the last portions of the fat are liquidated with much more difficulty than the principal mass of the fat deposits. According to Reicher ${ }^{51}$ the particles of fat in the blood, visible as ultramicroscopic particles (steatoconiæ) disappear in a suggestive manner at the time of the antemortem nitrogen rise. From the studies of Abderhalden and his associates ${ }^{52}$ no evidence exists for the supposition that there is a change in the chemical character of the body proteins from inanition.

In view of the fact that access to water prolongs the life of fasting animals, it is strange that, as found by Heilner, in a fasting animal (contrasted with a well fed animal) it occasions an increase of nitrogen elimination, referable to increase of break-down of nitrogenous body substance, but not to a flushing out of end-products of metabolism. ${ }^{53}$

Carbohydrate Metabolism.-The nitrogen exchange of a fasting animal is by no means the same thing as the minimal nitrogen metabolism. By feeding carbohydrates there is accomplished a sparing of protein depending on the amount of food, possibly (according to investigations made in the laboratory of $\mathrm{E}$. Voit) reaching in maximum nearly fifty-five per cent. ${ }^{54}$ The nitrogen elimination in the urine, which in a fasting human being is seldom less than ten grams, may, according to Landergren, be reduced by free exhibition of carbohydrates and fat to five or six grams, or even less.

The supposition that glycogen disappears rapidly and completely from the body of a fasting individual has undergone, as previously stated, some modification, as a result of recent investigations upon the subject of formation of sugar from protein. It is now realized that in an individual ren-

${ }^{81}$ K. Reicher (Berlin), Zeitschr. f. exper. Pathol., 5, 750, 1909.

${ }^{52}$ E. Abderhalden, P. Bergell and T. Dörpinghaus, Zeitschr. f. physiol. Chem., 41, 153, 1904.

${ }^{53}$ E. Heilner (C. Voit's Lab.), Zeitschr. f. Biol., 4\%, 539.

${ }^{s}$ M. Wimmer (Physiol. Instit., Veterinary High School, Munich), Zeitschr. f. Biol., 5\%, 185, 1911 . 
dered almost free of glycogen by fasting there may take place formation of glycogen de novo. Thus Zuntz observed, in rabbits which had lost almost all their glycogen from combined inanition and strychnine convulsions, the reappearance of glycogen at the conclusion of a protracted chloral narcosis. $^{55}$ After all that has been said of the formation of sugar in connection with phloridzin diabetes and pancreatic diabetes, there is little occasion for surprise in this. Stiles and Graham Lusk observed in a fasting dog poisoned with phloridzin that while the amount of nitrogen eliminated underwent diminution the sugar formation fell at the same time, thus maintaining unaltered the quotient $\frac{D^{56}}{N \text {. }}$

The Urine in Inanition.-The acidosis of inanition is a striking anomaly of metabolism. Reference to this phenomenon has been made above in connection with the acetone bodies, where it was stated that we have every reason to look upon the formation of $\beta$-oxybutyric acid and diacetic acid in the fasting individual as related to the breakdown of fat. The proportion of acetone bodies in inanition urine may at times be very considerable; thus D. Gerhardt and W. Schlesinger found in a case of hysterical vomiting forty grams of oxybutyric acid in the urine in the course of twentyfour hours. The natural result of the abnormal acid production in the body is an increased elimination of ammonia in the urine; Brugsch observed as much as thirty-five per cent. of ammonia nitrogen. For fuller details in this connection reference may be made to the monograph of $C$. von Noorden. ${ }^{57}$

A great deal of trouble has been expended upon the analysis of inanition urine. From among the discoveries which have invariably rather poorly rewarded the labor expended in this direction, special mention may be made of the observa-

${ }^{w}$ Cf. Literature (N. Zuntz and Vogelius, Nebelthau, Külz, Frenzel); Th. Brugsch, l. c., p. 300 .

${ }^{56}$ Stiles and Graham Lusk, Amer. Jour. of Physiol., 10, 77, 1903.

${ }^{57}$ C. von Noorden, 1. c., pp. 529-536. 
tions of Benedict and Cathcart in reference to the increase of creatin in comparison with creatinin and the occasionally noted occurrence of "albumoses." 58

Respiratory Quotient.-Much attention has been given to observations upon the matter of the respiratory quotient in inanition. As the fasting individual, after the glycogen supplies have been used up, lives upon fat and protein the respiratory quotient must lie between the figures of protein breakdown (0.8) and of fat decomposition (0.7). Benedict, as a matter of fact, from experiments upon fourteen fasting human being's in Atwater's respiration apparatus, found in all after the first day of fasting that the quotients were very uniformly $0.74 .^{59}$

Hibernation.-Inanition experiments of the greatest interest may be observed in nature in case of hibernating animals. In these the exchange is found very much lowered when the temperature falls to $16^{\circ}$ to $12^{\circ} \mathrm{C}$.; as in the case of the hedgehog, to one-tenth to one-twentieth of the normal; in the dormouse, it is said, even to one-hundredth. Studies have been made upon marmots and bats also. Observation of the respiratory quotient in such animals shows completely paradoxical results; at times the figure is remarkably low, less than has ever been observed in any other conditions (below 0.5, even down as low as 0.23). ${ }^{60}$ Only a small fraction of the oxygen taken in appears as carbon dioxide in these animals, a point which must be interpreted as indicating that the fat (which constitutes the bulk of the reserve material of the hibernating animal) is incompletely burned. However, there are probably formed intermediate oxygen-

${ }^{58}$ Literature upon the Urine of Inanition: Th. Brugsch, l. c., pp. 301-306.

${ }^{6} \mathrm{G}$. F. Benedict, The Influence of Inanition on Metabolism, published by the Carnegie Institution of Washington, 1907.

${ }^{\infty}$ In hibernating bats, however, according to studies of P. Hári (F. Tangl's Lab., Budapesth), Pflïger's Arch., 130, 112, 1909, the respiratory quotient is generally not lower than that found in prolonged inanition experiments in other animals $(0.65-0.7)$; only exceptionally were the figures below 0.5 . 
bearing products which are principally retained within the body. Possibly we have here instances of the much debated formation of carbohydrate from fat. This retention of oxygen explains the very odd feature of occasional accession of weight by the fasting hibernating animals. When the animal wakes up the respiratory quotient rapidly rises to about 1.0, corresponding to the combustion of carbohydrates. ${ }^{61}$

Rhine salmon; Batrachian Larvœ.-Other extremely instructive experiments in the field of the physiology of inanition provided by nature are met in the Rhine salmon and batrachian larvæ. It is known that the male salmon, when ascending the Rhine from the sea, fasts for many months and develops the sexual organs at the expense of the wasting musculature. It is also known that, for example, the larva of the obstetrical toad absorbs its tail in the course of weeks of fasting, while the legs are growing out from the rump. It is, however, impossible to go into further detail in connection with these remarkable subjects.

Sensation of Hunger.-A few words more in conclusion in reference to the sensation of hunger. This is apparently conducted along the vagus paths. Cocainization of the vagi in the neck, and so, too, of the pharyngo-œsophageal mucous membrane, is said to seemingly remove in dogs the sensations of hunger and thirst. ${ }^{62}$ According to Camnon, who has graphically registered the gastric movements in man by means of a balloon inserted into the stomach, the feeling of hunger is excited by contractions of the gastro-intestinal canal. $^{63}$ So much for the subject of inanition.

${ }^{61}$ Literature upon Exchange in Hibernation: O. Polimanti, Bull. accad. med. Roma, 30, 227, 1904; A. Löwy, Handb. d. Biochem., 4', 177-178, 1908; F. Reach (Durig's Lab., Vienna), Biochem. Zeitschr., 26, 391, 1910; E. Weinland and M. Riehl (Physiol. Instit., Munich), Zeistchr. f. Biol., 49, 37, 1907.

${ }^{62}$ A. Valenti (Pavia), Arch. di farm., 8, H. 6, cited in Centralbl. f. d. ges. Biol., 10, No. 326, 1910.

${ }^{83}$ W. B. Cannon and A. L. Washburn (Harvard Medical School), Amer. Jour. of Physiol., 29, 441, 1912. 


\section{PARENTERAL NUTRITION}

The remainder of this lecture will be given over to the practically important problem of parenteral feeding.

The physician is often enough brought face to face with a case in which the incapacity of the diseased gastro-intestinal apparatus brings with it an impossibility of providing the body with the food necessary for maintenance of life. Here the question forces itself upon him whether it may not be possible to introduce the food into the body, disregarding the intestinal tract, by direct "parenteral" route. The feeling that this is a problem in which the physiological chemist can render an important and immediate service to the practitioner of medicine finds expression in the large number of experimental studies, which in the course of the last few year's have been directed especially to the question of parenteral protein administration. What results have been obtained?

Parenteral Introduction of Protein.-The older physiologists were for the most part of the opinion that heterologous protein introduced into the system is not assimilated, but is simply passed out with the urinary excretion. This, however, as a matter of fact is by no means entirely true. It is true that sometimes an albuminuria is observed after parenteral administration of protein ${ }^{64}$; eggalbumin seems to pass into the urine especially easily. (In normal human beings albuminuria has been noted after the ingestion of six raw eggs, evidently due to portions of the albumin which passed the intestinal wall without undergoing cleavage.) ${ }^{65}$ However, elimination of this sort is by no means the rule. There is no doubt that the economy is able to retain and consume large amounts of parenterally introduced specifically foreign protein (among others, for example, foreign blood serum, ${ }^{66}$ egg albumin, ${ }^{67}$ casein, ${ }^{68}$ or vegetable albumin ${ }^{69}$ ).

*f. W. Cramer (Physiol. Instit., Edinburgh), Jour. of Physiol., 37, 146, 1908; J. Castaigne and M. Chiray, C. R. Soc. de Biol., 60, 218, 1906.

${ }^{65}$ W. Cramer, l. c., p. 157. 
Modern methods of immunity investigation (particularly by precipitins and anaphylaxins) make it possible to follow up the fate of proteins which are introduced into the system; such substance may be recognized for days in the circulating blood, in the peritoneal fluid and in various tissues. It has been found possible to substitute two-thirds of the required food protein in a dog by horse-serum injected subcutaneously without disturbing the nitrogen equilibrium..$^{70}$ Homologous protein is evidently better tolerated than foreign protein. ${ }^{i 1}$ After free transfusion of homologous blood directly from an artery of one dog into a vein of a second dog there is usually observable in the latter an increase of the nitrogen elimination as evidence of an increased protein break-down; i2 but at times this may not oceur. Maintenance of nitrogen equilibrium seems impossible, however, even with infusion of specifically identical serum. ${ }^{73}$ Kornel v. Körösy, ${ }^{74}$ as well as Lerene, has been able to prove (contrary to opposed statements $)^{\text {Ts }}$ that it is of no consequence, as far as the fate of proteins injected intravenously is concerned, whether they have passed with the circulating blood through the intestinal wall or not.

${ }^{66}$ E. Heilner (Physiol. Instit., Munich), Zeitschr. f. Biol., 50, 26, 1908; P. Rona and L. Michaelis, Pflïger's Arch., 124, 578, 1908.

${ }^{67}$ Cramer, 1. c.; V. C. Vaughn, J. G. Cumming and C. B. M. Glumphy (Lniv. of Michigan), Zeitschr. f. Immunitätsfor., 9, 16, 1910.

${ }^{68} \mathrm{~L}$. Michaelis and P. Rona, Pflüger's Arch., 121, 163, 190 s.

${ }^{\bullet}$ L. B. Mendel and E. W. Rockwood (Yale Univ.), Amer. Jour. of Physiol., 12, 336, 1905 .

${ }^{70} \mathrm{P}$. Rona and L. Michaelis, Pfiüger's Arch., 1.2.4, 579, $190 \mathrm{~s}$.

${ }^{71}$ U. Friedemann and S. Isaak, Zeitschr. f. exper. Pathol., 4, 830, 1907, and earlier works; F. Lommel (D. Gerhard's Clinic, Jena), Arch. f. exper. Pathol., $58,50,190 \tau$.

¿2 P. Hâri (F. Tangl's Lab., Budapesth), Biochem. Zeitschr., 3't, 111, 1911; cf. also H. D. Haskins (Western Reserve Univ.), Jour. of Biol. Chem., 3, 321, 1907. 1912.

${ }^{73}$ G. Quagaliariello (Bottazzi's Lab., Naples), Arch. di Physiol., 10, 150,

${ }^{74}$ K. v. Körösy (Physiol. Instit., Budapesth), Zeitschr. f. physiol. Chem., $69,313,1910$.

${ }^{75}$ E. Freund and H. Popper (Vienna), Biochem. Zeitschr., 15, 272, 1909. 
As to the question of the practical applicability of parenteral introduction of protein, it should be understood that the procedure is anything but a harmless expedient. ${ }^{76}$ It would not necessarily mean very much that after parenteral introduction of protein an unusual amount of ammonia was noted in the urine and a percentage increase in the purin figures. ${ }^{i 7}$ The observation of an œdematous swelling of the mammary glands after casein injection might be related with a specific sensitivity of the latter toward casein. ${ }^{78}$ But we cannot but be startled by statements like those of Friedemann and Isaak, ${ }^{79}$ to the effect that intravenous introduction of serum albumen is not followed by toxic effects in fasting dogs, but in well fed animals in nitrogen equilibrium usually induces symptoms which end in death. The many experiences with anaphylaxis, and the danger of repetition of parenteral introduction of protein brought to light in recent years (the "serum diseases" from the therapeutic use of diphtheria antitoxin serum, etc., undoubtedly belong here in part) must necessarily very much depress any hope of making parenteral protein feeding ever of any great practical value in medicine. E. Heilner 80 regards it as probable that the phenomena of "anaphylaxis", are due, not so much to the production of abnormal toxic intermediate products of protein metabolism, as to the relative resistance of substances which under other circumstances are rapidly elaborated.

Possibly, however, a greater practical importance may attach to the parenteral introduction of the products of hydrolytic cleavage of protein than to the parenteral ad-

${ }^{76} \mathrm{Cf}$. the careful investigations in Tangl's Laboratory by P. Hári, C. Rudó and S. Cserna, and L. Ornstein (Biochem. Zeitschr., 44, 1, 40, 94, 140, 1912) upon the influence of intravenous and intraperitoneal infusion of blood, and of subcutaneous feeding with bloodserum-glucose mixtures.

"S. v. Somogyi (Physiol. Instit., Budapesth), Zeitschr. f. physiol. Chem., $71,125,1911$.

${ }^{\text {is }} \mathrm{P}$. Rona and L. Michaelis, 1. c.

T2 U. Friedemann and S. Isaak, 1. c.

${ }^{80}$ E. Heilner (Physiol. Instit., Munich) Zeitschr. f. Biol., 58, 333, 1912; cf. therein Literature. 
ministration of protein. From studies in this connection by Stolte, Salaskin and Kowalewski, Abderhalden and his associates, and from those of Wohlgemuth, but particularly from very recent investigations in Bottazzi's laboratory, ${ }^{\text {s1 }}$ the results clearly indicate that aminoacids injected into the blood are eliminated only in a small fraction by way of the kidneys, that the bulk disappear within the body, and that there is no intrinsic reason why we should not attribute to them the possibility of taking part in the up-building of protein in the system. It seems, too, that aminoacids can be introduced directly in the veins of an animal in quantities quite sufficient for the nitrogen requirements of the animal without the necessity of fearing severe toxic phenomena. Our experience with the matter is, however, as yet not extensive enough to justify a final opinion.

The ability of the body to handle parenterally introduced proteins is explicable from the investigations of Abderhalden and his collaborator's, who have shown by the "optical method" that the plasma of animals, after parenteral injection of proteins and high molecular products of proteincleavage, possesses the power to catabolize these substances. It seems that under these circumstances the formed elements of the blood and other body cells give off peptolytic ferments, just as, according to Abderhalden and to Heilner, after parenteral introduction of compound carbohydrates (as cane-sugar, milk-sugar and starch) ferments appear de novo in the plasma which induce cleavage of these substances. ${ }^{82}$

Parenteral Feeding wiıh Sugar.-What may be accomplished in the way of parenteral nutrition with sugar?

In this connection attention may be called to a series of very interesting observations recently collated by $W$.

${ }^{81}$ G. Buglia (F. Bottazzi's Lab., Naples), Zeitschr. f. Biol., 58, 162, 1912, and earlier studies; ci. therein Literature.

${ }^{82}$ Abderhalden's works on the proof of proteolytic and peptolytic ferments after introduction of specifically foreign and blood-foreign proteins and peptones are collected in Abderhalden's Synthesis der Zellbausteine (Berlin, J. Springer, 1912), pp. 119-120. 
Kautsch ${ }^{83}$ upon a group of forty persons. Subcutaneous injections of grape-sugar are apparently from these studies well borne up to five per cent. strength; stronger solutions occasion pain. So, too, intravenous infusions of as much as 1000. cubic centimetres of a five to seven per cent. solution of grape-sugar are remarkably well tolerated. Only a small fraction of the sugar thus incorporated appears in the urine. The worse the state of general nutrition the greater the quantity of sugar which is tolerated. A woman with puerperal sepsis, peritoneal symptoms, vomiting and diarrhœa, received each day for six days a solution of sugar, going as high as two litres a day, with a concentration of the solution gradually increasing up to nine per cent.; she recovered. Kautsch urges that intravenous nourishment with grape-sugar be tried also in severe hysterical vomiting, in serious catarrhs of the stomach and intestine, as well as in cholera. Intraperitoneal injections of a five per cent. solution of glucose in human beings give rise, according to $\mathrm{A}$. Sclimidt, to considerable peritoneal irritation. ${ }^{8+}$

It was formerly thought that cane-sugar, when introduced parenterally, passes entirely into the urine; but, according to recent investigations by E. Heilner ${ }^{85}$ and by L. B. Mendel, ${ }^{86}$ this is by no means the case. Thus, if one to two grams pro kilogram of body weight be injected into cats or dogs, either intravenously or intraperitoneally, only sixtyfive per cent. is recoverable in the urine. As above stated, we must assume that there occurs a fermentative cleavage of the disaccharide in the blood (perhaps by a protective ferment formed ad hoc). After parenteral introduction of

${ }^{83}$ W. Kautsch (Augusta-Victoria Hospital, Berlin-Schöneberg), Deutsch. med. Wochenschr., 1911, 8.

A. Schmidt and H. Meyer (Dresden), Deutsch. Arch. f. klin. Med., 85, $119,1905$.

${ }^{85}$ E. Heilner (O. Frank's Lab., Munich), Zeitschr. f. Biol., 56, 75, 1911.

${ }^{88}$ L. B. Mendel and J. J. Kleiner (Yale Univ., New Haven), Amer. Jour of Physiol., 26, 396, 1910.

${ }^{87}$ L. B. Mendel and P. H. Mitchell (Yale Univ.), Amer. Jour. of Physiol., 1\}, 239, 1905 . 
glycogen there may be found in the urine a body similar to achroodextrin. ${ }^{\mathrm{s} \tau}$ Soluble starch appear's in the urine if injected rapidly but does not appear if gradually introduced; it evidently undergoes conversion into sugar in the blood.ss

Parenteral Feeding with Fat.-Finally what of parenteral nutrition by fat? It has been stated in connection with the discussion of fat metabolism that the subcutaneous introduction of fat as a nutrient as recommended by Leube has not been approved in practice, and cannot be maintained, because it turns out that olive oil, introduced drop by drop, is absorbed from the subcutaneous tissue so very gradually, that only a few grams can be absorbed in the course of a day. ${ }^{89}$ However it appears that these failures have been due entirely to the faulty methods of introduction. Intraperitoneal absorption of injected fats takes place very rapidly in man and the lower animals; and it may be added that the oil injections have a less irritative effect than either sugar- or protein-solutions. ${ }^{90}$ However even from the subcutaneous tissue resorption of oil takes place when it is emulsified with lecithin and water, apparently rapidly enough for the economy to obtain in this way at times from half to threefourths of its required calories. ${ }^{91}$ It is quite likely that medical practice of the future will have to reckon with these hitherto insufficiently regarded subjects.

${ }^{8 s}$ F. Verzár (Tangl's Lab.), Biochem. Zeitschr., 34, 66, 1911.

${ }^{\circledR}$ H. Winternitz, Zeitschr. f. klin. Med., 50, 80, 1903; Yandell Henderson and E. F. Crofutt, Amer. Jour. of Physiol., 1/, 193, 1905; E. Heilner, Zeitschr. f. Biol., 5.t, 54, 1910.

${ }^{\circ} \mathrm{A}$. Schmidt and H. Meyer, l. c.

${ }^{r 1}$ L. H. Mills, Arcl. int. Med., 7, 694, 1911, cited in Centralbl. f. d. ges. Biol., 1911, No. 2902. 


\section{CHAPTER XXI}

\section{METHODS OF STUDY OF GAS EXCHANGE. MAIN-}

TENANCE METABOLISM AND GROWTH. ENERGY EXCHANGE AFTER INGESTION OF FOOD

In the course of these lectures reference has frequently been made to estimation of the volume of gas exchange, of the respiratory quotient and similar matters. An explanation of the methods which we have at our disposal for determining these values has, however, not been presented, and the opportunity should be taken at this time to repair this neglect, by at once outlining the technic of the modern study of gaseous metabolism ${ }^{1}$ as fully as seems to pertain to general biochemical training.

\section{METHODS OF GAS EXCHANGE STUDIES}

Pettenkofer Type of Respiration Apparatus.-A respiration experiment may be conducted on Pettenkofer's principle by placing the individual concerned in an enclosed space through which a current of air is passed by a pump mechanism. The volume of the air is measured by means of a gasmeter, and an aliquot portion is analyzed for its water and carbonic acid by means of sulphuric acid- and baryta-receivers. The respiration apparatus of Sondén and Tigerstedt, the respiration chamber of which, a room lined with sheet zinc, is large enough to accommodate a number of persons at the same time, works on this principle; but the gas samples from it are analyzed by a volumetric method. The method is very exact, the error in carbonic acid (as shown by control experiments in which known amounts of oil were

${ }^{2}$ Literature upon Respiration Apparatus: A. Jaquet, Ergebn. d. Physiol., 2, 458-462, 1902; W. O. Atwater, ibid., 3, 498-512, 1904; A. Magnus-Levy, Handb. d. Pathol. d. Stoffw., 2d ed., 1, 19S-212, 1906; A. Loewy, Handb. d. Biochem., 4', 133-144, 1908; O. Cohnheim, Physiol. d. Verdauung und Ernährung, pp. 360-365, 1908. 
burned) being scarcely greater than two per cent. Jaquet's respiration apparatus is based upon the same principle.

Regnault and Reiset Type of Respiration Apparatus.The principle of renewal of a circulating current underlies the respiration apparatus of Regnault and Reiset, in which the same body of air after having its carbonic acid removed is constantly repassed through the respiration chamber, the oxygen being renewed from a gas reservoir as required. Although in its original form this apparatus was only suited for the study of small animals, Hoppe-Seyler constructed a form on the same principle, the respiration chamber of which afforded continuous accommodation for a human being, being of about five cubic metres dimension. A more capacious and rery much more satisfactory type on the same principle may be seen in the large respiratory apparatus constructed by N. Zuntz and C. Oppenheimer, in the Physiological Institute of the Agrieultural High School in Berlin, with a capacity of eighty cubic metres. A tread mill, enabling the performance of desired movements uphill and downhill as well as exactly prescribed traction, is built in. Moreover the trachea of an enclosed animal can be connected by conducting tubes with measuring apparatus so that separate study of pulmonary breathing and gas exchange through the skin and intestine can be carried on. By means of special provisions the apparatus makes it possible to have any desired temperature, atmospheric moisture and (by fans) also any atmospheric movements act upon human beings, to make changes in the proportions of oxygen and carbonic acid in the air, and thus in some degree to produce artificially any sort of climate. The apparatus can be arranged for employment on Pettenkofer's principle as well as on that of Regnault and Reiset. Ordinarily it is used in the latter manner, and the air for respiration purposes is chilled in a tower seven metres high from contact with a system of cooling pipes down to a temperature of $-10^{\circ} \mathrm{C}$., and ex- 
exposed to a shower of caustic potash, being thus freed thoroughly of its moisture and carbonic acid. In the Children's Clinic in Düsseldorf there is a similar apparatus arranged for the study of the gas metabolism of infants. Control experiments with combustion of alcohol in this apparatus have shown an average error of 0.4 per cent. in carbonic acid determination, which is to be regarded as a very remarkable performance. ${ }^{2}$

Respiration Calorimeter of Atwater and Benedict.-The apparatus of the American physiologists, Atwater and Benedict, is undoubtedly to be regarded as the most complete thus far constructed for the study of the respiratory and general metabolism. The respiration chamber of this apparatus is a room provided with a table, bed and folding chair in which the experiment subject may eat, drink, sleep, work and remain for days. The room is surrounded by a double layer of air, there being three walls. There is included a system of water pipes, very much like a hot water system of heating, which takes away any excess of heat; knowing the amount of water which passes through the apparatus in the course of the experiment and the amount of heat it acquires in passage, the total amount of heat produced can be readily determined. There are, however, arranged in the walls about the respiration chamber thermometers and a system of wiring for electrical heating. The thermometers are connected with a galvanoscope, the steadiness of which is assurance of the constancy of the temperatures during the experiment. An attendant keeps the galvanoscope constant throughout, correcting for the least variation, either by altering the current of water circulating through the walls or by the electrical heating appliance. It is not difficult to keep the current of air even in temperature in this way from the time of its admission to its exit from

2. Züntz and C. Oppenheimer, Biochem. Zeitschr., 1', 361, 1908; A Schlossmann, C. Oppenheimer and H. Murschhauser, ibid. 
the apparatus. Tests are made before and after in order to determine exactly the amounts of carbonic acid and water given off from the body by the lungs and skin. Proper provisions are made for the introduction of food and drink and the removal of the solid and fluid excreta. These are analyzed, not only for nitrogen, fat, carbohydrate and inorganic constituents, but also (by means of a calorimeter bomb) for their combustion temperature, thus providing all conditions for a complete report of the energy exchange and metabolism. The reliability of the apparatus is determined for control purposes at the beginning and at the end of each experiment by burning in it an exactly known quantity of alcohol. As evidence of the precision attained with the apparatus it may be added that in the alcohol experiments the average results for three years show the recovery of 100 per cent. of the theoretically calculated quantities of carbon dioxide, 103.1 per cent. of the water, and 100.2 per cent. of the heat. ${ }^{3}$ Such results are magnificent and marvelous, and, uninteresting as they-may sound, may well make the heart of every friend of exact nature-study beat higher.

Method of Zuntz and Geppert.-The great strides in the study of metabolism would have been impossible, however, if the results obtained by these bulky, costly and complicated apparatuses just described were not supplemented by the device of Zuntz and Geppert. The individual experimented upon in this case inhales atmospheric air through a mouthpiece, and the volume of expired air is measured by a gas meter; the separation of the inspired and exhaled air being accomplished by a suitable valve. A small portion of the exhaled air is automatically taken up from time to time and analyzed volumetrically in two burettes. Besides the permanent form of the apparatus Zunz also devised a portable form, adapted to studies in travel, mountain trips and at the

${ }^{3}$ Atwater, 1. c., p. 514. 
sick bed. This method is only suited for brief experiments (minutes up to several hours), particularly in determining the effect of muscular effort, individual nutrient materials and medicinal agents, etc., but not for estimating the metabolic exchange over longer periods. Magnus-Levy ${ }^{4}$ expresses the following opinion of the Zuntz method: "For exact measurement of the actual exchange for a whole day or longer the twenty-four experiments are absolutely authoritative. Only from them can we learn to practically realize the nutritional requirements, etc.; they constitute the exact basis for quantitative consideration of scientific and, too, practical questions in nutrition. The method makes it possible to fully collate all the influences bearing upon metabolism. However, it is not so well adapted for the precise determination of the value of each individual external factor. Where it is essential to have as sharp differentiation and determination as possible of such influences experiments of short duration are of more significance, and, because of their readier technic, have come to occupy a very much greater field. This is especially true where one is dealing with the estimation of relatively small differences."

Other Methods.-Among other forms of apparatus designed for the measurement of gas interchange may be mentioned the head respiration apparatus of E. Grafe, ${ }^{5}$ which is snugly adjusted by means of an inflatable rubber collar; also a new transportable respiration apparatus of Benedict; ${ }^{6}$ and, lastly, a device of Douglas, in which the exhaled air is collected in a bag which the subject carries on his back, and after the close of the experiment analyzed.

Recent forms of respiration apparatus satisfying moderu requirements and used for small animals have been con-

${ }^{4}$ A. Magnus-Levy, 1. c., p. 212.

${ }^{5}$ E. Grafe (Med. Clin., Heidelberg), Deutsch. Arch. f. klin. Med., 95, 529, 1909 ; ef. also Zeitschr. f. physiol. Chem., 65, 1, 1910.

${ }^{6}$ F. G. Benedict (Carnegie Lab., Boston), Amer. Jour. of Physiol., 24, 345, 1909. 
structed by $\mathrm{H}$. Murschhauser, ${ }^{7} \mathrm{H}$. B. Williams ${ }^{\mathrm{s}}$ and F. Tangl.'

Studies of the gas exchange of aquatic animals require a special technic, elaborated for observations on fish by Zuntz, in association with Knauthe and Cronheim, ${ }^{10}$ for lower marine organisms by Jolyet and Regnard and by Vernon. ${ }^{11}$

In conclusion the writer must not neglect to refer to the great importance of Rubner's calorimeter in the development of metabolic study; this relatively simple apparatus must be credited, too, with a number of very important discoveries, which may be offered as proof that in physiology often far more is attained through judicious proposals of problems and precise and skillful performance of work than by elaborate and costly apparatus. ${ }^{12}$ On the other hand the study of metabolism itself teaches us that without a certain minimum of auxiliary means and power and the nervus rerum requisite for procuring them, even the best arrangement of researches must remain without result and the most industrious hands without a task. The prime point in the mechanical theory of heat, which has been occasionally cited in these lectures in its popular rendering ("from nothing, nothing comes"), is applicable as well in the modern study of metabolism. Just here the old hemisphere can learn much from the new. Yet if unfortunately we are unable to bring into existence a Carnegie Institution or a Rockefeller Institute, a very great deal can, nevertheless, be done in biochemistry with more modest means.

${ }^{7}$ H. Murschhauser (Acad. Pediatric Clinic, Düsseldorf), Biochem. Zeitschr., 42, 262, 1912 .

${ }^{8}$ H. B. Williams (Cornell Univ., New York), Jour. of Biol. Chem., 12, 317,1912 .

P. Tangl (Budapesth), Biochem. Zeitschr., 44, 235, 1912.

${ }^{10} \mathrm{~W}$. Cronheim, Zeitschr. f. Fischerei, 15, 319, 1911 ; separate pub. by Bornträger Brothers, Berlin.

${ }^{11}$ Literature on Respiration of Aquatic Animals: O. v. Fürth, Vergl. chem. Physiol. der niederen Tiere, pp. 121-130, Jena, 1903.

${ }^{12}$ O. Cohnheim, 1. c., p. 363. 
Question of Part Taken by Elemental Nitrogen and Hydrogen in Metabolism.-The advances in technique of respiration investigation have done away with the old subject of debate as to the part taken by nitrogen as an element in the processes of metabolism. The final proof that no nitrogen in free condition is ever eliminated from the body and that the statements to the contrary by other authors are due to error's of observation has been attained through the careful investigations of Carl Oppenheimer ${ }^{13}$ and of Krogh. ${ }^{14}$ Oppenheimer was able to show, too, that elemental hydrogen has just as little to do with metabolism as does nitrogen, and that even when in high tension in the blood hydrogen does not undergo combustion in metabolism. ${ }^{15}$ Ammonia, which is occasionally met in exhaled air, to all appearances is due merely to processes of decomposition going on in the mouth and bronchial tubes. ${ }^{16}$

\section{MAINTENANCE EXCHANGE AND GROWTH}

The possibility of continuing respiration experiments on human beings for a very long time and under nearly normal conditions makes it also possible to determine the exchange taking place in maintenance. A. Löwy states: "By the term maintenance exchange may be understood that basic volume of metabolism which (excluding those tissue activities providing for transient requirements or producing extra efforts) is essential for the maintenance of the continuous vital functions. The maintenance metabolism of every adult individual presents a constant volume which remains uniform for years and decades of years, as long as the body characteristics of the individual do not become changed to an

${ }^{13}$ C. Oppenheimer (Zuntz's Lab., Berlin), Biochem. Zeitschr., 1, 177, 1906; 4, 328,1907 .

${ }^{1 *}$ A. Krogh (Copenhagen), Sitzungsber. d. Wiener Akad., 115"”, 1906; cf. therein Literature.

${ }^{15}$ C. Oppenheimer (Zuntz's Lab., Berlin), Biochem. Zeitschr., 16, 45, 1908.

${ }^{16}$ Literature upon the Composition of Exhaled Air: A. Jaquet, Ergebn. d. Physiol., 2, 463-468, 1902; A. Löwy, ibid., 4', 144-154, 1908. 
important degree." ${ }_{17}$ To determine the maintenance exchange (minimal metabolism) ${ }^{18}$ it is obvious that complete body rest and a state of fasting are essential. Reference has been made repeatedly to the fact that any sort of muscular activity increases exchange in a marked degree. Johannson recognizes three types of "rest"': complete enforeed rest, rest in bed, and rest in the room, in the last of which there may be permitted alternation of quiet sitting, reading, writing and other light occupations. It is very instructive to note that the exchange in rest in bed is upwards of twenty per cent., and in rest in the room fifty to sixty per cent. higher than that in enforced rest. It may thus be perceived that the actual determination of the maintenance exchange is by no means an easy task. It is essential to exclude not only the activity of the striated musculature but also that of the involuntary muscle of the gastrointestinal canal, and of that of the periodically acting glands as well. That this is not possible in a literal sense of course goes without stating; we do the best we can, and are careful to determine the gas exchange in a period of fasting, about twelve hours after the last meal, in a restful posture, and with most careful avoidance of all voluntary movements. The fact is, however, that for one and the same person under these conditions, in the course of many years, exactly the same oxygen consumption and the same carbonic acid production are usually obtained in the same period of observation. ${ }^{19}$ Sleeping or waking play no important part.

Significance of Surface Development and Volume of Body Protein.-It will be readily appreciated that in com-

${ }^{17}$ A. Löwy, Handb. d. Biochem., f', 172, 1908.

${ }^{18}$ Literature upon Maintenance Exchange: A. Magnus-Levy, Handb. d. Pathol. d. Stoffw., 2d ed., 1, 213, 222-225, 279-296, 1906; A. Löwy, Handb. d. Biochem., 4', 172-199, 1908.

19 Thus, for example, A. Löwy (Deutsche med. Wochenschr., 1910, 1797) observed in an experiment subject at absolute rest and during fasting the following oxygen consumption (cubic $\mathrm{cm}$. pro minute): in 1888, 236.0; in $1895,227.9$; in $1901,230.7$; in $1902,238.1$; in $1903,228.0$. 
parison of different individuals the determination of the maintenance metabolism will give different numerical values, which will not harmonize well if we base our results on the unit of body weight. It does not depend so much upon the size of the body as upon the amount of active protoplasm in particular. A strong muscular individual will consume more energy than one of equal weight in whom the musculature is replaced by the dead weight of large fat deposits. The surface development, however, as correctly recognized by C. Bergmann about the middle of the past century, but first actually proved by Rubner, is a matter of great importance in this connection. The larger the surface in comparison to the body mass the greater the heat elimination, ceteris paribus; and the greater the heat loss, necessarily the greater the heat production must be to maintain constancy of body temperature. As small individuals, in proportion to their body volume, have a greater extent of surface, they necessarily produce proportionately a greater amount of heat. It has been proved in many cases that while the ratio between exchange and body weight is irregular, almost constant figures are obtained if the amount of metabolism is calculated in proportion to the unit of body surface. Therefore there can be no question as to the importance of this factor. Exclusive emphasis of this may, however, as in case of any one-sided consideration, miss the mark. Rubner himself proved that the difference between the exchange in big and little guinea pigs is still evident if heat elimination is excluded by providing a surrounding temperature of $30^{\circ}$. Moreover an analogous difference in the metabolism of coldblooded animals (fish), in which temperature regulation does not enter at all, has been shown by Jolyet and Regnard, and by Knauthe. E. Voit found that maintenance exchange in poorly nourished individuals decreases, independently of the body surface, with loss in the volume of body protein. 
From these facts the author is inclined to believe (as, too, from the objections of Zuntz and his pupils and those of H. Friedenthal and others) that we may conclude that maintenance exchange does not depend merely upon the surface area of the body, but also, and in very distinct manner, upon the amount of active protoplasm, and doubtless also upon a number of other items which we cannot entirely overlook. ${ }^{20}$

The female sex does not show any lower activity in maintenance metabolism than the male; but in senility there is a notable diminution, and in childhood exchange is always distinctly higher than in adult life, whether determined in relation to body weight or to surface area of the body. If the amount of gas interchange in a man be taken as 100 , according to Magnus-Levy and Falck, it is 78 in a senile individual and in the child it may reach about 110 .

Energy Calculation in Infancy.-Special attention should be devoted to the energy calculation in infancy. The infant's exchange is peculiar in that, even when determined for the surface unit, it is decidedly low during the first month of life, and only reaches by a gradual rise the level characteristic of childhood about the end of the third month. ${ }^{21}$ The method of energy computation introduced by Camerer into the study of child nutrition has since come to be a matter of considerable consequence to pediatrists. Heubner and Rubner have attempted to systematize the matter of energy recording in infants, deducting from the "native calories" of the food the number of calories lost in the fæces and urine and thus arriving at the "net calories" which are actually available to the infant. By dividing the number of native calories introduced into the body by the body weight Heubner's energy-quotient is obtained, which refers to the num-

${ }^{20}$ Cf. A. Löwy, Handb. d. Biochem., 4', 186, 1908; H. Friedenthal (Lake Nicholas, Berlin), Centralbl. f. Physiol., 23, 437, 1909; J. Howland (Graham Lusk's Lab., New York), Zeitschr. f. physiol. Chem., \%4, 1, 1911.

${ }^{x}$ Cf. A. Löwy, Handb. d. Biochem., 4', p. 189, 1908. 
ber of calories a child must receive daily pro kilogram in order to develop satisfactorily. According to Heubner's views a breast-fed child is able to store up more reserve power than an artificially fed child. Extensive computation experiments have been carried out in the laboratories of Tangl and of Zuntz; energy observations bearing upon food requirements of the infant have been made by $\mathrm{A}$. Czerny and his pupils, as well as by a very large number of pediatrists. Direct measurements of maintenance metabolism have been carried out within the last year or two especially by Schlossmann, in Düsseldorf, by means of the above described respiration apparatus with due conformity to all modern requirements. The infants are quieter than one would expect in the respiration experiments and tolerate well even rather long fasting. In this way the production of $\mathrm{CO}_{2}$ and oxygen consumption were found to be dependent not upon the age, but primarily upon the surface area. ${ }^{22}$

Laws of Growth.-In addition attention has been given to the application of the method of energy observation to the study of growth. In a previous lecture (Vol. I of this series, p. 376, Chemistry of the Tissues) reference was made to the credit due especially to Tangl and his collaborators for their efforts to determine the developmental work necessary to the building up of the embryo.

In relation to the growth of the child, C. Oppenheimer was the first to call attention to the fact that if the accessions in weight of breast-fed children of even age be compared, there will be found a direct proportion to the amount of milk ingested. Later on it was shown in Graham Lusk's

${ }^{22}$ Literature upon Energy Computation in the Child: L. Langstein, Ergebn. d. Physiol., 4, 851-890, 1905; A. Czerny and F. Steinitz, Handb. d. Pathol. d. Stoffw., 2 d ed., 1, 441-445, 1907; E. Müller (Zuntz's Lab.), Biochem. Zeitschr., 5, 193, 1907; F. Tangl (Budapesth), Pflüger's Arch., 104, 453, 1904; M. Rubner and O. Heubner, Zeitschr. f. exper. Pathol., 1, 1, 1905; P. Reyher (Berlin), Jahrb. f. Kinderheilk., 61, 553, 1905; A. Schlossmann and H. Murschhauser (Düsseldorf), Biochem. Zeitschr., 26, 14, 1910. 
laboratory that the growth of pigs runs parallel with the value in calories of the ingested food; and analogous results were obtained by Rost in case of young, growing dogs of the same litter, fed on meat, fat and bone-ash. ${ }^{23}$ Rubner has succeeded by his careful and systematic studies in formulating certain rules characterizing the energetics of growth.

First, the law of constant consumption of energy, an expression of the observation that the number of calories necessary to double the weight of a newly born individual (horse, cow, sheep, pig, dog, cat, rabbit), in spite of the enormous difference in time consumed in attaining the doubled weight, is practically the same for all species, reckoned upon the unit of weight. The building up of one kilogram of body substance requires about 4800 calories. An exception is met in the case of man, in whom about six times this amount is required. Man is exceptional in that, while in the animals enumerated, of one hundred net calories introduced about thirty-four are fixed (quotient of growth $=$ 34 ), human beings are able to retain only about five. From the law of constant consumption of energy it follows that the shorter the period of development, the more actively must the energy-metabolism take place. As, however, the amount of the latter is, in accordance with Rubner's views, to be regarded as a function of the surface area, we arrive at the conclusion that the smaller the animals the more rapidly must they grow. Rubner has, however, also attempted to deduce a rule covering the length of life. He calculated the amount of energy which is consumed in a kilogram of living protoplasm from the stage of full development to death, and found this again constant for all domestic animals under investigation. But here, too, man occupies an exceptional position, as human protoplasm is said to possess the capacity of

${ }^{23}$ C. Opppenheimer, Zeitschr. f. Biol., 49, 158, 1901; M. B. Wilson, Amer. Jour. of Physiol., 8, 197, 1902; E. Rost, Arb. a. d. kaiserl. Gesundheitsamt, $18,206,1902$. 
transforming a much greater amount (about quadruple) of energy. ${ }^{24}$

Flattering as this exceptional position may be for the members of the species Homo sapiens, a uniformity broken by so striking an exception cannot well help arousing from the very outstart serious thoughts as to the validity of the law itself. From observations made in Zuntz's laboratory by Gerhartz it would seem that the maintenance requirement for the growing dog is not, as Rubner has it, simply a function of the surface area; ${ }^{25}$ and, more particularly, $\mathrm{H}$. Friedenthal has brought forward a series of observations which in general do not conform to Rubner's laws of growth. ${ }^{26}$ It will probably be in every way more valuable if, instead of stating his own opinion upon the subject, the author presents the judgment of N. Zuntz, one of the best authorities upon the physiology of metabolism: "The views of Rubner as to the remarkably uniform amount of energy (except in case of man) consumed by an organism in course of growth to double its weight are in the meantime shaken by the discoveries of Friedenthal, and man forced from the special position which seemed to belong to him. And it is impossible to suppress considerable doubt as to the validity of the idea that living matter after transforming a given number of calories is incapable of further activity, and that, therefore, death naturally ensues when a certain number of calories per kilogram of bodyweight have been converted. But the way these conceptions were developed is

${ }^{24}$ M. Rubner, Arch. f. Hygiene, 66, 1908; Das Problem der Lebeusdauer und seine Beziehungen zu Wachstum und Ernährung, 1908; Kraft und Stoff im Haushalt des Lebens, Leipzig, Akad. Verlagsanstalt, 1909. Rubner has recently (Sitzungsber. d. preuss. Akad., 1911, 440) taken up the question of the ratio of wear. It has been calculated that on full nitrogen-free diet about onethousandth of the total nitrogen supply of the body is daily eliminated in the urine and fres, so that in the course of a few years a complete renewal of all tissues must necessarily take place.

${ }^{25}$ H. Gerhartz (N. Zuntz's Lab.), Biochem. Zeitschr., 12, 97, 1908.

${ }^{28} \mathrm{H}$. Friedenthal, Berliner physiolog. Gesellsch., June 3, 1910; Centralbl. f. Physiol., 24, 705, 1910; ef. also the rejoinder by Rubner. 
full of suggestions for every one trained in natural science." 27 The author believes that Rubner's efforts will be by no means in vain, and will surely be of use in the solution of the problem of growth; although perhaps it will be many decades before the vast material from observation upon the various forms of life can be collected and placed upon a broad, comparative-physiological basis, so as to enable us hereafter to take up the deduction of generally valid laws.

\section{ENERGY EXCHANGE AFTER INGESTION OF FOOD}

We may here turn our attention to energy exchange after the intake of nutrient materials.

If the body is to remain in complete (both in material and in energy) equilibrium after the ingestion of food, metabolism must proceed in accordance with an equation which Robert Tigerstedt ${ }^{28}$ formulates as follows: "Combustion heat of food = combustion heat of the urine and fæces + heat loss from evaporation of moisture, carbonic acid output, conduction and radiation + heat loss from absorption of heat by ingesta + heat loss from externally useful work not restored to the body as heat."'

Physiological Utilization Value.-In attempting to get a proper insight into the utilization value of nutrient material it is necessary primarily to consider that the full energy value in calories of a food can be fully realized only if it be completely consumed in the economy. This actually takes place in case of the fats and carbohydrates, their oxidation in the course of metabolism continuing to their transformation into carbonic acid and water. But with the proteins it is different, these substances not being entirely burned into carbonic acid, water, nitrogen and sulphuric acid; their nitrogen appearing in the urine in the form of urea and a number of other organic compounds. Therefore in attempting the determination of the physiological availability of

${ }^{27}$ N. Zuntz, Centralbl. f. d. ges. Biol., 10, No. 2S, 1910.

${ }^{2 s}$ R. Tigerstedt, Handb. d. Biochem., f", 1, 1910. 
protein, the amount of energy which is lost in the urine and faces must be deducted from the total energy which is obtained by burning the protein in a calorimetric bomb; and in case exactness is important there must also be subtracted the swelling- and solution-heat of the protein and the solution- heat of the dried urinary substance.

In an experiment of Rubner's ${ }^{29}$ one gram of muscle protein was found to yield directly a combustion heat of 5754.0 small calories; of which 185.4 calories were lost with the fæces and 1094.5 calories with the urine. In addition 28.8 calories were taken up as solution- and swelling-heat of the protein and 21.5 calories as solution-heat of the urinary substances. There remained, therefore, 4423.8 small calories as the specific physiological utilization value of one gram of protein. Rubner estimated a somewhat smaller value for the protein of the ordinary mixed diet of man, and as already stated, proposed the following standard figures:
1 g. Protein
4.1 large calories
1 g. Fat
1 g. Carbohydrate
9.3 large calories
4.1 large calories

Slightly different standard values have been proposed by Atwater and by the Zuntz school (protein, 4.31; fat, 9.46 starch, 4.18)..$^{30}$

The exactness of these values is shown by the following: Rubner determined in a dog the heat production and gas interchange. From analysis of the latter and of the urine and frees it was calculated just how much protein, fat and carbohydrate were actually consumed, and how much heat, therefore, the animal must have produced. Comparison of this theoretically computed heat production with direct observation of heat production showed an almost complete agreement (a difference of between one-half and one per cent.).

${ }^{2}$ Cited by F. Tangl, Ergebn. d. Physiol., 3", 45, 1909.

${ }^{30}$ Cf. Literature: A. Löwy, Handb. d. Biochem., 4', 2S0, 1908. 
Range of Metabolic Increase.-The rariations of metabolism after the ingestion of a given food have been followed to the end of its effect; and it has been shown that every intake of food is followed by a rise in gas exchange usually ending within twelve hours. The increase in the in-take of oxygen and in the production of heat is least after ingestion of fat, is larger in case of carbohydrates, and greatest in case of protein. Magnus-Levy observed that even after an intake of 200 grams of butter or bacon-fat the consumption of oxygen rarely went beyond the amount in fasting by over ten per cent., but after eating a ration of bread in the first hour an increase of 33 per cent. above the fasting level may be reached in the oxygen consumption. After a meal of meat a marked and longer increase of gas interchange is to be observed. In experiments of Johansson, Landergrén, Sondén and Tigerstedt on feeding days as compared with fasting days an average increase of thirty-five per cent. was noted. Rubner determined the caloric requirement in a dog and then on three different days fed the animal on one day exclusively on protein, on another exclusively on fat, and on another exclusively on carbohydrate, the amounts being in each case equivalent; his results showed on the protein day an increase in heat output of 19.7 per cent.; on the fat day, 6.8 per cent.; on the carbohydrate day, 10.2 per cent. ${ }^{31}$

The question next arises how this increase in metabolism is to be interpreted.

Work of Digestion.-In Speck's opinion, as, too, in that of Mering and Zuntz, this rise in metabolism is not due to combustion of the resorbed material but rather to the work of digestion, this including not only the work of the musculature of the gastrointestinal tract but also the heightened demands of the collective glandular apparatus connected therewith ; and in addition the increased cardiac and respiratory activity must also be taken into consideration. There

${ }^{31}$ Cf. A. Jaquet, Ergebn. d. Physiol., 2', 478-486, 1908. 
cannot be any doubt but that an important part of the increase in gas metabolism after intake of food should be assigned to this account. But a number of authors, as C. Voit, Rubner, Magnus-Levy, Jaquet and others are opposed to special emphasis of this factor. Important doubts have been raised as to whether the special rise in metabolism after protein feeding, which Rubner has spoken of as the specific dynamic effect of the protein, is to be explained entirely by the digestion work. ${ }^{32}$

Specific-dynamic Effect of Proteins.-It is to be understood that the idea of a specific-dynamic action of proteins is not in the least antagonistic to the "law of isodynamics." In accordance with the latter the different food materials may in the matter of heat production be mutually interchanged according to the full value of their physiological availabilities and take part in the production of heat with their full energy values; but according to Rubner's idea particularly in case of the proteins a greater part of the energy is lost by change into heat for the activities of the cellular life as such.

As heat production within the body of the warm-blooded animal has to do with compensating for the loss of heat in the body surface, Rubner is of the opinion that the specificdynamic influence of foods can be seen in the clearest possible relation by excluding the surface heat loss by providing a temperature equal to that of the body in the surrounding medium. He therefore kept a dog at $33^{\circ} \mathrm{C}$., first determined the minimal metabolism in fasting, and then gave for a time a diet made up of proteins, or of fats, or carbohydrates, with the same caloric equivalent as the fasting requirement, and observed the production of heat. Increase of heat production was observed, for sugar, 5.8 per cent.; for fat, 12.7 per cent., but for proteins, 30.9 per cent. A protein diet with the same caloric value as the hunger-requirement is in-

${ }^{82} \mathrm{Cf}$. Literature concerning the specific dynamic action and the work of digestion; L. B. Mendel, Ergebn. d. Physiol., 11, 457_460, 1911. 
capable accordingly of maintaining the organism in equilibrium; and taking the fasting energy requirement as 100 , an amount of energy equivalent to about 140 in the form of protein is required to reëstablish the caloric equilibrium. Graham Lusk ${ }^{33}$ expresses this in the following schema:

Fasting requirement in potential energy $=100$ calories. One hundred and forty calories are given in the form of meat protein :

\section{0 calories}

100 calories

$=$ the amount of heat set = the potential energy, free in the catabolism of the protein, available instead of heat to be obtained by chemical regulation.

With reference to Rubner's much debated idea that protein in metabolism is split into a nitrogenous and a nitrogen-free moiety, and that the energy obtained from the first by oxidation is not available for the vital cellular activities to the same degree as the energy present in the other part, the author prefers to refrain from any detailed comment, as the idea seems to him altogether hypothetical. ${ }^{34}$ But it may be mentioned that recent very exact calorimetric and gasometric experiments by Williams, Riche and Graham Lusk $^{35}$ seem to favor the idea, as after free meat feeding a formation de novo of sugar from protein seemed to take place (v. sup., p. 234 et seq.). Unquestionably the caloric effect of meat feeding is sure to be influenced in a very important degree by such a process.

It might be supposed that, in reference to the question upon precisely what the specific-dynamic effect of protein

${ }^{83}$ Graham Lusk: Ernährung und Stoffwechsel, 2d ed., translated into German by Leo Hess, pp. 141-148, 1910.

${ }^{34}$ Cf. A. Magnus-Levy, Handb. d. Pathol. d. Stoffw., 2d ed., 1, 226, 231, 1906.

${ }^{35}$ H. B. Williams, J. A. Riche and G. Lusk (Cornell Med. College), Jour. of Biol. Chem., 12, 349, 1912. 
depends and to what degree the work of digestion is to be held for the related phenomena, possibly experiments with parenterally introduced protein or "mock feeding" would be suitable methods of definitely differentiating the points in question; however, according to the judgment of as experienced an expert in this subject as W. Caspari ${ }^{36}$ this does not seem to be the case. A number of authors are disposed to the view that introduction of protein acts in a sense as a direct stimulant which excites the cells of the body to increased oxidation processes. Possibly the recent observations of E. Grafe, suggesting that over-nutrition in animals and human beings induces a decided exaggeration of the combustion processes, may be interpreted in this sense; a man, in whom in the course of six weeks an increase of weight of fifty per cent. was attained by excessive hypernutrition, manifested a very marked exaggeration of heat production not only after introduction of food but also in periods of fasting (in this last condition an increase of eighty per cent.). ${ }^{3 \tau}$ Zuntz and Hagemann have found that the increased consumption of oxygen in the horse after feeding maize amounts to about twenty-five per cent. more than when the same amount of oats is fed, and they remark that it would be quite a risk to assume in this connection any work-increase on the part of the digestive tract capable of raising the metabolic process by as much as one-fourth. They believe the most likely idea is that there is some unknown chemical substance in the corn which stimulates the cells of the animal body to exaggerated oxidations. Jaquet ${ }^{38}$ comes to the conclusion from this that if such possibility be

${ }^{36}$ Literature in reference to the Specific-dynamic Effect of Protein: A. Jaquet, Ergebn. d. Physiol., 2', 478-486, 1902; A. Löwy, Handb. d. Biochem., 4', 266-271, 277-284, 1908; R. Tigerstedt, Nagel's Handb. d. Physiol., 1, 351-375, 1901 ; Handb. d. Biochem., 4", 1-42, 1910; W. Caspari, ibid., 4', 775-778, 1911.

${ }^{37}$ E. Grafe and D. Graham (Med. Clinic, Heidelberg), Zeitschr. f. physiol. Chem., 78, 1, 1911; E. Grafe and R. Koch (Med. Clinic, Heidelberg), Deutsch. Arch. f. klin. Med., 106, 564, 1912.

${ }^{38}$ A. Jaquet, I. c., p. 486. 
accepted in case of maize, there is no reason why it should be debated for the proteins in general.

Contrary to the attempt to refer the specific-dynamic effect of protein to a heightened renal activity, Tangl has proved that it is manifested as well after the kidneys have been extirpated..$^{39}$

Gigon takes the middle ground between the Zuntz and the Rubner hypotheses, accepting the digestive work as playing an important part. Although the economy in its minimal metabolism is independent of the immediate introduction of food, there is to be observed after protein introduction an increase of protein combustion in which, too, processes of intermediate conversion of protein into carbohydrate and of the latter into fat are involved. ${ }^{40}$

${ }^{39}$ Tangl (Budapesth), Biochem. Zeitschr., 34, 1, 1911.

to A. Gigon (Basel), Pflüger's Arch., 140, 509, 1911. 


\section{CHAPTER XXII}

\section{OXIDATION FERMENTS}

Theory of Action of Oxidases.-The fact that the nutrient substances, not affected by molecular oxygen at low temperature, are oxidized with the greatest ease within the economy into their end-products is a really wonderful phenomenon. One can at once realize how remarkable this is by reflecting upon the intense heat requisite to completely burn up a bit of protein upon platinum foil, although it is mere play for the body to break down large quantities of protein, and that, too, almost completely. The problem of just how this can be accomplished has occupied students of nature ever since they began to delve into the enigma of life from the chemical point of view. The thought must necessarily at once obtrude itself that the oxygen must exist in an extremely effective, "active" form; and in harmony with the advances in chemical science efforts have been faithfully made to give concrete form to this idea.

The idea of an ozonization of the intracorporeal oxygen, emanating from the original brain of Schönbein, although it deeply impressed his contemporaries, has not been able to withstand criticism. The supposition upheld by HoppeSeyler of an activation of the molecular oxygen by rupture of the oxygen molecule after the manner of a reduction process proved more fruitful. The observation, for example, that in the presence of oxygen palladium foil charged with hydrogen is capable of oxidizing indigo may as a process be outlined in somewhat the following manner:

$$
\mathrm{Pd}_{2} \mathrm{H}+{ }_{\text {HO.H }}+{ }_{\text {HO.H }}+\mathrm{O}_{2}=2 \mathrm{Pd}_{2}+2 \mathrm{H}_{2} \mathrm{O}+\mathrm{H}_{2} \mathrm{O}_{2} \text {, }
$$

peroxide of hydrogen being thus generated with its effective oxidizing capacity.

Traube seems to have been the first to adopt the idea of 
an "oxidizing-ferment" and to give expression to the happy thought that there occur in the body readily oxidizable substances ("autoxidizable") which have the power of transferring the oxygen in active form to substances which are oxidizable with difficulty ("dysoxidizable"), such as the nutrient materials. On this as a foundation Engler and Bach later built up, with their associates, their peroxide theory. In this theory it is supposed that the oxygen attaches itself to the autoxidizable substances in the form $\begin{array}{r}-0 \\ 1 \\ -0\end{array}$ and produces addition-products of the type $\ddot{\mathrm{R}}>_{0}^{0}$ (moloxide) or of the type $\underset{\mathrm{R}-\mathrm{R}-\mathrm{O}}{\dot{\mathrm{R}}}$. As a special instance of such peroxide formation the production of hydrogen peroxide may serve, zinc in the presence of water and oxygen being regarded as exerting an oxidizing action: $\mathrm{Zn}+{ }_{\mathrm{OH} . \mathrm{H}}^{\mathrm{OH} . \mathrm{H}}+\mathrm{O}_{2}=\mathrm{Zn}(\mathrm{OH})_{2}+\mathrm{H}_{2} \mathrm{O}_{2}$. According to Engler and Herzog oxidations of this type may be represented by the following schema: $\mathrm{A}+\mathrm{O}_{2}=\mathrm{AO}_{2}$, or again in the sense of an equivalence, $\mathrm{A}+\mathrm{O}_{2} \rightleftarrows \mathrm{AO}_{2}$ (as, for example, hæmoglobin, oxygen and oxyhæmoglobin). A second, not an autoxidizable substance, B ("acceptor") can be oxidized by $\mathrm{AO}_{2}$ in the sense: $\mathrm{AO}_{2}+\mathrm{B}=\mathrm{AO}+\mathrm{BO}$.

By analogous process we may, for example, explain why indigo is not attacked by molecular oxygen, although, if an indigo solution is shaken up with benzaldehyde, both substances become oxidized. The benzaldehyde is transformed, presumably under the influence of the atmospheric oxygen, into benzoyl-hydrogen peroxide $\left(\begin{array}{r}\mathrm{C}_{6} \mathrm{H}_{5} \cdot \mathrm{COH}+\mathrm{O}_{2}=\mathrm{C}_{6} \mathrm{H}_{5} \cdot \mathrm{CO} . \mathrm{O} \\ \mathrm{H} . \mathrm{O}\end{array}\right)$, and this then (with formation of benzoic acid, $\mathrm{C}_{6} \mathrm{H}_{5}$. COOH) acts as an oxidizing agent upon the indigo.

But to return to the above schema, $\mathrm{AO}$ (the oxide of the autoxydator) is capable of oxidizing another molecule of $\mathrm{B}$, 
the acceptor $(\mathrm{AO}+\mathrm{B}=\mathrm{A}+\mathrm{BO})$, and the autoxydator, $\mathrm{A}$, is thereby regenerated; and the final effect of the whole process seems given by the equation, $2 \mathrm{~B}+\mathrm{O}_{2}=2 \mathrm{BO}$. A in the above acts as a catalysator and simply conveys two atoms of oxygen to two atoms of $\mathrm{B}$.

These points generally acquire increased physiological interest from certain findings by Kastle and Loevenhart, indicating that inorganic and organic peroxides (as lead-, manganese- and benzoyl-peroxide) are capable of producing a blue color with tincture of guaiac, just as vegetable tissues do. ${ }^{1}$

With these introductory remarks, which naturally make no pretense in any way to completeness, we may at once proceed to consideration of the oxidases.

Only the principal points are here presented, especially as F. Battelli and Miss Lina Stern have recently collected the general literature of the subject (over six hundred original papers) in an excellent and easily accessible monograph. ${ }^{2}$

Peroxidases and Oxygenases.-In the confused mass of observations which relate to the oxidation ferments a certain degree of system was first developed by the extensive studies of Bach and Chodat. Following these writers we use the term peroxidases for those ferments which manifest their influence only in the presence of peroxides of organic or inorganic character, catalytically accelerating their disintegration with the result of setting free active oxygen. Those peroxides which we fancy as substances, not of fermentative nature, but capable of taking up oxygen, acting oniy weakly

${ }^{1}$ Literature upon the Theory of Action of Oxidases: J. Loeb, Vorlesungen über die Dynamik der Lebenserscheinungen, pp. 30-35, 1906; W. Manchot, Verh. d. Phys.-Med. Ges., Würzburg, 39, 1908, S. A.; J. H. Kastle, The Oxidases, U. S. Hygienic Lab. Bull., 50, 24-30, 1909; C. Oppenheimer, Die Fermente, 3d ed., 338-341; A. Montuori, Mem. della Soc. ital. delle Scienze, ser. 3, Tomo XVI, Roma, 1910; C. Engler and R. O. Herzog (Karlsruhe), Zeitschr. f. physiol. Chem., 59, 327, 1909; F. Battelli and L. Stern, cf. next reference: pp. 251-259.

${ }^{2}$ F. Battelli and L. Stern (Geneva), Ergebn. d. Physiol., 12, 96-268, 1912. 
as oxidizing agents in themselves but acquiring powerful oxidizing influence by contact with the peroxidases, are called oxygenases by Bach and Chodat-a term which is obviously not particularly fortunately selected as it suggests for these substances the idea of a ferment nature which does not belong to them. In their work on vegetable material of different kinds Bach and Chodat succeeded in separating the oxygenases and peroxidases from each other by fractional precipitation with alcohol, etc. The peroxidases, in spite of their presumed enzymic nature, are fairly resistant substances, which can be kept for years under proper conditions; but the oxygenases are extremely labile and, in accord with their peroxide character, are at once broken up by water with formation of hydrogen peroxide. It is scarcely any wonder that while the peroxidases are met in the vegetable kingdom in very wide, one might almost say general distribution, oxygenases are to be recognized only exceptionally。 ${ }^{3}$

No further discussion will be given to the vegetable peroxidases. What, however, of the distribution of animal peroxydases?

Sources of Error in the Study of Peroxidases.-In undertaking, some years ago, in association with E. v. Czyhlarz, ${ }^{4}$ to answer this question, the author recognized at the outstart that the confusion prevailing upon the subject was due to failure to take into consideration a number of important. items.

In the first place, as long as we continue to look upon the peroxidases as ferments, we should insist, too, upon their basic differentiation from the peroxidase-like action of hæmoglobin. Guaiaconic acid and similar reagents in the

${ }^{3}$ Literature upon Animal Peroxidases: A. Bach and Chodat, Biochem. Centralbl., 1, 417, 1903; A. Bach, ibid., 9, 1909; Kastle, 1. c., 110-119; Vernon, 1. c., pp. 216-217; Oppenheimer, 1. c., 342-349, 353-361, 386-390; F. Samuely, Handb. d. Biochem., 1, 570-572, 1909; E. v. Czyhlarz and O. v. Fürth, Hofmeister"s Beitr., 10, 358, 1907; F. Battelli and L. Stern, 1. c., 217-238.

${ }^{4}$ Czyhlarz and Fürth, l. c. 
presence of peroxide of hydrogen are, however, just as readily changed into their colored derivatives by minute quantities of blood as by a vegetable peroxidase or bit of living plant tissue. In view of the great practical difficulty to thoroughly free vertebrate tissue of residual amounts of blood it seems by no means an easy task to differentiate between the influence of blood and the effect of peroxidases.

Further difficulties are met in the fact that the action of peroxidases is closely connected with the presence of peroxide of hydrogen; that the tissues, however, contain at the same time agents, the catalases, to be considered hereafter, which disintegrate hydrogen peroxide and thus antagonize the peroxidases. It is clear, too, that easily oxidizable substances of various kinds may cause disturbance by abstracting the activated oxygen, thus diverting it from the reagents.

Finally, too, much of the confusion attaching to the question of the oxidases comes from the fact that under certain circumstances when guaiac resin (which since the time of Schönbein has been regarded more or less as a universal reagent for oxidases) is added to tissue extracts, even in the absence of hydrogen peroxide the characteristic blue reaction is observed. This has led to the recognition of "direct" and "indirect" oxidases. According to Bach and Chodat the former are, however, nothing more than mixtures of oxygenases (therefore of peroxides) and peroxidases. It should also be recalled that a solution of guaiac resin is likely to undergo spontaneous change if exposed to the air and can become charged with oxygen combined as in peroxides. This difficulty may be avoided by employing the active principle, guaiaconic acid, instead of the resin, using the acid in chemically pure state and in freshly prepared solution. Guaiaconic acid is properly employed, as Carlson has recommended, in combination with hydrogen peroxide but not with turpentine resin, as in the well known blood test proposed by the Dutch physician Van Deen in 1861, in which 
the bhe color was used as a blood test by shaking the specimen up in tincture of guaiac and old oil of turpentine. The action of the turpentine in this latter depends upon the incidental and inconstant presence of peroxides in it, developing especially in the formation of resin. ${ }^{5}$

Iodine Reaction.-In the detection of peroxidases in animal tissues the frequently employed iodine reaction of Bach and Chodat seemed to Czyhlarz and the author a fairly suited method (separation of iodine from acidulated iodide of potassium solution in the presence of hydrogen peroxide and detection of the liberated iodine by means of starch paste), in that (in differentiation from the oxidation of guaiaconic acid and other cyclic chromogens) the oxidation of hydriodic acid was not catalytically accelerated by hæmoglobin in the experiment conditions employed by the writers. They were able by this method to establish the presence of true peroxidases in leucocytes (pus cells), lymphoid tissue (bone marrow, spleen, lymph nodes), and in sperm. They emphasize the point, however, that the test can be regarded as conclusive only when the reaction is positive, not when it is negative, because of the impossibility of excluding inhibition of the reaction by albumins and other iodine-fixing tissue constitutents. As a matter of fact, J. Wolff and E. de Stöklin have been able to show that oxyhæmoglobin (present, of course, in all tissues) under certain changes of experimental conditions will also behave quite like a vegetable peroxidase toward iodide of potassium and hydrogen peroxide, if care is taken to immediately remove any excessive iodine. ${ }^{6}$ According to F. Battelli and Lina Stern this is also true if in arranging the reaction hydrogen peroxide is replaced by ethylhydroperoxide; although it is at present impossible to say what is the cause of the difference of behavior of the hæmoglobin to the two peroxides. The authors just re-

${ }^{5}$ Cf. B. Moore and E. Whitley, Biochem. Jour., 4, 136, 1909.

${ }^{8} \mathrm{~J}$. Wolff and E. de Stöcklin (Instit. Pasteur, Paris), Ann. Instit. Pasteur, 25, 319, 1911. 
ferred to note the fact that frequently the iodine reaction is noticeably weaker with blood than with many of the tissues, this point then serving to suggest the presence of a true peroxidase in the tissue apart from the blood which may be in them. ${ }^{7}$ The use of ethylhydroperoxide in place of hydrogen peroxide is undoubtedly a step in advance, as it is not affected by tissue catalases.

Oxidation of Formic Acid.-Another method for the detection of peroxidases in tissues, for which credit is due F. Battelli and L. Stern, depends on the ability of the tissues of higher animals to oxidize formic acid in vitro in the presence of hydrogen peroxide with production of carbonic acid ( $\mathrm{H} . \mathrm{COOH}+\mathrm{O}=\mathrm{CO}_{2}+\mathrm{H}_{2} \mathrm{O}$ ). By the use of this method, by determining the $\mathrm{CO}_{2}$, it has been shown that the liver more than other tissues has a particularly strong power of oxidizing formic acid. ${ }^{8}$

Purpurogallin Method.-A gravimetric method recommended for estimating peroxidases, used frequently by Bach and Chodat, depends on the oxidation separation of the relatively insoluble purpurogallin from a solution of pyrogallol.

Phenolphthalin Method.-In the experiments carried on with E. v. Czyhlarz the author has performed many estimations by the phenolphthalin method of Kastle and Shed. ${ }^{9}$ It was found that the oxidation transformation of the colorless phenolphthalin into phenolphthalein with its brilliant red color in alkaline solution is well adapted to spectrophotometric measurement, a sharply defined absorption band oceurring about the middle of the spectrum. However, the usefulness of the method is decidedly impaired by the fact that an alkaline solution of phenolphthalin may rapidly undergo spontaneous reddening in the presence of hydrogenperoxide.

${ }^{7}$ F. Battelli and L. Stern (Geneva), Biochem. Zeitschr., 19, 49-59, 1908.

${ }^{8} \mathrm{~F}$. Battelli and L. Stern (Geneva), Biochem. Zeitschr., 13, 44, 1908; Z. Sarafoff, Dissert. Univ. of Geneva, 1908, cited in Jahresber. f. Tierchem., 39, $528,1909$.

${ }^{\circ}$ Kastle and Shed, Amer. Chem. Jour., 26, 26, 1901. 
Lenkomalachite-green Method.--The author believes a real advance has been made in the discovery in leukomalachite-green of a reagent which possesses the advantages but not the disadvantages of phenolphthalin. The leukobase of malachite-green, in its chemical construction a tri-

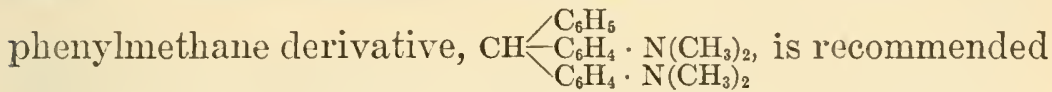
by $R$. and $O$. Adler ${ }^{10}$ as an extremely reliable reagent, the colorless solution of the substance being changed into malachite-green at once in the presence of hydrogen peroxide by very small amounts of blood. It was found by the author and his associate that a solution of the leukobase in acetic acid with hydrogen peroxide added serves also as an excellent reagent for the detection of peroxidases. The solution remains unchanged for a relatively long time; but on the addition of a small amount of a solution of a peroxidase at once an emerald green color appears, deepening more or less rapidly. As a properly diluted solution of malachite-green shows a sharply defined absorption band in the middle of the spectrum, it is quite possible to determine quantitatively by spectrophotometry the amount of malachite-green which has been produced by the enzymic influence from the leukobase with considerable accuracy. As the observation requires but a few moments, and can be repeated as often as may be desired and at whatever intervals may seem best in the same test, one is in position, even if only a few cubic centimeters of material be available, to follow the process of oxidation step by step and record it graphically by a curve (with the time as abscissa and the amount of newly formed malachite-green as ordinate).

Measurement of Oxygen Consumption.-C. Foà proceeds upon a difficult principle, registering by means of a Mosso phethysmograph the amount of oxygen consumed in the oxidation of aromatic substances (pyrogallol, hydrochinon, etc.) by peroxidases (the method being based on

${ }^{10} \mathrm{R}$. and O. Adler, Zeitschr. f. physiol. Chem., 41, 5S, 1904. 
the lowering of pressure within an enclosed system). ${ }^{11}$ This method has been improved by H. H. Bunzel in Washington; in the latter's method the containers are fastened to a shaking apparatus placed in a thermostat and the changes in pressure occasioned by the consumption of oxygen are read off on manometer tubes. ${ }^{12}$

Limits of Availability of Above Methods.-The adverse criticism which Foà expresses for all the existing methods except his own is certainly not correct in case of the malachite-green method; and in the author's opinion it is extremely doubtful whether his method is practically any advance over the latter. The total oxidizing effect performed by an extract or a tissue-pulp can be determined with approximate correctness by the methods mentioned and by several other procedures ${ }^{13}$ and compared. However, the principal difficulty in the study of tissue peroxidases is not to be found here. There are two great impediments in the way, over which research has hitherto been stumbling. The one is the impossibility to quantitatively extract the tissue peroxidases (the same is true of other "endoenzymes") from the tissues; the other is the blood in the tissues, which, because blood may also act like a peroxidase and because it can hardly be fully removed, makes all comparative study of the peroxidase-content of tissues a matter of uncertainty. That there are differences in this respect between the various tissues is shown by histochemical observation. If, for example, a cover-glass preparation of gonorrhœal pus be treated with a peroxidase reagent, as benzidinmonosulphite of soda, the leucocytic granules alone will become colored at a certain stage of hydrogen peroxide concentration; the myelocytes from the bone-marrow also are easily stained, while the lymphocytes react only at a higher

${ }^{11}$ C. Foà (Mosso's Lab., Turin), Biochem. Zeitschr., 11, 382, 1908.

${ }^{12}$ H. H. Bunzel, U. S. Dept. Agricult., Bureau of Plant Industry, Bull. No. 238, Washington, 1912.

${ }^{13}$ Cf. Literature: H. H. Bunzel, I. c. 
concentration and the erythrocytes at still higher degree of concentration of hydrogen peroxide. ${ }^{14}$ Another and perhaps seemingly impertinent question, however, is whether it is actually worth the trouble to devote so interminably great an amount of work to these matters. The author's personal views on the subject may be deferred until after the presentation of the problems of the peroxidase-nature of hæmoglobin and of the artificial peroxidases.

Peroxidase-itke Action of Hcmoglobin.-The question may be at once considered whether there is a special fundamental difference between the oxygen carrying action of hæmoglobin and that of the true peroxidases.

As this peroxidase-like action of hæmoglobin is also characteristic of its color constituent, hæmatin, but as the latter is in the fullest sense a thermostable substance, it might well be believed that there can be no suggestion of identity, because the peroxidases in accordance with theirferment character must necessarily be thermolabile substances. Formerly this was the common opinion; and it is true that generally when a tissue containing peroxidases is boiled its efficiency in this direction is seen to disappear. This, however, cannot be regarded as establishing a fundamental difference, as von Czyhlarz and the author, ${ }^{15}$ and other observers as well, have occasionally dealt with peroxidase solutions which retained their activity almost at the boiling temperature. Battelli and Stern in their peroxidase experiments with formic acid have noted an increase of activity with increase of temperature up to $38-40^{\circ} \mathrm{C}$. But from this point further increase of temperature caused a lowering of oxidation, which stopped almost completely at $65^{\circ} \mathrm{C}$.; while the oxidation of formic acid by hæmoglobin in the presence of hydrogen peroxide is distinctly more active at a temperature of 55-

${ }^{14}$ R. Fischel, Wiener klin. Wochenschr., 23, 1557, 1910; cf. also F. Winkler, Folia Haematol., 4, 323, 1907; 5, 17, 1908.

${ }^{15}$ E. v. Czyhlarz and O. v. Fürth, 1. c., p. 367; cf. A. van der Haar (Utrecht), Ber. d. deutsch. chem. Ges., 43, 1321, 1910. 
$60^{\circ}$ C. than at $38^{\circ}$ C. ${ }^{16}$ The tyrosinases, a special variety of peroxidases, dealt with at length in connection with the formation of melanin (Vol. I of this series, pp. 527-536, Chemistry of the Tissues), are thermolabile in a high degree.

Another rather characteristic point of difference between the oxygen convection by hæmoglobin and by the peroxidases was pointed out by the author's associate and himself. In graphic registration of the results obtained by the spectrophotometric malachite-green method, using the time values as abscissas and the appropriate amounts of oxidation product as ordinates, it became evident that the catalyzing reactions of hæmatin were represented by almost straight lines which proceeded from the coördinate starting point at different angles. The reaction of true animal peroxidases (obtained from pus cells), however, correspond to curves which after a constant, more or less sharp rise suddenly turn toward the horizontal and continue parallel to the abscissa axis. This corresponds closely with the curves which Bach and Chodat repeatedly observed in case of vegetable peroxidases. Bach, ${ }^{17}$ therefore (as well as Lesser ${ }^{18}$ and Buckmaster $),{ }^{19}$ is of the opinion that hæmatin behaves somewhat like a chemically definite catalysator, while the action of true animal peroxidases approaches that of other ferments.

We, therefore, have reason for the time being to regard the blood coloring matter as a "pseudoperoxidase" in contradistinction to the true oxidases.

On the other hand again, W. Madelung is of the opinion that the activation of peroxides by the hæmoglobin is functionally not different from their activation by the tissue peroxidases, inasmuch as apparently there also exist in the

${ }^{18} \mathrm{~F}$. Battelli and L. Stern, 1. c., p. 88.

${ }^{17}$ A. Bach (Geneva), Biochem. Centralbl., 9, 1909 Sep., p. 20.

${ }^{18}$ E. J. Lesser, Zeitschr. f. Biol., 49, 571, 1907.

${ }^{10}$ A. Buckmaster, Jour. of Physiol., 35, Proc. XXXV, 1907; 37, Proc. XI, 1908. 
tissues complex iron compounds which may be capable of conveying oxygen; the hæmoglobin is to be regarded as a compound of bivalent iron with an additional valence open for a loose attachment ${ }^{20}$ (vide infra, Chapter XXIV).

The blue respiratory coloring matter of the crustacea and mollusks, hamocyanin (Vol. I of this series, p. 224, Chemistry of the Tissues) also manifests peroxidase reactions in a striking way, here apparently related with the copper it contains. ${ }^{21}$

Chemico-Legal Detection of Blood by Means of Peroxidase Reactions.-Brief attention may be given to a practical phase of the peroxidase problem, the application of the peroxidase reactions of hrmoglobin to the chemical detection of blood for legal purposes. For this purpose, in addition to those methods which are based on a specific characteristic of blood coloring matter (as spectroscopic detection, or the demonstration of Teichmann's crystals), considerable use has been made of the peroxidase reactions, that is, of the colors which solutions of guaiac resin or guaiaconic acid, aloin, phenolphthalin, leukomalachite-green, benzidin, etc., assume in contact with hydrogen peroxide and blood. The marked sensitiveness of these reactions has led to their frequent use in the examination of drops of blood on clothing, walls and utensils; but the value of evidence thus obtained has been restricted before courts particularly because of the fact that there are a great many other substances which possess the power of conveying oxygen just as hæmoglobin does, as for example rust, a number of iron- and copper-compounds, oxide of lead, manganese oxide, chlorine, bromine, iodine, and, too, organic substances of all sorts as pus, saliva, milk, sweat and many vegetable materials. ${ }^{22}$

${ }^{20}$ W. Madelung (Heidelberg), Zeitschr. f. physiol. Chem., 71, 204, 1911.

${ }^{21}$ C. L. Alsberg, Arch. f. exper. Pathol: Schmiedeberg's Festschr., p. 40, 1908; C. Fleig, C. R. Soc. de Biol., 69, 66, 110, 1910.

${ }^{22}$ Literature of Legal Examination of Blood: O. Leers, Die forensische Blutuntersuchung, Berlin, J. Springer, 1910; cf. also O. Schumm and E. Westphal (Hamburg-Eppendorf), Zeitschr. f. physiol. Chem., 46, 510, 1905. 
The author has endeavored to perfect a method which shall make use of the great sensitiveness of the peroxidase reactions but be free of those sources of exror which are inherent to the older form of these tests and which have brought their forensic value into question. This object has been attained by combining a test described by Leers ${ }^{23}$ with Adler's leukomalachite-green test. Leers prepares a hæmatin extract by treating the object supposed to be contaminated with blood with a concentrated alcoholic solution of caustic potash. The hæmatin is dissolved out by shaking the solution well with pyridin, is then reduced by a reducing agent to hæmochromogen and examined spectroscopically for final detection. The author at first proceeds in the same way as Leers; but then the pyridin solution charged with the blood coloring matter in a small separating funnel is transferred to a filter paper spread out on a glass plate and a hydrogen peroxide solution of leukomalachite base in dilute acetic acid is added. The presence of hæmatin is shown by an intense green color. ${ }^{24}$ In this procedure the sources of error occasioned by the true peroxidases (as of pus, nasal mucus, milk and vegetable tissue) are excluded by previous boiling with concentrated caustic potash. Moreover, the disturbing features caused by inorganic catalysators need not be taken into consideration as, even though they are not thrown out (as is iron) by the potash in the form of inactive hydroxides, they will not dissolve in the pyridin solution. Material for testing, consisting of a few strands of a blood-soaked fabric, or blood stains on wood or iron implements may be successfully and with certainty identified, even if they had been previously boiled in water. The author believes that this method, which can be carried through in a very short while without special apparatus, may be relied upon to fairly answer the requirements of practice.

${ }^{23}$ Leers, 1. c., pp. 64-65, and Table ii, Fig. 2.

${ }^{24}$ For details of the process consult O. v. Fürth, Zeitschr. f. angew. Chem., $24,1625,1911$. 
Respiratory Coloring Substances.-When it is recalled that the color component of hæmoglobin, hæmatin, loses its peroxidase-like power when deprived of its iron by conversion into hæmatoporphyrin, and when recalled also that Gabriel Bertrand, who has devoted himself largely to the study of the oxidases, has shown that the effectiveness of many of these substances is related to the manganese they contain, ${ }^{25}$ the suggestion at once arises that the real point of the whole oxidase problem may perhaps be found in the catalytic action of metals, especially those which because of their power to exist in different stages of oxidation are likely to serve as oxygen carrier's. It is surely not an accidental matter that not only hæmoglobin, but also many other respiratory pigments which are found in the invertebrates, as the echinochrome of the seaurchins, hamerythrin, and the green chlorocruorin of marine worms (cf. Vol. I of this series, pp. 224, 225, Chemistry of the Tissues), contain iron; and in case of the blue hemocyanin in the blood of mollusks and crustaceæ, which apparently contains copper, it should be recalled that salts of copper possess in a high degree the ability of catalytically conveying oxygen. ${ }^{26}$ When, too, it is remembered that we know that colloidal metals ${ }^{27}$ or metals in combination with colloids are particularly active in this respect, there is every reason to justify the attempt to produce artificial oxidases.

Artificial Peroxidases.-Quite a number of experiments have actually been presented with this end in view. ${ }^{28}$ Thus Trillat ${ }^{29}$ found that in bringing together a salt of manganese, an alkaline hydroxide and a colloid, an association resulted which is entirely comparable to natural peroxidases.

${ }^{25}$ G. Bertrand and F. Medigreceanu, Compt. Rendu., 154, 1450, 1912.

${ }^{26}$ Cf. H. A. Colwell, Jour. of Physiol., 39, 358, 1909.

${ }^{27}$ Cf. C. Foà and A. Aggazzotti, Biochem. Zeitschr., 19, 1, 1909.

${ }^{2}$ Literature upon Artificial Peroxidases: J. H. Kastle, 1. c., pp. 122-131; C. Oppenheimer, Die Fermente, 3d ed., 348-351, 1909; F. Battelli and L. Stern, Ergebn. d. Physiol., 12, 241-243, 1912.

${ }^{29}$ A. Trillat, Compt. rend., 138, 274, 1904, and earlier contributions. 
Dony-Hénault ${ }^{30}$ obtained peroxidase-like products by mixing bloodserum or a mucilage with weak alkaline reaction with a salt of manganese and precipitating with alcohol, adding Rochelle salt as a suitable material to prevent the separation of manganese oxide. Euler and Bolin ${ }^{31}$ found a typical peroxidase prepared from alfalfa to be thermostable and certainly not an enzyme, but rather a mixture of neutral salts (especially potassium salts) of various vegetable acids (as citric acid, malic acid and mesoxalic acid), and that such salts are capable in plant structures and juices containing manganese of catalytically accelerating the oxidation of polyphenols, etc. According to J. Wolff 32 if yellow ferrocyanide of potassium be mixed in certain porportions with ferrous sulphate, blue colloidal ferrous ferrocyanide will be obtained. This substance behaves quite like a peroxidase and is thermolabile. The oxidases seemed to be peculiar in the specificity of their action (as, for example, a tyrosinase may fail to act upon hydrochinon). However, it has been found that artificial colloids may also manifest similar specificity. Thus iron in the presence of dibasic phosphate produces an oxidation of hydrochinon, but remains inactive if the phosphate is replaced by tribasic citrate.

Doubt as to the Ferment Character of Peroxidases.These and similar observations necessarily arouse serious doubts as to the enzymic nature of peroxidases. Bertrand ${ }^{33}$ regards the sensitiveness of a number of peroxidases, particularly the "laccases," toward acids as supporting his view of the rôle played by metals in oxidase-activity. If,

${ }^{30}$ O. Dony-Hénault (Instit. Solvay, Brussels), Bull. Acad. roy. de Belgique, 1907, 1908, 1909 .

${ }^{31}$ H. Euler and J. Bolin (Stockholm), Zeitschr. f. physiol. Chem., 57, 80, $1908 ; 61,72,1909$.

${ }^{32} \mathrm{~J}$. Wolff, numerous papers in Compt. rend. and in C. R. Soc. de Biol., 1908, 1909 ; partly in association with E. de Stöcklin; also Thesis, Paris, 1910, and Ann. Instit. Pasteur, 23, 841, 1909; 24, 789, 1910.

${ }^{33}$ G. Bertrand, Ann. Instit. Pasteur, 21, 673, 1907. 
for example, it be assumed that the laccase is a manganese compound which readily undergoes hydrolytic dissociation following the formula, $\mathrm{R} \mathrm{Mn}+\mathrm{H}_{2} \mathrm{O}=\mathrm{RH}_{2}+\mathrm{MnO}$, it may be at once appreciated why even a small amount of acid would arrest the action. In case of other peroxidases iron may play the same rôle. On the other hand, it must be proved that there really are peroxidases which are active in an acid medium and which are found to be free of manganese and of iron. ${ }^{34}$

Efforts have also been made to solve the question of the enzymic nature of peroxidases by study of their ferment kinetics. Bach and Chodat have noted in oxidation of pyrogallol by vegetable peroxidases that the amount of purpurogallin formed when there was excess of peroxidases was in direct proportion to the amount of hydrogen peroxide, but that when there was an excess of hydrogen peroxide it was in direct proportion to the amount of peroxidase, and that both these materials were used up in the process of oxidation. This may be interpreted on the supposition that in the formation of an intermediary product these substances react upon each other in constant proportions-a point distinctly opposed to the idea of a true ferment reaction. Other observations along similar lines have been made by the authors narned in connection with oxidation of hydriodic acid, by Czyhlarz and the author in case of the leukomalachite base, by Herzog ${ }^{35}$ in case of the leuko base of brilliantgreen and in case of vanillin. It would be premature, however, to attempt to make any simple relative deductions from all these complicated matters. It is to be kept in mind, too, that the subject is further complicated by the possibility of activation of "zymogens," "36 and that for the present there is no such thing as "isolation" of peroxidases, although recently at least we have learned that peroxidase preparations

${ }^{34}$ Cf. Bach, Ber. d. deutschen chem. Ges., 43, 364, 1910.

${ }^{35}$ R. O. Herzog, in association with A. Polotzky and A. Meier (Karlsruhe), Zeitschr. f. physiol. Chem., 73, 247, 258, 1911.

${ }^{36}$ A. Bach, Ber. d. deutsch. chem. Ges., 40, 231, 1907. 
may be freed from adnexed catalases and oxygenases by preparatory treatment with pyrogallol..$^{37}$

Probably C. Oppenheimer ${ }^{38}$ has fully and correctly grasped the present status of the question, when he states as his opinion that for the present at least we must accept the active, thermolabile peroxidases as ferments. "For the results indicating that various mixtures of salts of manganese and of iron act qualitatively in precisely the same way, in themselves prove nothing against an enzymic nature, as similar analogies are met in case of almost all ferments. Against this view, above all should be recognized the fact that we can demonstrate very active peroxidases which do not contain manganese or iron. True oxidase activity really has nothing essential to do with these salts, even though suggestions to the contrary perhaps exist. In the living tissue provisions would seem to be made that biological catalysing agents, ferments, should do what under other conditions inorganic catalysers are able to do."

Indophenoloxidases.-Attention should be directed briefly to several other types of oxidases, of which frequent mention is made in literature. Among these first are indophenoloxidases. The synthesis of indophenol from paraphenylendiamine and $\alpha$-naphthol,

$$
\mathrm{C}_{6} \mathrm{H}_{4}\left(\mathrm{NH}_{2}\right)_{2}+66_{10} \mathrm{H}_{7}(\mathrm{OH})+\mathrm{O}_{2}=\mathrm{C}_{6} \mathrm{H}_{4}<{ }_{\mathrm{N}}=\mathrm{C}_{10} \mathrm{H}_{6} \mathrm{O}+2 \mathrm{H}_{2} \mathrm{O} \text {, }
$$

was first made use of by Ehrlich in 1885 in his classical study of physiological oxygen requirements of the economy. From the standpoint of the oxidizing ferments Röhmann and Spitzer, and after them a great number of others, ${ }^{39}$ have employed the reaction, partly for histochemical purposes. Recently Vernon ${ }^{40}$ has endeavored to perfect a quantitative

${ }^{37}$ A. Kasanski (Moscow), Biochem. Zeitschr., 39, 64, 1911.

${ }^{88} \mathrm{C}$. Oppenheimer, 1. c., p. 351.

${ }^{32} \mathrm{~J}$. Pohl, Rosell, Abelous and Biarnès and others. Literature: J. H' Kastle, l. c., pp. 100-103; R. Spanjer-Herford (Braunschweig), Virchow's Arch., 205, 276, 1911; W. H. Schultze (Göttingen), Ziegler's Beitr., 45, 127, 1909 ; F. Winkler, l. c. 
method for the determination of indophenoloxidase in animal tissues. His results indicate that those mammalian tissues, which, according to Ehrlich, are highly saturated with oxygen and fail to change indophenol blue when injected intra vitam (as the muscle of the heart, tongue and diaphragm) are apparently rich in oxidases. On the other hand, tissues which reduce intra vitam indophenol blue to indophenol white (as the glands and the bulk of the striated and smooth muscles) prove to be much poorer in oxidase. The richness of the tissues in oxidases, therefore, runs parallel with the grade of their saturation with oxygen; and the idea necessarily arises that we may be dealing with a storage of oxygen in the form of organic peroxides or "oxygenases." Should this suspicion prove correct this reaction will serve as a test for oxygenases. Indophenol blue synthesis fails notably in the tissues of animals which have been killed by potassium cyanide (a frank "ferment poison"'). ${ }^{41}$

Purin Oxidases.-Another well defined group of oxidizing ferments is composed of the purin oxidases. These are ferments concerned in the physiologically important oxidation catabolism of the purin bases into uric acid and of this latter into allantoin. The most important information we possess of this subject was presented in earlier parts of these lectures (Vol. I of this series, p. 112, Chemistry of the Tissues; vide supra, p. 149) and need not be further dealt with here.

Aldehydases.-While the requirements of historical justice would forbid that the "aldehydases" be passed in silence we here come nevertheless into a comparatively unknown field. O. Schmiedeberg originally discovered that if arterialized blood be perfused through a fresh liver or lung and salicylaldehyde be added, salicylic acid is formed to some extent.

${ }^{\star}$ H. M. Vernon (Oxford), Jour. of Physiol., 42, 402, 1911; 43, 96, 1911; 4. $150,1912$.

${ }^{4}$ H. Raubitschek (Czernowitz), Wiener klin. Wochenschr., 1912, 149. 
Jaquet, thereafter, in Schmiedeberg's laboratory, was able to present evidence that even dead tissue, and in fact tissue extracts devoid of cells, are capable of oxidizing aldehyde. A colorimetric method, based on the red color which salicyclic acid gives with chloride of iron, was used in quantitative determination of the newly formed salicylic acid in these studies. The distribution of aldehydases in animal tissues was thereafter studied by a number of authors. ${ }^{42}$ Martin Jacoby elaborated a procedure in F. Hofmeister's laboratory which serves to separate aldehydases from proteins by a combination of salting out, and precipitation by alcohol and by uranylacetate. More recently Dony-Hénault and Mlle. van Duuren ${ }^{43}$ have submitted the problem of aldehydases to a renewed study and have convinced themselves that there were many important technical errors in the investigations of earlier authors. In order to avoid these, separation of the salicylaldehyde from the salicylic acid should be completed and the latter estimated, not by colorimetry, but by gravimetric method (as tribromphenol). It was found, moreover, in correspondence with the results of Abelous and Aloy,44 that oxidation of the aldehyde by the "aldehydase" occurs best in the absence of free oxygen, and that a given amount of the presumed enzymic solution is able to oxidize only a definite amount of aldehyde. This is clearly not an action like that of a catalysator, so much so that the ferment nature of the aldehydases becomes decidedly doubtful. Perhaps in this case, too, we are dealing with the action of peroxides which are transferring their oxygen to easily oxidizable substances. The lability of the "aldehydases" would not interfere with such a view.

Summary.-The author deems it time, however, to lead his readers out of the wilderness of academic discussion

42 Salkowski and Yamagiwa, Abelous and Biarnès, M. Jacoby, Rosell, Pfaundler, Zarichelli and others; cf. Literature: M. Jacoby, Ergebn. d. Physiol., 1', 233-234, 1902; H. M. Vernon, ibid., 9, 214-216, 1910.

${ }^{43}$ O. Dony-Hénault and Mlle. J. van Duuren, Bull. Acad. roy. Belg., 190\%, 537 ; Arch. intern. de Physiol., 5, 39, 1907.

4s J. E. Abelous and J. Aloy, C. R. Soc. de Biol., 56, 222, 1904. 
which has been indulged in all too long, into the open, and to raise the question as to precisely what effective additions have been gained from all this for our knowledge of the physiological processes of oxidation.

This much can be said in summarizing: In the tissues active catalytic agents, the "peroxidases," are widely distributed; which seem, just like the coloring matter of the blood, to be capable of conveying the oxygen from peroxides to very readily oxidizable substances. We find, too, in the statements bearing upon the oxygenases, the aldehydases and indophenoloxidases occasion for assuming that there are substances in the tissues charged with oxygen which are able to give this off to easily oxidizable matter; and these we may in a measure regard as peroxides. But that is all. We do not know whether the peroxidases are ferments are not. This from a plysiological viewpoint may fundamentally be a matter of indifference, because at any rate we are not able to define clearly the characteristics of a ferment. Forerly in this respect we were perhaps more fortunate; we frankly had no idea then what a ferment was; we were accustomed to being satisfied with statements that ferments were "coagulable" substances and allowed them, confessedly or by inference, to drift along in the turbid stream of proteins, that is, with those substances with which we could not even make a proper beginning. But the times have changed; and, particularly since we have learned to recognize that there are thermostable ferments, even the finest definitions and hypotheses, with which science of the present is blessed in the richest measure, cannot deceive us about the flimsiness of the ferment concept. We are really doing better by simply stopping and by holding fast to what we see; and that is the effect of the real or supposed "ferments," the catalytic acceleration of reactions. For our question it is quite enough from a physiological standpoint for us to know that in the tissues there are some sort of catalytic agents of unknown nature which are capable of conveying oxygen to easily oxidizable substances. 
Now, however, we come directly to the crucial point of the whole problem, to the question what are the actual oxidation functions which these catalytic agents or peroxidases accomplish.

In the middle of the past century, when attention was directed to the catalytic action of hæmoglobin and it became known that a single tiny droplet of blood could change a whole big vesselful of tincture of guaiac like magic to a beautiful blue color, there was hope that we were near to the solution of the great enigma of how the economy accomplishes its combustion processes. And all the many new color reactions of the peroxidases, which were gradually found out, in the pomp of their introduction invariably furnished new food for this hope, and invariably seduced research into following their footsteps. The author may confess from his own experience that he was never able to break away from the spell of suggestion that the way led hence into the mysteries of the vital processes of oxidation, until he had satisfied himself that a peroxidase, however active it might be, could never break down a single milligram of sugar. There is not the least basis for presuming that the oxidases have anything whatever to do with the vital combustion of proteins, carbohydrates and fats. The glitter of color-reactions should not be allowed to deceive us into believing that the functions of the oxidases in reality are of any great importance, and that they extend beyond a very superficial oxidation especially of easily seized hydroxylcontaining cyclic compounds, as the oxidation of formic acid into carbonic acid, etc. This is not to say that such oxidations are necessarily physiologically unimportant. The oxidation of the purin bases into uric acid, which may always be attributed to oxidizing ferments, is unquestionably an important process; and so, too, the oxidation of cyclic protein cleavage products into melanins, which the author originally proved, and which is now after thorough study of the problem from many sides (cf. Vol . I of this series, pp. 526528, Chemistry of the Tissues) a part of the assured posses- 
sions of physiology. The oxidases are capable of taking part in other ways in the catabolism of the cyclic complexes of the protein molecule, as (aside from their rôle as "respiratory enzymes" in the vegetable kingdom) in the production and destruction of suprarenin, and in all sorts of detoxifying processes in the animal body. The study of the oxidases has not, however, brought us appreciably nearer to the final secrets of life.

This evidence from the writer may seem very frank, coming from one who has devoted much time and labor upon the oxidases and who belonged among the number of those who "rode" the oxidases; it would undoubtedly be much more pleasant for the author if he could take the opposite position.

"If we were satisfied," thus Battelli and Stern conclude their monograph, "to ascribe to the oxidation ferments uncertain, ill-defined characteristics, we might also accept for them unlimited capacity for action, and assume further that they effect all the oxidations in process in the economy. In this case, however, the term of ferment would lose all exact meaning, and would express nothing more than protoplasm-activity or cell-activity. If one, however, thinks of the oxidizing ferments as constituting a well defined class of enzymes with clearly marked characteristics the answer must naturally be different. We will then be forced to confess that in animal tissue we know of no single agent manifesting the peculiar properties of the oxidation ferments as they have thus far been known, that possesses the ability to induce combustions such as are completely carried out in the animal body, and to reproduce even in the slightest degree such a process as muscle respiration, for example. We are, therefore, not justified in concluding that these combustions are caused by the agency of oxidizing ferments, and are compelled to acknowledge that the mechanism of these combustions is thus far unknown." 45

${ }^{45}$ F. Battelli and L. Stern, Ergebn. d. Physiol., 12, 267-268, 1912. 


\section{CHAPTER XXIII}

\section{CATALASES. TISSUE RESPIRATION}

\section{CATAlases}

IN close connection with the discusssion of oxidizing ferments the present lecture will be devoted first to the catalases. Here, too, the task of presentation has been materially lightened by the fact that F. Battelli and Miss Stern, who have themselves had an important part in the investigation of catalases, have critically reviewed all the literature upon the subject in a recent monograph. ${ }^{1} \quad$ As this is readily accessible to everyone the author may be permitted without going into details to satisfy himself with sketching in the main points.

Definition of Catalases. - The term catalase has been applied to ferments which are able to break up hydrogen peroxide into water and oxygen. As this oxygen is in molecular form, and inactive, it is essential to clearly differentiate the eatalases from the oxidizing ferments. The name "catalase" was originally given by Löw (1901); but our recognition of these substances goes back much farther. Even Schönbein was concerned with them, and Thénard as early as the beginning of the last century was aware of the fact that tissues of the most varied type, as well as blood fibrin and colloidal noble metals are capable of breaking up hydrogen peroxide. The phenomenon was sufficiently conspicuous to prevent the catalases from fading out from the perspective of physiological research. For a long time they were confused with the oxidizing ferments, an error first fully corrected by the investigations of Bach and Chodat. Senter, who obtained the catalase of the blood free from hæmoglobin, proposed the name "hæmase" for it; but such

${ }^{1}$ Literature upon Catalases: C. Oppenheimer, Die Fermente, 3d ed., 392408, 1909; F. Battelli and L. Stern, Ergebn. d. Physiol., 10, 531-597, 1910. 
a title is superfluous and for this reason has had but little recognition.

Demonstration.-F. Battelli and L. Stern have developed a method by which catalase preparations of extremely marked activity may be obtained. It is best to make use of horse-liver or beef-liver, which is finely divided, agitated with water for a long time and strained; the fluid is then precipitated with alcohol, the precipitate separated and redissolved in water, and the solution again precipitated with alcohol.

Finally there is obtained an amorphous powder of almost incredible catalyzing power. One gram is capable of breaking up, in ten minutes at room temperature, four kilograms of hydrogen peroxide with production of 1300 liters of oxygen. The preparation is quite permanent and may retain its activity unchanged for years. It is well known that a number of colloidal metals (as platinum, palladium, iridium and osmium) are also capable of manifesting extremely powerful catalyzing influence. It is calculated that a solution of osmium containing not more than $0.000,000,000,9$ gram of osmium in a cubic centimetre, is still capable of disintegrating hydrogen peroxide appreciably. ${ }^{2}$ Nevertheless Battelli and Stern believe (particularly when the presumably great molecular weight of the catalase is taken into consideration) that the activity of their catalase is infinitely greater than that of colloidal platinum.

Determination of Activity of Catalase Preparations.Determination of the activity of a catalase preparation may be carried out in different ways. A given quantity of tissue or of a preparation to be tested may be allowed to act upon a known quantity of hydrogen peroxide, and after a certain time the amount of oxygen formed may be determined or the quantity of remaining unchanged peroxide of hydrogen may be estimated. Or a dynamic method may be used, by

${ }^{2}$ C. Paal, with C. Amberg and J. Gerum, Ber. d. deutsch. chem. Ges., 40, 2201, 2209, 1907. 
measuring the height to which a column of mercury is raised by the oxygen set free in the reaction, that is, the pressure against which the catalase is able to act. ${ }^{3}$

If the activities of two catalase solutions are to be compared the "catalytic power" of each, in the author's opinion, should be worked out; this, too, according to Victor Henri, ${ }^{4}$ being the only proper basis for comparison of the effective ability of two colloidal metallic solutions. The reaction velocity of hydrogen peroxide cleavage is determined according to the equation $\frac{d x}{d t}=K(a-x), t$ being the time, a the amount of $\mathrm{H}_{2} \mathrm{O}_{2}$ at zero time, $\mathrm{x}$ the amount of $\mathrm{H}_{2} \mathrm{O}_{2}$ broken up in the time $\mathrm{t}$, and $\mathrm{K}$ a constant, expressing nothing more than that the amount of peroxide of hydrogen broken up in any fraction of time is in direct proportion to the amount of $\mathrm{H}_{2} \mathrm{O}_{2}$ at the moment present. A simple calculation gives $K=\frac{1}{C} \log \frac{a}{a-x}$ and determines the value of the constant $K$. If in addition it is desired to obtain the "catalytic capacity," the relation of the amount of the metallic solution employed to the quantity of hydrogen peroxide must also be taken into account.

The reaction kinetics of catalase action, in which we have an example of a "reaction of the first class," according to Senter, has been the subject of study at the hands of quite a number of authors. ${ }^{5}$ It is, however, impracticable to enter into this subject here, as it falls entirely in the domain of physical chemistry. There are, too, a number of studies concerned with the analogies in the action of the catalases and of colloidal metals. According to Liebmann platinum catalase may perhaps be thought of as consisting primarily of a labile oxygen combination of platinum, which then induces the separation of the peroxide of hydrogen $\left(\mathrm{Pt}_{2}+\right.$

${ }^{3}$ W. Löb and P. Mulzer, Biochem. Zeitschr., 18, 339, 475, 1908.

"V. Henri, C. R. Soc. de Biol., 60, 1041, 1906.

'Senter, Raudnitz, Lockemann, Thies and Wichern, Issajew, Bredig and Faitelowitz, Euler, Herlitzka, Bach, Iscoveso, Loeb and Mulzer, and others; cf. Literature: Batelli and Stern, l, c. 
$\mathrm{O}_{2}=2 \mathrm{PtO} ; \mathrm{PtO}+\mathrm{H}_{2} \mathrm{O}_{2}=\mathrm{Pt}+\mathrm{H}_{2} \mathrm{O}+\mathrm{O}_{2}$ ). According to Schade, ${ }^{6}$ however, an intermediate oxide formation does not occur, and, too, the phenomena are not the resultant manifestations of a great surface development as believed, but the action of electrical forces. In differentiation between the action of catalases and colloidal metals special point has. been made of the difference in sensitiveness to high temperatures, and of the fact that the action of catalases is strictly specific, while colloidal metals may not only dissociate peroxide of hydogen but may also blue tincture of guaiac, set free iodine from hydriodic acid, etc. An interesting analogy is seen in their behavior with cyanogen which paralyzes catalases as well as colloidal metals, and in each instance when it is driven off the catalyzing power reappears. ${ }^{7}$

Physiological Significance of the Catalases.-Important as all this may be to the physical-chemist, the special interest from our standpoint lies in the question of the rôle played by the catalases in the play of interchange of forces actively engaged in the living body.

It was once hoped that an answer to this question would be fortheoming from comparison of the catalase contents of tissues in a wide group of physiological and pathological conditions; but unfortunately very little of value has been attained.

The commonly expressed view that the amount of catalases in the tissues is an index of the intensity of the combustion processes therein is shown to be untenable directly by the fact that, as proved by Battelli and Stern, the tissues of the adder and toad are even richer than the tissues of warm-blooded animals in catalases; and, too, muscles, in spite of their marked respiratory activity, show but a small proportion of catalases. 8 The presumption of a parallelism between the proportions of catalases and peroxidases in

${ }^{\circ} \mathrm{H}$. Schade (Kiel), Zeitschr. f. exper. Pathol., 1, 603, 1905.

${ }^{7}$ Cf. O. Löw, Centrabl. f. Bakteriol.. II, 21, 1, 1908; T. Bokorny, ibid., 193.

${ }^{8} \mathrm{Cf}$. also E. J. Lesser (Halle), Zeitschr. f. Biol., 49, 575, 1907. 
tissues has as little foundation as the assumption of an antagonism between them, as declared by the younger Ostwald on the basis of a few studies on lower forms of animal-life, and suggested as being connected with the problem of phototropism. So, too, the assumption of this last-mentioned author, that catalase plays a part in fertilization processes in the egg, is not satisfactorily established; and there is just as little clear evidence from the sequential study of the amounts of catalase to be found in course of ontogenetic development. ${ }^{9}$ In many tissues the catalase proportions attain an importance at very early stages almost comparable to that of adult tissues. However, Battelli and Stern hold there is a relation between the marked increase in catalases noticeable a few days after birth in the liver of guineapigs and the access of function of the organ. Along the same line of thought, in connection with a loss in catalase content in livers the seat of fatty degeneration from phosphorus poisoning, a coincident increase in the catalases in the blood and other tissues has been interpreted as a "compensatory participation by the tissues in catalase production." In the author's opinion, however, it is at least just as appropriate to think of an outflow of the catalases previously fixed in the liver and their distribution by the bloodstream to the tissues. There does not seem to be any contradiction to this view in the fact that catalase experimentally introduced into the bloodstream is soon destroyed; it is altogether possible that artificially isolated catalase is less well protected against destroying agencies than that which passes into the circulation when the liver becomes involved in fatty degeneration. Battelli and Stern believe that the ability to inactivate catalase is a property of some special substance which they call anticatalase. Such substance cannot, however, be looked upon as a true serum antibody, because (according

- Battelli and Stern, 1. c.; L. B. Mendel and C. S. Leavenworth (Yale Univ., New Haven), Amer. Jour. of Physiol., 21, 85, 1908; G. Tallarico (Pavia), Arch. di Farmacol., \%, 535, 1908. 
to de Waele and Vandevelde) nothing of the kind can be recognized either in normal serum or in the serum after immunization by the ordinary methods employed in immunology. ${ }^{10}$ Battelli and Stern also assume that the ability of the serum and of extracts of many tissues to prevent the destructive effect of "anticatalase" upon catalase to be due to a special substance, philocatalase. Activation of the "philocatalase," again, is held as the function of another special material, the "activator of philocatalase." It may be remarked in connection with a terminology of this sort that a union of complicated physical-chemical factors can be thought of as possibly combining to bring about the effects which are characterized by the words "catalase, anticatalase, philocatalase and activator of catalase." If the purpose be to employ some such terms for the unknown summation of this sort of manifestations of energy by undefined physical-chemical factors, there is, of course, no objection to be made; but there is no reason as yet for the idea, as far as the author sees, that we are necessarily dealing here with "special substances."

In connection with other investigations in reference to the significance of catalase action, the suggestion that these substances are somehow concerned in the conversion of fat ${ }^{11}$ is quite unproven. In contradiction to the assumption of Löw that the catalases are intended to protect the living cells against the toxic action of the hydrogen peroxide supposed to be produced in the processes of oxidation, Bach and Chodat have brought forward the fact that this substance is not especially toxic (quite a number of the lower plants thrive very well in a one per cent. solution of peroxide of hydrogen). Although, again, others have suggested the belief that the catalases supposedly are protective to the organism against

${ }^{10}$ H. de Waele and A. J. J. Vandevelde (Ghent), Biochem. Zeitschr., 9, 264, 1908.

${ }^{11}$ H. Euler (Stockholm), Hofmeister's Beitr., 7, 1, 1906. 
the peroxidases, ${ }^{12}$ it should be stated in contravention that Bach and Chodat hold that in setting up a system of $\mathrm{H}_{2} \mathrm{O}_{2}+$ peroxidase + oxidizable substance + catalase, the catalase can not disturb in the least the oxidizing action of the peroxidase, but breaks up only the remnant of peroxide of hydrogen, which was not consumed by the peroxidase. ${ }^{13}$

Finally, contrary to the belief of Jolles ${ }^{14}$ and Ewald ${ }^{15}$ that catalases are able to facilitate the separation of oxygen from oxyhæmoglobin, it may be regarded as proved (from the studies of E. v. Czyhlarz and the author $)^{16}$ that powerfully active catalases are incapable of accelerating the oxidation of ammonium sulphide by oxyhæmoglobin, as well as of phenolphthalin by hydrogen peroxide in the presence of hæmatin. There is, therefore, no basis whatever for assuming an oxidizing power for the catalases.

In reviewing the above, it must in honesty be acknowledged that we not only know nothing positive about the physiological operation of the catalases, but also that we do not even know whether they have any important physiological significance at all, and whether they may not perhaps be altogether accidental and non-essential. Each year in his lectures the author is in the habit of presenting before his students the experiment in which a few drops of blood are placed in a large beaker glass and drop by drop hydrogen peroxide is added. The audience wonders and is pleased as the reaction fiercely goes on with a violent and voluminous production of froth; and the lecturer also wonders and is pleased at the remarkable and imposing manifestation of nature. But does this say that the phenomenon has any part in the vital processes? May it not be thought that physiologists are "obsessed" by the catalases by the very fact of their imposing appearance? The author would

${ }^{12}$ A. Herlitzka, Rendic. Accad. dei Lincei, 16, 473, 1907, and earlier papers. ${ }^{13}$ Cf. Battelli and Stern, l. c., p. 594.

${ }^{14}$ A. Jolles, Fortschr. d. Med., 22, 1229, 1904.

${ }^{15}$ IV. Ewald, Pflüger's Arch., 116, 334, 1907.

${ }^{16}$ E. v. Czylharz and O. v. Fiirth, Hofmeister's Beitr., 10, 389, 1907. 
not be mistaken! This is not to say that this is actually the case; but the author believes that it is possibly true.

\section{TISSUE RESPIRATION}

In the failure of the oxidases and catalases to fulfil the hopes that were rested upon them, we have endeavored in other lines to approach the problem of the combustion processes of the living body.

Cardinal Respiration and Accessory Respiration.-In the first place the systematic studies of F. Battelli and L. Stern should receive attention. These authors make a differentiation between the cardinal respiration and the accessory respiration of animal tissues. The former is by far the more important, although, too, much the more labile process, and involves the life of the cells. In many tissues (especially richly in muscles) there is an agent of unknown nature, "pnein," which is capable of increasing the cardinal respiration of the tissue as this becomes progressively weaker after the death of the animal. By washing out the "pnein" for the most part the tissues thus freed manifest a very low respiratory activity, but by introduction of pnein this can be very distinctly increased. The pnein is looked upon as an "activator of the fundamental respiratory process," but has no influence upon the accessory respiration. It is apparently a substance resistive to boiling temperature, to pepsin and trypsin; soluble in water and dialysable, slightly soluble in alcohol, insoluble in ether. In various animal tissues there is also an agent which decreases the cardinal respiration ; it is known as "antipneumin."

While the cardinal respiration is not dependent upon agencies of ferment type, apparently the accessory respiration is. The intake of oxygen in the latter is not under all conditions accompanied by the formation of carbonic acid. While the cardinal respiration, as stated, is of very labile nature, the accessory respiration may remain unchanged in tissues for twenty-four hours or more. If a tissue is finely 
ground up and treated with alcohol or, better, with acetone, and quickly dried in vacuo over sulphuric acid, a tissue powder may be obtained which is capable of taking up no inconsiderable amount of oxygen and of producing carbonic acid.

The tissue respiration is deteriorated by poisons like prussic acid, oxalates and fluoride of sodium; is, on the other hand, increased by slight alkaline concentrations. Introduction of glucose, citric acid, malic acid or fumaric acid increases very decidedly the tissue gas interchange at times. These substances moreover are capable of oxidizing ethyl alcohol to aldehyde and the latter into acetic acid, and of converting succinic acid into malic acid ( $\mathrm{COOH} . \mathrm{HC}_{2} \cdot \mathrm{CH}_{2}$. $\left.\mathrm{COOH} \longrightarrow \mathrm{COOH} . \mathrm{CH}(\mathrm{OH}) . \mathrm{CH}_{2} \cdot \mathrm{COOH}\right) .{ }^{17}$

Experiments along similar lines have been conducted by Olav Hanssen in F. Hofmeister's laboratory. ${ }^{18}$ Ground-up tissue was kept in agitation in flasks at body temperature, oxygen being conducted through the medium; and the gas passing off was tested for its content of carbonic acid. The experiments of Harden and Maclean tend in the same direction, indicating that isolated tissue under the conditions described do not produce any more carbonic acid from sugar in an atmosphere of oxygen than in a nitrogen or hydrogen atmosphere. ${ }^{19}$ Buytendyk in turn sealed the tissue in a measured amount of special salt solution and tested the diminution of oxygen content of the latter; under these conditions, too, the cardinal respiration could be readily distinguished from the accessory respiration. ${ }^{20}$ Finally Lussana performed the same sort of experiments under more nearly

${ }^{17}$ F. Battelli and L. Stern, Biochem. Zeitschr., 21, 488, 1909; 28, 145, 1910; $30,172,1910$; 31, 478, 1911 ; 33, 315, 1911 ; 36, 114, 1911 ; Ergebn. d. Physiol., $12,215-216,1912$.

${ }^{18}$ O. Hanssen (F. Hofmeister's Lab., Strassburg), Biochem. Zeitschr., 22, $433,1909$.

${ }^{10}$ A. Harden and H. Maclean, Jour. of Physiol., 43, 34, 1911.

${ }^{50}$ F. J. J. Buytendyk (Utrecht), VIII Int. Physiol. Kongr., Vienna, Sept. 27-30, 1910 . 
"physiological" conditions, using, besides physiological salt solution, also blood serum and blood itself. In this case respiration was less marked in homologous serum than in physiological salt solution. After extirpation of the kidneys substances are thought to accumulate in the blood having an unfavorable influence upon the tissue respiration. ${ }^{21}$

Reducing Tissue Components.-Another group of phenomena usually regarded as connected with the processes of tissue respiration involve the reducing power of tissues and tissue constituents.

Paul Ehrlich, in the course of his studies of the oxygen requirement of the body, injected methylene blue into animals. This coloring material is changed by reduction into its leukocombination; by oxidation the latter may be returned into the original dye. It may be easily noted in the animals thus injected with methylene blue in which of the tissues the blue dye has retained its color and in which it has been decolorized, to be restored when atmospheric air gains access to it. The reduction of the methylene blue in the tissues can be followed by titration with titanium chloride. ${ }^{22}$ A number of other examples of reducing actions have been met from time to time in the body; as the reduction of nitrates to nitrites, of arsenic acid to arsenious acid, of nitrobenzol to aniline, of iodates to iodides, of tellurates to tellurium, of sulphur to sulpluretted hydrogen, etc. ${ }^{23}$

Such reductions have been looked on by many authors as predicating the existence of reducing ferments (reductases). Thus deRey-Peilhade ascribed the reduction of finely emulsified sulphur into sulphuretted hydrogen, which a number of tissues are capable of inducing, to a ferment, "philothion,"

${ }^{21}$ F. Lussana (Bologne), Arch. di Fisiol., 6, 269, 1909; 8, 239, 1910 ; 9, 575, 1911.

${ }_{22}$ H. Wichern (Ireipzig), Zeitschr. f. physiol. Chem., 5\%, 365, 1908.

${ }^{23}$ Literature upon Reducing Actions of the Tissues: A. Heffter, Mediz. naturw. Arch., 1, 82-103, 1907; T. Tunberg, Ergebn. d. Physiol., 11, 328-344, 1911. 
the physiological function of which he supposed to consist in the reduction of oxygen coming into the tissues into water. ${ }^{24}$

All these observations have, however, appeared in an entirely new light since Heffter ${ }^{25}$ subjected them to systematic study. It was shown that certainly in large part the phenomena which are connected with the autoxydizability and reducing power of protoplasm are occasioned by the presence of sulphydril groups (SH). The beautiful violet color struck by sodium nitroprusside with alkali sulphides may be traced to the sulphydril groups. Arnold was able to show that a number of proteins give the reaction, and that it can also be due in tissue extracts no longer containing

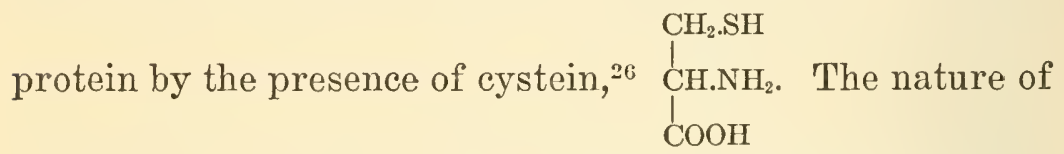
the changes and the mode of action by which sulphydril groups react with oxygen is illustrated in the autoxidation of thiophenol $\left(\mathrm{C}_{6} \mathrm{H}_{5} . \mathrm{SH}\right)$, which takes up oxygen when shaken with air, peroxide of hydrogen being produced as an intermediate material. ${ }^{27}$ Heffter would represent the reaction of the sulphydril groups in the tissues accordingly by the following schema:

$$
2 \mathrm{R} . \mathrm{SH}+\mathrm{O}_{2}=\underset{\mathrm{R}-\mathrm{S}-\mathrm{S}}{\mathrm{R}}+\mathrm{H}_{2} \mathrm{O}_{2} ; 2 \mathrm{R} \cdot \mathrm{SH}+\mathrm{H}_{2} \mathrm{O}_{2}=\underset{\mathrm{R}-\mathrm{S}-\mathrm{S}}{\mathrm{R}}+2 \mathrm{H}_{2} \mathrm{O} \text {. }
$$

It is possible to fancy that the transformation of cystein into cystin (occurring spontaneously and at low temperature) may perhaps take place in this manner.

${ }^{24}$ Cf. also D. F. Harris (Birmingham), Biochem. Jour., 5, 143, 1910; A. Montuori, Memoirie della Soc. ital. delle Scienze, serie III, 16, 237, 1910; Arch. ital. de Biol., 55, 197, 1911.

${ }^{25}$ A. Heffter, 1. c., and Hofmeister's Beitr., 5, 213, 1904; Arch. f. exper. Pathol., Schmiedeberg Festschr., 253, 1908; B. Strassner (Heffter's Lab.), Biochem. Zeitschr., 29, 295, 1910.

${ }^{26} \mathrm{~V}$. Arnold (Lemberg), Zeitschr. f. physiol. Chem., 70, 300, 314, 1911.

${ }^{27}$ According to Engler and Broniatowski. 
To quote Heffter :28 "The principal results of the above investigations may be summarized by stating that the reductions of methylene blue, of sulphur, tellurium oxide, etc., by animal and regetable cells are not the effects of enzyme action. ${ }^{29}$ They are to be referred to the presence of proteid substances which contain one or more sulphydril groups. The readily detached hydrogen of this group may, as shown by the behavior of cystein and similar compounds, exert strong reducing action. It is also capable of directly uniting. with molecular oxygen. For this reason the sulphydril compounds of the tissues are autoxidizable. Herein, at least in part, may be seen an explanation of the affinity of the cells for oxygen as well as of the possibility of formation of hydrogen peroxide." Certain tissue constituents may act in this connection as catalyzators and accelerate the reduction bronght about by the sulphydril groups.

One would be going too far, however, to refer all reductions in the tissues to the influence of the sulphydril groups. The reduction of nitrates and of nitrobenzol, for example, seems to rest on a different basis. ${ }^{30}$ Attention has been called, especially by the investigations of S. Fränkel and his associates, ${ }^{31}$ to the strong reducing action of unsaturated tissue phosphatids. However, as we possess no basis at the present time for holding that reductions of this kind are actually concerned in the vital combustions it seems altogether too early to attempt to base "A Theory of Tissue Respiration Through Intermediary Bodies" on this status.

Oxygen Consumption in the Blood.-As a sequel to the

${ }^{28}$ A. Hefiter, Med. Naturw. Arch., 1, 103, 1907.

${ }^{2}$ Abelous, Iscoveso and others have likewise expressed doubt as to the enzymic nature of the reductases.

${ }^{30}$ Cf. also A. Bach; Arch. Sc. nat. Genève, 32, 27, 1911, cited in Centralbl. f. d. ges. Biol., 1911, No. 2555; Biochem. Zeitschr., 31, 443, 1911.

${ }^{31}$ S. Fränkel and A. Nogueira, Biochem. Zeitschr., 16, 378, 1909; S. Fränkel and L. Dimitz, ibid., 21, 337, and Wiener klin. Wochenschr., 1910, No. 51; S. Fränkel, Dyuamische Biochemie, pp. 31-34, 1911. 
problem of the reducing constituents of the tissues we may next take up the question of the consumption of oxygen in the blood. Although earlier recognized that blood which has been standing for a long time becomes impoverished in oxygen, it was shown by the studies of Eduard Pflüger and of Alexander Schmidt in the sixties that not inconsiderable amounts of oxygen may disappear from the blood withdrawn from a vein with coincident production of carbonic acid. Then when the search was made for the reducing substances which it was presumed must necessarily be particularly rich in the blood in asphyxia it was quickly realized that only the blood corpuscles, but not the serum of the asphyxia blood, were capable of fixing oxygen, and that the lymph of asphyxiated animals was also free from reducing substances. ${ }^{32}$ More recently the question of oxygen consumption in the blood has been systematically studied particularly by $P$. Morawitz and his pupils. They confirm the view that even in condition of extreme asphyxiation there is no transfer of substances with affinity for oxygen from the tissues to the blood stream, which would be at all capable of oxidation in the mere presence of oxygen. The oxilation processes which take place in the blood are obviously connected with the blood cells. While the blood corpuscles of adult human beings manifest only a minor oxygen consumption, the erythrocytes of young individuals exhibit this feature to a highly important degree. The blood platelets, too, seem to have something to do with oxygen consumption. It is a very striking point that the blood of rabbits rendered anæmic by a subchronic phenylhydrazin poisoning should (in contrast with normal blood) show in vitro a marked oxygen consumption and carbonic acid formation. This was proved to be independent of the serum and the lencocytes, and was due to the numerous young erythrocytes in the blood; the con-

${ }^{22}$ Literature: N. Zuntz, Hermann's Handb. d. Physiol., 4", 92, 1882. 
sumption of oxygen apparently serves as an index of the intensity of the regenerative processes in the blood. ${ }^{33}$

There is an interesting point in the fact that the ability of the body to reduce atoxyl to a trypanocidal substance (which is in immediate relation with its therapeutic effects) is, according to the studies of Levaditi and Yamanonchi, evidently comnected with the blood. ${ }^{34}$

The fact that the iron-bearing red corpuscles are the elements which dominate the consumption of oxygen by the blood seems to have given fresh reason for the belief, which for the last hundred years has been constantly recurring, of the importance of iron in connection with animal oxidations. Yet it is clear that this factor may be overestimated, when it is recalled that sea-urchin spermatozoa, which are very closely analogous to young red blood cells in this matter of oxygen consumption, have been found to contain no iron. ${ }^{35}$

In the end we invariably come back to the recognition of the fact that the power of conducting the vital combustion processes is an innate peculiarity and function of living protoplasm, a truism which in reality, to be honest, is strictly not something which we know but rather a standing witness to our lack of knowledge, a fact which cannot be hidden by the most brilliant definitions and hypotheses of natural philosophy except in the most pitiful manner.

Living and Dead Protein.-We contrast the "living' protein" of Pflïger (the "active protein" of Löw or "biogen" of Verworn) with the ordinary "dead" protein. The living protein is held to be distinguished by special lability, as to the cause of which different hypotheses have been promulgated. Pflïger believed that the carbon and nitrogen atoms

${ }^{33}$ P. Morawitz, Arch. f. exper. Pathol., 60, 298, 1909; Deutsch. Arch. f. klin. Med., 100, 191, 1910; 10.3, 2.53, 1911; S. Itami (Med. Clinic, Heidelherg), Arch. f. exper. Pathol., 6?, 93, 1910: O. Warburg (Med. Clinic, Heidelberg), Zeitschr. f. phỵsiol. Chem., 69, 452, 1910; M. Onaka, ibid., r1, 193, 1911.

${ }^{34}$ T. Yamanouchi, C. R. Soc. de Biol., 68, 1910.

${ }^{35}$ E. Masing (Zoölog. Station, Naples, and Med. Clinic, Heidelberg), Zeitschr. f. physiol. Chem., 66, 262, 1910. 
in his living protein combine to form cyanogen radicals, which are entirely absent in the "dead" protein. The principal argument advanced in support of this view, to the effect that disintegration products of the living protein like urea, creatin and nuclein bases in some instances contain the cyanogen radical, and in some instances can be produced artificially from cyanogen compounds, seems to the author decidedly open to question. Verworn in his biogen theory has formulated views which are somewhat better defined. "By the intramolecular addition of inspired oxygen the biogen molecule finally arrives at the maximum of its readiness to undergo decomposition, so that only very slight influences are required to bring about the union of the oxygen atoms with the carbon of the cyanogen. The material of the non-nitrogenous groups of atoms afforded by the explosive decomposition of the biogen molecule can easily be regenerated by the residue of the biogen molecule from the carbohydrates and fats that are present in the living substance. If, finally, the living substance dies, with the absorption of water, the labile cyanogen-like compound of nitrogen passes over again into the more stable condition of the ammonia radical, the nitrogen uniting with the hydrogen of the water." 36

On the other hand for several decades Löw has maintained the hypothesis that the labile character of living protoplasm depends upon a coexistence of aldehyde groups and amino groups. ${ }^{37}$ The basis assumed for this hypothesis is somewhat as follows: First, the fact that aminoaldehydes, as the compound ${ }_{\mathrm{COH}}^{\mathrm{CH}_{2} \cdot \mathrm{NH}_{2}}$, are very labile substances; again, living, in contrast to dead, protoplasm may be held to show its aldehyde nature in its ability to reduce dilute alkaline silver solutions; and finally those substances which either

${ }^{36}$ M. Verworn, Allgem. Physiol., 2d ed., p. 489, 1897; Lee's Amer. Ed., p. $483,1899$.

${ }^{37}$ O. Löw, Die chemische Energie der lebenden Zellen, 2d ed., Stuttgart, 1906. 
react with aldehyde groups (as hydrocyanic acid, hydrazine, hydroxylamine, semicarbazide) or fix amino groups (as formaldehyde and nitrous acid) are all protoplasmic poisons. In opposition to all such hypotheses it must be said that since Franz Hofmeister brought to light a typical protein like eggalbumin in crystalline form, the conception of a "living" protein" has lost all its original significance for the chemist (cf. Vol. I of this series, p. 3, Chemistry of the Tissues). It is not in the structure of the protein molecule but in the organization of the cell that the great wall looms up from which unfortunately it can still be called to us: "Nach drüben ist die Aussicht uns verrant." We would not continue: "Thor, wer dorthin die Augen blinzend richtet," but hope and trust that science, forging onward in triumph, will some day force a breach in this wall as well. That, however, this may come to pass from theoretical speculation the author does not believe, however much he may otherwise prize intellectual argument and however highly he may appreciate the heuristic value of a hypothesis as a precedence for investigation.

Methods of Study of the Respiration of Isolated Organs. - Unfortunately in physiology it is often necessary to be satisfied to follow to some length phenomena which we do not understand and which we cannot explain. This is exemplified by the fact that, although we have scarcely even approached the real nature of the combustion processes in the living body, we have learned at any rate to perform quantitative investigations of the respirations of individual organs. Experimentation along these lines dates as far back as to Carl Ludwig and his school. Although until a few years ago it was possible only indirectly to determine in isolated cases from studies of the energy transformations of the general body what share in these the activities of individual organs take, to-day this can be directly accomplished.

This may be done by studying the changes in the composi- 
tion of the blood gas of the artificially perfused organ in situ, taking samples of the blood from the artery and from the vein for testing. Of course, the amount of blood passing through the organ in a unit of time must be known. Formerly it was customary to make use of Ludwig's stromuhr for this purpose. At present Brodie's method is found an improvement, the organ being enclosed hermetically in a capsule, the vein pinched shut for a measured length of time and the blood at the same time allowed to flow on in the artery; the increase in volume in the organ thus occasioned is measured oncometrically.

Blood Gas Analysis, Barcroft and Haldane's Method.The methods to be considered for analysis of the gases of the blood in studies of this sort are in part based upon the use of Pflüger's mercury pump, in part upon the application of Haldane's method of determining the oxygen in the blood by driving it out of the blood by means of potassium ferricyanide after laking. Anyone desiring fuller details of the method may be referred to the excellent paper of Joseph Barcroft, ${ }^{38}$ in which the technic of determinations of this sort is set forth with the greatest completeness. As one cubic centimetre of blood is sufficient for the estimation by the Barcroft-Haldane method of gas analysis, it has the advantage of enabling one to work with small organs and to make comparisons of them. The apparatus consists of a small glass receptacle into which by means of a three-way cock the sample of blood to be analysed is introduced directly from the vessel of the animal. The receptacle is so arranged that the oxygen of the sample of blood is set free by potassium ferricyanide, and the increase of pressure thus produced is measured by a manometer. A similar procedure, in which, instead of the ferricyanide, tartaric acid is used, serves for the determination of the carbonic acid by freeing it from its alkaline combinations. The oxygen

\footnotetext{
${ }^{38}$ J. Barcroft (Cambridge), Ergebn. d. Physiol., 9, 763-794, 1908.
} 
measurement for one cubic centimetre of ox blood or cat's blood, for which hæmoglobinometric estimation had given an average result of $0.197 \mathrm{ccm}$., was with this apparatus 0.198 ; in one cubic centimetre of a soda solution of known content determination yielded, instead of 0.421 cubic centimetres of $\mathrm{CO}_{2}$, mean results of 0.420 and 0.423 . These results indicate an almost incredible exactness, and it is certainly not too much to say that this method of Barcroft and Haldane should be included among the most brillant achievements thus far accomplished by precise work in the field of physiological technic.

In the study of tissue respiration occasionally there may be occasion for analyzing the gases contained in salt solutions. Thus, for instance, Vernon transfused excised mammalian kidney with Ringer's solution, and thereafter analyzed the latter for its content of gas. The capillary tube method of gas analysis employed in such studies, in which a small bubble of gas that has been drawn into a capillary tube is analyzed, has been brought to a high grade of efficiency through the efforts of Barcroft and Hamill, Brodie and Cullis, and of Krogh. ${ }^{39}$

Cohnheim's Respiration Apparatus for Isolated Organs. -Otto Cohnheim, moreover, has introduced a respiration apparatus for isolated organs constructed on the principle of the respiration apparatus of Atwater and Benedict. A given amount of oxygen is circulated in a closed system; due to the oxygen consumption by the organ the volume of the oxygen is lowered, and this diminution is determined by a manometer; and finally from a small bomb enough oxygen is allowed to enter to bring the manometer back to its original register. The loss in weight of the bomb gives the amount of oxygen consumed; the carbonic acid is weighed after absorption in moist soda lime. Many isolated organs may be studied immersed in Ringer's solution; in other cases the oxygen

${ }^{89}$ Cf. T. G. Brodie, Jour. of Physiol., 39, 391, 1910. 
is introduced directly by way of the blood vessels of the organ which may remain in situ..$^{40}$

Thunberg's Microrespirometer.-If, finally, there be occasion to study the respiration of very small organs, Thunberg's microrespirometer will serve the purpose fairly well. The apparatus consists of two small flasks which are joined hermetically by a horizontal capillary tube. A droplet of oil within this capillary tube moves toward the side of lower pressure. An organ is placed in one of the flasks; when if the respiration quotient ${ }^{41}$ is greater than 1 , that is if more carbonic acid be produced than the amount of oxygen consumed, the indicator drop moves away from the organ, but in the reverse case toward the organ. If a small amount of potassium hydrate, however, be placed at the bottom of the vessel the carbonic acid is absorbed and the movement of the droplet directly expresses the intake of oxygen.

By methods of this sort the individual organs have been tested under the most varied physiological conditions. The detailed results of study may be passed over and only the most important points in question involved may be here indicated with all brevity. The answers to these are at best for the most part rather contradictory. ${ }^{42}$

Gas Interchange of Muscle.-In case of the skeletal muscles the relations between their functional efficiency and gas exchange have been the subject of a large number of investigations, particularly at the hands of C. Ludwig, v. Frey, Chauveau and Kaufmann, Zuntz and Thunberg. The last named author found by the aid of his microrespirometer that the intake of oxygen by a frog's muscle is in a general way a measure of the irritability of the muscle, but

${ }^{40}$ Otto Cohnheim, VIII internat. Physiol. Kongr. Vienna, Sept., 1910; Zeitschr. f. physiol. Chem., 69, 89, 1910.

${ }^{41}$ The respiratory quotient, however, may be falsified in these experiments by the fact that lactic acid of post mortem development displaces carbonic acid from any carbonates which are present.

${ }^{42}$ Literature: J. Barcroft, Ergebn. d. Physiol., 7, 699-762, 1908. 
that a muscle rendered incapable of excitation by some poison continues to show a not inconsiderable capacity for taking up oxygen. According to Verzár the quantity of acid entering into the blood in connection with muscular contraction is sufficient to reduce the affinity of the hæmoglobin for oxygen. The fact that for a considerable time after the expiration of a contraction muscle shows an increase in its oxygen consumption is significant of the importance of oxygen in the process of its recovery. ${ }^{43}$ Systematic studies of the gas interchange of the smooth muscle of the stomach and intestine have been made by O. Cohnheim by his method. ${ }^{44}$

Numerous studies have been made of the gas exchange of the heart. They are largely devoted to comparison of the cardiac muscle with the skeletal muscles, the relation of gas interchange with the rhythm and mechanical actions, the influence of vagus stimulation and of various poisons (as calcium chloride, chloroform, alcohol, digitalin, adrenin, etc.). The method of perfusing the surviving heart of a warm-blooded animal with blood which Rohde has carefully worked out in R. Göttlieb's laboratory promises important results in combination with the modern methods of blood gas analysis. ${ }^{45}$

Oxygen Requirement of Nervous Tissue.-The respiratory processes of the nervous system have been studied particularly by Hill and Nabarro, F. W. Frölich ${ }^{46}$ (in Verworn's laboratory) and by H. Winterstein. ${ }^{4 \pi}$ Frölich believes that on augmentation of their oxygen allowance the excitability of nerves is increased up to a certain degree,

${ }^{43}$ F. Verzár (Physiol. Lab., Cambridge), Jour. of Physiol., 44, 253, 1912; ef. also G. C. Mathison, Jour. of Physiol., 13, 347, 1911.

${ }^{14}$ O. Cohnheim, Zeitschr. f. physiol. Chem, 5/, 461, 1908; O. Cohnheim and D. Pletnew, Zeitschr. f. physiol. Chem., 69, 102, 1910.

${ }^{4}$ Yeo, W. E. Dixon (Cambridge), Brodie and Cullis, Locke and Rosenheim, G. D. Cristina (Naples), Arch. di. Fisiol., 5, 347, 1908; E. Rohde (R. Göttlieb's Lab., Heidelberg), Arch. f. exper. Pathol., 68, 401, 1912.

${ }^{48}$ F. W. Frölich (Verworn's Lab., Göttingen), Zeitschr. f. allgem. Physiol., 8, 131, 1903.

${ }^{\pi}$ H. Winterstein (Rostock), Zeitschr. f. allgem. Physiol., 6, 315, 1906. 
and that beyond this limit all the oxygen taken up by nervous substance is accumulated as an oxygen store.' On the other hand Winterstein showed in case of the isolated frog's spinal cord that after asphyxiating his preparation in an atmosphere of nitrogen there was no more oxygen taken up at time of recovery than in ordinary respiration. He concluded from this that oxygen storage does not take place in the living body, and that asphyxiation is not the result of exhausting the oxygen store but is due rather to accumulation of anærobic cleavage-products apparently of an acid character; of course lactic acid is to be thought of at once.

Gas Interchange of the Salivary Glands.-The gas exchange of the salivary glands has been thoroughly investigated by Barcroft, at the suggestion of Langley (in sequence to the older studies of Chauveau and Kaufmann and of Moussu and Tissot). Stimulation of the chorda undoubtedly increases the gas exchange of the submaxillary gland; the influence of sympathetic stimulation is more difficult to determine, as the effect is masked by a reduction of the blood flow. Barcroft believes, however, that the sympathetic is not directly inhibitive to metabolism in the gland. He showed (in collaboration with Piper) that injection of adrenin calls forth a very much increased demand for oxygen in the gland, apparently occasioned by stimulation of the sympathetic. There first was a rise in blood pressure after the injection, then an increase in the secretion of saliva; the increase in oxygen consumption, however, reached its maximum after the salivary secretion was almost finished. The conclusion from this is that it is not the secretion itself but the recovery and the restoration of secretory material which calls out the main expenditure of energy. ${ }^{48}$

Gas Exchange in the Liver and Kidney.-In case of hepatic gas exchange it is apparently proved that it is more

${ }^{48}$ J. Bareroft, 1. c. p. 731-74l ; J. Barcroft and H. Piper, Jour. of Physiol., 44, 359, 1912. 
active in well fed animals than in fasting subjects from the studies of Bareroft and Shore. ${ }^{49}$ In the kidney the interchange of gases is undoubtedly increased in the course of an experimentally induced diuresis (as indicated by investigations of Barcroft, Brodie, Cullis and Hamill). One may strikingly maintain, according to Vernon, the gas interchange at a fairly constant level for many hour's by perfusing a fresh mammalian kidney with Locke's solution to which have been added a little blood-serum and urea. ${ }^{50}$

Gas Exchange of the Intestine.-Finally it should be added that the gas exchange of the intestine has been investigated by v. Frey, Cohnheim and by Brodie ${ }^{51}$ (in association with Halliburton, Vogt and Cullis), and that the results would indicate that whenever there is an increase of absorption (whether induced by contact of water, dilute salt solutions, peptone or dilute acids) a rise in the gas exchange ensues.

The examples cited are sufficient to show the lines along which these studies tend. The most important general result that stands out is the fact that practically always increased functional performance by an organ is accompanied by an increase in its gas interchange.

Anoxybiotic Processes.-These considerations of tissue respiration may be concluded with a short reference to anoxybiotic processes.

Bunge in 1883 called attention to the remarkable fact that there are animals which are capable of living in the absence of oxygen. These are the intestinal worms, parasitic in the warm-blooded animals, forms of life whose needs for heat-production are necessarily reduced to a minimum, as they normally inhabit a living incubator. Mud-dwelling forms live under comparable respiratory conditions to those

to J. Barcroft and L. E. Shore (Physiol. Lab., Cambridge), Jour. of Physiol., 45, 296, 1912.

${ }^{50}$ H. M. Vernon (Oxford), Jour. of Physiol., 35, 53, 1906; 36, 81, $1907-08$.

${ }^{81}$ Brodie, in collaboration with W. C. Cullis, W. D. Halliburton and H. Vogt, Centralbl. f. Physiol., 23, 324, 1909; Jour. of Physiol., 40, 136, 173, 1910. 
of the intestinal worms. Bunge's studies were made upon the ascarides of the cat, horse and pig and, too, upon leeches. He found that the former can exist for from four to six days outside the body in a practically oxygen-free fluid, manifesting very active movements, and, obviously as the result of cleavage processes in their tissues, giving off abundant amounts of carbonic acid. These studies by Bunge were later continued by Ernst Weinland in Munich. The latter was at once struck by the large amount of glycogen contained in the intestinal parasites; the dried substance of an ascaris may consist of as much as one-third and that of a tænia of as much as one-half of glycogen. Obviously the anoxybiotic decomposition of this carbohydrate, a form of fermentation process, is the most important source of energy from which these types of life provide their requirements. According to Weinland the sugar is decomposed in them into carbonic acid, valerianic acid and hydrogen, according to the following equation: $4 \mathrm{C}_{6} \mathrm{H}_{12} \mathrm{O}_{6}=$ $9 \mathrm{CO}_{2}+3 \mathrm{C}_{5} \mathrm{H}_{10} \mathrm{O}_{2}+9 \mathrm{H}_{2}$ (although it should be added the formation of hydrogen has not been directly proven). Ernst J. Lesser has discovered that a marked anoxybiotic glycogen decomposition may also be observed in earthworms, which may amount to six times the rate of oxybiotic glycogen decomposition, and in which in addition to carbonic acid a volatile fatty acid, apparently valerianic acid, appears. Methane, hydrogen and alcohol are apparently not present. The previously presented efforts seeking to establish an alcoholic fermentation as a normal process of intermediate metabolism in the animal economy, therefore receive no support, at least from these investigations. ${ }^{52}$

${ }^{52}$ Literature upon Anoxybiotic Vital Processes in Animals: O. v. Fürth, Vergl. chem. Physiol. der niederen Tiere, pp. 134-136, Jena, 1903; E. J. Lesser, Zeitschr. f. Biol., 52, 282; 53, 533; 54, 1; 56, 467, 1911; Ergebn. d. Physiol. 8, 786-796, 1909. 


\section{CHAPTER XXIV}

THE COLORING MATTER OF THE BLOOD. THE GASES OF THE BLOOD. GAS INTERCHANGE IN THE LUNGS. PHYSIOLOGY OF ALPINISM

\section{HEMOGLOBIN}

THE processes of tissue respiration naturally predicate the existence of arrangements which make possible introduction of oxygen and elimination of the carbonic acid formed in the combustion changes. These provisions in the warm-blooded animals are, as is well known, provided by the red coloring matter of the blood. In a previous lecture (v. Vol. I of this series, pp. 211-227, Chemistry of the Tissues) consideration has been given to the component hæmatin, and its derivatives; attention may therefore here be devoted, from a physiological standpoint, to hæmoglobin as a whole. ${ }^{1}$

Production of Hamoglobin Crystals.-Hæmoglobin, it is well known, belongs to the group of crystallizable proteins. In many readily crystallizable types of blood one may obtain beautifnl hæmoglobin crystals by the simple method of Hoppe-Seyler, by laking the blood and placing it in a cold place (perhaps with addition of a little alcohol). Following the Hofmeister method of albumin crystallization, F. N. Schulz obtained beautifully formed crystals of hæmoglobin by taking a mass of red blood cells, making a laked solution with water, and then adding an equal volume of saturated solution of ammonium sulphate. The precipitate of globulin-like substances is then filtered off and the filtrate allowed to stand. By the process of salting out resulting from the gradual evaporation the hæmoglobin separates in the form of crystals.

Variability of Hamoglobin.-The crystals obtained from

${ }^{1}$ Literature upon Hæmoglobin: Franz Müller, Handb. d. Biochem., 1, 662666, 670-678, 1909; 0. Cohnheim, Chemie der Eiweisskörper, 3rd Ed., 1911. 
the blood of different animal species vary considerably. As a rule they form needles, prisms and plates of rhombic system; the hexagonal crystals of the squirrel and the tetrahedra of guinea-pig hæmoglobin are well known. Formerly much importance was made of such differences. It has been shown, however, that by repeated recrystallization one form of crystal can be converted into another; ${ }^{2}$ that therefore we are dealing with a typical heteromorphism which may be looked upon as an expression of a certain molecular instability. When we take up the question of the chemical identity of hæmoglobin, however, there are a number of other factors to be taken into consideration. In the first place it should be remembered that even by repeated reerystallization it is not always possible to exclude with certainty the admixture of other high molecular substances. Besides it is an important point (confirmed particularly by the studies of Barcroft and his collaborators) to remember that the dissociation of oxyhæmoglobin into hæmoglobin and oxygen is subject to an influence from the salts and the carbonic acid in the surrounding medium and of course, too, from numerous other factors. ${ }^{3}$ We know, moreover, that hæmoglobin is an extremely labile substance, the protein component of which may undergo distinct changes even from being left exposed and from drying (Nencki's "parahamoglobin") without this being necessarily evinced by any important change of form or even any loss of refractive power. And, finally, attention lias been directed by the investigations of $\mathrm{H}$. Aron and Franz Müller ${ }^{4}$ to the point that differences between the behavior of blood solutions and pure hæmoglobin solutions may be caused by partial conversion of oxyhæmoglobin into methæmoglobin (vide infra), this being at times indeed met even in normal blood.

${ }^{2}$ M. Uhlik (Innsbruck), Pflüger's Arch., 104, 64, 1904.

${ }^{3}$ Barcroft and M. Camis (Physiol. Instit., Cambridge), Jour. of Physiol., 39, 118, 1909.

${ }^{4}$ H. Aron (N. Zuntz's Lab.), Biochem. Zeitschr., 3, 1, 1906; H. Aron and F. Müller (N. Zuntz's Lab.), Arch. f. (Anat. u.) Physiol., 1906; suppl. 110. 
Hcemochrome and Crystallized Blood Coloring Matter.When these points are kept in mind there is no need to be surprised that the observations made in reference to the red-blood coloring matter are not of a uniformly consistent nature. After Bohr had brought forward the real blood coloring matter, "hamochrome," in contrast to the crystallized coloring material obtained from the blood, the correctness of this counterview became the subject of warm discussion.

Thus Franz Müller assumed with Bohr "that the coloring matter of different individuals of the same species and of the same individual at different times may have different light absorption properties and a varying proportion of iron, and that these variations are particularly appreciable in conditions of blood regeneration and in pathological states." However even in the crystals produced from the native coloring material it would seem that the specific capacity for oxygen may be as individualized as in case of the blood coloring matter itself and may vary among different animal species. ${ }^{5}$

Individuality of Hamoglobin.-In contradiction to this position, however, it must be stated that studies by Abderhalden on goose-blood, ${ }^{6}$ similar observations in v. Zeynek's laboratory on the blood of sea turtes, ${ }^{7}$ and studies in the Heidelberg medical clinic ${ }^{8}$ of the blood of healthy and diseased human beings, bespeak throughout the individuality of pure hæmoglobin. Above all, however, the many studies, carried out with the utmost precision by the recently-deceased master of hæmoglobin research, G. Hüfner, and the

${ }^{5}$ F. Müller, Handb. d. Biochem., 1, 669, 675, 1909; cf. also A. Borustein and F. Müller, Physiol. Kongress, Heidelberg, 1907, Centralbl. f. Physiol, 21, $478,1907$. 1909.

${ }^{6}$ E. Abderhaiden and F. Medigreceanu, Zeitschr. f. physiol. Chem., 59, 165,

'F. Bardachzi (v. Zeynek's Lab., Prague), Zeitschr. f. physiol. Chem., $49,465,1906$.

${ }^{8}$ E. Masing (Med. Clinic of Krehl, Heidelberg), Deutsch. Arch. f. klin. Med., 9S, 122, 1909; E. Masing and R. Siebeck, ibid., 99, 130, 1910. 
extensive work of his pupil, Butterfield, ${ }^{9}$ emphasize the view that in iron proportions, ability to combine oxygen, and in spectrophotometry of pure, unchanged red blood coloring matter in all the instances of normal and diseased human beings and animals examined, there is no variation. Of course it has not been proved and (according to everything immunology and precipitin study indicate) is not even probable that the colorless protein components of all hæmoglobins of the general animal kingdom are actually identical among themselves. The molecular weight of hæmoglobin has been estimated by Hüfner as about 16,000 (from the iron contained, its capacity for $\mathrm{CO}_{2}$ fixation and from direct manometric measurements of the osmotic pressure of its solution if placed in a semipermeable cell). ${ }^{10}$ Who would care to undertake to prove that two substances with such a molecular weight are identical? But we have no reason to assume that the differences between different hrmoglobins (as far as they exist) manifest themselves by a difference in their iron content and their power of taking up oxygen. The observations bearing on these points, in the author's opinion, are satisfactorily explained by the previously-mentioned accessory factors and by the secondary processes of decomposition; and we doubtless would do well not to unnecessarily make it harder than necessary to comprehend the already complicated circumstance of oxygen fixation in the blood by assuming that there is an unlimited multiplicity of hæmoglobins. As 0 . Cohnheim ${ }^{11}$ cautions, since chemists who are disposed to study the physical-chemical balance between hæmoglobin and oxygen, work with pure and unchanged hæmoglobin, while the physiologists, who have to do with the question of oxygen-transportation in the economy, carry on their researches with blood as little changed as possible,

- E. E. Butterfield, Zeitschr. f. physiol. Chem., 62, 173, 1909.

${ }^{20} \mathrm{G}$. Hüfner and E. Gansser, Arch. f. (Anat. u.) Physiol., 1907, 209; E. W. Reid (Dundee), Jour. of. Physiol., 33, 12, 1905-06; J. Barcroft and J. V. Hill, ibid., 39, 428, 1909-10.

${ }^{21}$ O. Cohnheim, 1. c., p. 359. 
it may easily be seen how contradictory results may enter into the subject at once.

Importance of the Iron in the Blood Coloring Matter.Before going further the question of the importance of the iron in the coloring matter of the blood may be briefly discussed. In a previous lecture (v. Vol. I of this series, p. 213, Chemistry of the Tissues) it was stated that according to William Küster's investigations iron is present both in hæmin and in hæmatin in the ferric state; the ferri chloride group, $\mathrm{FeCl}=$, in hæmin and the ferri hydroxide group, $\mathrm{FeOH}=$, in hæmatin replacing the hydrogen atom in the imido group of pyrrol complexes. The ferri compound, hæmatin, can be reduced to the ferro compound, hæmochromogen. It seems, however, that hæmatin is not a component of oxyhæmoglobin, but of methæmoglobin, which has all the characters of a ferri compound. According to Küster the following connections exist:

Hæmoglobin = Globin + Hæmochromogen $\mathrm{R}>\mathrm{Fe}$

Oxyhæmoglobin = Globin + Hæmochromogen peroxide $\mathrm{R}>\mathrm{Fe} \ldots \mathrm{O}_{2}$

Methæmoglobin $=$ Globin + Hæmatin $\mathrm{R}>\mathrm{Fe}-\mathrm{OH}$;

and he is unable to recognize any force in Manchot's arguments that hæmoglobin is a ferri compound. ${ }^{12}$

Methamoglobin.-According to this view, the iron of methæmoglobin ${ }^{13}$ is trivalent ferric iron, which is no longer able to loosely fix oxygen and is much more stable than oxyhæmoglobin. The latter has a tendency to become methæmoglobin, and even in the living blood it is well known that a number of poisons are able to induce this transition. By a reducing agent (as ammonium sulphide or Stokes' reagent) methæmoglobin can be reconverted into hæmoglobin. Hüfner succeeded, it may be mentioned in passing, in

${ }^{12}$ W. Küster, Zeitschr. f. physiol. Chem., 66, 248, 1910; 71, 104, 1911; W. Manchot (Würzburg), ibid., 70, 230, 1910.

${ }^{13}$ Literature upon Methæmoglobin: O. Cohnheim, 1. c., 345-349. 
obtaining methæmoglobin in crystalline form (its acid solution produces a brown color). A fluorine combination of methæmoglobin may also be obtained in crystalline state, by mixing a solution of methæmoglobin with concentrated solution of sodium fluoride-ammonium sulphate, and chilling to $0^{\circ}$ C. ${ }^{14}$

\section{BLOOD GASES}

Technic of Blood Gas Analysis.-The technic of blood gas analysis belongs among the most difficult and yet the most carefully worked out chapters of physiological technology. To some extent it has been dealt with in the previous lecture; but here, too, reference must be limited to a few brief statements, and the various handbooks must be consulted for details. ${ }^{15}$

As the union between hæmoglobin and oxygen is broken in a vacuum, it is possible to withdraw the latter from the blood by means of an air-pump. The distinguished rôle accorded Pflüger's blood-gas pump in the history of physiology is a matter of common knowledge. More modern apparatuses of this kind have been proposed by Zuntz, Bohr, and by Buckmaster and Gardner. ${ }^{16}$ More recently the pump methods have given way more and more to the chemical method of blood-gas analysis, which is not only much more satisfactory and simpler, but has in addition the great advantage of being adapted to the employment of very small quantities of blood. As already stated, the oxygen is set free from the blood by potassium ferricyanide, and the method, perfected by Haldane, Barcroft, Brodie, Hamill and Franz Müller, works with a remarkably high degree of exactness.

The tension of the gases in the blood may be determined

${ }^{14} \mathrm{~J}$. Ville and Derrien, Compt. rendu, 140, 1195, 1905.

${ }^{15}$ Literature upon the Methods of Blood Gas Analysis: A. Löwy, Handb. d. Biochem., 4', 17-24, 1908; Franz Müller, Handb. d. biochem. Arbeitsmethod., 3, 555, 1910; 5, 1027-1034, 1912; Bohr, Tigerstedt's Handb. d. physiol. Methodik, 2, 1, 1910; J. Barcroft and P. Morawitz (Physiol. Instit., Cambridge), Deutsch. Arch. f. klin. Med., 93, 223, 1908.

${ }^{10}$ G. A. Buckmaster and J. A. Gardner, Jour. of Physiol., 40, 373, 1910. 
by means of blood gastonometers ${ }^{17}$ as used by Pflüger, Frederieq, Bohr, Krogh and Löwy. They all depend on the principle that blood is brought in contact with a mixture of gases until a complete tension balance is attained and the partial pressure of the gases is then determined. The balance is quickly obtained if the volume of gas is reduced to a minimum as in a microtonometer.

In the method of Haldane and Lorraine Smith the oxygen is determined in a specimen of blood by means of ferricyanide; in another specimen the oxygen is forced out by carbon monoxide and the color of the carbon oxide blood compared with a carmine solution of known proportions. Plesch has proposed a wedge hæmoglobinometer; the blood to be tested, diluted 200 times, is converted into carbonoxide blood by shaking it up with illuminating gas and this compared with a standard fluid (blood with known proportion of carbon oxide). The apparatus consists of two graduated tubes, one of which receives the blood to be tested, the other the standard fluid. In the latter is a wedge arranged so that the visual thickness diminishes from below upwards. The result is read off by observing the tubes through a small aperture and moving one tube until the colors coincide. In a method devised by Zuntz and Plesch, which has been found applicable to the study of circulating blood in the living animal, the carbon oxide is forced out of the blood by potassium ferricyanide, oxidized into carbonic acid by passing over glowing platinum, the carbonic acid absorbed by potassium hydrate and the earbon oxide determined by Barcroft-Haldane method from the observed change of pressure. Dreser has also devised a method for determining the carbon oxide combined in small quantities of blood; in which he uses a small mercury pump, measuring the amount of gas obtained in a capillary tube.

The new nitrous oxide method devised by Zuntz in collaboration with Markoff and Franz Müller provides a very

\footnotetext{
${ }^{17}$ Cf. Literature in Ch. Bohr, Skandin. Arch. f. Physiol., 17, 205, 1905.
} 
satisfactory mode, applicable also to estimation of the circulating blood in the living human body. The subject inspires from a gasometer which contains a gas mixture of known composition rich in nitrous oxide but providing sufficient oxygen. The amount of nitrous oxide taken up by the blood during respiration is determined by analysis. On the basis of the determinations of Siebeck as to the intake of nitrous oxide by blood it can then easily be determined how much blood must have passed through the lungs to have taken up at the given partial pressure the amount removed from the mixture. ${ }^{18}$

Objective Hamoglobinometry and Spectrophotometry.Attention should be paid to two recent methods of interesting device. In each the purpose attempted is an objective hæmoglobinometry intended to make the observer independent of the question of keenness of his subjective senseperceptions. This is accomplished by J. Plesch by replacing the eye of the observer in comparing the concentrations of color solutions by a selenite cell traversed by an electric current. It is well known that selenium possesses the property of changing its electrical conductivity under the influences of light, apparently owing to a polymerization due to the light. By having the light coming from a fixed source traverse a trough filled with the color solution before falling upon the selenium cell, the variation in current resistance, which may be measured by a sensitive galvanometer, is made to serve as an objective index of the degree of light absorption. ${ }^{19}$

The other method referred to is a photographic record of intensity dispersion in blood spectra recently perfected by Wolfgang Heubner. ${ }^{20}$ The method of spectrophotometric

${ }^{18}$ J. Markoff, Franz Müller and N. Zuntz, Zeitschr. f. Balneol., 4, Nos. 1415, 1911-12.

${ }^{10} \mathrm{~J}$. Plesch (N. Zuntz's Lab.), Biochem. Zeitschr., 1, 32, 1906.

${ }^{20}$ W. Heubner (Göttingen), VIII Intern. Physiologen-Kongr., Wien., Sept., 1910 ; Deutsche med. Wochenschr., 1911, No. 11; W. Heubner and H. Rosenberg, Biochem. Zeitschr., 38, 345, 1911. 
measurement in special application to hæmoglobin and its derivatives has been brilliantly developed by G. Hüfner. ${ }^{21}$ "The direction of prospective improvement of method," says Hüfner, "was indicated beforehand in the recording of the spectral image photographically, so often done previously with good results. The method is particularly advantageous because the long-drawn photometric observation can be interrupted for the quickly accomplished recording on the spot of the general spectral field, allowing, for example, rapid chemical reactions which occur with a change of light absorption to be followed with ease and exactness." It is a matter of interest that the fundamental studies which have led to the development of the photographic-photometric method, have been applied by an astronomer (K. Sehwarzschild) to the study of the stars-a fine example of organic exchange between two widely separated, flourishing branches of the tree of modern science.

Coefficients of Absorption, Invasion and Evasion.-Consideration of oxygen fixation in the blood must necessarily be based upon the general laws of solution of gases in fluids. We have therefore to deal with the coefficients of absorption, invasion and evasion. The absorption coefficient is that amount of gas which is contained in one cubic centimetre of a fluid saturated with gas at $0^{\circ} \mathrm{C}$. and at $760 \mathrm{~mm}$. pressure. That quantity of gas which at given temperature and $760 \mathrm{~mm}$. pressure will penetrate into the fluid in the course of one minute through a surface of one square centimetre is known as the invasion coefficient. That quantity of gas which will escape in one minute from a surface of one square centimetre, providing one cubic centimetre of the fluid contains one cubic centimetre of gas, is spoken of as its evasion coefficient.

Oxygen is absorbed in the plasma, but is peculiarly com-

${ }^{21}$ Literature upon Spectrophotometry of the Hæmoglobins: Bürcker, Tigerstedt's Handb. d. physiol. Methodik, 2', 68, 1910. 
bined in the hæmoglobin of the blood. The solvent capacity of the plasma for oxygen does not appreciably differ from that of water. In spite of the fact that the plasma therefore contains relatively little oxygen, this particular fraction of the oxygen is in precise consideration of the greater importance, for the tissue cells do not come in direct contact with the oxygen-bearing red blood corpuscles, but with the plasma only. The erythrocytes serve as a reservoir from which the plasma-oxygen is continuously supplied.

Tension Curves. - The intake of oxygen into the blood naturally depends to a very marked degree upon the oxygen pressure in the air. For each given pressure there corresponds a definite amount of fixed oxygen. By taking the pressures as abscissas and the corresponding amounts of oxygen taken into the blood as ordinates, a tension curve may be constructed. The course of the curve indicates how much oxygen is combined by the hæmoglobin at a given pressure. If the total amount of oxygen in a unit volume of blood be known for this particular moment, it is possible to come to a conclusion as to the amount which is fixed by the affinities of hæmoglobin and how much is available in free state.

The general type of such tension curves is always the same in all sorts of blood and hæmoglobin solutions. Invariably the line is that of a curve with its concavity toward the axis of the abscissa, sharply ascending and then continuing asymptomatically, this being expression of the fact that the fixed amount of gas, as the pressure is gradually raised, increases far more quickly at a slight pressure than at higher pressure. Even at an oxygen pressure of $160 \mathrm{~mm}$. which about corresponds to the partial pressure normal for the atmospheric oxygen, the hæmoglobin seems to be within a slight percentage of saturation with oxygen. The maximal capacity for oxygen fixation both of fresh blood and of hæmoglobin solutions prepared by different methods has been found by Hüfner, and a number of other inves- 
tigators as well, to be 1.34 cubic centimetres of oxygen for one gram of hæmoglobin. ${ }^{22}$

If the course of the pressure curves, however, is more closely inspected, marked differences will be noted on comparison of normal laked blood and solutions of isolated hæmoglobin obtained from different animal species and individuals, which have led Bohr and his followers to assume the existence of a multiplicity of hæmoglobius and particularly to differentiate "hrmochrome" from hæmoglobin.

As a matter of fact, the line of the tension curves may be influenced by a number of physical and chemical factors. ${ }^{23}$

Influence of Carbonic Acid Pressure.-As one of the most important factors of this type we have come to recognize carbonic acid. According to the studies of Bohr, Hasselbach and Krogh the ascent of the curve becomes the less sharp the greater the quantity of carbonic acid in the blood. Given the same oxygen pressure, there will be less oxygen fixed the more carbonic acid there is present; this may be expressed in other words by saying that carbonic acid may raise the dissociation pressure of oxyhæmoglobin, that is, increase its tendency to give off oxygen. We are bere dealing with a purposeful provision of the economy which makes it possible to have ain especially ready oxygen release from the arterial blood at precisely such places where for any reason carbonic acid accumulates in the tissues and where a danger from oxygen impoverishment is threatened.

Influence of Temperature.-Another important factor in connection with oxygen tension is the temperature (as shown by the experiments of Paul Bert, Barcroft, Löwy and Caspari). The power of taking up oxygen by hæmoglobin is diminished with increase of temperature. In increased temperature from fever or from severe muscular exertion, 1911.

${ }^{22}$ Cf. Literature: O. Cohnheim, Chemie der Eiweisskörper, III Ed., p. 343,

${ }^{23}$ Literature upon the Dissociation of Oxyhæmoglobin: Ch. Bohr, Nagel's Handb. d. Physiol., 1, 57-68, 70-103, 1905; A. Löwy, Handb. d. Biochem., 4', 47-55, 1908. 
therefore, the oxygen supply to the tissue is favored by increased dissociation of the oxyhæmoglobin. ${ }^{24}$ According to Hasselbach ${ }^{25}$ a transitory lowering of the oxygen fixing power of the blood can be produced by lowering of the atmospheric pressure.

Influence of the Salts in the Medium, and Other Factors. -The saline constituents of the medium are also undoubtedly of much physiological importance. If a ten per cent. hæmoglobin solution in one per cent. soda solution be prepared the oxygen fixation is apparently firmer than in blood under comparable conditions. ${ }^{26}$ Barcroft and his colleagues ${ }^{27}$ have concluded that the course of the pressure curve is so highly dependent upon the nature and concentration of the salts of the surrounding medium, that we can scarcely contemplate the formulation of a generally applicable dissociation curve. If an examination be made, for example, of one and the same hæmoglobin dissolved in distilled water, in 0.7 per cent. salt solution, and 0.9 per cent. calcium chloride solution, and in the presence of sodium bicarbonate or sodium monophosphate, altogether different pressure curves result. By adding the salts which belong in the corresponding blood corpuscles to a solution of dog (or human) hamoglobin the characteristic curve for the particular blood will be obtained.

Physical-chemical Conception of Oxygen Fixation by Hamoglobin.- The entrance of lactic acid into the blood may also distinctly modify the course of the curve of oxygen pressure. According to Barcroft more favorable conditions for the supply of oxygen to the tissues are likely to obtain at great heights because of diminution of the blood alkalescence.

${ }^{24}$ Cf. A. Durig, Handwörterb. d. Naturwissensch., Jena, G. Fischer, 1, 692.

${ }^{25}$ K. A. Hasselbach, Festschr. O. Hammersten, Wiesbaden, 1906; cited in Jahresber. f. Tierchemie, 36, 166, 1906.

${ }^{26}$ Cf. A. Löwy, Handb. d. Biochem., 4', 52, 1908.

${ }^{27} \mathrm{~J}$. Barcroft, with Camis and Roberts, Jour. of Physiol., 39, 118, 143, 1909. 
Sufficient has been said to indicate that very complex conditions prevail in connection with the fixation of oxygen by hæmoglobin and that it is scarcely possible to express these by a simple formula. For a long time the Hüfner formula, $\mathrm{C}_{o}=\mathrm{K} \mathrm{C}_{r} \frac{\mathrm{P}_{o} \mathrm{~A}_{t}}{760}$, was popular ( $\mathrm{C}_{o}$ representing the amount of oxyhæmoglobin, $\mathrm{C}_{r}$ that of reduced hæmoglobin, $\mathrm{K}$ a constant, $\mathrm{p}_{\mathrm{o}}$ the oxygen tension at the surface of the solution, and $\mathrm{a}_{\mathrm{t}}$ the absorption coefficient at temperature, $\mathrm{t}$ ). Later, however, objections from various sources have been raised against this formula. Thus Bohr assumes in the first place that while the combination of iron-free globin with iron-containing hæmochromogen may be hydrolytically

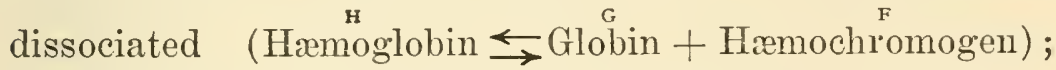
on the other hand there may be an equilibrium, $\mathrm{F}_{0} \leftrightarrows \mathrm{F}+$ $2 \mathrm{O}_{2}, \mathrm{~F}_{0}$ representing the iron-containing hæmoglobin fraction combined with oxygen. From this assumption Bohr arrives at a rather complicated formula of dissociation..$^{28} \mathrm{~V}$. Henri believes that we may more satisfactorily harmonize theory and practice by assuming that two molecules of hæmoglobin unite with one molecule of $\mathrm{O}_{2} \cdot{ }^{29}$ Manchot ${ }^{30}$ is of the opinion that hrmoglobin is capable of combining oxygen and other gases in the same way that sulphate of iron combines nitrous oxide or chlorate of copper fixes carbon monoxide, and holds that the laws of equivalence and mass action are sufficient to explain the complex phenomena. Barcroft and Hill ${ }^{31}$ regard it as almost beyond doubt that dissociation of oxyhæmoglobin takes place in accord with the equation, $\mathrm{H}_{\mathrm{b}}+\mathrm{O}_{2}, \leftrightarrows \mathrm{H}_{\mathrm{b}} \mathrm{O}_{2}$, and follows the law of mass action; has a high temperature coefficient and increases four-fold

${ }^{28}$ Cf. A. Löwy, Handb. d. Biochem., 4', 53-54, 1908; B. v. Reinbold, XVI internat. Mediz. Kongress, Budapesth, 1909, S. A.

${ }^{29}$ V. Henri, C. R. Soc. de Biol., 56, 339, 1904.

${ }^{30} \mathrm{~W}$. Manchot (Chem. Instit., Würzburg), Ann. d. Chem., 3\%0, 241, 1910; 372, $179,1910$.

${ }^{11}$ J. Bareroft and A. V. Hill (Physiol. Lab., Cambridge), Jour. of Physiol., $39,411,1910$. 
for every $10^{\circ}$ rise of temperature. However, W. Ostwald ${ }^{32}$ looks on the whole problem from an entirely different standpoint, introducing in opposition to the theory of dissociation and chemical combination a theory of adsorption, and expressing the belief that the complex phenomena of gas fixation in the blood are far better regarded as purely physical adsorption phenomena and that they can be dealt with mathematically by means of the formula of adsorption. The author is not in a position to form a personal opinion in regard to this difficult subject and believes it best to await with patience the future conclusions of physical chemists in this problem.

Similar differences of opinion obtain as to the physicalchemical interpretation of carbon monoxide hæmoglobin, nitrous oxide hæmoglobin, cyanhæmoglobin, sulphhæmoglobin and acetylenehæmoglobin. It is scarcely likely to be regarded as appropriate here to spend any time on the length and breadth of this subject and in the end come to no satisfactory conclusion. It should be sufficient to call attention to the authoritative statements which may be found in the papers of Ch. Bohr, A. Löwy, and F. Müller. ${ }^{33}$

Carbonic Acid Combination in the Blood.-Turning now to the consideration of carbonic acid combination in the blood, we approach a subject of even more complicated character than that of oxygen fixation, as carbonic acid enters into combinations subject to dissociation with the inorganic as well as with organic constituents of the blood. Important researches upon this subject have been prosecuted by Pflüger, Gaule, Setschenow, Zuntz and A. Löwy, Bohr, Torup, Jaquet, Nagel and others. ${ }^{34}$

A portion of the carbonic acid exists in the blood as

${ }^{32}$ W. Ostwald, Zeitschr. f. Kolloidchem., 2, 264, 294, 1908; cited in Jahresber. f. Tierchemie, 38, 187, 1908.

${ }^{33}$ Ch. Bohr, Nagel's Handb. d. Physiol., 1, 120-128, 1905; A. Löwy, Handb. d. Biochem., 4' 43-44, 65-7 1, 1908; F. Müller, ibid., 1, 681-706, 1909; Handb. d. biochem. Arbeitsmethod., 3', 664-703, 1910.

${ }^{24}$ Literature upon Carbonic Acid Combination in the Blood: Ch. Bohr, Nagel's Handb. d. Physiol., 1, 68-69, 103-117, 1905; A. Löwy, Handb. d. Biochem., 4', 55-64, 77, 1908. 
alkali carbonate, and as such is subject to hydrolytic dissociation in accordance with the law of mass action: $\mathrm{Na}_{2} \mathrm{CO}_{3}+$ $\mathrm{H}_{2} \mathrm{CO}_{3} \rightleftarrows 2 \mathrm{NaHCO}_{3}$. While from a solution of bicarbonate of the same concentration as in the blood only about one quarter of the total carbonic acid can be withdrawn even by pumping all day long, if blood be subjected to the vacuum of a pump the whole amount of earbonic acid is freed within but a few hours. This remarkable feature is explained by the fact that there are substances of an acid character contained in the blood which displace the carbonic acid with the assistance of the vacuum. Further analysis of this phenomenon has shown that the carbonic acid is withdrawn more slowly from the serum alone than from the general blood: the latter therefore contain substances manifesting acid characteristics in higher degree. These substances of acid character with which we are here concerned are the hæmoglobin and other proteins of the blood. We may conceive that the earbonic acid and protein of acid type, and other acids which gain access to the blood, as lactic acid, are in competition for the possession of the blood alkali and apportion it among themselves in accordance with the law of mass action. But the situation is still more complicated by the fact that the proteins have the dual nature of acids and bases; and not only may be capable of combining alkali to their carboxyl, but may be capable of fixing acids to their ammonia rests, among them carbonic acid. The two processes may go on at the same time; but it should be added that a relatively high carbonic acid pressure is required in order to separate hæmoglobin from its alkaline combinations, but that combination between hæmoglobin and carbonic acid can take place even where the carbonic acid pressure is low. This last feature is apparently of the greater physiological significance.

What is the nature of the combination of carbonic acid with hæmoglobin? While, as has been seen, the intake of oxygen into hæmoglobin is markedly influenced by the pres- 
ence of carbonic acid, in the reverse carbonic acid combination proves to be relatively independent of the degree of oxygen saturation of the hæmoglobin. ${ }^{35}$ From this it has been concluded that carbonic acid enters into combination with the globin component, not the hæmatin, of the hæmoglobin.

In the matter of the nature of the combination of carbonic acid with proteins, Siegfried's carbaminoreaction (v. Vol. I of this series, pp. 86-88, Chemistry of the Tissues) seems suited to furnish some suggestion. The statement may be recalled that aminoacids are capable of loosely fixing carbonic acid in accordance with the equation:

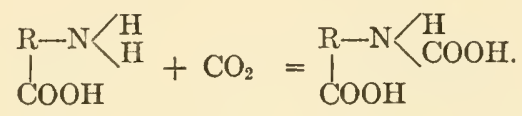

Siegfried, basing his views upon observations upon polypeptids, believes that any place in the body where protein and carbonic acid combine, the latter is fixed as above; from which standpoint the observations upon $\mathrm{CO}_{2}$ fixation in the blood, especially those of Sertoli, Setschenow, Bohr and others, appear in a new light. ${ }^{36}$

Process of Exchange Between the Blood Corpuscles and. Serum.-The proteid substances are contained in the blood partly in alkaline combinations, and there can be no doubt that when carbonic acid comes in contact with them a portion of the alkali is withdrawn through the mass action of the carbonic acid. The increase in the amount of diffusible alkali in the blood serum which has been noted by $\mathrm{N}$. Zuntz and A. Löwy and by L. Fredericq when carbonic acid is introduced into the blood, finds an explanation from this view, Zuntz assuming that alkaline carbonate passes in this way from the blood cells into the plasma. Hamburger has, however, observed that coincidently with this the chlorine

${ }^{36}$ A. Löwy, Handb. d. Biochem., 4', 56, 1908, ascribes some ability, even though but small, to oxygen to displace carbonic acid from the blood.

${ }^{36} \mathrm{M}$. Siegfried (Leipzig), in collaboration with C. Neumann and $\mathrm{H}$. Liebermann, Zeitschr. f. physiol. Chem., 4/, 85, 1905; 46, 401, 1905; 54, 423, 437,1908 . 
proportion of the serum diminishes. Gürber attempts to explain the process by supposing that hydrochloric acid is separated from the sodium chloride by the mass action of the carbonic acid $\left(\mathrm{NaCl}+\mathrm{H}_{2} \mathrm{CO}_{3}=\mathrm{HCl}+\mathrm{NaHCO}_{3}\right)$, the hydrochloric acid becoming fixed in the blood cells and the carbonate remaining in the serum. Koppe in turn assumes more complicated processes of wandering of the ions. Whoever is particularly interested in this question may find full information in the excellent work of Hamburg ("Osmotischer Druck und Ionenlehre"). ${ }^{37}$ "However we may theoretically regard them," say A. Löwy, "the processes of interchange between the blood cells and the serum constantly indicate the existence of some important means of regulation with the purpose of maintaining the carbonic acid tensions in the body at as low and unharmful a level as possible."

\section{GAS EXCHANGE IN THE LUNG}

We may here turn to the much discussed question of the kind of forces by which the gas exchange takes place in the lungs. Bohr and his followers for a long time have maintained the view that the purely physical processes of diffusion are not sufficient to explain the phenomena, and that it is essential to ascribe to the endothelial cells of the alveoli the ability to functionate as secretory elements.

Mechanism of Gas Exchange.-Any extensive historical development of the general question, upon which a great sum of most subtile physiological work has been expended, may be the more appropriately dispensed with, as the matter at issue seems at present to be finally settled. The most recent studies upon this subject, those of Leon Fredericq, Douglas and Haldane, ${ }^{38}$ R. duBois-Reymond, ${ }^{39}$ and

${ }^{87}$ Literature: Hamburger, Osmotischer Druck und Ionenlehre, 1, 291 et seq., Wiesbaden, 1905; A. Löwy, Handb. d. Biochem., 4', 63-64, 1908.

${ }^{38}$ L. Fredericq, Arch. internat. de Physiol., 10, 391, 1911 ; J. S. Haldane and C. G. Douglas (Oxford), VIII internat. Physiol. Kongr., Wien, Sept., 1910 ; Proc. Roy. Soc., 82B, 331, 1910; cited in Biochem. Centralbl., 10, No. 2633 ; Proc. Roy. Soc., 84B, 568.

so R. duBois-Reymond (Berlin), Arch. f. (Anat. u.) Physiol., 1910, 257; Berliner. physiol. Ges., July 2, 1909; Centralbl. f. Physiol., 23, 953. 
particularly those of Krogh, ${ }^{40}$ a pupil of Bohr's, all agree that both the absorption of oxygen and the separation of carbonic acid in the lungs normally takes place exclusively by diffusion, and that the assumption of special vital forces regulating the gas exchange has become superfluous. Haldane and Douglas alone ${ }^{41}$ believe that if (as in carbon monoxide poisoning, in violent muscular exercise, and in case of oxygen deficiency in the respired air) there occurs a deficiency of oxygen in the tissues, through a regulatory process the oxygen is secreted by active forces; that in this way the oxygen tension in the arterial blood is apparently distinctly raised above that of the air in the pulmonary alveoli, which could not be reconciled with ideas of processes of simple diffusion. R. duBois-Reymond, however, notes in answer to this that if normally the gas exchange is the result of simple diffusion, it would not be easy to see how the pulmonary epithelial cells may be supposed to suddenly acquire a power of gas secretion; that aside from this the histological appearances give no basis for ascribing to these cells any such activity. It may therefore be held that we are fully justified in dropping the hypothesis of gas secretion by the pulmonary epithelium.

Secretion of Oxygen in the Swim-bladder of Fish.-We know from comparative physiology of an unmistakable example of undoubted oxygen secretion actually performed by an organ in nature; this is the swim-bladder of fishes. Long ago Biot was struck by the fact that the gas filling the swim-bladder (an organ apparently primarily serving hydrostatic purposes) may consist largely of oxygen; and this is true particularly of fishes which come from the deeper sea levels. When it is recalled that the partial pressure of oxygen within the swim-bladder in marked depths may

${ }^{40}$ A. Krogh, Skandin. Arch. f. Physiol., 23, 248, 1910; cf. also P. Trendelenburg (Zoöl. Station, Naples), Zeitschr. f. Biol., 57, 495, 1912.

${ }^{41}$ C. G. Douglas and J. S. Haldane (Physiol. Lab., Oxford), Jour. of Physiol., 44, 305, 1912, and earlier contributions. 
reach the enormous degree of ninety atmospheres, while that of the surrounding water amounts to only about onefifth of an atmosphere, it is at once evident that here there can be no possibility of a diffusion process, but that necessarily we are dealing with a true oxygen secretion. Moreau showed that if the swim-bladder be emptied by puncture with a trocar it becomes filled again by secretion of a gas consisting mainly of oxygen. Bohr was able to prove that this secretory process is under the regulation of the nervous system, and that on section of the intestinal branches of the vagus nerves it fails. ${ }^{42}$

In conclusion it may be well to briefly touch upon the question of the means at disposal of the economy to compensate by the function of other organs for loss of the respiratory work of the lungs.

Partial Pulmonary Exclusion.-Hellin's experiments in reference to unilateral excision of the lung may be mentioned first, which have attained a certain degree of actual success, from the prevailing efforts of surgeons to bring the lungs into the field of accessibility to operative procedures. Hellin had observed that rabbits, one lung of which he had excised, usually bore the procedure well. The dyspnœa at first appearing generally disappeared in the course of a few hours; and, what was even more remarkable, the amount of eliminated carbonic acid, which was obtained from the single lung after the operation, was quite as large as that which was previously excreted from the two lungs together. This was made possible primarily by an increase in the work of the heart, which in consequence soon became hypertrophied. There later developed a distinct dilatation of the blood-vessels of the lung, and in the end there was a distinct hypertrophy of the alveolar pulmonary tissue itself. ${ }^{43}$

${ }^{42}$ Literature upon Gas Secretion in the Swim-bladder: Ch. Bohr, Nagel's Handb. d. Physiol., 1, 163-166, 1905; W. Cronheim, Handb. d. Biochem., 4", 431-432, 1910.

${ }^{43}$ D. Hellin (Warsaw), Arch. f. exper. Pathol., 55, 21, 1906. 
Cutaneous Respiration.-While in amphibia, as is well known, cutaneous respiration ${ }^{44}$ plays an important function and may in fact replace the pulmonary respiration, this is altogether subsidiary when we come to deal with the keratinized epiderm of warm-blooded animals. According to the coinciding investigations of Regnault and Reiset, Zülzer, Bohr and others, the skin at best coöperates to the extent of one per cent. of the total gas exchange. This has been confirmed, too, by recent studies in Zuntz's Institute, ${ }^{45}$ in which the arm of the experiment subject was surrounded by a gas mixture containing about ninety per cent. of oxygen in a closed glass sleeve, and the oxygen consumption determined. The results showed again (extending the calculation to the entire body surface) that the intake of oxygen by the skin does not exceed about one per cent. of that by the lungs. The severe lesions, perhaps fatal, which are met in animals in which the most of the skin has been varnished, are certainly therefore not due to a fault of the cutaneous respiration. (Usually these are regarded as connected with the marked chilling of the animals; yet there are cases in which this explanation is insufficient. The latter have led Babák and other authors to revive the old supposition of an accumulation of some unknown poisonous material within the body; but nothing positive is known about it.)

Oxygen is absorbed much better by the serous membranes than by the skin. Thus O. Pascucei has proved by certain admirable experiments that guinea-pigs are able to remain alive in an atmosphere of nitrogen, if oxygen be furnished to them intraperitoneally. ${ }^{46}$

Intestinal Respiration.-An exchange of gases may also take place in the intestinal wall between the intestinal con-

${ }^{4}$ Literature upon Cutaneous Respiration: Ch. Bohr, Nagel's Handb. d. Physiol., 1, 160-163, 217-218, 1905; A. Löwy, Handb. d. Biochem., 4', 167-171, 1908.

${ }^{45} \mathrm{G}$. Franchini and L. Preti (Lab. of N. Zuntz), Biochem. Zeitschr., 9, $442,1908$. 1909.

${ }^{40}$ O. Pascucci (Luciani's Lab., Rome), Arch. per le Scienze med., 33, 347, 
tents and the blood, although this is in general not a matter of physiological importance. There exist certain fishes (mud lamprey, Cobitis fossilis, and some others) which have a proper intestinal respiration. In such instances the midintestine seems by the marked development of the network of capillaries in its walls and by a peculiar type of epithelium to have acquired adaptation for a respiratory function to such a degree as to actually enable the animals to provide from the intestine a part of their oxygen requirements from the air that has been swallowed.

\section{PHYSIOLOGY OF ALPINISM}

In connection with the discussion of the processes of gas interchange, a brief excursion into the field of those phenomena which we customarily include under the term "physiology of alpinism" may be permitted. ${ }^{47}$ It would scarcely be appropriate to entirely neglect the extensive literature occupied by investigations upon this subject. Nevertheless the author does not hesitate to confess that he would not care to attempt to find a way through the labyrinth of contradictory and confusing observations, in which everyone who ventures into these matters finds himself at once ensnared, were it not that one of the bestinformed experts in the subject, A. Durig, ${ }^{48}$ has recently treated the problem comprehensively and in such a manner that his statements may serve as a welcome guide.

Sources of the Observation Material.-To the Italian physiologist, Angelo Mosso, belongs the credit of having by his personal initiative made possible the construction of an observatory adapted to physiological studies at high altitudes, Capanna Margherita, situated at an altitude above

${ }_{47}$ Literature upon the Physiology of Alpinism: A. Mosso, Der Mensch auf den Hochalpen, Leipzig, Pub. Veit \& Co., 1899; A. Jaquet, Ergebn. d. Physiol, 2', 521-531, 1903; O. Cohnheim, ibid., 2', 612-638, 1903; Ch. Bohr, Nagel's Handb. d. Physiol., 1, 210-216, 1905; Kronecker, Die Bergkrankheit, Deutsche Klinik, 11, 17-146, 1907; A. Löwy, Handb. d. Biochem., 4', 199-231, 1908.

4s A. Durig, Wiener klin. Wochenschr., 24, No. 18. 
sea-level of 4500 metres on Monte Rosa, and of having thus provided means for systematic studies in this field. The Mosso Institute, situated at a height of about 3000 metres on Colle d'Olen, conducted by Aggazzoti, makes it possible to combine observations made at different heights from the sea-level, and supplement each other. Thanks to a series of scientific Monte Rosa expeditions conducted by N. Zuntz, A. Löwy, A. Jaquet, A. Durig, and O. Cohnheim, ${ }^{49}$ an important amount of observation material has been collected to date. This has been supplemented by many earlier observations, by the investigations of an expedition to Teneriffe made by Durig, H. v. Schrötter and Zuntz, ${ }^{50}$ by observations by Douglas, Haldane, Y. Henderson, and Schneider at the top of Pike's Peak in Colorado, ${ }^{51}$ by a number of balloon ascents made for physiological purposes, ${ }^{52}$ and by experiments in the pneumatic cabinet.

It is well known that in many human beings, as soon as they have attained a certain height above the level of the sea, the symptoms of "mountain sickness" set in. The rather manifold and varying symptom complex of this condition has been thoroughly described by Angelo Mosso in his work, "Der Mensch auf den Hochalpen." 53 It was believed most probable that the whole symptom complex was to be classed as due to oxygen diminution in the respired air. It was essential, however, in order to reasonably

${ }^{40}$ Shumburg and N. Zuntz (1895); A. Löwy, J. Löwy, L. Zuntz (1896); Jaquet and Stähelin (1900); N. Zuntz, A. Löwy, F. Müller and Caspari (1901); Durig and Zunz (1903); Durig (1905); ef. Literature: A. Löwy, Handb. d. Biochem., 4', 225, 1908; A. Durig, Pflüger's Arch., 113, 1906; A. Durig in collaboration with W. Kolmer, R. Rainer, H. Reichel and W. Caspari (1906), Denkschr. d. Wiener Akad., 86, 1909; A. Durig and N. Zuntz., Biochem. Zeitschr., 39, 435, 1912; O. Cohnheim, Commissioner of Health Kreglinger and Medical Student Kŕreglinger, Zeitschr. f. physiol. Chem., 63, 413, 1909; O. Cohnheim, G. Kreglinger, L. Tobler, O. H. Weber, ibid., ₹8, 62, 1912.

${ }^{50}$ A. Durig, H. v. Schrötter, N. Zuntz, Biochem. Zeitschr., 39, 421, 1912.

${ }^{51}$ C. G. Douglas, J. S. Haldane, Y. Henderson and E. C. Schneider, Proc. Roy. Soc., LXXXV, 65B, 1912 ; cited in Centralbl. f. d. ges. Biol., 13, No. 1196, 1912.

${ }^{52}$ Hallion and Tissot, 1901; H. v. Schrötter and N. Zuntz, 1902.

A. Mosso, Der Mensch auf den Hochalpen, Leipzig, Pub. Veit \& Co., 1899. 
arrange the observation material, as a preliminary to eliminate all the factors connected with fatigue, cardiac overexertion, and the like. The amount of influence of climatic factors was, however, necessarily to be included in the study.

Influence of Climatic Factors.-In the first place the effects of cold, which is very appreciable at great heights, are to be thought of; but it should be remembered that the maintenance metabolism in Greenland was not found any greater than in the tropics and that, as Durig remarks, "the vital flame does not burn any more briskly under the influence of cold than in the sun-browned Indians." A number of other climatic factors, as the wind, rarefaction, the ionization and electrical potentials of the atmosphere have no more definite effect upon metabolism, as far as can be recognized. Therefore the fall in oxygen pressure necessarily must be regarded as the most important item for consideration. ${ }^{54}$

Increase of Blood Corpuscles.-One of the most striking alterations developing in elevated climatic conditions is the increase in the number of red blood corpuscles in the unit of volume of a sample of withdrawn blood. At present the majority of writers incline to the assumption that this is not an actual increase, but that, as Zuntz believes, either the distribution of the corpuscles is so altered that a larger proportion of them are accumulated in the dilated dermal capillaries, or on the other hand there exists a concentration of the blood as the result of a passage of fluid from the vessels (which might be thought of as connected in the first place with an increased evaporation or in the second place with a process of forcing the plasma out from the action of vasomotor factors). That rapidly developed, transitory changes of the blood, such as for example have been observed inside of an hour in a balloon ascension, may reasonably be related with causes of such a character, can scarcely be doubted. That a more protracted sojourn on mountain

${ }^{54}$ Cf. A. Löwy, Deutsche Med. Wochenschr., 1904, 121. 
heights brings about an actual increase in the total hæmoglobin is a view adopted by many authors. Thus, for example, C. Foà holds that there is new formation of red blood cells, with a heightened activity of the bone marrow. Durig believes a final decision of the question will not be had until our methods of determining the total hæmoglobin and the total capacity of oxygen combination are perfected; he calls attention to the fact that chlorosis is not cured by high climate without appropriate treatment of other character, and that we do not find after return from the elevation the least increase of iron elimination and not a sign of jaundice, as would be probable were there any massive, important destruction of red blood cells.

Then, too, within recent times, sources of error of which we had no idea before, have come to be recognized. Thus Bürker was able to prove that the hitherto commonly used counting chamber of Zeiss gives too high results at a high elevation, from the concentration of the blood from increased evaporation. Bürker has constructed a new chamber by which this error is avoided. With the latter he found at an elevation of 1800 metres only a minor increase of the erythrocytes, of not above five per cent. O. Cohnheim and his associates, in their most recent investigations in the Monte Rosa district, conducted with great precision and with the employment of various methods, at elevations of 2900 and 4500 metres have failed to recognize in human beings and in the dog any physiologically important increase in hæmoglobin. ${ }^{55}$

Changes in Cardiac Activity.-As is well known, disturbances in connection with the cardiac activity are prominent features in the symptom complex of mountain sickness; and it is not always easy in these very cases to rule out the factors connected with over-exertion. Durig, Zuntz, and their associates, found the pulse rate practically unchanged

${ }^{65} \mathrm{O}$. Cohnheim, G. Kreglinger, L. Tobler and O. H. Weber, Zeitschr. f. physiol. Chem., 78, 62, 1912; cf. therein the Literature. 
up to an elevation of 3000 metres (Colle d'Olen); at a height of 4500 metres at the Margherita cottage, however, an increased pulse frequency manifested itself from the day of the ascent on, in all the members of the expedition, which gradually diminished somewhat, but did not fall to the normally observed rate even in the course of a month, and proved to be independent of any passing rise of temperature; then, too, the pulse rate was persistently very changeable. After returning into the valley this variability not only disappeared at once, but the pulse rate fell even below normal. Apparently we should attribute symptoms of this character to an abnormality in the function of the vagi. The form of the pulse curve, and, too, the blood pressure showed no typical changes, at least wherever no overexeriton had taken place.

Changes of Respiration. - The study of the changes in the respiratory activity occupies a very large field in the physiological literature upon alpinism, as might be supposed.56 The economy has a tendency to compensate for the reduction in the partial pressure of oxygen by an increase of ventilation; thus in a very large majority of cases it may be observed at high elevations that the depth of breathing increases. Apparently the organism can also protect itself against a decrease in the atmospheric oxygen by a relative increase of the amount of oxygen absorbed, and too by an acceleration of the circulation of the blood. ${ }^{57}$ Increase in the depth of breathing has, it is true, been noted by A. Löwy and F. Müller also at the seashore. On the other hand, according to Durig, a distinct increase of ventilation effort begins to be noticeable only from altitudes of 3000 metres and upwards. However, no basic type of adaptation of the respiratory mechanism can be distin-

${ }^{86}$ Literature: J. S. Haldane and E. P. Poulton (Physiol. Lab., Oxford), Jour. of Physiol., 3\%, 390, 1908; R. O. Ward, ibid., 378; J. Barcroft (Physiol. Inst., Cambridge), Jour. of Physiol., 42, 44, 1911.

${ }^{57}$ Cf. J. Tissot, Jour. de Physiol, 12, 492, 520, 1910. 
guished; nor can it be in any degree predicted that sojourn at a moderate elevation will necessarily bring about proportionately a more powerful ventilation of the lungs.

At very high elevations (above 4500 metres) the danger of dyspnœa undoubtedly becomes impending. Even trifling interference with breathing, as from lacing the shoes, may call out a feeling of oppression, and ability to perform labor seems very much reduced. Yet even at a height of 6000 metres, which was attained by Whymper on Chimborazo, mountain sickness may fail to appear. In direct connection with the dyspnoea there also occurs sleeplessness. The members of Himalaya expeditions, usually at heights of about 6000 metres, on going to sleep were almost immediately wakened by dyspnœic symptoms. The breathing may even assume a periodic character, quite like the Cheyne-Stokes type. The woman Himalayan climber, Mrs. Bullock-Workman, believes that the greatest difficulty attending the attainment of the highest mountain peaks of the world is the loss of sleep, as naturally the number of sleepless nights increases with the height of the mountain.

Acapnia.-In connection with mountain sickness acapnia is a subject which has also been frequently discussed. The fact that a stay in very rarefied air is better sustained provided carbonic oxide is mixed with the respired atmosphere was proved some time since by the Zuntz school. There is reason, doubtless, in this relation to think that the carbonic acid, as has been previously pointed out, may be concerned in increasing the dissociation tension of oxyhæmoglobin and thus facilitating the supply of oxygen to the tissue. According to the acapnia theory of Angelo Mosso the symptoms of mountain sickness may be thought of as due, not so much to the lessened pressure of oxygen, as to a carbonic acid impoverishment of the blood and to the loss of the normal stimulative excitation which carbonic acid exercises upon the respiratory centre. The demonstrative force of the material brought forward by the Mosso school in favor of 
this view (as the contribution by B. Aggazzotti of observations upon the pathological phenomena in an orang-outang produced by rarefaction of the air and ameliorated by administration of carbonic acid) is warmly contested, however, by others.

For the rest, certain experiments conducted in Kronecker's laboratory show how difficult it is to come to a correct interpretation of matters of this sort. It was proved in the first place that rats and rabbits in atmospheres of pure oxygen, if the pressure be distinctly diminished, become dyspnœic even though the partial oxygen pressure be relatively high. In the second place it would appear that the air hunger of animals in rarefied air disappear quite as well when the normal pressure conditions are produced by addition of nitrogen (instead of oxygen). From which it may be logically conclnded that the dyspnoea occurring in places where the air is rarefied is not primarily due so much to oxygen deficiency as to a mechanical disturbance of the pulmonary circulation. ${ }^{58}$

A lowering of atmospheric density corresponding to an elevation of about 6000 metres (356 millimetres of mercury) must in fact be regarded as critical, as Boycott and Haldane in personal experiments observed at this grade the appearance of cyanosis, dyspnoa and loss of consciousness. ${ }^{59}$ At this degree of atmospheric rarefaction scarcely more than half the existing hæmoglobin is saturated with oxygen according to N. Zuntz and A. Löwy. This agrees with observations made in Graham Lusk's laboratory upon dogs which were rendered unconscious by half saturating their blood with carbon monoxide. ${ }^{60}$ Similar experiments were performed even earlier in Zuntz's Institute by Frankel, Geppert and Löwy. Aggazotti's orang-outang became apathetic at an atmospheric pressure of about 340 milli-

${ }^{58}$ R. Frumina, A. Rosendahl (Physiol. Instit., Berne), Zeitschr. f. Biol., $52,1,16,1909$.

${ }^{69}$ A. E. Boycott and J. S. Haldane, Jour. of Physiol., 87, 355, 1908.

${ }^{\infty}$ Graham Lusk, Ernährung und Stoffwechsel, 2nd Ed., p. 239, 1910. 
metres, and fell into a sleep-like state at 300 millimetres, with the breathing of dyspnœic character. ${ }^{61}$ Zuntz and Levenstein observed rabbits die after being kept for several days at a barometric pressure of from 300 to 400 millimetres under a bell-jar; autopsy showed an enormous fatty degeneration of the internal organs. ${ }^{62}$

Loss in Alkalescence of the Blood.-The loss of alkalescence of the blood observed by Mosso and his pupils may be regarded as directly related with the oxygen deficiency at high elevations. In animals on Capanna Margherita a loss of 30-40 per cent. of blood alkalinity was observed in estimations following the Löwy-Zuntz method; a slighter loss of alkalinity was noted where an analogous rarefaction of the air was obtained by the air'-pump. It is scarcely a mistake to attribute this diminution of alkalescence to a passage of lactic acid into the blood. ${ }^{63}$ We know since the investigations of Araki that any kind of oxygen impoverishment in the body leads to an increased formation and eventually, too, to an increased elimination of this acid. ${ }^{64}$ In conformity with the present attitude of science we are justified in holding that lactic acid may largely come from destruction of sugar. That in turn an accumulation of acid in the blood, by making demands upon the alkali which is usually combined with carbonic acid, is harmful to the respiratory function of the blood is obvious. This at once suggests a comparison with the acid intoxication of diabetic coma, although in the latter condition the materia peccans is not lactic acid but $\beta$-oxybutyric acid. But, as above stated, according to Barcroft lactic acid facilitates the giving off of oxygen from hæmoglobin to the tissues. In view of the connection between lactic acid formation and carbohydrate metabolism

${ }^{61}$ A. Aggazzotti (Turin), Arch. ital. de Biol., 4/, 39, 1905.

${ }^{e 2}$ G. Levenstein (N. Zuutz's Lab.), Pflüger's Arch., 65, 278, 1897.

${ }^{88}$ A. Mosso, G. Galeotti, A. Aggazzotti, Arch. ital. de Biol., 41, 80, 384, 397, 1904, and Rendic Accad. dei Lincei Roma, XIII, XV.

${ }^{04}$ Cf. P. v. Terray (Physiol. Instit., Budapesth), Pflüger's Arch., 65, 393, 1897. 
it is of considerable interest that according to Durig's statements quite large dosages of grape sugar were consumed on Monte Rosa just as readily as in the flat country and that ceteris paribus, the respiratory quotient manifested no alteration in the former place.

Increase of Energy Exchange.-A very important resultant symptom of living at high altitudes is the increase of the mininal metabolism. "By determining the amount of energy exchange at different altitudes," says Durig, ${ }^{65}$ "it is plainly shown that at the higher levels an increase of the combustion processes appears, suggested even in the lower elevations. This increase was present on Monte Rosa within the first hour of arrival, and disappeared only on our return into the valley, suddenly as it had appeared. While a flame burns more lively in atmospheres with the richer supply of oxygen, our body exhibits the opposite behavior. A more abundant supply of oxygen may not be able to quicken its oxidation processes; a diminished chance of acquiring oxygen stimulates them. ..."'

The capacity to perform mechanical work seems appreciably diminished at high elevations; thus Zuntz and Schumburg found their ability to perform labor on the top of Monte Rosa only approximately one-third of their capacity in Berlin. R. F. Fuchs found that in manual labor the oxygen consumption at a level of 3000 metres was distinctly, although not very greatly increased; a very marked increase became evident, however, at levels above 4000 metres (although in this matter the influence of acclimation and training should be regarded as of decided importance). It may thus become appreciable why in case of most of the mountain climbers the mountain sickness does not show itself below levels of over 4000 metres. ${ }^{66}$ However, it is impossible without further investigation to under-

${ }^{e 5}$ A. Durig, Wiener klin. Wochenschr., 24, No. 18.

${ }^{\oplus}$ R. F. Fuchs and T. Deimler, Sitzber. d. physik. med. Soc., Erlangen, 41, 1909 : Centralbl. f. d. ges. Biol., 10, No. 708. 
stand why the symptoms of momtain sickness, as a rule, first appear in the Andes and in the Himalayas at much greater heights than in the European Alps. Obviously there must be, aside from the rarefaction of the atmosphere, quite a number of other climatic factors which are to be taken into consideration.

Nitrogen Retention.-Besides the increased energy exchange there is manifested in elevated climates a notably increased tendency to the retention of nitrogen. This was observed by Jaquet and by Durig, as well as by G. v. Wendt, and must necessarily be regarded as a protein storage. The observations of Durig upon the nitrogen fractionation in the urine showed no basis (contrary to A. Löwy, who holds that there are faults of protein metabolism and an increase of aminoacids in the urine in individuals sojourning at high levels) for the idea that protein catabolism takes place at all differently from the process as seen in the lower plains. G. v. Wendt ${ }^{67}$ holds, as the result of his investigations, that the often observed nitrogen retention of elevated places is not to be explained as a retention of intermediate compounds, but as connected with the new formation of living substance, particularly of the muscles. This in no wise excludes the possibility that under certain circumstances mountain sickness may bring about a toxic protein destruction; but we may well regard an abnormal accumulation of fatigue products and not the elevated climate itself as responsible for this, if the author be correct in his conjecture. Then, too, one should think of the processes of protein destruction and fatty change observed by Zuntz and his pupils occasionally in locations of atmospheric rarefaction as perhaps connected with accumulation of an excessive amount of lactic acid in the tissues.

All in all it may be seen that friend Mephisto was not very far wrong when he answered Faust who was striving to gain the mountain heights in the rush of the Walpurgis

\footnotetext{
${ }^{67}$ G. v. Wendt, Skandin. Arch. f. Physiol., 2/, 247, 1911.
} 
night and who said: "There many a puzzle must yield its secret," with the reply: "Yet many a puzzle, too, is twining its tangle there." Here in fact, as so often in our wandering, we find ourselves hemmed in at each step of the way by a world of new enigmas for which the future alone will find a solution. At all events, however, we must acknowledge our indebtedness to all those men to whom the thirst for knowledge lent power and energy to endure up there upon icy mountain-heights, with the roar of storms about them, for many weeks at a stretch, cold, loss of sleep, bodily discomforts and privations of every sort, and to carry on from day to day with fixed purpose and with patience their arduous and often tedious work of investigation. 


\section{CHAPTER XXV}

\section{FEVER}

Is concluding our study of metabolism this last chapter may with propriety be devoted to the old and, to the thoughtful physician, the daily recurring enigma of fever, with discussion of the attitude assumed by modern biochemistry toward this problem.

Customarily such a discussion should begin with a sober presentation of a number of definitions relating to the general concept of fever; but this may well be dispensed with, because the author believes that those whom he is addressing all realize what is meant by the term, and because, too, he has never quite grasped why scientists so often burden life with insistence upon definitions of things whose real nature they themselves are unable to sharply and clearly depict.

Total Metabolism.-The naïve concept of a man "fever raging through his veins" approaches the idea that "an internal fire," whose mildly tempered warmth under normal conditions protects the body from chill, is being fanned into a wild consuming flame. We may therefore begin by determining whether and to what extent we are justified in assuming in fever the existence of an exaggeration of the vital combustion processes. ${ }^{1}$

The idea of exaggeration of combustion processes in fever, which dominated the older pathology, was first disturbed by Senator, who was able to point out that in experimentally infected febrile animals it is not necessary that invariably and under all circumstances there be more

${ }^{2}$ Literature upon the Total Metabolism in Fever: A. Jaquet, Ergebn. d. Physiol., 2', 548-553, 1903; C. Speck, ibid., 31-35; Fr. Kraus: Noorden's Handb. d. Pathol. d. Stoffw., 1, 614-630, 1906; L. Krehl, Pathol. Physiol., 5th Ed., 482-485, 1907; A. Löwy, Handb. d. Biochem., 4 199-213, 242-243, 1908; P. F. Richter, ibid., 4", 105-112, 1910; Graham Lusk, Ernälırung und Stoffwechsel, 2nd Ed., 287-293, 1910. 
oxygen taken in and more carbonic acid given off than normally. The real condition of affairs was clearly indicated primarily by studies conducted by Friedrich Kraus and A. Löwy on febrile human beings by employing the Zunz-Geppert methods. Their observations were supplemented by those of Riethus, Steyrer, Grafe, ${ }^{2}$ and Rolly ${ }^{3}$ and by the animal experiments of May (on rabbits, infected with swine erysipelas) and of Stähelin (on dogs inoculated with surra trypanosomes), and by observations upon the hyperthermia of heat-puncture. All in all it is now apparently settled that there is no basis for supposing that there exists any ratio between oxidation increase and rise of temperature, and that actually the former may at times not exist. In general, however, metabolism is moderately increased in the febrile human being. Yet we must of necessity inquire whether this increase of metabolism is really inherent to the nature of fever or whether it may not rather be the result of accessory factors.

Infuence of Increased Muscular Activity.-As one such factor we must in the first place consider an increase of muscular activity. This may occur to a marked degree in the violent muscular contractions of a rigor. However, even the extra effort manifested in the general motor restlessness and in the more rapid heart action and respiratory movements must by no means be undervalued. "If one excludes the rise in temperature occasioned by muscular movements," says Krehl,4 "which may be manifested even without the existence of fever and therefore properly is not to be regarded as belonging to it, the heat production during fever would be found to range in the proportion 110-160: 100; figures like 120-130: 100 may be regarded as average. ${ }^{5}$

${ }^{2}$ E. Grafe (Med. Clinic, Heidelberg), Deutsch. Arch. f. klin. Med., 101, 209, 1910. 1911.

${ }^{3}$ F. Rolly (Med. Clinic, Leipzig), Deutsch. Arch. f. klin. Med., 103, 93,

${ }^{4}$ Krehl, l. c., p. 483.

${ }^{5}$ Cf. also E. Grafe (Med. Clinic, Heidelberg), Deutsch. Arch. f. klin. Med., $101,209,1910$. 
These are but trifling accessions, if we recall that Rubner was able to raise the heat production to $160: 100$ in the dog merely by overfeeding with protein, and that they can be multiplied by severe muscular movements."

Rise of Reaction Velocity of Metabolic Processes with the Temperature.-A second important element must be recognized in the rule governing chemical processes of every sort, whether they take place within or outside the body, that every rise of temperature is associated with an increase in the velocity of reaction. Indeed, according to Vant'Hoff, for a rise of ten degrees of temperature the rapidity of reaction may be observed to be doubled or trebled. This "reaction-velocity-temperature" rule (RVTrule or RGT-rule, as Kanitz calls it) ${ }^{6}$ holds in a very great number of biological processes. Thus, for instance, it has been proved in the assimilation and output of carbonic acid by plants, in the budding of yeast, cell-division of fertilized frog-ova and sea-urchin ova, the frequence of action of the pulsating vacuole in infusoria, the heart beat in cold-blooded and warm-blooded animals, in the rhythmic movements of the frog's œsophagus and the small intestine, and in the transmission of stimulation processes in nerves. ${ }^{7}$ Obviously the rule is effective only up to that limit of temperature (about $40^{\circ} \mathrm{C}$.) within which beginning protein coagulation does not give rise to disturbing changes.

The dependence of the gas metabolism upon temperature was recognized some time since by Pflüger in case of coldblooded animals. In the warm-blooded animal as well, in which normally the influence of the surrounding temperature is masked by regulatory processes, the same feature is manifested, provided these are partly excluded by section of the cord or by curare poisoning. In fact, as previously stated, the minimal metabolism in inhabitants of the tropics 1907.

- Cf. A. Kanitz, R. O. Herzog, R. Abegg, Zeitschr. f. Elektrochem., 1905-

'Literature: K. Spiro, Handb. d. Biochem., 2', 4, 1910. 
is neither greater nor less than that in inhabitants of the temperate zones, ${ }^{8}$ yet their body temperature is also constant; but from the effects of hot baths (including hot air baths and radiant light baths) by which the temperature of the body is raised to $38-39.5^{\circ} \mathrm{C}$., a very distinct and sometimes a very important increase of metabolism is attained. ${ }^{9}$ In an individual suffering from ichthyosis (fish-scale disease), in which affection the output of water through the sweat glands and in comnection therewith the heat regulation as well, are apparently decidedly diminished by simple sojourn in a well-heated room (in spite of the fact that the body temperature never exceeded $39^{\circ}$ C.) the exchange was increased to double the normal.

It therefore seems quite plausible that if the body temperature is raised by any single cause this temperature accession in itself drives the exchange up. Friedrich Kraus ${ }^{10}$ says definitely in this connection that, if from the gross amount of oxygen requirement found in human beings with fever there be subtracted the amount due to grossly visible muscular movements and besides the excess due to the increased fever heat itself, a neat amount, not very important in the average, will remain. Increase in the combustion processes can be safely said not to be the cause of fever; and in fact one would hesitate in a given case to class this as one of the characteristic features of fever, and would be forced to acknowledge that excessive muscular exertion, in spite of the fact that it raises the gas exchange to a multiple of the normal, leaves the individual temperature of the healthy body at the normal level.

${ }^{8}$ According to Eykmann, Aron, and others.

- Observations of IV. Winternitz and O. Pospischil, H. Winternitz, H. Salomon, Linser and Schmidt: Literature: A. Löwy, 1. c., pp. 212-214. According to recent experiments of H. Murschhauser (Sehlossmann's Clinic, Düsseldorf), Zeitschr. f. physiol. Chem., 79, 301, 1912, a long-continued exposure to external temperatures of $+5^{\circ}$ in the first place and of $+35^{\circ}$ in the second place need not give rise to any important change in the metabolism provided the body temperature is not altered. Cf. also J. Ignatius, L. Lund and O. Wärri (Helsingfors), Skandin. Arch., 20, 226, 1909.

${ }^{10}$ F. Kraus, l. c., p. 628. 
Frugality of the Body in Chronic Febrile Conditions.It would be altogether a mistake to assume, for the rest, that the organism in a state of fever deals with its material in any especially extravagant manner. In fact precisely the opposite is apparently true. At least in the later part of the course of very slowly declining cases of typhoid fever and, too, in pulmonary phthisis, C. von Noorden repeatedly observed that the body cells of human beings in protracted fever are able to functionate very economically on a consumption of 20 to 25 calories pro kilogram of body weight. This may explain how chronic febrile subjects after having at first lost rapidly in body weight, later, in spite of a notably lower ingestion of food, are able to maintain for a long period their body weight at almost constant level. ${ }^{11}$ It may be added, too, that Montouri, ${ }^{12}$ who transferred the blood of an experimentally overheated dog into the jugular vein of a second $d o g$, thought that he observed that it contained substances which inhibited heat production in the normal organism. However, many objections are possible against this type of experiments.

Respiratory Quotient.--Upon the bearing of the respiratory quotient in fever the views of authorities are somewhat contradictory, many being of the opinion that it is not lower than in the normal state, ${ }^{13}$ while others hold that a reduction exists. ${ }^{14}$ However, it seems scarcely likely to go lower than $0.7 .^{15}$ We are clearly justified in ranking fever metabolism along with inanition metabolism, in which (according to Zuntz) the quotient likewise presents a lower value; but in both cases the economy endeavors to carry energy demands continuously put upon it principally at the expense of its fat supply.

${ }^{11}$ Cf. Fr. Kraus, 1. c., p. 629.

${ }^{12}$ A. Montouri, Richerche biotermiche, Giannini, Naples, 1904; cited in Centralbl. f. Physiol., 19, 285, 1905.

${ }^{13}$ Cf. Rolly, Deutsch. Arch. f. klin. Med., 103, 93, 1911, and earlier papers

${ }^{14}$ P. F. Richter, 1. c., pp. 109-111.

${ }^{15}$ E. Grafe (Med. Clinic, Heidelberg), Deutsch. Arch. f. klin. Med., 101, 209,1910 . 
Reduction Power of the Tissues.-That but little is to be expected 'from attempts to estimate the reduction capacity of the tissues of febrile subjects by the decolorization of methylene blue and similar methods, is indicated from what has been above said in reference to the character of such processes. One author ${ }^{16}$ observed in experimentally-induced fever an increased, while another ${ }^{17}$ observed a reduced reduction power. The author is inclined to look upon the whole subject as a rather unfortunate one, which leads only to fictitious results, which cannot give any information as to vital processes.

Decreased Heat Elimination.-Krehl and Soetbeer ${ }^{18}$ found that in frogs which they had inoculated with pathogenic microörganisms the production of heat increased with the fever; they hold "that in animals in which the influence of the nervous system upon heat production in muscle is thoroughly excluded, a distinct rise in heat production takes place from the influence of infection." We would of necessity from this assume that at times in fever the production of heat can be increased. Yet Krehl himself on the ground of his extensive studies conducted in association with Matthes, ${ }^{19}$ arrived at the opinion that, no matter whether the oxidations may or may not be raised in the body in fever, the chief basis of temperature accession is not to be found in an increased heat production but in a decreased heat elimination.

Modern experimental results therefore bring us to the same conclusion to which Traube from his own celebrated studies came, regarding the essential cause of fever as referable not to the increased production of heat but to a disturbance of heat elimination. He attributed fever to a spasmodic constriction of peripheral vessels interfering with the normal outlet of heat from the body surface. It

\footnotetext{
${ }^{16}$ C. A. Herter, Amer. Jour. of Physiol., 12, 457, 1904.

${ }^{17}$ V. Schläpfer, Zeitschr. f. exper. Pathol., 8, 181, 1911.

${ }^{15} \mathrm{~L}$. Krehl and F. Soetbeer, Arch. f. exper. Pathol., 40, 275, 1897.

${ }^{19}$ L. Krehl and M. Matthes, Arch. f. exper. Pathol., 38, 284, 1897.
} 
should be recalled in this connection that if a healthy man steps into a cold bath, a contraction of the peripheral arteries may result in a transitory rise in the body temperature; after leaving the bath the blood flows in full proportion to the surface and the skin reddens. In chills the skin, as the result of vascular contraction, looks bloodless, and in response to stimulation of the cutaneous nerve endings which are sensitive to cold, the production of heat in the muscles increases reflexly. Replacement of the stimulus from cold by a warm covering about the body may in conformity reduce the production of heat. ${ }^{20}$

Protein Destruction.-Proceeding with consideration of the metabolic processes in fever, we come first to the problem of febrile protein destruction. ${ }^{21}$

Undoubtedly fever may be associated with a marked protein disintegration which manifests itself by an increased urea elimination. Frequently this latter feature fails to put in appearance until after the fever has already declined. Thus, for example, Naunyn observed in a case of typhus exanthematicus on the tenth day of the febrile course a urea elimination of only ten grams, but on the fourteenth day, with the temperature down to normal, the urea excretion reached ninety grams. It is not an easy matter to formulate a proper interpretation of an "epicritical nitrogen elimination" of this sort. It cannot be held that the elimination of already formed urea has been retarded; Naunyn has convinced himself that urea accumulation does not take place in the tissues of febrile individuals, and that the body in the state of fever can readily excrete urea, which is itself very diuretic when experimentally introduced into the circulation. It seems much more plansible on the other hand

${ }^{20}$ Cf. Graham Lusk, 1. c., pp. 285-292.

${ }^{21}$ Literature upon Protein Metabolism in Fever: C. Speck, Ergebn. d. Physiol., 2', 27-30, 1903; F. Kraus, Noorden's Handb. d. Pathol. d. Stoffw., 1, 590-610, 1906; L. Krehl, Pathologische Physiologie, 5th Ed., 491-495, 1907; Graham Lusk, Ernährung und Stoffwechsel, 285-288, 294-302, 1910; P. F. Richter, Handb. d. Biochem., .', 112-119, 1910. 
that the febrile affection may induce some degenerative change in organic structures (as may be recognized morphologically in the parenchymatous degeneration of glandular tissues and the hyaline coagulation of muscles), and that a gradual elimination of tissue constituents which have been rendered useless is responsible for the epicritical urea excretion. The destruction of protein may sometimes attain an extremely high grade in febrile affections. Thus, for example, according to Friedrich Kraus, ${ }^{22}$ it is not a very rare occurrence in pneumonia to encounter an increase of nitrogen elimination corresponding to as much as half a kilogram of muscle tissue per diem. Friedrich Müller has recorded a case of typhoid fever in which the patient lost in the course of a single week an amount of nitrogen which would correspond with a daily destruction of 360 grams of muscle.

The question next arises how this increased protein decomposition is to be interpreted. The first thought that the hyperthermia itself is the immediate cause of this destruction must be rejected. Naunyn succeeded in superheating. rabbits experimentally for periods of two weeks so that their body temperature exceeded $41^{\circ} \mathrm{C}$. as an average, and yet there was not the least trace of parenchymatous or fatty degeneration appreciable in their organs. In man, according to Linser and Schmidt the status of experimental heating seems to be that as long as the temperature remains below $39^{\circ} \mathrm{C}$. no increase of nitrogen elimination is to be noted, but that it becomes apparent as soon as the temperature exceeds $40^{\circ} \mathrm{C}$. But the protein decomposition does not bear any fixed relation with the height of the fever. Senator long since made observation of the fact that in malaria if the temperature be artificially kept low by quinine, there is not necessarily any diminution of the protein destruction. Deucher saw the reverse, that in typhoid fever various antipyretics may lower the loss of nitrogen inde-

${ }^{22}$ L. c., p. 596. 
pendently of any lowering of the temperature. ${ }^{23}$ In sepsis in spite of a low grade of fever a marked protein disintegration may be noticeable. The hyperthermia alone is therefore not sufficient to explain the exaggerated nitrogen elimination in fever to say the least.

The resorption of inflammatory exudates is no better adapted to furnish a complete explanation.

A very important factor unquestionably is to be recognized in the toxogenic protein decomposition occurring in infectious diseases, associated with the development of lesions of the tissue cells from disease poisons. But even this explanation is not sufficient in all cases; thus, for example, it does not hold for the protein destruction which accompanies the heat puncture (puncture into the corpus striatum). It is obvious that we are not to confuse an increased breakdown of protein with an increase of oxidation, as has been sometimes done. In fact even a reduction in the processes of oxidation from lack of oxygen may lead to an increased protein destruction.

Inhibition of Febrile Protein Destruction by Increasing Carbohydrate Food.-Many authors are inclined to emphasize the feature of inanition in febrile protein destruction. Thus F. Voit found that the protein breakdown after superheating may be decidedly repressed by free exhibition of non-nitrogenous food, and May was able to lower the nitrogen elimination even more decidedly in febrile animals by injecting solutions of sugar than in starving animals. v. Leyden and Klemperer ${ }^{24}$ have attempted to do away with tissue destruction in febrile human beings by full nourishment, and have called attention in this connection to the fact that two liters of milk with an additional ten per cent. of milk sugar, with a calory equivalent of more than 2000 , are sufficient to approximately cover the daily nutritive re-

${ }^{23}$ P. Deucher (Sahli's Clinic, Berne), Zeitschr. f. klin. Med., 57, 429, 1905.

${ }^{24}$ v. Leyden and Klemperer, v. Theyden's Handb. d. Ernährung, 2, 345, 1904. 
quirement of a bed-fast human being. Schaffer ${ }^{25}$ was able to maintain a case of typhoid fever on a diet low in protein, but rich in carbohydrate (consisting of milk, milk-sugar, cream, eggs and arrowroot) at approximate nitrogen balance. Similar attempts have recently been carried out at the Heidelberg medical clinic by Grafe, ${ }^{26}$ who obtained practical nitrogen balance in febrile human subjects by an exhibition of food of fifty calories per kilogram; as the result of which he regards the assumption of a toxogenic protein decomposition as superfluous. There is thus no doubt of the fact that destruction of protein in fever can be materially lessened by administration of judiciously selected food.

We may perhaps approach most nearly to the truth by holding that the destruction of protein in fever is caused by a combination of influences from the above-mentioned factors, of which now one, now another, may come to be dominant according to circumstances.

Elimination of Nitrogenous Metabolic End-Products.In view of the extensive destruction of protein which may take place in fever it is not at all remarkable that the elimination of nitrogenous end-products of metabolism may present certain abnormalities. ${ }^{27}$ According to statements already made in reference to "endogenous" cellular metabolism it can be readily appreciated how in fever sometimes a decided increase in the output of uric acid and of creatinin (or the total creatin + creatinin) ${ }^{28}$ has come to be observed in connection with the increased protein decomposition, and how at times certain residua of protein metabolism (or products of incomplete protein decomposition) may be met in increased quantity in the urine. The fre-

${ }^{25}$ P. A. Schaffer (Cornell Med. College, New York), Jour. of Amer. Med. Assoc., 51, 974, 1908.

${ }^{26}$ E. Grafe (Med. Clinic, Heidelberg), Vortr. auf d. Karlsruher Naturforscher Vers., 1911, cited in Centralbl. f. d. Ges. Biol., 13, No. 982.

${ }^{\pi}$ Cf. Literature, P. F. Richter, 1. c., pp. 119-123.

${ }^{2}$ Cf. also V. C. Myers and G. O. Volovic, Amer. Jour. of Physiol., 29, Proc. Amer. Physiol. Soc., XV1II, 1912. 
quent occurrence of albumoses in the urine of febrile individuals observed by Krehl and Matthes may be classed here; as, too, the much discussed shifting of the relation of the carbon to the nitrogen in the urine. ${ }^{29}$ It would be scarcely wrong to assume that in the latter group the oxyproteic acids are certainly included, that is, high molecular products of protein cleavage which, however, no longer yield typical proteid reactions. Uncertainty on this point is due especially to the fact that we unfortunately, up to the present time, have no exact method of determining the oxyproteic acids in the urine. In this connection the diazoreaction in febrile urine comes suggestively in a new light. (This is met with regularity in typhoid fever and typhus exanthematicus, in advanced phthisis, measles, as well as in puerperal fever and septic processes of various kinds, in severe cases of pneumonia, scarlet fever and erysipelas.) ${ }^{30}$ There is at present every reason for assuming (vide supra, p. 139) that the diazoreaction is connected with one of the oxyproteic acids, and probably with one which owes its chromogenic character to a contained cyclical group coming from the protein molecule (apparently histidin), and which may be regarded as the mother substance of the normal yellow urinary coloring matter, urochrome.

Acidosis and F at Destruction.--Sometimes in examining the urine of febrile cases the amount of ammonia is found somewhat increased in proportion to urea. This is a manifestation of an acidosis of moderate degree, to which attention was first directed by v. Jaksch and to which since then considerable study has been devoted..31 It by no means attains the grade met in diabetes. And in the blood, as P. Frankel determined in the laboratory of Friedrich Kraus by the aid of the method of electric concentration chains, it is not possible to recognize any change of the hydrogen ion

\footnotetext{
${ }^{2}$ A. Löwy, Scholz, May, Rolly, Magnus-Alsleben, and others.

${ }^{\text {av }}$ Cf. F. Kraus, l. c., pp. 660-662.

${ }^{31}$ Cf. Literature: F. Kraus, 1. c., pp. 656-660, 1906; P. F. Richter, 1. c., pp. 123-125, 133-136, 1910.
} 
acidity; but it must be remembered that the body has available means to keep its juices neutral as long as the excess of acid does not reach too high a degree. According to the present status of our knowledge we may refer the increased production of acetone bodies ( $\beta$-oxybutyric acid, diacetic acid, acetone) in fever to a heightened fat destruction, which becomes so manifest from the wasting occasioned by prolonged ferer that any further proof seems superfluous. Blumenthal noted in streptococcus infections a higher grade acetonuria than in other febrile affections, and Bottazzi saw in diphtheria the curve of the acetone bodies fall under the influence of the curative serum; which facts will probably, in the writer's opinion, be brought into relation with variations in the intensity of fat destruction.

Relation of Carbohydrate Metabolism to Fever.-A great number of investigations have been directed to the relations of carbohydrate metabolism to fever. Although the studies in relation to the amount of sugar in the blood of animals exposed to cold, to heat and of febrile animals do not admit of any simple interpretation as far as the author sees, ${ }^{32}$ there is not the least reason to doubt that destruction of carbohydrates in the tissues, and especially in the liver, is involved to a very important degree in the processes of heat production in the body, and (as inter alia is indicated from observations by Cavazzani) is subject to regulatory influences from the nervous system. This is illustrated in a very sugcestive manner by obserrations by Dubois and also by E. Weinland, ${ }^{33}$ showing that in the marmot as it wakes from its hibernation the glycogen supply falls within a few hours to half its quantity, and that the temperature coincidently rises. Hirsch and Rolly have suggested that glycogen-free

${ }^{32}$ G. Embden, H. Lüthje and E. Liefmann, Hofmeister's Beitr., 10, 265 , 1907 ; H. Senator, Zeitschr. f. klin. Med., 67, 253, 1908; R. Lépine and Boulud, C. R. Soc. de Biol., 69, 379, 1910; A. Hollinger (Liithje's Clinic, Frankfurt a. MI.), Deutsch. Arch. f. klin. Jled., 92, 217, 1908.

${ }^{2}$ E. Weinland and M. Riehl (Physiol. Instit., Munich), Zeitschr. f. Biol., $50,75,1908$. 
animals are not exempt as a matter of fact from infectious fever, but are exempt from the hyperthermia of the heat puncture. But as meanwhile it appears from studies of Senator and P. F. Richter that, even in animals rendered practically free of glycogen by a combination of starvation and strychnine poisoning, the heat puncture remains effective although in a lessened degree, there need be no occasion for entering into the interpretations which have been proposed for the former experiments. It is safe to say that there is no form of hyperthermia which is invariably connected with an increased accumulation of glycogen in the tissues. $^{34}$

Changes in the Constitution of the Blood Plasma.-A characteristic alteration of the blood has been persistently sought for. There are two features, as far as the author sees, which have been brought out: an increase of globulin and an increase of fibrinogen in proportion to the other proteins of the blood (cf. Vol. I of this series, pp. 194 and 244, Chemistry of the Tissues). The increase of globulin, which has been observed by a large number of authorities, ${ }^{35}$ is a feature of inanition conditions of various kinds; while increase of fibrinogen, according to T. Pfeiffer, is apt to be met especially in infections due to pneumococci and streptococci. It apparently goes hand in hand, according to P. T. Müller, with a fibrinogen enrichment of lymphadenoid tissues, especially the bone marrow. Of course the idea is suggested that the "hyperinosis," or increase in the amount of fibrinogen in the blood, which occasions the "crusta phlogista" (that well-known coagulation phenomenon of the old physicians), may be connected with an increased production of fibrinogen in the bone marrow.

${ }^{34}$ Literature upon the Relation of Carbohydrate Metabolism to Fever: F. Kraus, 1. c., pp. 630-634, 1906; A. Magnus-Levy, Handb. d. Biochem., 4', 363-364, 1909; I. Wohlgemuth, ibid., 3', 173-174, 1910; P. F. Richter, ibid., 4", 125-128, 1910.

${ }^{35}$ Joachim, Langstein and Mayer, Moll, Cavazzuoli ; Literature: F. Kraus, 1. c., pp. 611-613, and P. F. Richter, i. c., p. 137. 
Water Economy in Fever.-Since the investigations of Leyden the assumption of a water retention in fever has played an important part in the pathology of the latter condition. Howerer, there is certainly nothing in such water retention that is really characteristic of fever. Schwenkenbecher and Inagaki ${ }^{36}$ showed in Krehl's clinic that in typhoid patients the loss of water may exceed the average intake. However, in many of the infectious diseases a certain tendency to water retention seems to prevail. Studies conducted in Rudolf Gottlieb's laboratory in reference to the importance of the tissues as water depots, have indicated that when physiological salt solution is introduced intravenously in dogs all the soft parts take up water, even to a higher degree than does the blood. The highest importance as a place for storage of water must be attributed to the muscles; they take up about two-thirds of the water deposited in the tissues, that is, more than would correspond to their percentage proportion in the body. About one-sixth of the water taken in is in the skin, and but very little in the intestines. ${ }^{37}$ The water retained in fever is thus to be sought, not in the blood, but in the tissues. Schwenkenbecher and Inagaki ${ }^{38}$ found in their studies upon the amount of water in the tissues of individuals who died from febrile affections that it was relatively increased in proportion to their dry substance. Krehl ${ }^{39}$ says: "It is not easy to say at once why this relative excess of water in the body is not adjusted, although at other times even a large intake of fluid (three or four liters, or more) is at once eliminated. This much only is to be suspected, namely, that the increase in humidity for the most part involves particularly the tissue elements and the excess of water does not enter the

${ }^{36}$ Schwenkenbecher and Inagaki (Krehl's Med. Clinic, Strassburg), Arch. f. exper. Pathol., 54, 168, 1906.

${ }^{37}$ W. Engels (Lab. of R. Gottlieb, Heidelberg), Arch. f. exper. Pathol., 51, $346,1904$.

${ }^{3}$ Schwenkenbecher and Inagaki (Krehl's Med. Clinic, Strassburg), Arch. f. exper. Pathol., 55, 203, 1906.

${ }^{39}$ L. Krehl, Pathol. Physiologie, 5th Ed., p. 509, 1907. 
lymph and blood circulation. There is thus developed an increase in the capacity of the cells for imbibition under the influence of many of the infectious diseases." This feature seems at any rate to be more important than other factors which have been held responsible for the retention of water, as, for example, a decrease of output (or at least a failure of increase of output) of water by the skin ${ }^{40}$ (although it is recognized that at the subsidence of fever the perspiratory secretion is usually increased in proportion to the fall in temperature). ${ }^{41}$ Neither the experiments of Stähelin on febrile animals nor those of Carpenter and Benedict on human beings favor the idea of a suppression of the cutaneous output of water. ${ }^{42}$ There is just as little conviction in the attempt to explain the phenomenon by the view that fever induces a retention of sodium chloride (vide infra) because of renal inefficiency and that this in turn leads to the water retention.

Swelling of Cellular Protoplasm.-It would seem that the most important item which is to be considered here has been heretofore overlooked, an increased acidification of the tissues from the accumulation of $\beta$-oxybutyric acid above discussed (vide supra, p. 436). Perhaps, too, an accumulation of lactic acid may be considered. From what we have learned experimentally in regard to the relation of the formation of acids in the tissues to the occurrence of swelling of the latter (Vol. I of this series, pp. 255-257, Chemistry of the Tissues) it would appear quite probable that an increased fixation of water in the tissues of febrile subjects

${ }^{40}$ Cf. G. Lang (Med. Clinic, Tübingen), Deutsch. Arch. f. klin. Med., ₹9, $343,1903$.

"Schwenkenbecher and Inagaki (Krehl's Med. Clinic, Strassburg), Arch. f. exper. Pathol., 58, 365, 1905. The output of moisture through the skin is in general approximately in proportion to the temperature and to the incompleteness of saturation of the atmosphere and is at once increased by moderate muscular effort. Cf. A. J. Kalmann (Zoth's Lab., Gratz), Pflïger's Arch., 112, 561, 1906; E. Heilner (Physiol. Instit., Munich), Zeitschr. f. Biol., 49, 373, 1907.

Cf. Literature: F. Kraus, 1. c., pp. 635-638, and P. F. Richter, 1. c., pp. 130-131. 
might be referred primarily to this as a cause. Although Max Herz ${ }^{43}$ has proposed in this connection the hypothesis that a swelling of the cellular protoplasm may be the source of the heat of fever, the author is disposed to regard this view as a reversal of cause and effect; and in accordance with this belief it may be suggested, therefore, not that fever is occasioned by a protoplasmic swelling, but that on the contrary, fever, by occasioning an accumulation of acids in the tissues, may sometimes lead to an increased swelling of the latter.

Chlorine Retention.--In connection with the retention of water in the economy of febrile subjects it is necessary to consider also the retention of chlorine. It is a fact well known for a very long time that at the height of many febrile diseases (especially pneumonia, typhoid fever and scarlet ferer, but not malaria) that the urine is strikingly deficient in chlorides. ${ }^{44}$ In febrile tuberculous cases, too. as a rule there may be noted with temperature accession a fall in the elimination of sodium chloride, without necessary manifestation of change in the concentration of the urine. ${ }^{45}$ So, too, the same phenomenon has been observed in the fever induced experimentally by hay infusion and by trypanosomes. ${ }^{ \pm 6}$ Efforts have been made to explain this symptom in a variety of ways; for example, as a result of salt hunger caused by under-nutrition, as a result of retention of chlorine in degenerated tissue or in the protein in circulation as a compensation for a lowered osmotic pressure of the blood due to a markedly increased elimination of phosphoric acid, ete. Personally the author is of the opinion (in agreement with v. Hösslin) that all such explanations are aside from the mark, and that we are really

${ }^{43}$ M. Herz, Wärme und Fieber, Wien, 1893, p. 91.

${ }^{44}$ Literature on Chlorine Retention in Fever: F. Kraus, 1. c., pp. 662-663; P. F. Richter, l. c., pp. 12S-130.

${ }_{45}$ N. Meyerowitsch, Inaug. Dissert., Zürich, 1911; cited in Centralbl. f. d. ges. Piol., 1911, No. 1918.

${ }^{4 i}$ v. Hosslin: Zeitschr. f. Biol., 53, 25, 1909. 
dealing with a disturbance of the renal function caused by altered circulatory relations. The author has come to this view on the basis of observations upon reflex influences involving the renal capacity which he studied with C. Schwarz (Vol. I of this series, p. 382, Chemistry of the Tissues). In these studies the observers found that a peritoneal irritation produced experimentally by injection of pancreatic tissue, oil of turpentine or aleuronat, is capable of influencing the functional ability of the kidneys in such a manner as to lower in a very striking degree the quantity of dissolved constituents, particularly the sodium chloride, independently of the water elimination. From this the author would assume that a disturbance of circulation induced by the febrile condition may act in very much the same way.

As may be seen from what has been said above, the hope of more closely approaching the real nature of fever by examination of the metabolic processes has thus far not been fulfilled, and we are forced to return to the starting point of our inquiries, and, in connection with the previously described line of thought of Traube, seek an explanation of the process in a disturbance of heat regulation.

It is impossible to consider the development here of the whole physiology and pathology of heat mechanism, ${ }^{4 \tau}$ and the author feels that he must be satisfied to present only some of the most essential items.

Chemical and Physical Heat Regulation.-Following Rubner's comprehensive studies, it is essential to differentiate between chemical and physical heat regulation. While for maintenance of the body heat in case of low external temperature the dominating factor is apparently

"Literature upon the Processes of Heat Regulation: O. Löwy, Ergebn. d. Physiol., III, 339-354, 1904; R. Tigerstedt, Nagel's Handb. d. Physiol., 1, 593-606, 1905; F. Kraus, Noorden's Handb. d. Pathol. d. Stoffw., 2 Ed., 1, 639-655, 1906; L. Krehl, Pathol. Physiologie, 5th Ed., 472-489, 502-566, 1907; O. Cohnheim, Physiol. d. Verdauung und Ernährung, 408-412, 1908; Graham Lusk, Ernährung und Stoffwechsel, 2nd Ed., 71-80, 1910; P. F. Richter, Handb. d. Biochem., 4", 137-140, 1910; E. Cavazzani, Arch. di Fisol., S, 313, 523; cited in Jahresber. f. Tierchem., 40, 520, 1910. 
first a rise in the combustion processes going on in the body; in case of high external temperature there occurs an increased physical heat elimination, in connection with which besides evaporation through the skin and lungs we have also to consider the loss of heat by conduction and radiation and, too, by transfer of heat to the inspired air and to the ingested food. ${ }^{48}$ According to Rubner's experiments the boundary line between chemical and physical regulation is modified by the state of nutrition, in the sense that in a poorly nourished individual the physical elimination of heat first becomes apparent at higher temperature than in a well nourished one, which, moreover, corresponds with the experiences of daily life. ${ }^{49}$

Importance of the Nervous System in the Regulation of Temperature.-There is no doubt of the fact that the nervous system exerts an important influence upon the processes of heat regulation. This is indicated by the fact, well known since Pflüger's time, that in warm-blooded animals with the cervical cord divided the temperature regulation seems as good as lost, and these animals then behave toward changes in the external temperature as do poikilothermous animals. It also appears that such animals can scarcely be brought into a febrile condition by infectious material. A rather extensive failure of heat regulation may be noted even from the influence of deep nareosis. The excessive rises in temperature observed by many pathologists and experimentally studied by Naunyn and Quincke in injuries of the cervical cord, as in fractures of the cervical vertebræ, in which temperatures of $42-44^{\circ} \mathrm{C}$. sometimes occur, are of much interest; they are referred in their production to the combined influences of a more highly set heat regulation, decreased heat elimination and increased heat production in the muscles. ${ }^{50}$

Temperature rises have been observed from injury to

${ }^{4}$ Cf. Graham Lusk, l. c., p. 76.

49 Cf. O. Cohnheim, 1. c., pp. 412-413.

in L. Krehl, 1. c., pp. 476-477. 
a number of foci in the brain. By far the most constant of these is the so-called "lieat puncture." While penetration of the anterior part of the brain does not produce any important effect upon temperature, after injury to the corpus striatum intense and persistent rises in temperature are met with. As electrical irritation of this part of the brain is also capable of causing the same feature, we cannot be mistaken in assuming that the change in heat regulation ensuing from the heat puncture is to be regarded as an irritation symptom. It is a matter of secondary importance with us whether we hold that there exists a special "heat centre" or whether we adopt the view that (as for example, Tigerstedt ${ }^{51}$ believes) the nervous centres which preside over the muscles and other heat-producing organs, as well as those which innervate the cutaneous vessels, sweat glands and dominate the respiratory movements, functionate in a manner which amounts to the same thing as heat regulation. According to the works of Stefani and his pupils the vagus may be said to take an important part in heat regulation.

Fixation of Heat Regulation at a Higher Level.-P. F. Richter has attempted to frame a fundamental difference between the hyperthermia of heat puncture and of infectious fever, indicating that in the former but not in the latter the body has lost its ability to regulate temperature. This view has not, however, received confirmation from other sources. It is manifest that up to a certain degree the power of regulation of temperature is maintained in every form of hyperthermia. Liebermeister has held the view that the characteristic feature of heat regulation in fever is its "establishment at a higher level," regulation being actually retained but set, not for $37^{\circ} \mathrm{C}$., but for a higher temperature. This suggestion has been taken up by many authors, as Filehne, Stern, Krehl and Gottlieb. Friedrich Kraus, too, refers fever to "a condition of irritation of the

s1 Tigerstedt, l. c., p. 602. 
central regulatory apparatus in which the latter works somewhat like a harp, in which by pedalling a modulation into a different key is brought about; by fixing the whole rhythm the tune is changed from one key to another." 52 According to Schwenkenbecher in febrile subjects as in healthy individuals a rise in heat production is compensated by a rise in heat elimination. ${ }^{53}$

This does not say, however, that the heat-regulatory apparatus in fever functionates as efficiently as in normal conditions. The experiences of physicians indicate rather that the temperature of febrile subjects is more variable than that of healthy individuals, and that the former, for example, are more easily chilled by withdrawal of heat.

It may be said in a general way that the body temperature of the febrile subject, in spite of the fact that heat regulation is by no means excluded, rises because the heat elimination lags behind the heat production. "The process of temperature regulation," says Krehl, ${ }^{4}$ "cannot by any means be thought of as a simple one. Under all circumstances there exist influences which act in an appreciably separate manner upon heat production and upon heat elimination. Each of the two processes acts under different circumstances through different physiological agencies, the elimination of heat by conduction, radiation and evaporation of water, the production of heat by the decomposition of nutrient material or body substance. In my opinion in fever the whole group of these mechanisms is changed, and as a matter of fact the functional disturbances in different cases are surely not the same in their individual details. By and large the ability to regulate is retained. Almost always, or, as I believe, always, there prevails a state of excitation of the parts by which the heat production is

${ }^{82}$ Fr. Kraus, l. c., p. 644.

${ }^{53}$ Schwenkenbecher and Tuteur (Med. Clinic, Strassburg), Arch. f. exper. Pathol., 5\%, 285, 1907.

${ }^{64} \mathrm{Krehl,} \mathrm{1.} \mathrm{c.}$ 
increased, that therefore there exists a particular combination of disturbance of heat production and of heat elimination."

Increased Excitability of Heat Regulating Centres in Fever and its Reduction by Antipyretics.-As causative of such disturbance we may, in accordance with $R$. Gottlieb's statement, think of a condition of pathologically increased excitability involving the heat regulating centres. It is funclamentally one and the same thing whether this excitation is brought about by electrical or mechanical initiation (as in the heat puncture) or whether it is the result of stimulation by toxic bacterial products. It is, however, of the utmost significance that the antipyretics (as Filehne also has held) owe their effect clearly in the first place to a quieting of the heat-regulating centres which are in a state of pathological irritation, and that the typical fever remedies are also on the whole "analgesics" and "sedatives," that is, weak narcotics for the sensory area of the cerebral cortex. In conformity with this thought, for example, even small doses of morphine are capable of interfering with the hyperthermia of cerebral puncture. ${ }^{55}$

Pyrogenic Properties of Proteins and Protein Derivatives.-We may at this point turn to a brief consideration of those chemical agencies which possess the ability to act as excitants of fever when introduced into the blood stream.

Krehl and Matthes were first inclined to connect the observation that many febrile diseases are accompanied by an albumosuria directly with the production of fever in infectious diseases; but later they withdrew this opinion as incorrect. The question of the presence of albumoses in the blood, as previously stated, is apparently not as yet satisfactorily understood; but undoubtedly an albumosuria

${ }^{55}$ R. Gottlieb in H. H. Meyers' and R. Gottlieb's Experimentelle Pharmakologie, pp. 389 et seq., 1910; cf. therein, as well as in O. Löwy, Ergebn. d. Physiol., 3, 357-372, 1904, and in Noorden's Handb. d. Pathol. d. Stoffw., 2, 781-797, 1907, for a detailed analysiz of the action of antipyretics, also for appropriate Literature. 
can exist without fever, and it is probable that it were better related to a coincidence of the appearance of products of abnormal protein cleavage in the blood along with disturbance of the renal function. ${ }^{56}$

American authors hold that fever may be a result of parenteral digestion of protein, without the protein being of necessity of bacterial origin; that thus we are able by repeated subcutaneous injection of egg-albumin in rabbits to induce a typhoid-like fever. The difference between the action of the white of egg and of the typhoid bacilli in the body would seem to consist only in the fact that the egg. albumin is incapable of further development. ${ }^{57}$ Contrary to this idea Schittenhelm, Weichhardt and Hartmann, ${ }^{58}$ who injected intravenously into animals egg albumin, sheep serum, peptone, aminoacids and bacterial protein, come to a diametrically opposed conclusion, that animal proteins and their cleavage products have absolutely no effect toward raising temperature when introduced in quantities which have proved in ease of the bacterial proteins to be decidedly febrogenic. E. Nobel, in the laboratory of Edwin Faust, was able recently to isolate from colon bacilli killed by heat and from cultures of these microörganisms an abiuret thermogenic substance. ${ }^{59}$ The often-quoted statement that fibrin ferment acts to produce fever has been disproved by studies emanating from the medical clinic at Heidelberg. However, the destruction of non-specific or of antogenous blood cells in the circulation does produce fever; and, too, in the destruction of the very labile blood platelets pyrogenic substances seem to be set free. ${ }^{60}$

${ }^{86}$ Cf. F. Kraus, i. c., pp. 609-610.

${ }^{\pi} \mathrm{V}$. C. Vaughan and his associates (Univ. of Michigan). Jour. of Amer. Med. Assoc., 5.3, 629, 1909; Zeitschr. f. Immunitätsforschung, 9, 458, 1911.

${ }^{s}$ A. Schittenhelm, W. Weichhardt and F. Hartmann (Erlangen), Zeitschr. f. exper. Pathol., 10, 448, 1912.

${ }^{59}$ E. Nobel (Lab. of E. Faust, Würzburg), Arch. f. exper. Pathol., 68, 371, 1912.

${ }^{\infty}$ H. Freund (Med. Clinic, Heidelberg), Deutsch. Arch. f. klin. Med., 105, 44,$1912 ; 106,556,1912$. 
Fever Following the Introduction of Corpuscular Elements Into the Circulation.-It would seem, moreover, that even the simple presence of corpuscular body-foreign particles is sufficient to give rise to febrile temperatures. Wolfgang Heubner obtained a uniform and definite increase of temperature by injection of very fine suspensions of paraffine, and he suggests in the same line that in the paroxysms of malaria numerous corpuscular clements gain access to the blood stream at one time. ${ }^{61}$ The foundry fever of brass casters, a symptom-complex suggestively like malaria, is produced, according to investigations of K. B. Lehmann, by the very fine particles of zine or zine oxide gaining access to the lungs. ${ }^{62}$ It may well be that these particles pass from the alveoli of the lungs into the blood.

Hyperthermias Produced by Chemically Definite Substances.-We are aware, moreover, of a number of chemically definite substances which, appropriately applied, are able to give rise to fever. Here belong substances of the purin group. Thus Binz found that caffeine in doses insufficient to produce cramps or convulsions can act thermogenetically, which feature he attributed to a heightened nervous influence upon the muscles. So, too, A. R. Mandel succeeded in producing temperature rises in monkeys by means of xanthin, caffeine or decoctions of coffee, from which he regarded himself justified in ascribing an important rôle to the purin bases set free in toxic tissue destruction in relation to the production of fever (often accompanied by an increased elimination of purin bodies) ${ }^{63}$ Atropine and cocaine can also at times cause an access of temperature ${ }^{64}$ and, too, a number of the derivatives of anthrachinone. ${ }^{65}$ The most striking effect is, however, seen

"1 W. Heubner (Göttingen), Münchener med. Wochenschr., 1911, No. 46.

${ }^{2}$ K. B. Lehmann (Würzburg), Verhandl. d. Ges. d. Naturforsch., 78,362 , 1906.

${ }^{63}$ A. R. Mandel (New York), Amer. Jour. of Physiol., 10, 452, 1904, 20, $439,1909$.

* Cf. O. Lüwy, Ergebn. d. Physiol., 3', 355, 1904.

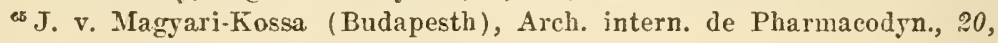
$157,1910$. 
in case of tetrahydronaphthylamine (first noted by Stern), which (according to researches emanating from the laboratory of H. H. Meyer) acts both as an excitant to the heat regulating centre and induces a condition of constriction of the blood-vessels of the skin, muscles, and kidneys. ${ }^{66}$ An increase of muscular action seems also concerned in the rise of temperature. ${ }^{6 \tau}$ Adrenin can also at times bring on a rise of temperature.

Salt-and Sugar-fever.-Finally may be mentioned the very remarkable "salt- and sugar-fever," which has recently received much consideration but which is as yet without explanation, a temperature exaggeration which has been noted in animals and human beings (especially in infants, but also in adults) after intravenous, subcutaneous, oral and rectal introduction of solutions of sodium chloride or of sugar, and which is apparently accompanied by an increased production of heat and increased protein metabolism. ${ }^{e 8}$

Significance of Fever.-In conclusion we may take up the question as to what particular importance fever possesses for the economy.

Since time immemorial physicians as well as patients have been thoroughly impressed with the idea that fever is harmful, and measures for its suppression have always occupied a large place in therapy. The development of scientific pathology at first seemed to support ideas of this kind, and we were disposed to look especially upon the parenchymatous and fatty degeneration of organs, a depression of the rasomotors and a weakening of the heart, as well as a loss of the hæmoglobin of the blood, as the immediate harmful effects of the heightened temperature itself. More recent studies, as those of Naunyn in particular, as well as those of Rolly and Meltzer, have disproved

" Jonescu (Pharmacol. Instit., Vienna), Arch. f. exper. Pathol., 60, 345, 1909.

${ }^{7} \mathrm{H}$. Mutch and M. Pembrey, Jour. of Physiol., 43, 109, 1912.

${ }^{6}$ Studies by Bingel, Cobliner, Finkelstein, H. Freund, E. Grafe, Friberger, Heim and John, Hort and Penfold, Nothmann, Schloss, Verzár. 
this view, and have proved that these patholugical features are not to be ascribed primarily to the influence of the fever heat but rather to intoxication by products of pathogenic microörganisms. Although even at present it is impossible to give any clear and precise answer to the question whether fever in itself is useful or harmful, the belief is making more and more headway that fundamentally we may regard the febrile temperature accession as a curative effort on the part of nature. We have access to a series of observations which indicate a favorable influence of hyperthermia upon infectious processes. Here may be mentioned the observations of Löwy and Richter upon pneumonia, diphtheria, chicken cholera and swine erysipelas, those of Rovighi upon septicæmia, of Filehne upon erysipelas, of Rolly and Meltzer upon infections with anthrax, streptococci, pneumococci and bacterium coli. From this standpoint the elevated temperature can either act directly to harmfully influence the bacteria, or it may, on the other hand, increase the bactericidal power of the blood, or the production of antibodies. Observations like those of Rolly and Meltzer, Lüdke, Fukuhara, Lissauer and others upon the formation of agglutinines and hamolysines in fever, make it clearly probable that we owe to the elevated temperature an important part in the production of antibodies. ${ }^{69}$ Modern pharmacologists also are taking the position, as H. H. Meyer and Gottlieb, ${ }^{70}$ that in application antipyretics serve far better if employed as fever narcotics, and that it is better to counteract certain associated features of the fever (as rapid cardiac action and respiration, restlessness, headaches, loss of appetite, etc.) than to depress the high temperature.

Here, too, then experimental investigation is relentlessly clearing away errors venerable from their age in order to make new paths for new endeavors.

an Literature upon the Significance of Fever for the Economy: P. F. Richter, 1. c., pp. 140-146.

${ }^{7 n}$ H. H. Meyer and R. Gottlieb, Experimentelle Plarmakologie, p. 398, 1910. 
Epilogue.-We are come to the close of our long and arduous journeying. The author begs to be permitted before separation to cordially thank every one who has accompanied him in sympathetic thought thus far. He has conducted this excursion as well as he knew how, through wide tracts in the world of organic activity; and has interpreted the everchanging abundance of visions which were open to his eyes to the best of his understanding. He knows full well that the future will again and again declare his interpretations wrong, and that to other eyes, provided with better spectacles, many things will necessarily appear in different light. And too he is well persuaded that many a subject which to-day we imagine an absolute fact, will only provoke an indulgent smile from our successors. "Man is doomed to blunder as long as he strives." And the author must therefore be satisfied with the consciousness of the honesty of his effort.

That which may in some measure console us for the inadequacy of our knowledge is the consciousness that all of us who are endeavoring to solve the enigmas of the world of life are engaged in a glorious service, and that to us who live to-day has been granted the merciful faror of enjoying together a great cultured epoch in which the world-in spite of every social and political ealamity which so often takes our breath-is hastening forward in winged course to new ambitions.

Let us then for, ourselves take heed that all the building stones, whether great or small, on which the living generation of nature searchers of to-day tests out its powers, may come to contribute to the establishment of the marvellous structure of future culture and learning from which we hope for oncoming generations all that we dream of but may not see: the freedom of the people from avoidable evil of body and soul, from want and from error, and the triumph of true humanity. 



\section{INDEX}

A

Abderhalden on food value of advanced products of protein clearage, 64

on parenteral introduction of proteins and sugars, 511

on protective ferments in blood, 218

on proteolytic tissue ferments, 21, 218

test in pregnancy, 96

Abscess, alimentary galactosuria in, 287

proteolytic factors in, 87

Absorption of albumoses, 57 aminoacids, 57

coëfficient, $5 S 7$

of fat, parenteral, 379

fever, 86

from intestine influenced by age and disease. 54

of protein cleavage products in intestine, 53

of protein cleavage products in stomach, 17

of protein, iodized, 57

Acapnia in alpinism, 604

Accessory respiration, 563

Acetalanin, $4 \pi 6$

Acetaldehyde, condensation into aldol, 435

in fat formation from carbohydrate, 390

in glucose fermentative catabol. ism, 347

Acetamide, 112

Aceto-acetic acid. 431

and acctone, separation of, 449

from aldol. 435

catalytic enzyme action on, 447

determination of, $44 \mathrm{~S}$

in diabetic coma, 441

from ethyl alcohol, 435

and $\beta$-oxybutyric acid, reversibility of, 442

Acetonæmia and lipæmia, reversibility of, 374

Acetone. 431

and aceto-acetic acid, separation of, 449

bodies, 431

benzol derivatives in forma. tion of, 439

and butyric acid and capric acid ingestion, 434
Acetone bodies and cancer, 432

chemical relation between, 431,442

from compounds with branched and cyclic chains, 437

crotonic acid in formation of, $43 \mathrm{~s}$

and diabetic coma, 431, 440

dimethylacrylic acid in formation of, 438

ethylbutyric in formation of, 438

from fatty acids with even carbon chains, 432

from glycerol, 439

interrelation of, 445

isoamylamine in formation of, 438

isovaleraldehyde in formation of, 438

isovalerianic acid in formation of, 438

from leucin, 438

and lipæmia, 432

$\beta$-oxyisovalerianic acid in formation of, 438

phenvlalanin in formation of, 439

and phosphorus poisoning, 432

from protein cleavage products, 437

relation to fat of body and of food, 431

and starvation, 432

tyrosin in formation of, 439 determination of, $44 \mathrm{~S}$

from fat catabolism. 393

iodoform method of determination, 448

mercuric eyanide method of determination, 448

Messinger-Huppert method of determination, $44 \mathrm{~S}$

nitrophenyl-hydrazine method of determination, $\mathbf{4 4 8}$

production from a-aminoacids, 434

production from oxybutyric and aceto-acetic acids, 447

sodium bisulphite method of determination, 448

Acetophenone, 112

Acetyl-aminobenzoic acid, 111

reduction product of nitrobenzaldelyde, 471 
Acetyl figure of fats, 385

Acetylenehæmoglobin, 592

Acetylization processes in anabolism and catabolism of aminoacids, 474

animal body, 474

Acetylphenylaminoacetic acid, 475

Acholia, 120

Aclıroödextrine, 196, 219

like substance in urine, 512

Acid, see specific name of acid

Acid albumin of gastric contents, 16 albuminates of gastric contents, 14

production of snails, 12

Acidity of gastric juice, origin of, 9 determination of, 11

physico-chemical explanation of, 11

Acidosis, 102, 103

and ammonia elimination, 442

and carbohydrate deficiency, 439

in diabetes, 259

in fasting, 505

and fat destruction in fever, 620

and loss of hepatic function, 102 urea elimination in, 442

Acridin, oxidation of, into oxyacridon, 469

Acromegaly and glycosuria, 314 hypophysis in, 314

Addison's disease, hypoglycæmia in, 306

Adenase, 149

Adenin, 149

conversion into uric acid, 149

Adipocere, 414

Adrenal, chromium affinity of, 306 diabetes, 300

pancreas in, 310

suppression of, by nephrotoxines, 303

glycosuria, hypophysis in, 315

kidney in, 302

suppressed by ergotoxin, 263

regulative influence over carbohydrate metabolism, 304, 309

Adrenalin, see Adrenin.

Adrenals, exclusion of, inhibiting puncture glyeosuria, 305

regulative effects of carbohydrate metabolism, 309

squeezing of, followed by glycosuria, 304

and sugar puncture, 304

thyroid and pancreas, interaction of, 313

Adrenin, 214, 215, 300, 555

mode of action in producing glycosuria, 301

increase in hlood, after sugar puncture, 307

Adsorbing media, 44
Adsorption of acids in eapillary media, 13

capacity of enterokinase, 42

phenomena, 11, 271, 592

theory, 592

Agar-agar in diabetic diet, 271

Agglutinin formation in fever, 634

Alanin, 45, 59, 60, 64, 93, 239, 450,

$458,460,473,474$

catabolism of, 466

production from non-nitrogenous material, 474

sugar formation from, 240

Alanyl, 93

Alanyl-glycin, 45, 93

Alanyl-glyeylglycin, 93

Alanyl-leucin, 93

Albumin, Bence-Jones, 55

removal of, from urine, 206

Albumoses, absorption of, 57

in blood, absorption of, from intestine, 56

in gastric digestion, 16

stimulative in pancreatic secretory aetivity, 41

in urine in autolytic processes in body, 86

in urine of fever, 620

Alcaptonuria, 470

Alcohol in animal tissues, 329

antiketogenic influence of, 436

in diabetes, $26 \mathrm{~s}$

in fattening, 400

as a food, 400

in glucose metabolism, 345

glycogen formation and, 231

Alcoholic fermertation in animal tissues, 328

of sugar, 345

by zymase, 327

Alcoholism and gout, 186

lipæmia of, 377

Aldehydases, 551

Aldol, condensation of acetaldehyde into, 435

in fat formation from carbohy. drate, 390

in glucose fermentative catabolism, 348

as source of $\beta$-oxybutyric acid, $391,43 \pi$

transformation into aceto-acetic acid, 435

Aleuronat in diabetic diet, 271

Aliphatic fatty acids, Knoop's theory of catabolism of, 392

side chains and fatty acids, decomposition of, 464

Alkalescence, changes of, in gout, 178

Alkali of bile in emulsification of fats, 367

inlibiting gastric secretion, 8

in sugar catabolism, 341 
Alkalinity of tissues in relation to gouty deposits, 184

Alkalosis, 102

Alkylation in animal body, 476

Allantoin, 81, 153

from autolysis, 160

as end-product of purin metab. olism in mammals, 158

fate of experimentally introduced, 163

formation of, in mammals, $15 \mathrm{~S}$

location of formation of, 160

production by protoplasmic poisons of, 159

uricase in production of, 161

from uricolysis, 158

Wiechowski's method of estimation, 169

Alloxyproteic acid, 137

Alpinism, acapnia in, 604

alkalinity of blood in, 606

atmospheric pressure ill production of, 605

blood corpuseles in, 601

capacity for work in, 607

cardiac activity in, 602

climatic factors in, 601

minimal metabolism in, 607

nitrogen retenticn in, 608

observation material in, 599

physiology of, 579, 599

respiration in, 604

sleeplessness in, 604

Amides in metabolisin of vegetarians, 67

plants, 67

Amido-fat combination, 412

Aminoacids, absorption of, 57

acetone production from, 434

acetylization processes in anabol-

ism and eatabolism, 474

benzoylated, 111

in blood, 559

catabolism of, 462,466

catabolism of, by veasts, 467

deaminization of, 82

determination, quantitative, of, $119, \quad 120$

elaboration of, by lower vegetable forms, 471

elimination of, 115

in disease, 116

as test of hepatic function, 116

in gastric digestion, 16

in intestinal contents, 53

in intestinal contents, determination of, 53

ketonic acids in production of, 69 optically active, inhibiting proteolysis, 94

in plants, 67

sugar formation from, 238, 239
Aminoacids, synthesis of, 69

in urine, 115 in body, 472

in urine, increased in diabetes, 269

in-Aminobenzoic acid, 98

Aminobenzoic acid, 111

Aminobutyric acid, 473

Aminocaproic acid, 473

Aminophenol, reduction product of nitrobenzol, 471

Aminuria, alimentary, in functional test of liver, 116

Ammonia in correction of acidity of body, 104

elimination and acidosis, 102, 441, 442

in diabetic coma, 441

in fever, 102

in hepatic disease, 102

from other causes than acidosis, 442

in protein metabolism, 498 exhaled, 520

Ammonium acetate in feeding, 69

Ammonium carbonate, 100

in formation of urea, 97

carbonate in formation of urea, 97,100

citrate in feeding, 68

salts, nutritive value of, 68

in synthesis of proteins, 67

Amphibia, gastric digestion in, 19

Amygdalic acid, 475

Amylopsin in carbohydrate digestion, 195

Anærobic respiration, 329

Anaphylactic phenomena from protein absorbed from intestine, 55

Anaphylaxis, 95, 510

from proteins absorbed from bowel, 55

Aniline, hydroxylation into paraamidophenol, 468

Anoxybiosis, 329,577

Anthrachinone as a heat-producing agent, 632

Anticatalase, 560

Antifat treatment, 397

Antiferments, 24

Antiketogenic property of alcohol, 436 property of carbohydrates, 439 substances, 442

Antileucoproteases, 88

Antipancreatin, 260

Antipepsin, 24, 25

Antipneumin, 563

Antipyretics acting to reduce excita. tion of heat regulating centres in fever, 620

Antisepsis required in autolysis, 76

Antitrypsin, 49, 88 
Antitryptic treatment of suppurations, etc., 88

Aqueous humor, sugar in, 211

Arabinose and galactose, 291

in glucose cleavage, electrolytic, 344

chronic pentosuria, 290

Arabonic acid in electrolytic clearage of glucose, 344

Arginase, 76, 105

Arginin, 84, 105, 119, 131

as source of creatin, 131

Arnold reaction, 135

Aromatic substances in urine, 319

Aseptic autolysis, 77

Asparagin, autolytic cleavage of, 82 nutritive value of, 68

Asparaginic acid, sugar formation from, 240

Asphyxia and autolysis, 89

blood in, 568

Winterstein's theory of, 5i 6

Assimilation limit of sugars, 232

Atmospheric pressure in alpinism, 60.5

Atwater and Benedict's respiration calorimeter, 516

Autodigestion, 75

of stomach, antipepsin in, 25

resistance against, 24

Autolysates, antibacterial and antitoxic influences of, 86

Autolysis, 75

allantoin production by, 160

asepsis and antisepsis needed in, 76,77

and asphyxia, 89

bacterial processes in relation to, 86

Benson and Well's method of following, 79

earbonic acid influencing, 89

colloids influencing, 89

drugs influencing, 90

extrinsic factors, 89

of exudates, 85

fat phanerosis in, 409

in involution of uterus, 85

in pathological processes, 83

products of, 76

in blood and urine, 86

progress of, methods of observing, 79

protection of living cells from, 81

in regressive changes in living body, 85

stimulated by phosphorus, chloro-

form, narcotic agents, etc., 84 variability of, 79

a vital process? 78

as a vital process, objections to, 80
Autolytic tissue ferments and physiological activity of tissue, 79

Autolytic tissue ferments and erepsin, 51

Autoxidizable body substances, 535

Autoxyproteic acid, 137

\section{B}

Bacteria and autolysis, 86

creatinin production, 129

fat catabolism, 392

in fat formation in autolysis, 410

in lab-process, 30

nutritive value of, 68

Bang's method of sugar estimation, 200

Bareroft and Haldane method of blood-gas analysis, 572

Barium, double salt of eresol-glycuronic and cresol-sulphuric acids, 319

Basedow's disease and glycosuria, 312

Batrachian larvæ, fasting studies upon, 507

Bence-Jones albumin, 5.5

Benedict and Gephart's method of urea estimation. 107

Benedict and Meyer's method of transforming creatin into creatinin, 123

Benedict's transportable respiration apparatus, 518

Benson and Well's method of following autolytic processes, 79

Benzaldehyde, action in indigo, 535

Benzidin-monosulphite of soda reaction on gonorrheal pus and other cells, 542

Benzoic acid 10 ?

dehydration derivative from hexahydrobenzoic acid, 469 deliydration derivative from quinic acid, 469

and glycocoll in formation of hippuric acid, 107

source of, in formation of hippuric acid, 107

Benzol derivatives and acetone bodies, 439

disruption into muconic acid, 469

hydroxylation into phenol, 468

Benzoylated aminoacids, 111

Benzoyl-leucin, 111

Bertrand's method of sugar estimation, 206

Bile in fat digestion, 359

emulsification, 367

solution, 367

reflux of, into stomach, 35

in solution of fatty acids and lipoids, 367

in starch digestion, 197

salts, activation of steapsin by, 363

Biogen, 569 
Birds, gastric digestion in, 19

Blood, alkalinity in alpinism, loss in, 606

aminoacids in, 59

carbohydrates otlier than glucose in, 208

carbonic acid combination in, 592 cells in hæmic glycolysis, 340 increase at elevations, 601 and serum, carbonic acid excliange between, 594

changes, plasmatic, in fever, 622 chemico-legal detection by peroxidase reactions, 545

coëfficients of oxygen absorption, invasion and evasion, 587

detection by v. Fiirth's method, 546

detection by pyridin-leukomalachite green metlod, 546

dust particles, 369

ester-splitting ferment of, 370,402

in fasting, 501

fat cleavage in, 401

fat masking in, 370

fat, passage of, from, 375

gases, 579

gas analysis, Barcroft and Haldane, 572

technic of, 584

exchange between cells and serum, 394

glucosamine in, 209

glucose in, 205

glycogen in, 209

glycolysis in, 338

ferment in fibrin in, 340

lencocytes in, 339

lipase in, 401

lipolytic function of, 370

maltases, irvertases and gluceses in serum of, 218

maltose in, 209

methylene-blue reaction in diabetes, 266

oxygen capacity of, influence of carbonic acid on, 589

oxygen capacity of, influence of salts on, 590

oxygen capacity of, influence of temperature on. 589

oxygen capacity of, maximum, 588 oxygen capacity of, physicalchemical conception of, 590

oxygen consumption, 561

oxygen tension curves of, 588

Plesch's method of hæmoglobinometr $\mathrm{V}, 586$

proteins of, 56

proteins and protein-derivatives passing into, 54

rest nitroger in, 58

serum, peptolytic power of, 95
Blood, sucré immédiat and sucrê virtuel in, 208

sugar of, 205

sugal estimation, 205

sugar, free of, 207

Body-foreign substances, fate in body, 463

Body protein, surface development and volume of, 521

Bohr on oxygen fixation by hæmoglobilı, $59 \mathrm{i}$

Brass-workers' fever, 632

Braunstein's metlod of urea estimation, 107

Bread substitutes in diabetic diet, 271

Bromine-crotonic acid method of quantitative determination of oxybutyric acid, 450

Bunge and Schmiedeberg method of estimation of hippuric acid, 113

Butyric acid, 393, 426

in glucose fermentation, 347 poisoning and coma, 433

\section{C}

Cadaveric wax, 414

Cadaverin, 118

Catfeine, 167

Calcium paracaseinate, 28 salts as activators of trypsinogen, 42

Calculi, uric acid, 182

Calorimeters, 514

Cammidge reaction, 293

Camphor-glycuronic acid in urine as possible functional test of liver, 323

Cancer and acetone bodies, 432

colloid metals destroying, 90

high molecular residual substances in urine, 146

urochromogen in, 145

Cane-sugar, assimilation of, 229

behavior after parenteral introduction, 229

fate after parenteral intro. duction, 197

Capanna Margherita, 599

Capric acid, 426

Caproic acid, 426

Caprylic acid, 426

Carbanino-reaction, Siegfried's, 594

Carbohydrases, 211

Carbohydrate, antiketogenic influences of, 439

cleavage of, in intestine, 195

cleavage of, in mouth, 194

clearage of, in stomach, 195

conversion into fat, 387

deficiency and acidosis, 439

digestion of, 194

digestion, amylopsin in, 195

in intestine, 195

pancreas in, 195 
Carboliydrate digestion, ptyalin in, 194 in stomach, 195

fat formation from, 386

and fatty acids, route between, 447

food limiting protein destruction in fever, 6is

of food, milk-fat originating from, 425

formation de novo. 236

metaholism in fasting, 504 fever, 621

and hypophysis, 314 interia il secretory glands, 800

regulation of, by adrenals, 304,309

thyroid in relation to, 311

other than glucose in blood, 208

products, resorption fronı intestine, 197

in protein molecule, 233 determination of, 233

resorption and removal of pancreas, 196

-splitting ferments, 211

of liver, 214

of muscle, 215

of pancreas, 196, 364

in plants, transformation of fat into, 387

Carbon elimination in protein metalsolism, 498

Carbon monoxide hamoglobin, 592

Carbonic acid, autolysis influenced by, 89

combination in blool, 592

exchange between blood cells and serum, 594

pressure influencing oxygen capacity of blook, .j8!

Carlonyldiurea, 165

Cardiac activity in alpini-m, 602

Carnitin, 133

Cascin, 28, 233, 494, 49.5

in milk, form of, 429

Catabolism of higher fatty acids, liver in, 385

Catalase, 538, 556

and colloid metals, .58 comburstion processes, 559

peroxidases, 559

physiological significance of, 559

preparations, 557

determination of actirity of, 557

reaction, kineties of, 5.58

of tissue, increase after birth, 50

Catalytic agents in cataholism of sugar, 342

enzymes in cataholism of oxybutyric and aceto-acetic acids, 447
Catalytic pancreatic constituent in sugar cataholism, 343

Cell fat, 412

and depot fat, 384

organization, the basis of life, 571

Cells. peroxidases in, 539

varions, in production of ereatinercatinin, 129

Cellular proteolytic enzymes, 51

protoplasm in fever, changes in, 624

Cellulose, cleavage by lower forms of life, 201

determination of, 200

digestion of, 198

by eytase, 200

by enzymes of food, 202

importance of infusoria to, 204

loy intestinal micrö̈rganisms, 202

food ralue of, 203

marsh-gas production in digestion of, 202

as snlstitute for other carboliydrate food in dialsetes, 200

Cheese, formation of, 28

ripening of, and fat formation from protein, 415

Chemico-legal detection of blood by peroxidase reactions, 545

Child, protein requirement of, 486

Childbed, lactosuria of, $2 S 4$

Chitin, 233

Chittenden's experiments in nutrition and energy, 484

Chloral, $31 \mathrm{~s}^{\circ}$

Chloral, reduction to trichlorethyl aleohol, $47 \mathrm{I}$

Chlorine retention in ferer. 624

Chlorocruorin, 547

Chloroform increasing autolysis, 84

Cholesterinæmia in diahetes, 374

Cholestcrol-ester steatosis, 421

Cholesterol steatosis, 42?

Cholic acid, 113, 119

Cholin, 86

Cholin and sceretin, differentiation between, 39

secretin and vasodilatins, relations of, 39

Chondroitin-sulphuric acid in urine, 147

Chorda tympani and sugar of submaxillary salivary gland, stimulation of. 278

Chromaffin system, relation to other glands with internal secretion, 316

Clrromium affinity of adrenal, 306

Chyluria, 375

Chyme, passage into intestine of, 3.3 Chymosin, 26 
Citric acid fermentation, 348 synthesis of glycolic acid, 348

Classification of protcolytic ferments, 94

Climate and food, 487

Coccrgeal gland, fat of, 427

Coëfibients of oxygen absorption. invasion and evasion, 587

Colmheim's respirometer for isolated organs, 572

Cold, glycogen and exposure to, 225 glycosuria from, 299

Colloidal metals and catalases, 558

Colloids, autolysis influenced by, 89 urinary, 147

Colorimetric method of diastase estimation, 212

of sugar estimation, 200

Coma diabeticum and acetone lodies, 431

alkaline treatment of, 441

and lipremia. 373

Combined acid of gastric juice, 14

Combustion processes, see also respiration of tissues, gas exchange, etc.

in alpinism, 607

and catalases, 5.59

in fever, 610

and oxidases, 555

Condensation of aldol into fat. 390

of digestion products, 61

Conjugate benzoic-acid derivatives. 478

sulphates, 477

Conjugation of glycuronic acid, conditions of, $318^{\circ}$

Corpulence, see Obesity

Corpuseular substances. pyrogenesis from introduction into blood of, 631

Creatase, 124

Creatin, 122

from arginin, 131

and creatinin, relations of, 123

determination, quantitative, of, 123

from guanidin-acetic acid, 131

metabolism and female generative organs, 130

in fimctional hepatic test, 129

from muscle, 128

Creatinase. 124

Creatinin, 122

determination, quantitative, of, 122

production by bacteria, 129

Creatin-creatinin, endogenous and exogenous distribution of, 125

excretion in disease, 127

in fever, 619

in humger, 127
Creatin-creatinin metabolism, 125

production, kidney in, 129

liver in, 129

muscle in, 128

various tissues in. 12 ?

relations of tissue-protein decomposition to, $126^{\circ}$

Crotonic acid, determination of, 450 in formation of acetone bodies, $438,46.5$

Curdling of milk, bacterial involvement in, 30

Cutaneous respiration, 596

Cyanlræmoglobin, 592

Cyclic nuclei, disruption of, 469 oxidation of, 468

Cyclopoiesis, 497

Cystein, 118, 475, 566

Cystin, 118

Cystinuria, 118, 119

Cytase, 200

\section{$\mathrm{D}$}

Darmstidter's method of quantitative determination of oxybutyric acid, 449

Dead and living protein. 569

Deamidases, $76,81,149$

Deaminization, $81,82,471$

of aminoacids, 82

Degenerative changes in liring body, autolysis in, 85

Depot fat and cell-fat, 384

Detoxification by glycuronic acid conjugation, 319

of hirdrocsanic acid by thiosul. phates, 477

phenols, by sulpluric acid, sulphurons acid, persodin, etc., 477

by sulphuric acid and sulphur rests in body, 477

Detoxifying agents, glycocoll and ornithin as, 112

Dextrin in diabetes, minary, 267

Dextrin-like substances. resorption of, 198

Diabetes, acidosis in, 2.59

adrenal, 300

mechanism of, 301

pancreas in, 310

renal influence in, 302

and sugar puncture, 304

suppression by nephrotoxins, 303

agar-agar in diet in, 271

alcohol in, 268

aleuronat in diet in, $2 \bar{l}$

aminoacids increased in urine in, 269

cellulose substituted for other car-

bohydrate food in, 200 
Diabetes, dict in, 271

duodeual, 250

fat catabolism in, 269

fatty, 269

glandular, 278

and glycuronic acid excretion, Meyer's theory of, 320

human, 263

etiology of, 263

glycogen of liver in, 265

hyperglycæmia in, 266

liver in, 264

pancreatic degeneration in, 263

and pancreatic, 265

Iceland moss in diet in, 271

inulin in diet in, 271

lecithinæmia in, 374

lipogenic, 269

medicinal treatment of, 272

methylene-blue reaction of blood in, 266

mineral water in treatment of, 272

oatmeal diet in, 271,442

pancreatic, 247

discovery of, 247

diastasic power of liver in, 253

glycogen formation in liver in, 253

metabolism in, 258

sugar-consumption in, $\mathbf{2 5 7}$, 259

sugar-elimination in, 259

sugar-formation from carbohydrate-free material in liver in, 253

symptoms of, 249

pentosuria in, 289

phloridzin, 275

lyyperglycæmia alsent in, 275

kidney in, 276

mechanism of, 280

metabolism in, 279

sugar-formation in kidney in, 277

protein-decomposition in, 267, 269

renal, 303

respiration experiments in, 271

respiratory quotient in, 242

Röntgen rays in, 269

substitutes for bread in, 271

urinary dextrin in, 267

Diabetic cholesterinæmia, 374 coma, 440

alkaline treatment of, 441

and acetone bodies, 431 lipæmia, 373

economy, oxidizing processes in, 257

lipæmia, 270, 373

lipoidrmia, 373
Diabetogenous obesity, 270

Diacetic acid, see Aceto-acetic acid

Diacetyl in creatin determination, 123

Dialuric acid in synthesis of uric acid, 156

Diaminopropionic acid, deaminization of, into glyceric acid, 471

Diaminuria, 118

Diastases, augmentation of, 220 determination, quantitative, of, 212

in embryos, 216

hepatic, 214

inactivation of, 220

isolation of, 219

muscle, 215

origin of, 216

pancreas in production of blood-, 217

reactivation of inactive, 220

starches, various, as affected by, 219

Diastasic power of liver in pancreatic diabetes, 253

Diazo-reaction, 145

in fever, 620

and histidin, 146

imidoazol compounds, 145

oxyphenylacetic acid, 145

tyrosin, 145

urochromogen, 139

Diet in diabetes, 271

gout, 192

growth, 497

lipæmia, 377

in obesity, 397

use of protein-cleavage products in sickroom-, 66

Dietary allowance, 482

Diethylmethylsulphinium hydroxide, 132,476

Diethylsulphide, 132, 476

Digestion, adaptation of enzvmes to food, 196

of carbohydrates, 194

fats, 350

gases of, 203

gastric, comparative physiology of, 18

of living tissues, 25

of proteins, 1 extent of, 15

rapidity of, 17

intestinal, of proteins, 50

products, synthesis of, 60

resistance of aquatic animals to, 26

work of, 529

Diglycyl-glycin, 45

Dimethylacrylic acid in formation of acetone bodies, 438

Dimethylguanidin, 133 
Dioxyacetone, 461

in alcoholic sugar, 346

Disaccharides, assimilation of, 229 glycogen formation from, 229 resorption of, 197

Dombrowski's urochrome, 139

Douglas' respiration apparatus, 518

Dreser's method of determining $\mathrm{HCl}$ in gastric juice, 12

Drugs, various, influencing autolysis, 90

Ductless glands and carbohydrate metabolism, 300

see also Glands with internal secretion, and specific glands

Duodenal diabetes, 250

Dynamic effect of protein, specific-, 529

Dysoxidizable substances in body, 535

Drszooamylia, 254

\section{$\mathrm{E}$}

Echinochrom, 547

Eckenstein and Blancksma method of acetone determination, 448

Eck's fistula animals, intoxication on meat diet in, 603

Eck's fistula and urinary purin, 153

Eclampsia, increase of chondroitinsulphuric and nucleinic acids in urine in, 147

Elastin, adsorption of pepsin by, 23 failure to be absorbed from intestine, 55

Electricity increasing lydrolyzation of starch, 220

Electrolytic clearage of sugar, 343

Electromotor power of hydrogen ion chains of gastric juice, measurement of, in estimating acidity of juice, 12

Elevations, see Alpinism

Embden's schema of sugar cataholism in living body, 460

views of fat catabolism in iiving body, 392

Embryos, diastases in, 216

Energy computation in infant feeding. 523

exchange in alpinism, 607 after food ingestion, 514 and surface development, 522 expense in fasting, 503

law of conservation of, influencing study of nutrition, 2

law of constant expenditure of, 525

requirement and protein requirement, 486

value of food, Rubner's standard figures of, 528
Enterokinase, 41

adsorption by fibrin of, 42

origin of, 42

Envelopment of sugar in colloids of blood, 209

Enzyme carbohydrate-splitting, 211 rôle of pancreas in pro-

-duality, 219 duction of, 196

glycolytic, 256

of food in cellulose digestion, 202

Enzymic catabolism of aminoacids, 467

Epiguanin, 167

Epilogue, 634

Eppinger-Falta selema of interaction of internal secretory glands, 313

Eppinger-Falta schema of interaction of internal secretory glands, Asher's modification of, 316

Erben's method of oxyproteic acid determination, 144

Erepsin, 50, 78, 79

panereatic, 43

Erepsin and autolytic tissue ferments, 51

Erepsins, tissue, 51, 76

Ergotoxin, 263

Erythrocytes, sugar content of, 210

Erythrodextrin, 196

Esters, cleavage in tissues of, 403

Ester-splitting ferment in blood, 370, 402

Ethyl alcohol in production of acetoacetic acid, 435

Ethylbutyric acid in production of acetone bodies, 438

Ethylhydroperoxide, 540

Ethylokrinin, 38

Ethyl sulphide, 476

Excretion coëfficient of sugar. Falta's, $26 \mathrm{~s}$

\section{F}

Falta's excretion coëficient of sugar, 268

Fasting, acidosis in, 505

Batrachian larvæ studies in, 507

blood in, 501

carbohydrate metabolism in, 504

endurance in, 499

energy expense in, 503

fat covering energy expense in, 503

fat imporerishment in, 503

glycogen formation from protein in, 505

hibernation studies in, 506

hunger sensation in, 507

lipxmia in, 504

metabolism in, 499

total, in, 501

nitrogen elimination in, 503 
Fasting, nitrogen metabolism and minimal nitrogen metabolism in, 504

protein exelnange in, 503

lespiratury quotient in, 506

Rline salnon, studies on, in, 507 urine in, 505

water in, 504

weight loss in, 500

Fat absurption, parenteral, 379

acetrl figure of, 385

of liody and of food, relation of acetone bodies to, 431

from carbohylrates, characteristies of, 388

place of formation of. 389

catabolism and acetone bodies, 393

in animal body, 392

by bacteria, 392

Innoop's theory of, 433

in plants, 391

clearage in blood, 401

intestine, location of, 366

in absence of pancreatic secretion, 366

by intestinal microörganis=111s. 366

and solution of cleavage prod. ucts, 352

sinthesis, enzymic, 40.5

of coccygeal gland, $42 \bar{i}$

combined in protein in blood, 371

decomposition in diabetes, 269

depot, and cell. 384

destruction and acidosis in fever, 620

digestion and absorption of. $\mathbf{3 . 5 0}$

influence of pancreatic juice and lile upon, 359

in stomach, 35 )

distribution in body, 380

duodenal reflux into stumach caused by, 350

of embryo chicks, 383

emulsification by bile, 367

influence of alkali of bile upon, 367

energy expense in fasting covered by, 503

feeding, fat-splitting in blood influenced by, 402

feeding, parenteral, $3 s 0$

of food, milk-fat derived from, 424

foreign, assimilation of, 381 deposit of, 381

formation from carbolydrate, cliemistry of, 390

protein, 40.) adipocere, 414
Fat formation from protein, lacteria in, 410

Hoft'man's ffy maggot experiment, 413

ripening of cheese, 415

in kidney, 420

from sugar, 386

form of hxmic, 367

and glycogen, antagonism between, 373,380

from glycogen, place of formation of, 389

impoverishment from phloridzin, 243

in fasting, 503

of infants on natural and artificial food, $38:$

infusoria capable of digesting, 40 3 inlibiting gastric secretion, 8

iodized and bromized, deposit of, 381

liver as site of storage of availahle, 386

masking in blood, 370

and fatty degeneration, 371

metaholism, 378

in phloridzin diabetes, 279

theory of pancreatic intluence upon, 361

migration of, in certain fish, 376 of milk, origin of, 423

origin of, from carbohydrates of food. 425

origin of, from food fat, $4 \leq 4$

mobilization and lipæmia, 37.2

nonsaponifiahle, behavior in in-

testine, 354

parenteral resorption of, 379

feeding with, 513

passage of. from blood into urine, 375

from blood stream, 375

through placenta, 376

phanerosis in autolysis, 409

and fat mobilization, 419

in fatty degeneration, 418

nature of, 412

protein combination in llood, 371 separation of, 371

resorption, exclusion of pancreas aflecting, 361

by intestine, rapidity of resorption of. 358

in intestine, 351

histological observations oll, 3.5.)

patll of, 368

respiration experiments on conversion of carbohyrlates into. 387 
Fat of sebaceous glands, 427

separation from protein combination of, 371

of species and races, 388

-splitting tissue ferments, 401, 405

stained, behavior in intestine as

to resorbability, 359

in stool, 360

storage in body, 380

sugar formation from, 240,241 in plants, 246

supply and protein destruction, 378

synthesis in intestinal wall, 353

by reversal of action of lipase, 365

transformation in body, 382

into carbohydrate in plants, 387

types met in various animals from types of food, 382

utilization as influenced by arti-

ficial use of pancreatic juice and bile, 360

Fattening, 39s

alcohol in, 400

from carbohydrate feeding, 399

fat feeding. 400

proteid feeding, 399

Fatty acids, acetone bodies from lower, with even carbon chains, 432

and aliphatic side chains, decomposition of, 464

combination witl aminoacids. 412

disintegration of long chains into short clains of, 434

formation hy mieroürganisms of higher, 413

Knoop's theory of catabolism of aliphatic, 392

liver in oxidizing higher, 38j

in milk, lower. 426

route from earbolyydrates to, 447

solvent power of bile upon. 367

sugar formation and, 243

degeneration, distribution of, 419

and fatty infiltration, 406

fatty infiltration in. 416

and fat masking, $3 \check{\text { l }} \mathrm{l}$

and fat phanerosis. 418

of kidney, 419

and lactic acid accumulation in blood, 371

of liver in phospliorus poisoning, 415

Rosenfeld's experiment in, 416

Rosenfeld's theory of, $\mathbf{4 1 7}$ diabetes, 269
Fatty infiltration of kidney, 4:0

of liver in phosphorus poisoning, 415

and fat mobilization, 419

and fat phanerosis, 419

in various pathological conditions, 417

Feeding with carbohydrate in fattening. 399

fat, 400

protein, 399

Feeding, parenteral, 508

with carbohydrate, 511

with fat, 379,513

witl protein and protein derivatives, 62,508 danger of, 510

Fehling's method of sugar estimation, 206

Ferment-character of peroxidases, $5 \mathbf{4} 3$

Ferment-clearage and synthesis of fat by lipase, 406

Ferment, fat-splitting gastric, 350

pancreatic, 359

Ferments, carbolyydrate-splitting. 211

fat-splitting tissue, 401, 405

glycolytic, 256

tissue, 3it

nature of, 21

oxidizing, 534

peptolytic, 75,95

proteolytic gastric, 20

pancreatic, 41

tissue, 75, 91, 218

detection of, 92

in purin metabolism, 149

thermolabile and thermostable, 533

Fermentation, law of peptic, 22

$$
\text { tryptic, } 47
$$

method of sugar estimation, 206

Fetal lipsemia, $376^{\circ}$

Fever, 610

aciclosis and fat destruction in, 620

albumoses in urine in, 620

ammonia elimination in, 102,620

anthrachinone prodıcing, 632

hlood plasma changes in, 62.2

carbohydrate metabolism in, $6: 21$

chlorine retention in, 624

chondroitin-sulphuric and nucleinic acids in urine in, 147

from corpuscular elements introduced into blood in, 630

creatin-ereatinin elimination, 619

diazoreaction in, 620

frugality of econony in, 614

globulinæmia in, 622

and glycogen, 225

heat elimination decreased in, 015 production in, 611 regulating centres, increased excitability of, 630 
Fever, heat regulation, by ehemical and physical means in, 626

fixation of, at ligher grade, 628

by nervous system, 627

hyperinosis in, 622

metabolic velocity in, 612

metabolism, total in, 610

muscular activity influencing heat production, 611

nitrogen elimination in, 616 end-products, elimination of, 619

oxygen capacity of blood in, 589 oxyproteic acids in urine, 620 protein destruction in, 616 limited by carbohydrate food in, 618

from purins, 632

and purin, urinary, 153

pyrogenic property of proteins and protein-derivatives, 630

pyrogenesis from chemically definite substances, 632

reducing power of tissues in, 615 resorption, 86

R. V.T. rule in, 612

respiratory quotient in, 614

salt, 633

significance of, 633

sugar, 633

swelling of cellular protoplasm in, 624

toxogenic influences in protein destruction in, 618

uric acid eliminations in, 619

water economy in, 623 retention in, 623

Fibrin, glycolytic ferment in, 340

Fish, gastric digestion in, 19

migration of fat in, 376

oxygen secretion in swim-bladder of, 596

Fistula, gastric, 3

of oesophagus, Pawlow's, 3 pancreas, 35

Fistulous dog, poly-, 70

Fly-maggot experiment of Hoffman in formation of fat from protein, 413

Folin's method of estimation of crea. tinin, 122

Folin and Schafier's methou of uric acid estimation, 168

Folin's method of urea estimation, 106

Folin's method of hippuric acid estimation, 114

Food, adaptation of pancreatic secre tion to, 46

amount required, 482

calory computation in in. fants, 523
Food, cleavage products in nutritional experiments, 4.96

and climate, 487

elementary, 495

ingestion, energy exchange after, 514

metabolic increase after ingestion of, 529

requirements, 482

simple substances as, 495

as stimulus to gastric secretion, i

Tigerstedt's formula for metabolic equilibrium from, 527

utilization value of, 527

value, Rubner's standard figures of, 482,528

withdrawal of, 499

Formaldehyde in electrolytic cleavage of glucose, 344

glycogen formation from, 231

Formic acid in electrolytic cleavage of glucose, 344

fermentative glucose catabolism, 348

oxidation test for peroxidases, 540

Formol titration method of aminoacid determination, 119

Freighting-theory of pancreatic activity, 43

Fructose, 241

Fructose, glycogen formation from, 227

Fuld's method of pepsin estimation, 21

Furfuracrylic acid, 474

Furfurol, 474

Furfurol reactions, 324

F. Fiirth and Charnass method of lactic acid quantitative determindtion, 452

จ. Fïrth and Charnass method of lactic acid quantitative deternination, improvements by Emhden laboratory, 454

\section{G}

Galactose and arabinose, 291

assimilation in diabetes, 228

limit of, 228

availability of, in economy, 286

glycogen formation from, 227

Galactosuria, alimentary, in hepatic disturbances, 286

Gas analysis of blood, Bareroft and Haldane method, 572

technic of, 584

exchange of heart, 575

intestine, 577

liver and kidneys, 576 
Gas exchange in lungs, 579, 595 methods of study of, 514 in muscle, 574

nervous tissue, 575 salivary glands, 576

Gases of blood, 579

Gastrectomy, 19

Gastric contents, loinding of hydrochloric acid by protein bodies in, 14

passage into intestine of, 33 defieiency in certain fish, 18 digestion in amphibia, 17, 19 comparative physiology of, 18

preparatory to tryptic digestion, 17

of proteins, 1

extent of, 15

fistula, 3 velocity of, 16

secretin, 8

secretion, 7,8

acid determination in, 12 inhibition of, 8

mechanical stimuli to, 6 nervous mechanism of, 4 psychic influences upon, 5 and salivary glands, 7 stimuli to, 6

ulcer, 26

Gelatine, nutritive value of, 70

Ginsburg's method of oxyproteic acid determination, 143

Glands of internal secretion and carbohydrate metabolism, 300

interrelation of, 312316

Gland, mammary, phloridzin influencing, 279

salivary submaxillary, sugar produced by, under nerrous stimulation, 278

thyroid, removal of, 311

in relation to carbohydrate metabolism, 311

interrelation with other internal secretory glands, 312-316

Glandular diabetes, 278

Gliadin, 493-495

Globulinæmia in fever, 622

Glucase in blood-serum, 218

Glucese in blood-serum, $21 \mathrm{~S}$

Gluconic acid, 258

in electrolytic cleavage of glucose, 344

Glucosamine, 233, 234, 258

in blood, 209

glycogen formation in relation to, 230
Glucose, 196

alcoholic fermentation of, $34 \tilde{j}$

assimilation limit of, 228

lowered by hyperthyroidism, 312 removal of parathyroids, 311

in blood, 205

catabolism of, Wohl's schema, 345

into lactic, acetic, formic and carbonic acids in blood, 339

electrolytic cleavage of, 343

estimation, methods of, 206

fermentative catabolism of, 347

formation from protein, 231

glycogen formation from, 227

lactic acid from, 458

tolerance and hypophyseal obesity, 315

transformation of lævulose into, 282

ultra-violet rays as clcavage agent of, 344

Glucosides in blood, 208

Glutaminic acid, 493

sugar formation from, 240

Glutaric acid, antiketogenic influence of, 443

preventing phloridzin glycosuria, 281

Clutinase, 43

Glyceric acid deaminization product of diaminopropionic acid, 471

Glycerinaldehyde, 231

in glucose catabolism, 345

as lactic acid producer, 460 intermediate product in sugar catabolism, 460

Glycerol, acetone bodies from, 439

steatosis, 422

sugar formation from, 240

Glycocholic acid, 113

and taurocholic acid salts in

activation of steapsin, 363

Glycocoll, 64, 93, 108, 115

and benzoic acid in formation of hippuric acid, 107

detoxifying influence of, 112

and ornithin, conjugation of benzoic acid with, 478

sugar formation from, 240

synthesis of, from acetic acid and ammonia, 111

Glycogen, 221

in blood, 209

ehemistry of, 222

consumption of, 225

content of liver in human diabetes, 265

crystalline, 222

detection of, microchemical, 223

determination, quantitative, of, 221 
Glycogen, determination, quantitive of, P'fligers' metliod of, $2 \cdot 21$

disappearance from liver in use by muscle, ...t

in adrenal diabetes, 301

in diseases, various, 225

distribution of, 224

and fat, antagonism between, $37: 3$ 380

into fat, place of transformation of, 389

formation and alcohol, 2.31

from cane-sugar, 22?

formaldehyde, 2:31

glucose, fructose, galactose, 227

and glucosamine, 230

in liver, in pancreatic diabetes, 253

perfused, $2 \cdot 20$

phloridzin influencing, 278

from maltose, 229

pentose, 230

protein in fasting, 50.5

and sugar acids, 231

hepatic, 226

levulose in formation of, 228

microchemical identification, 22:

molecular weight of, 22.2

muscle demand for, 224

neoformation of, 236

pliysiology of, $2 \cdot 23$

protection of, against catalysis, 343

removal from body of, 224

Glycosenic function of liver, disturbances of, 225

Glycolaldehyde, 231

Glycolysis, 327

alkali influeucing, 341

in blood, 338

blood-cells in, $3 \pm 0$

Colnnheim's pancreas-muscle experiment in, $3: 32$

views of, objections to. 339

in diabetes, 2.5.5

pancreas in, $256.3: 2$

in surviving organs, $: 337$

Glycolytic enzrume, 256

theory, objections to. $3: 3$

ferment in fibrin, 340

muscle ferment, 332

tissue ferments, 334

Glyconeogenesis, 2:37

Glycosuria and acromegaly, 314

adrenal, absence of thyroid influencing, 311

relation of renal function to. 302

from squeezing adrenal gland, 304
Glycosuria, alimentary, absence of thyroid influencing, 311

experimental, of various types, 295

from hypophyseal extract, 314 postoperative, 297

refrigeration, 29!

renal, $29 j$

salt, 298

from sugar puncture, relation of adrenal to, 304

sympathetic nervous excitation, 304

thoracic duct fistula, 252 toxic, 298

Glycuronic acid, $258,288,317$

conditions of conjugation of, $31 \mathrm{~S}$

conjugate, 317

conversion into $\lambda$-xylose, 321

retection and estimation of, 323

determination, quantitative, of, 32.)

excretion a $\mathrm{nd}$ diabetes, Mever's theory of, 320

in respiratory diseases, 320

in diagnosis of diseases of intestine and liver, 322

intoxications, 320

occurrence of, in bolly, 32.2

origin of, from sugar oxidation, 319

splitting of conjugate, by glucoside-splitting ferments, 317

Glyeyl-alanin. 4.5

Flyeyl-glycin, 4.5, 9.3

Glyeyltryptoplane in detection of proteolytic tissue ferments, 92

Glycyityrosin in detection of protcoly tic tissue ferments, 9.2

Glyoxylic acid, 100-112

Goldschmiedt's reaction in intestinal diseases, 322

test for glycuronic acid, 32.5

Gonorrhoral pus, coloration of granules benzidin-nonosmlplite of soda, 542 Gout, 170

allinity of tissue for uric acid in, 176

and alcololism, 186

alkilinity of tissues in relation to mic acid deposit in gout, 184 and chronic lead poisoning in. 186 curve of uric acid excretion in acute exacerbations of, 174

delaved transformation of nucleins in, 174

experimentally attempted, 185 geographical distribution of, 187 gluain, 150 
Gout, localization of uric acid depositions in, 182

meat diet, excessive, influence of, in, $18 \pi$

and nephritis, 175 plumbism, 186

production of, experimental attempts, 185

protracted nucleinic acid feeding in, 187

specific sulstances in, 172

tissue alkalinity influencing deposits in, 184

treatment, dietary, of, 192

medieinal, of, 191

radiun in, 188

water, alkaline, in, 184

uric aeid curve in acute exacerbations of. $17 t$

decomposition rednced in, 173

formation increased in, 171

in blood in, 170

retention in, 176

solubility of, 181

in alkaleseence variations, 178

complex conditions of, 181

nueleinie acid in 1 nencing, 180

Gouty tophi, localization of. 18?

Grafe's head respiration apparatus, 515

Gross method of trypsin estimation, 46

Growtl, diet in, 497

laws of, 524

and maintenance metalolism, 514 urinary purin, 15:3

Gruitzner's method of estimation of pepsiu. 21

of trypsin, 47

Guaiac reactions with peroxides, 536

Guaiaconic acid reactions. 537

Guanase, 149

lack of, in economy of log, 150

Guanidin-acetic acid, 131

methylation of, in produetion of ereatin, 1:3

Guanin. 149

conver-ion into urie acid, 148

gout in $\log , 150$

Giinzberg's method of acid determination in gastric juice, modifieations of, 12

Hiemase, 556

\section{$\mathrm{H}$}

Hrematin, 58.3

Hæmatoporphyrin, 547

Hæmic sugar, 203
Hæmochrome, 581

Hiemochromogen, 583

Hæmoconiosis, 369

Hæmoeyanin, 545, 547

Hiemerythrin, 547

Himoglobin, 579

composition of, 583

erystallized, 579, 581

individuality of, 580,581

iron in, importance of, 582

molecular weight of, 582

peroxidase-like aetion of, 543

and peroxidases, differences between, 544

oxygen fixation by, Bohr on, 591

Henri on, 591

Hïfner's formula for, 591

Manchot on, 591

Ostwald on, 592

capacity of, physicalelremical conception, 590

capacity of, salts influeneing, 590

capacity of, temperature influeneing, 589

variability of, 579

Hixmoglobinometry, Plesch's improvement in, 586

Haldane and Smith method of blood gas analysis, 585

Hamster, gastric digestion in, 20

Hammersclilag's method of estimating pepsin, 21

Haptogenic membranes of milk globules, 428

Haskin's method of urea estimation. 106

Heart, activity in alpinism, 602

diastase content of muscle of, 216 gas exchange of, 575

and lung preparation of Starling. 256,340

surviving, glycolysis in, 2.56, 337. 340

Heat centre of brain, 627

in fever, antipsretic reducing exeitability of, 630

elimination in fever, 615

produeing substances, 6.30

production of anthrachinone, 632 chemically definite substanees, 632

and combustion processes. 610

of fever, muscular activity involved in, 610

and glrcogen, 225

by particulate liodies introduced into blood, 631

protein, speeific-dynamic action of, in, 492, 52! 
Heat production by purin, 632 tetrahydronaphthylamine, 633

regulation in fever, chemical and physical, 626

fixation of, at higher level, 628

by nervous system, 627

regulating centres, increased exeitability of, 630

Hemielastin, 55

Henri's method of estimation of trypsin, 46

Henri on oxygen fixation by hæmoglobin, 591

Henriques and Gammeltoft's method of urea estimation, 107

Henriques and Sörensen's method of hippuric acid estimation, 113

Henriques and Sörensen's method of aminoacid estimation, 120

Hepatic affections, high molecular residual substances in urine in, 147

diastase, 214

diseases, lævulose tolerance decreased in, 283

functional tests, 116, 129

protagon, 410

Heteroxanthin, 167

Heubner method of spectrophotometry of blood, 586

Hexahydrobenzoic acid, dehydration in to benzoic acid, 469

Hibernation, metabolism in, 117, 506

Hippuric acid, 107

elimination in carnivora and man, 109

estimation, quantitative, 113

formation in herbivora, 109

His's method of uric acid estimation, 168

Histidin and diazoreaction, 146

in construction of urochrome, 141

Histozyme, 109

Hoffman's experiment in fat formation from protein in fly larvæ, 413

Holmgren's method of determining $\mathrm{HCl}$ of gastric juice, 13

Homogentisic acid, disruption of, 470

Hopkins' method of uric acid estimation, 168

Hormones of internal secretory glands, classification of, 313

Hryntschak's method of hippuric acid estimation, 114

Huifner formula for oxygen fixation by hæmoglobin, 591

Human diabetes, 263

Hunger, see also Fasting and Starration

metabolism in, 499

sensation of, 507
Hunger and thirst, endurance of, 499

Hydrochinon, hydroxylation derivative of phenol, 468

Hydrochloric acid, fixation in gastric contents by protein substances, 14

ionic theory in explanation of formation in stomach, 11

origin of gastric, 9

Hydrocyanic acid, 98

poisoning, thiosulphates in, 477

Hydrogen and nitrogen in metabolism, elemental, 520

Hydroxylamine method of sugar estimation, 206

Hydroxylaminoacetic acid, 100

Hyperinosis in fever, 622

Hypergiycemia in diabetes, 266

absence of, in phloridzin diabetes, 275

Hyperthermia, see Fever, Heat

Hyperthyroidism and diabetes, 312

lowering of glucose tolerance by, 312

Hypoglycæmia in Addison's disease, 306

Hypophyseal obesity, 316 -

Hrpophysis, relation to other internal secretory glands, 316

extirpation of, suppressing adrenal glycosuria, 315

glycosuria from extracts of, 314

relation of, to carbohydrate metabolism, 314

Hypoxanthin, 149

\section{I}

Iceland moss in diabetic diet, 271

Imidazol nucleus, 158

Imidoazol compounds in diazoreaction, 145

Imidoazolaminoacetic acid, 146

Imidoazolaminopropionic acid, 146

Imino-allantoin, 165

Immunity against trypsin parenterally introduced, 48

Inanition, see Fasting

Indigo, action of benzaldehyde on, 534

Indol, hydroxylation of, into indoxyl, 468

Indophenol blue injections, 551

oxidases, 550

synthesis, 550

Indoxyl, lyddroxylation derivative from indol, 468

Infant, calory computations of food for, 523

energy computation in, 523

fat of naturally and artificially fed, 383 
Infant feeding, importance of food supply of nurse, 425

glycuronic acid in urine of, 322 lactosuria in, 285

Infectious diseases, autolysis from toxins of, 85

Infusoria, ability to digest fats by, 403 importance of, in digestion of cellulose, 204

Inosite, 458

Intermediate metabolism, 75

Internal secretion of pancreas. conviction of, by lymph, 252

evidence from blood transfusion and parabiosis, 252

secretory glands and carbohydrate metabolism, $300^{\circ}$

Eppinger-Falta schema of interrelation, 313

Eppinger-Falta schema of interrelation, Aslner's modification, 316

hormones of, classified, 313

interaction of, 312

specific and indirect effects of removal of, 312

Intestinal juice, reflux into stomach of, 35

loop method of study of intestinal resorption of fats, 358

respiration, 598

villi, Pavy's theory of transformation of carbohydrate into fat by, 377

Intestine, absorption of products of protein cleavage in, 53

absorption from, influenced by disease and by age, 54

carbohydrate clearage in, I9j

chyme into, passage of, 33

digestion of proteins in, 50

digestion of proteins in, extent of 52

fat cleavage in, 366

gas exchange of, 577

Goldschmiedt's reaction in affections of, 322

glycuronic acid in diagnosis of affections of, 322

permeability of wall of, 54

proteins and protein derivatives passing through the wall of, 54

Intoxications and glycogen, 225

Introduction, 1 glycuronic acid excretion. 320

Innlin in diet of diabetes, 271

glycogen formation from. 230

Invertase in blood serum, 218

Invertin in carbohydrate metabolism. 195
Iodine method of determining $\mathrm{HCl}$ in gastric juice, 13

reaction for peroxidases, 539

stimulating autolysis, 91

Iodized fats, deposit of, 381

proteins, absorption of, 57

Iodoform method of determination of acetone, 448

Ionic theory of hydrochloric acid formation in stomach, 11

Iron, importance in hæmoglobin of, $547-583$

Islands of Langerhans in diabetes, degeneration of, 263

Isoamylalcohol, 467 function of, 249

Isoamylamine, 467

in production of acetone bodies, 438

Isobutyric acid, 426

intoxication, 434

Isodynamics, law of, 529

Isovaleraldehyde, acetone formation from, 438

Isovalerianic acid, 426

acetone formation from, 433 , 467

\section{J}

Jacoby's method of estimation of trypsin, 46

Jaffe's creatinin reaction, 123

Jaundice and urinary purin, 153

Jecorin, 209, 410

Jolleg' test for pentoses, 292

\section{K}

Karnitin, 133

Fetonic acids, transformation into aminoacids, 69

Kidney to adrenal diabetes, relation of, 302

chondroitin-sulphuric and nucleinic acids increased in urine in diseases of, 147

and creatin-creatinin production, 129

fat formation in, 420

fatty degeneration of, 419

infiltration of, 420

impermeability to sugar, normally of, 259

and liver, gas exchange in, 576

in phloridzin diabetes, rôle of, 276

secretory ability of, inhibition of glycosuria by altering the, $26^{\circ}$ ?

peritoneal irritation altering, 262

sugar formation in phloridzin diabetes in, 277 
Kisch's method of diastase determination, 213

Knapp's method of sugar estimation, 206

Knoop's theory of catabolism of aliphatic fatty acids, 392 decomposition of ligher fatty acids, 427, 464

fat catabolism, 433

Kowarski's method of uric acid estimation, 168

Krïger and Schmid's method of uric acid estimation, 168

Kumagawa-Suto's methou of sugar estimation, 206

\section{L}

Lab-ferment, 14, 26

separation from propepsin, 23

Lab-process, bacterial involvement in, 30

physiological pupose of. 30 ultramicroscopy of, 29

Laccase, .j48

Lactacidogen, 4.56

Lactam and lactim forms of mates, 179

Lactase in intestine. 195

Lactation and lactosuria. 284

Lactic acid, I.55, 239. 341.452, 474

and autolysis, 457

determination, Ryfle el's method, 455

in fat formation from carbolyydrate, 390

f a t-pirotei n combination, agency in separation of, 371

fermentation by lactolase 328

in glucose catabolism. 345

fermentation, $34 \mathrm{~s}$

and muscle activity, 454

and muscle, amount of, 454

and oxybutyric acid, deter-

mination togetler of, 455

postmortem formation of, 456

quantitative determination by v. Fijrth and Charnass method of, 4.52

quantitative determination by v. Fiirth and Charnass method of, improvements in, by Emloden laboratory, 4.54

production from glycerinaldehyde of, 460

production from sugar (racemic acid as intermediate product), 462

and rigor mortis, 4.59
Lactic acid, sources of, 456

and sugar, interchange of, 461

in synthesis of uric acid, list urine, 462

Lactokonids, 29

Lactolase, 328

Lactose, fate of parenterally introluced, 197

Lactosuria, 284

in clildbed, 284

infants, 285

and lactation, 284

Lxvulose in amniotic fluid and urine of calves, 283

assimilation in diabetes of, 225

detection of, 281

glycogen formation from, 228

Seliwanoff"s test for, 281

tolerance of, lowered in hepatic rlisease, 283

transformation of glucose into, 282

Levulosuria, 281

alimentary, 283

in pregnancy, 283

pure, 283

urogenous. 282

Langerlans, degeneration of islands of, in lumman diabetes. 263

islands of, function of, $2 \frac{19}{2}$

Lanolin. unabsorbability in intestine of, 3.54

Lauric acid, 426

Law of conservation of energy influencing study of nutrition. 2

constant expenditure of encrgy, 5.5

growtl, $5: 24$

isodynamics. $5 \geq 9$

length of life, Rubner's, 52.5

peptic fermentation. 22

tryptic fermentation, 47

Lead poisoning and gout, chronic, 186

Lecithin as activator of steapsin, 363

in blool in diabetes, 374

Lefèvre and 'Tollens' determination of glyeuronic acid, ::25

Leucin, (il, $111,467,473$

acetone bodies from, $43 \mathrm{~S}$

benzoyl-, 111

catabolism of, 466

sugar formation from. 239

Leucocytes, diastase from, 216

glveogenic content of, in diabetes, 254

in hamic glycolrsis, 339

lipase from, 403

proteolytic ferments from, si

Leucomalachite green method of detection and estimation of peroxidases, 541 
Leucoprotease, 57,88

Leukxmia and urinary purins, 153

Liebig's method of urea estimation, 106

Life in cell organization, 571

Rubuer's law of leugth of, 525

Lipæmia, 368

and acetone bodies, 374,432

and acidosis, 374,432

of diabetes, 270,373

and diabetic coma, 373

dietary, 377

in fasting. 504

fetal, 376

from mobilization of fat deposit, 372

and narcosis, 374

of obese alcololies, 377

pathological. $37: 3-374$

of salmon, 373

Lipase of blood, 401

distiuguished from pancreatic lipase, 402

leucocytes, 403

pancreas, 359

reverse ferment action of, 36.5

of stomacl. 350

tissue-activation of, 404,405 cliaracter of, 405

vegetable, 406

Lipogenic diabetes, 269

Lipoid, importance in nutrition of, 379

essential in mutrition, 490

solvent power of bile upon, 367

steatosis, 422

Lipoidremia in diabetes, 373

Lipolytic ferment in blood, $\frac{101}{2}$ of pancleas, 3.5?

stomacl, 350

tissues, 403

function of blood. 370

Lipoproteids, 412

Lipuria, 375

Liver, of acute yellow atropliy, a utolysis in, 83

ammonia elimination in diseases of, 102

and creatin-creatinin production, 129

in chloroform poisoning, autolysis in, 84

cirrhosis, urinary purin in, 153

in diabetes, human, 264

diastase of, 214

blood from, 218

diastasic power in pancreatic diabetes, 253

exclusion of, 101

fat storage in, 386

finctional tests of, $116,129,286$. 323

galactosuria, alimentary, in affections of, 286
Liver, glycogen content of, in human diabetes in, 2.53

and diseases of, 225

formation in pancreatic dia. betes in, 25.3 perfused, 226 phloridzin influencing, 278

supply, disappearance of, $2: 4$ glycuronie acid in diagnosis of affections of, 322

and kidney, gas exchange of, 576 oxidizing function of, in catab-

olism of ligher fatty acicls, 385

in phosphorus poisoning, 410

fat accumulation in, 415

of pregnaner, 417

sugar formation in pancreatic diabetes from carbohrdrate-free material in, 253

sugar puncture, adrenin, etc.. affecting diastase of, 214

urea formation in, 100, 101

Living and dead protein, 569

tissues, digestion, in stomach, of, 25

London's studies upon protein digestion. 70

Jïw"s active protein, 569

Iudwig and Salkowshi metlod of estimation of uric acid. 168

Lungs, extirpation, partial, of, .596

pas interehange in, 579,595

oxygen secretion in, 596

respiration by, 594

I.ysin, 119

\section{M}

Mlaintenance excliange, 502, 520 metabolism and growth, 514

Mammary gland, phloridzin influencing, 279

Nalonic aeid in urie acid synthesis, 156

Maltase. 229

in blood, 197, 218

intestine, 195

Maltose, 196

assimilation of, $\mathbf{2 2 9}$

in blood, 209

glycogen formation from, 229

parenterally introduced, 197

Man an exception to Rubner's laws of growtl, 525

Manchot on oxygen-fixation by hiemoglobin, 591

Mandelic acid-esters, 406

Nanganese as catalyzing agent in sugar catalysis, 343

peroxide, 536

Marsh-gas fermentation in inte-tine, 202 
Mass action, 592, 593

Mastlipæmia, 377

Meat diet in gout, excessive, 18

Meat reaction in urine, 135

Medicinal treatment of diabetes, 272

Medulla oblongata, carbohydrate regulating centre in, 313

Melanin, 141, 544, 554

Melanin-like products in urine, 141

Melituria, mixed, 282

Mendel's schema of creatin-creatinin elimination, 125

Menstruation and creatin metabolism, 130

Mercuric cyanide method of determining acetone, 448

Mercuric cyanide method of determining sugar, $206^{\circ}$

Mercury stimulating autolysis, 91

Mesityl oxide, detoxification by sulphydril, 478

Messinger-Huppert method of acetone determination, 448

Metabolic equilibrium, Tigerstedt's formula of, 527

increase after food ingestion, 529 extent of, 529

minimum, 483

nitrogenous end-products, elimination in fever of, 619

velocity in fever, 612

Metabolism, carbohydrate

internal secretory glands in, 300

regulation by adrenal, 301-

fat, 378 309

in fever, 610

frugality of body in chronic febrile conditions in, 614

intermediate, 75

and internal secretory glands, 316 minimal, 483,521 in alpinism, 607

protein, maintenance by protein derivatives, 72

MTetals, colloid, 547, 548, 556

Methæmoglohin, 580, 583

iron in fever combination in, 583

Methane in intestine, 202

Methylbutyric acid, 439

Metlyyl-glyoxal in glucose catabolism, 345

Methyl-guanidin, 133

Methyl-phenyl hydrazine osazone, 282

Methyl-pyridylammonium hydroxide, 132,476

Methyl-pyridin, 133

Methylated purin derivatives, 166

Methylation process in metabolism, 132

Methylene blue, injections of, into living tissue, 565
Mett's method of pepsin estimation, 21

Meyer's theory of blood glycolysis, 339

Mieroörganisms in curdling of milk, 30

intestinal digestion of cellulose, 202

formation of higher fatty acids, 413

Microrespirometer of Thunberg, 574

Milk, casein of, 429

curdling, bacterial involvement in, 30

ultramicroscopy of, 29

lower fatty acids in, 426

modification of fats from food of nurse, 424

haptogenic membrane of, 428

Milk-fat, origin of, 423

from carbohydrates of food, 425

from fat of body, 424

from fat of food, 424

Mineral water in diabetes, 272

gout, 179,184

obesity, 397

Minimal metabolism, 483, 521 protein, 484

"Mock feeding," 3

Monomethylxanthin, 167

Monosaccharides, resorption of, 197

Monte Rosa expeditions, 600

Mörner-Sjöquist method of urea estimation, 106

Mosso Institute, 600

Mountain sickness, see Alpinism

Mouse cancers and treatment by col. loidal methods, 90

Mucin, 233

digesting ferment of pancreas, 43

Muconic acid, disruption derivative from benzol, 469

Muiller's method of determining $\mathbf{H C l}$ of gastric juice, 12

Museular activity and purin metab. olism, 153

Muscle as source of creatin, 128 creatin content of, 128,131

diastase, 215

gas interchange of, 574

glycogen in, 224

glycolysis in surviving, 337

glycolytic ferment in, 332-334

hyaline degeneration of, in fever, 617

juice and pancreatic extracts, glycolysis from, $332-334$

lactic acid in, 454

Muscular influence on heat production in fever, 611

rest, 521

tonic contracture, 128

Myelinosis, 422 
Myeloid cells, absence of lipase from, 403

Myristic acid, 426

Myxœedema, 311-316

\section{$\mathrm{N}$}

Naphthaline, hydroxylation into naphthol, 468

Naphthol, hydroxyl derivative from naphthaline, 468

Naphthoresorein test for glycuronic acid, 324

Narcosis and lipæmia. 374

Nareotics, autolysis from the cellular changes from, 84

Nationalities, protein requirements of, 486

Nephritis and gout, 175

Nephrotoxins suppressing adrenal diabetes, 303

Nerve, sympathetic glycosuria from irritation of, 304

Nerrous stimulation of chorda tympani and sugar of submaxillary salivary gland, 278

mechanism of gastric secretion, 4 pancreatic secretion, 36 system in temperature regulation, 627

tissue, gas exchange of, 575

oxygen requirements of, 575

Neuberg's test for glycuronic acid in urine, 324

Ninhydrin reaction, Abderlıalden`s, 96

Nitrobenzaldehyde, 111

reduction to acetylaminobenzoic acid, 471

Nitrobenzol, reduction to aminophenol, 471

Nitrogen balance, 491 and protein ingestion, 493

elimination in fasting, 503 fever, 616

exchange in fasting and minimal nitrogen metabolism, 504

metabolism, minimal, 504

rest, 58

retention in alpinism, 608

urinary rest-, 136

and hydrogen as element in metabolism, 520

Nitrogenous end-products, elimination in ferer of, 619

Nitrophenylhydrazine method of determining acetone, 448

Novain, 133

Nuclear destruction and urinary purin, 152

Nucleases, 76,150

Nucleins, delayed transformation in gout of, 174

Nucleinases, 152
Nucleinie acid in urine, 147

combination of uric acid infiuencing solubility of uric acid, 180

feeding and gout, 1S7

parenterally introduced, fate of in mammals, 159

Nucleosides, 151

Nucleosid deamidases, 152

Nucleotids, 152

Nucleotidases, 152

Nurse, importance in feeding infants of food of, 424, 425

Nutrition on diet of elementary foodstufts, 495

parenteral, 508

Nutritional requircments, $4 \$ 2$

value of different proteins, 493

products of advanced protein cleavage, $\mathbf{6 4}$, 67

\section{0}

Oatmeal diet in diabetes, 271,442

Oats starch, action of diastase on, 219

Obesity, 378

diabetogenous, 270

gas exchange in. 394

hypophrseal, 315

metabolism in, 394

nature of, 394

and overfeeding, 396

thyroid medication in, 398

treatment of, 397

Occupation determining food requirements, 483

Esophageal fistula, 3

Oil, cod-liver, 389

subcutaneous introduction of. 379 test breakfast, 35

Orcin test for glycuronic acid in urine, 324

Organs, Colnheim's respiration apparatus for isolated, 573

methods of respiration, study of isolated, 571

Ornithin, 118,478

detoxifying influence of, 112

and glycocoll, conjugation of benzoic acid with, 478

Ornithuric acid, 113, 478

Osborne-Mendel diet in rats, 496

Ostwald on oxygen fixation by hæmoglobin, 592

Ovary, relation to internal secretory glands, 316

Overfeeding and obesity, 396

Oxalic acid and sugar catabolism, 320 originating from various substances. 321

Oxaluria, 320

Oxidase-like action of hæmoglobin and iron, 547 
Oxidases, 76,534

direct, 538

indirect, 538

in purin metabolism, 152

and respiratory coloring sub-

stances, 547

summary of, 552

Oxidation of fatty acids and aliphatic side chains, Friedmann and Dakin schema of, 464

ferments, 534

processes, 534

processes in diabetic economy, 257

of nitrogenous substances, vital, 99

and reducing powers of tissue, importance of sulphydril to, 566

Oxidizing processes in diabetes, 257

Oxyacridon, oxidation derivative of acridin, 469

Oxybutyric acid, 431

from aldol, 391, 435

and aceto-acetic acid, reversibility of, 446

bromine-crotonic acid method of quantitative determination, 450

catalytic enzyme action on, 447

colorimetric estimation of, 450

Darmstiadter's method of quantitative determination, 449

in diabetic coma, 440

determination, quantitative, of, 449,450

from fat catabolism, 393

in febrile urine, 620

and lactic acid, determination of, together, 455

in normal metabolism, 436 , 446

polarimetry of, 449

Schaffer's method of quantitative determination of, 450

from shortening of long fatty acid chains, 439

by synthesis from tyrosin, 439

Oxygen absorption, invasion and evasion coëfficients of blood, 587

consumption in blood, 567

measurement of, in estimation of peroxidases, 541

fixation capacity of blood, influence of carbonic acid pressure on, 589

fixation capacity of blood, influence of salts on, 590

fixation capacity of blood, influence of temperature on, 589
Oxygen fixation capacity of blood, maxinum, 5s8

fixation capacity of blood, physical-chemical conception of, 590

fixation by hæmoglobin, 591, 592 requirement of nervous tissue, 575

secretion, 596

tension curves of blood, 588

Oxygenases, 536

Oxyhæmoglobin, composition of, 583

peroxidase-like action of, 539,543

Oxyisovalerianic acid in formation of acetone bodies, 438

Oxyisophenylacetic acid in diazoreaction, 145

Oxyphenylacetic acid, 145

Oxyproteic acid, 137

elimination and sulphur elimination, 145

elimination of, and tissue destruction, 145

fractionation of, 137

in normal and pathological conditions, 144

quantitative determination of, 143

Ozonization of corporeal oxygen, Schönbein's theory of, 534

\section{$\mathbf{P}$}

Panchrmotic dog, 70

Pancreas, activation of steapsin by salts of biliary acids, 363

adaptation to cleavage of milksugar, 197

in adrenal diabetes, 310

adrenals and thyroid interaction of, 313

in blood glycolysis, 339

carbohydrate digestion and resorption, 196

degeneration of, in human diabetes, 263

extirpation, interrupted, of, 248 partial, of, 260

of, section of cord and nerves influencing, 249

in fat digestion, 359

in fat metabolism, theory of influence of, 361

in glycolysis, 332

internal secretion of, 252

islands of Langerhans of, 249

renal impermeability to sugar influenced by, 259

rôle of, in production of blood diastase, 217

in carbohydrate digestion, 195,196

mucin-splitting ferment of, 43

peptone-splitting ferment of, 43 
Pancreas, proteolytic ferment of, 33 relations of, to other interual secretory glands, 316

Pancreatic activator of glycolytic ferment, 332

diabetes, diastasic power of liver in, 247

discovery of, 247

glycogen formation in liver in, 253

metabolism in, $25 \mathrm{~s}$

sugar consumption in, 259

elimination in, 259

formation from carbolydrate-free material in liver in, 253

digestion of proteids, 33

erepsin, 43

fistula, 35

hormoue, 261

internal secretion activating glycolytic enzyme, 256

juice, influence on fat digestion, 359

obtaining, for diagnostic pur poses, 35

reflex into stomach of, 35 ,

proteolytic fermentation, law of, 47

secretion, actiration of, 41

adaptation to foods of, 46

nervous mechanism of, 40

stimuli to, 36

nervous, to, 38

from secretin, 37

steapsin, question of complexity of, 364

Paraamidophenol, hydroxyl derivative from aniline, 468

Paracasein, 28

Parachymosin, 2S

Paraffin, non-absorbability of, in intestine, 354

Parahæmoglobin, 580

Parahydroxyphenylacetic acid, derivation of, from parahydroxyphenylethylamine, 467

Parasites of alimentary canal, resistence of, to digestion, 24

Paratlyyroids, glucose assimilation lowered by removal of, 311

relation to other secretory glands, 316

jemoval of, 311

and thyroid, differentiation between, 311

Paraxanthin, 167

Parenteral absorption of fat, 379

feeding with fat, 513

introduction of protein, 62, 508

dangers of, 510

protein cleavage products, 510
Parenteral introduction of sugar, 511 trypsin toxicity of, 48

i $m$ in u $n$ i zation against, 48

Pavy's theory as to production of fat from carbohydrate by intestinal villi, 377

Pawlow's metlood of diastase estimation, 212

Pawlow's mock-feeding, 3 csophageal fistula, 3 pancreatic fistula, 35 ventriculus, 4

Pentamethylene diamine, 118

Pentosans in plants, $28 \mathrm{~S}$

Pentoses, detection of, 292

in electrolytic cleavage of glucose, 344

glycogen formation from, 230

syutlietic production of, in pentosurics, 291

in tissue construction, 288

vegetable, in metabolism of herbivora, 289

Pentosuria, 288

alimentary, 289

chronic, 290

in diabetes, 289

Pepsin, 14, 20

adsorption by elastin, 23

determination, quantitative, of, 21

isolation of, 20

methods of estimation of, 21

passage of, into intestine, 23

and rennin, quality of, 31

separation from gastric juice by means of elastin, 23

Peptic digestion, comparative, 19 preparatory to tryptic diges. tion, 17

fermentation, law of, 22

Peptoids in gastric digestion, 16

Peptolytic power of blood-serum, 95 tissue ferments, 75

Peptones, action of erepsin in, 16, 50 sugar formation from, 237

Peritoneal irritation, kidney secretion altered by, 261, 262

Peroxidases, 536

artificial, 547

and catalases, 559

in cells, 539

detection of, by oxidation of formic acid, 540

doubt as to ferment character of, 548

and hæmoglobin, differences betrveen, 544

leucomalachite green method of detection and quantitative est $\mathrm{i}$ mation, 541 
Peroxidases, limits of availability of methods of estimation of, 542

measurement of oxygen consumption in estimation of, 541

purpurogallin method of detection, 540

sources of error in study of, 537

Peroxidase-like action of hæmoglobin, 539,543

Persodin in phenol poisoning, 477

Pettenkofer type of respiration apparatus, 514

Pflüger's living protein, 569

method of glycogen estimation, 221

on fat formation from protein, 407

on sugar formation from protein, 233

Pfliiger-Bleibtreu-Schöndorf method of urea estimation, 106

Phenol, derivation from benzol, 468

detoxification by sulphuric acid in body, 477

hydroxylation into hydrochinon, 468

poisoning, persodin in, 477

Phenol-glycuronic acid, constitution of, 318

Plienolphthalin method of detecting peroxiclases, 540

Phenylacetic acid, 478

Phenylalanin, 108, 473

catabolism of, 467,470

in production of acetone bodies, 439

Plienylaminoacetic acid, 47.5

Phenylaminobutyric acid, 475

Phenylglyoxylic acid, 475

Plienylhydrazinsulphonic acid method of sugar estimation, 207

Phenylpropionic acid, 108, 112 oxidation of, 465

Phenylpropionylglycocoll, 112

Philocatalase, 561

Philothian, 565

Plloridzin, 275

action of, on mammary gland; 279

fat impoverishment from. 243

fate in body of, 280

influencing glycogen formation in liver, 278

-diabetes, 275

glutaric acid preventing glycosuria of, 281

hyperglyesmia absent in, 275

livpoglycemia of, 275

kidney in, 276

mechanism of, 280

metabolism in, 279

sugar formation in kidney in, 277
Phloroglucin in detection of glycuronic acid, 324

Phorone, detoxification by sulphydril, 478

Phospliates in sugar catalysis, 342

Pliospliatids of tissue as reducing agents, 567

Phosphoric acid in alcolıolic fermentation of sugars, 347

Phosphornucleases, 151

Phosphorus poisoning and acetone bodics, 432

autolysis in, $8:$ :

fat collection in liver in, 415

and fat phanerosis, 84

hemic changes in, 84

liver in, 84,410

and urinary purin, 153

Plitlialic acid, parenteral introduction of, 468

Picraminic acid, reduction product of pieric acid, 471

Picric acid, reduction to picraminic acid, 471

Pike's Peak expedition, 600

l'ilocarpin stimulating pancreatic secretion, 41

acting on glandular activity and urinary purin, 153

Placenta, fat passage through, 376

Plants, fat catabolism in, 391 sugar formation from fat in, 246

Plasteins, 31

possible application in synthesis of protein digestive products, 61

Plesch's improvement in hæmoglobinometi'v, 586

Plumbism and gout, 186

Pnein, 563

Pneumonia, chondroitin-sulphuric and nucleinic acids in urine of, 147

Pneumonic and other exudates, autolysis of, 85

Polarimetric estimation of sugar, 206

Polarimetry of oxybutyric acid, 449

Polyfistulous dog, 70 action of erepsin on, 50

Polypeptids, tryptic action on, 45 racemic, splitting of, by proteolytic ferments, 93

Polysaccharides, assimilation of, 229 fate of, in alimentation, 197 glycogen formation from. 229

Potassium as catalytic agent in sugar catalysis, 343

l'otato starch, diastase acting on, 219

I'regnancy, Abderhalden's test in, 96 lævulosuria in, 283

Prochymosin, 28

Propepsin, 23

separation of, from lab-ferment, 23 
Prosecretin. 3S

Protagon, hepatic. 410

Protamines acted on by arginase, 10.

Proteases, is

Protective ferments of Abderlalden in blood, $21 \mathrm{~s}$

Proteic acid, fractions of, 135

Proteid substances in body, variety of, 73

Proteins, absorption from intestine, $54.5 \overline{5}$

of iodized, 57

ammonium salts in synthesis of, 57

carbohydrate group in, 233

catabolism in metabolism, relocity of, $49 \mathrm{~s}$

cleavage products, absorption of, in intestine, 5:3

parenteral introduction of, 510

as source of acetone bodies, 437

value of, 64

value of, in sick-room diet, 60

constancy of tissue, 493

construction from aminoacids, 493

derivatives and proteins in blood, 54

and derivatives, pyrogenic properties of, 630

destruction in diabetes, $267-269$

in fever, 616

in ferer limitation of, by carbohydrate feeding, 618 in phloridzin diabetes, 279

sugar elimination in relation to, 234

supply of fat influencing. $37 \mathrm{~s}$ digesting tissue ferments, $\overline{7} 5$ digestion and assimilation, sum. mary of, 72

in intestine, $50-52$

products, spnthesis of, 60

in stomach, 15, 53

ecollomics in fasting, 503

effects of excessive, 492

exchange in fasting, 503

extent of digestion of, in stomach. 15

extent of digestion of, in intestine, 52

fat production from. 406

adipocere, 414

in cheese ripening, 415

Hoffman's fly larva experiment, 413

Pfliger's views on, 407
Protein feeding with products of adranced cleavage of, 64

glucose formation from, 23

in heat production, 492

leterospecific and homospecific, 493

ingestion of lieterospecific and homologous. 494

ingestion and nitrogen balance, 493

living and dead, 569

metabolisın, maintenance of, by protein derivatives, 72

stimulation of, by urea subcutaneously introduced, 499

minimal, 484

pancreatic digestion of, 33

parenterally introduced, 62, 503 danger of, 510

physiological value of different, 493

requirement, $4 \mathrm{St}$

in different types of lifework, 486

growing child, 486

low limit of, 488

of nationalities, 486

and total energy requirement, 486

specific drnamic action of, 492 . 529

sugar formation from, 233,238 respiration experiments upon, 236

Weinland's experiments on. 237

surface development and protein volume of body, 521

synthesis from ammonium salts, 67

products of adranced protein cleavage, 63

tissue and circulating, 491

of plants, mechanical means of utilization of, 490

Proteolysis, inhibition of, by products of protein clearage, 94

Proteolytic ferments, bacterial, 87 classification of, $9+1$ gastric, 20

leucocytic, 87

pancreatic, 41

of tissue. 75,87

A bd er ha ld e u's studies of, 91, 218 detection of, 87,92 detection of, by glycyltyrosin, silh peptone and glycyltryptophane. 92 detection of, optical metlod, 92 
Proteolytic ferments of tissue, optical determination of, 92

Protoplasmic poisons producing allantoin, 159

Pseudopepsin, 23

Pseudoperoxidase, 544

Psychic influences on gastric secretion, 5 secretion of stomach, 3

Ptyalin, 194

Puerperium, lactosuria of, 284

Pulmonary extirpation, partial, 596 respiration, 594

Puncture, sugar-, 296

Purin deamidases, 152 decomposition in intestine, 164 endogenous and exogenous, 148, 152

fate of parenterally introduced, 162

as heat-producing material, 632 metabolism, 148

enzymes concerned in, 149

in mammals, allantoin as end-product of, 158

and muscular activity, 153

in monkeys, 164

pathology of, 170

methyl derivatives of, 166

nucleases, 151

nucleus, 157

oxidases, 551

sonthetic formation of, in mammals, 157

urinary, in disease. 153

and nuclear destruction. 152

Purpurogallin method of detection of peroxidases, 540

Putrescin, 118

Pylorus, closure of, from influence of intestinal contents, 34, 351

influence of fat upon, 351

mechanism of action of, 33

Pyridin, 132, 476

compounds, 133

-leucomalachite green method of blood detection, 546

Pyrimidine nucleus, 157

Prrogenesis from chemically definite substances, 632

proteins and protein derivatives, 630

purins, 632

Pyrogenic substances, 631

Pyromucic acid. 478

Pyroracemic acid in glucose metabolism, 345

Quinic acid, dehydration into benzoic acid, 469

employed in treatment of gout, 191
Quinolin, oxidation into quinolinquinon, 469

Quinolin carboxylic acids in gout treatment, 191

Quinolin-quinon, oxidation derivative of quinolin, 469

\section{$\mathbf{R}$}

Racemic acid, 474

intermediate product in catabolism of sugar to lactic acid, 462

Radium stimulating autolysis, 91

Radium therapy in gout, 188

Rectal feeding with digestion products, 66

Red blood-cells, sugar content of, 210

Reducing components of tissue, 565

influence of tissue phosphatids, 567

and oxidizing powers of tissues, importance of sulphydril to, 566

power of tissues in fever, 615

processes in body, 471

Reductases, 565

Reduction methods of sugar estimation, 206

Reductonovain, 133

Refrigeration glycosuria, 299

Regnault and Reiset type of respiration apparatus, 515

Renal diabetes, 276, 303 glycosurias, 295

Renuet ferment, 26

Remmin and pepsin, duality of, 31

Reptiles, gastric digestion in, 19

Resorption, see also Absorption

of carbohydrate products from intestine, 197

from stomach, 17

Respiration, accessory, 563

anærobic, 329

apparatus for aquatic animals, 519

Benedict's transportable, 518

Douglas' 518

Grafe's, 518

for isolated organs, Cohnheim's, 572

Pettenkofer's, 514

Regnault and Reiset type of, 515

Ruloner's 519

for small animals, 518

Thunberg's microrespirometer, 574

Zuntz and Geppert type of, 517

calorimeter, Atwater and Benedict's, 516 
Respiration cardiual, 563

changes of, in alpinism, 603

cutaneous, 596

experiments on conversion of carbohydrates into fat, 387

in diabetes, 271

intestinal, 598

of isolated organs, methods of study of, 571

peritoneal, 598

pulmonary, 594

tissue, 563

Respiratory coloring substances, 547 diseases, glycuronic acid excretion in, 320

quotient in diabetes, 242 fasting, 506

fever, 614

Rest, grades of, 521

Rest, nitrogen, 58 urinary, 136

R. G. T. rule in fever, 612

Robertson's method of estimation of trypsin, 46

Röntgen rays in diabetes increasing glycosuria, 269

and urinary purin, 153

Rosenfeld's experiment as to source of fat in liver in phosphorus poisoning, 416

Rosenfeld's theory as to fatty degeneration, 417

Rubner's calorimeter, 519

laws of growth, 525

law of length of life, 525

standard calory figures of food, 482,528

figures of food value, 528

Ruminants, gastric digestion in, 20

R. V. T. rule in fever, 612

Ryffer's method of lactic acid determination, 455

\section{$\mathrm{S}$}

Saccharic acid, 258

in electrolytic cleavage of glucose, 344

St. Martin's method of urea estimation, 106

Salaskin and Zalewski's method of urea determination, 106

Saliva, action of, on carbohydrates, 194

Salivary glands, gas exchange of, 576 submaxillary, sugar in, in nervous stimulation, 278

Salkowski's urinary colloids, 147

Salmon, fat mobilization in, 373 inanition studies in, 507 lipæmia of, 373

Salt fever, 633

Salts, influence of, upon oxygen capacity of blood, 590
Sapokrinin, 38

Saturation limit of sugars, 232

Schaffer's method of oxybutyric acid determiuation, 450

Schütz-Borissow law of peptic fermentation, 22

applied to trypsin, 47

Sclerema neonatorum, 383

Sebaceous glands, fats of, 427

Secretin, 36, 37

and cholin, differentiation of, 39

cholin vasodilatin, relations of, 39 gastric, 8

Secretins, multiplicity of, 38

Secretion, gastric inhibition of, 8 psychic influences upon, $\tilde{5}$ stimuli to, 6

of oxygen, 596

pancreatic, 37, 40

Selen-metliyl, 132,476

Seliwanoff's test for lævulose, 281

Seromucoid, 56

Serum, peptolytic power of blood-, 9.5 and blood-corpuscles, carbonic acid exchange, 594

disease, 510

Sick-room diet, advanced proteincleavage products in, 66

Siegfried's carbamino-reaction, 594

Silk peptone in detection of proteolytic tissue ferments, 92

Skin of infants, fats of, 383 respiration, 596

Sleep, loss of, in alpinism, 604

Slosse's schema of sugar catabolism in blood, 339

van Seyke's method of aminoacid determination, 120, 448

Snails, acid production by marine, 12

Soaps, resorption of, in intestine, 357

Sodium bisulphite method of acetone determination, 448

biurate, 178

ellloride retention in fever, 624 as source of gastric hydrochloric acid, 9

hemiurate, 178

mollourate, 178

quadriurate, 178

Solipeds, gastric digestion in, 20

Spectrophotometry of blood, Heubner's method of, 586

Spleen, freighting theory of actiration of trypsin, 4.5

Sprigg's method of pepsin estimation, 21

Starch, action of diastase on various types of, 219

glycogen formation from, 230

hydrolyzation of, increased by electricity, 220

hydrolyzation of, increased by ultraviolet rays, 220 
Starvation, see also Fasting and acetone bodies, 432

endurance of, 499

intluencing fat cleavage in blood, 402

metabolism in, 501

weight loss in, 500

Steapsin, activation of, by biliary salts, 363

question of complex nature of, 364

reactivation of inactive, 36.5

reverse ferment action of, 365

Steatosis, $41 \overline{5}, 422$

cholesterin-ester, 421

Steenbock's method of lipprric acid estimation, 114

Stereoisomeric substances, behavior in bodv, 479

Stereokinases, 480

Stoklasa on zymases in animal tissues, 328

Stomach, acidity of, determination of, 12

autodigestion of, resistance to, 24 bile influencing digestion in, 197 carbohydrate cleavage in, 195 comparative physiology of, 19 contents, passage of, into intestine, 33

digestion of living tissues in, 25 diverticulum of Pawlow's, 4 extent of protein digestion in, 53 extirpation of, Is

fistula of, 3

food as stimulus to secretion of, 6 livdrochloric acid of, 9

hydrochloric acid of, combined, 14 hydrochloric acid of, free, 12

lipase of, 350

movements of, 33

nervous mechanism of secretion of, 4

passage of food into intestine from, 33

passage of intestinal contents into, 34

protein digestion in, 1

psvchic influences on secretion of, 5

rapidity of protein digestion in, 17 resorption in, 17

secretion of, 7

inhibition of, 8

nervous mechanism of, 4

psychic influences, 3,6

and salivary glands, 7

stimulation of, 5,6

taste influencing, 6

ulcer of, 26

Pawlow's ventriculus, 4

Sucré immêdiat and sucré virtuelle in blood, 208
Sucrê virtuelle and glycuronic acid, 322

Sugar acids and glycogen formation, 231

ill aqueous humor, $21 \mathrm{I}$

in blood, estimation of, 205

in blood-cells, red, 210

catabolism from alkali, 341

in blood, Slosse's schema of, 339

glycerin-aldehyde as intermediate product in, 460

in living body, Embden's schema of, 460

and oxalic acid, 320

catalytic agents in catabolism of. 342

centre near liypophysis, 314

in medulla, Bernard's, $2: 25$

consumption in pancreatic dia-

betes, 257,259

destruction in econony, 327

distribution in blood, 210

electrolvtic cleavage of, 343

elimination, relation of fatty acids to, 243

and pancreatic diabetes, 2.5?

and protein decomposition, 234

coëfficient of, Falta's, 268

envelopment in colloids in blood, 209

estimation, methods of, 206

in fat formation, 386

fever, 633

formation, from alanin, 240

from aminoacids, 238, 239

from asparaginic acid, 240

from carbohydrate-free material, 253

from fat, 240

from fat in plants, 246

from fat, D|N quotient. 243

and higher fatty acids. 243

from glutaminic acid, 240

from glycerol, 240

from glycocoll, 240

in kidney in phloridzin dia. betes, 277

from levein. 239

from peptone. $2: 3 \vec{i}$

protein, $233,236,23 \bar{i}, 238$

free, in blood, 207

incomplete oxidation of, Mever's theory, 320

in intestine, dilution of, before resorption, 198

and lactic acid, interchange of, 461

nitrogen quotient $(\mathrm{D} \mid \mathrm{N})$ in re

origin of sugar from fat. 243

origin of glveuronic acid from oxidation of, 319 
Sugal, parenteral feeding with, 511 puncture, 296

and adrenals, 304

eflect of, on glycogen in liver, 225

effect lost after exclusion of adrenals, 305

increase of adreniu in blood, $30 \pi$

condition of adrenals in, 306 saturation and utilization, limits of, 231

as souree of lactic acid, 458

tolerance in hyperthyroidism, 312 parathyroid loss, 311

hypophyseal excess, 314 loss, 315

thyroid deticiency, 311

Sulphanilic acid, 98

Sulphhæmoglobin, 592

Sulphur elimination in protein metabolism, 498

and oxyproteic acid elimination, 145

Sulphur rests and sulphur compounds in hydrocyanic acid poisoning, 477

Sulphuric acid as a detoxifying agent in body, 477

Sulphrdril, importance in relation to autoxidizability and reducing power of tissue, 566

Suppurative processes, proteolytic factor in, 87

antileucoprotease - treatment, 88

Suprarenal and suprarenin, see Adrenal and Adrenin

Surface development and energy exchange, 522

volume of body protein, 521

tension changes in study of lipolytic ferments. 404

Simpathetic nervous stimulation in production of glyeosuria, 304

sensitization by livpophrsis constituents, 315

Sympathicotonia and glycosuria, 314 Sinthesis of proteins, ammonium salts in, $6 \overline{7}$

aminoacids in. 63

digestive products, 60

\section{$\mathrm{T}$}

Tartronic acid in synthesis of uric acid, 156

Taurin, 98, 119, 479

Taurocarbaminic acid, 479

Taurocholic acid, 119

Tellurmethyl, 132, 476

Temperature of body, see also Heat production, Fever
Temperature increasing the metabolic velocity in fever, 612

influencing oxygen eapacity of blood, 589

Teneriffe expedition, 600

Tension curves of oxpgen in blood, $58 s$

Tetracarbonimide, 165

Tetraglycyl-glycin, 45

Tetralydronaphthylamine in pyrogenesis, 633

Tetramethylamine diamine, 118

Theobromine, 167

Theophyllin, 167

Thiosulphates in detoxification of hydrocyanic acid, 477

Thiourea, 476

Thirst and huuger, endurance of, 499

Thoracic duct fistula, glycosuria from, 252

Tlumberg's microrespirometer, 574

Thyroid, adrenals, pancreas, interaction of, 313

gland in carbohydrate metabolism, 311

medication in obesity, 398

and parathyroids, diflerentiation of, 311

relation of, to other internal secretory organs, 316

removal of, 311

Tigerstedt's formula for metabolic equilibrium, 527

Tissne affinity for uric acid in gont, 176

enzymes, 75

proteolytic, 75

respiration, 563

Tollen's reaction for glyeuronic acid, 324

Tophi, localization of gouty, 18?

Toxicity of trypsin, parenterally introduced, 48

parenterally introduced, immunization against, 48

Toxogenic influences in the protein destruction of fever, 618

Trichlorethyl alcoliol, reduction produets of chloral, 471

Triglyerl-glyein, 45

Trimethylamine, 134

in urine. method of determination, 134

Trioxyglutaric acid in electrolytic cleavage of ghucose, 344

Trypsin, action of, on polypentids. 45 conversion of, into zymoid, 44 estimation, quantitative, of, 46 fermentation rule of, 47 immunization against parenterally introduced, 48

individuality of, 43 
Trypsin passage of, into stomach, 23 toxicity of, when parenterally introduced, 48

-zymogen, 41

Trypsinogel, 41 activation of, $41,42,43$

Trypsoid, 44

Tryptases, 76

Tryptophane, 64, 497

Tuberculosis, urochromogen and diazoreaction in, 145

Tyrosin, 64, 98, 145

catabolism of, 467,470

in formation of acetone bodies, 439

oxyphenyllactic acid

by moulds, 472

importance of, in foods, 497

reacting with diazo-bodies, 145

Tyrosinase, 544, 548

\section{U}

Ulcer of stomach, origin of, 26

Ultramicroscopy of lab-process, 29

Ultra-violet rays causing carbohydrate cleavage, 344

increasing starch hydrolyzation, 220

Uraminoacids, 98, 478

Urates, lactam and lactim forms of, 179

solubility of different urates and uric acid, 181

Urea, aminoacids in formation of, 97 , 100

ammonium carbamate in formation of, 97

carbonate in formation of, 97,100

elimination in acidosis, 442 postconal, 105, 498

estimation, quantitative, of, 106

formation in body, theories of, 97, 98, 99

a general cellular function, 102

liver in, 100, 101

perfusion experiments in, 100

place of formation of, in body, 101

stimulating protein metabolism, 499

in synthesis of uric acid, 156

Ui ic acil, from adrenin and guanin, 149

affinity of tissue for, in gout, 176

alkali combinations of, 178 and allantoin, 158

bacillus, 165

curve in gout, 174
Uric acid, dccomposition of, reduced in gout, 173

diathesis, 182

deposition in gout, 182, 184

elimination in fever, 619

leukæmia, 153

estimation of, quantitative, 168

excretion in acute gouty exacerbations, 174

fate of intermediate, in mammals, 158

in $\operatorname{man}, 160$

orally introduced, 162,164

parenterally intro-

fixed, 182 duced, 159,162

formation in birds and reptiles, synthetic, 154

formation in birds and reptiles, oxidative, 157

gout, 171

exogenous and endogenous, 148

in mammals, oxidative, 157

increased in blood in gout, 170

influence of nucleinic acid in, 180

integrative factor, 162

loosely combined, 182

regeneration of, 165

retention in gout, 176

solubility in relation to gout, 179,181

in variations of alkales. cence in gout, 178

synthesis, absence of, in mammals, 157

Uricæmia, 171

in birds and reptiles, 154

endogenous, 171

retention, 171

Uricase, 161

absence in human tissures of, 160

Uricolysis, 158, 164 in monkeys, 164

Urinary colloids of Salkowski, 147 dextrin in diabetes, 267

purin, origin of endogenous, 153 rest, nitrogen, 136

Urine, aromatic substances in, 319

in fasting, 505

fat from blood in, 375

lactic acid in, 462

removal of albumin from, 206

rest-nitrogen in, 136

Urocaninic acid, 146

Urochrome, 138

chemical status of, 140 
Urochrome, Dombrowski's 139, 141 true (Weiss), 139, 141 and histidin, 141

Weiss' method of estimation, 139

Urochromogen, 138 in cancer, 145 and diazoreaction, 139

in fever, 144,620 tuberculosis, 145

Uroferric acid, 147

Uromelanin, 141

Uropyrrol, 140

Uterine disturbances and creatin metabolism, 130

Utilization limit of sugars, 232 value of food, 527

\section{V}

Vagus, influence of section on hepatic diastase, 215

Vasodilations, secretin and cholin, relations of, 39

Vegetable fibre, digestion of, 198 food, mechanical preparation of coarse, 490

Vegetarianism, 4S5, 488 amides in metabolism in, 67

Velocity of protein catabolism, 498

Ventriculus, Pawlow's, 4

Verworn's biogen, 569

Vital oxidation of nitrogenous substances, 99 processes, 534

Vitiatin, 133

Voit's dietetic allowance, 482

Vollhard's method of pepsin estimation, 21

modifications of, 22

rule of fermentation applied to pancreatic digestion, $4 \overline{7}$

\section{W}

Wacker's colorimetric method of sugar estimation, 207
Water, alkaline mineral, in treatment of gout, 184

mineral, in diabetes, 272

economy in fever, 623

in fasting, 504

retention in fever, 623

withdrawal of, 500

Weight in fasting, loss of, 500

'Veiss' method of estimation of urochrome and urochromogen, 139 urochrome, 139

Wiechowski's method of allantoin estimation, 169

of hippuric acid estimation, 114

tissue-powder method of diastase determination, 213

Wohlgemuth's method of diastase determination, 212

Work in alpinism, capacity for, 607

Worms, anoxybiotic processes in intestinal, 577

\section{$\mathrm{x}$}

X-rays, see Röntgen rays,

Nanthin, 149

fate of parenterally introduced, 164

Xanthoxidases, 149

Xylose, 288

conversion of glycuronic acid into, 321

\section{$\mathbf{Y}$}

Yeast catabolism of aminoacids, 467

\section{Z}

Zein, 490,495

Zuntz and Geppert type of respiration apparatus, 517

Zymases in animal tissue, 328 vegetable world, 327

of yeast and alcoholic fermentation, 327 




\section{COLUMBIA UNIVERSITY LIBRARY}

This book is due on the date indicated below, or at the expiration of a definite period after the date of borrowing, as provided by the rules of the Library or by special arrangement with the Librarian in charge.

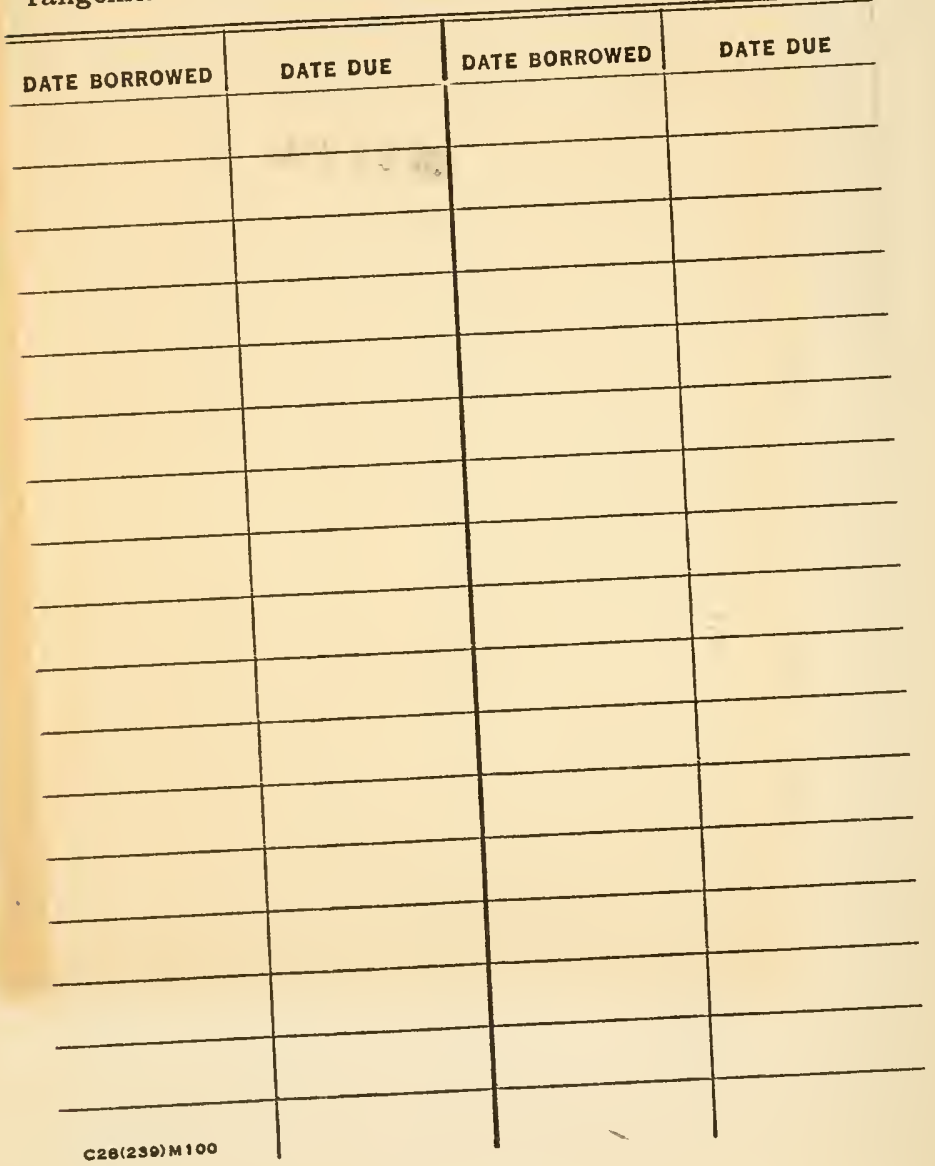




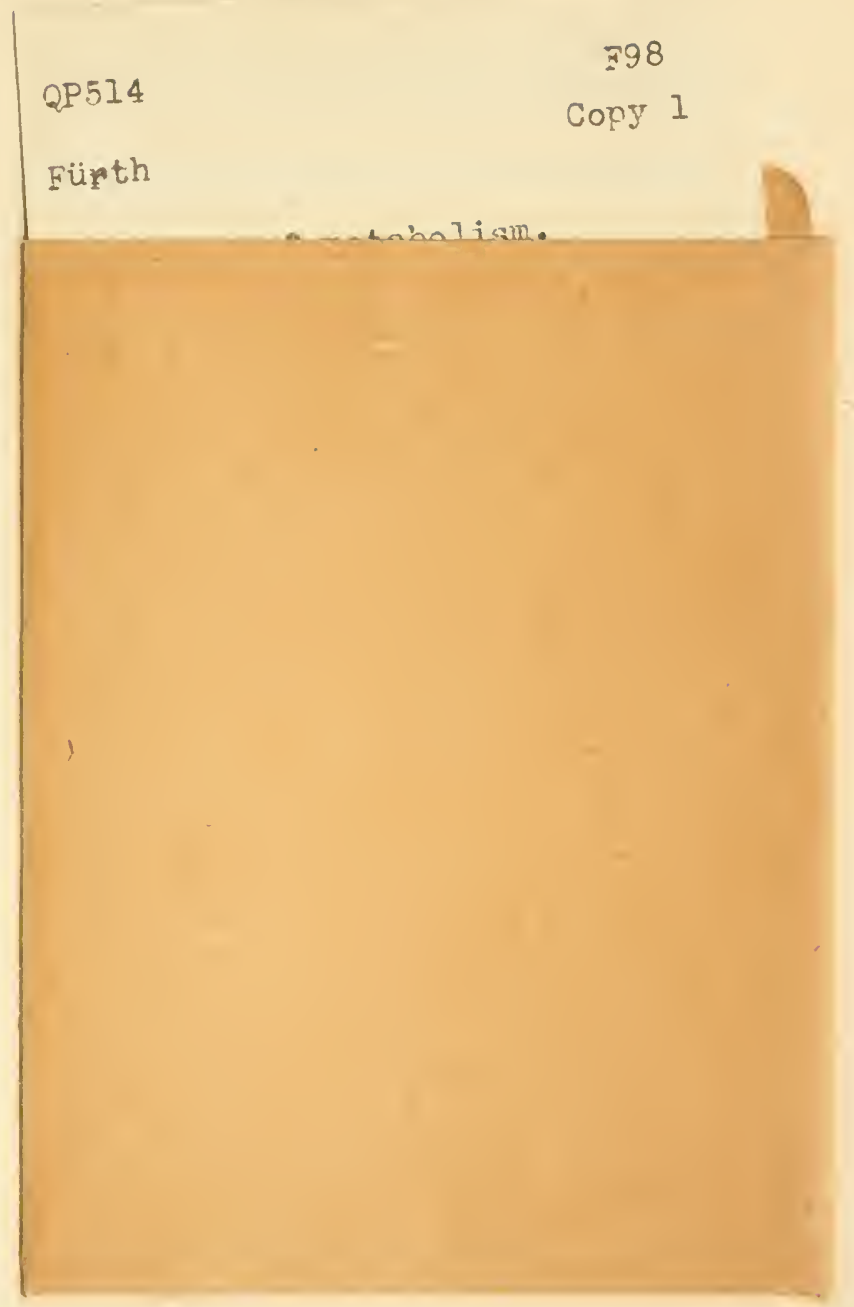


